\title{
Academic Search Complete
}

Magazines and Journals

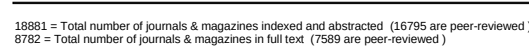

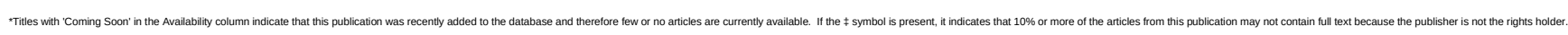

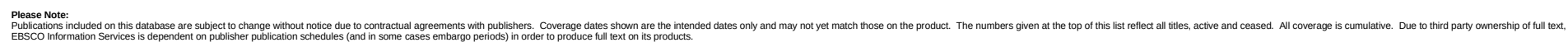

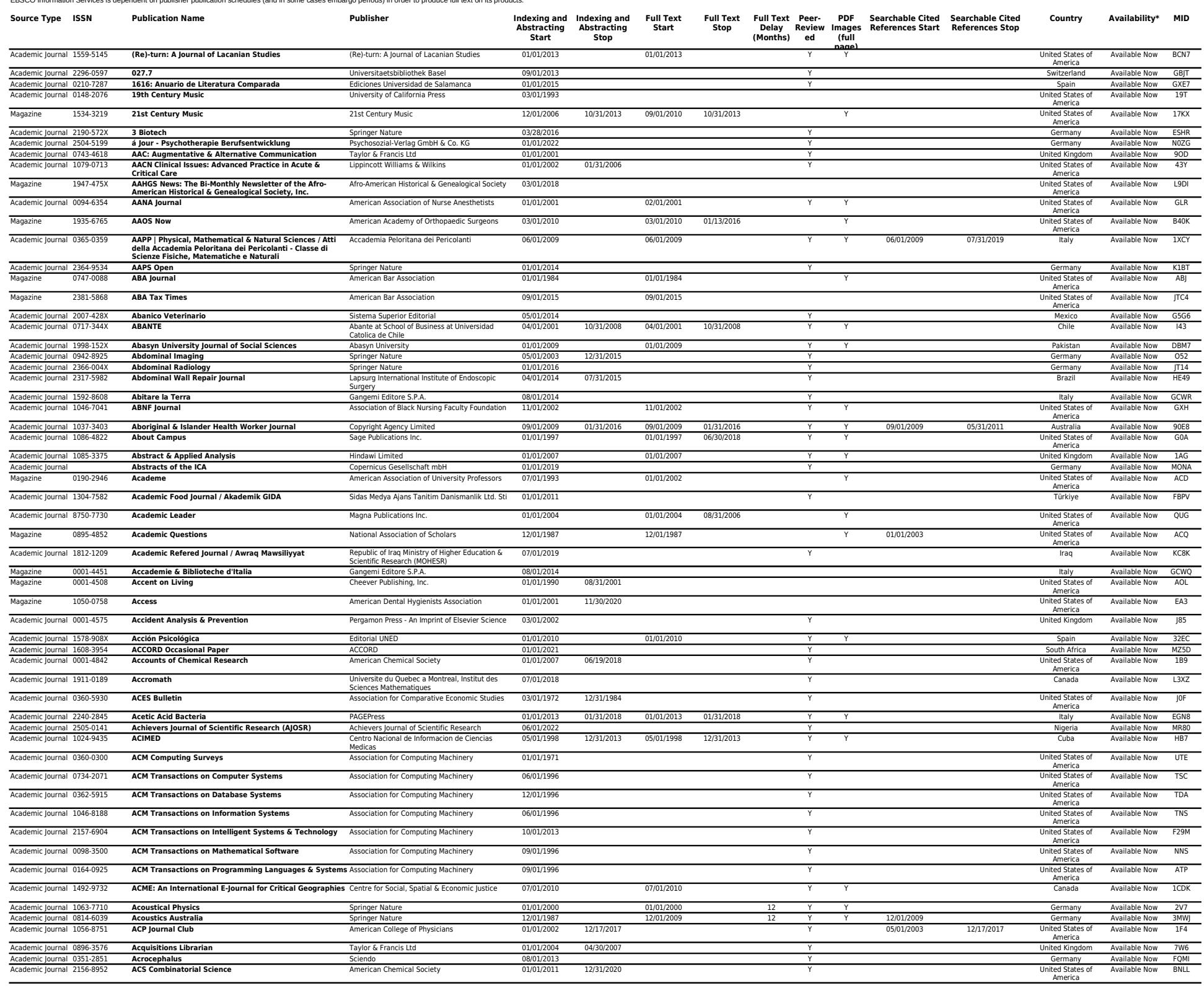




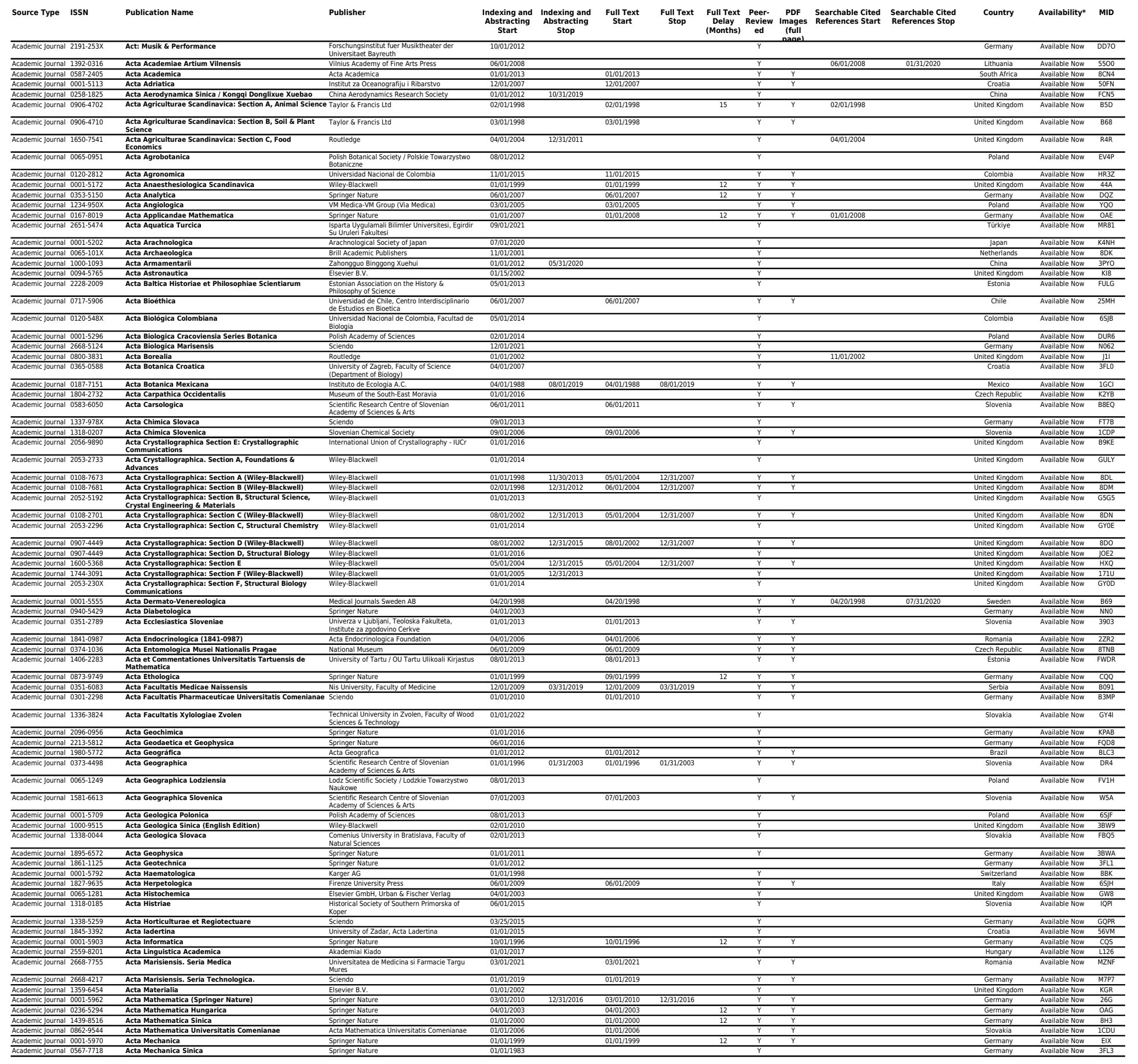




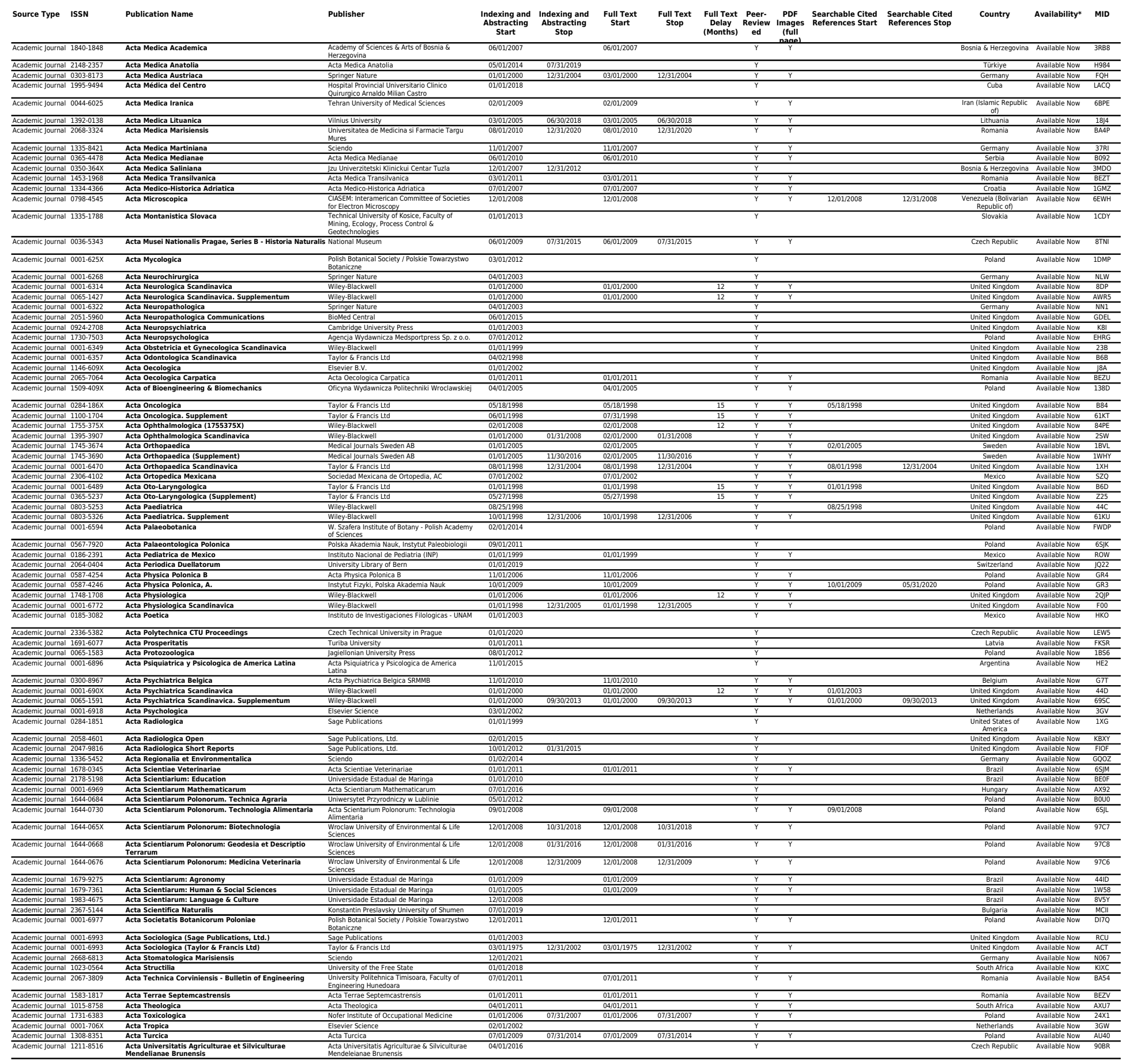




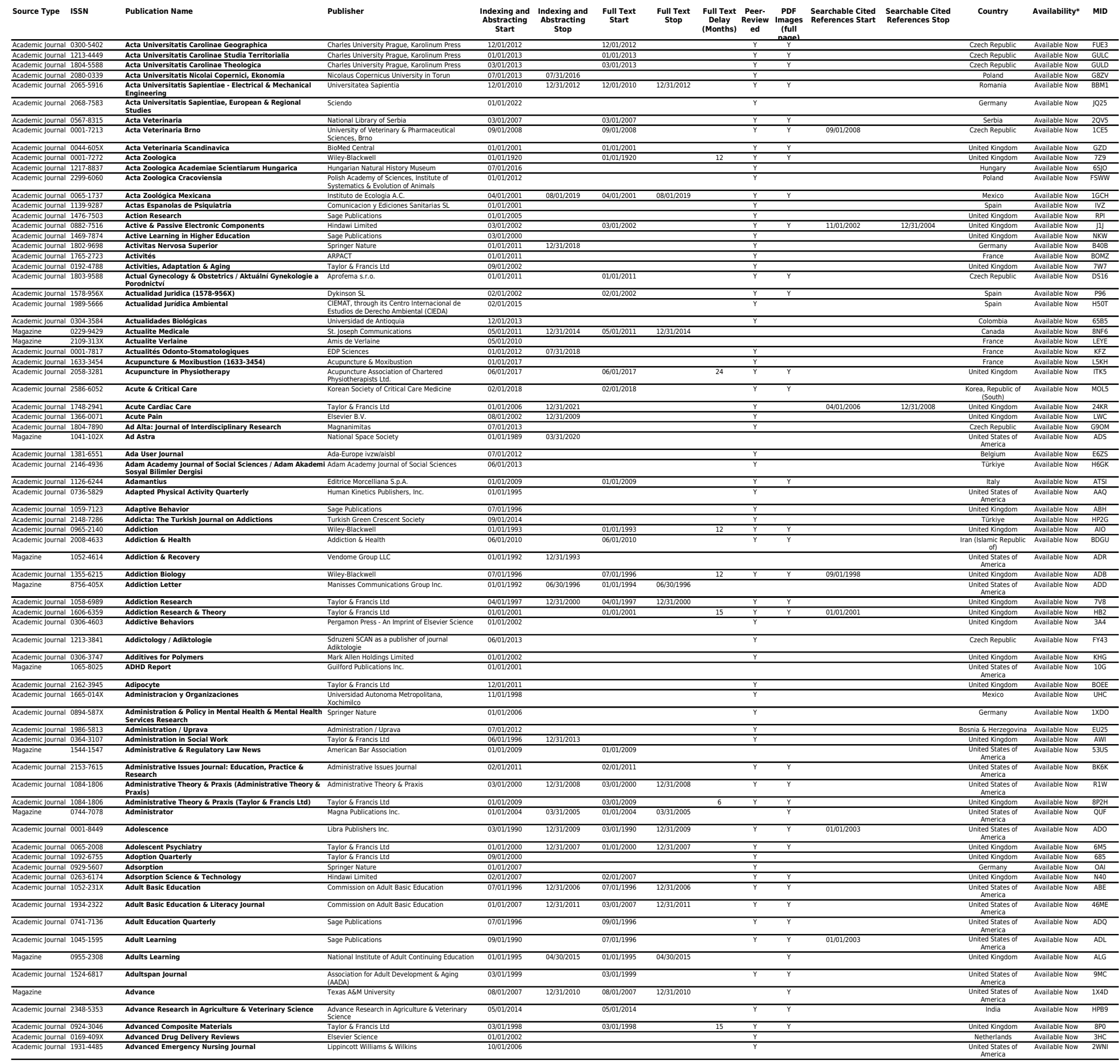




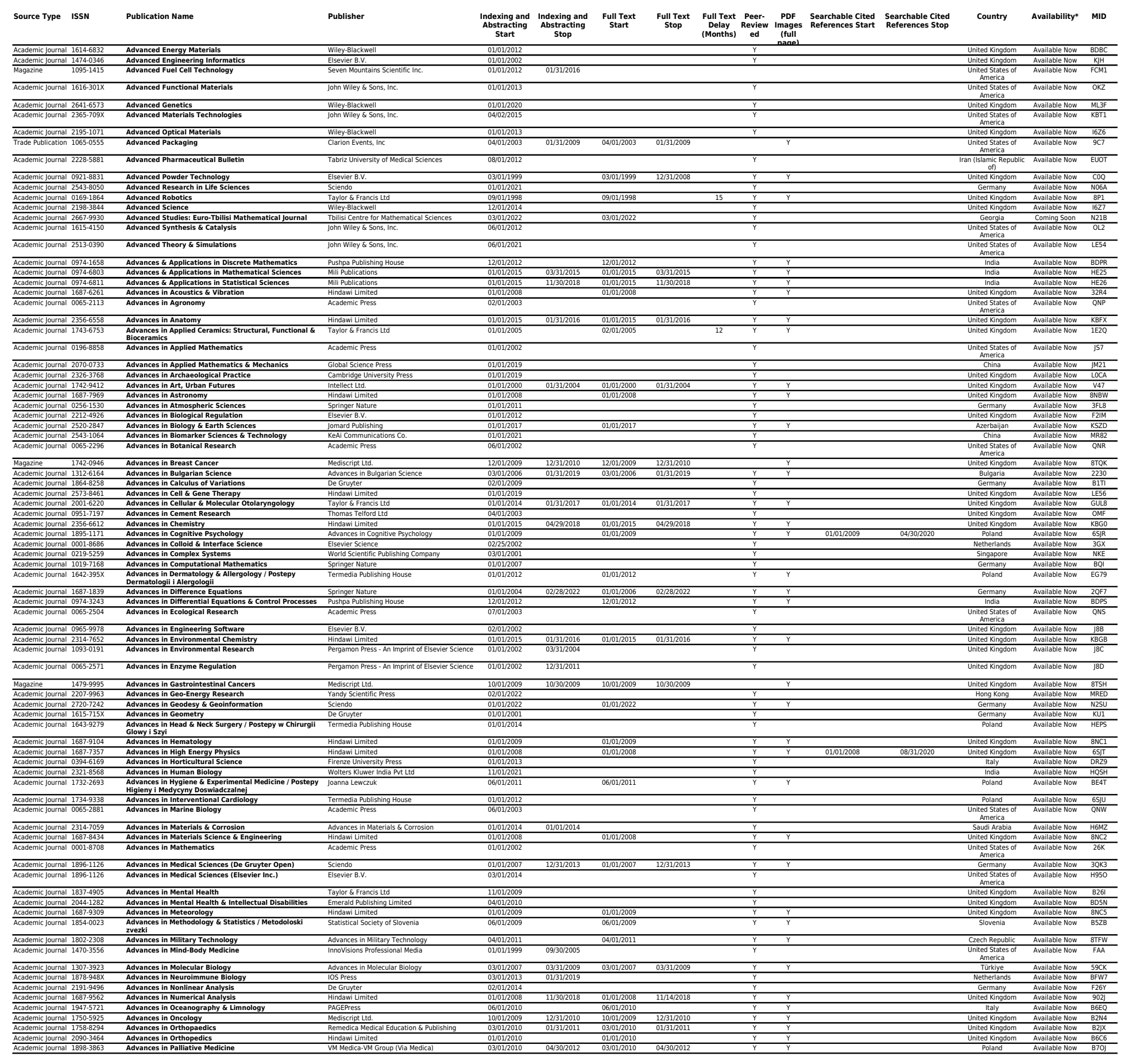




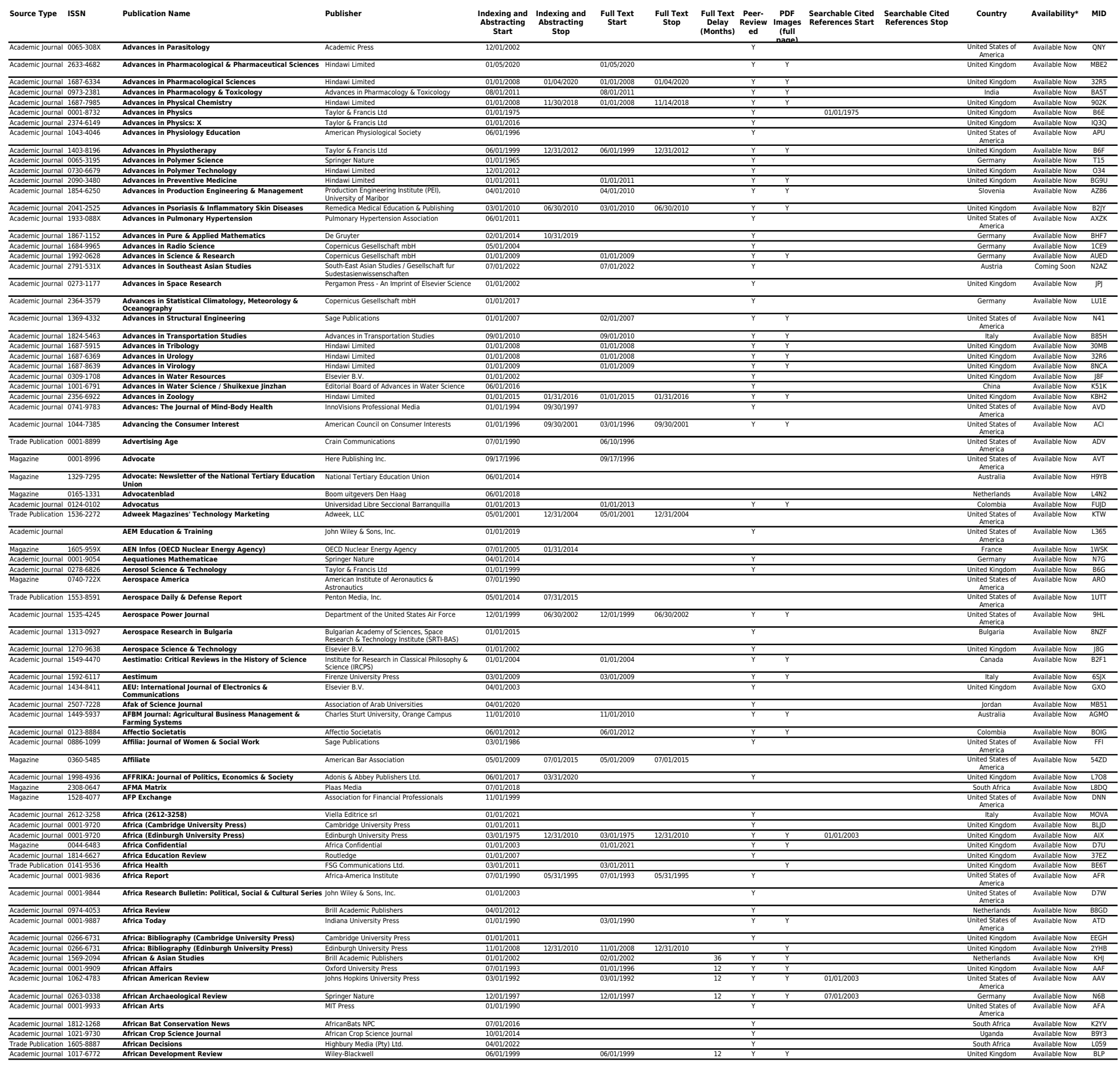




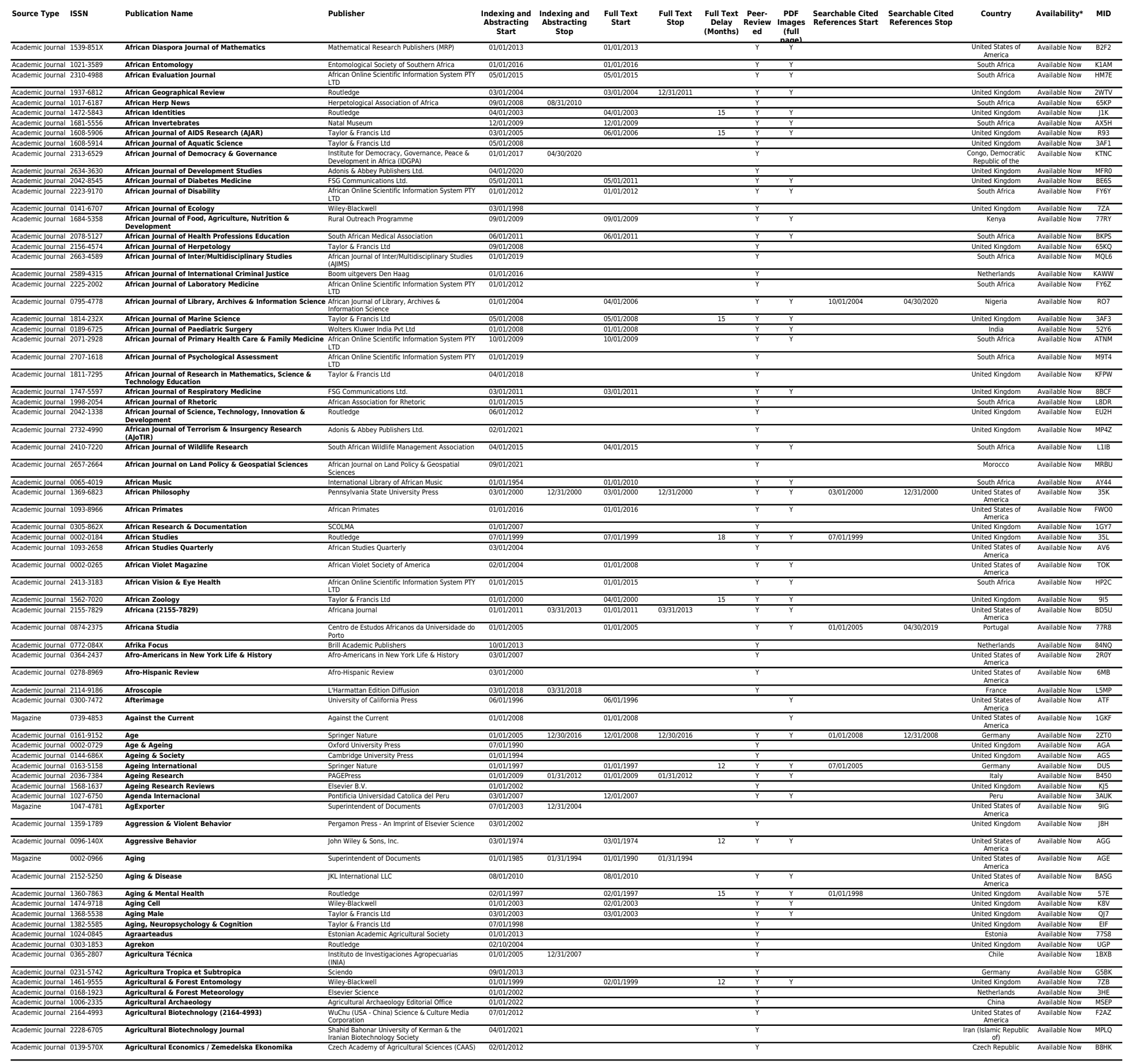




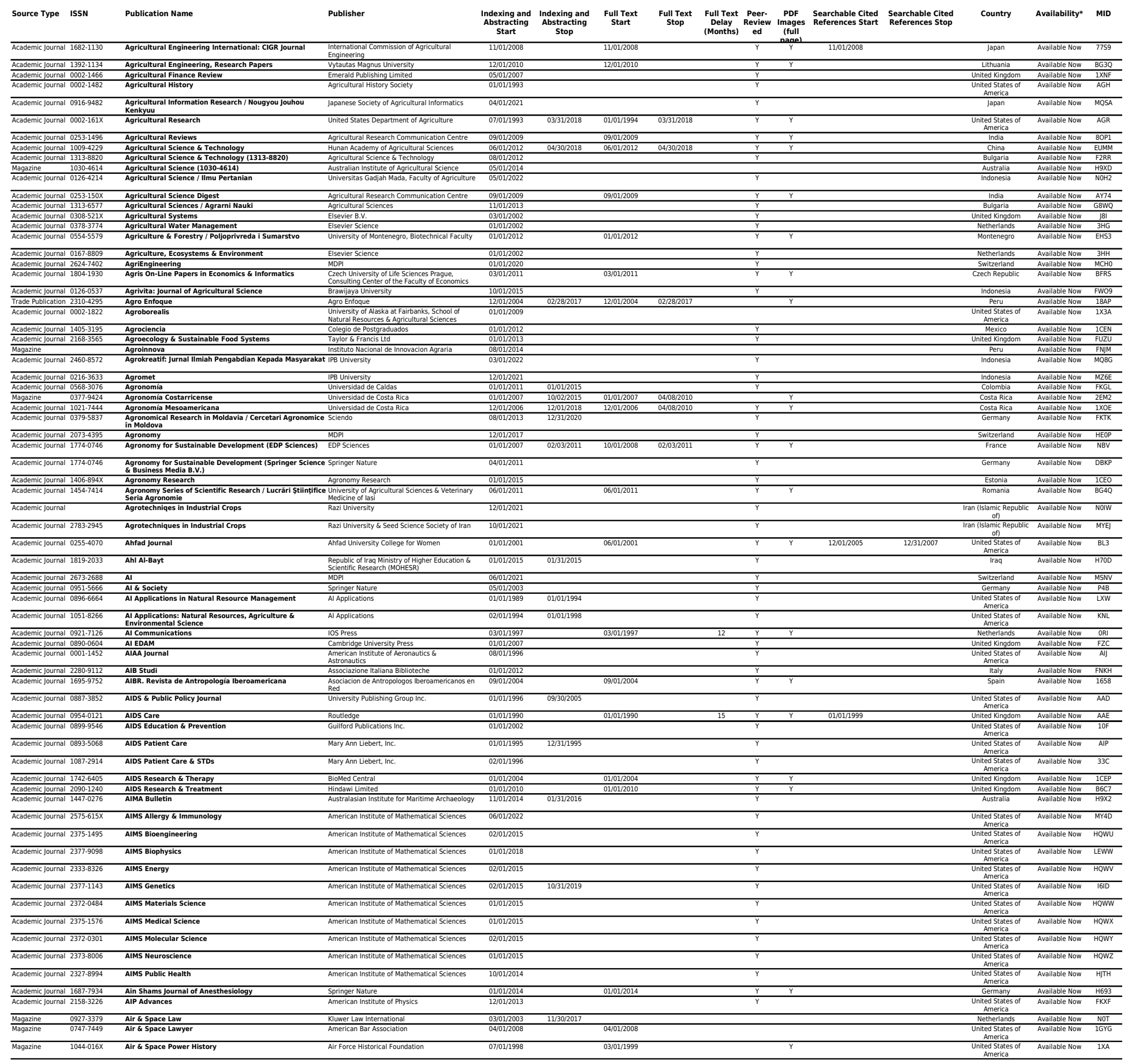




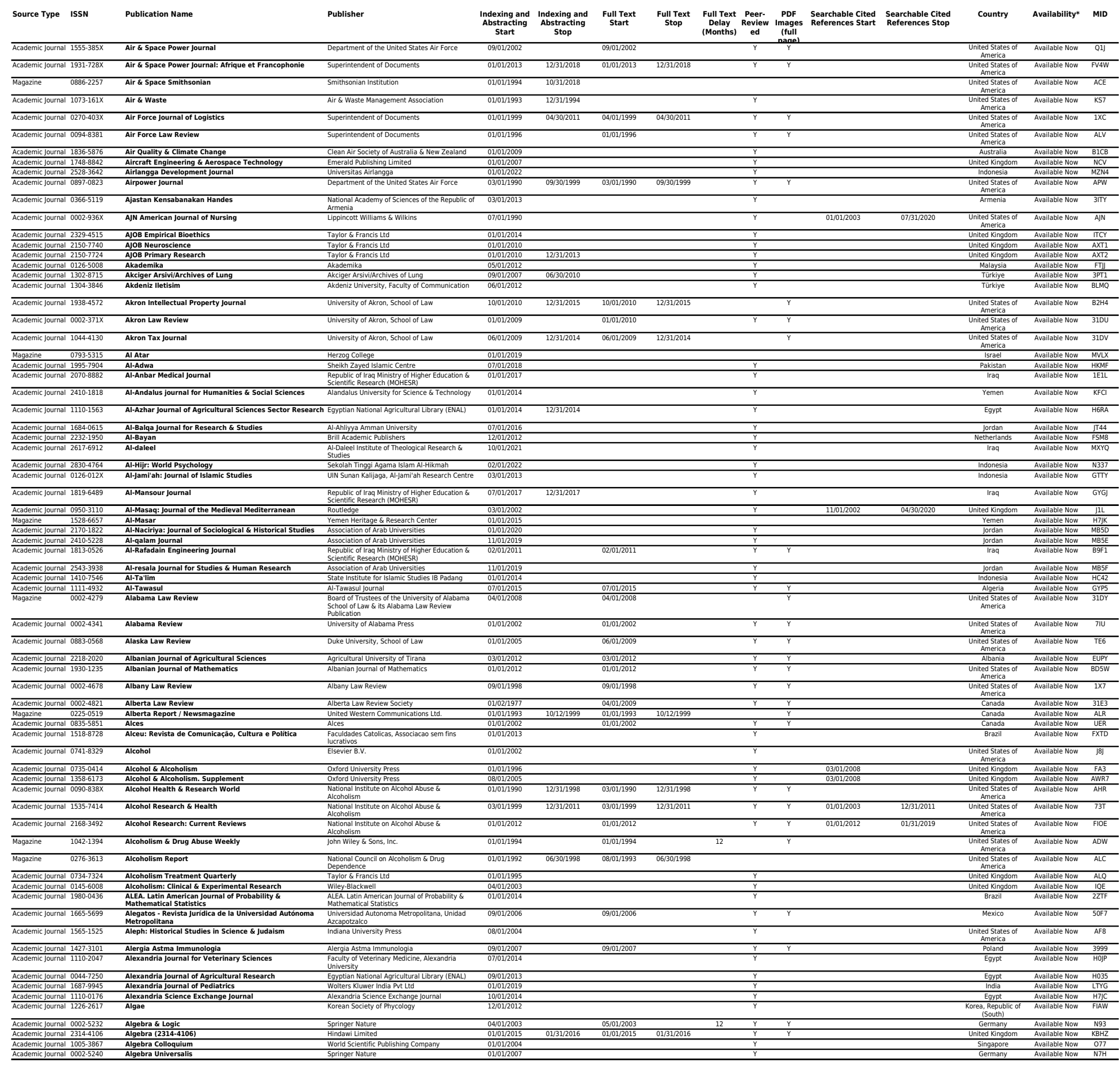




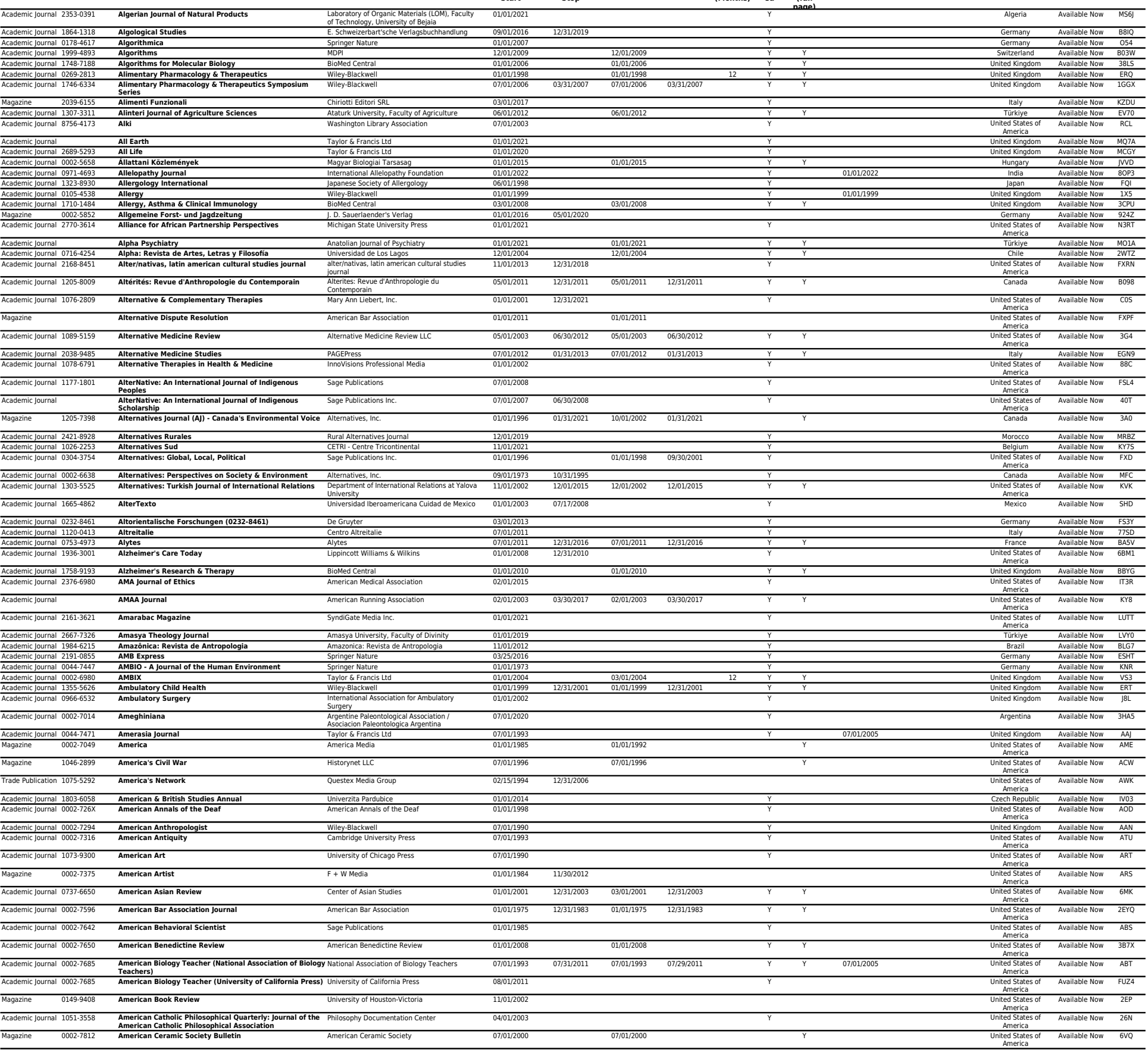




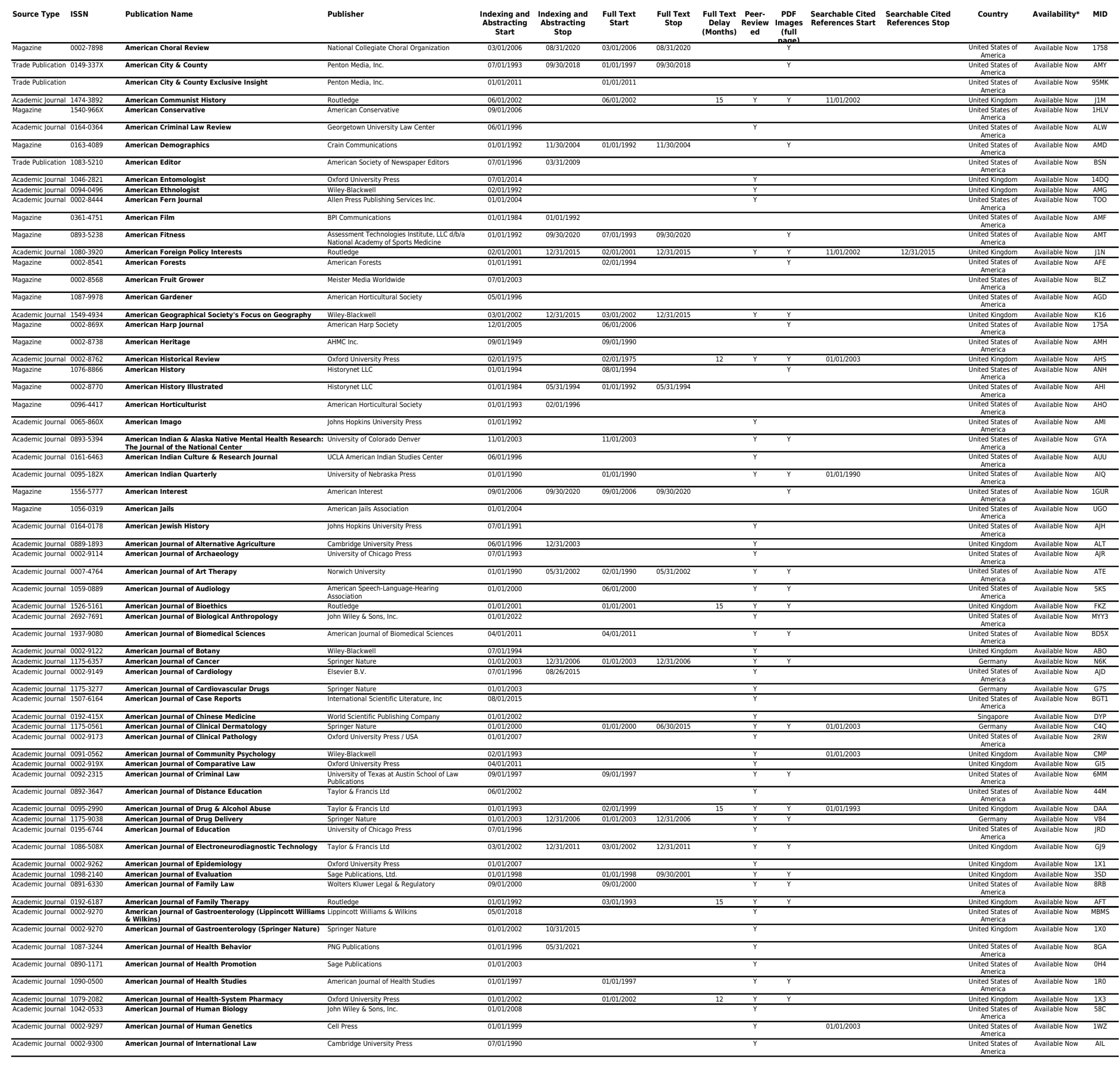




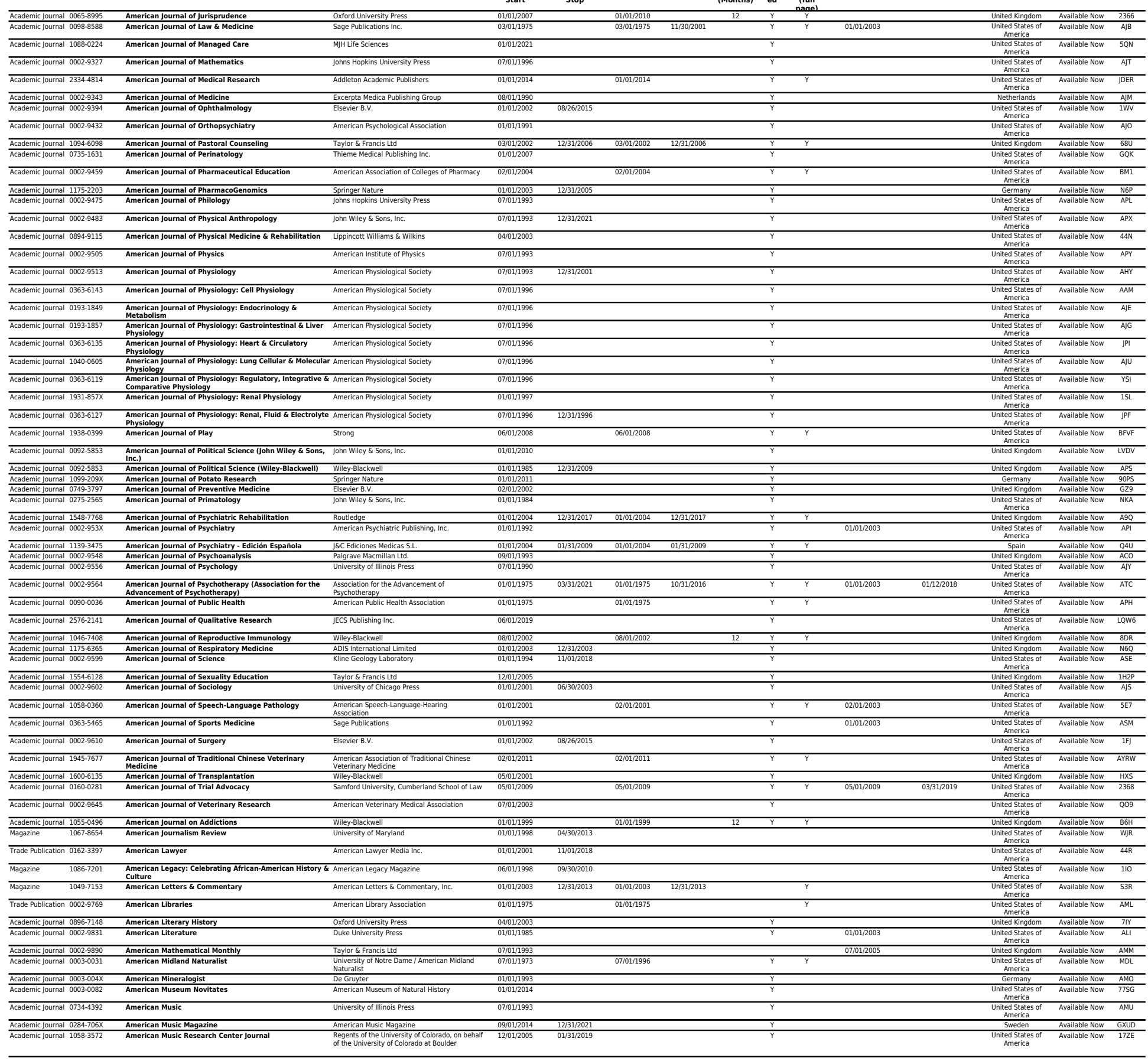




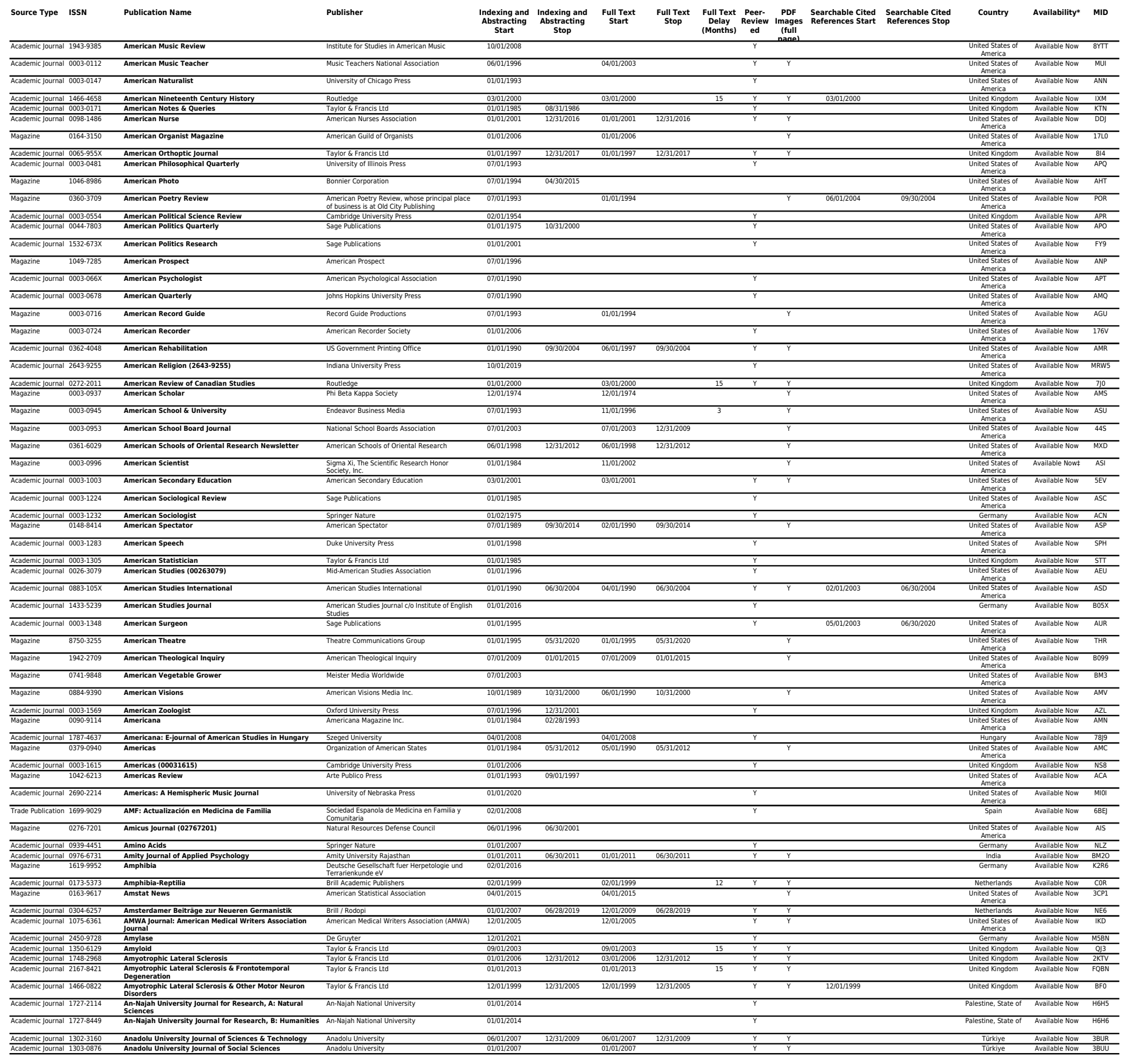




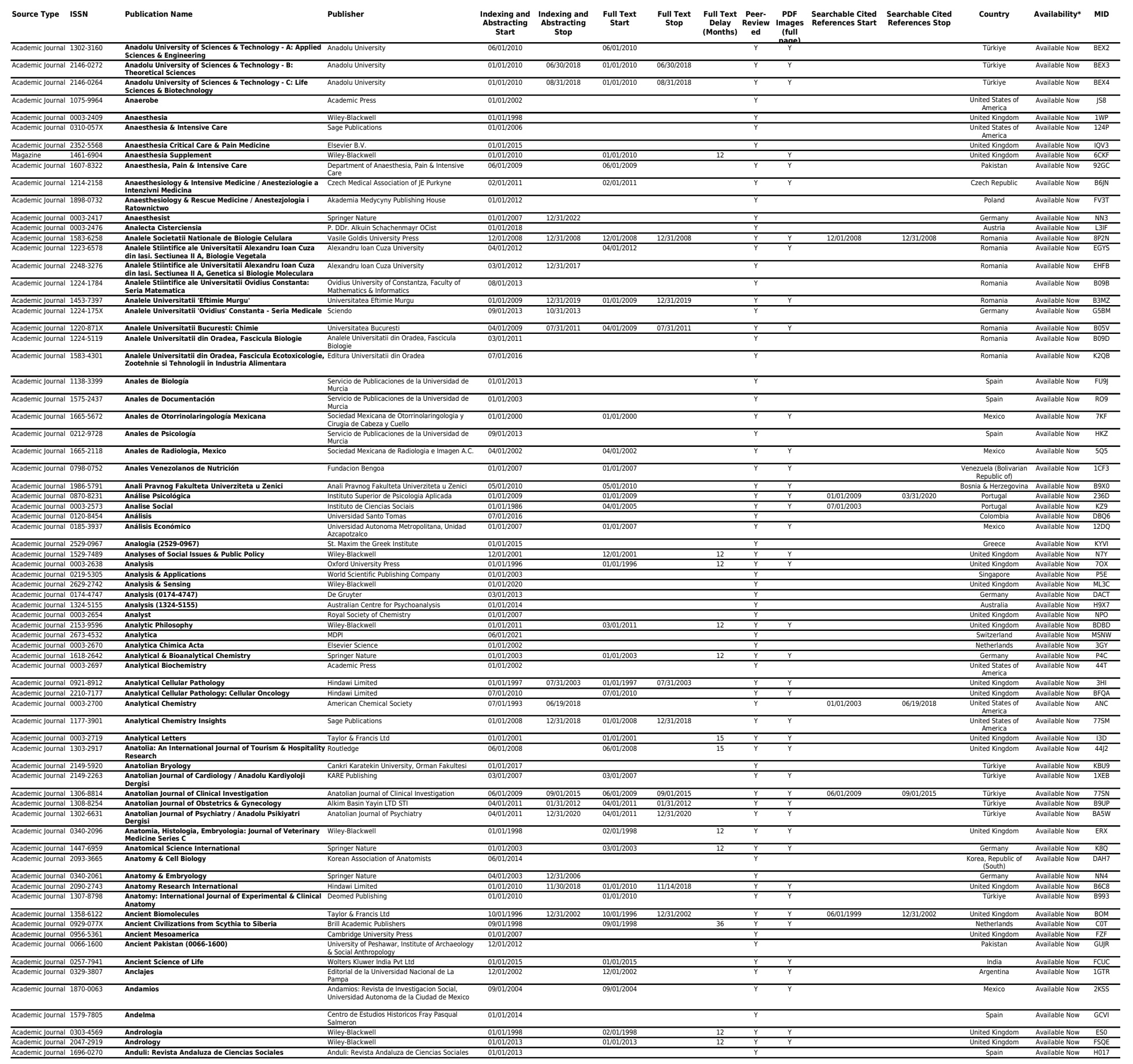




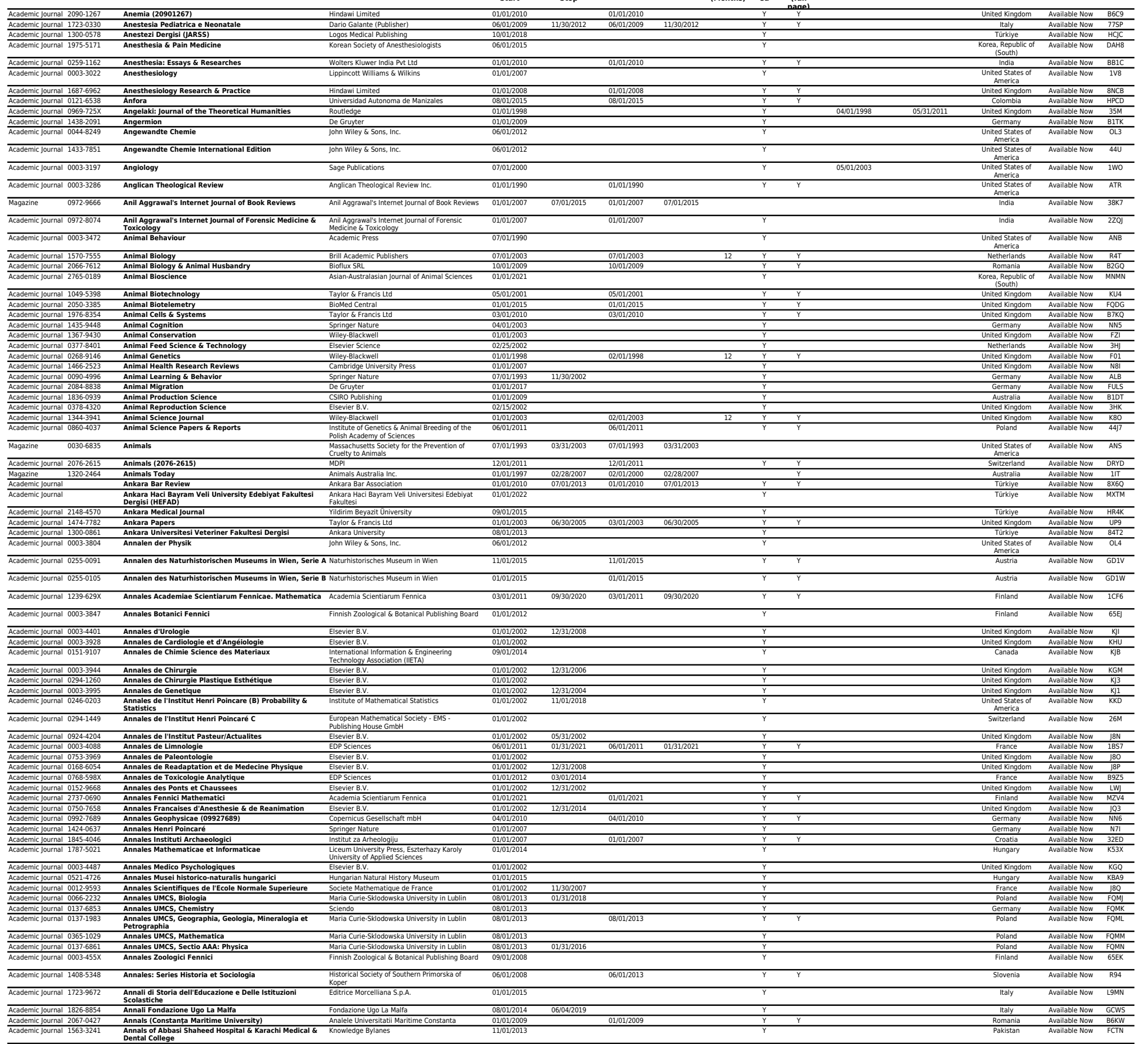




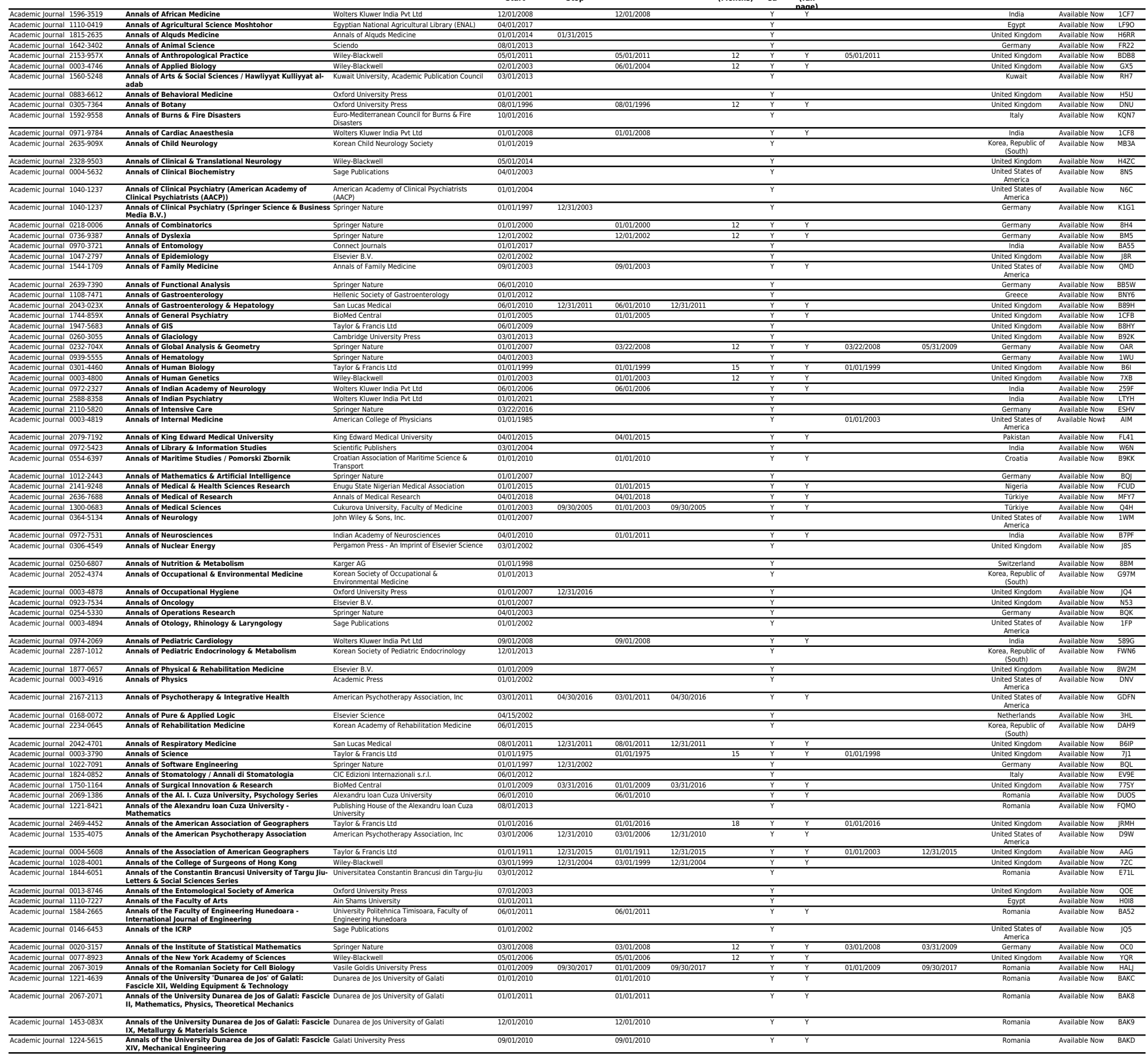


Source Type ISSN Publication Name Publisher

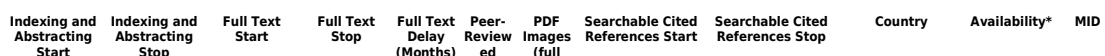

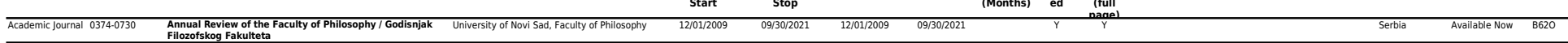

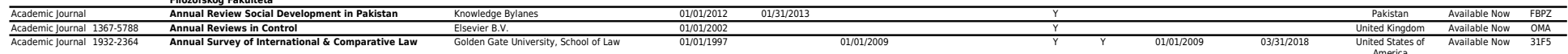

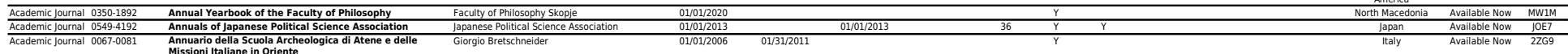

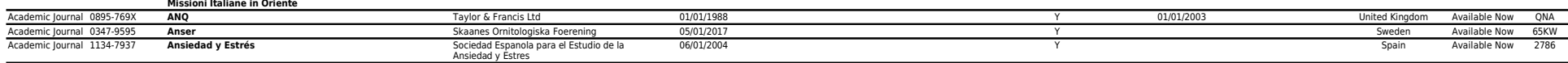

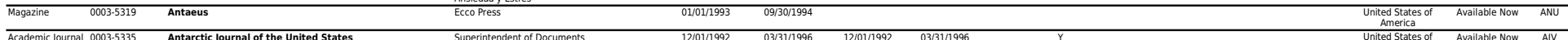

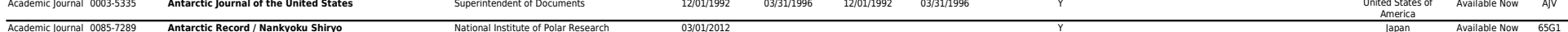

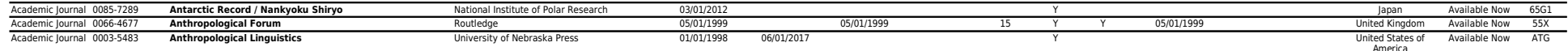

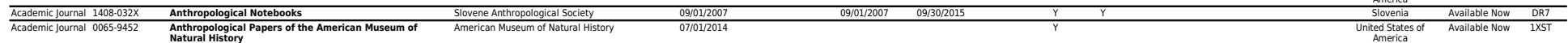

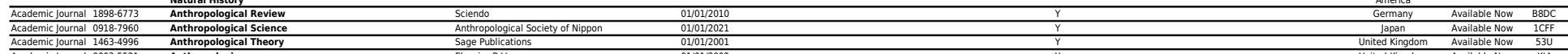

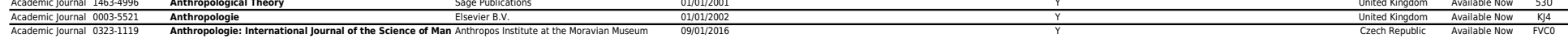

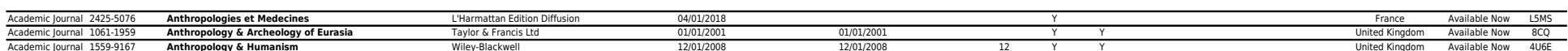

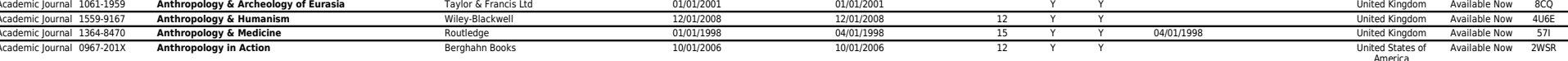

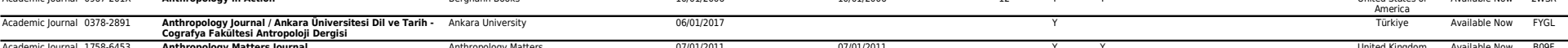

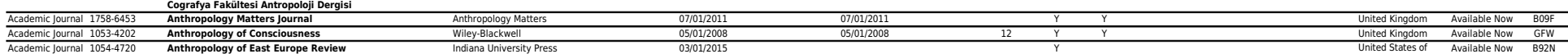
America Redurasia

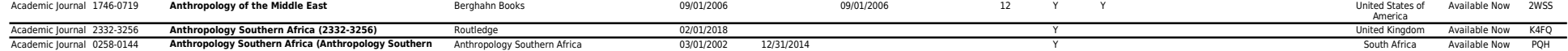

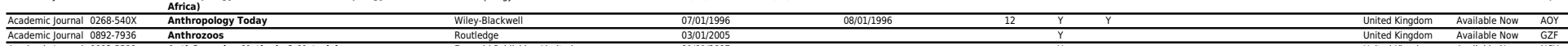

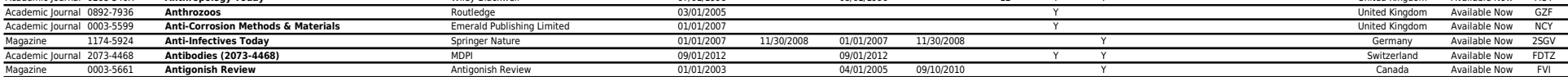

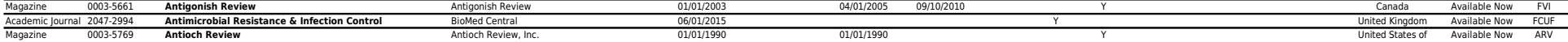

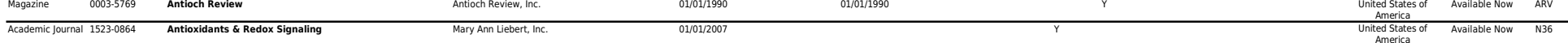

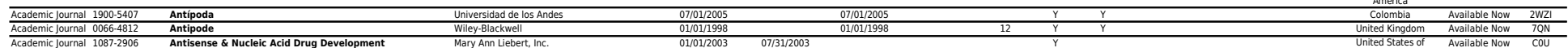

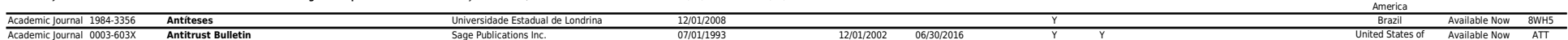

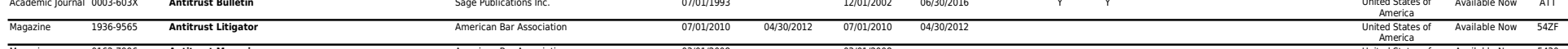

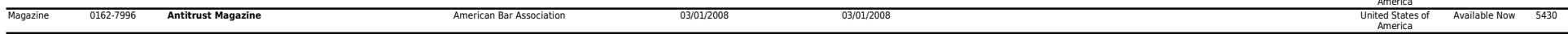

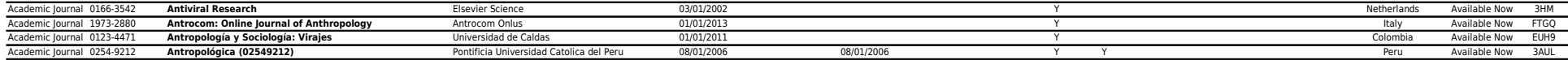

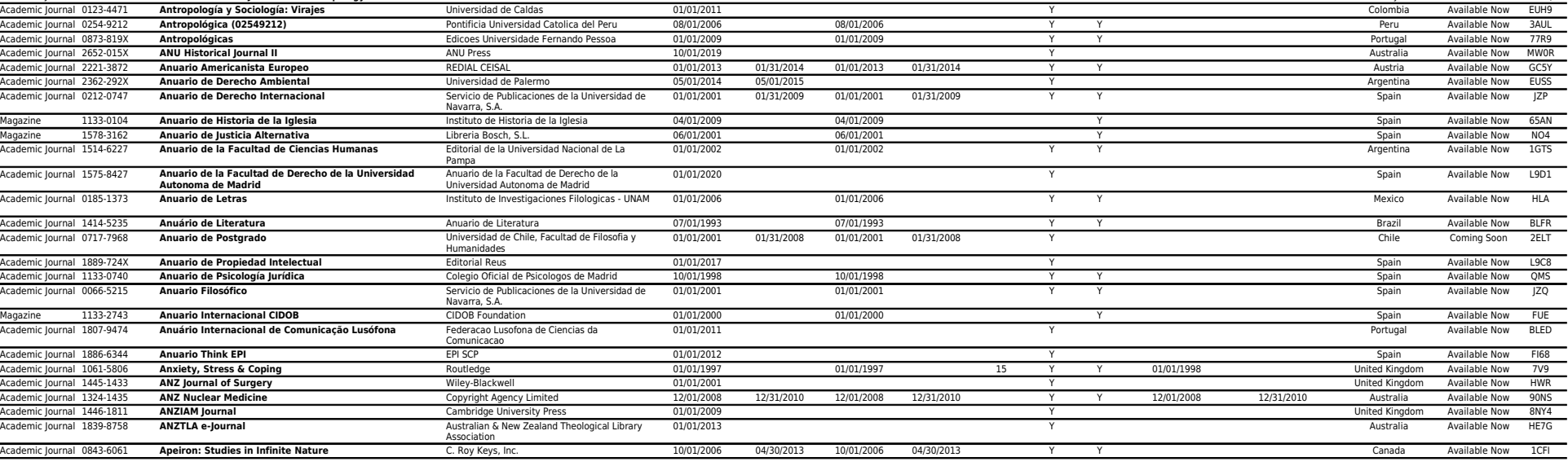




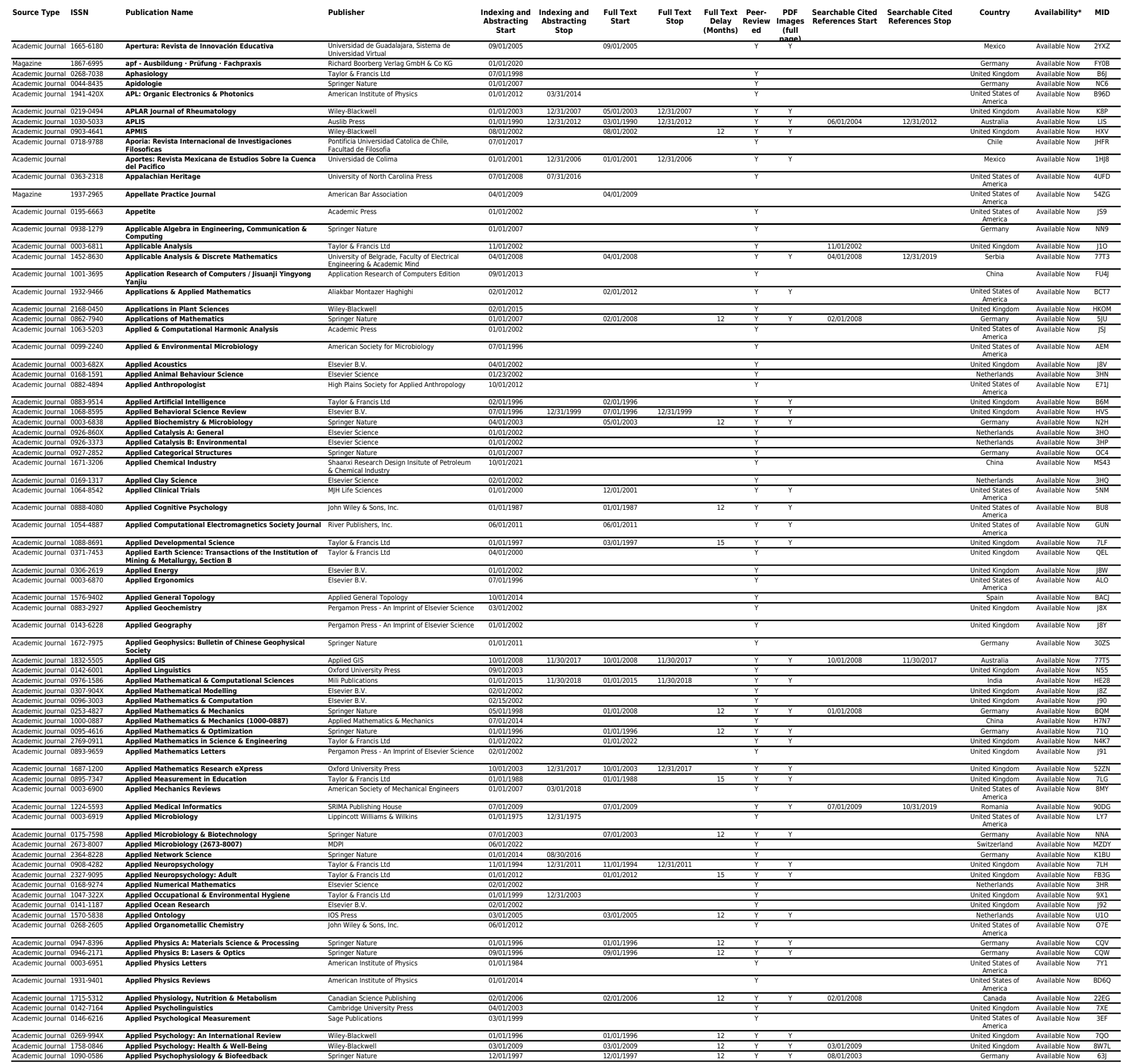




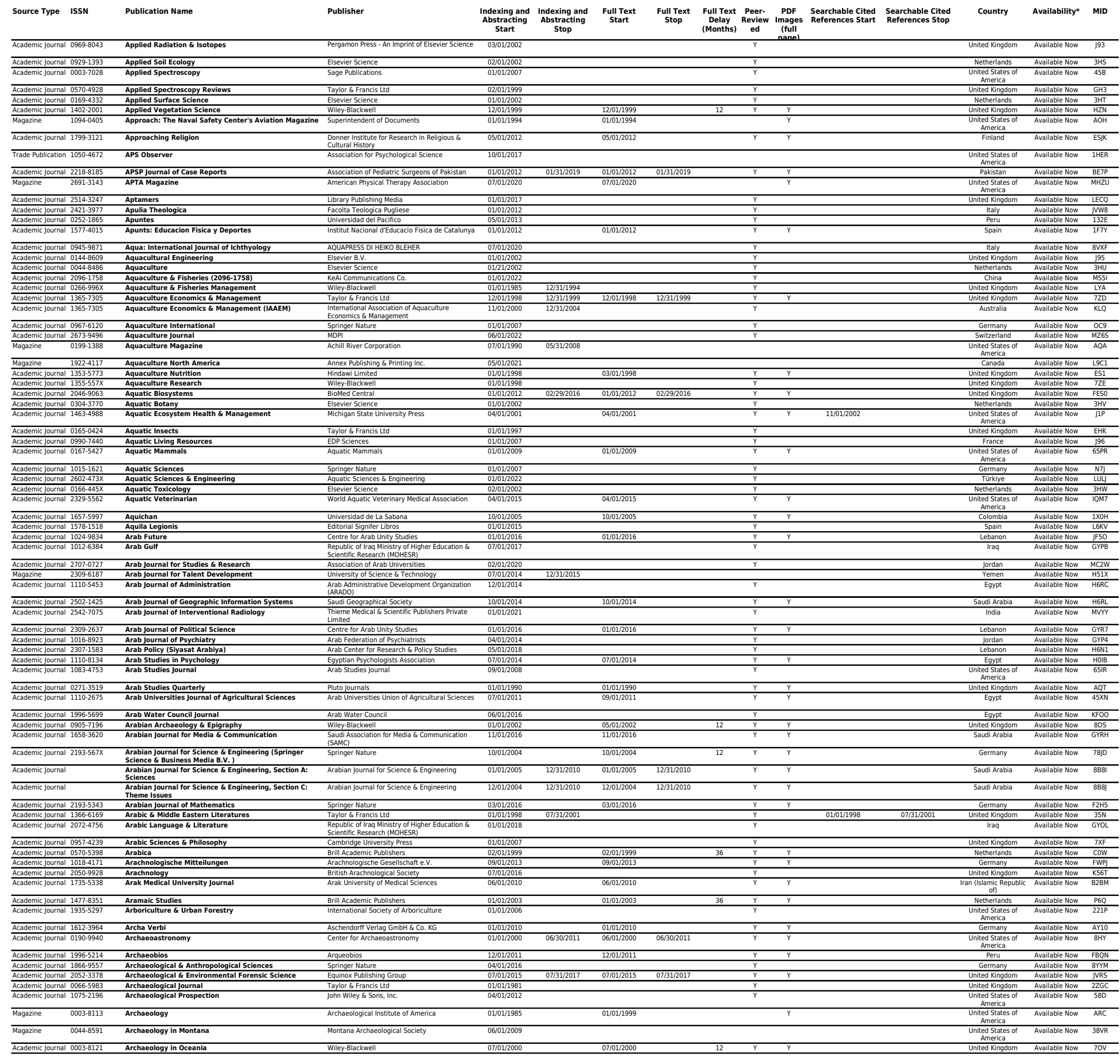




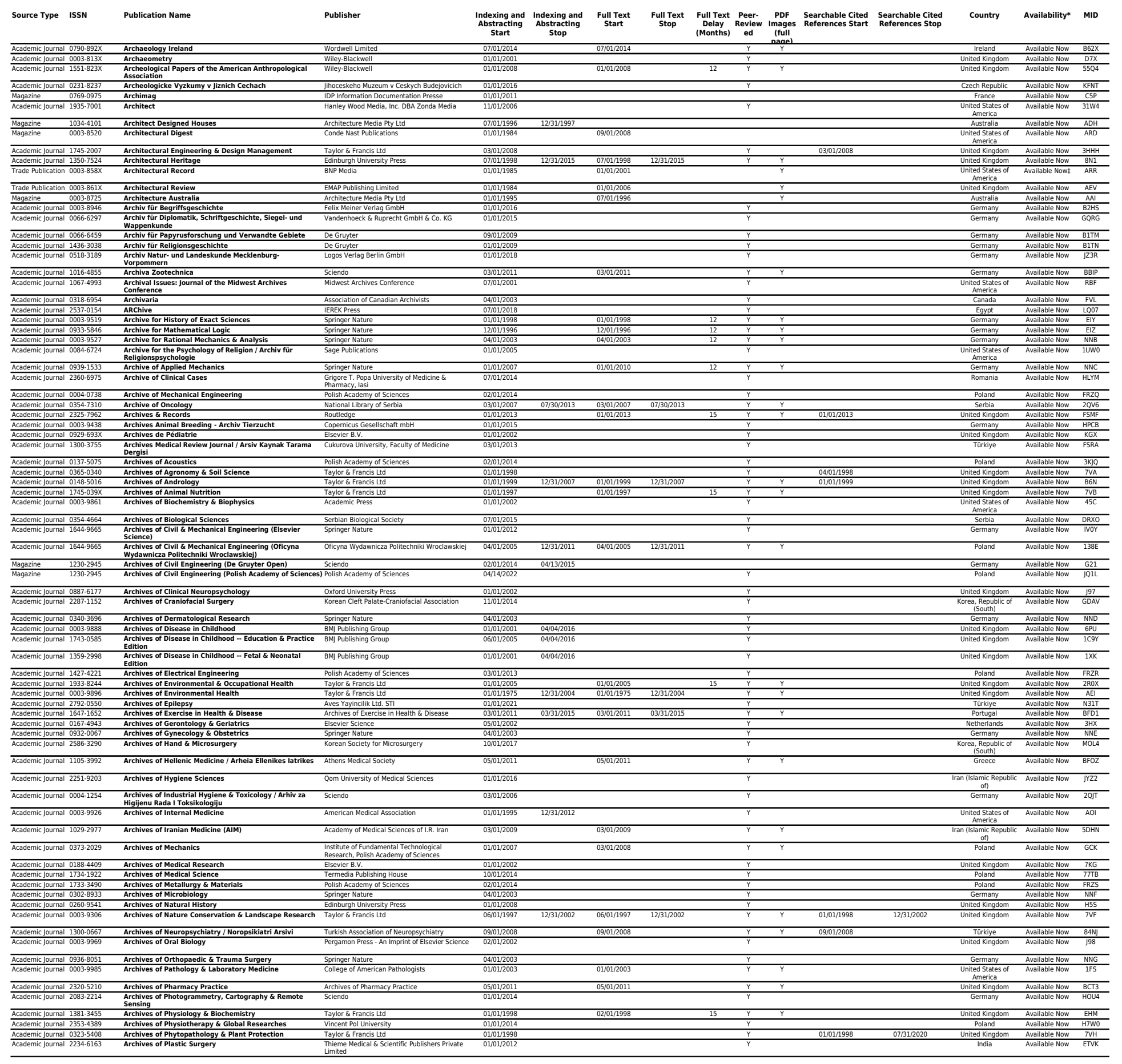




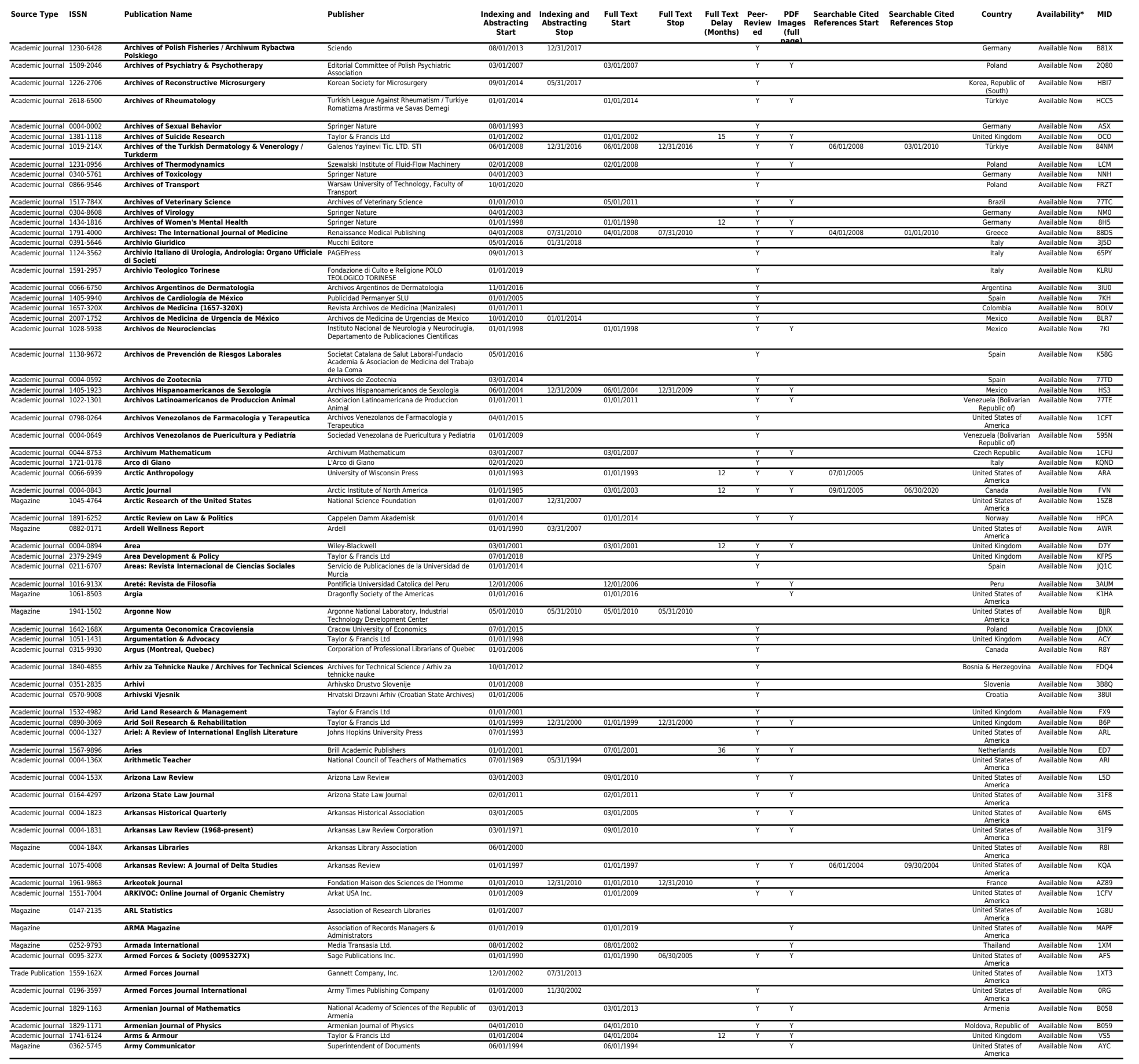




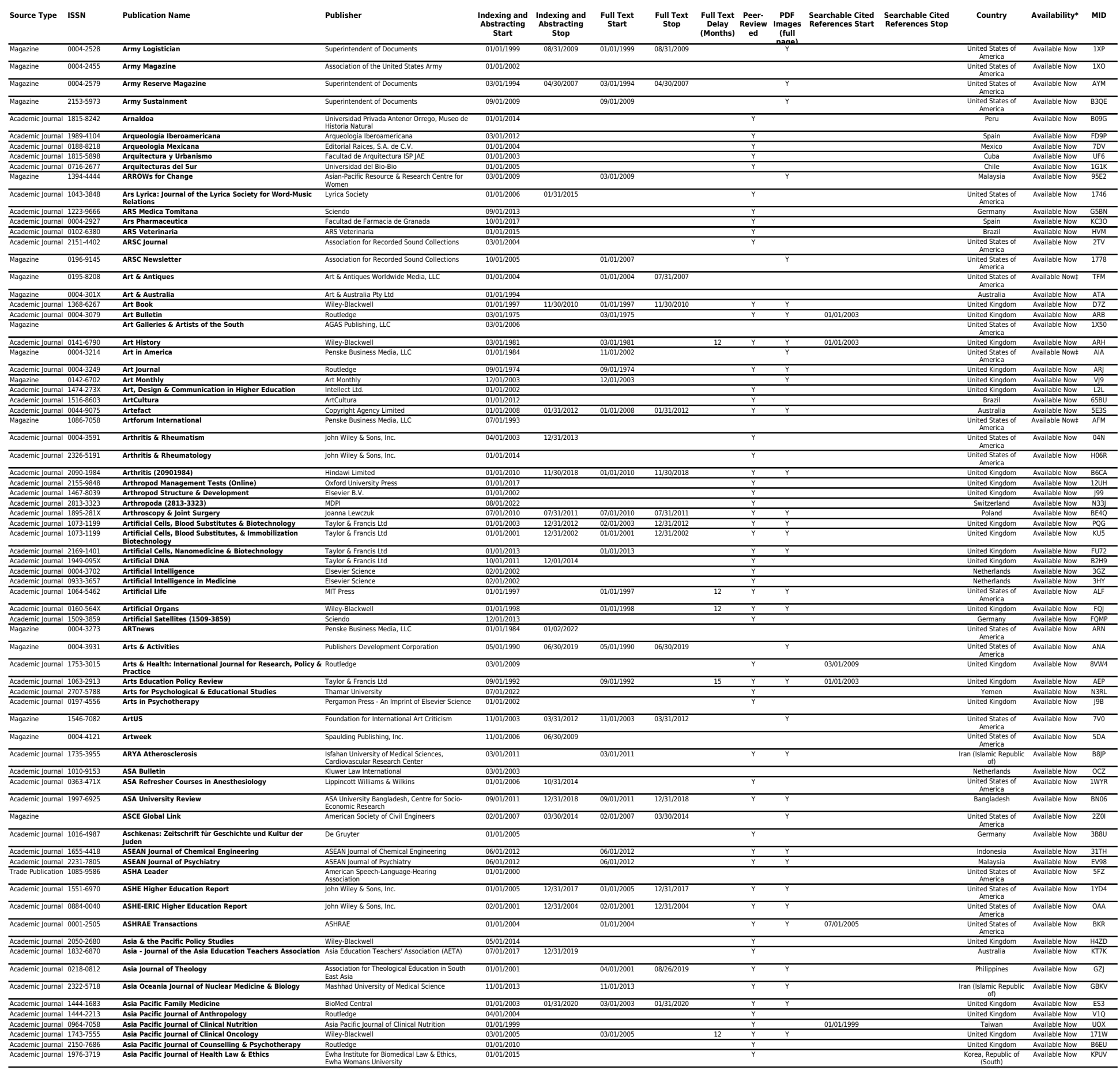




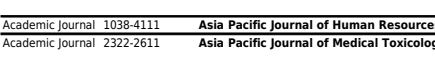

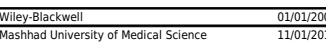

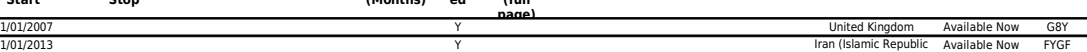

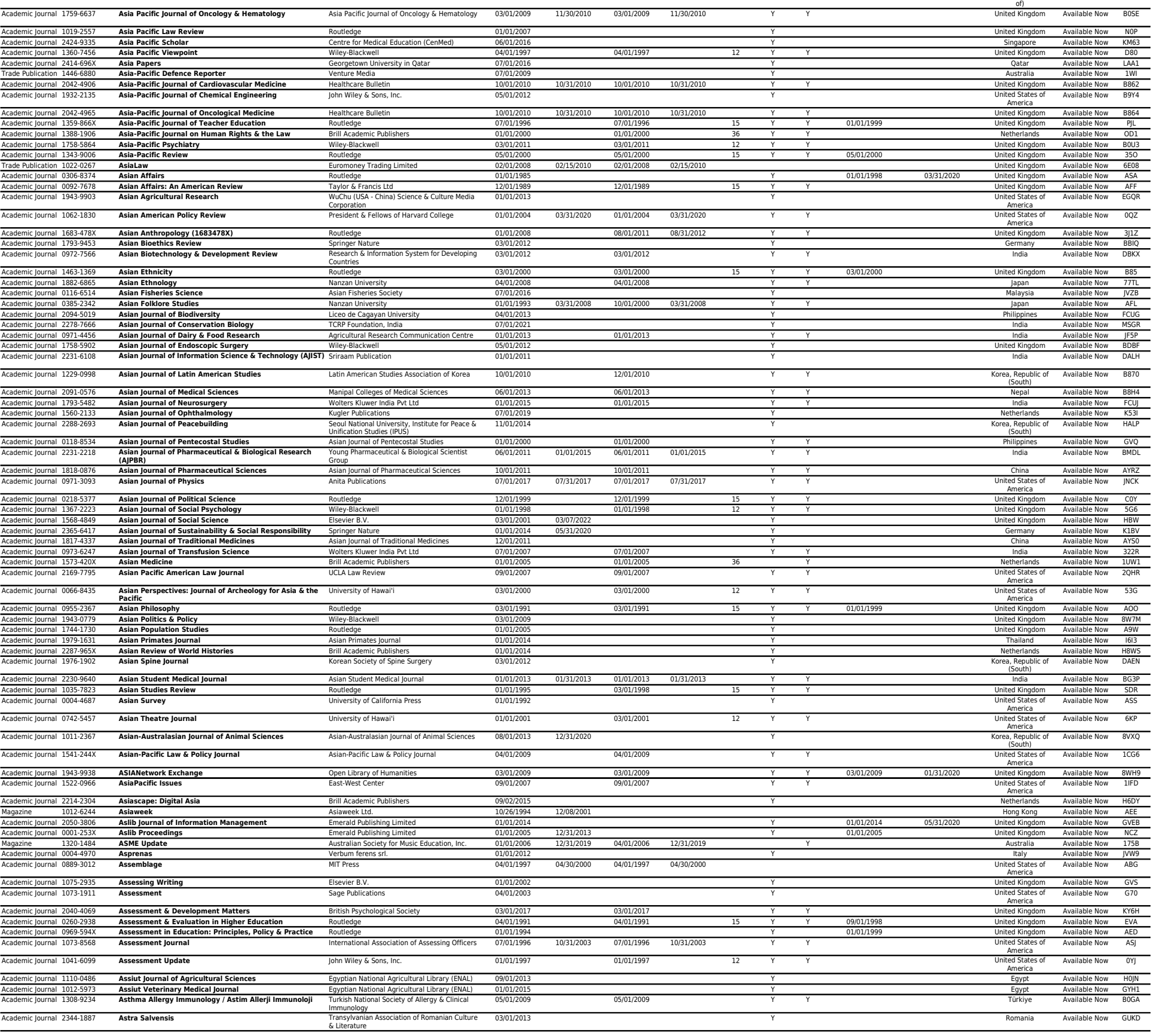




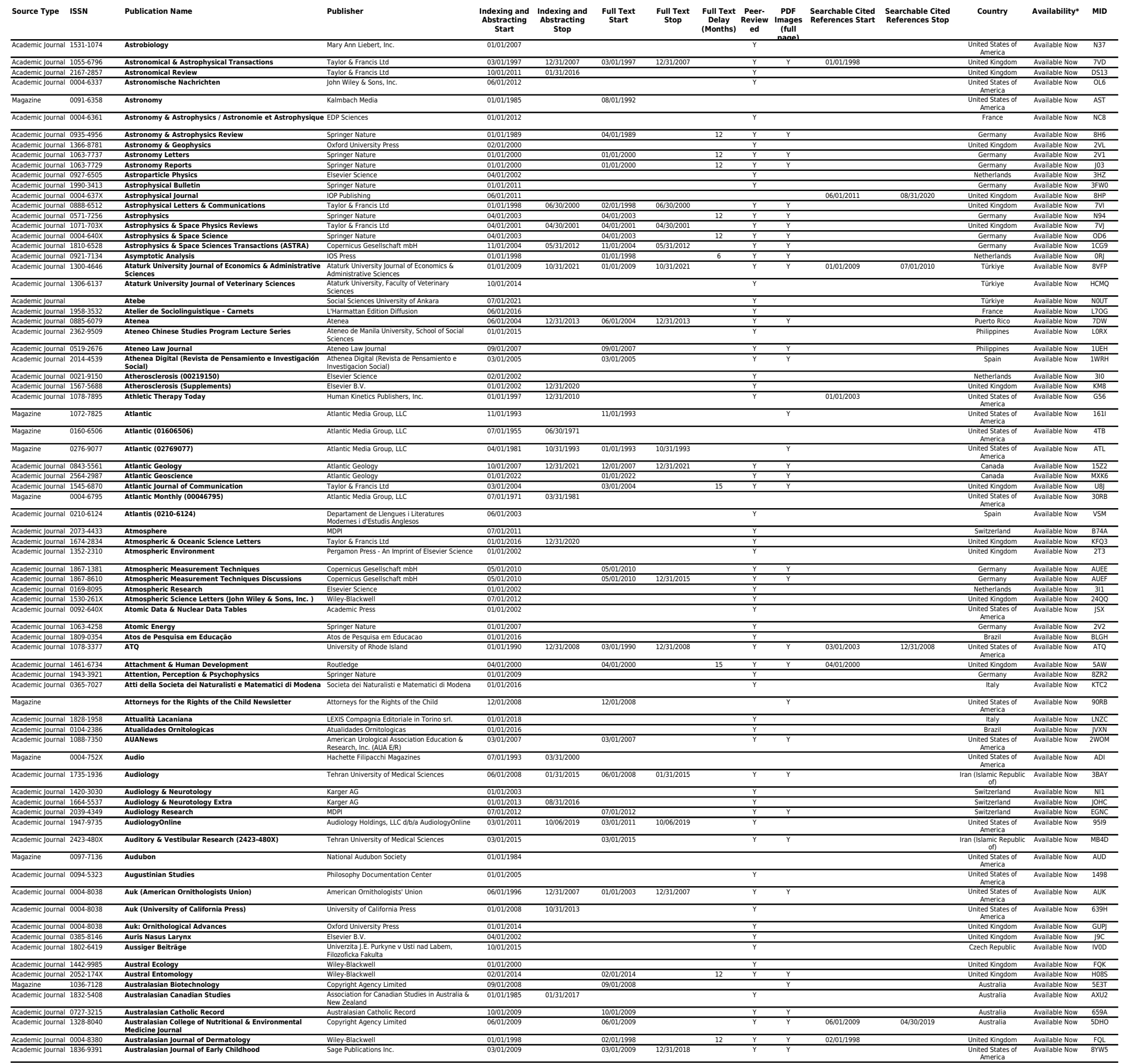




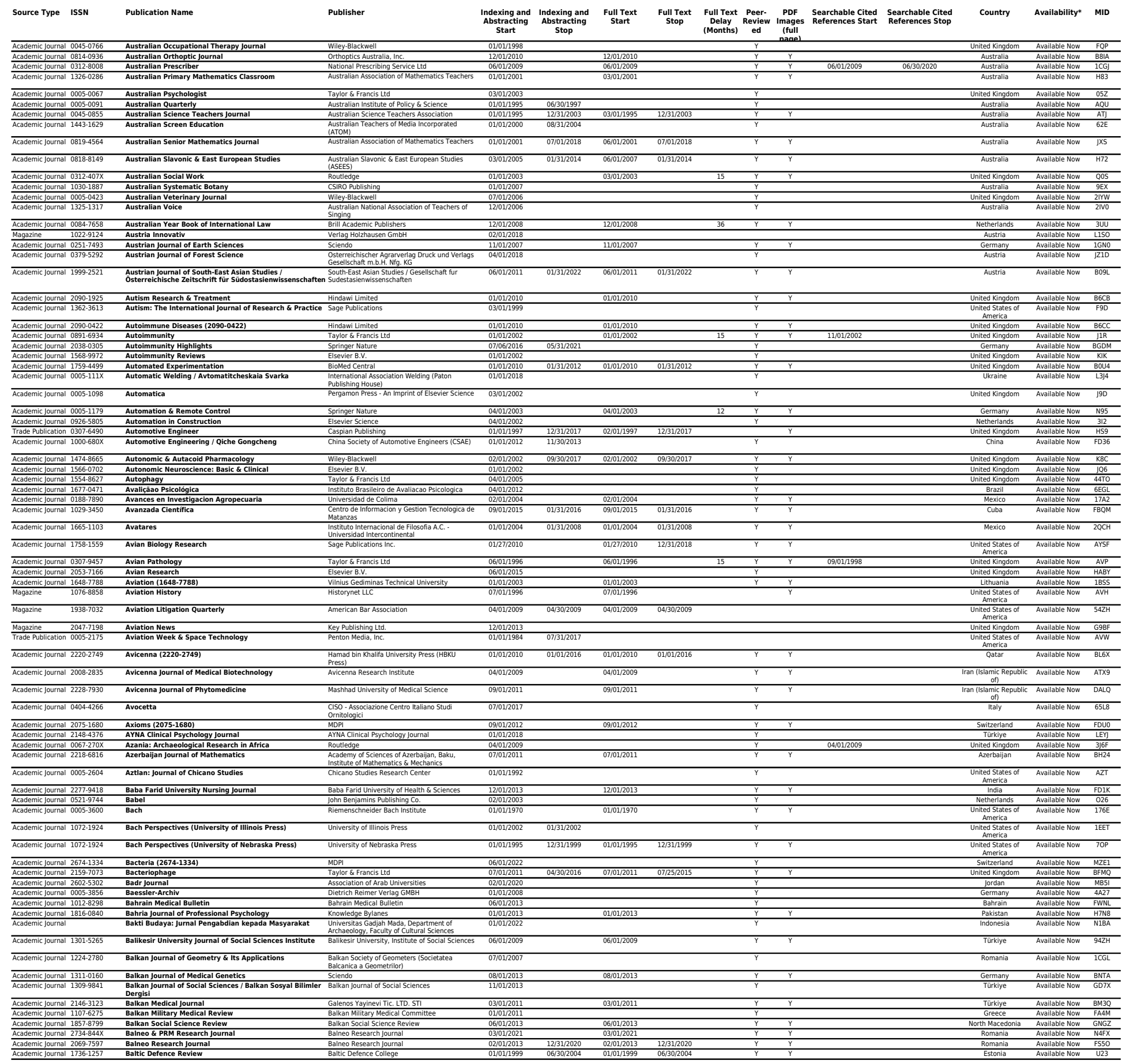




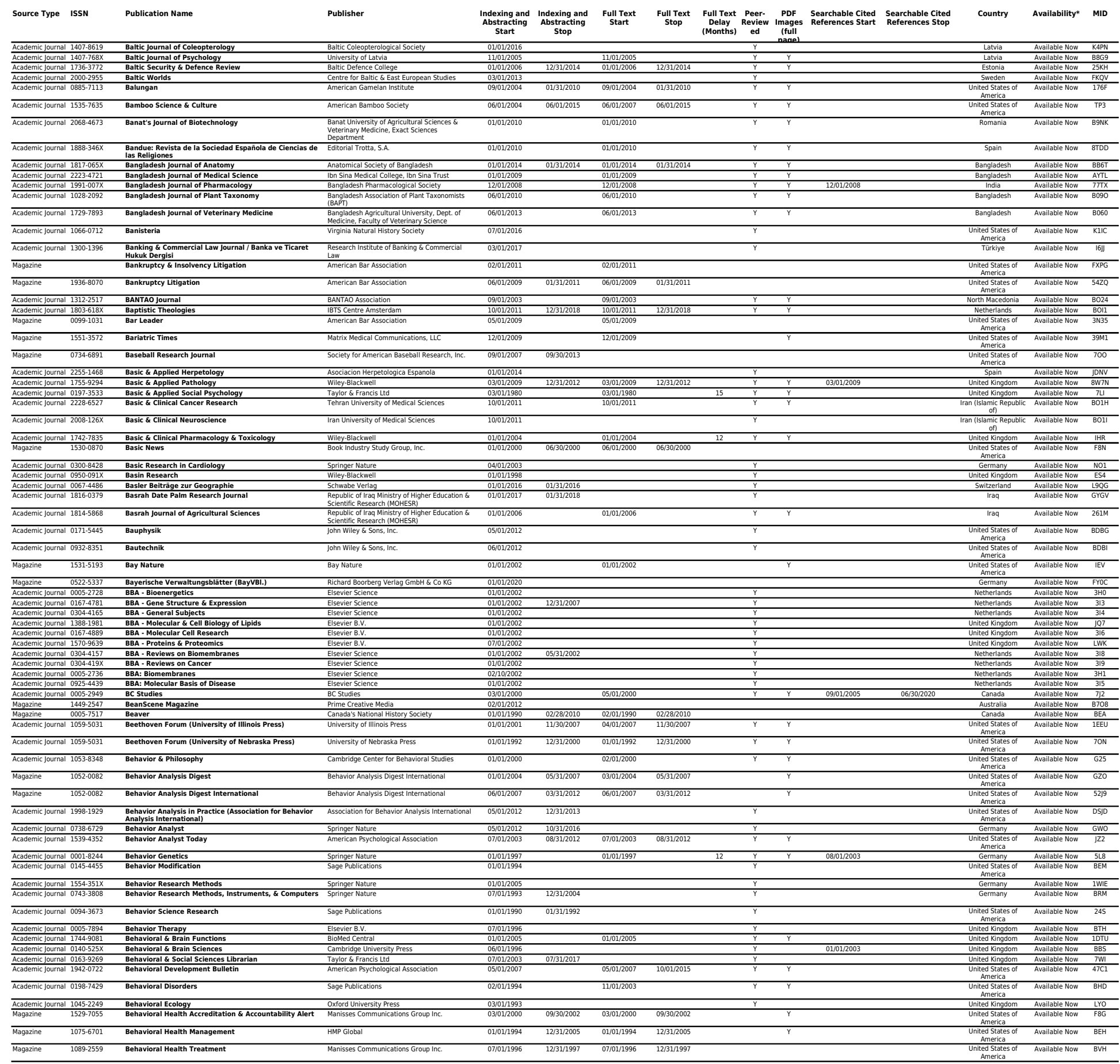




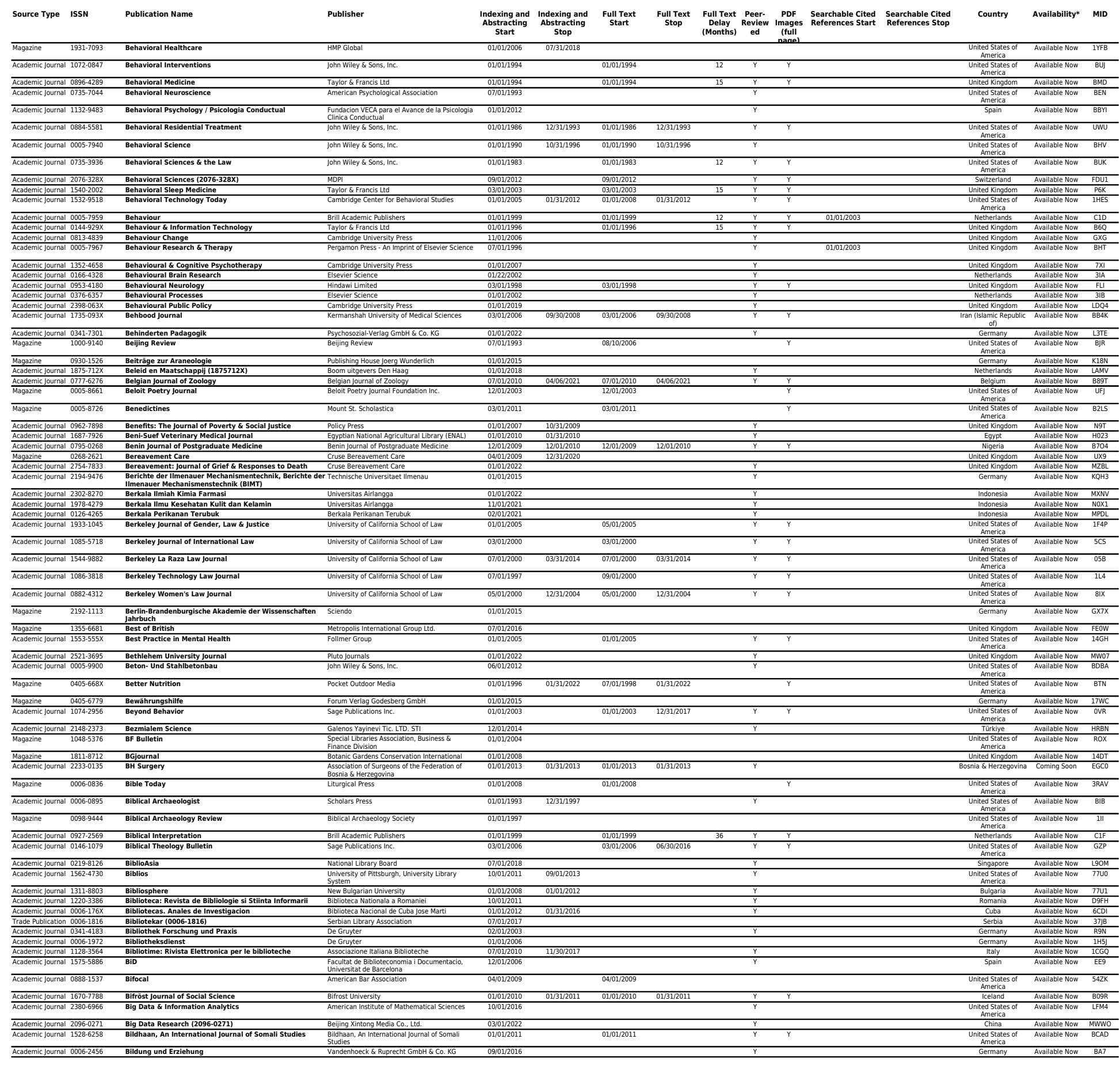




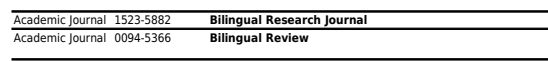

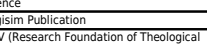

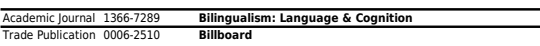

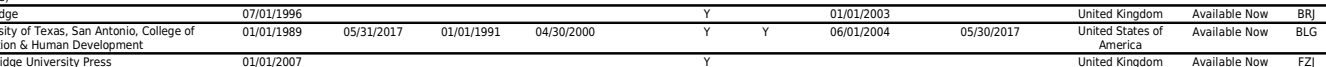

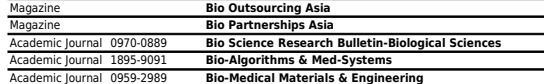

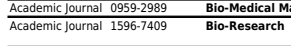

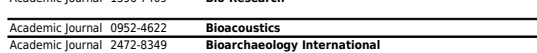

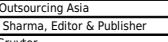

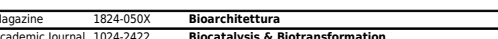

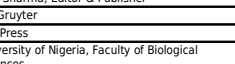

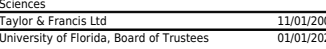

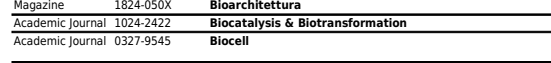

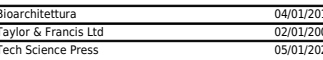

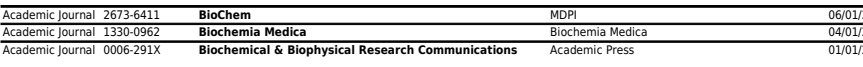

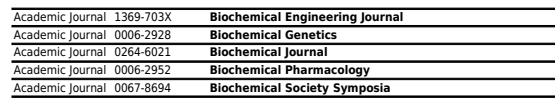

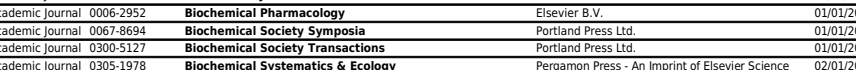

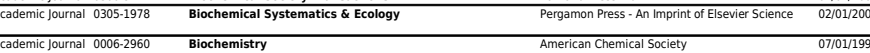

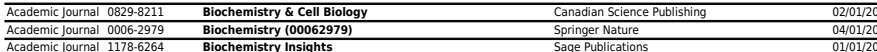

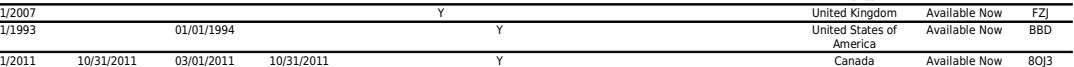

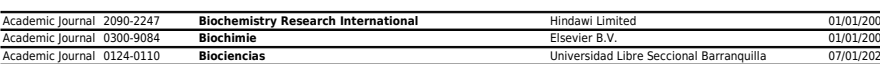

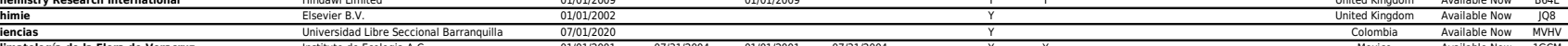

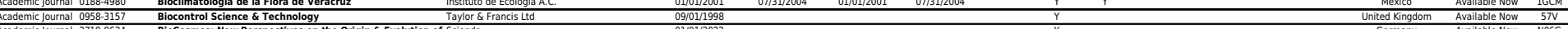

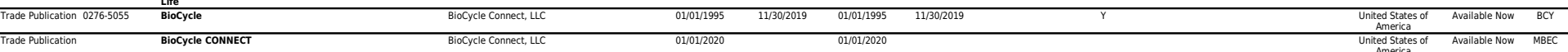

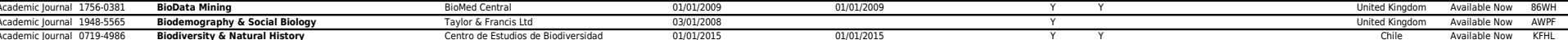

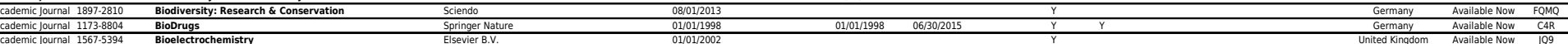

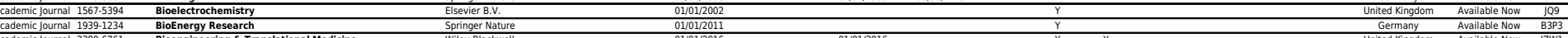

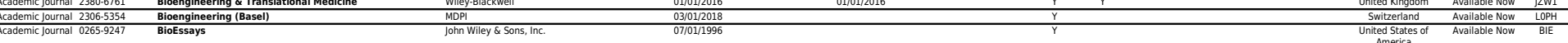

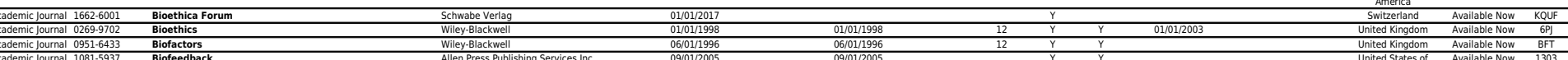

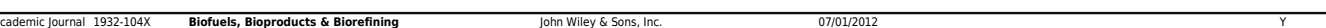

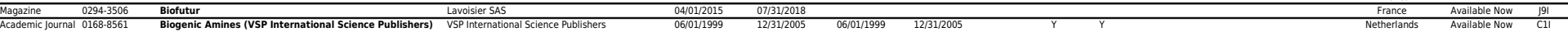

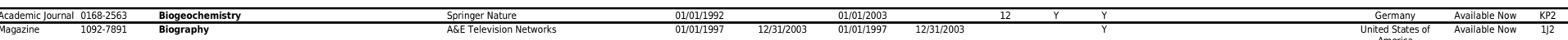

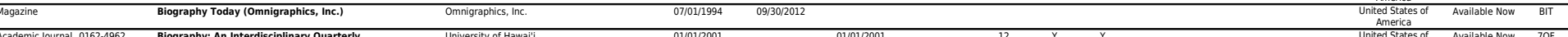

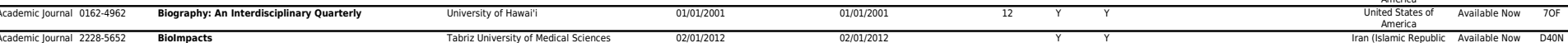

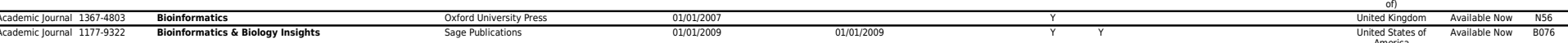

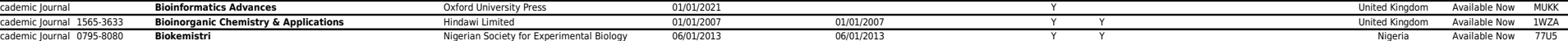

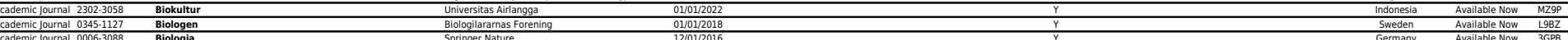

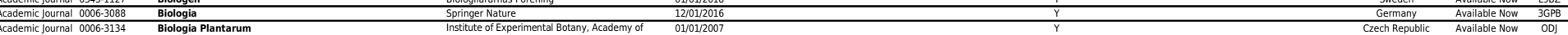

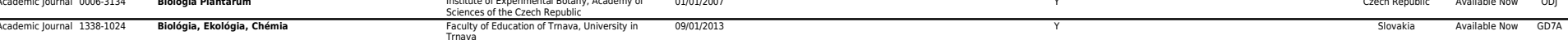

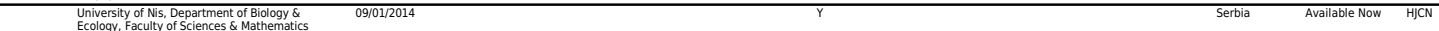

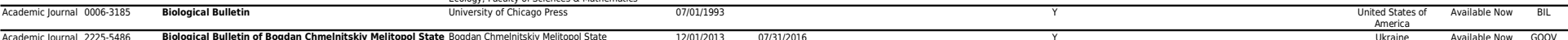

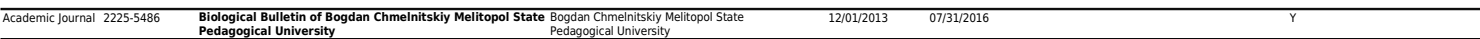

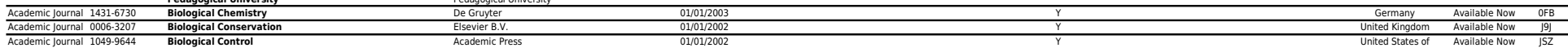

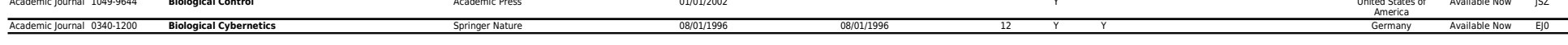




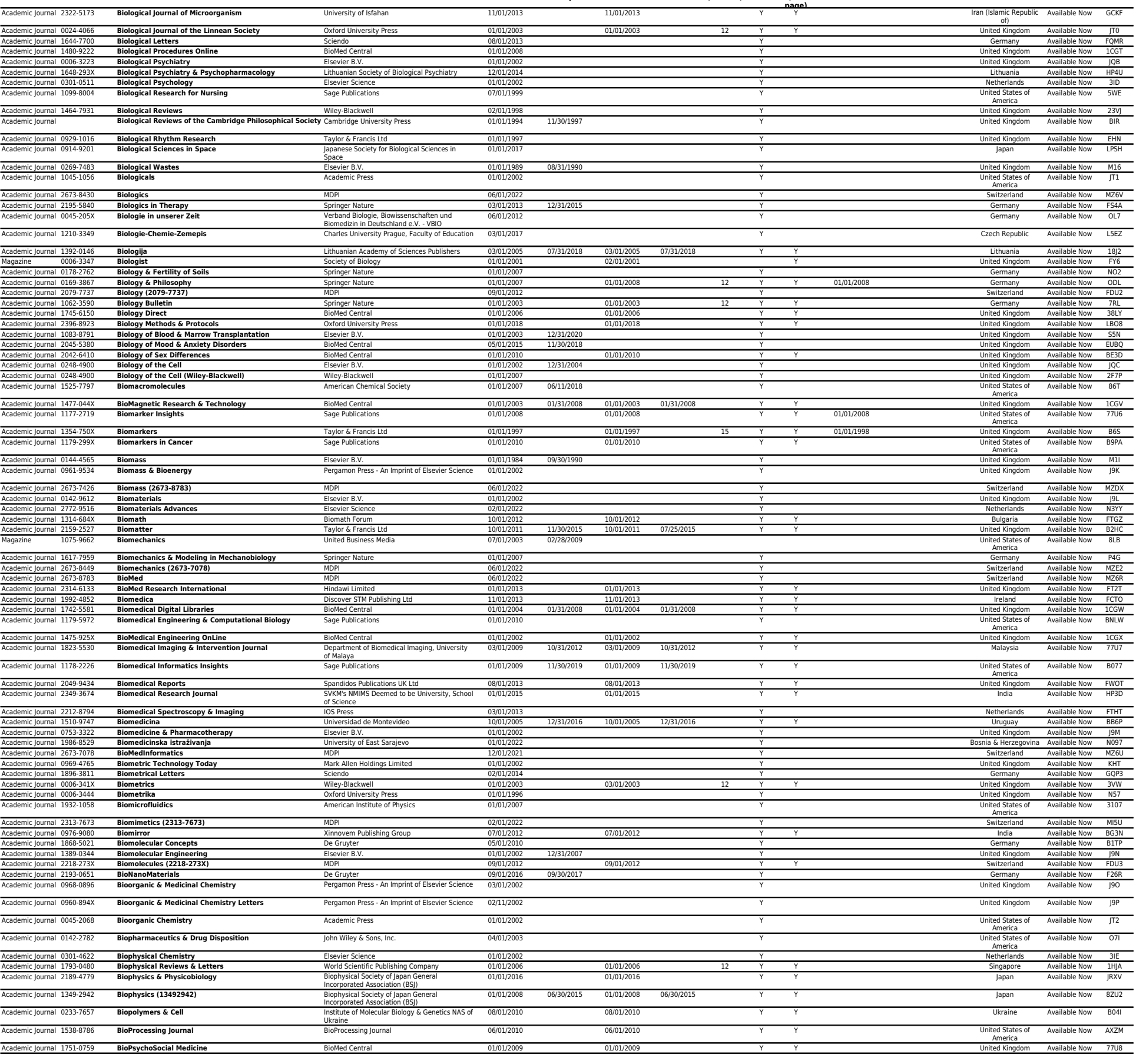




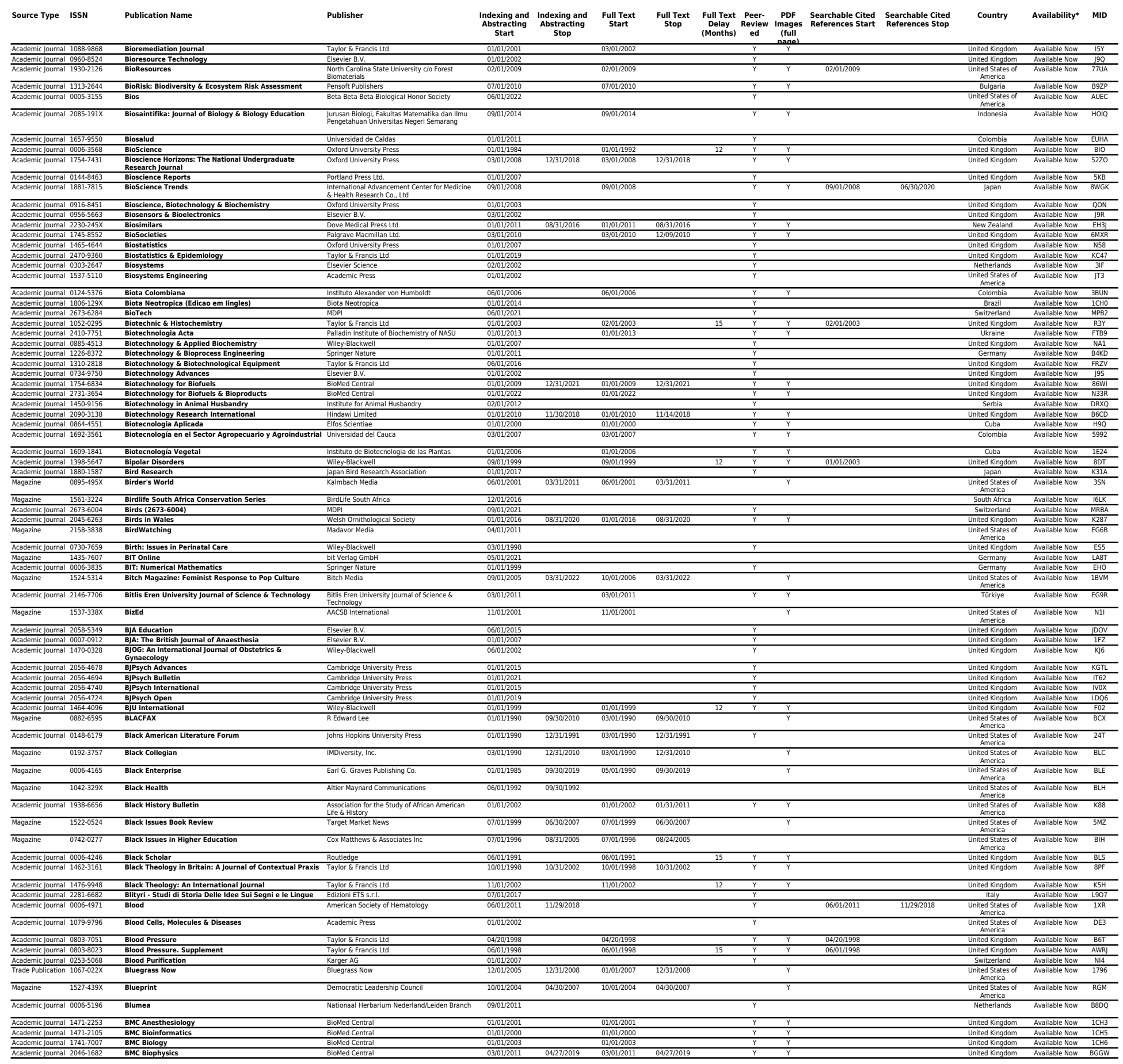




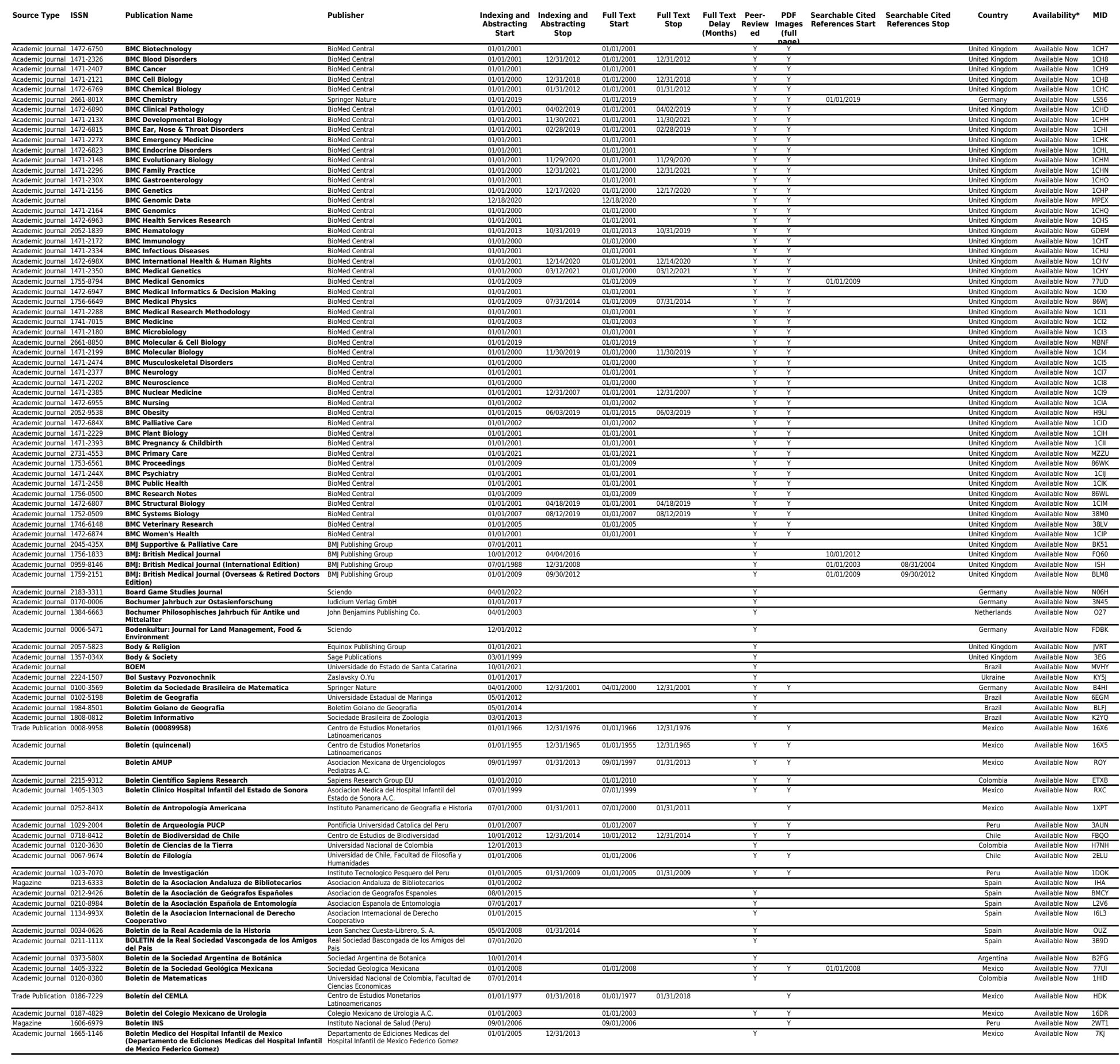




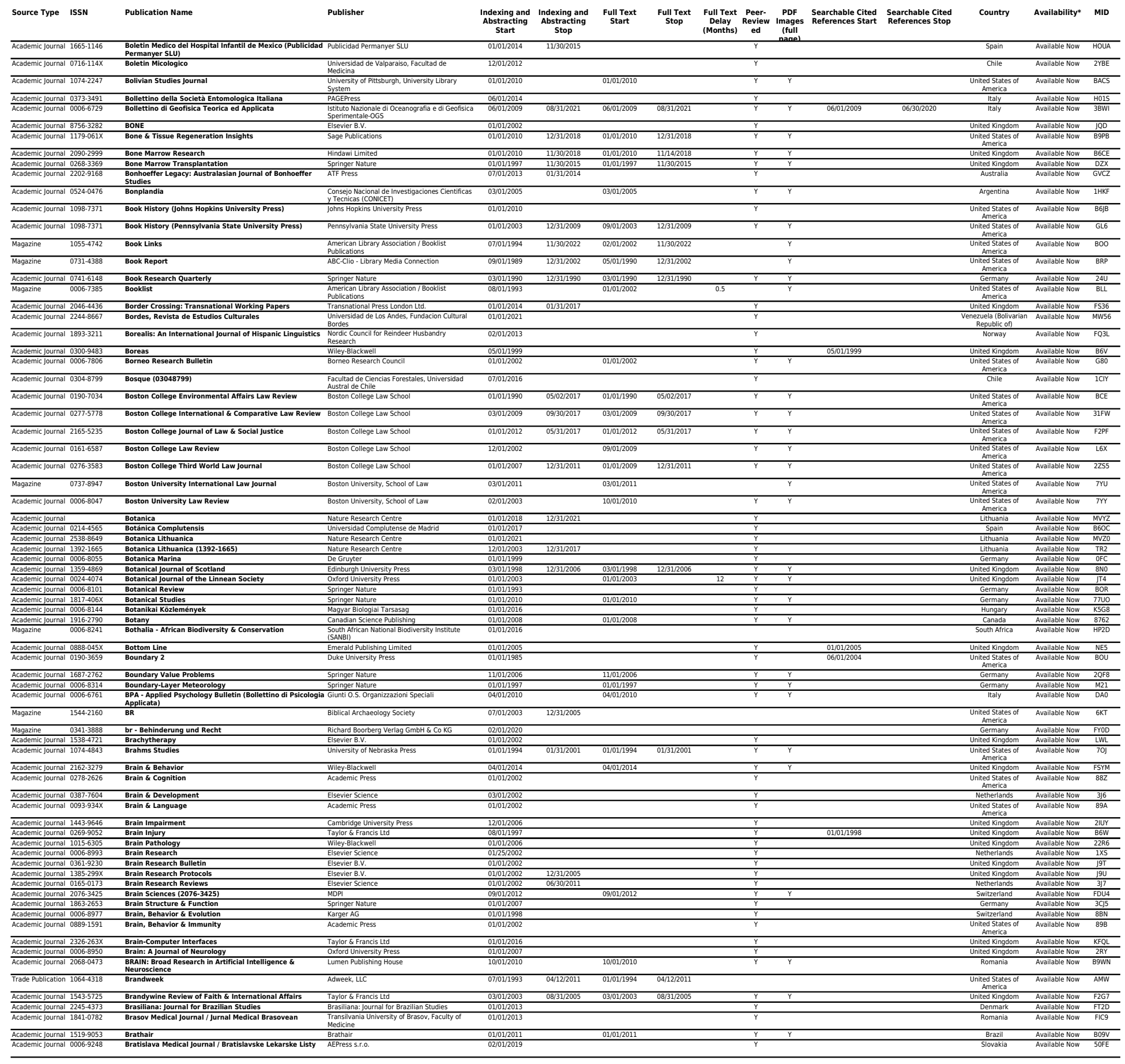




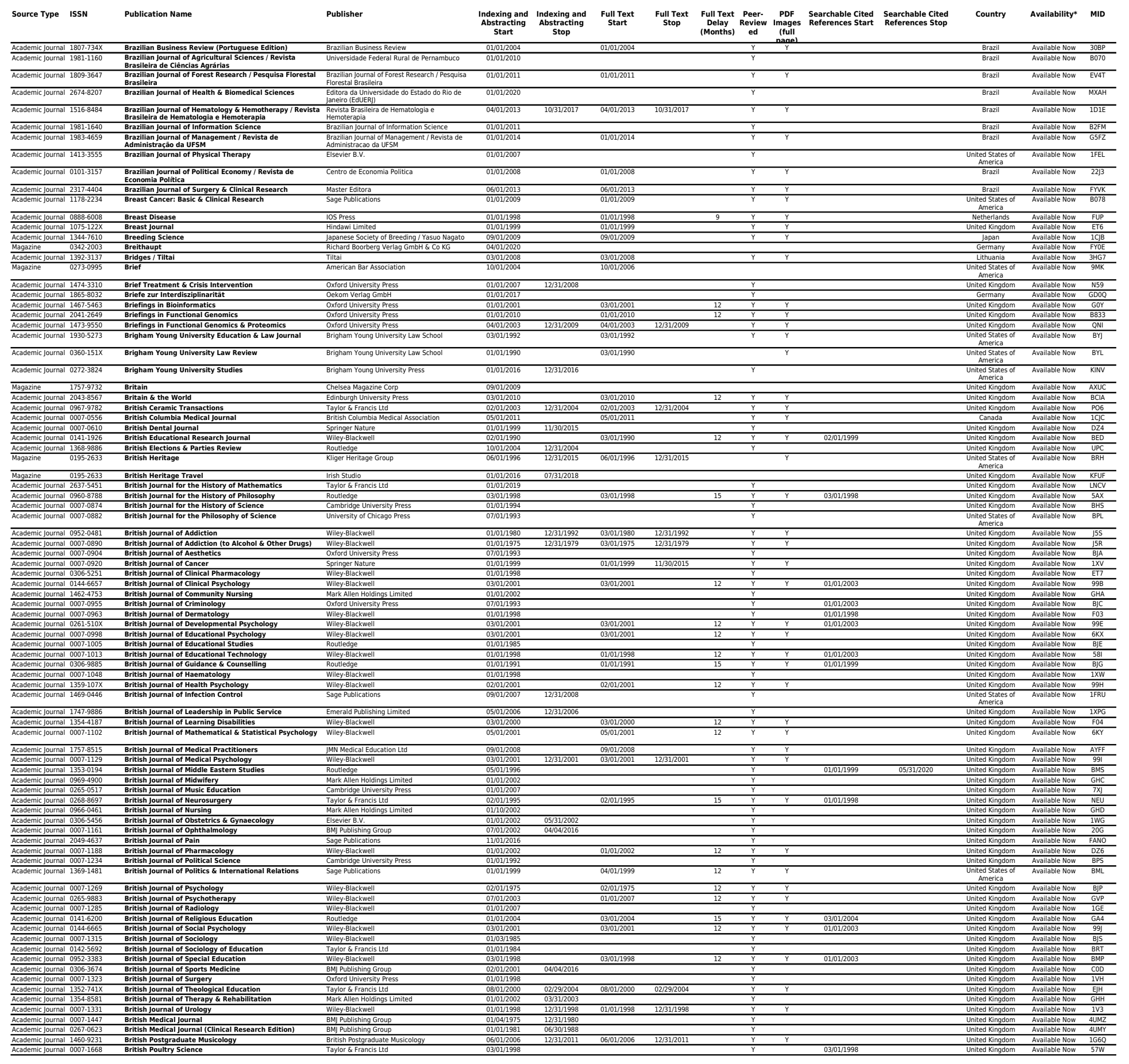




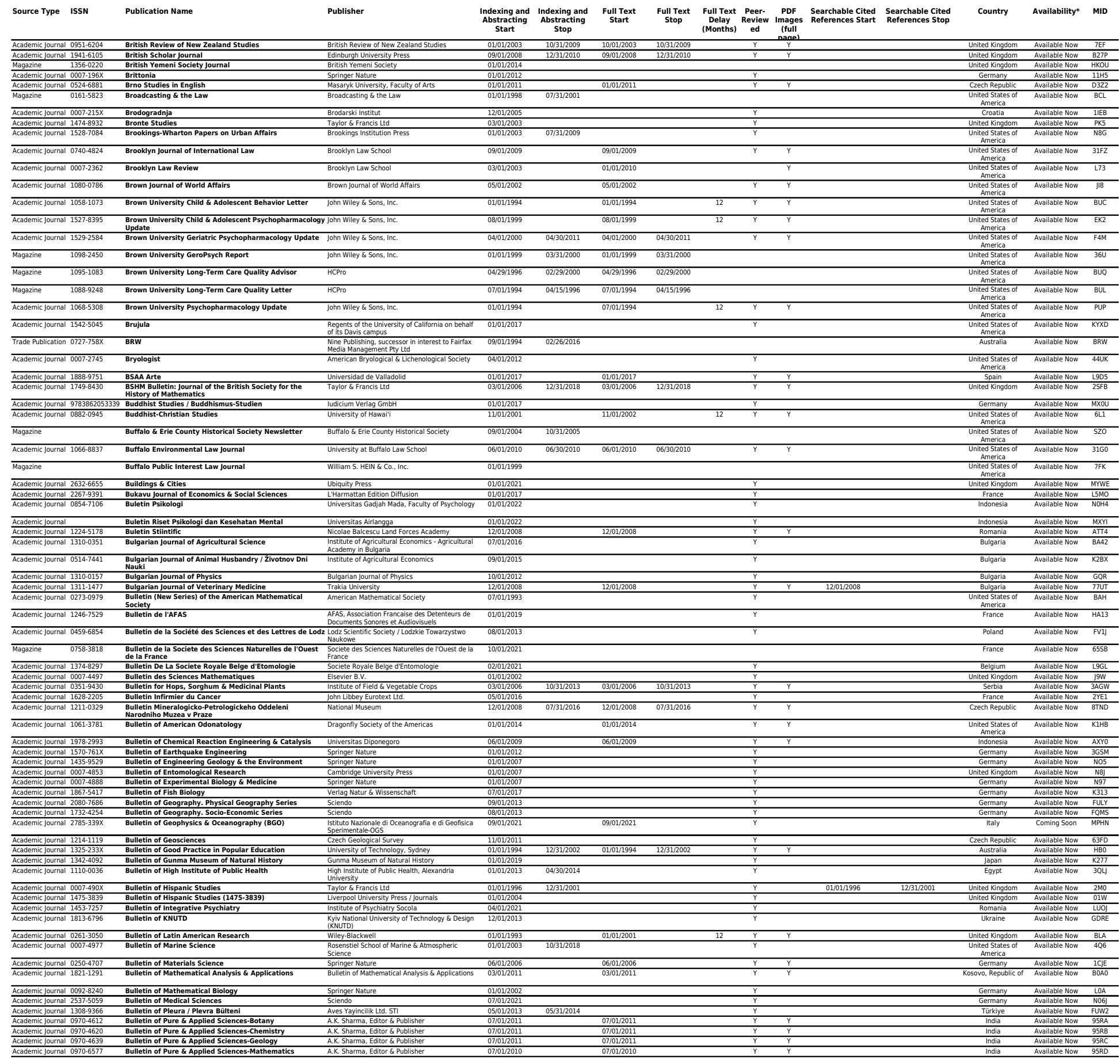




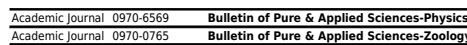

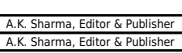

$\frac{0.07012011}{07701212010}$

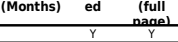

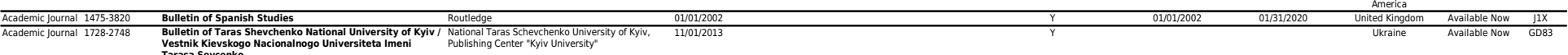

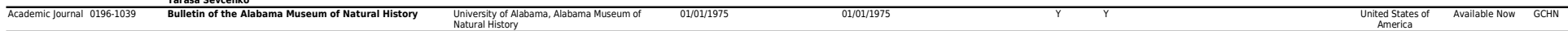

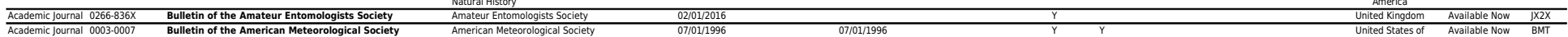

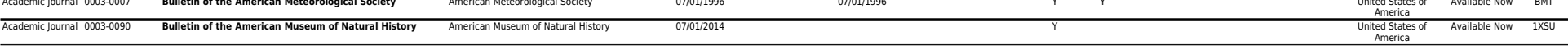

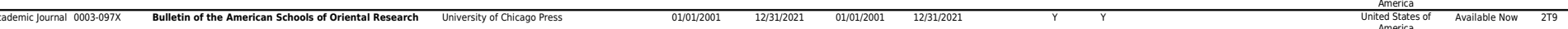

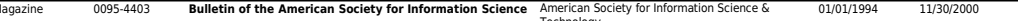

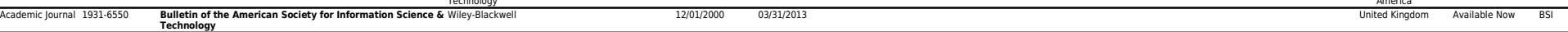

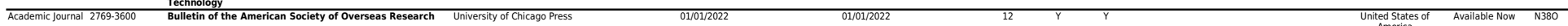

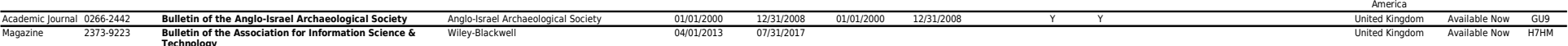

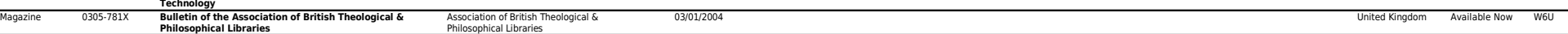

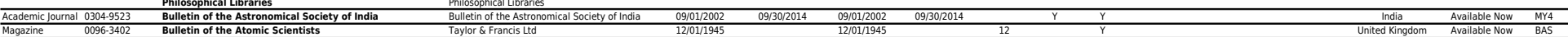

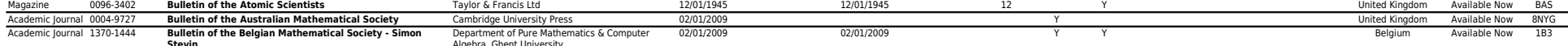

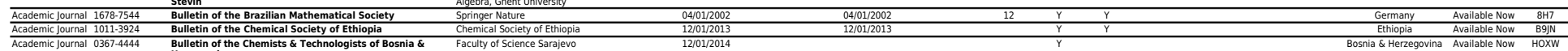

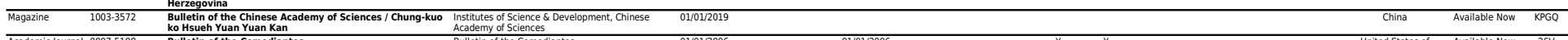

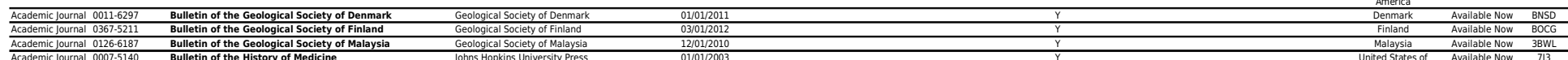

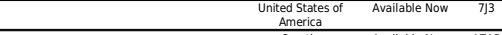

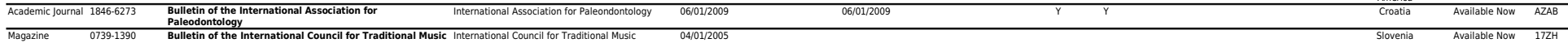

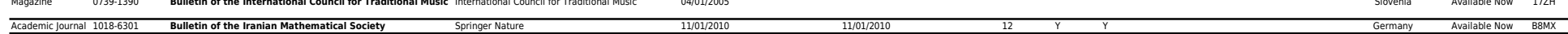

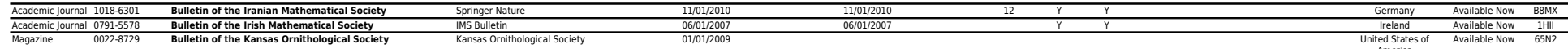

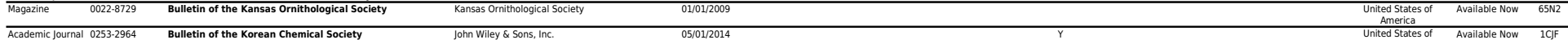

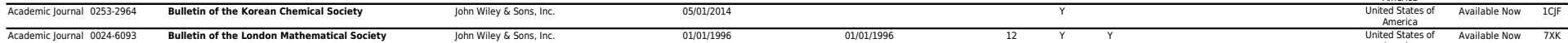

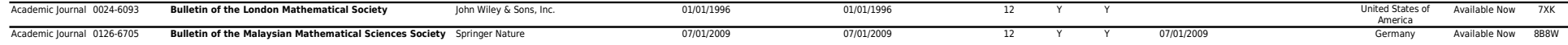

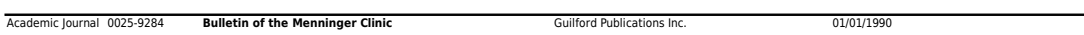

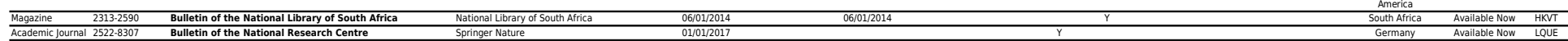

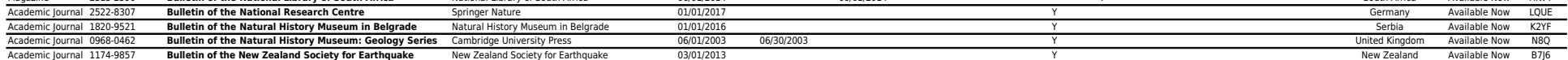

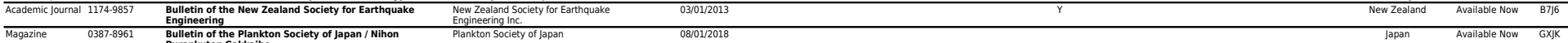

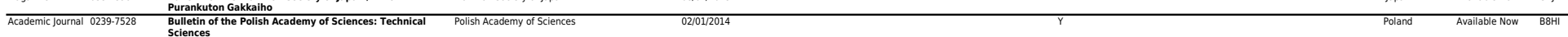

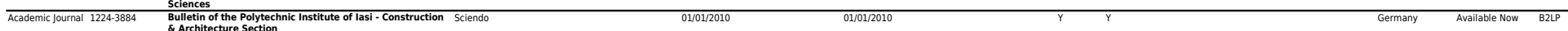

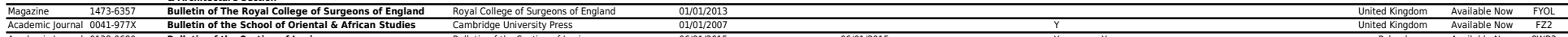

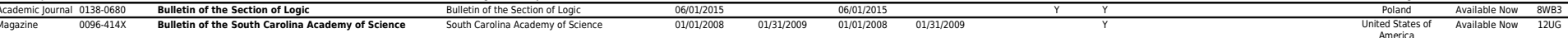

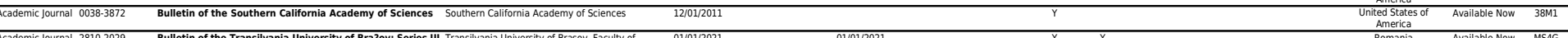

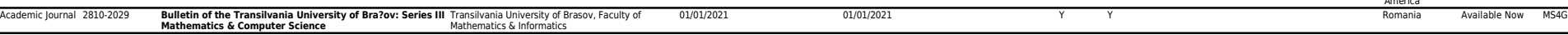

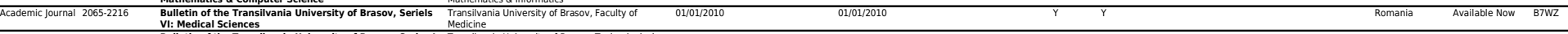

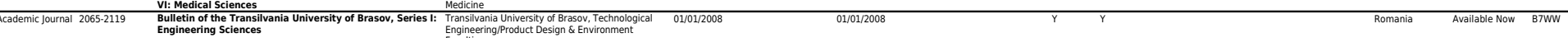

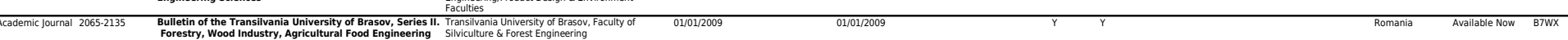

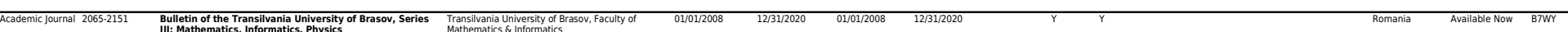

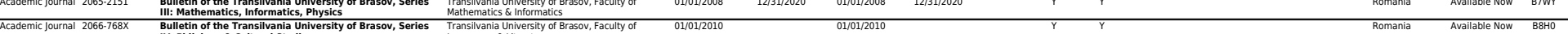

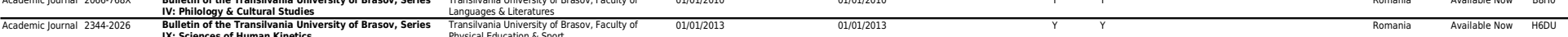

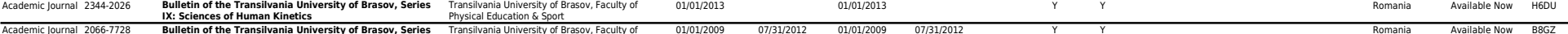

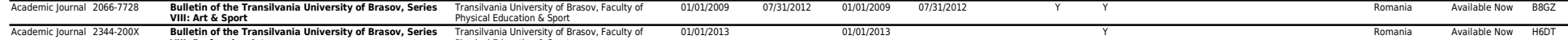

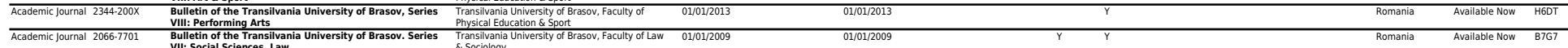

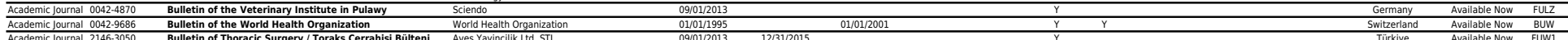

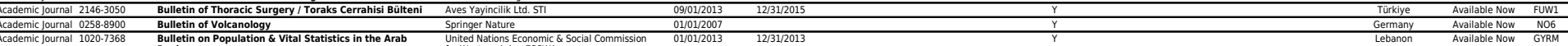

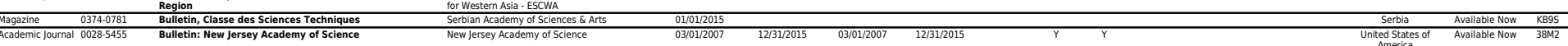




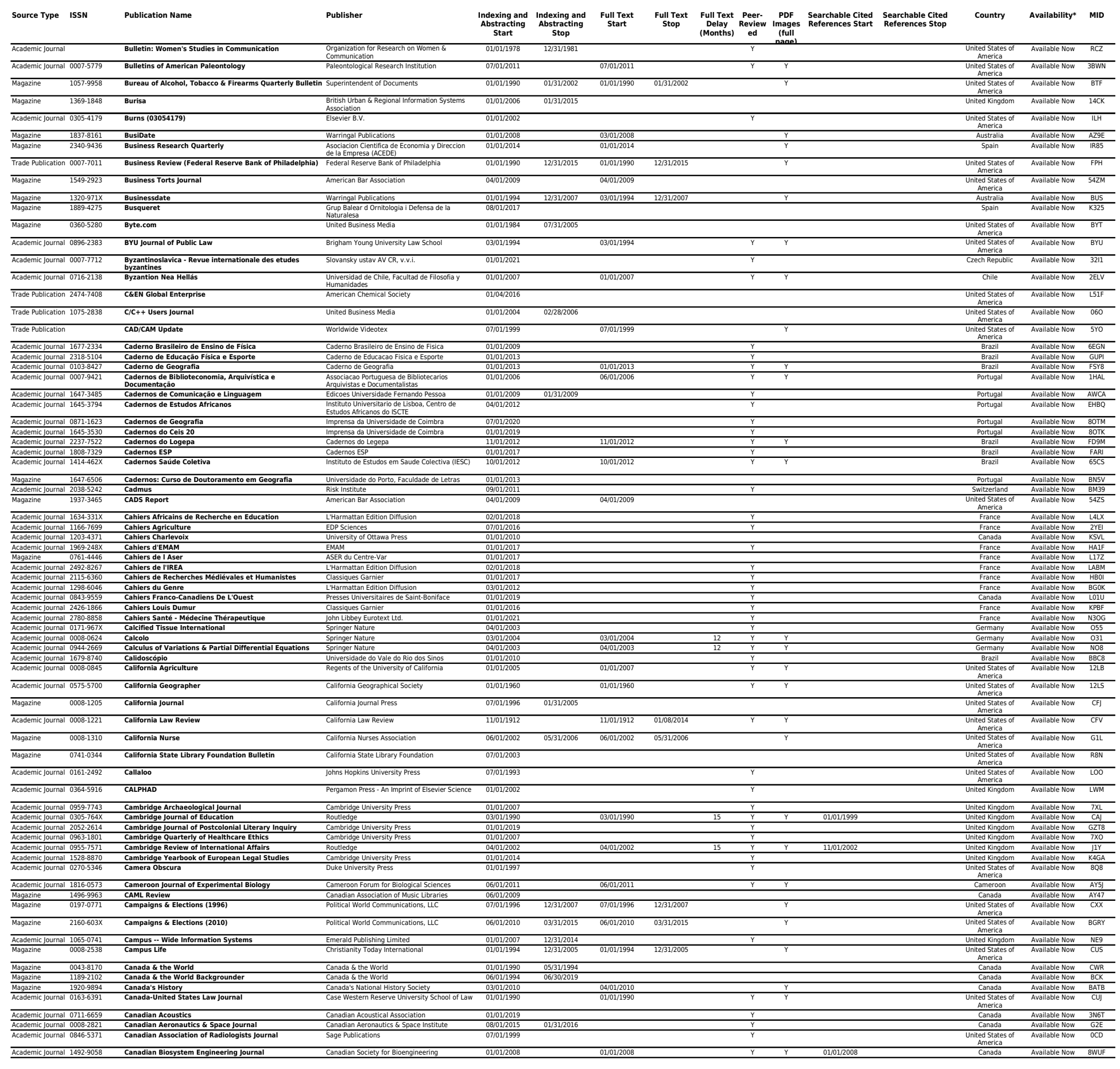




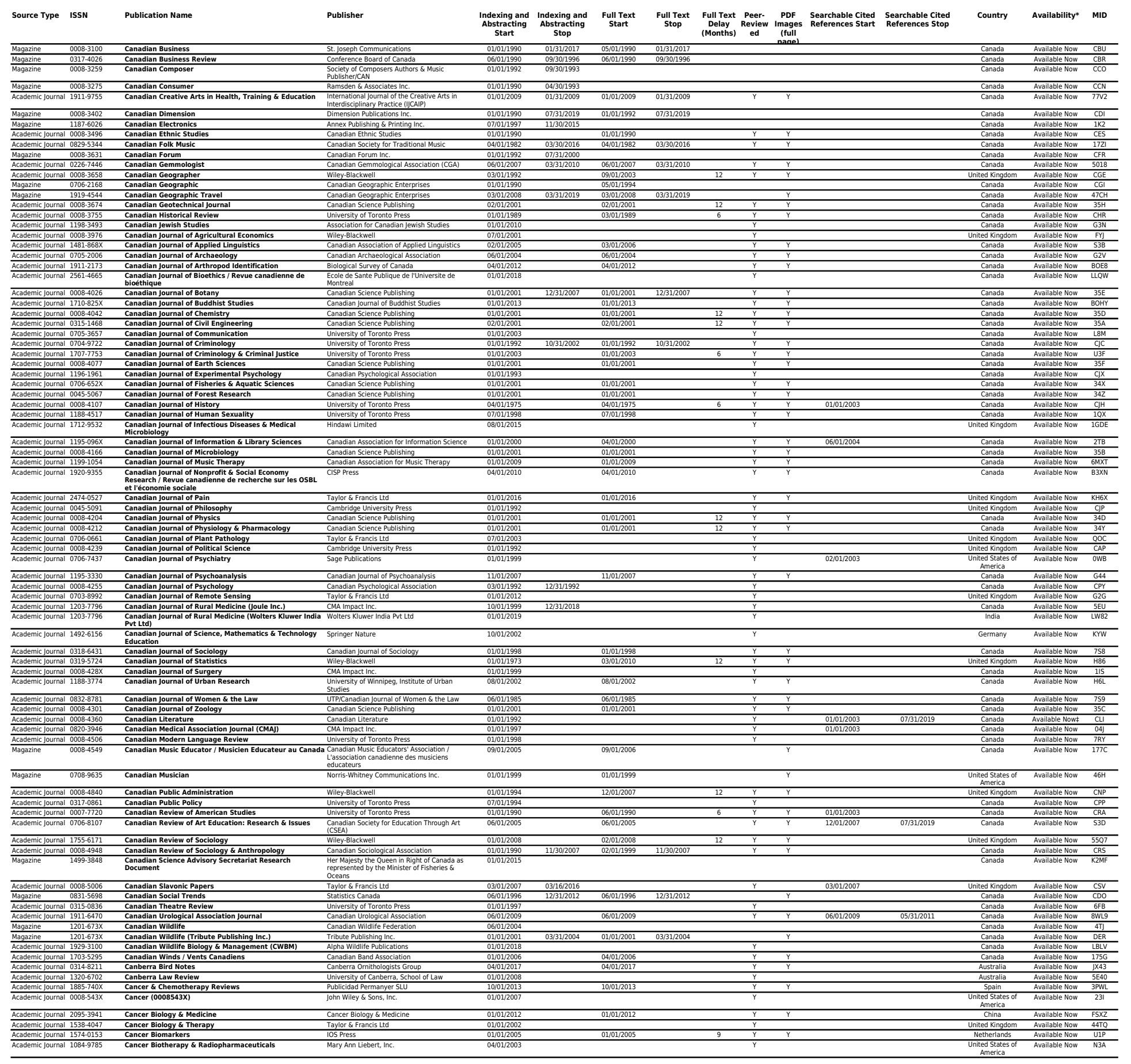




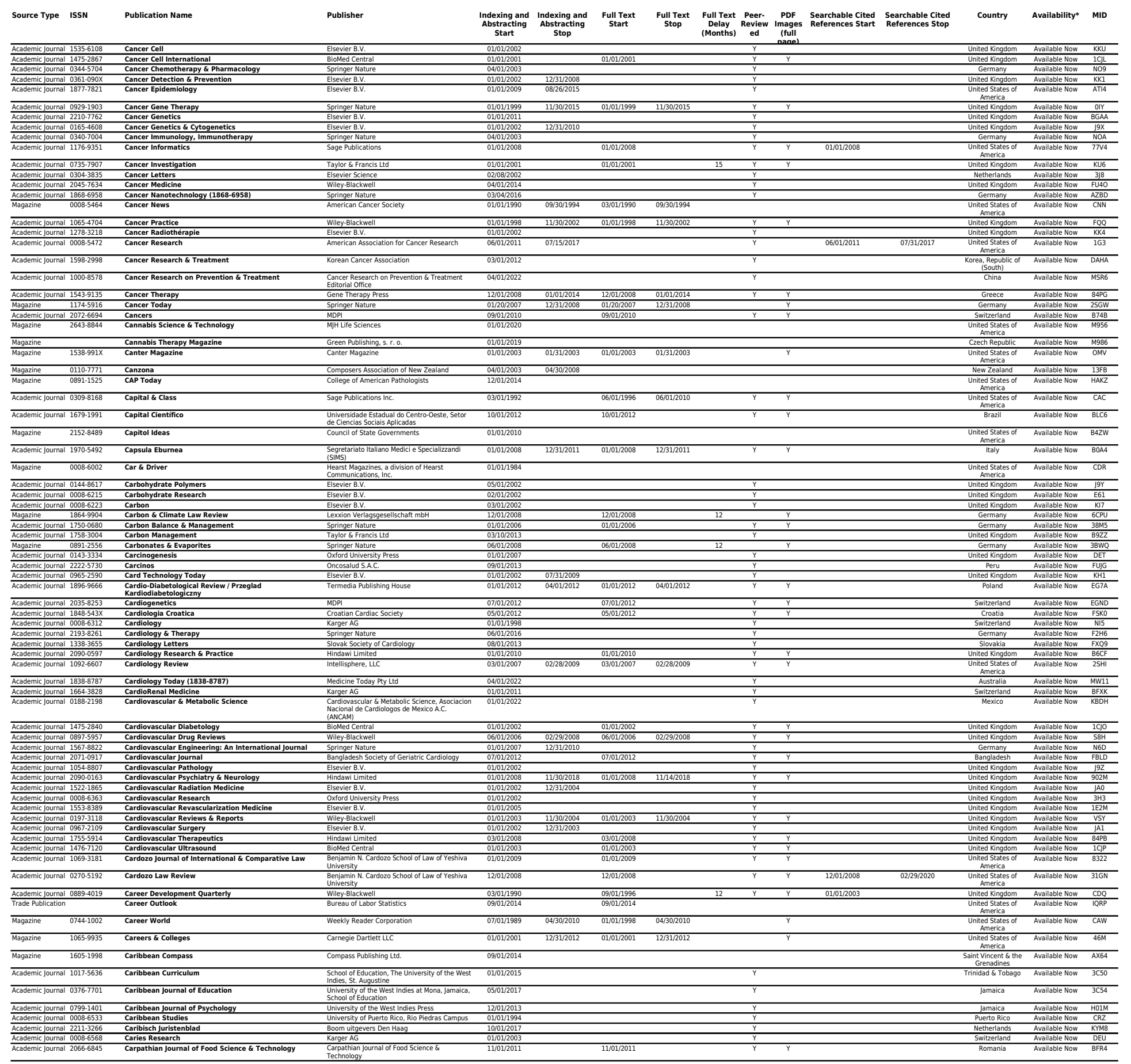




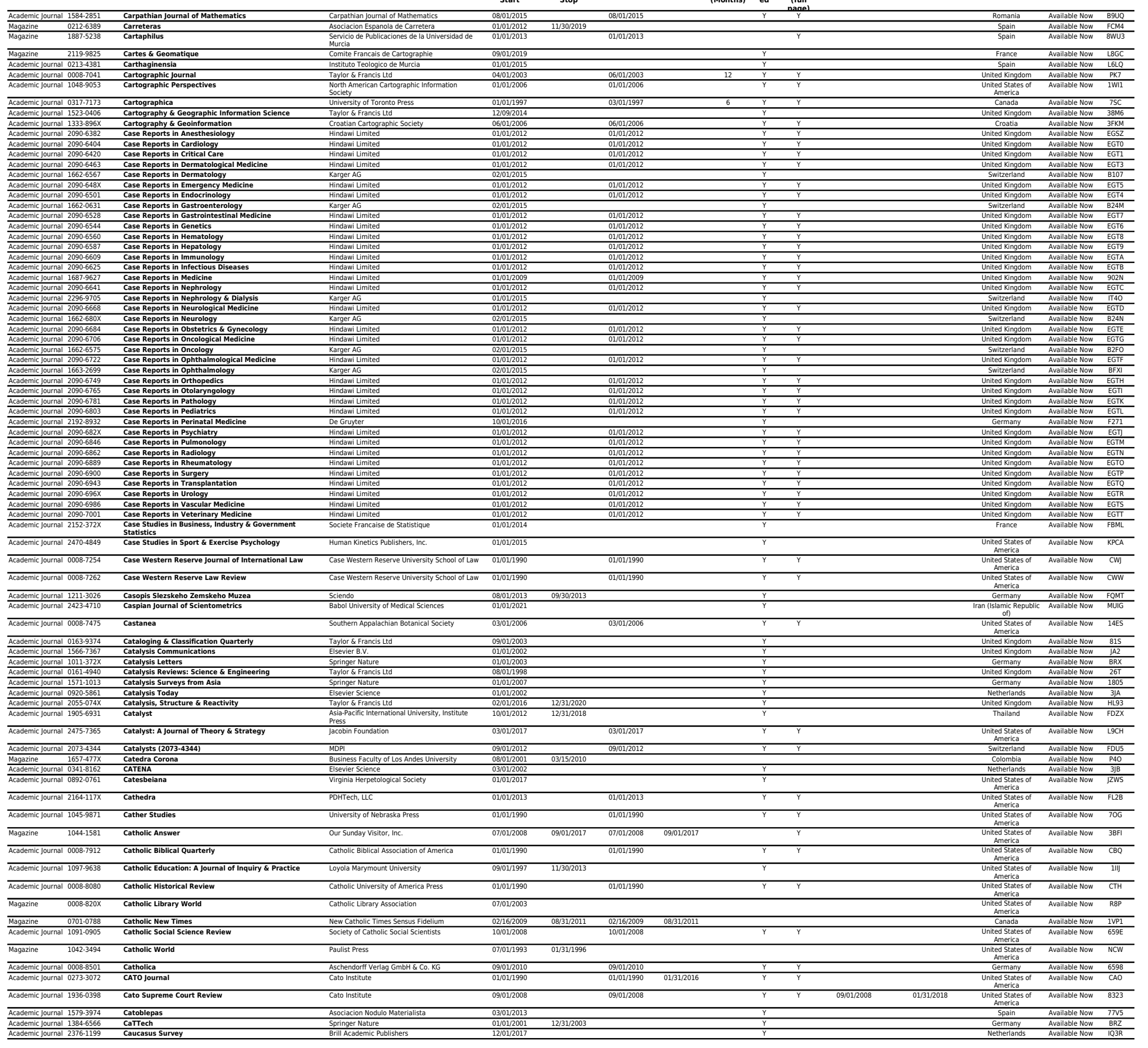




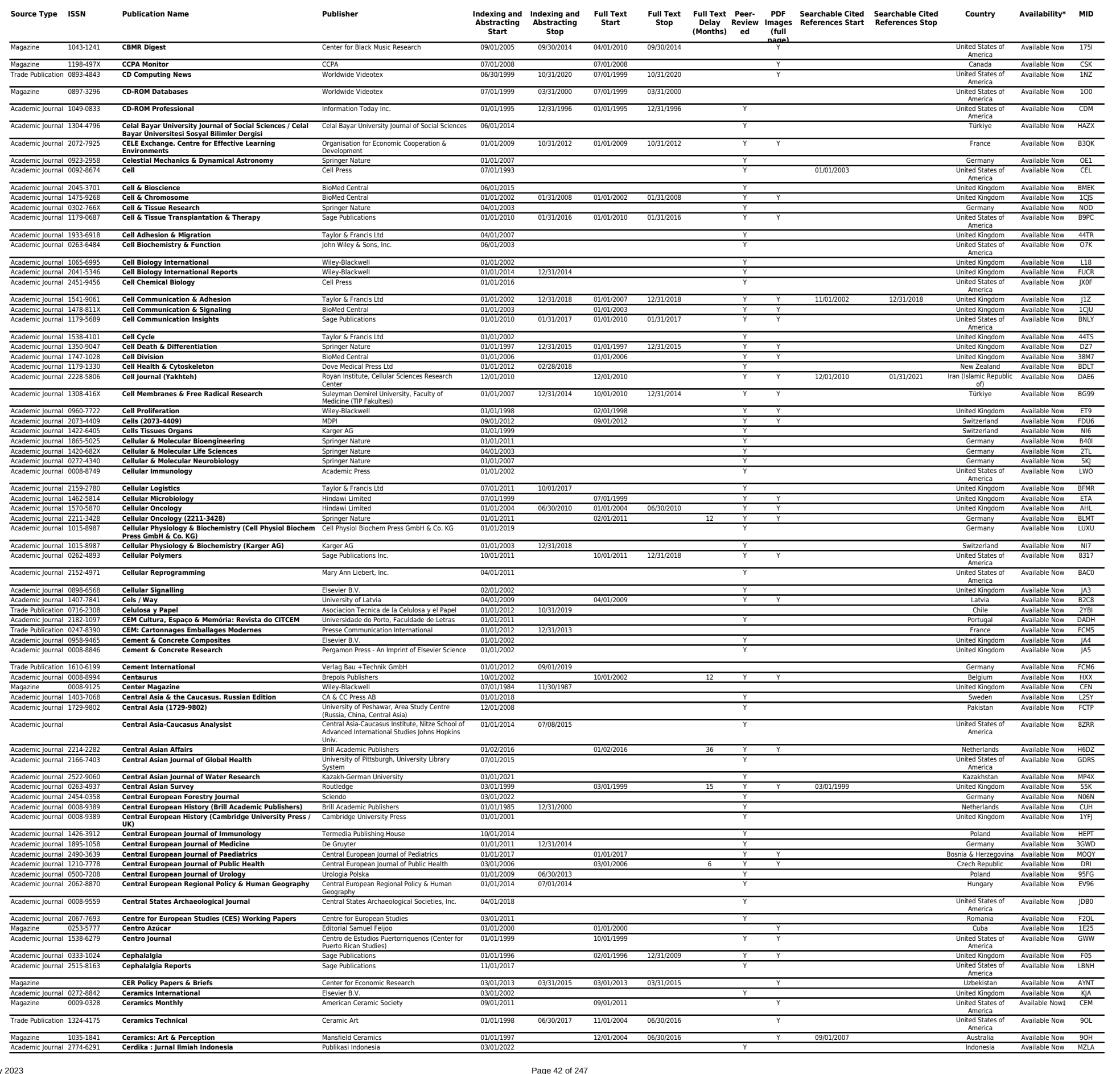




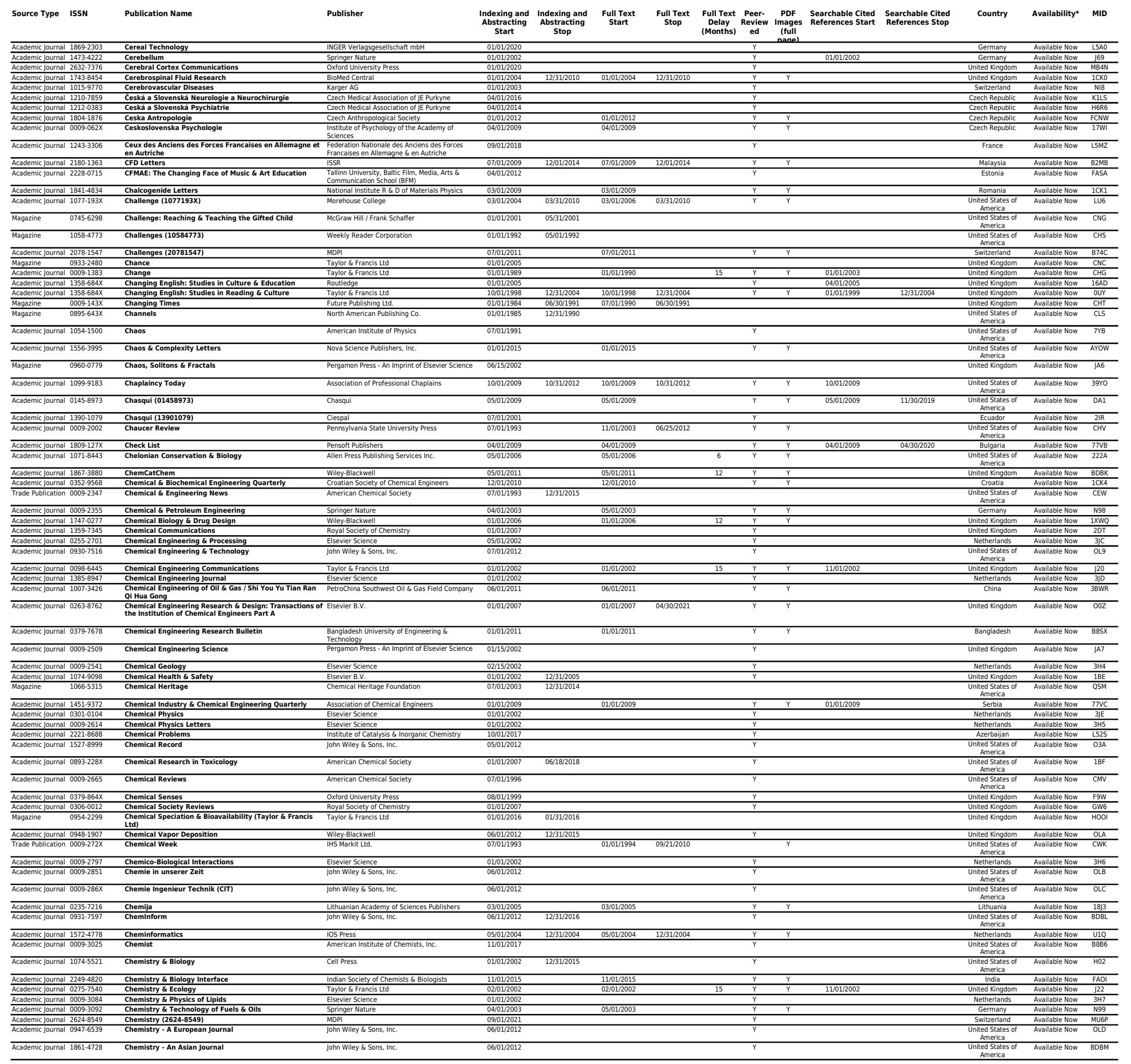




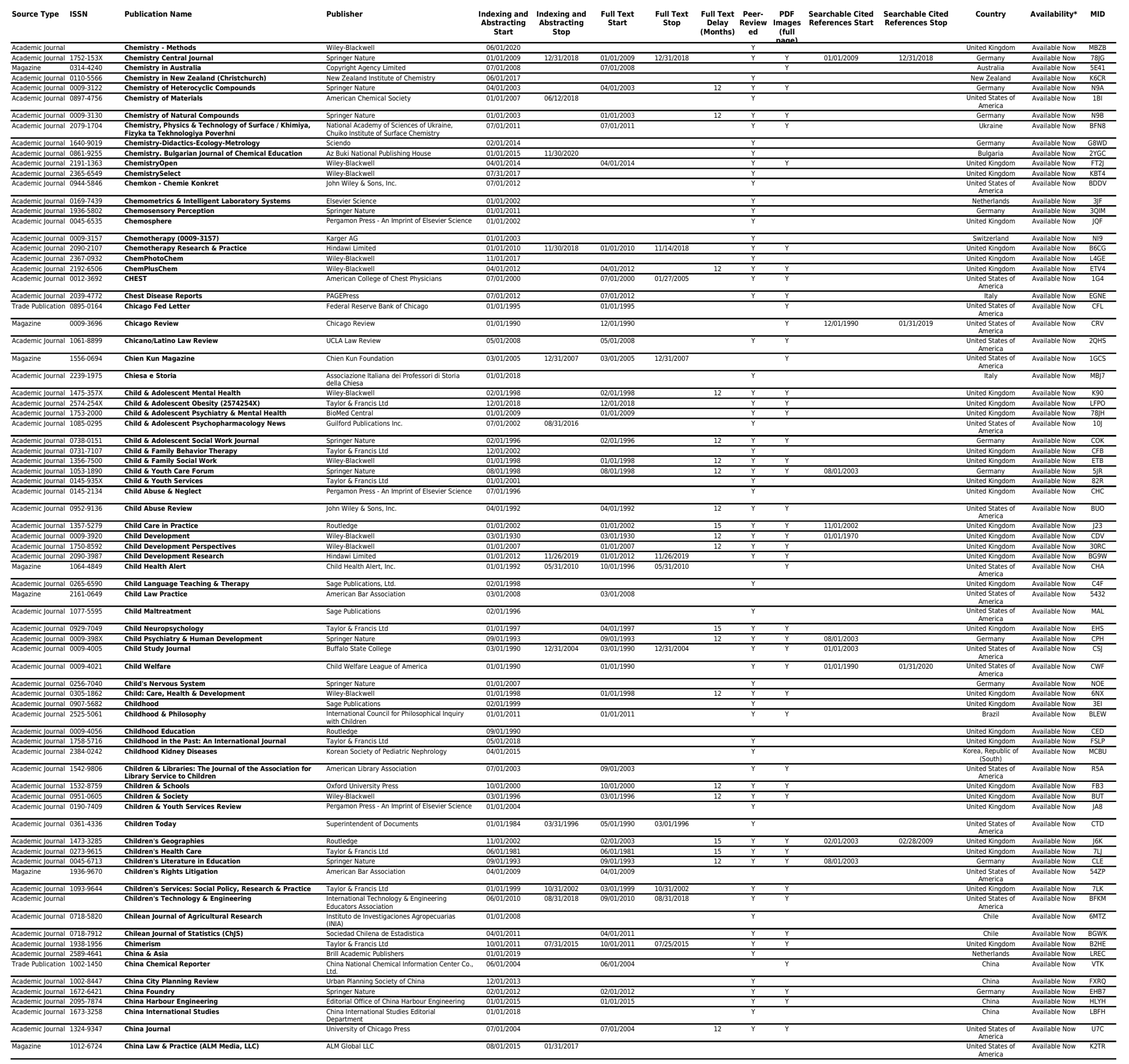




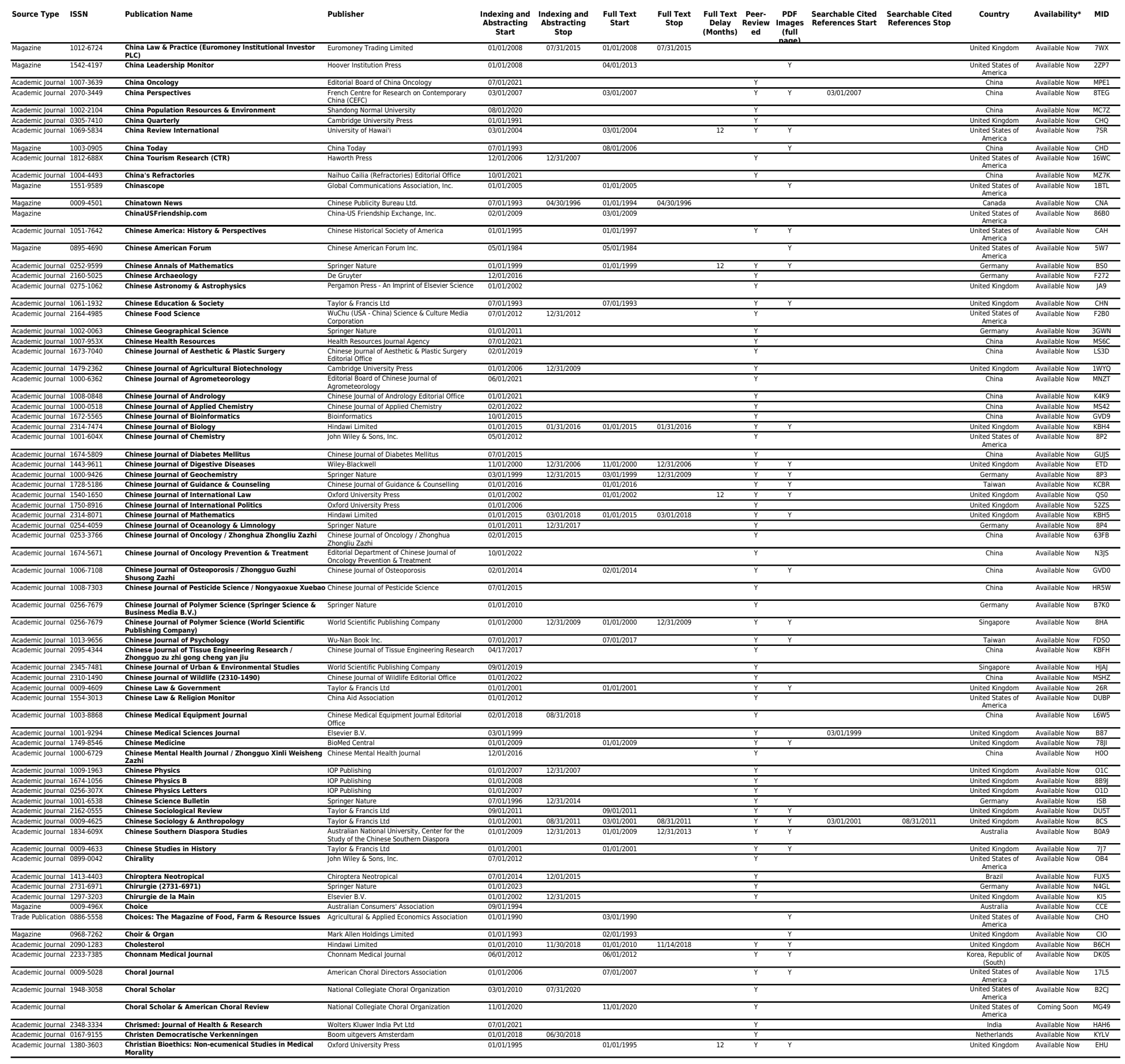




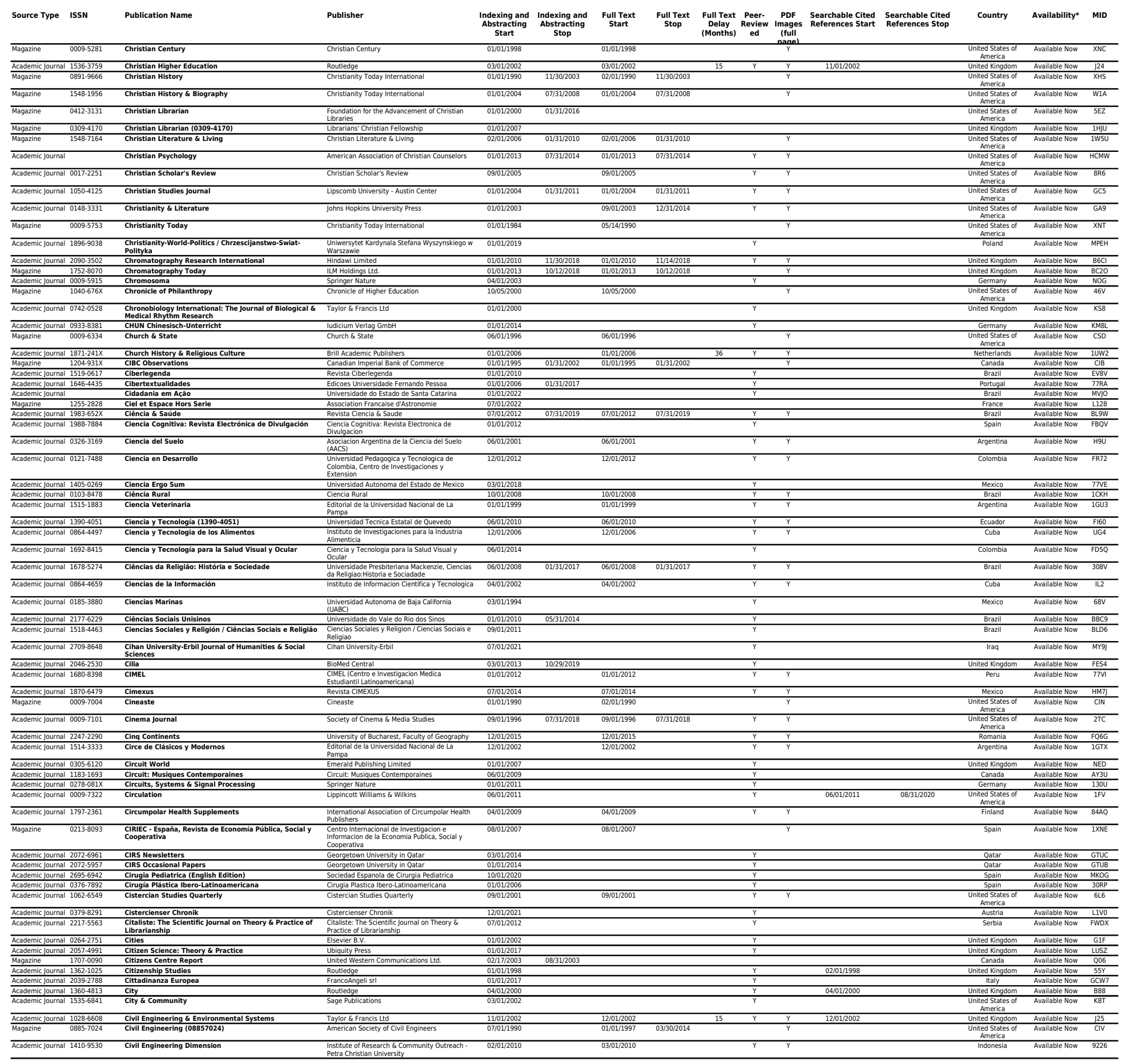




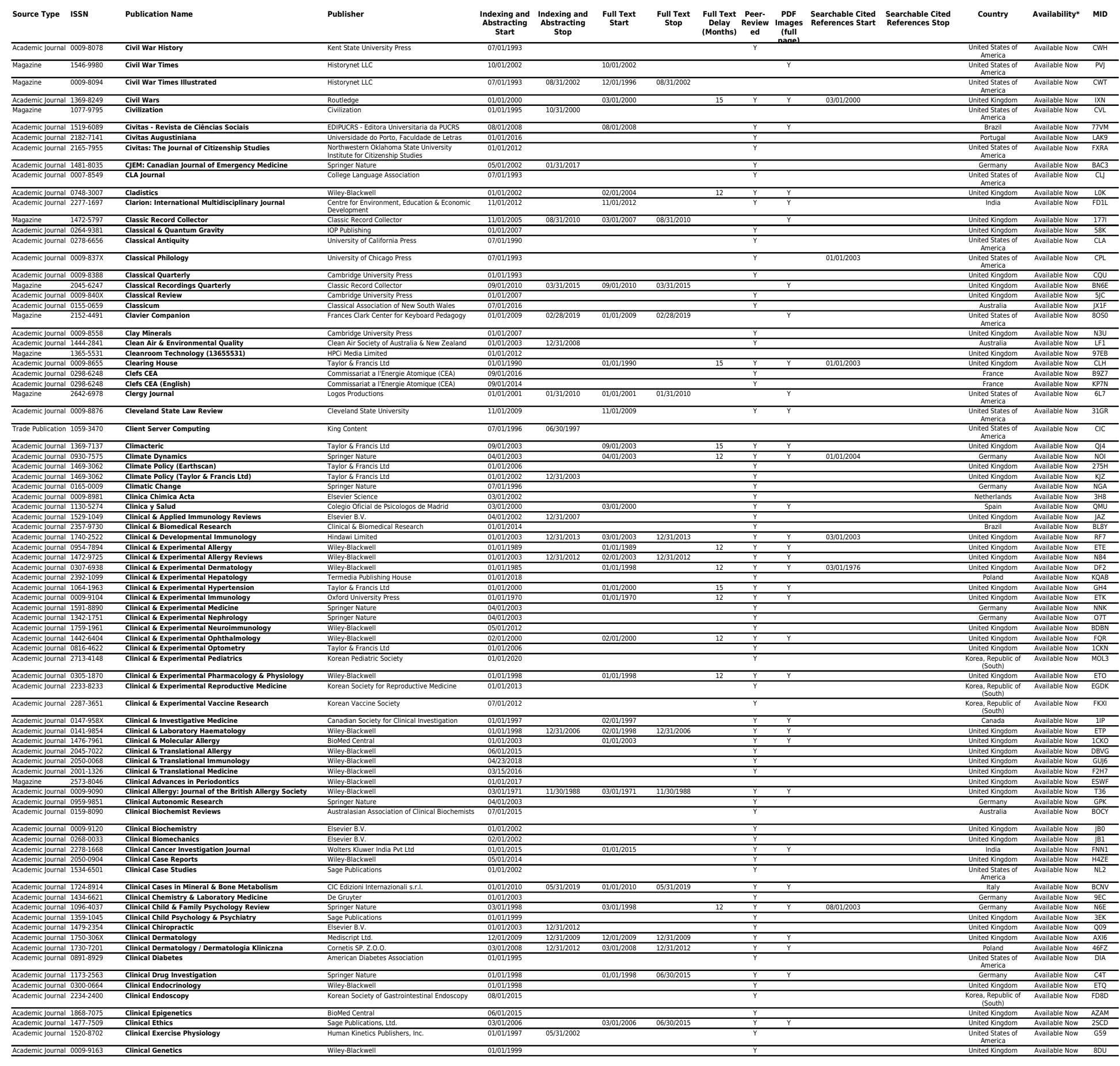




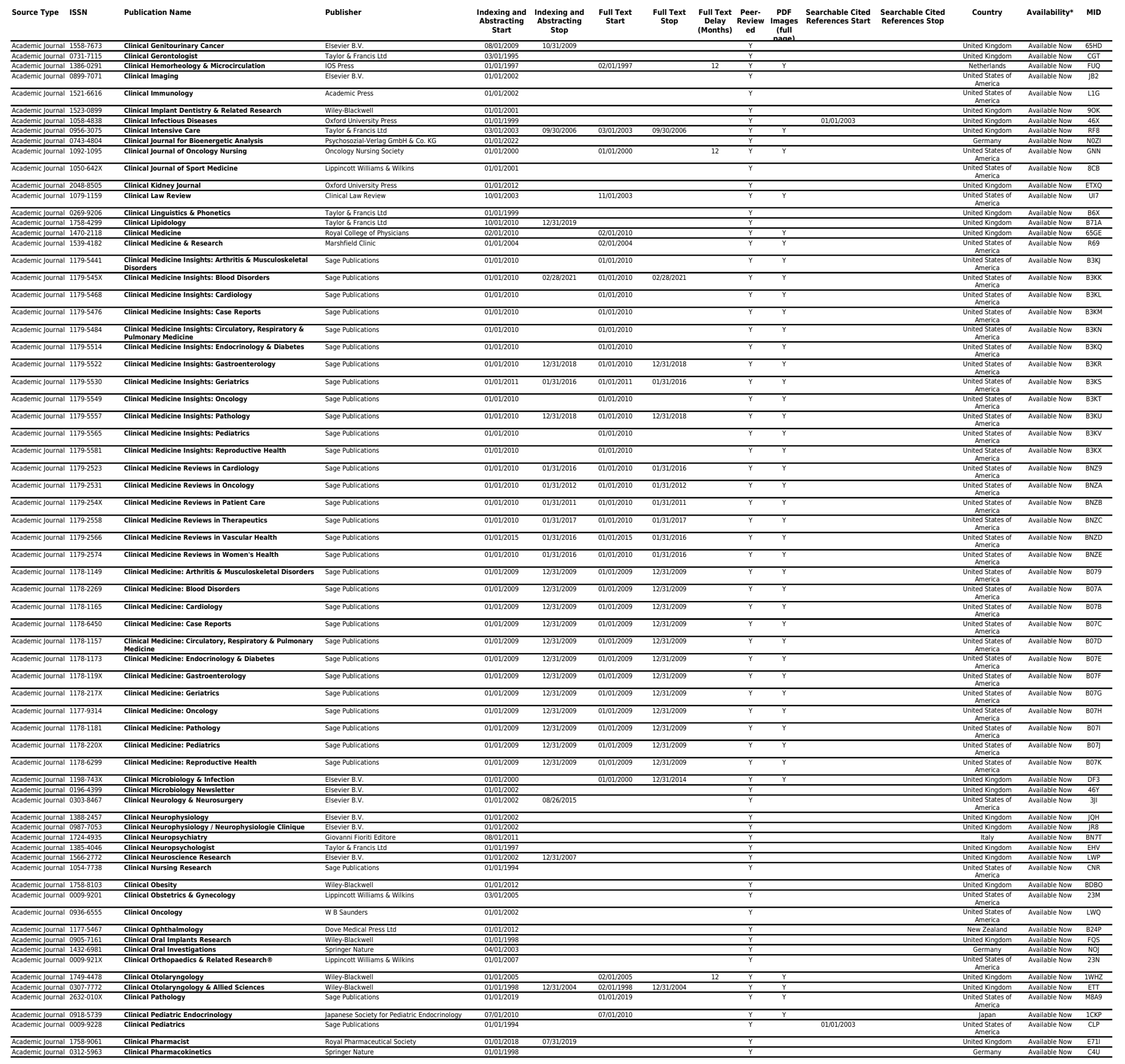




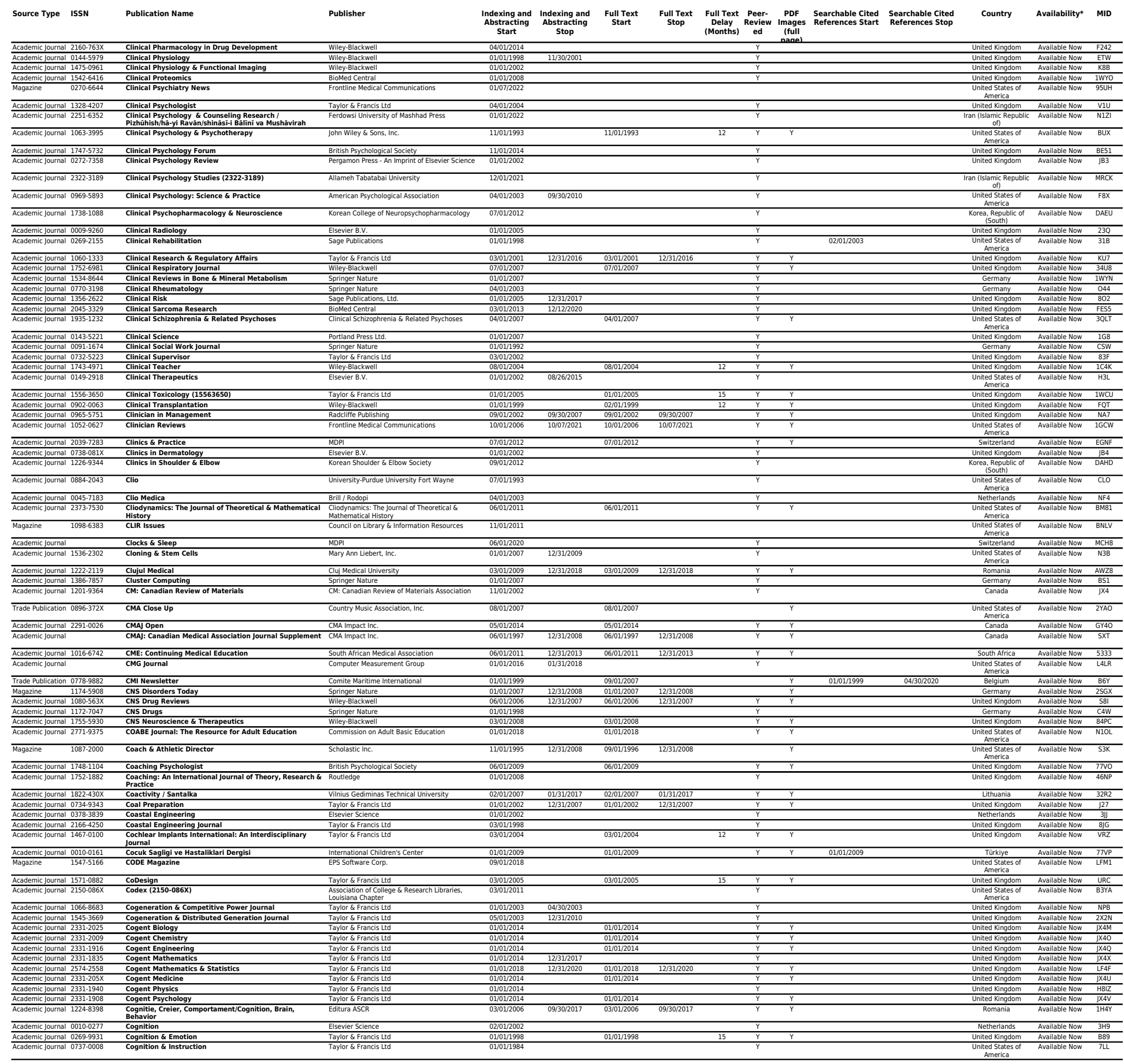




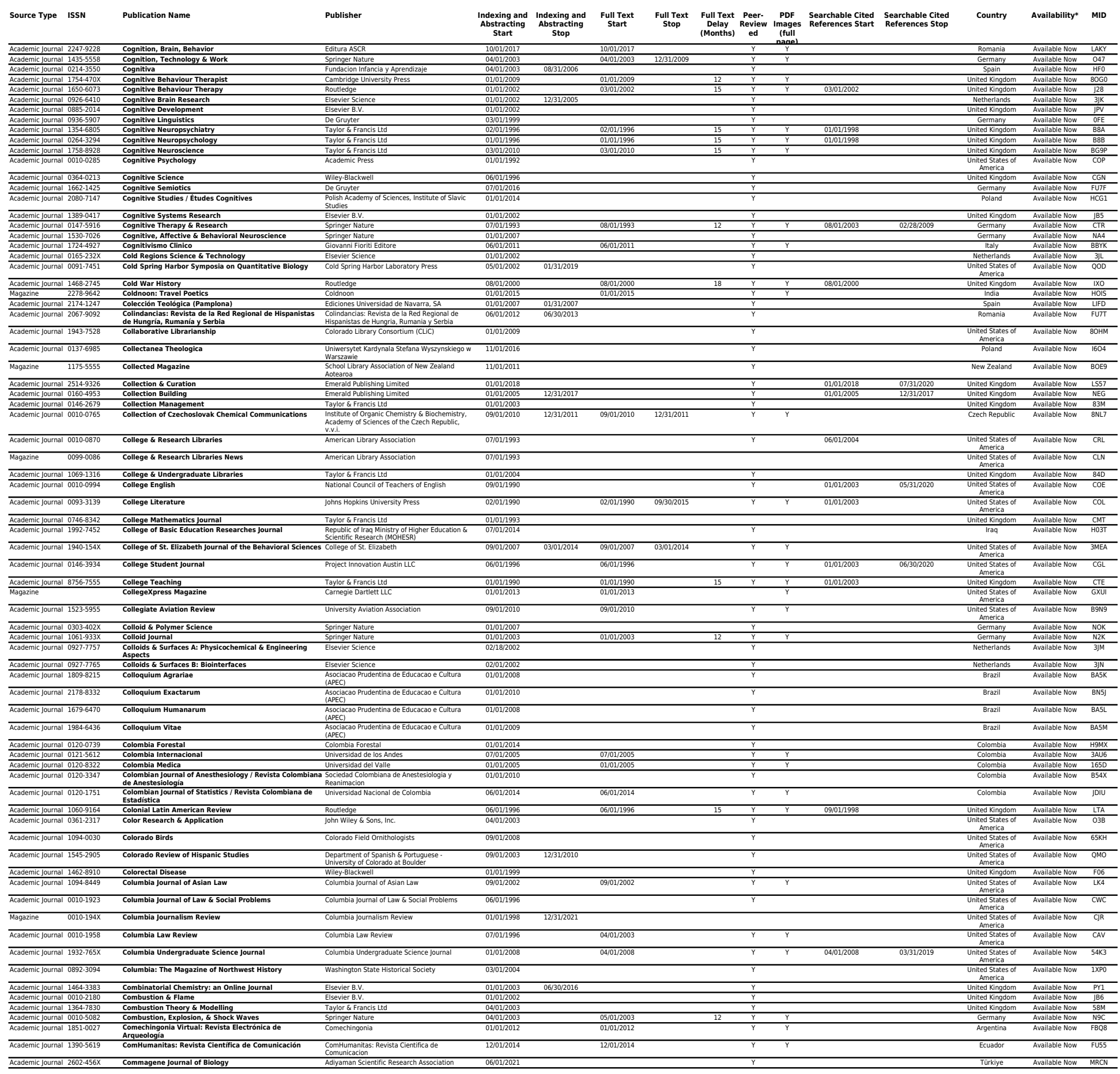




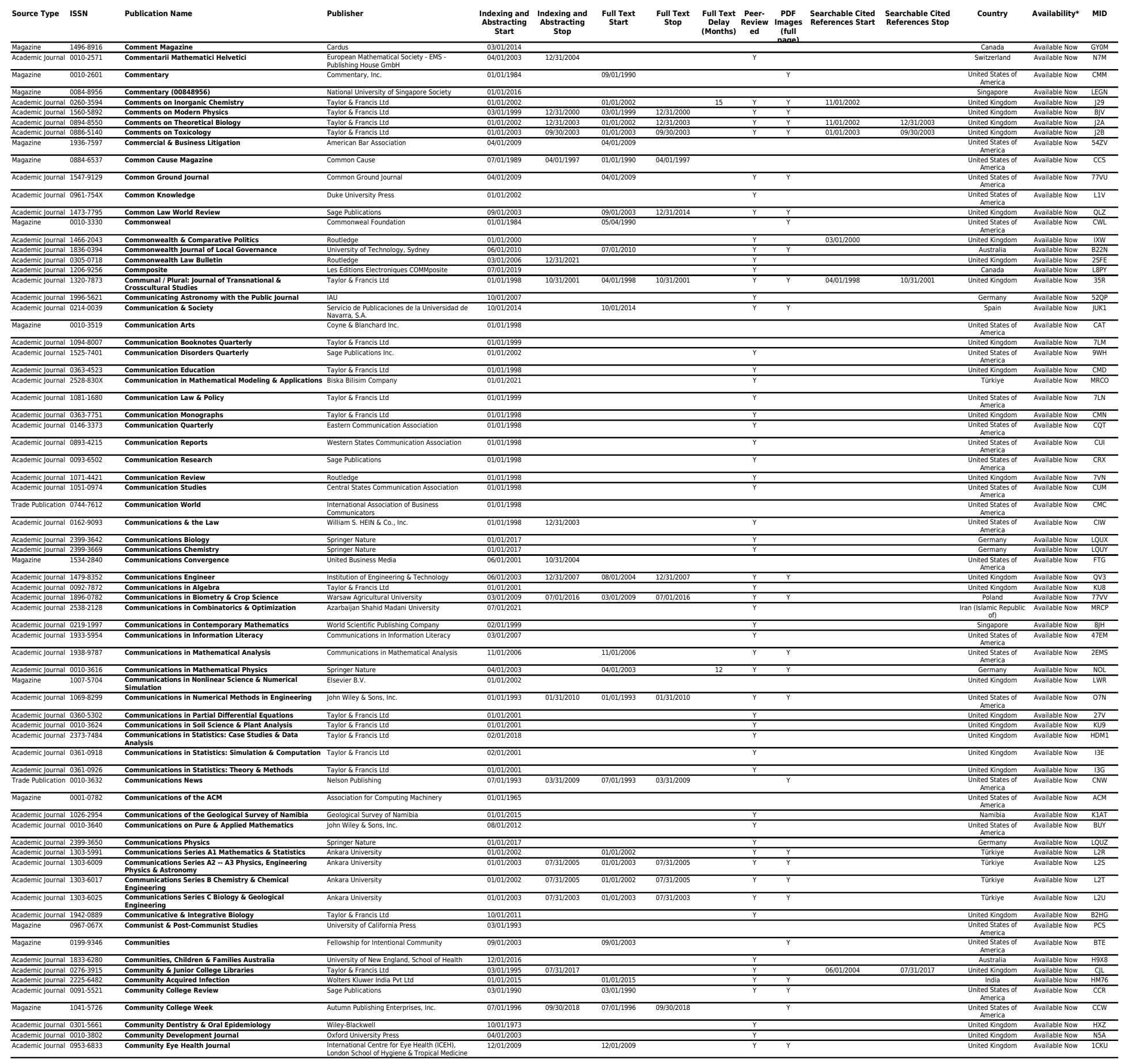




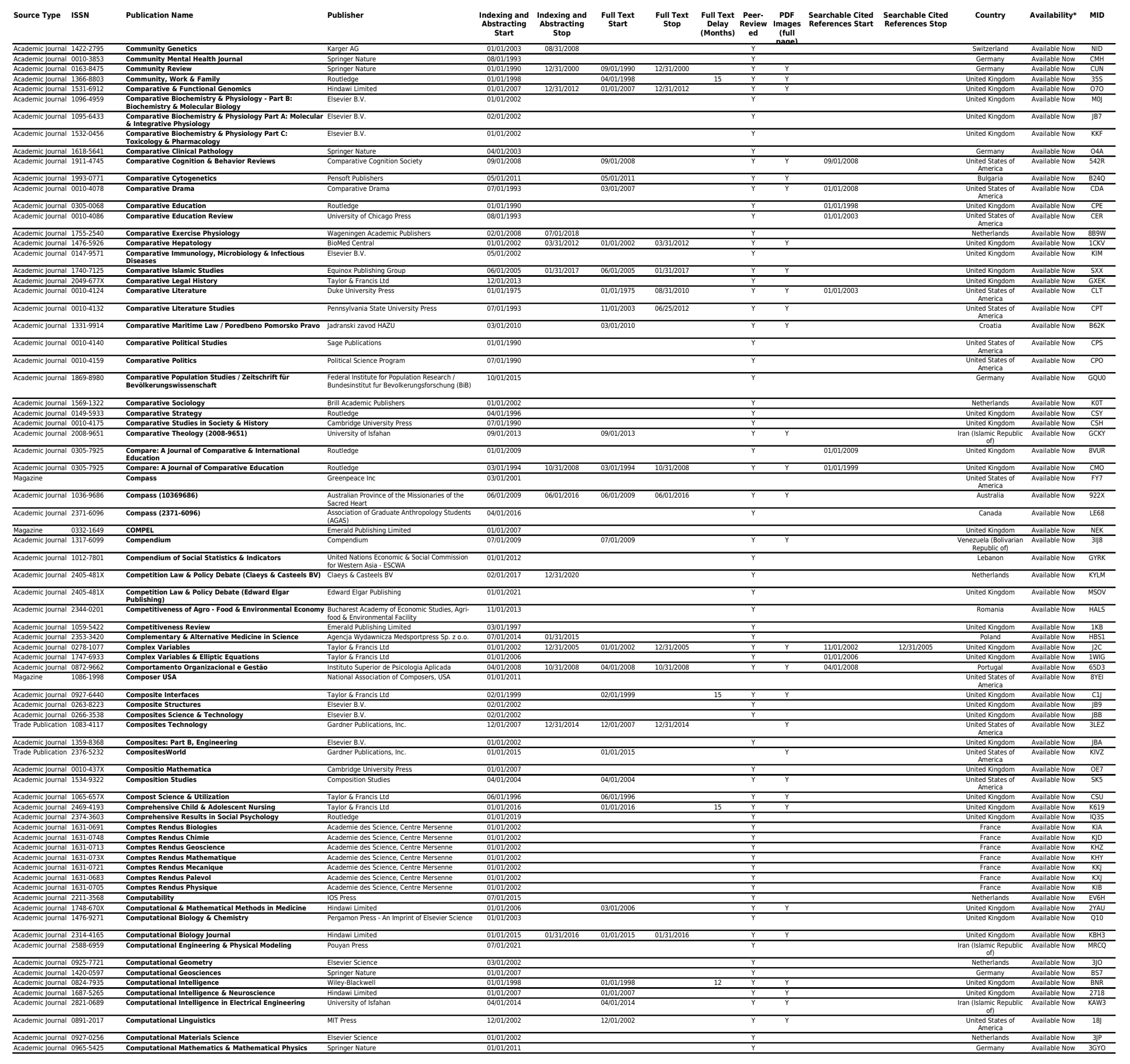




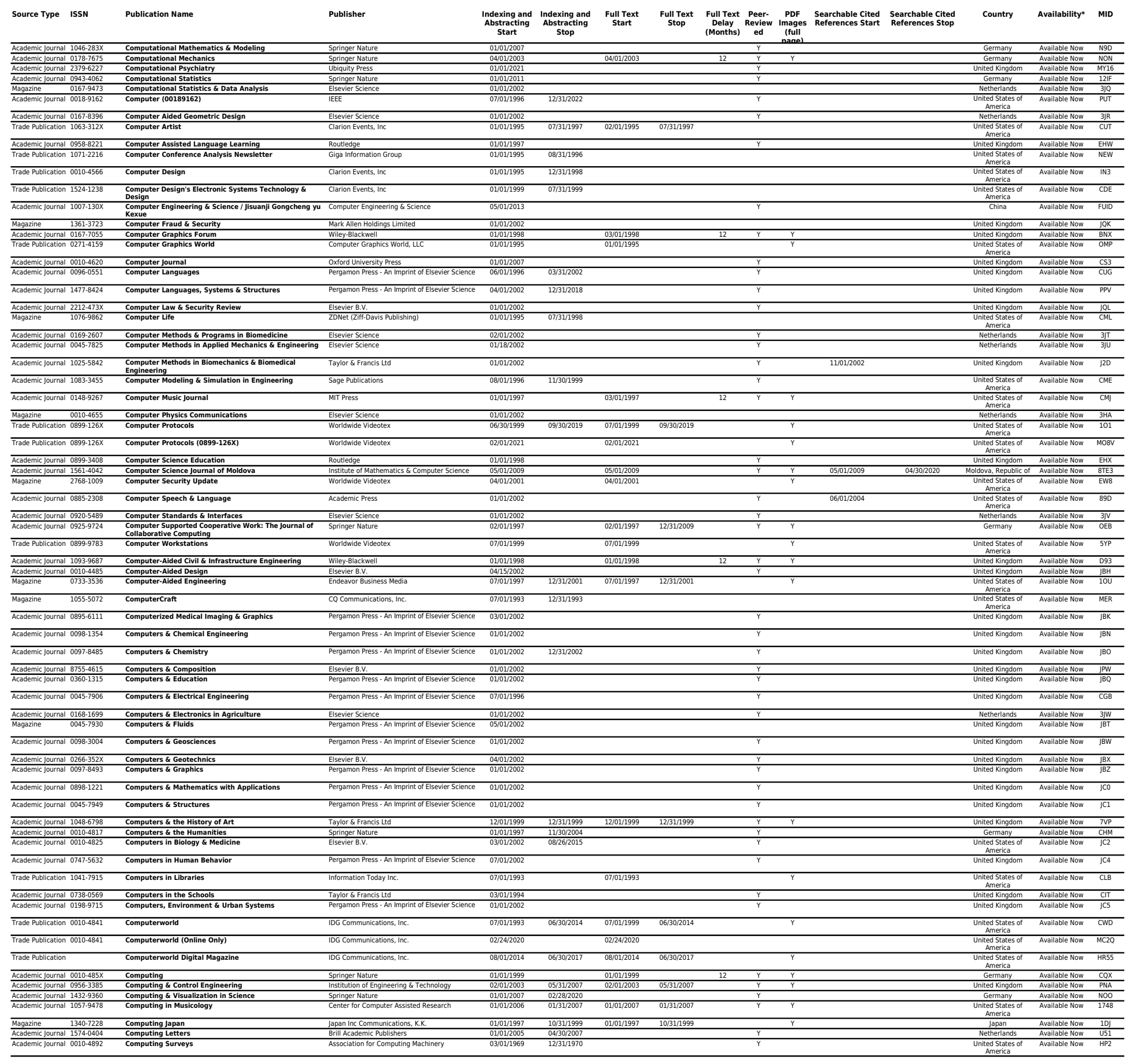




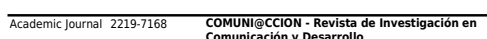
Universidad Nacional del Atiplano

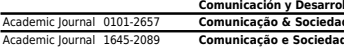

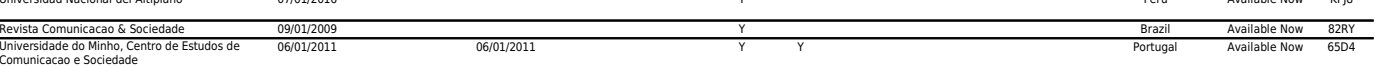
Comunicacion y socice clournal 0214 .0039

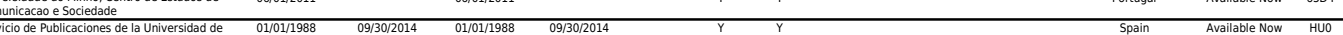
iversidad de Guadalaiara

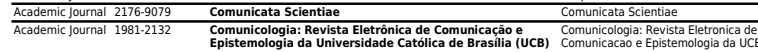

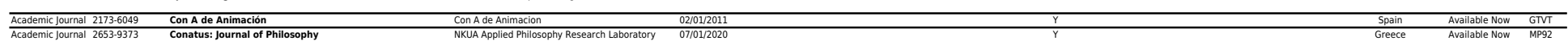

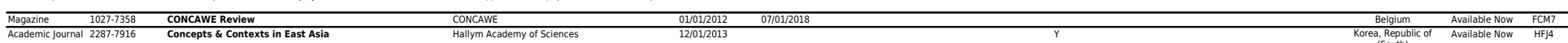

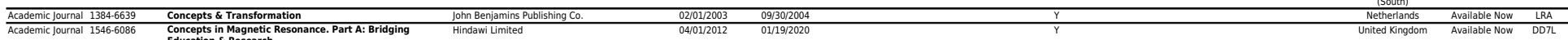

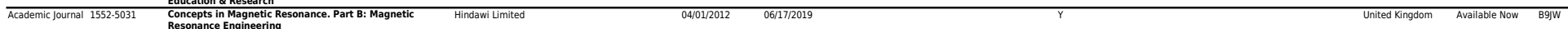

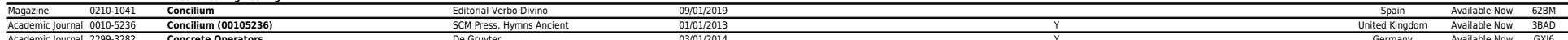

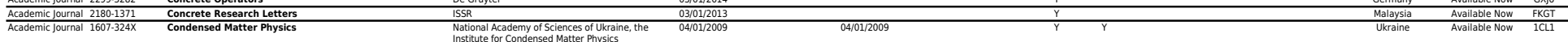

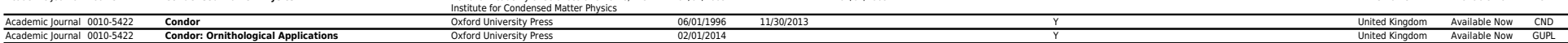

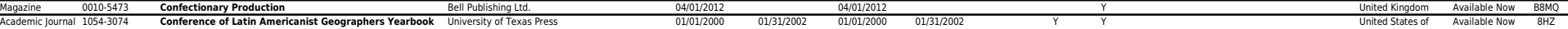

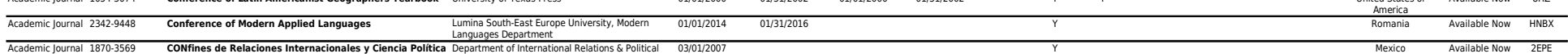
Thanch

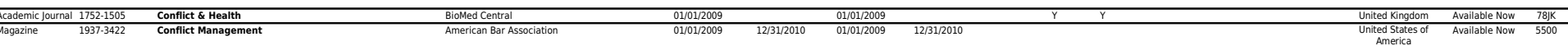

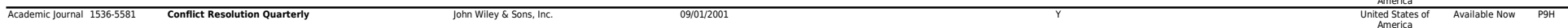

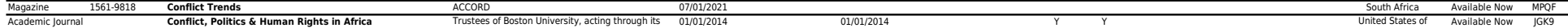

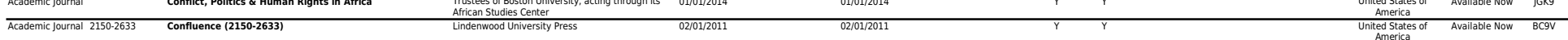
Cananda Avalable Now LEEL

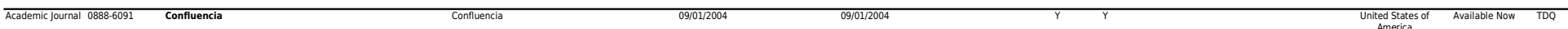

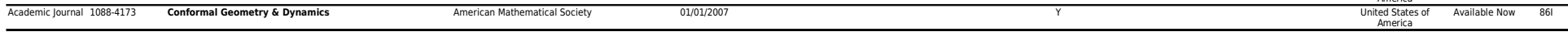

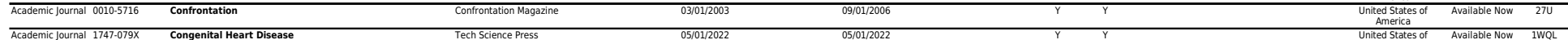

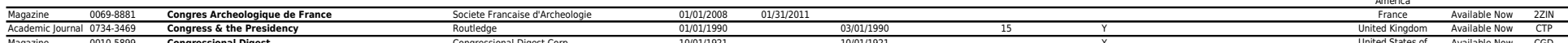

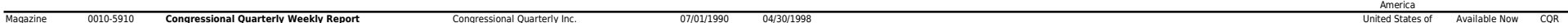

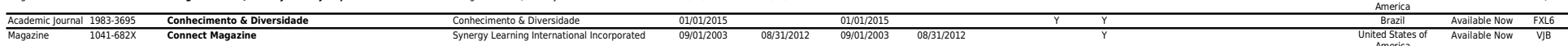

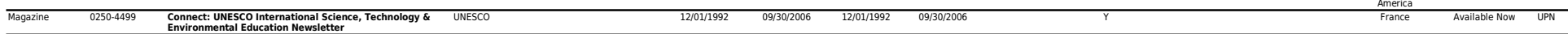

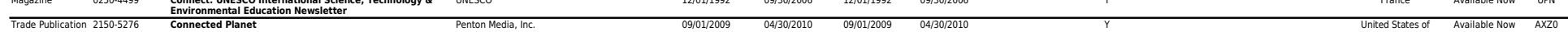

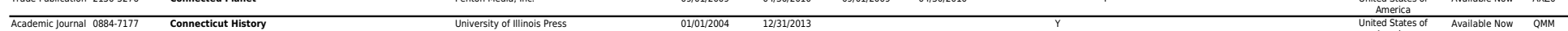

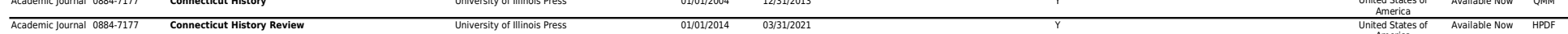

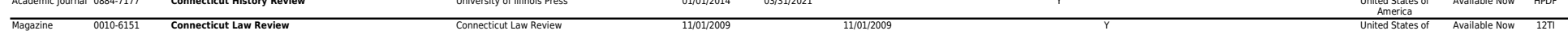

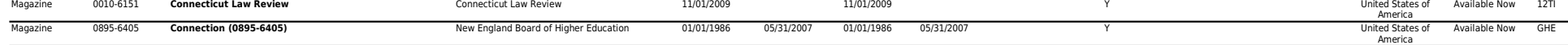

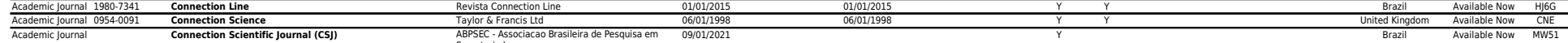

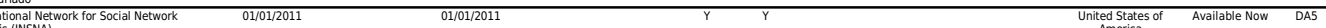

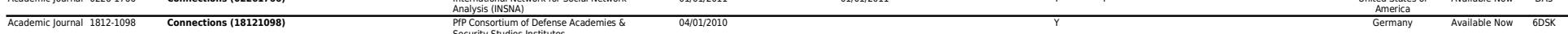

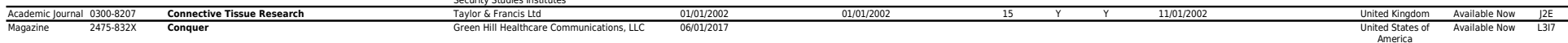

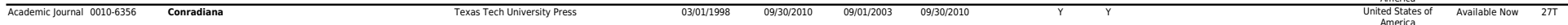

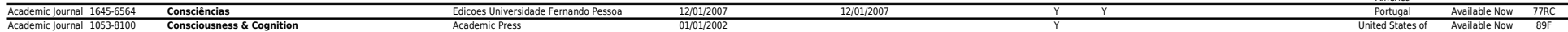

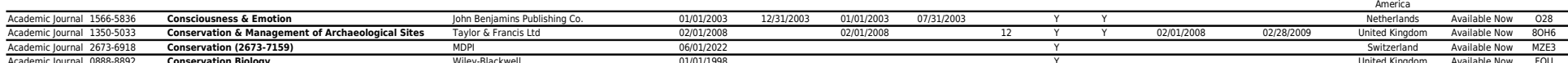

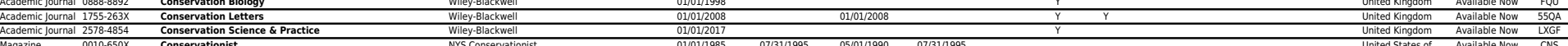

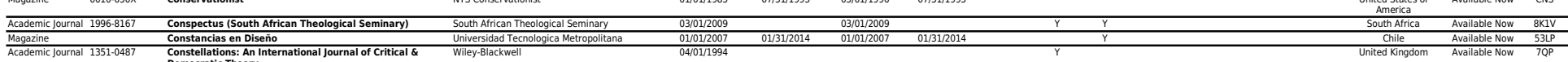

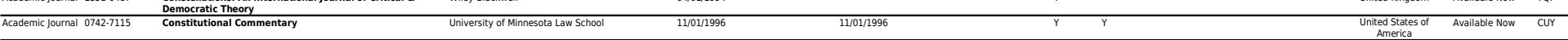

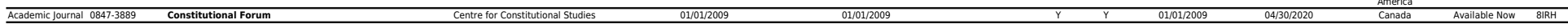




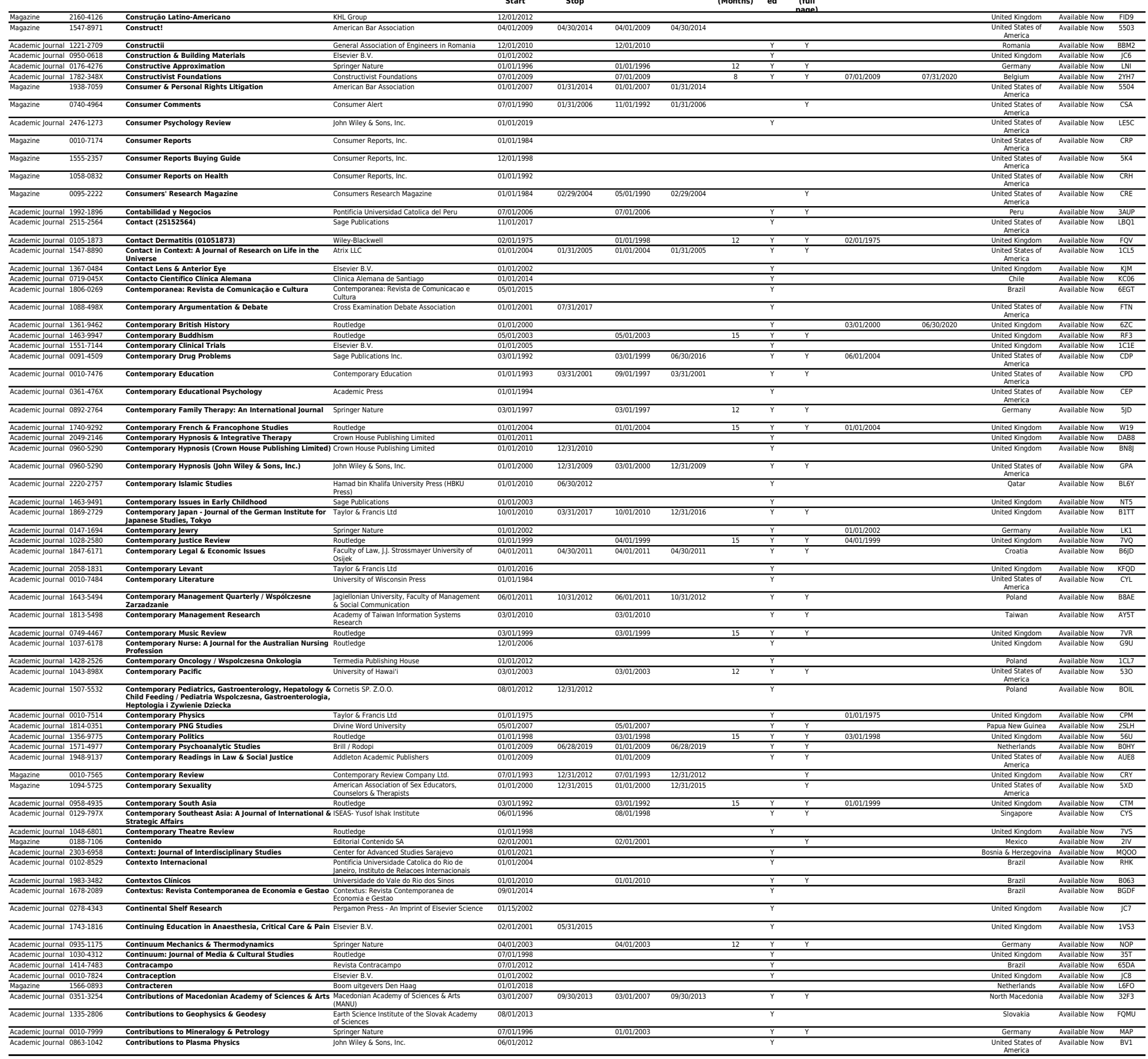




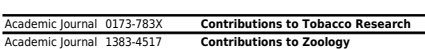

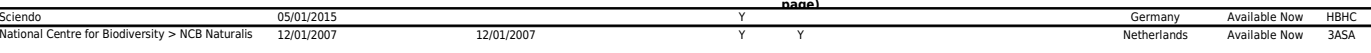

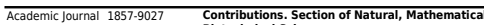

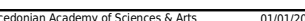

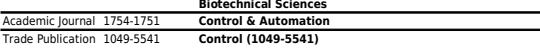
01012001

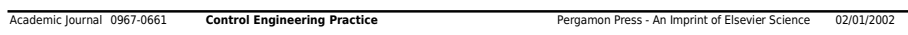

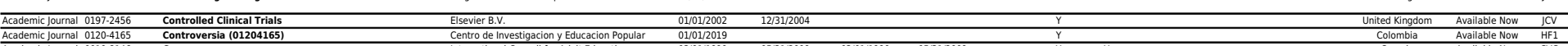

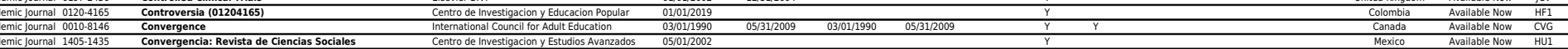

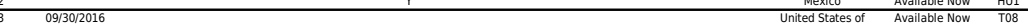

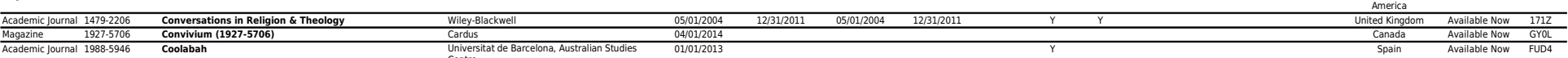

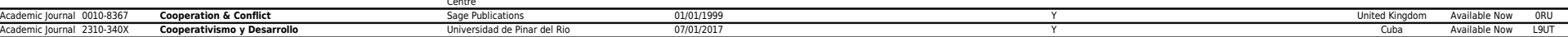

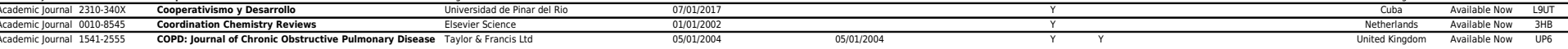

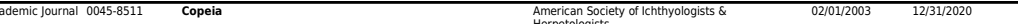

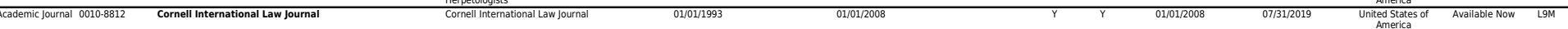

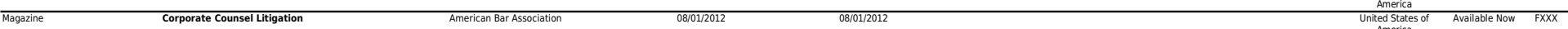

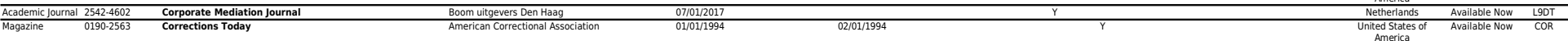

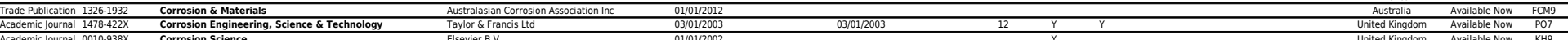

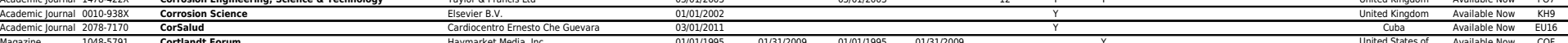

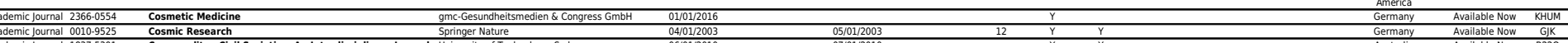

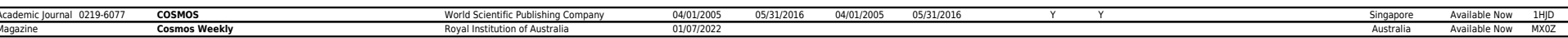

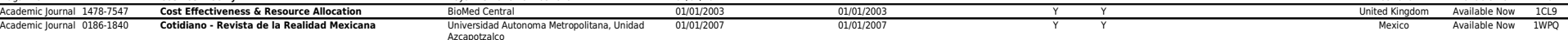

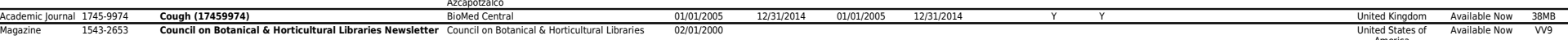

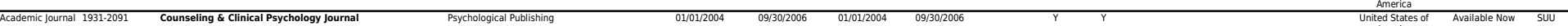

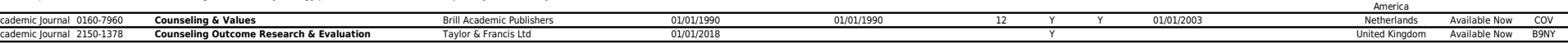

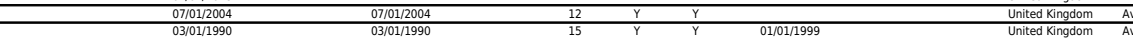

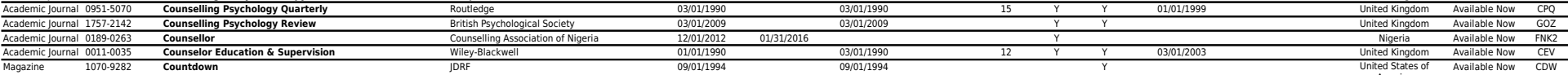

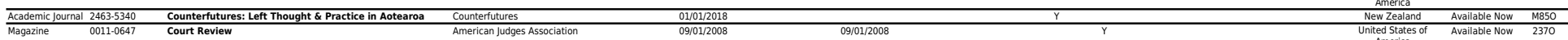

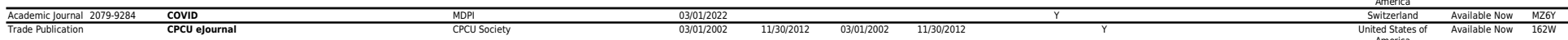

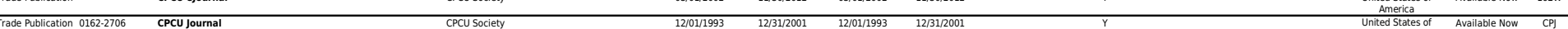

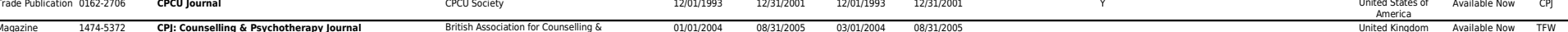

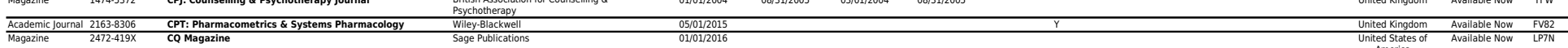

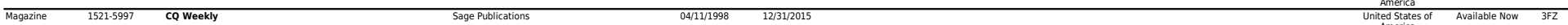

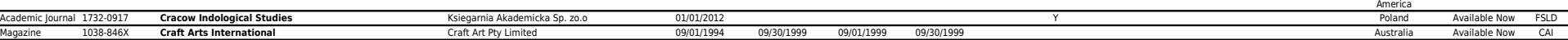

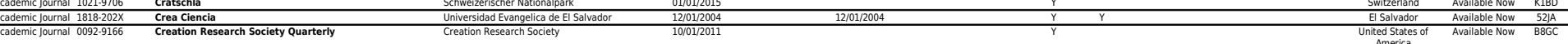

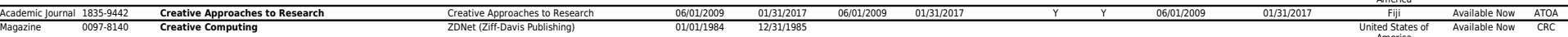

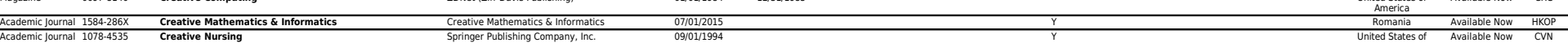

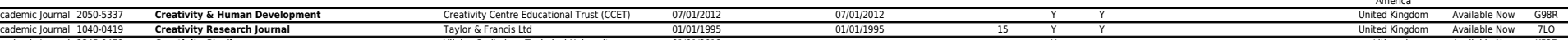

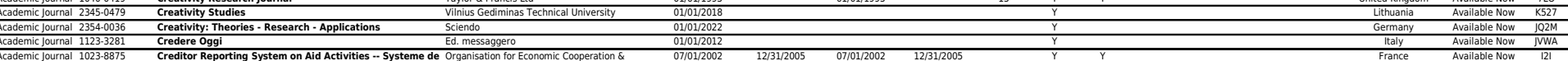

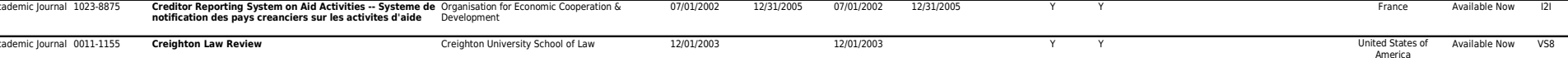

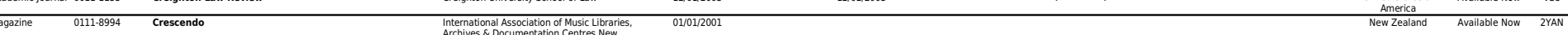

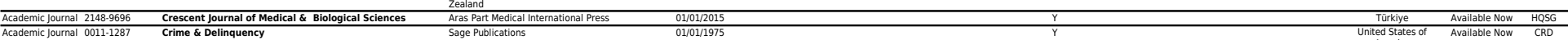

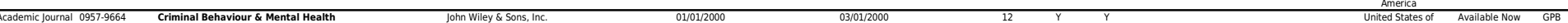

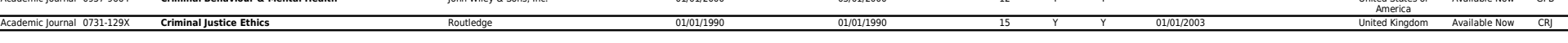




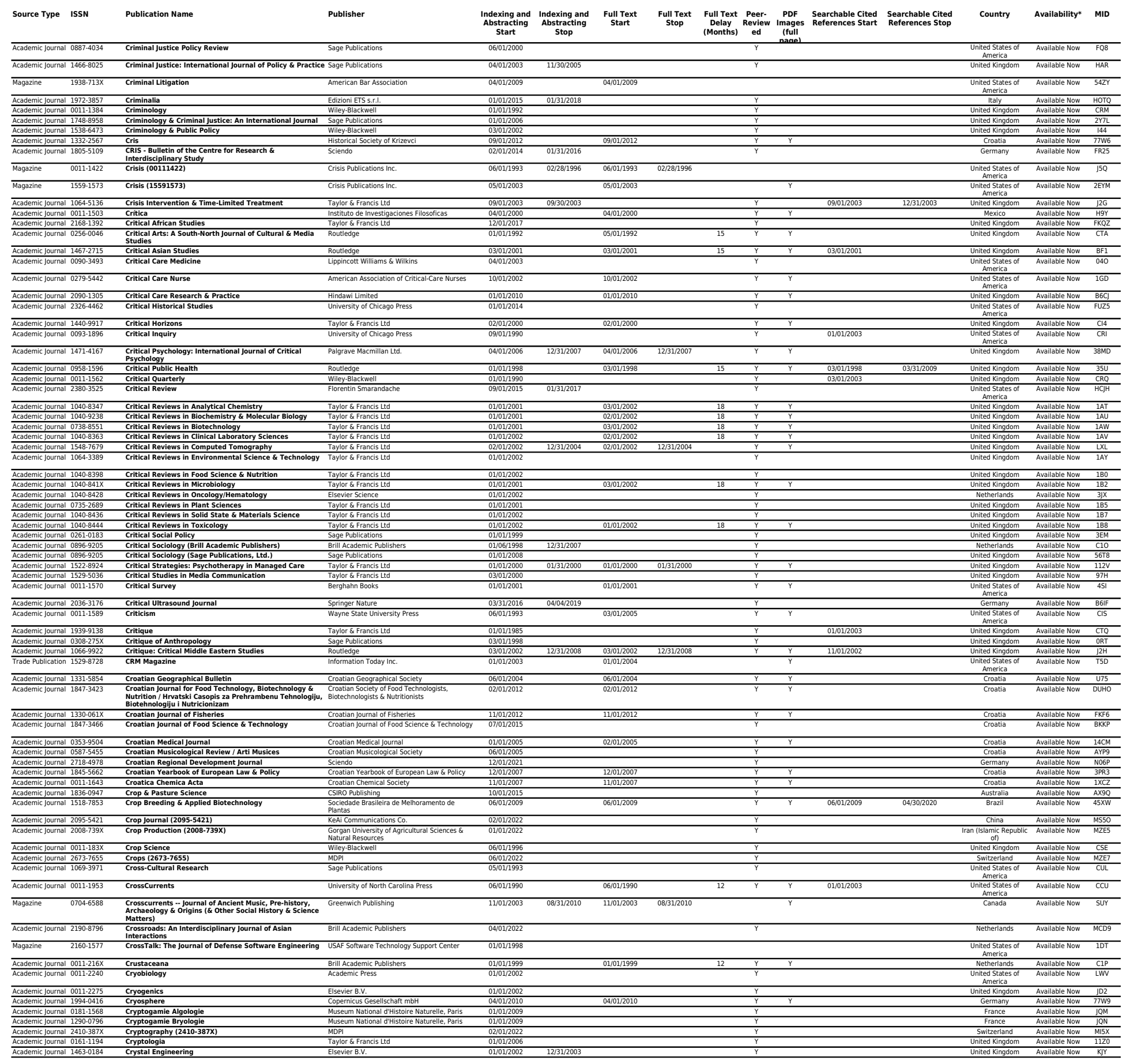




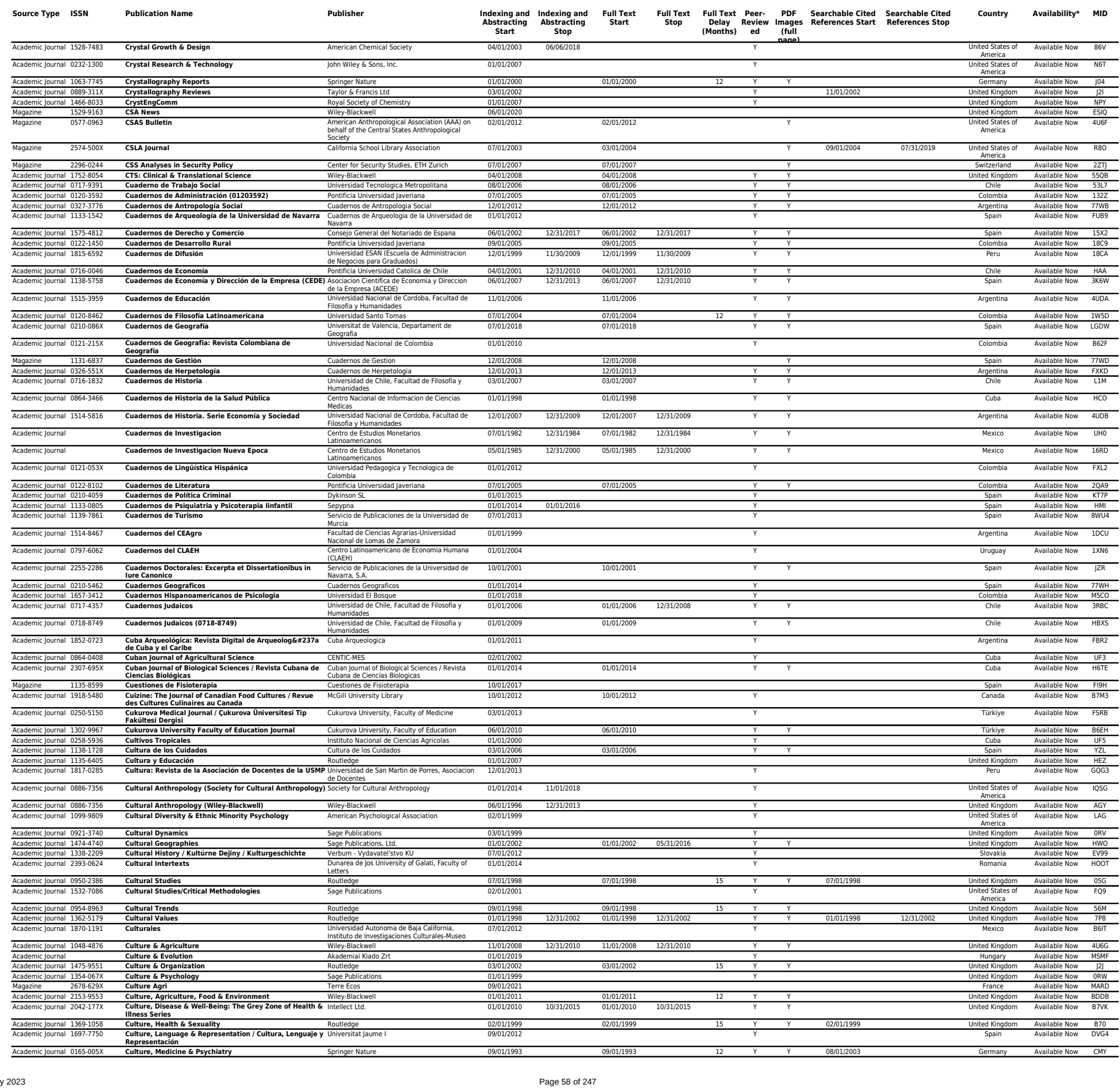




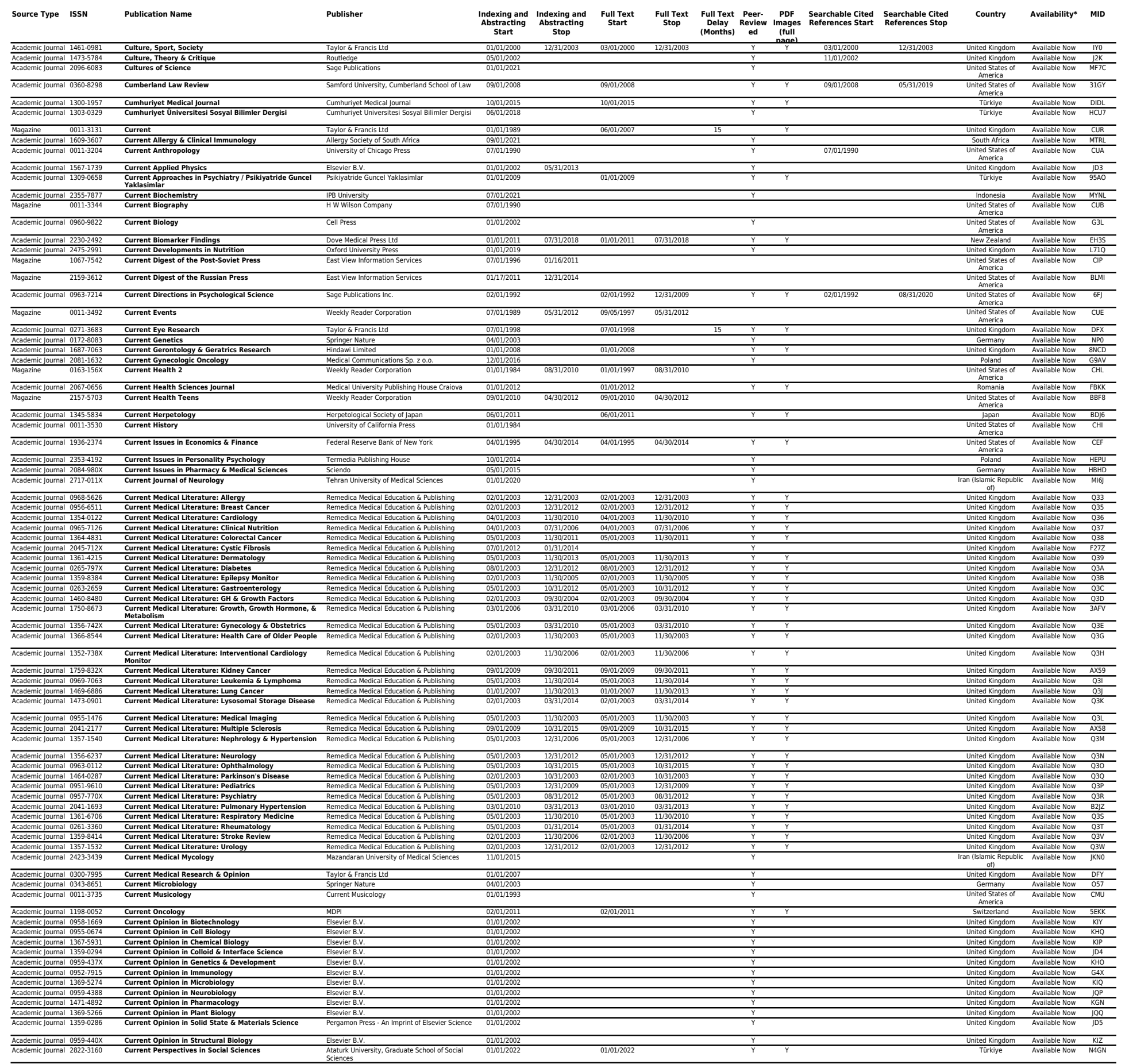




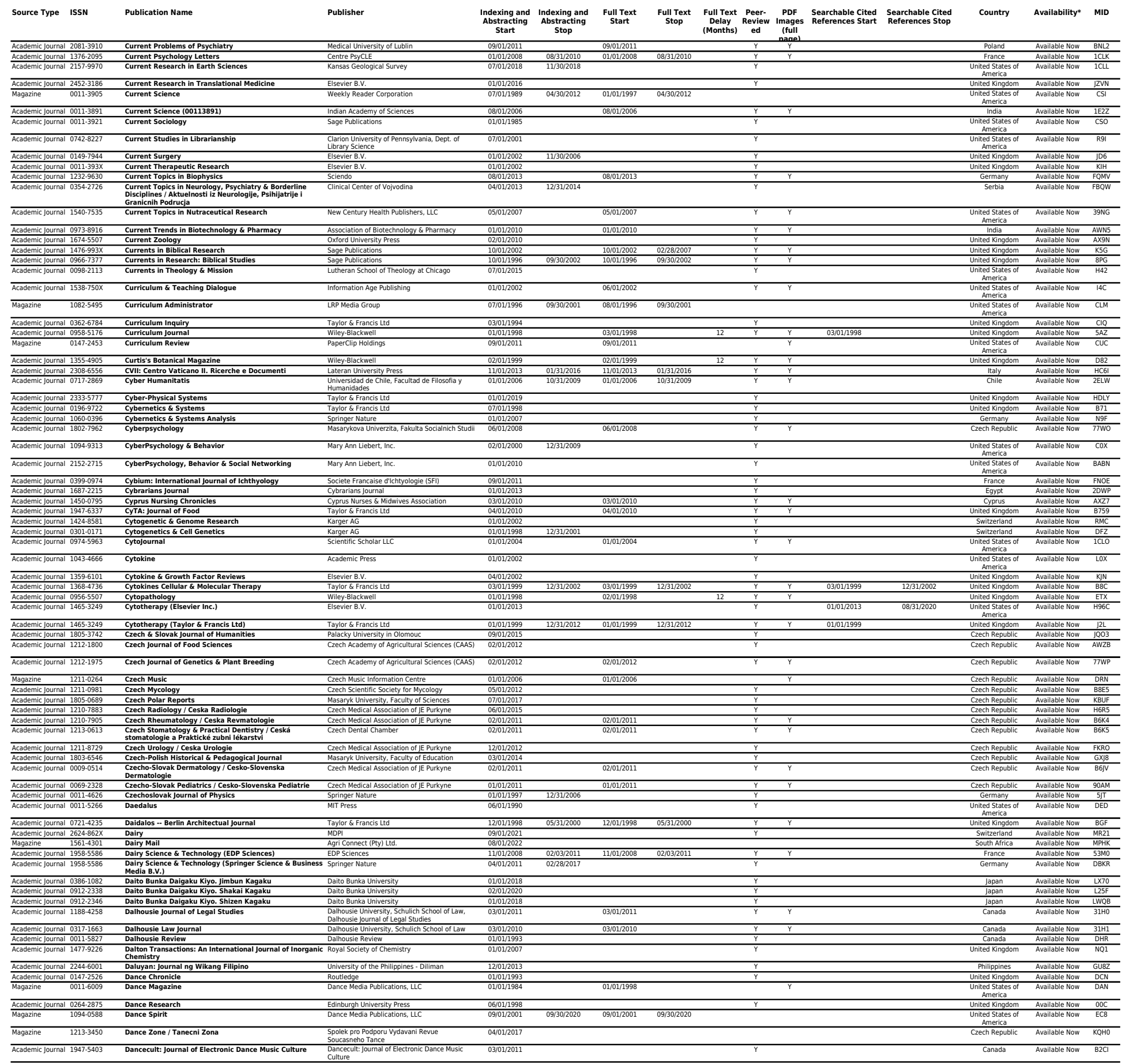




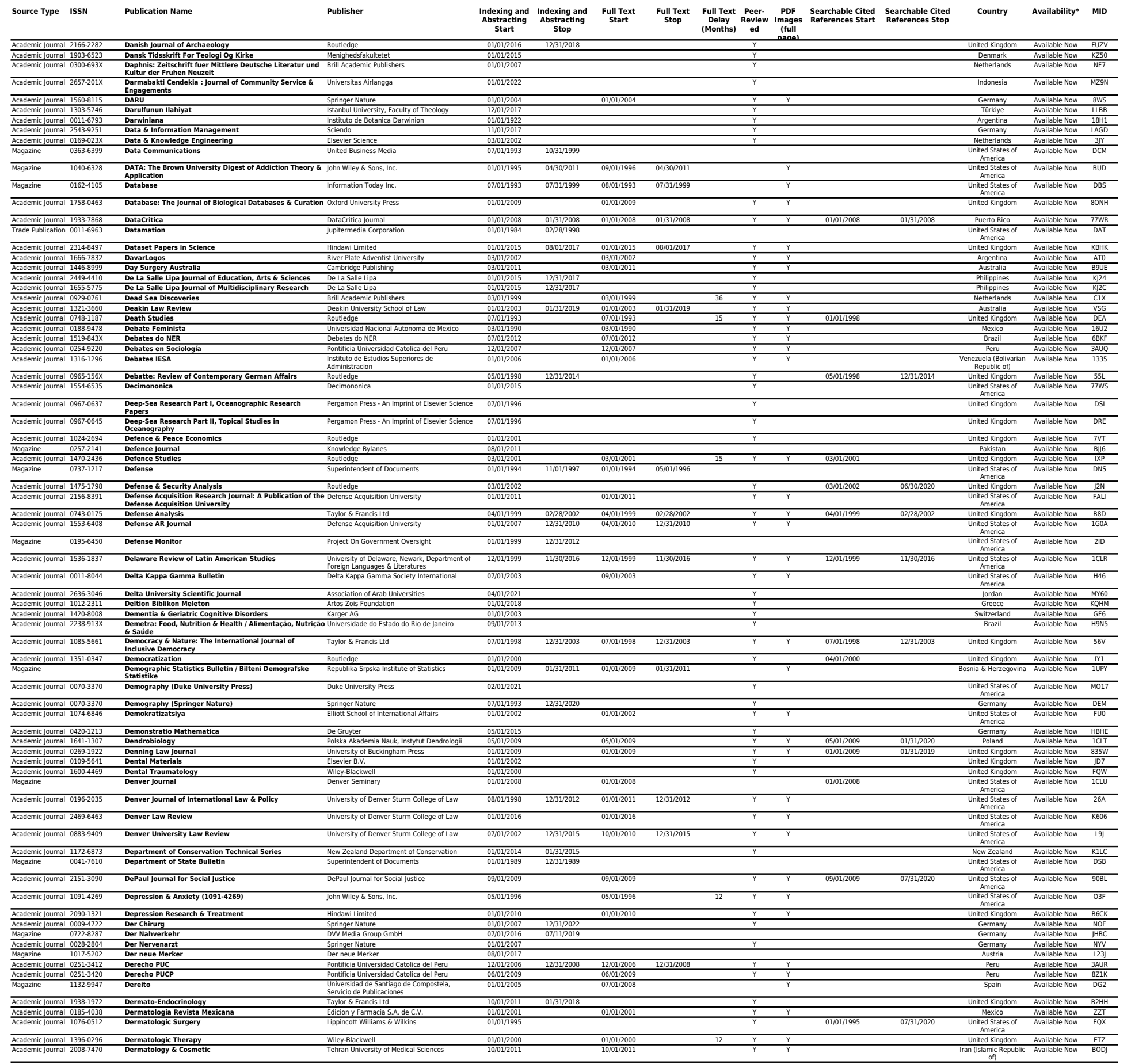




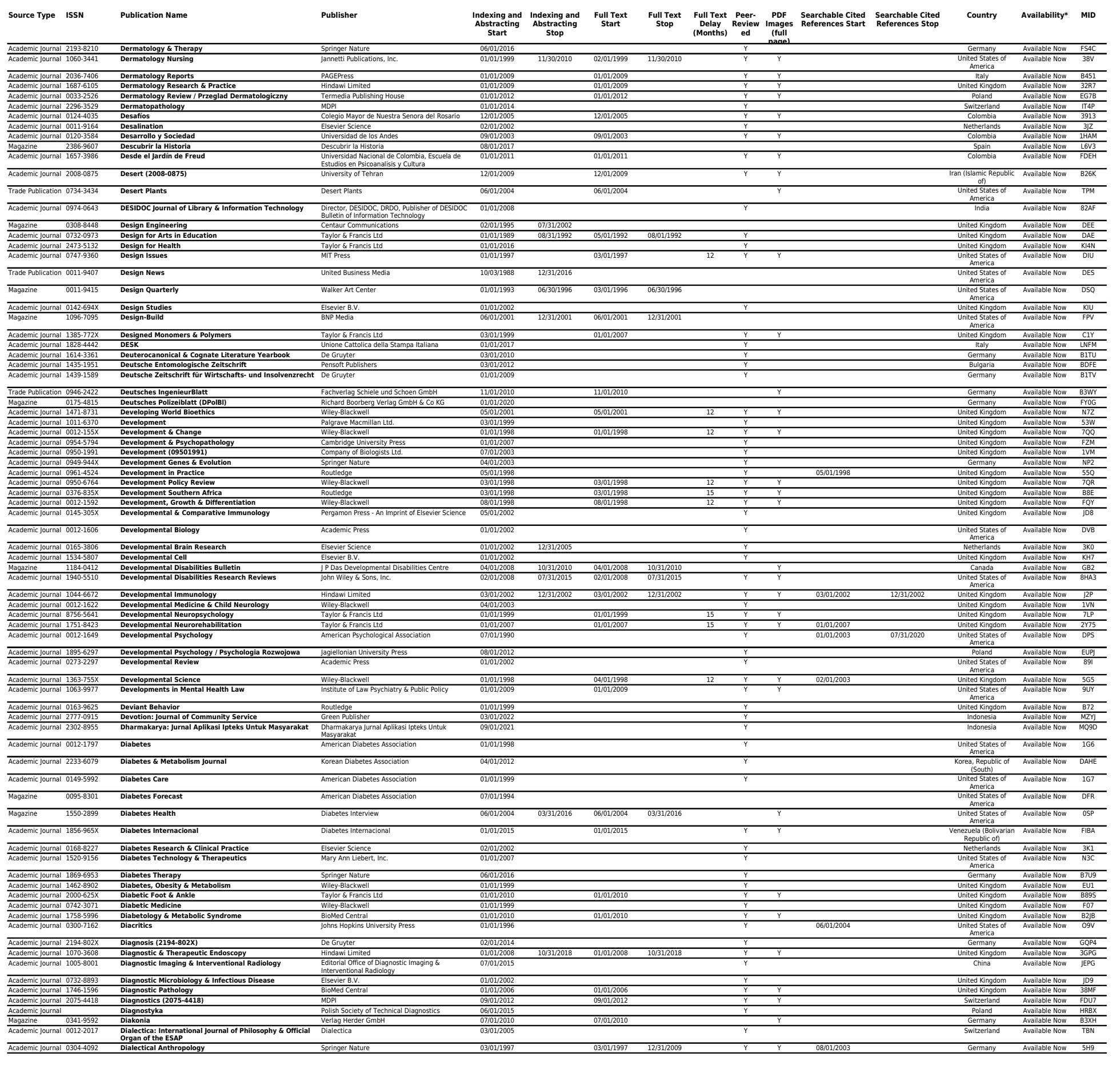




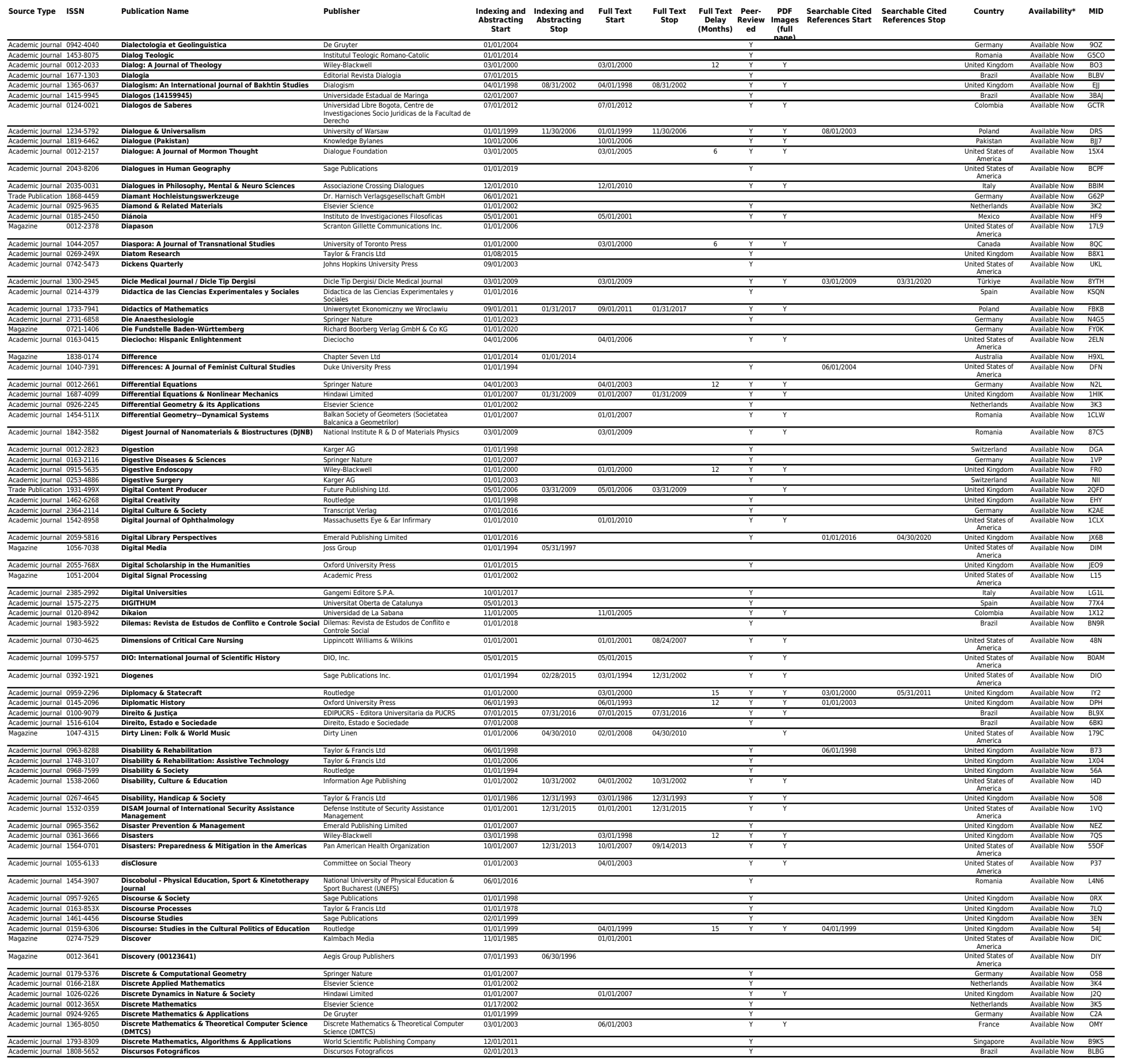




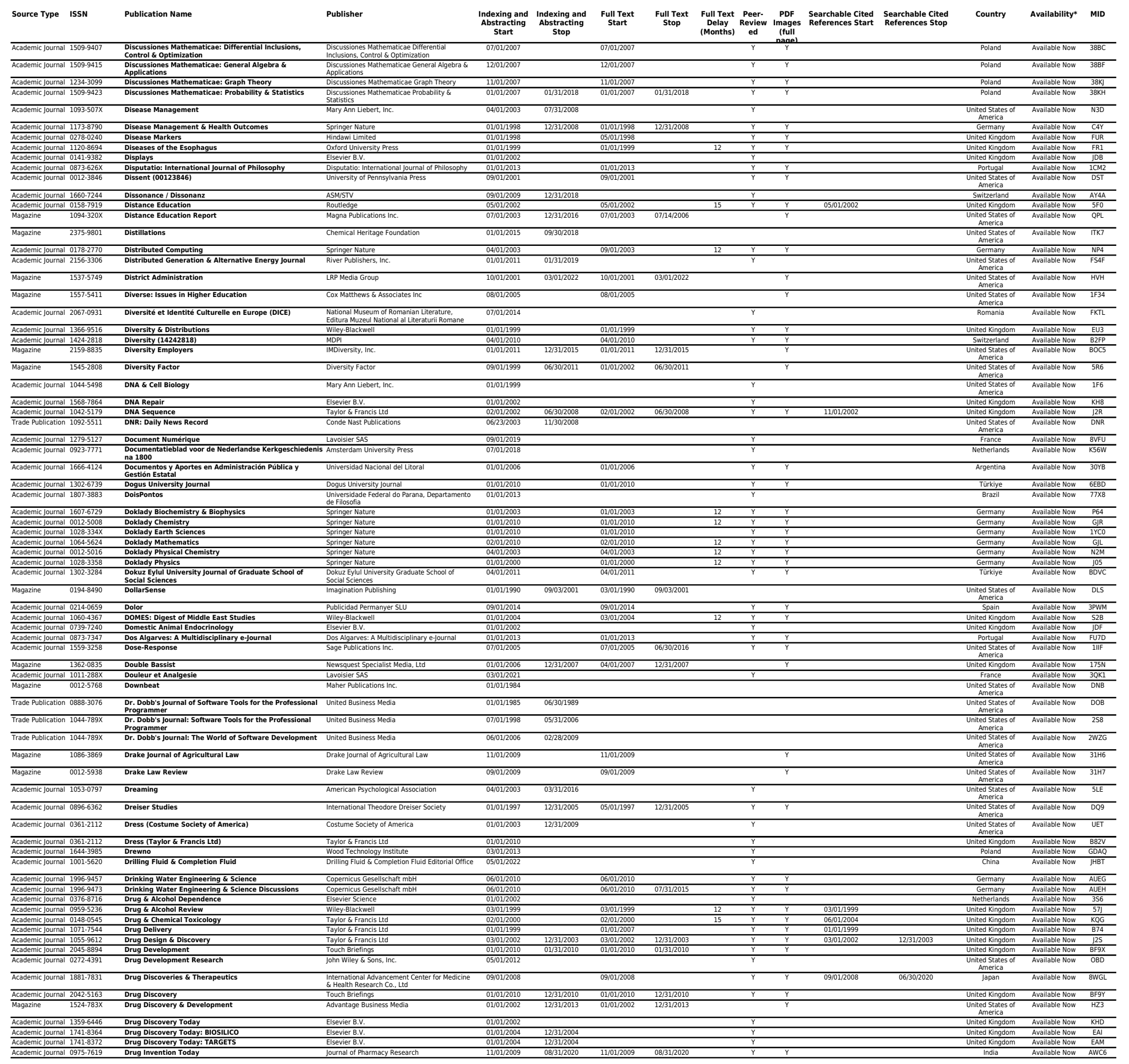




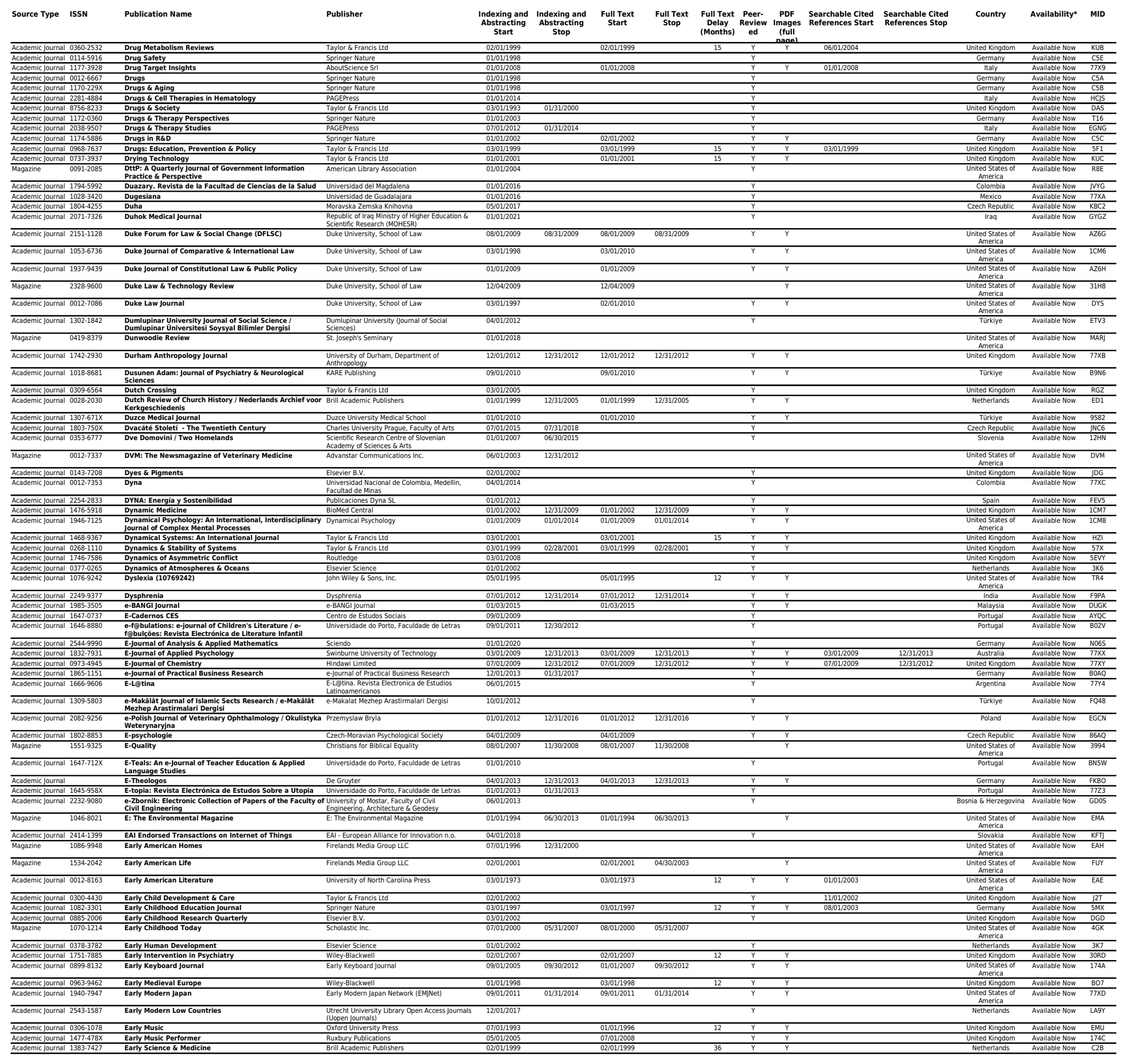




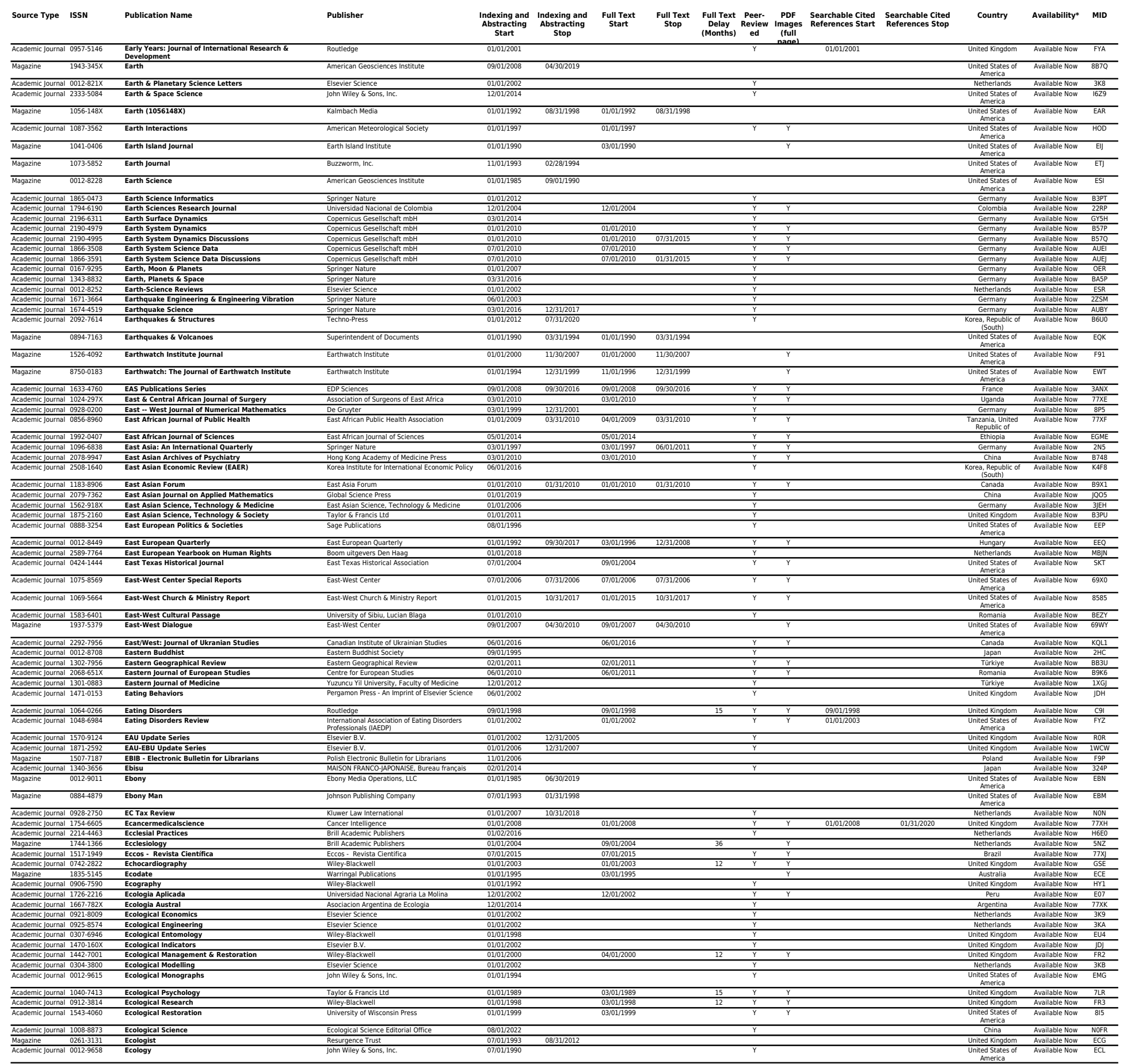




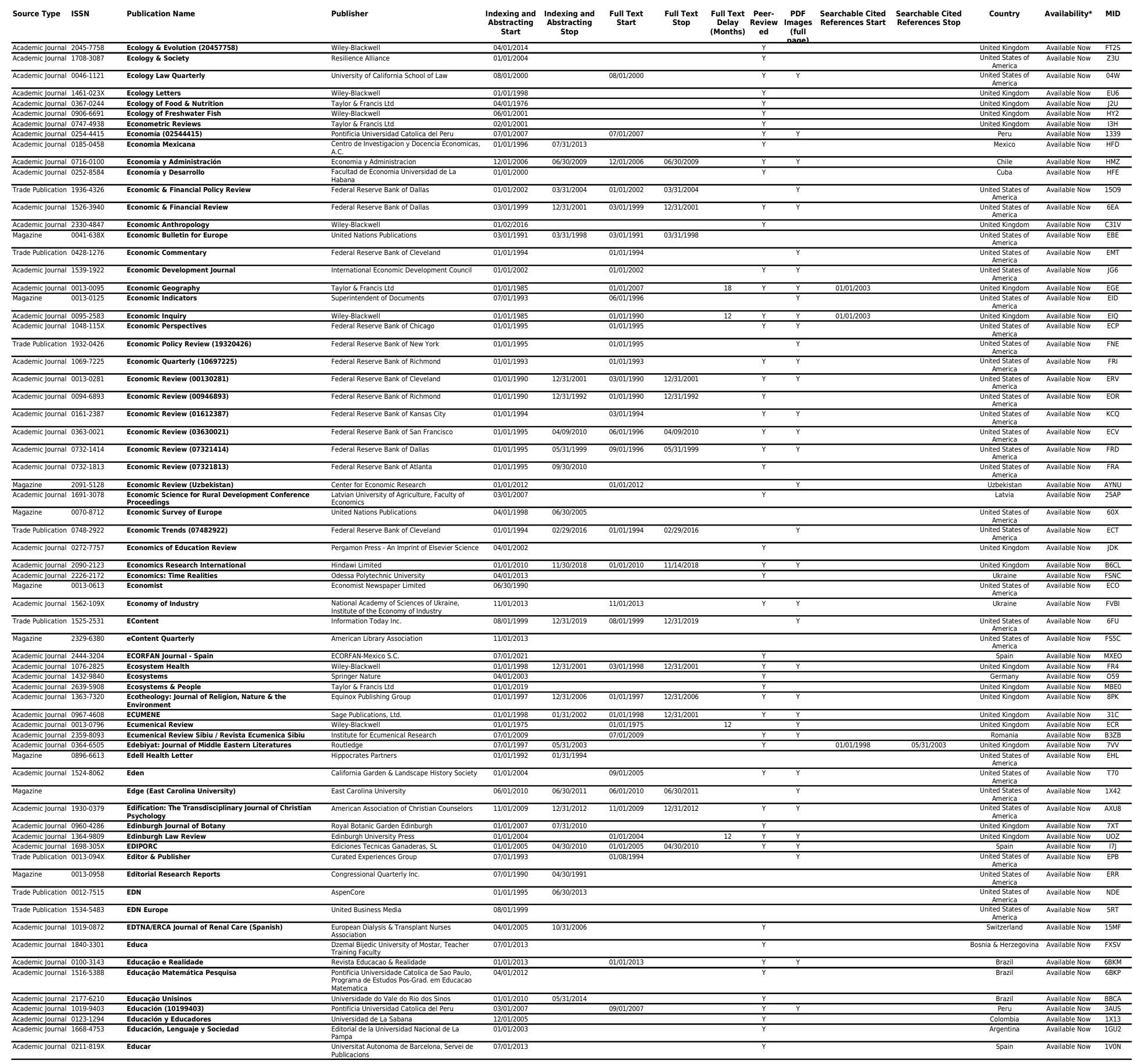




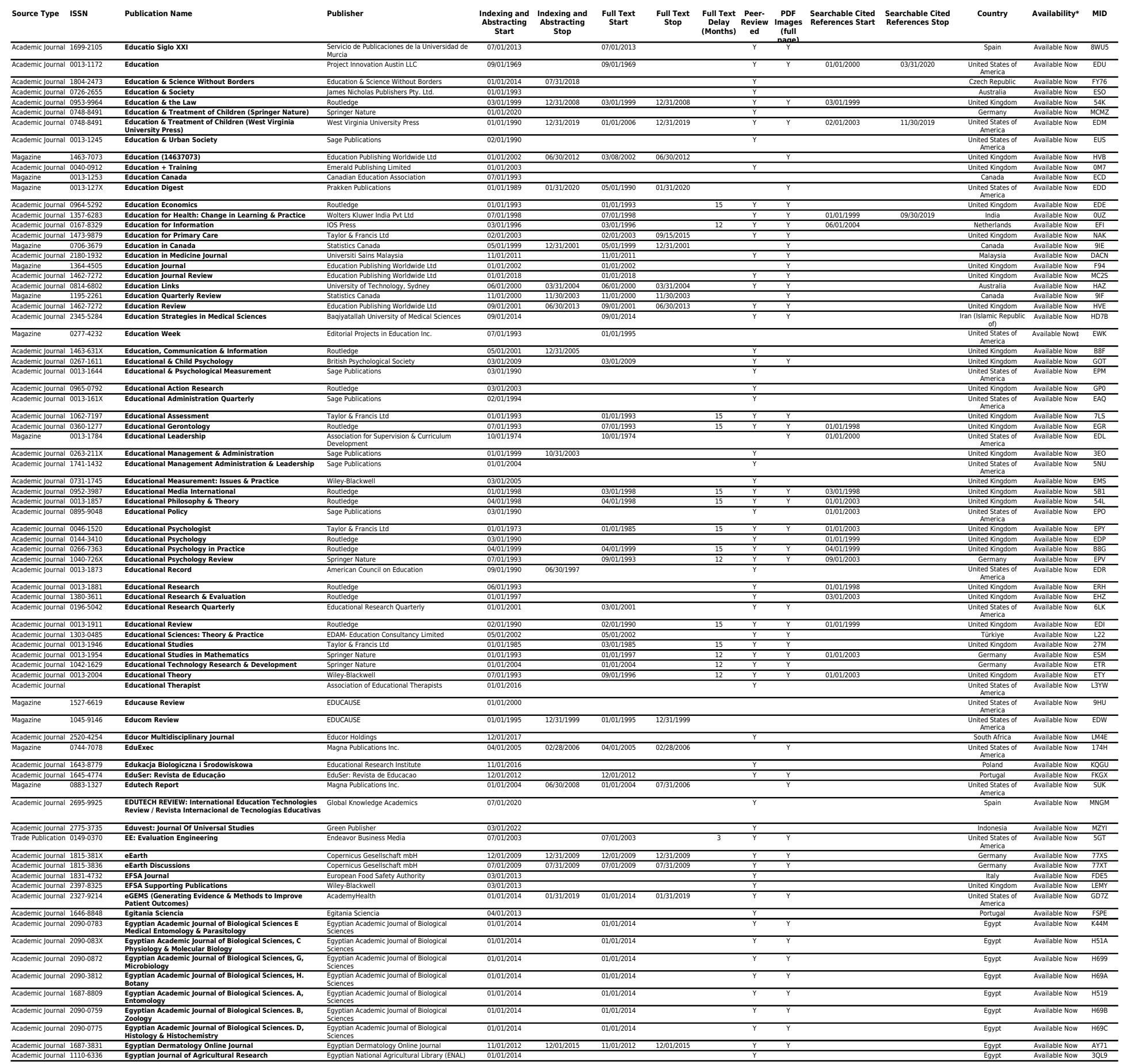


Acdememc Jưral $1110-6131$ Egyptian Juurnal of Aquatic Bilology \& Fisheries

Acadenic Journal 1687-1502 Egyptian Journal of Biochemistry \& Molecular Biology

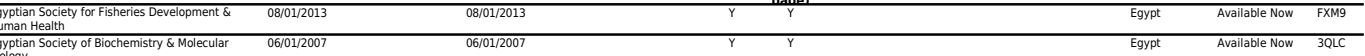
Egyptian Joumal of Biological Pest Control Geptian Jounal of Chest Diseases \& Tuberculosis

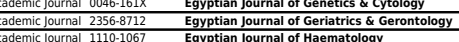

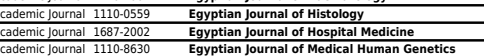

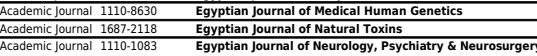

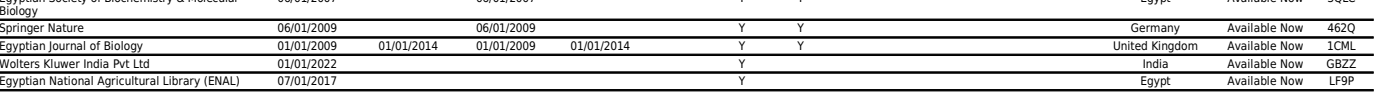

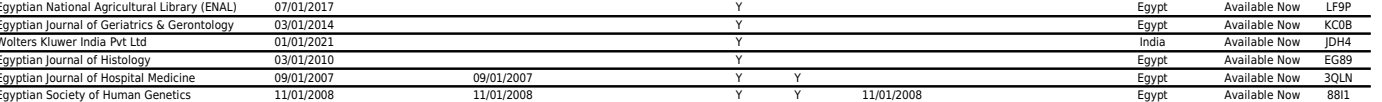

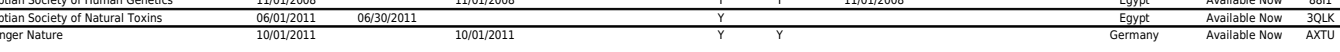

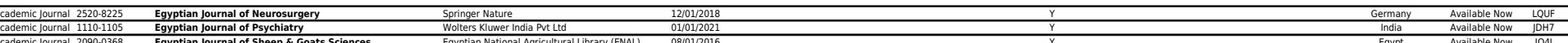

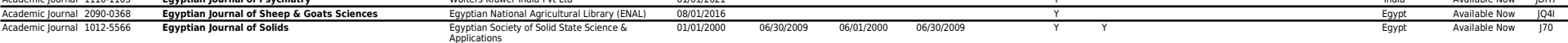

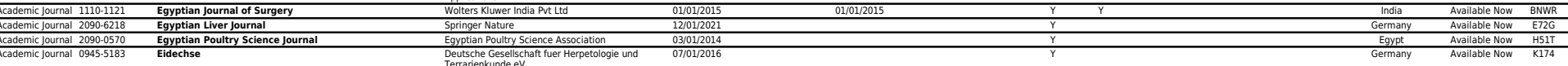

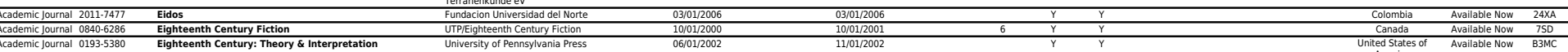
\begin{tabular}{lll}
\hline Academic Journal 0098-2001 & Eighteenth-Century Life \\
\hline Academic Journal 0013-2586 & Eighteenth-Century Studies
\end{tabular}

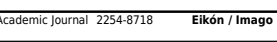

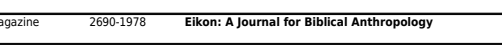
Academic Jurnal 1679-4508 Einstein (16799508

\begin{tabular}{ll}
\hline Accdemic J Jurnal 1559.5501 & Einstein Journal of Biology \& Medicine \\
\hline Accdemic J ournal 0724.6706 & Einstein Quarterly: Journal of Biology \& Medicine
\end{tabular} Gistein Quarteryy: Journal of Biology \& Medicine Eirene

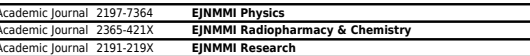

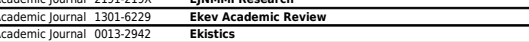

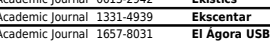

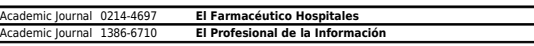

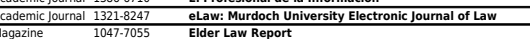
Mgazine

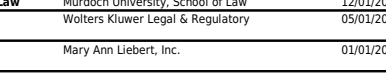

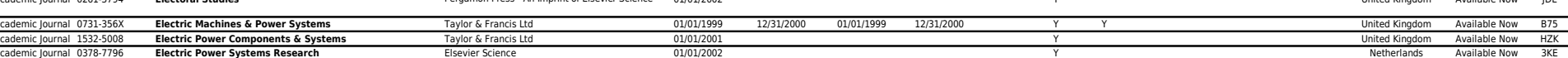

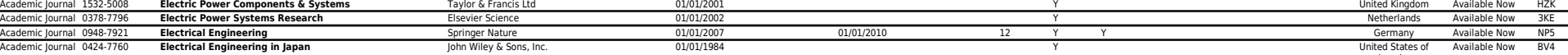

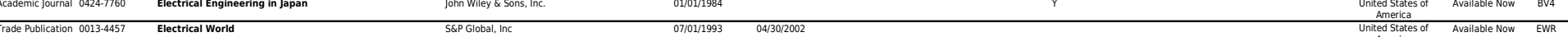

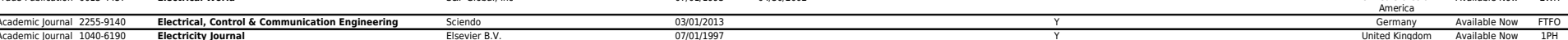

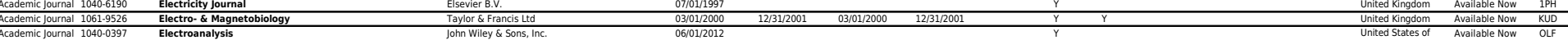

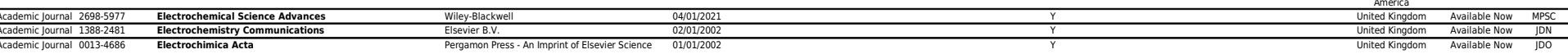

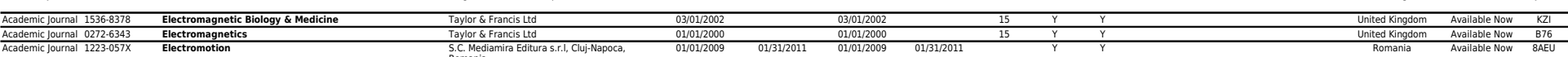

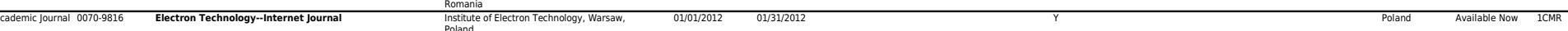

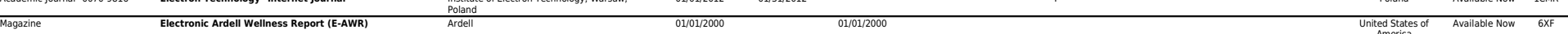

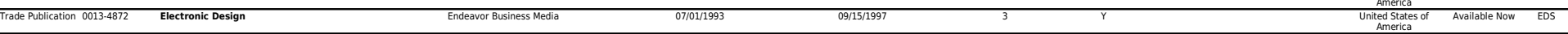

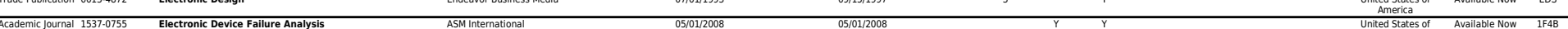

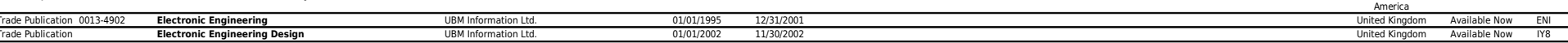

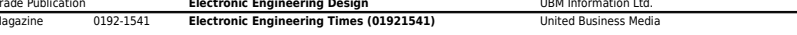

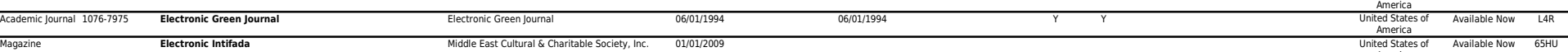

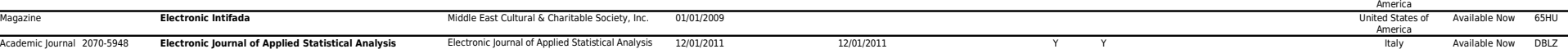
Electronic Journal of Applied Statistical Analysis
(EASAS)

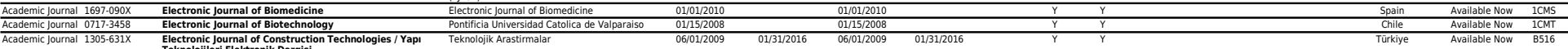

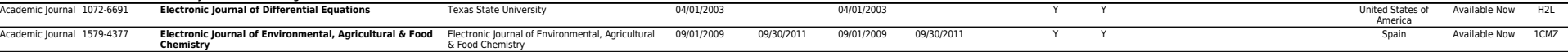


Academic Journal 2316-3507 Electronic Journal of General Medicin

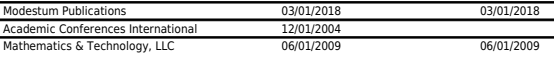

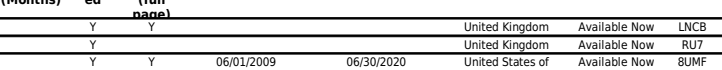

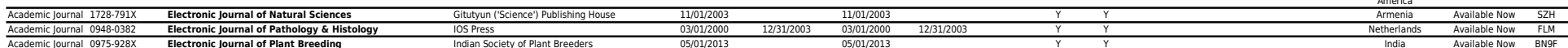

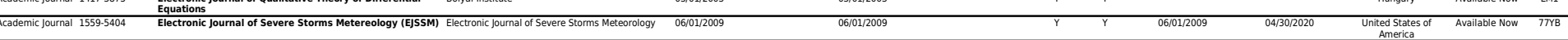

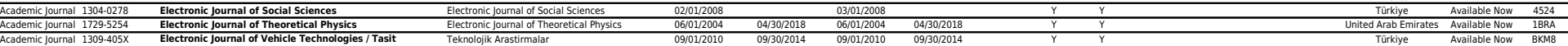

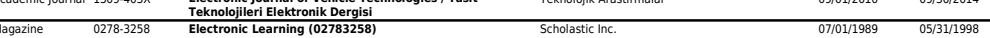

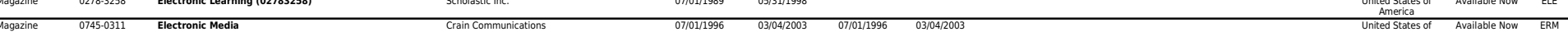

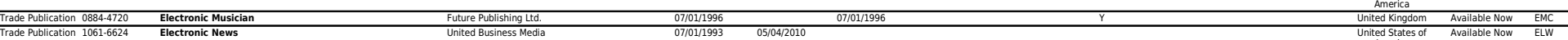

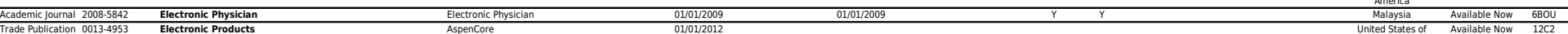
Unted Stateses of Avalable Now 86 6]

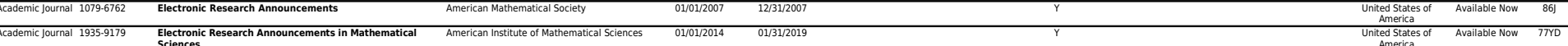

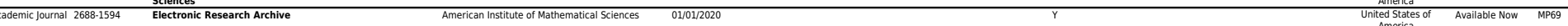
Electronic science \& Technology

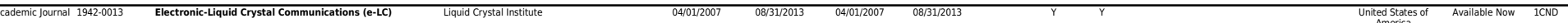

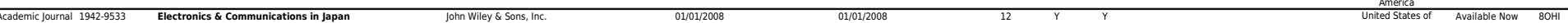

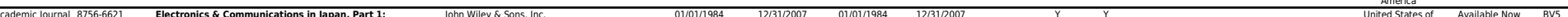

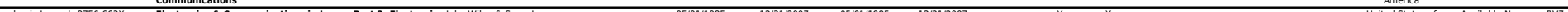

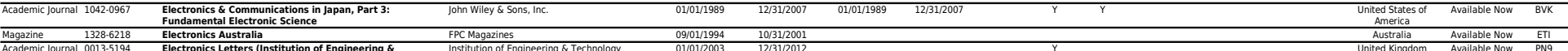

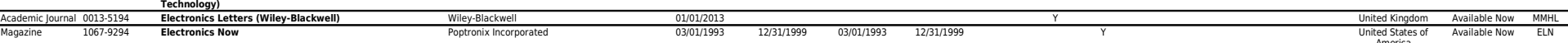

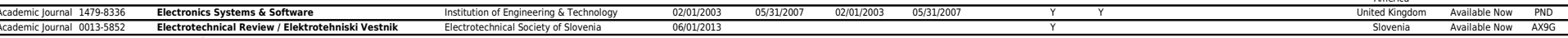

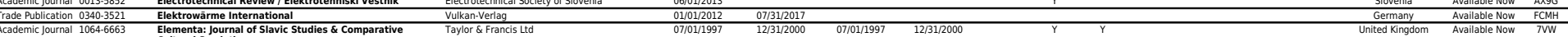

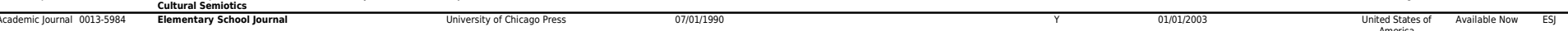

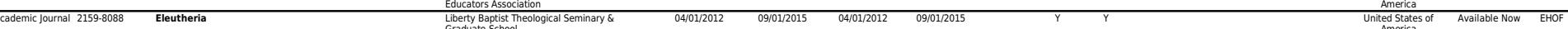

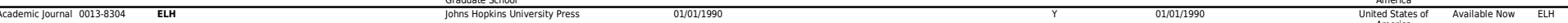

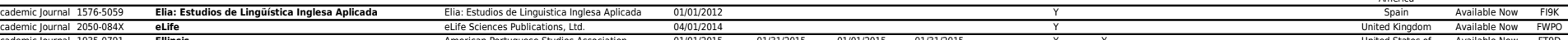

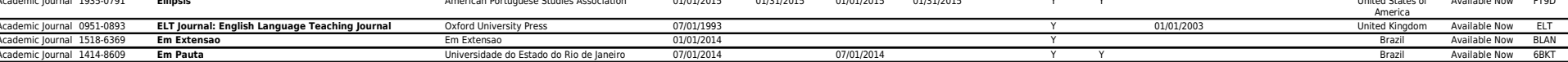

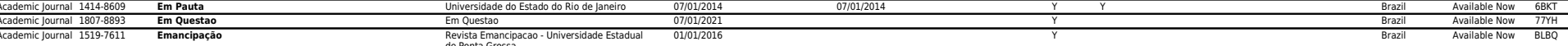

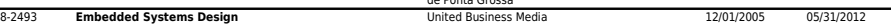

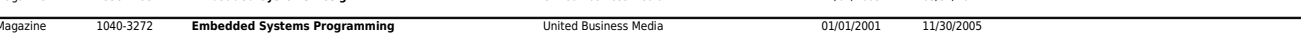

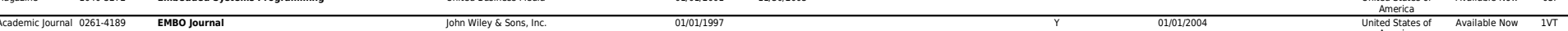

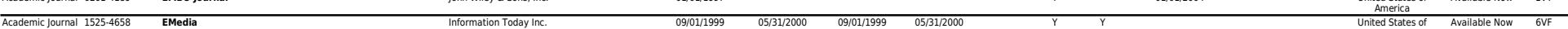

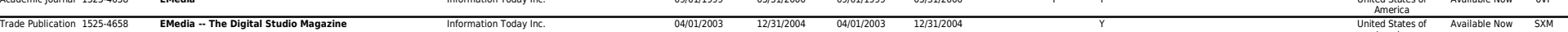

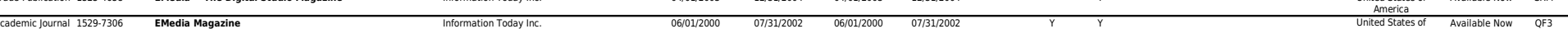
tedemic Jurnal 1529-300

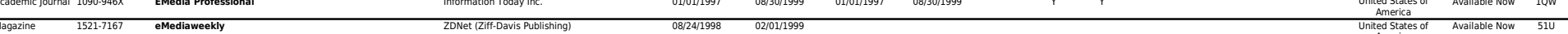

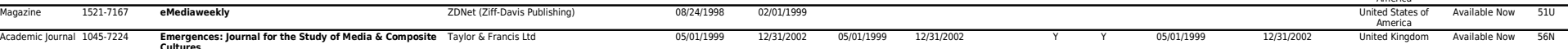

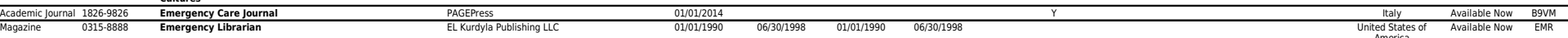

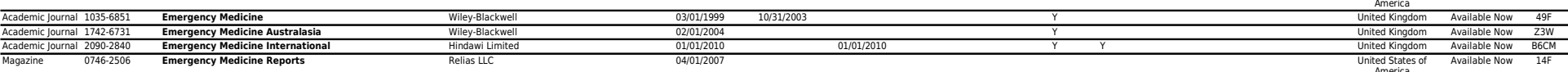

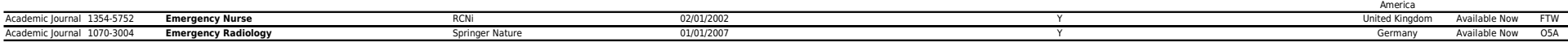

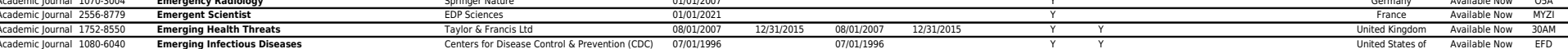

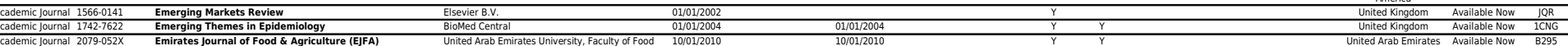

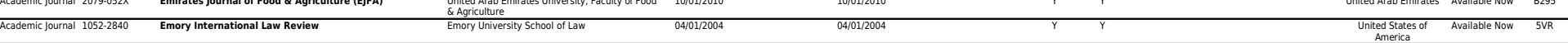




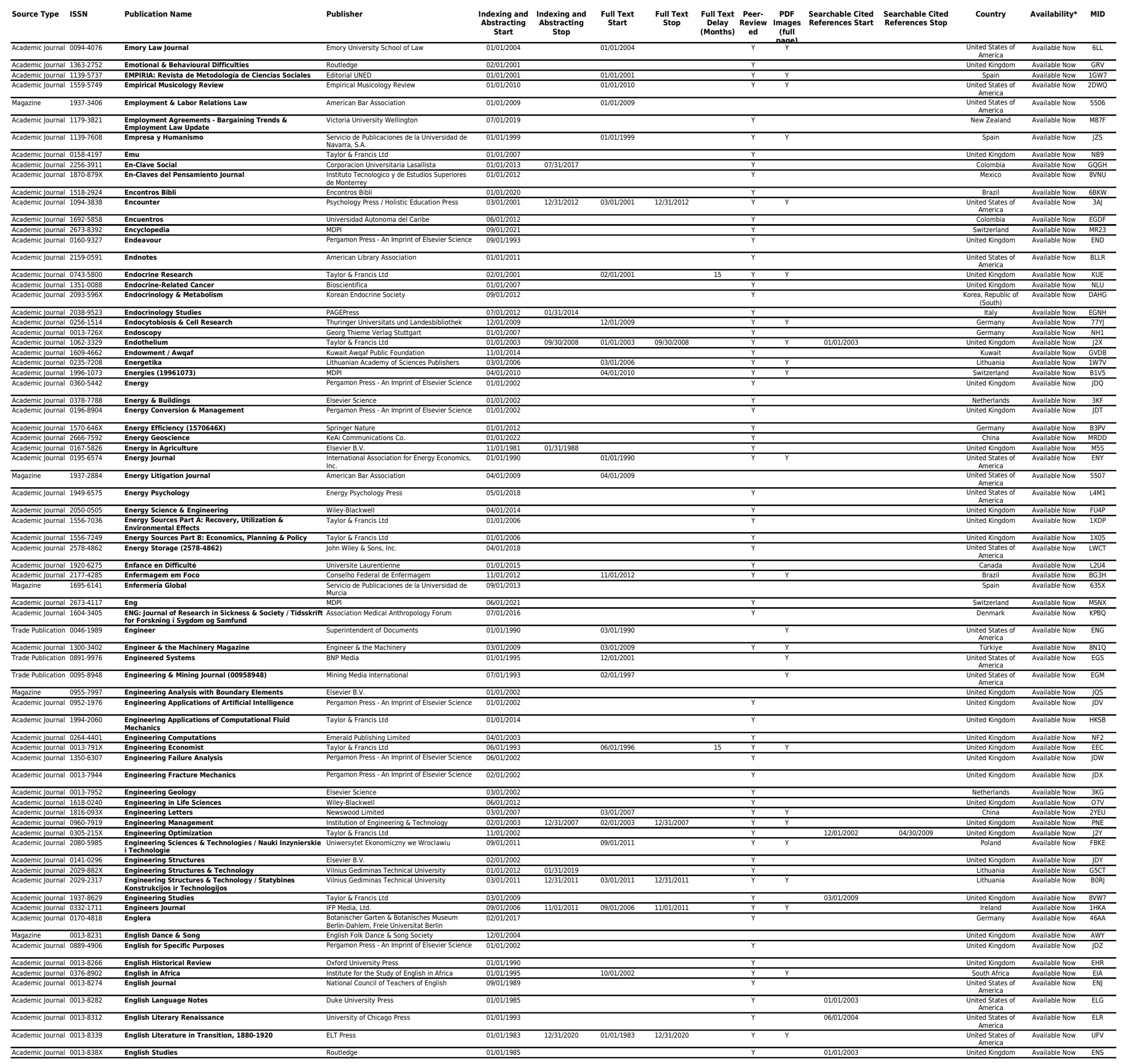




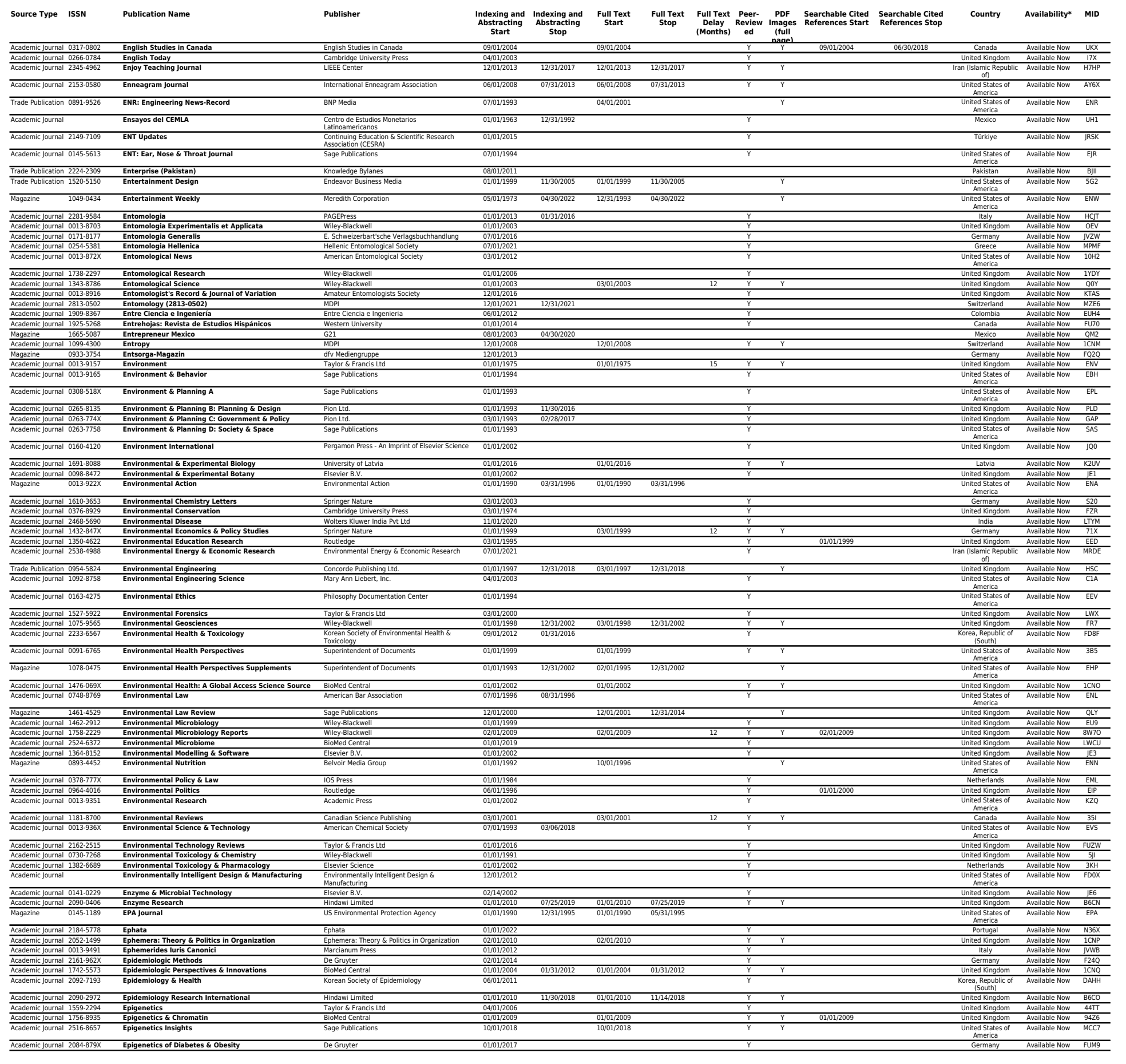




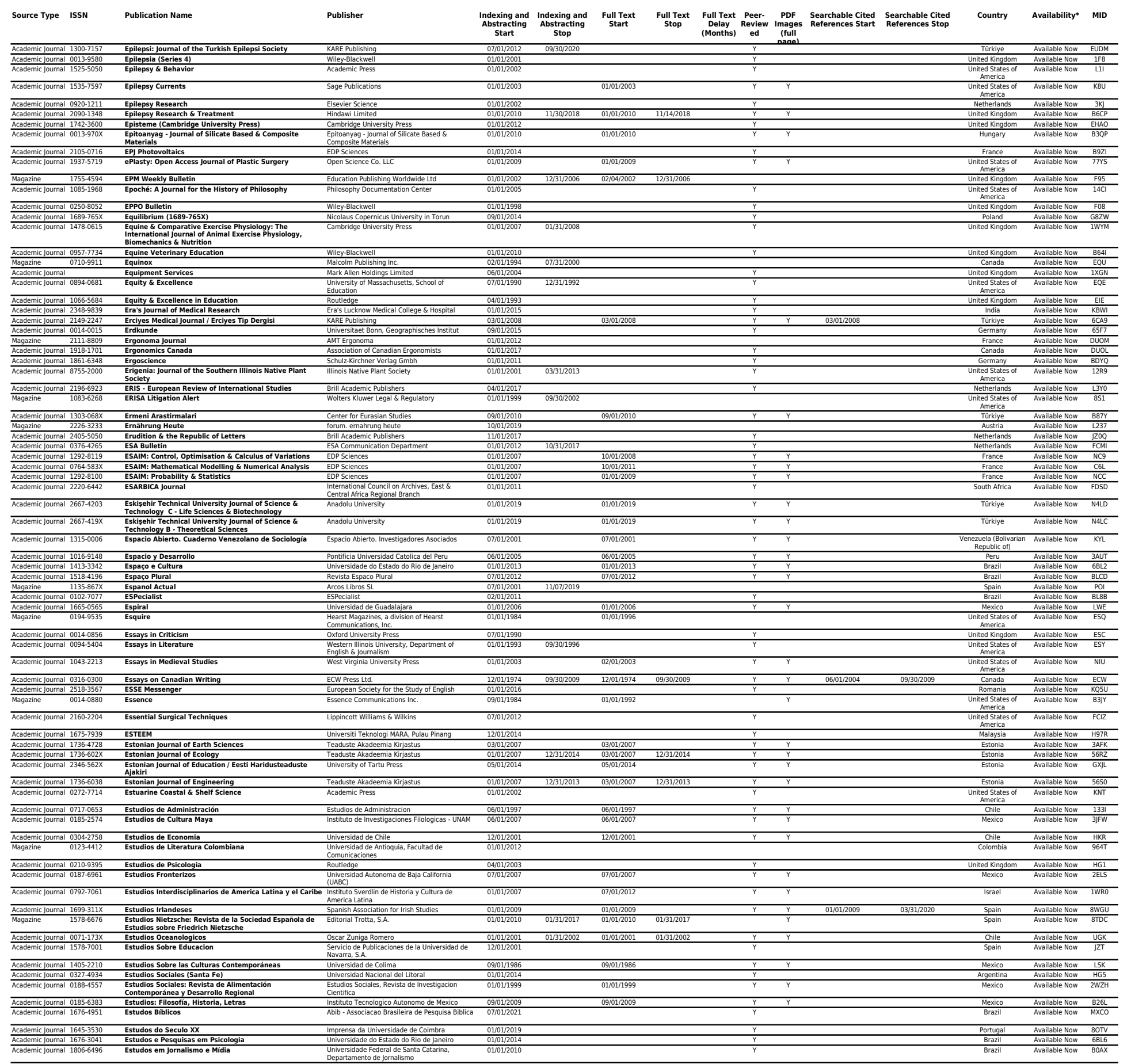




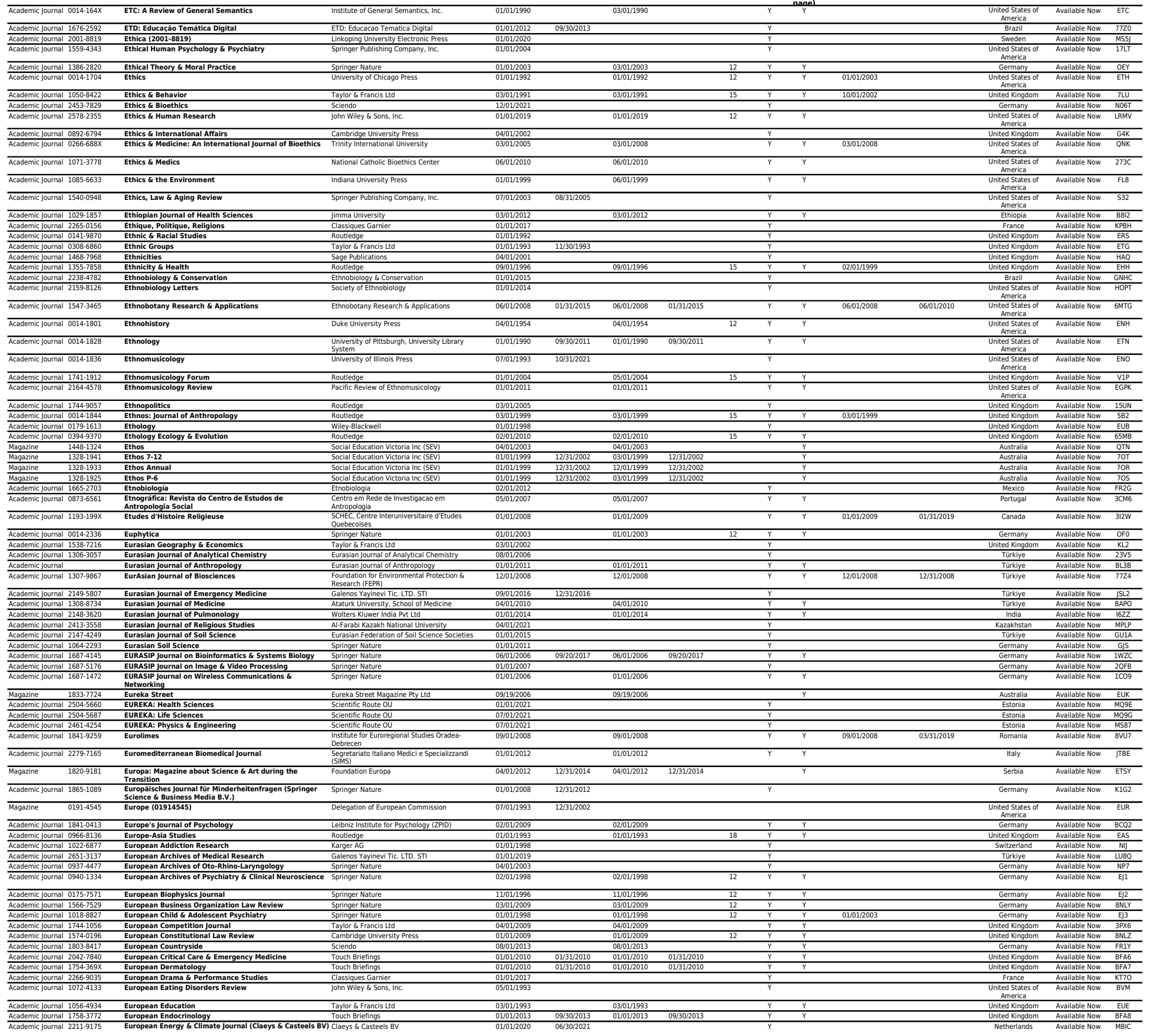




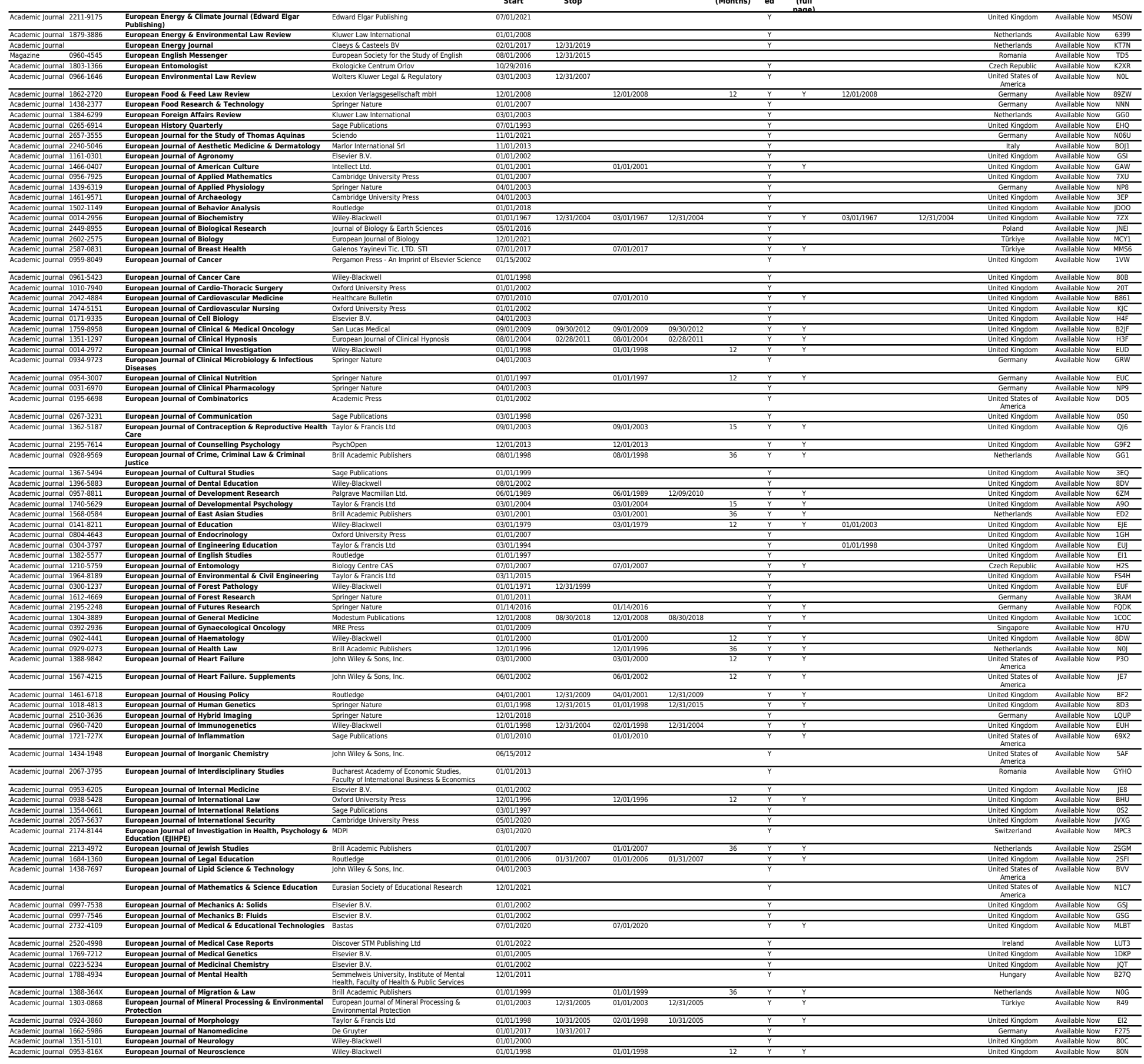




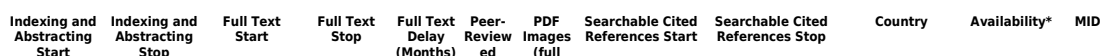

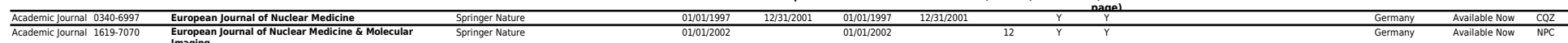

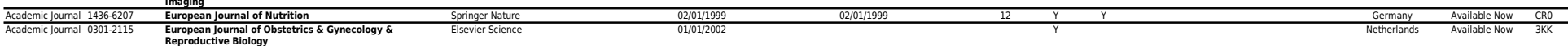

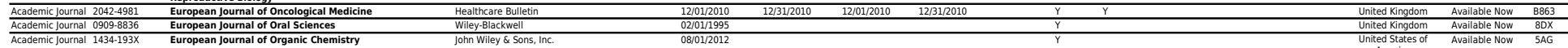

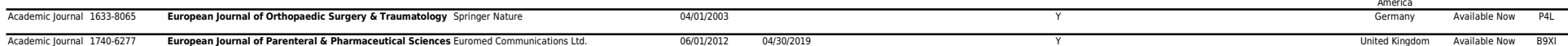

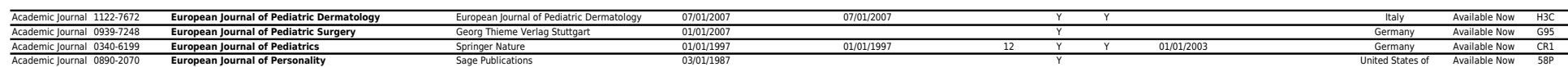

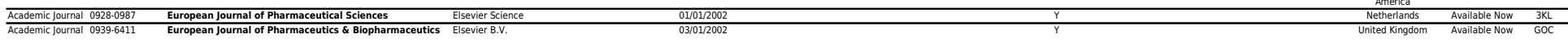

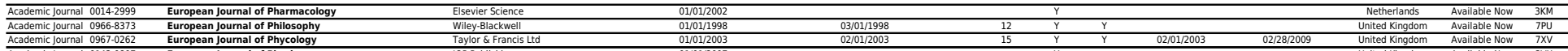

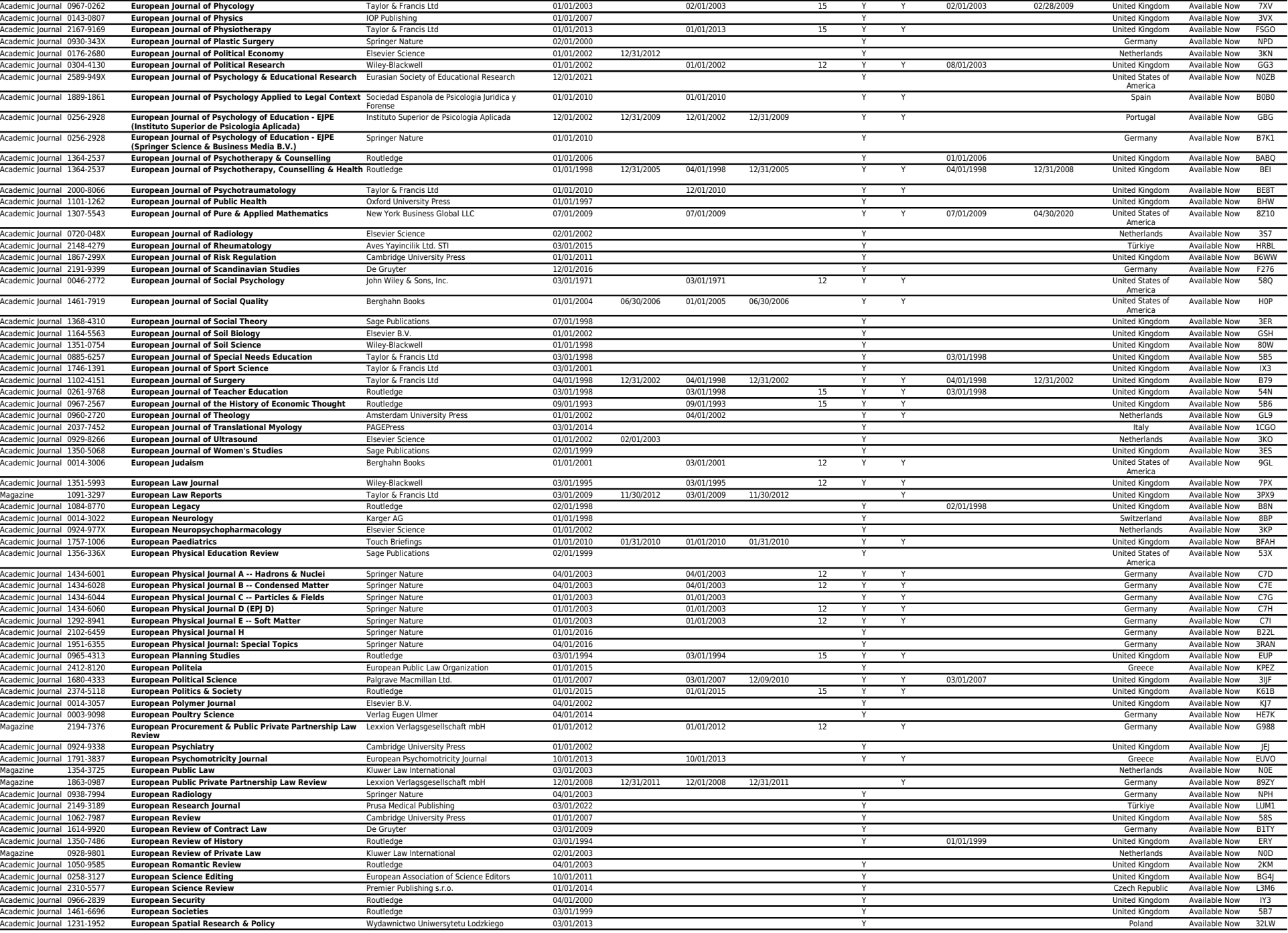




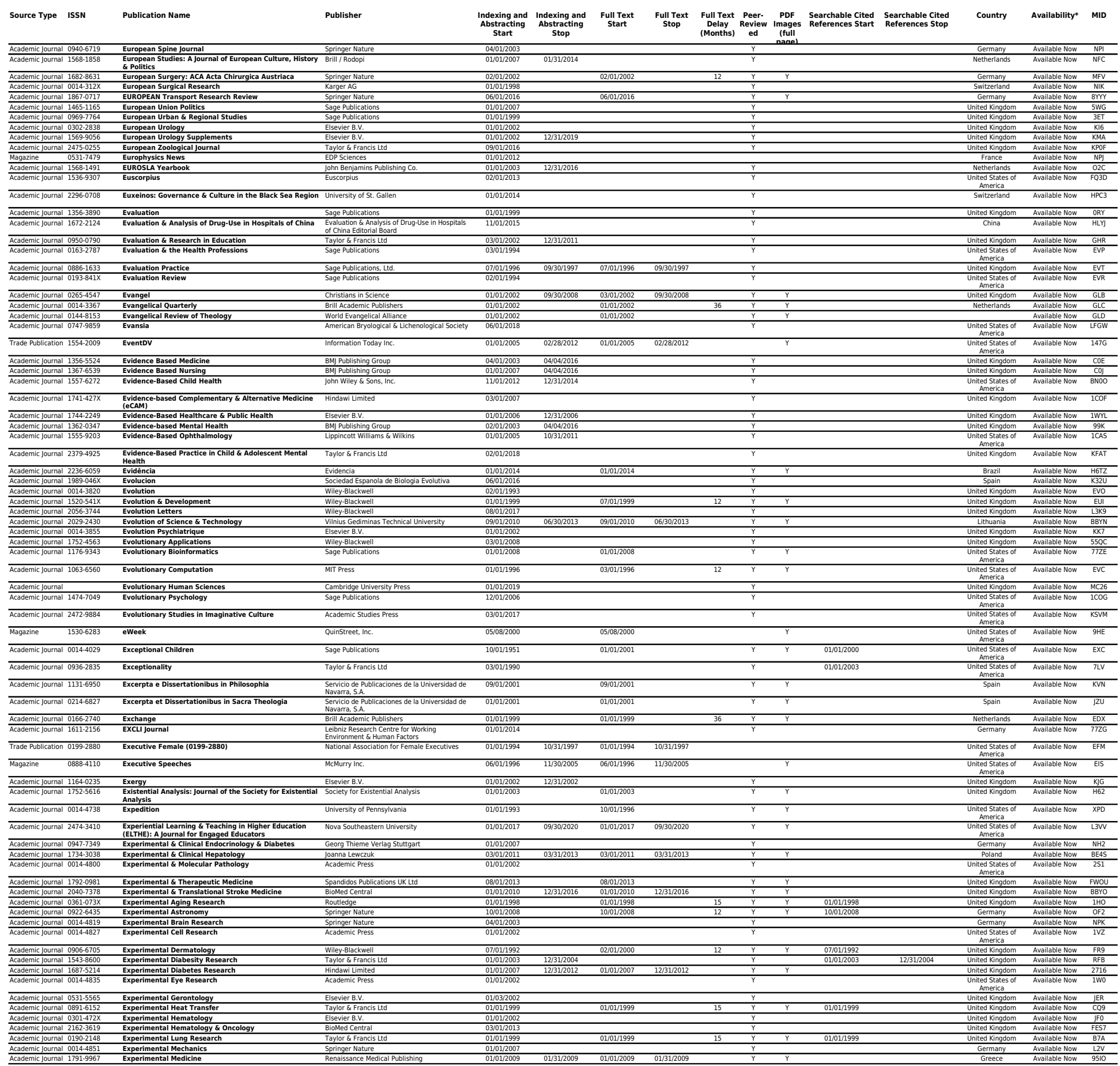




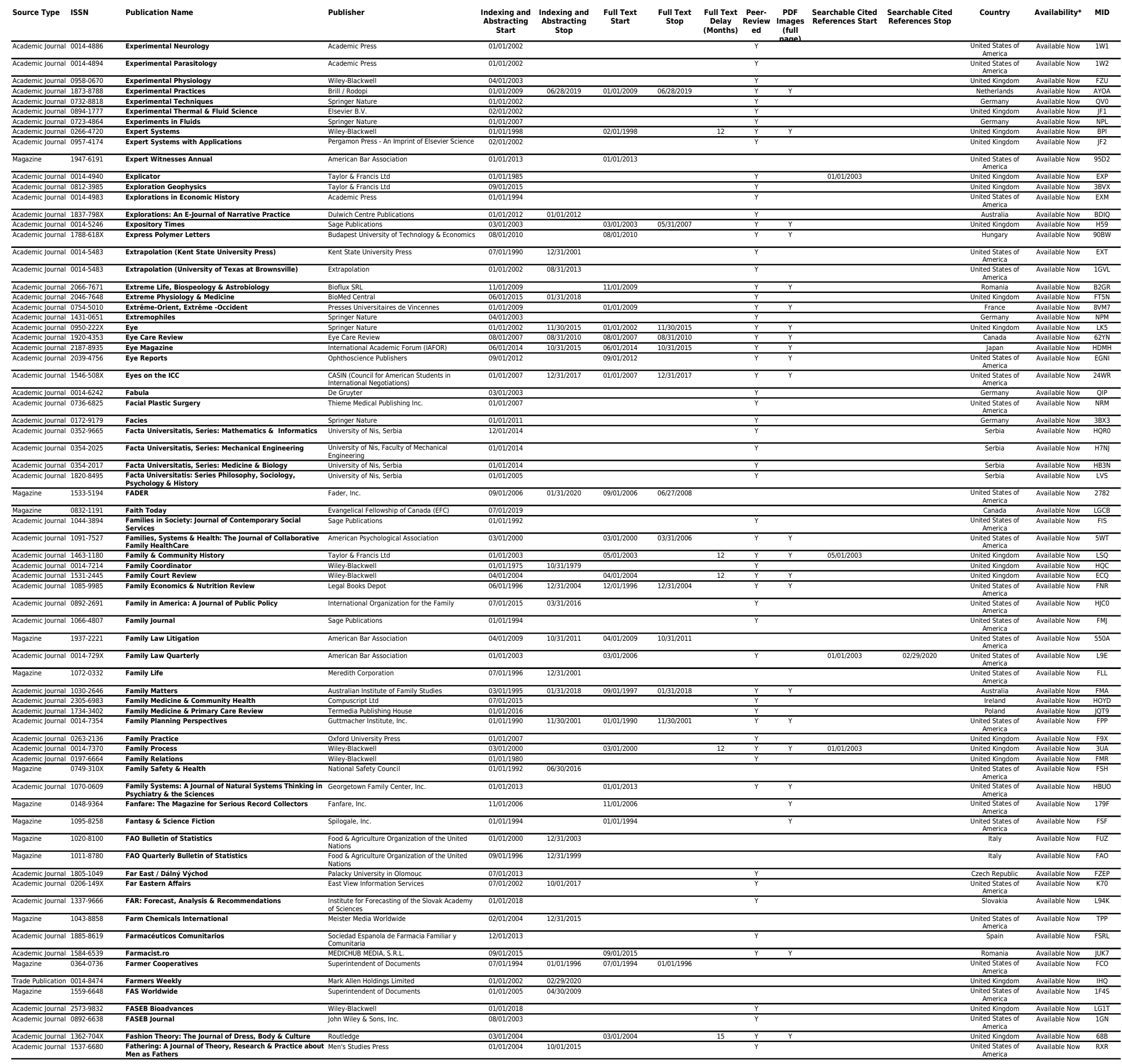




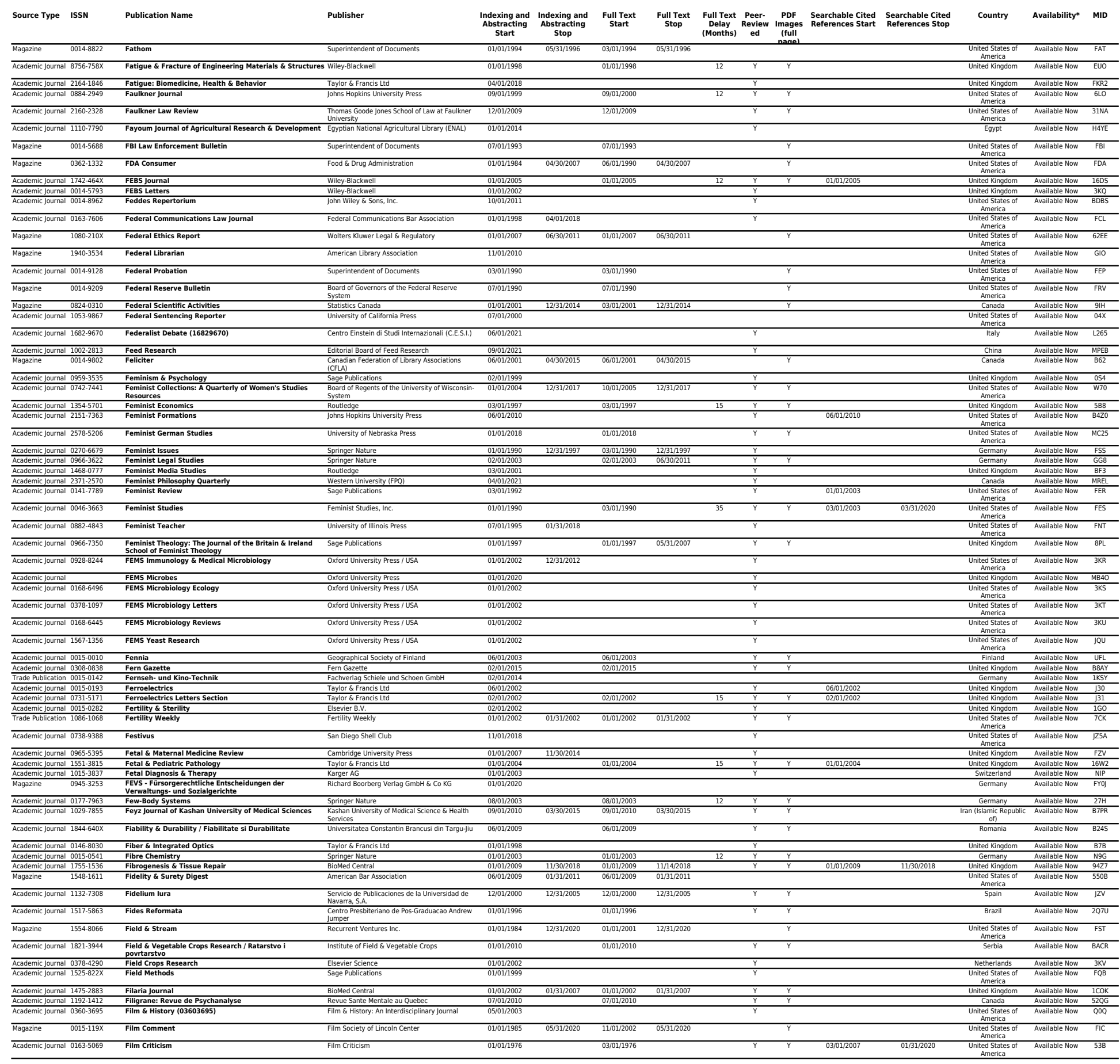




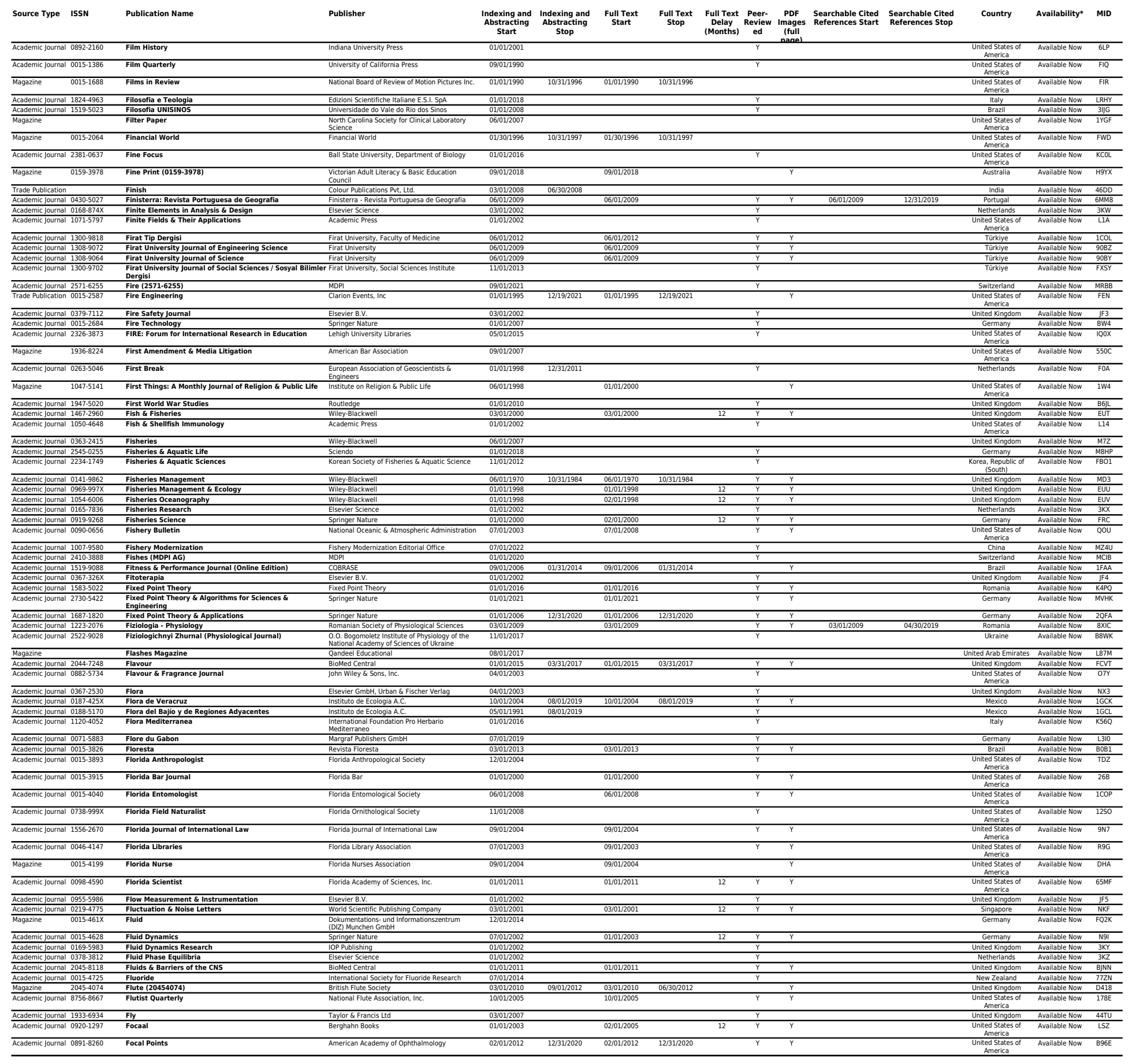




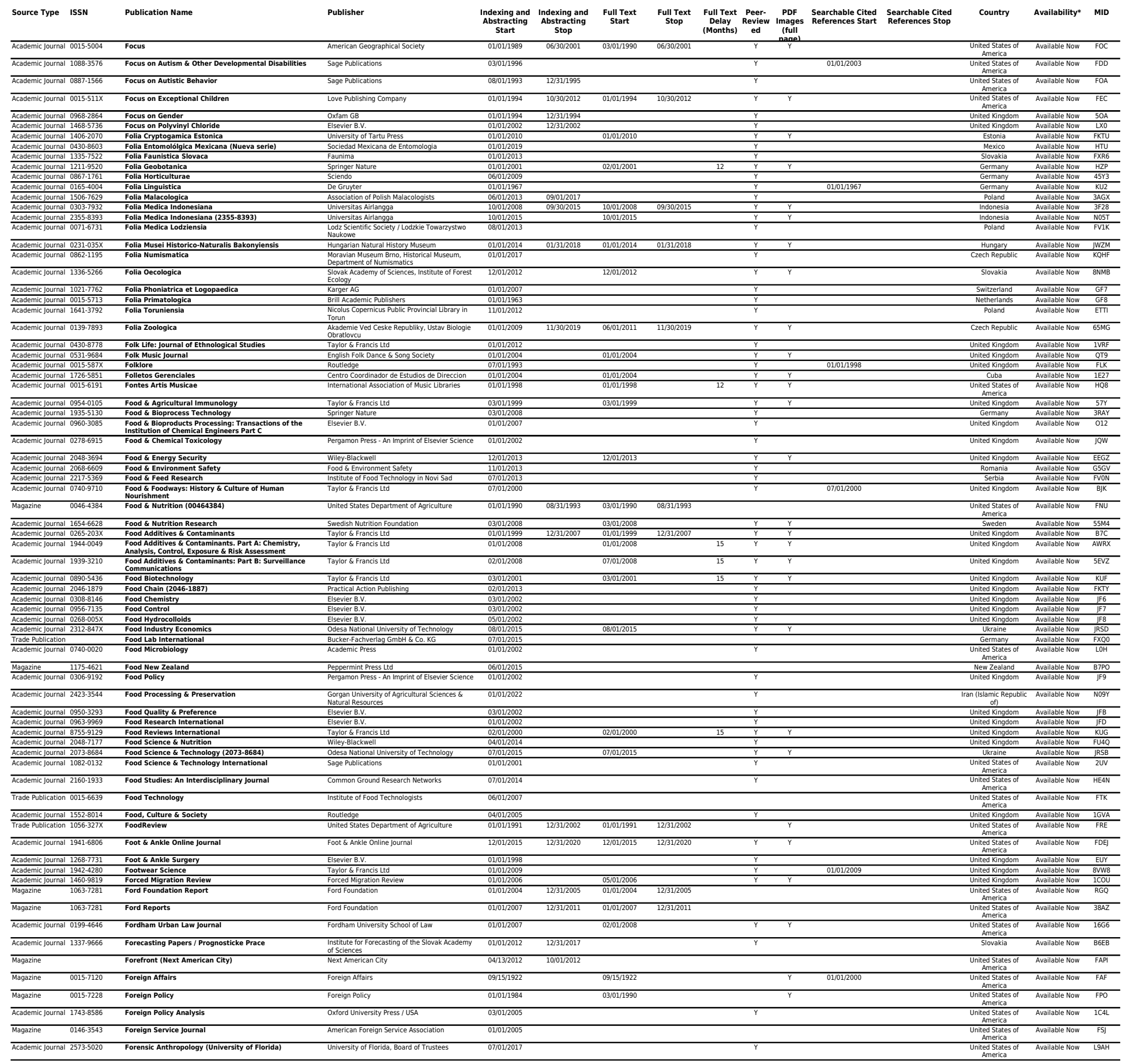




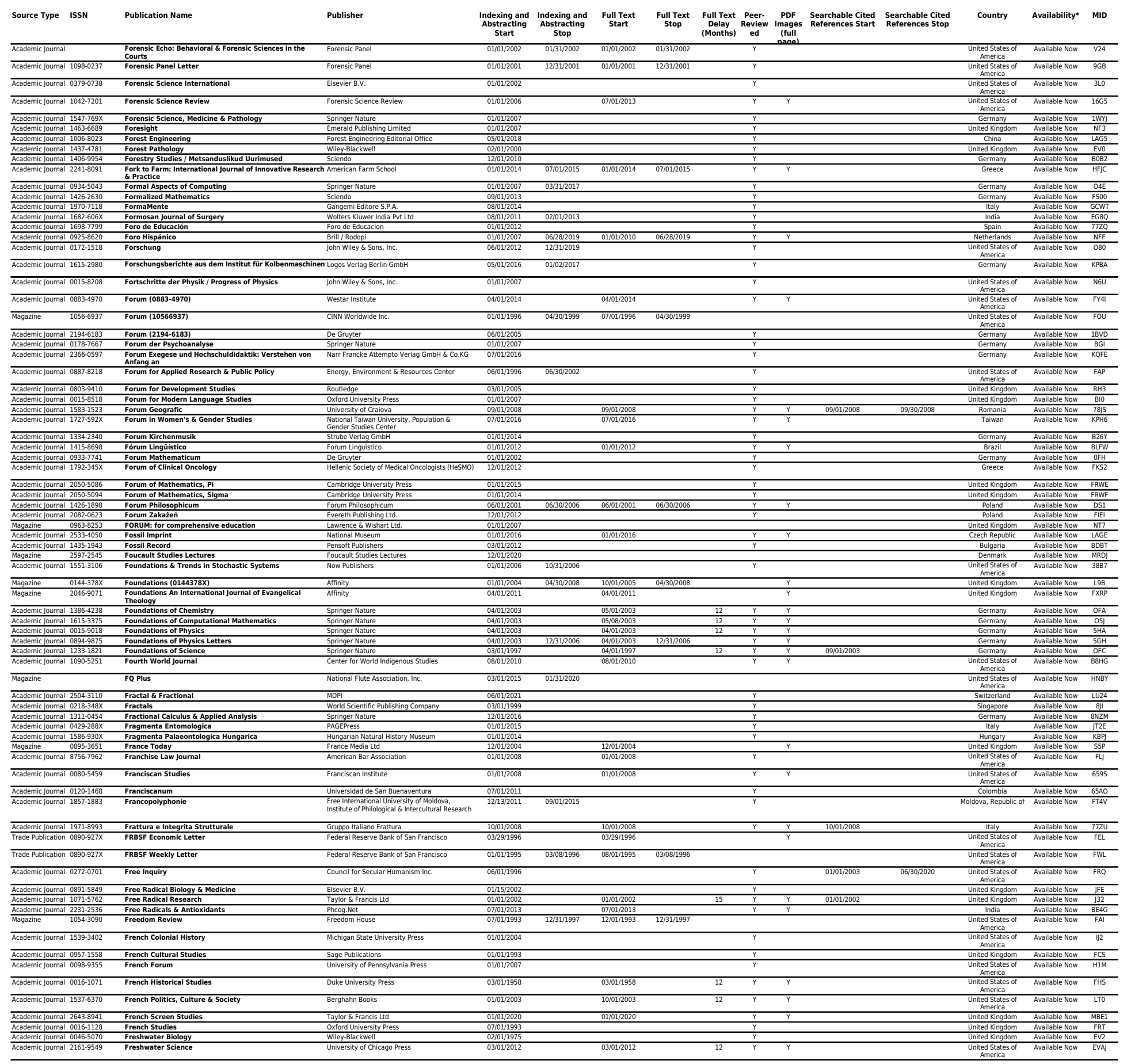




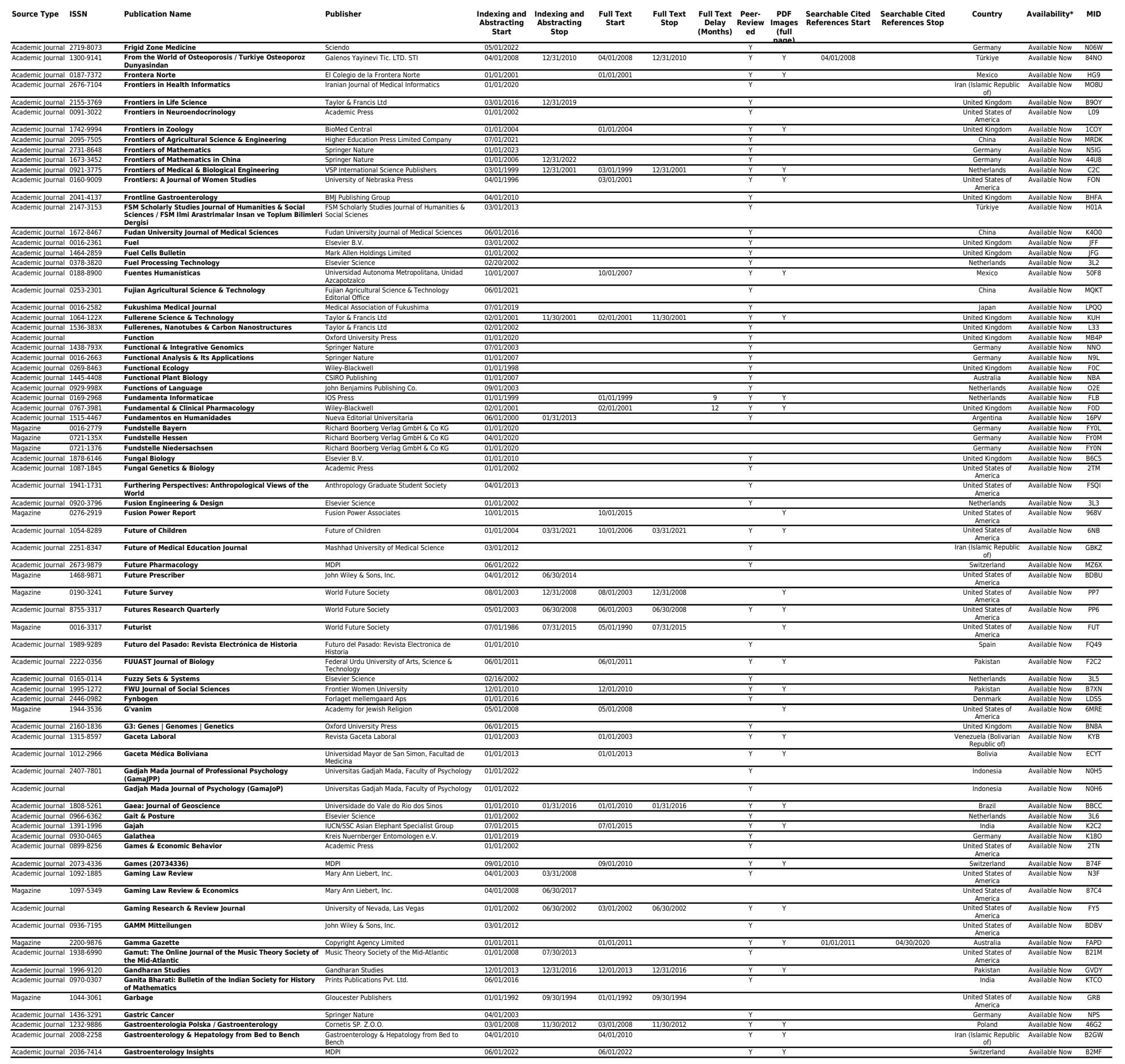




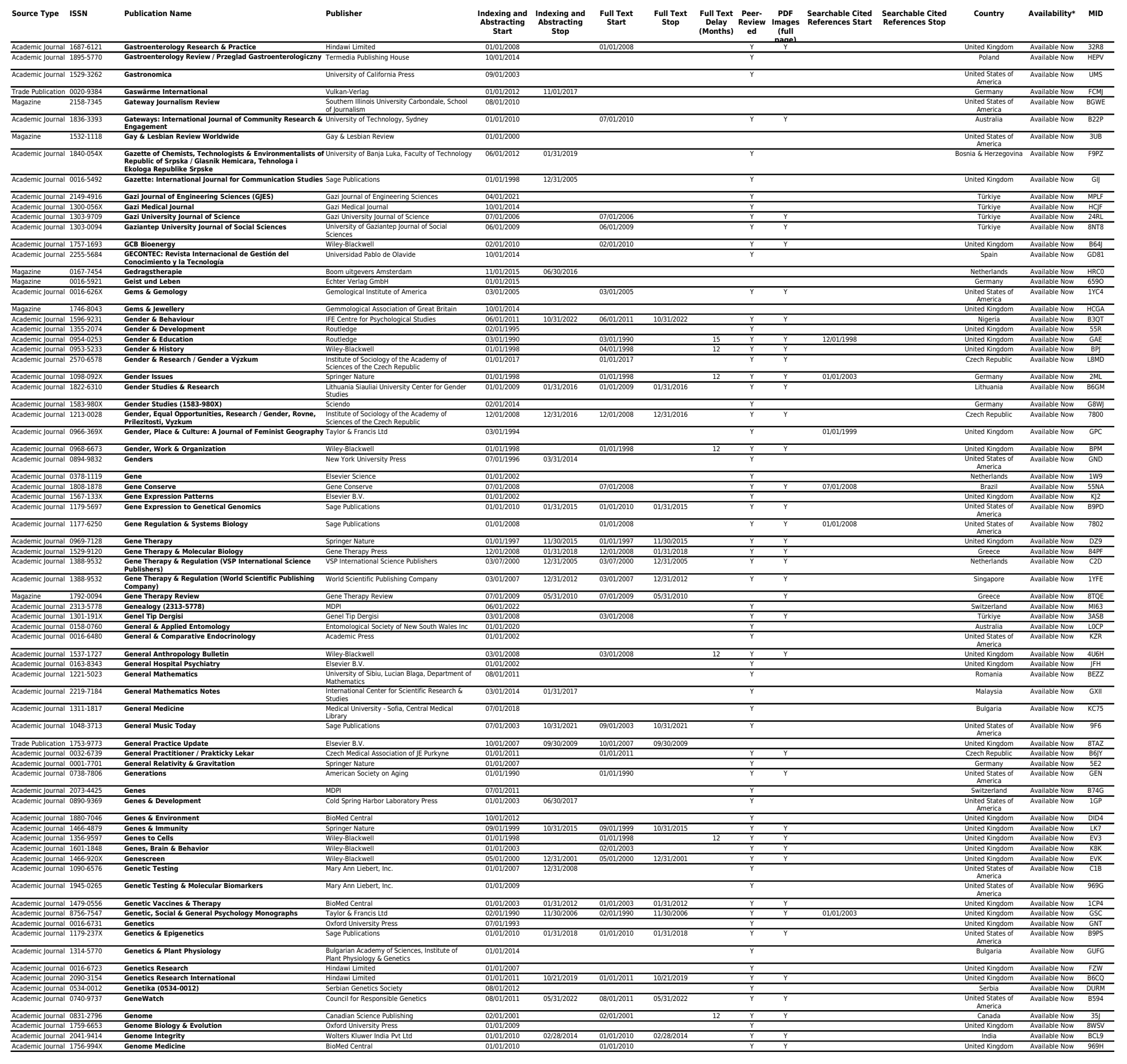




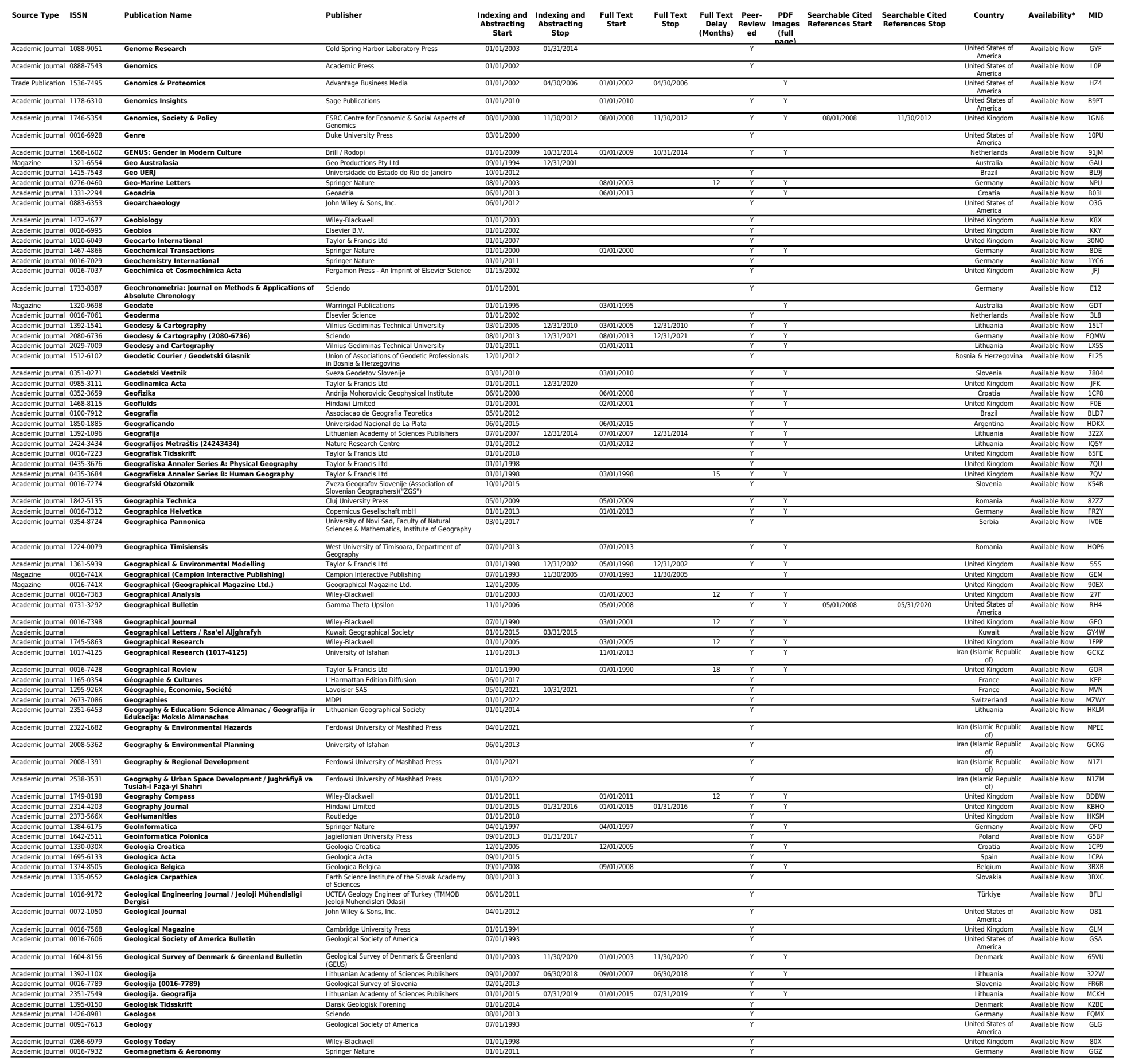




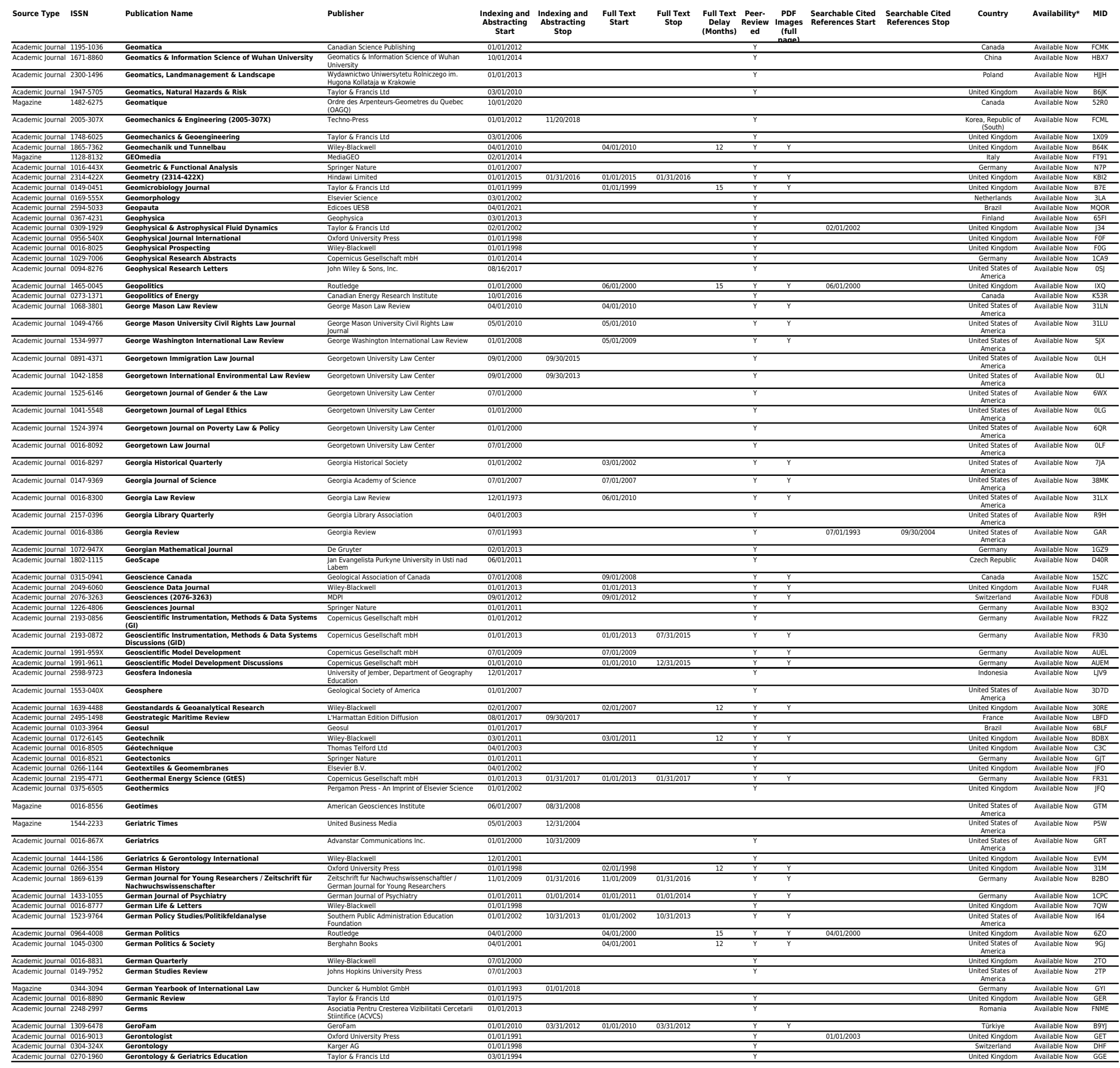




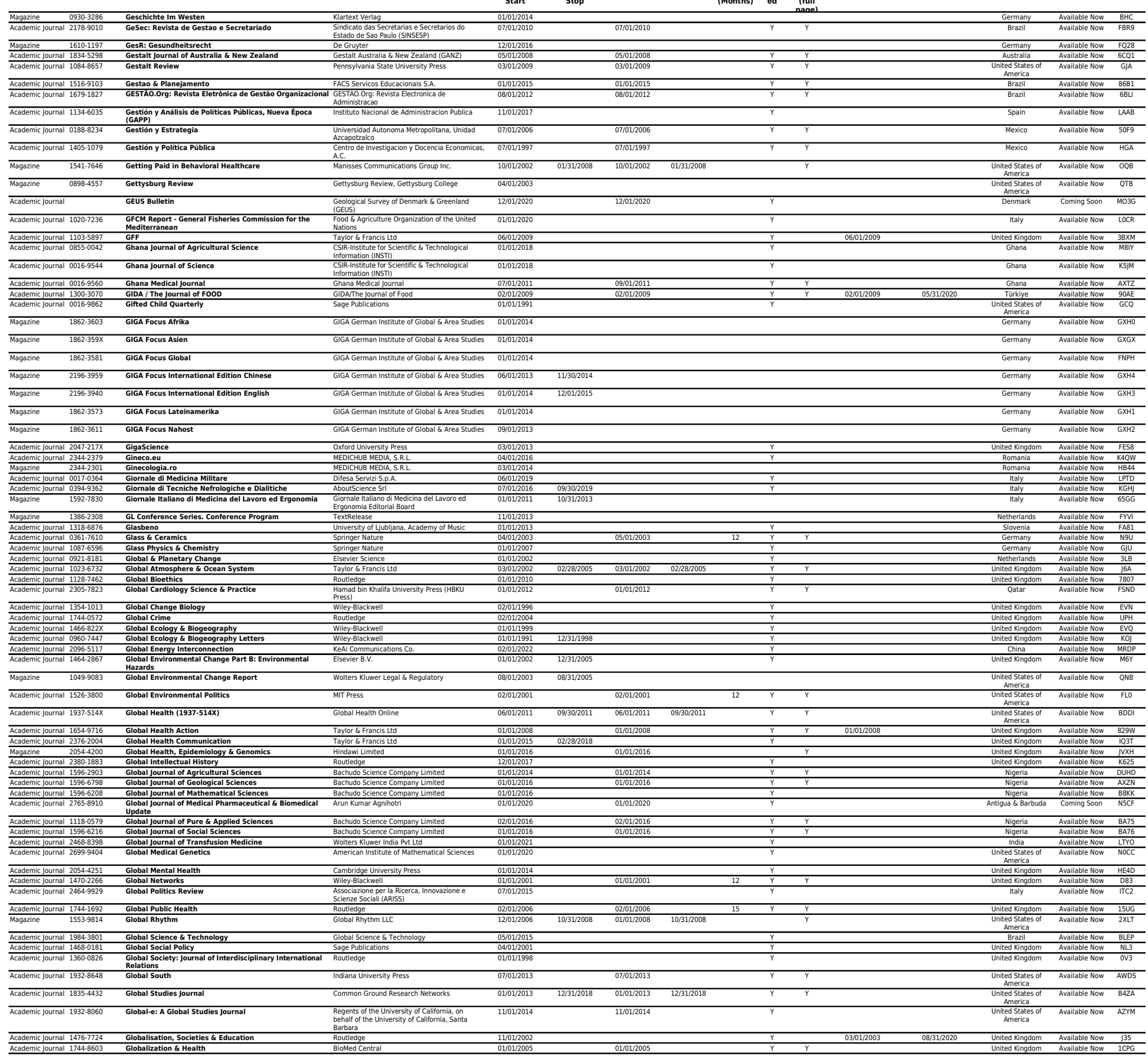




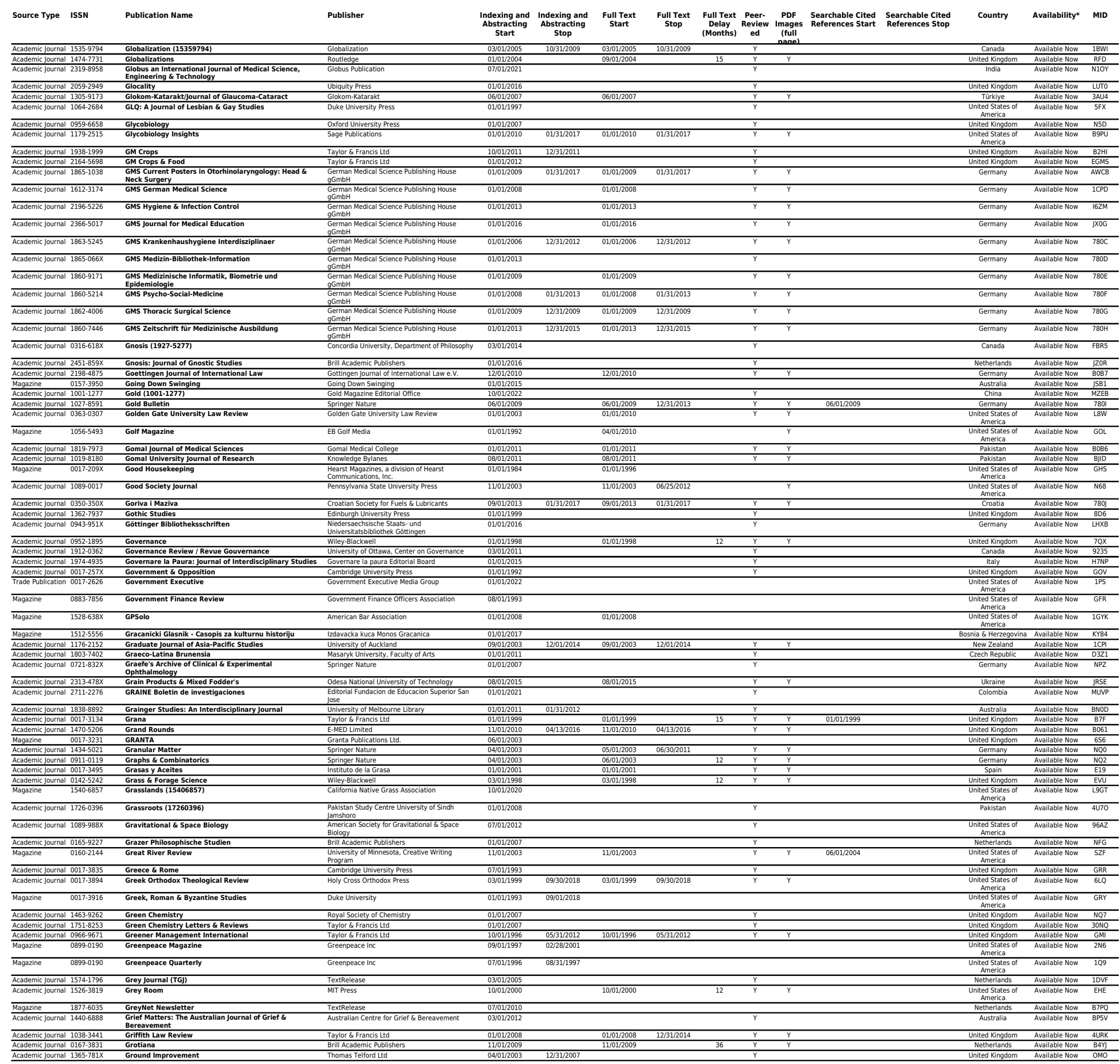




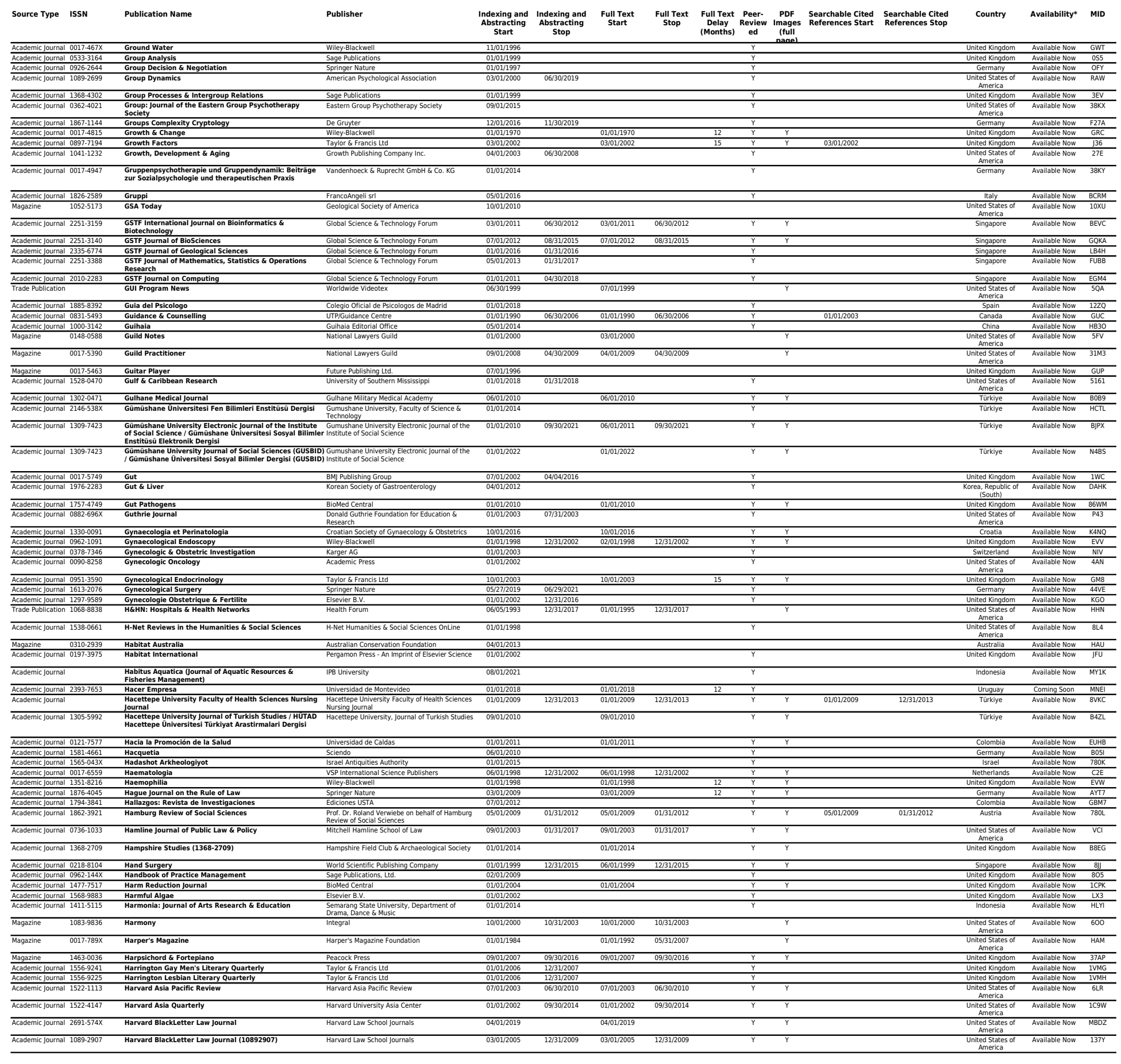




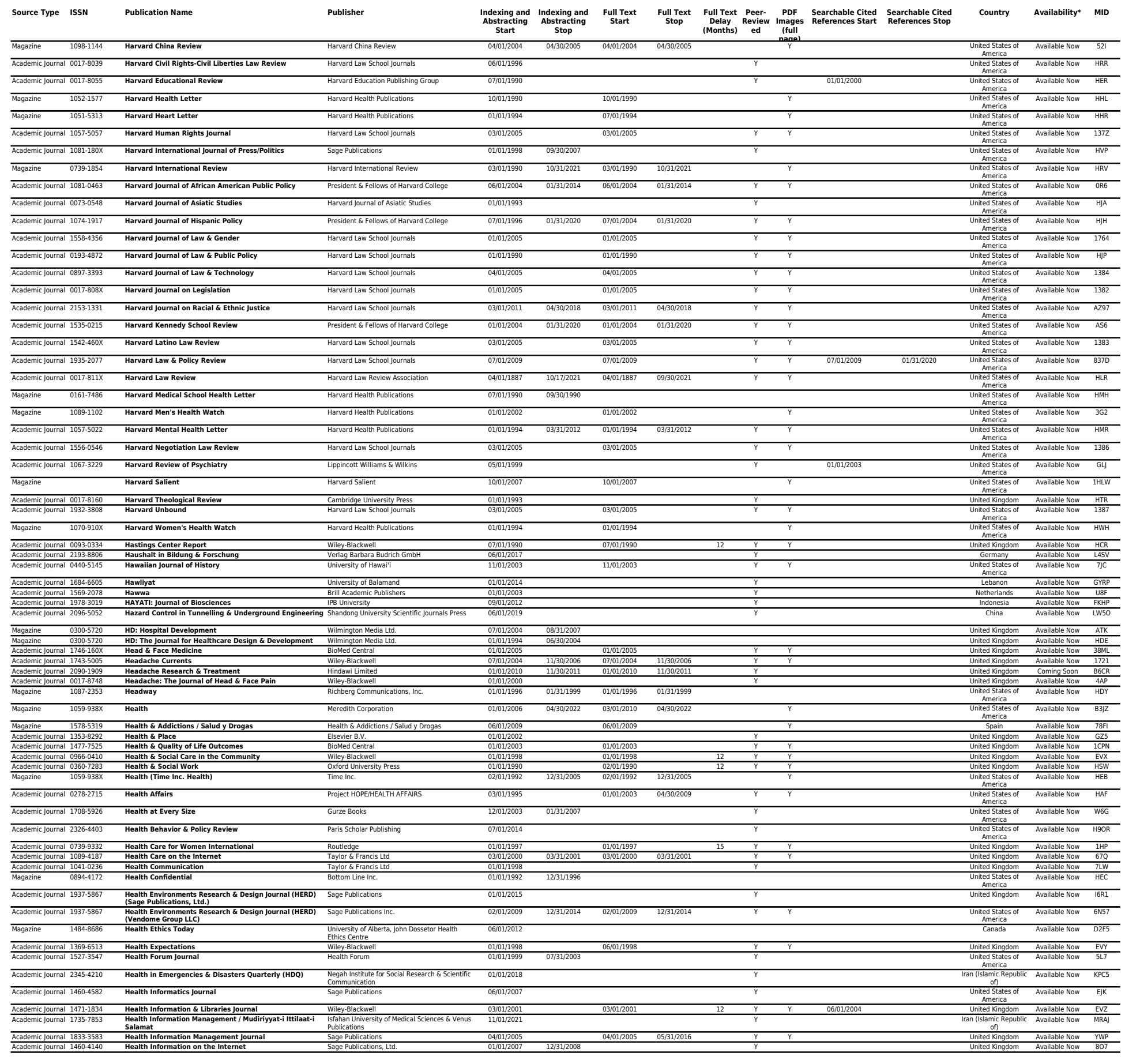




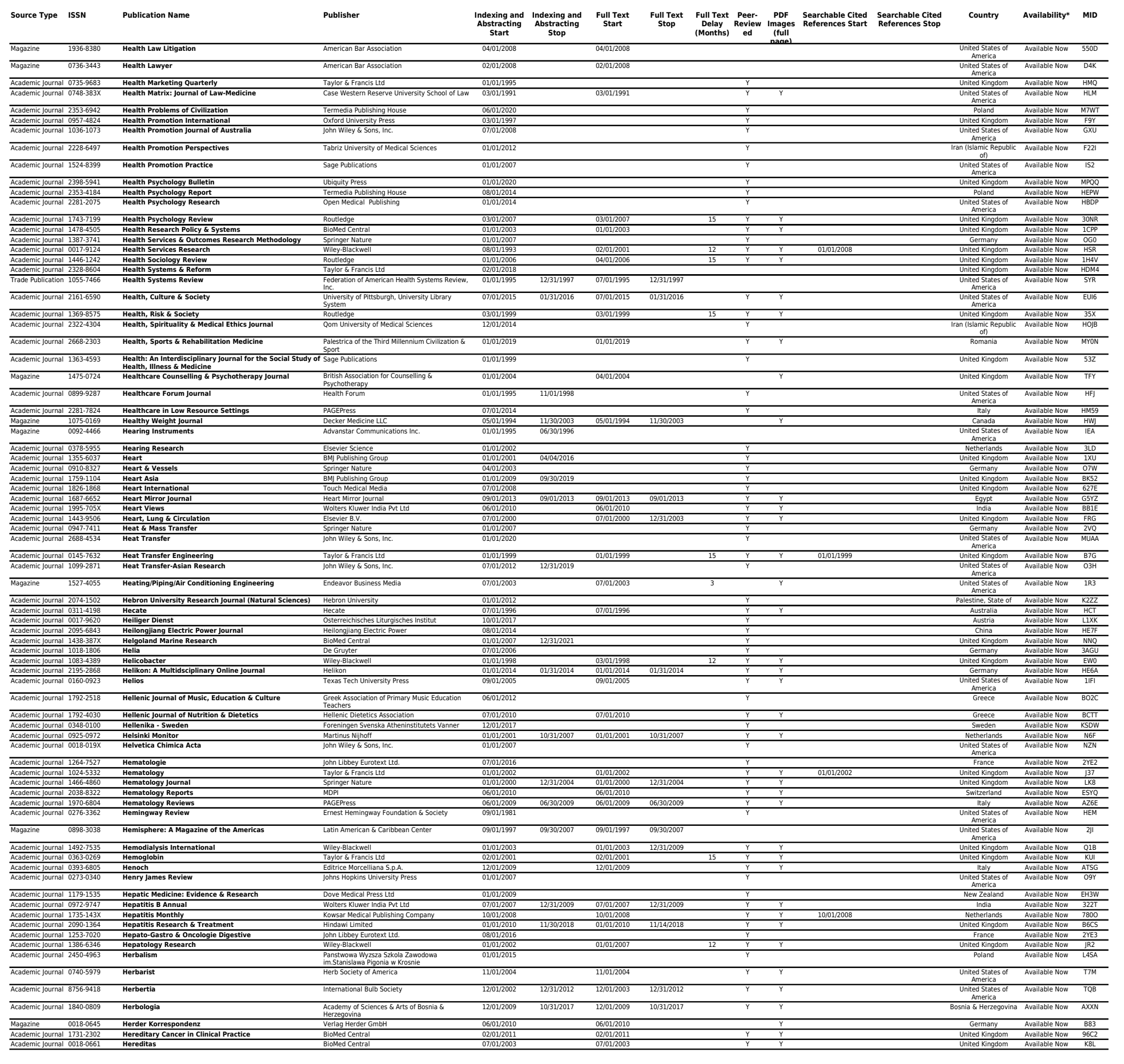




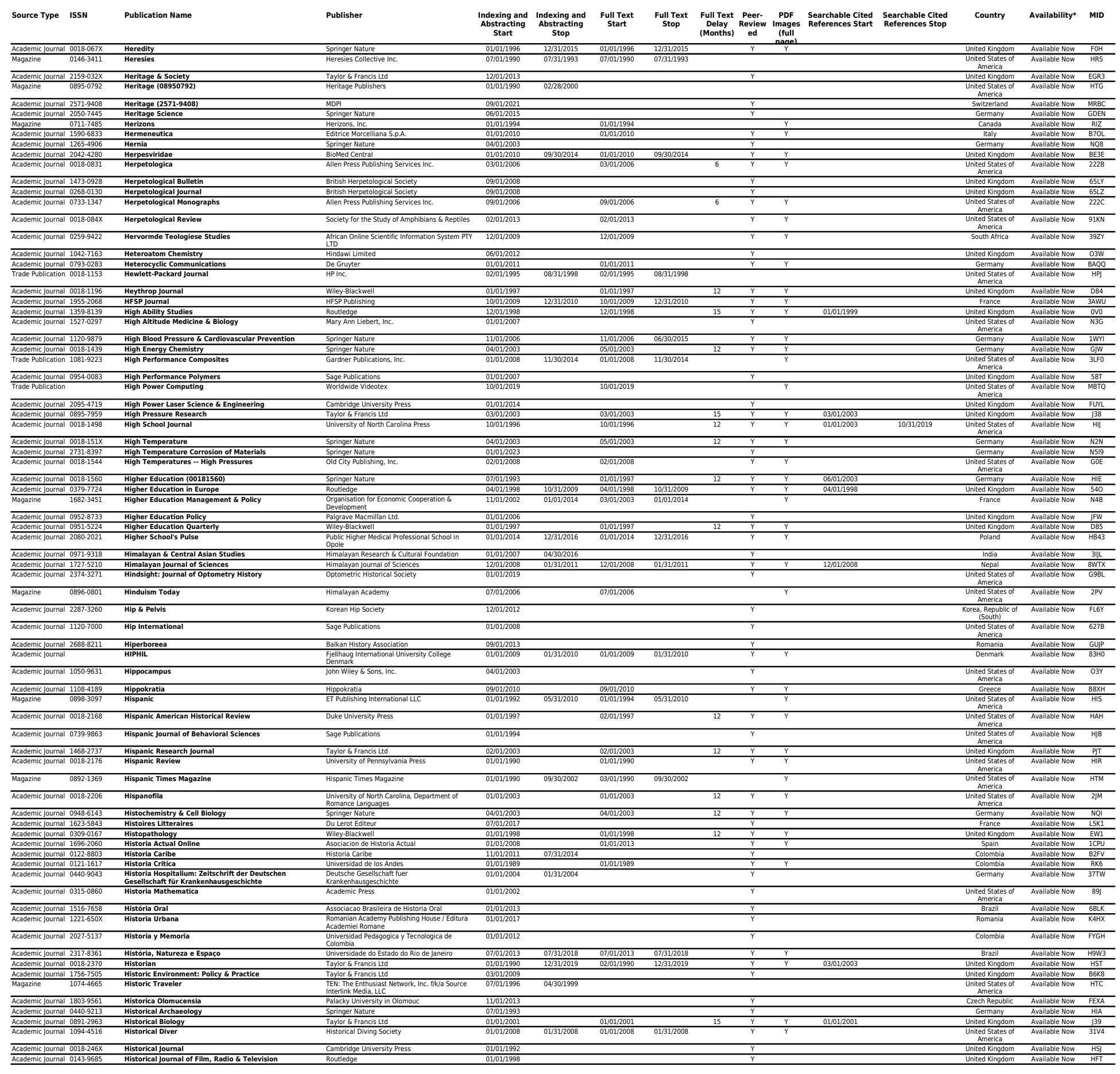




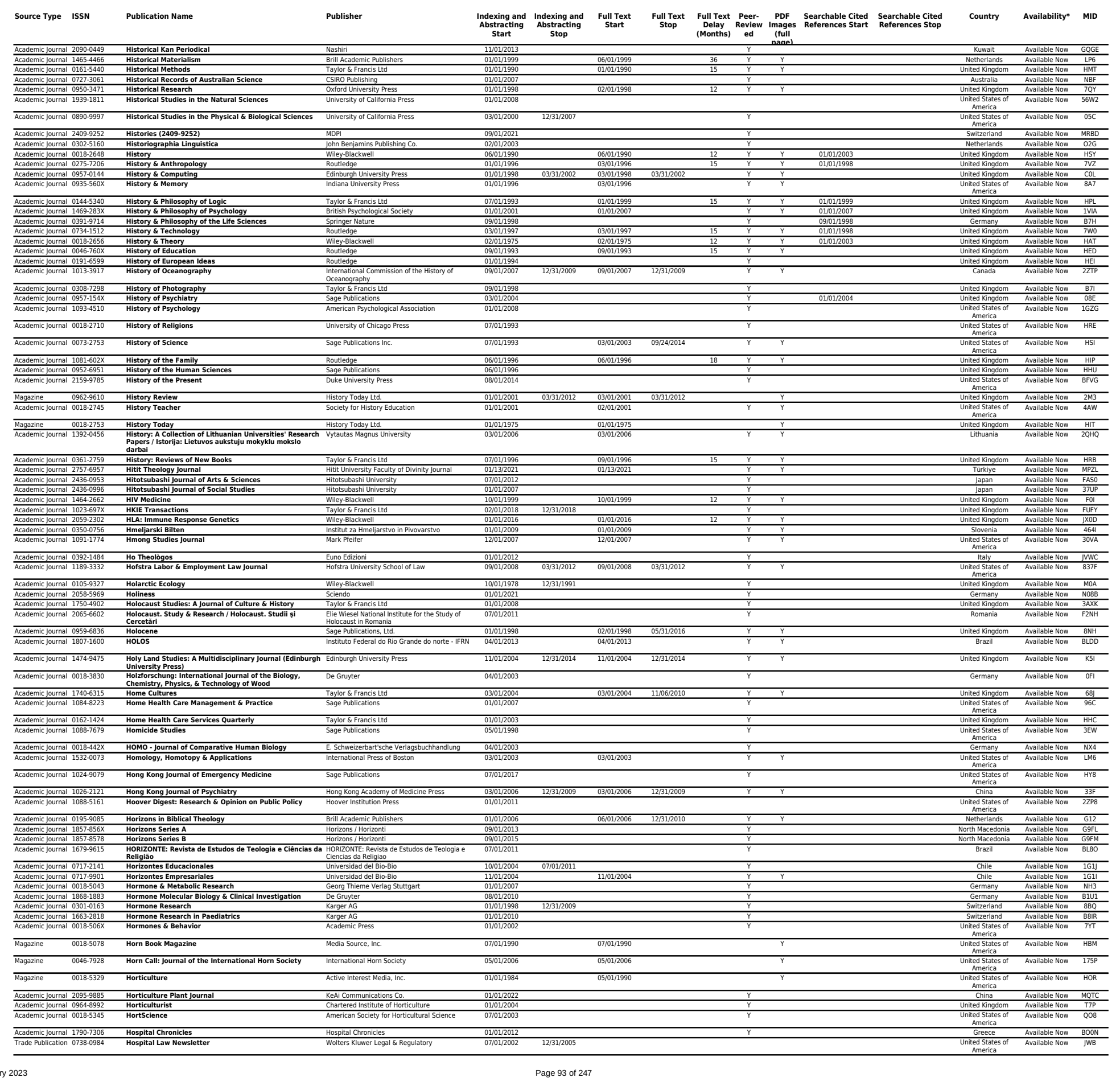




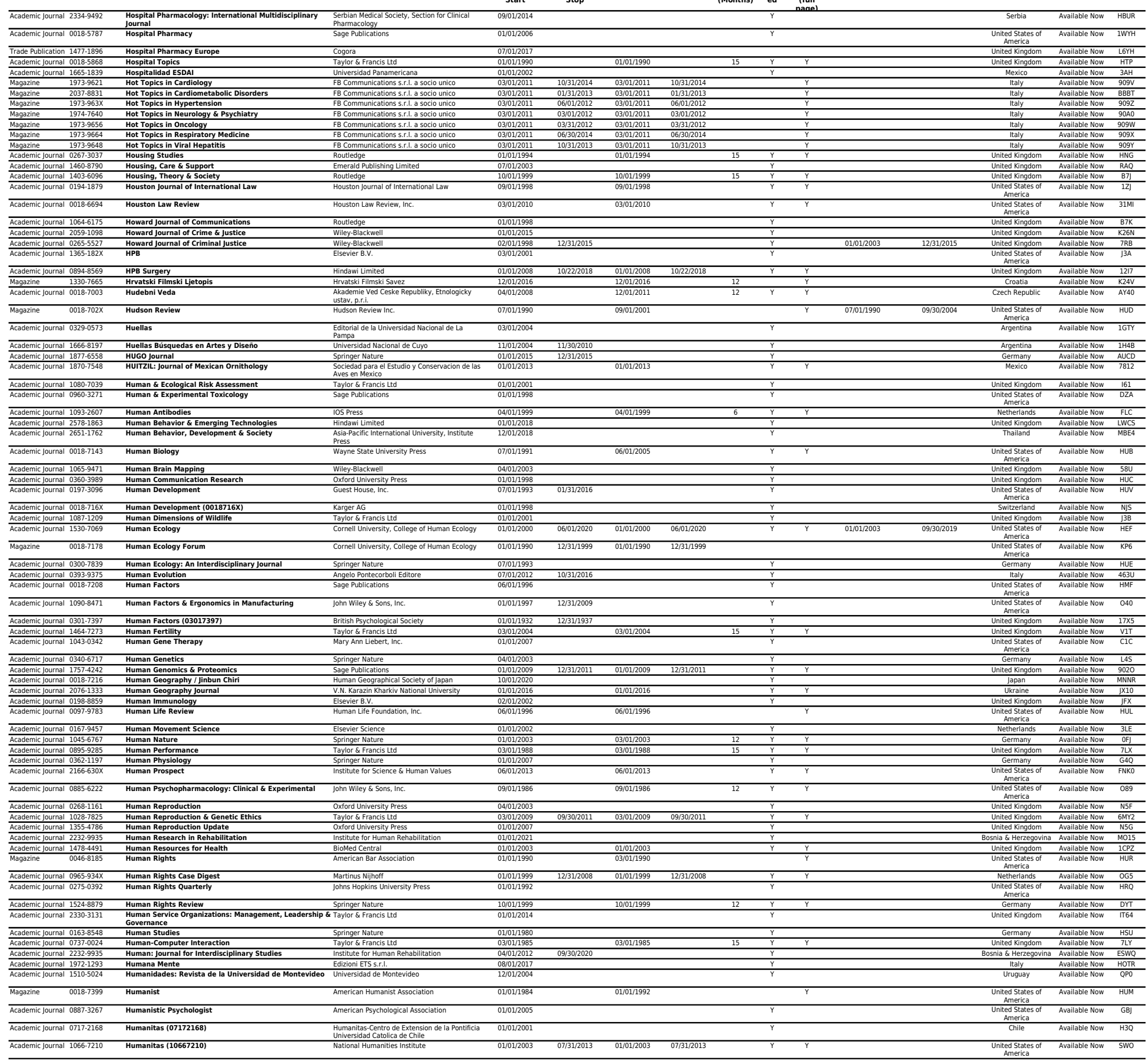




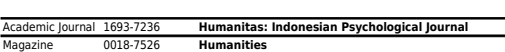

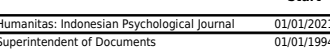

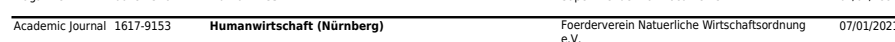

O101019994

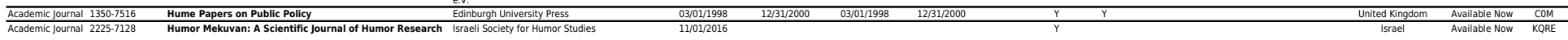

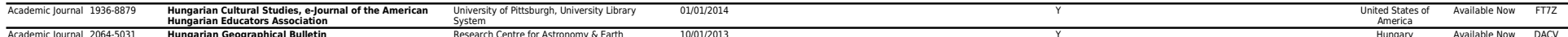

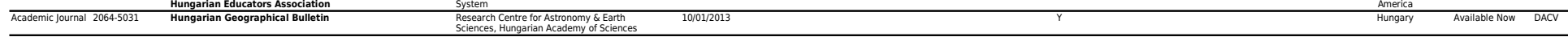

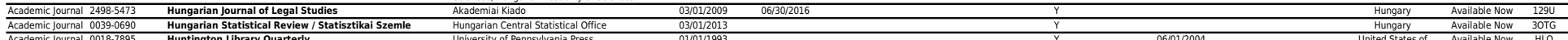

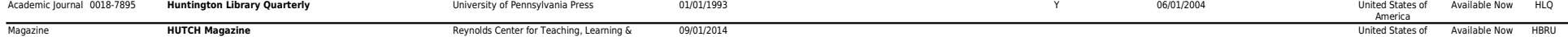

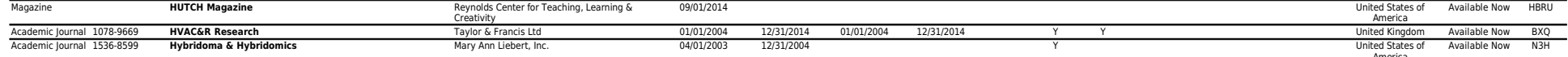

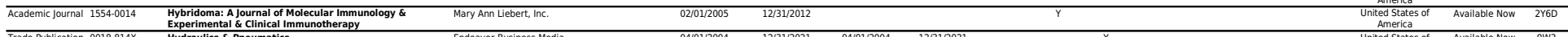

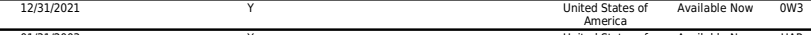

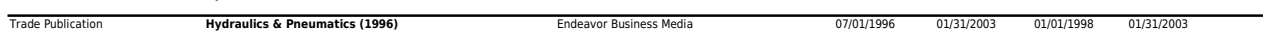

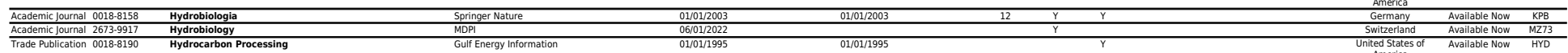

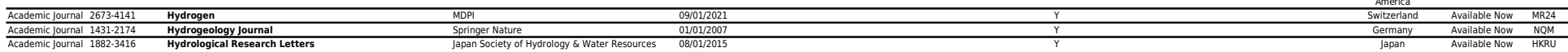

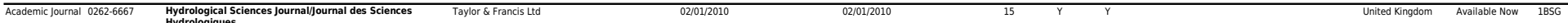

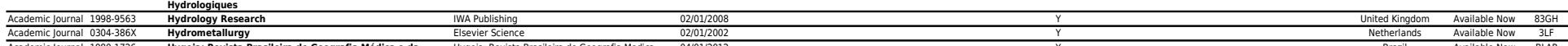

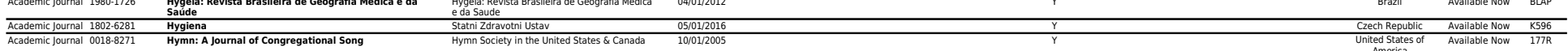

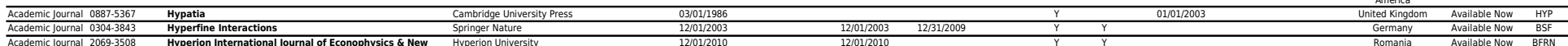

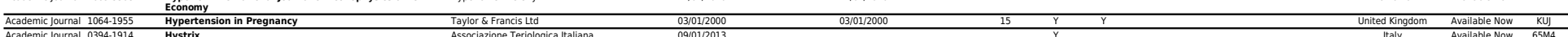

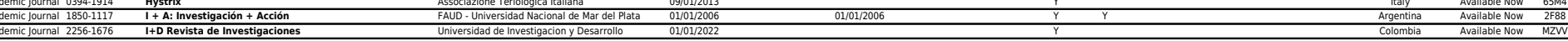

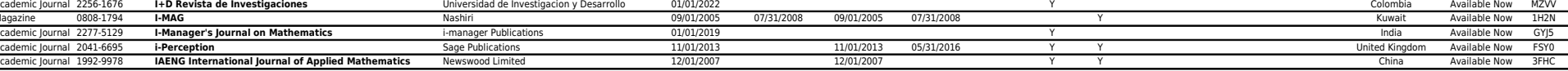

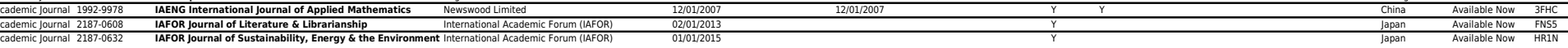

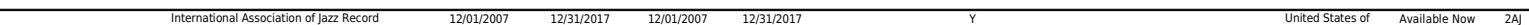
Collectors

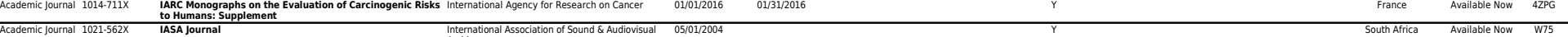

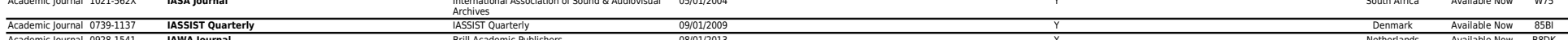

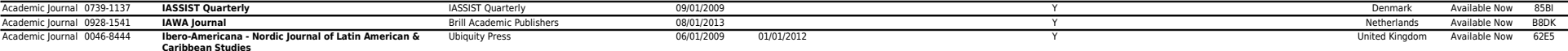

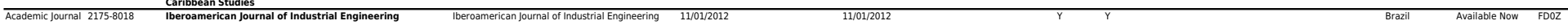

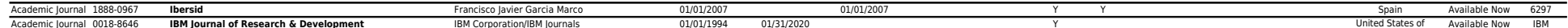

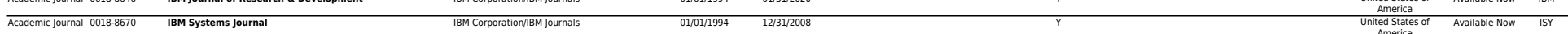

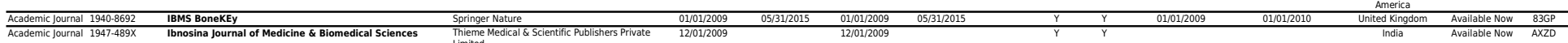

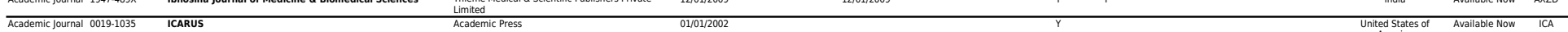

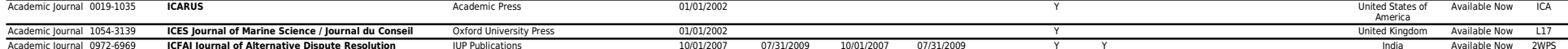

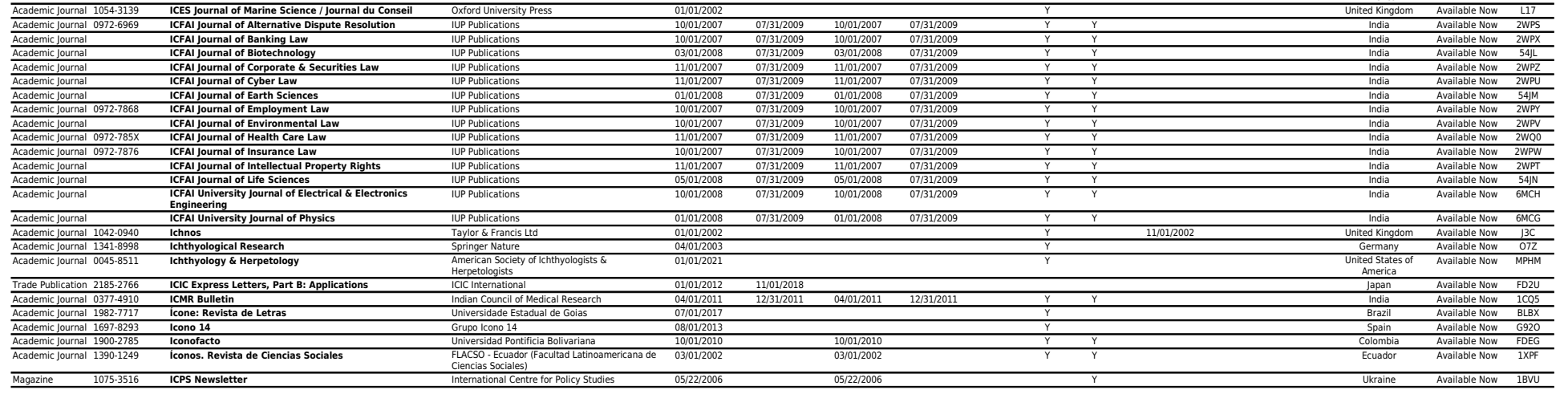

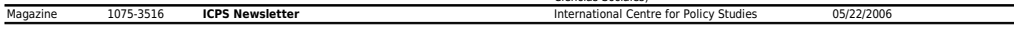




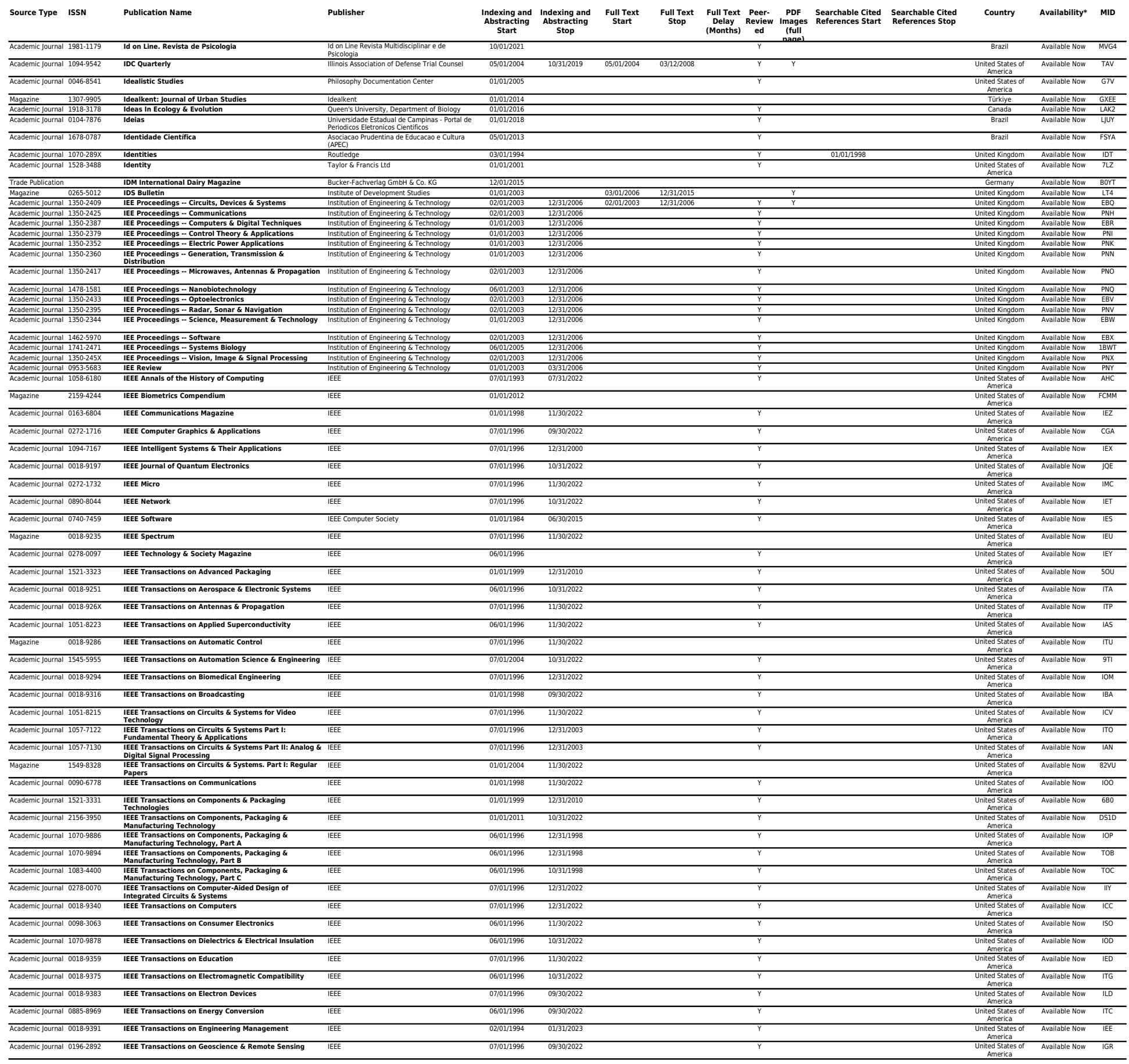




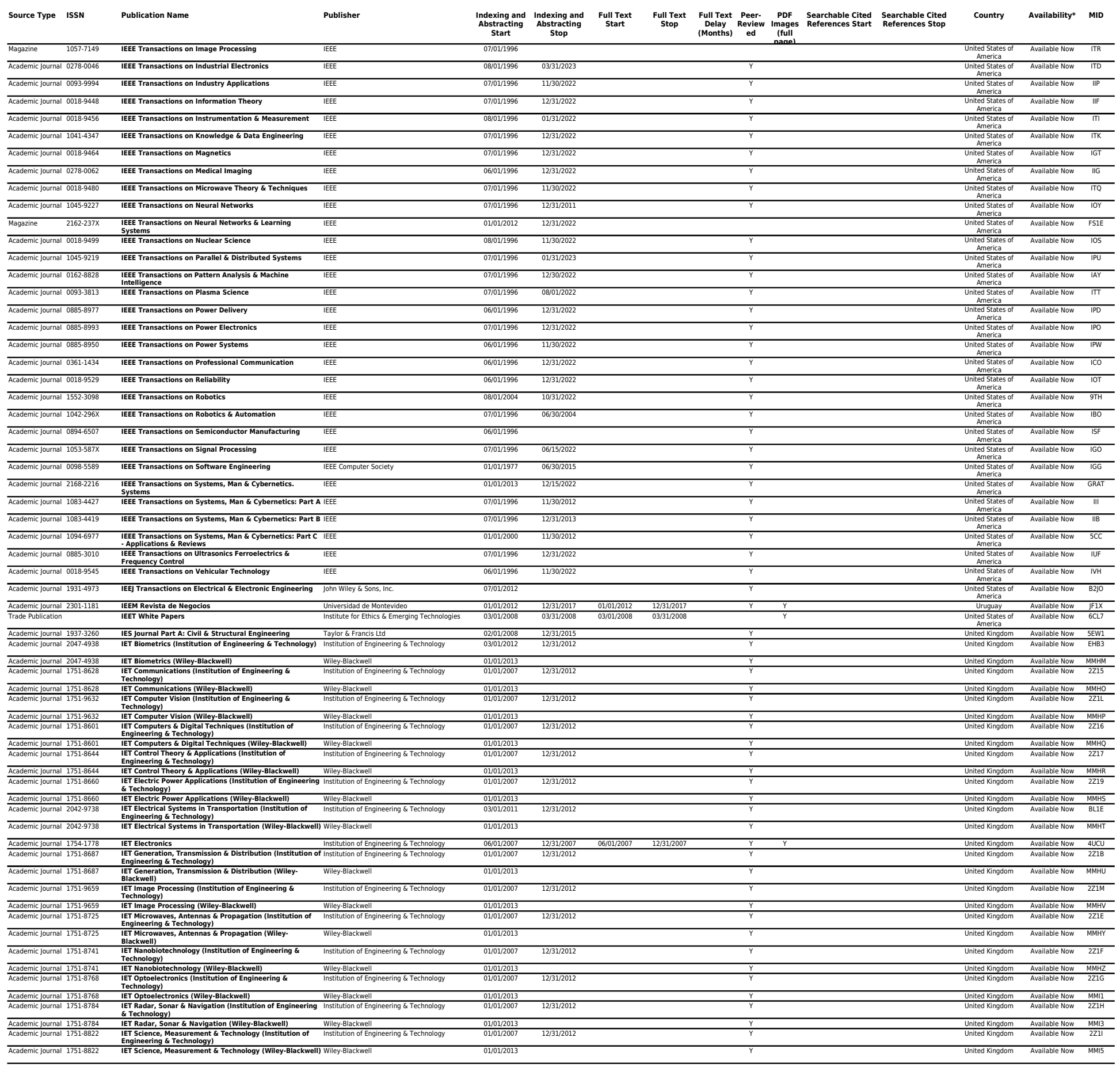




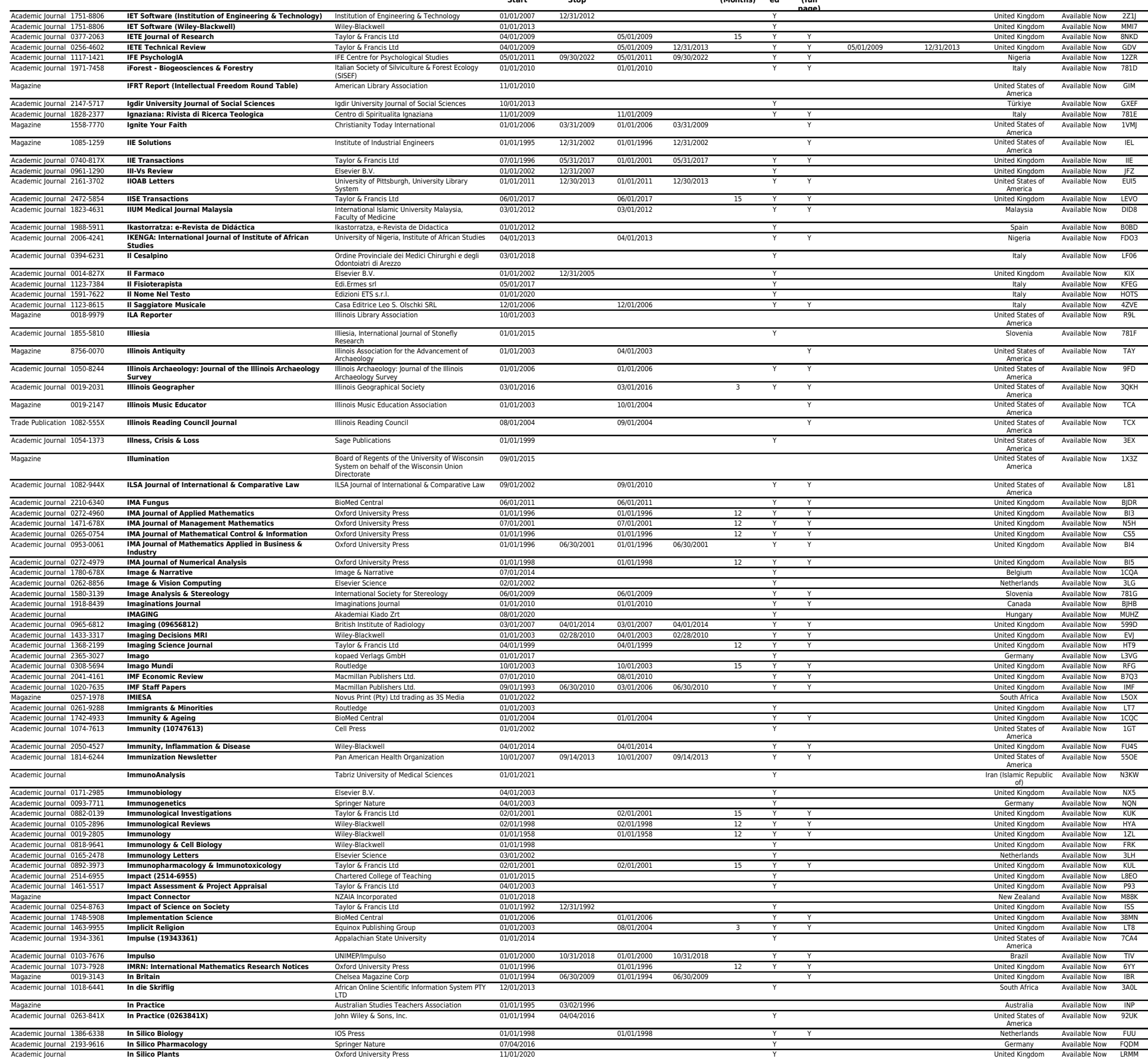




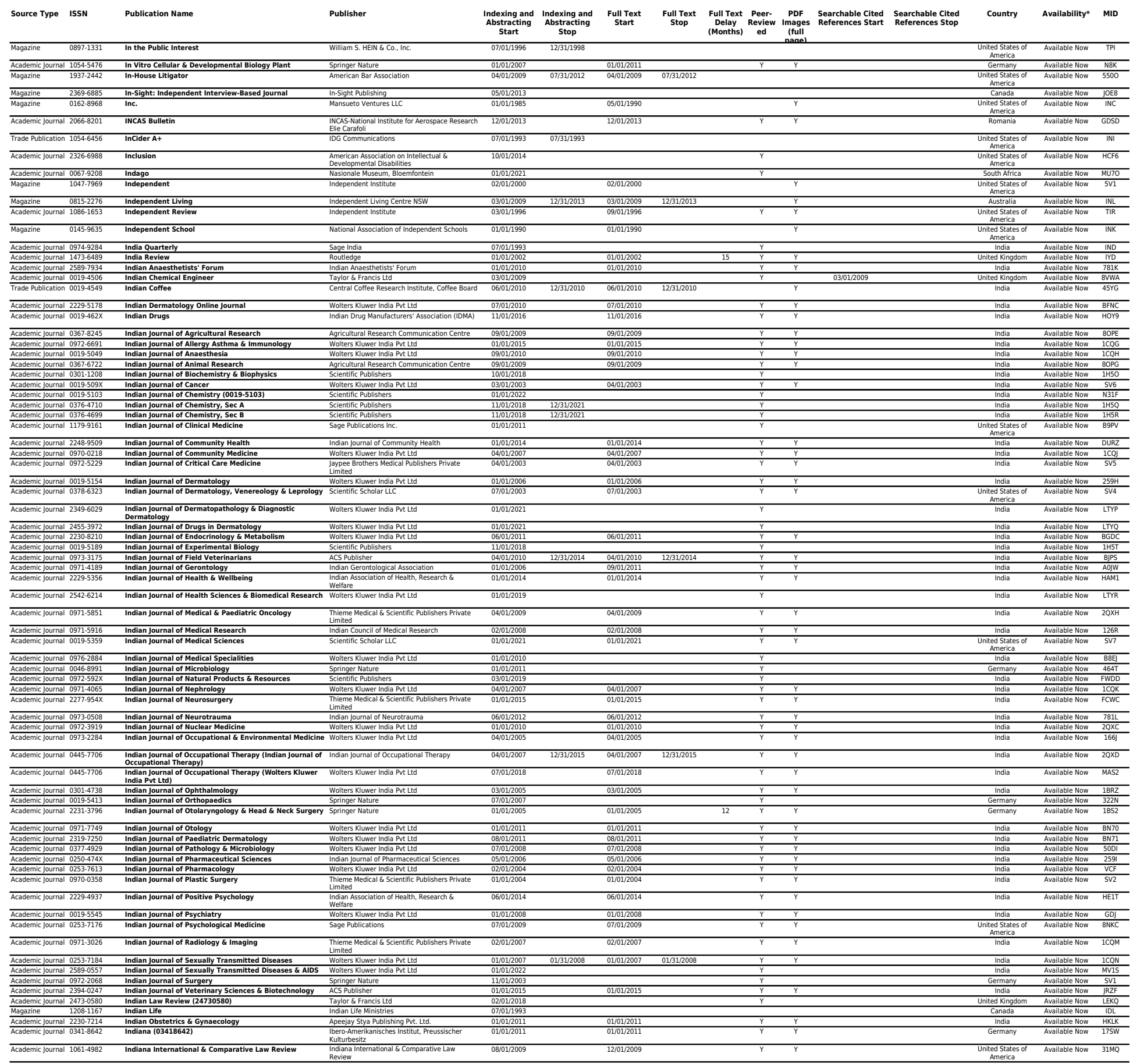




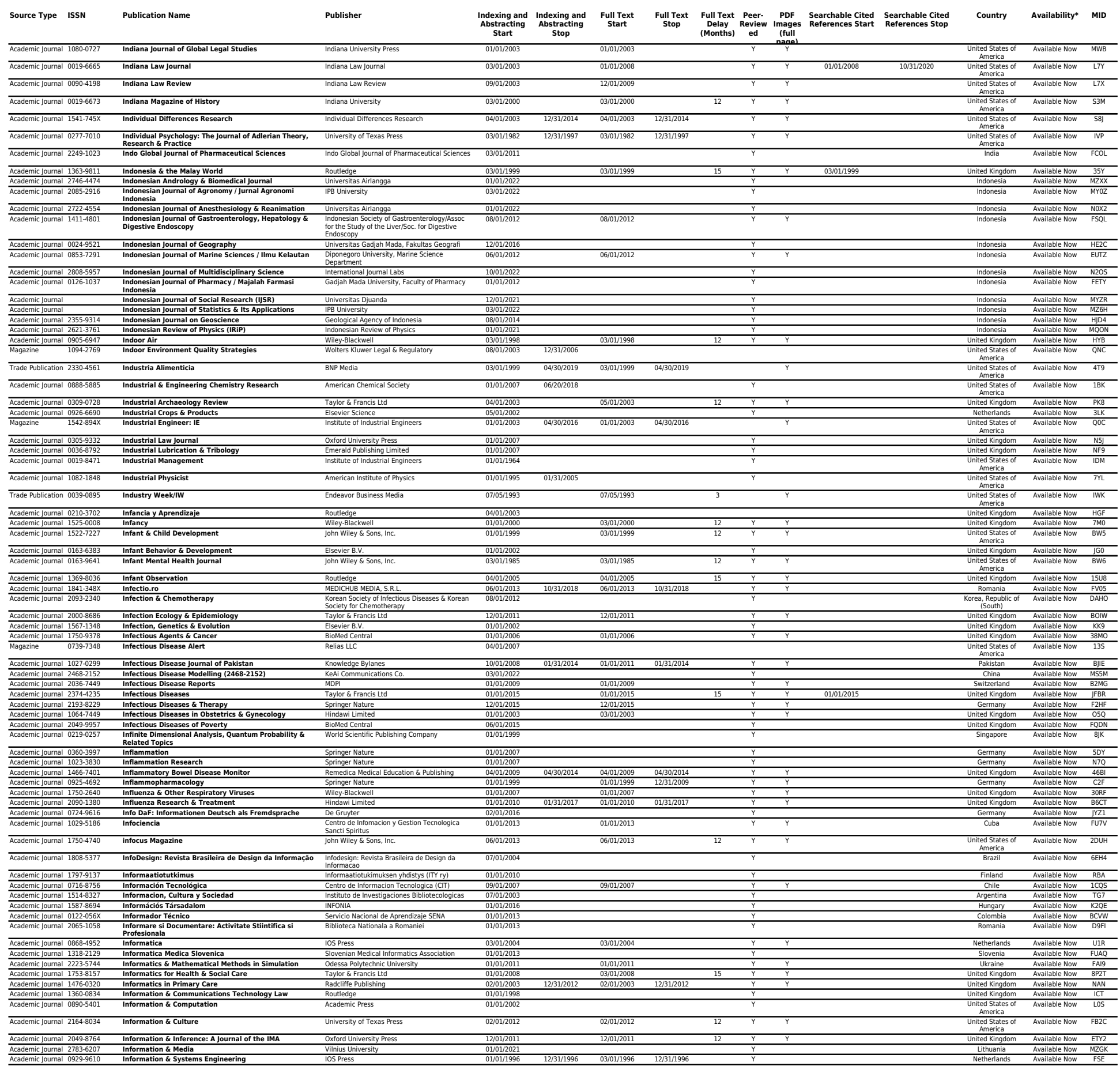




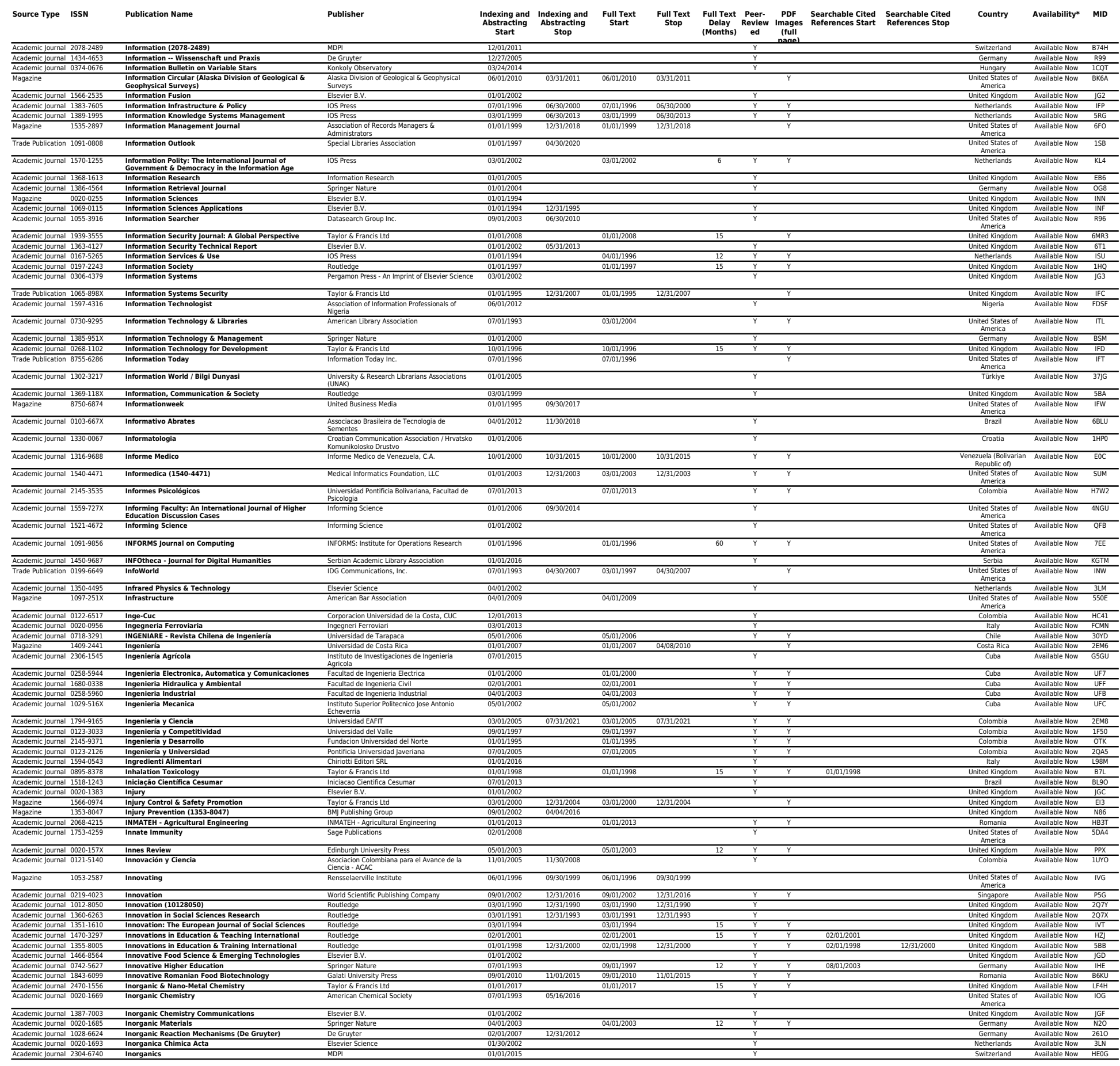




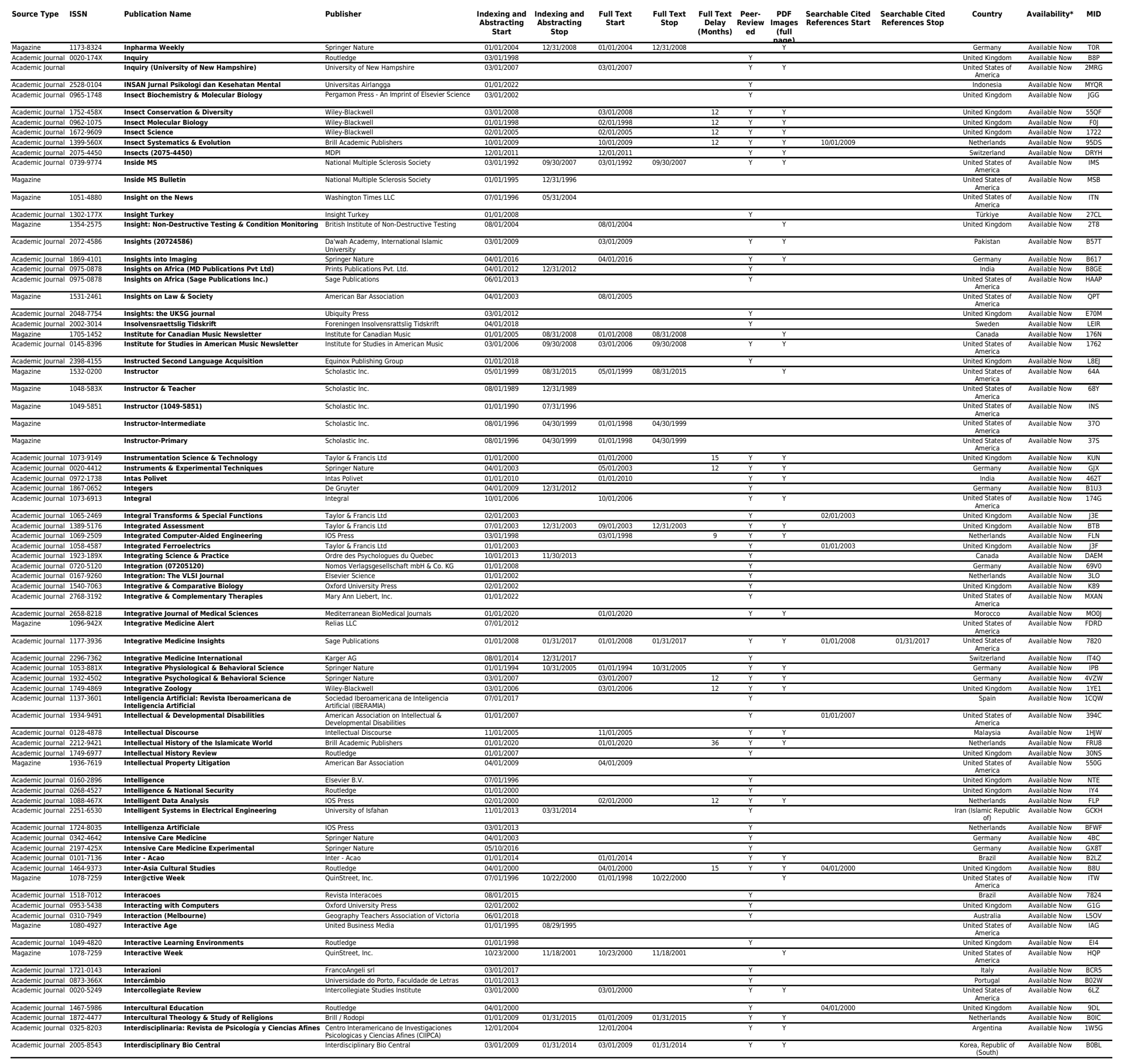




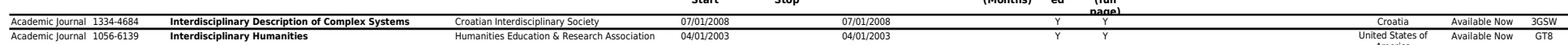

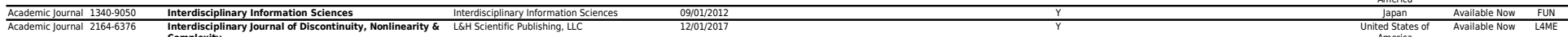

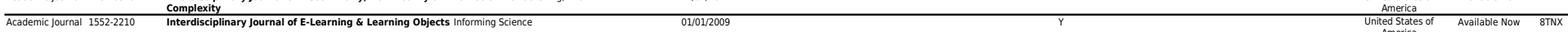

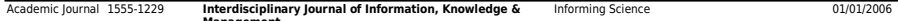

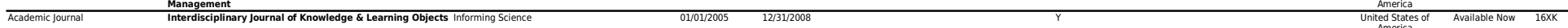

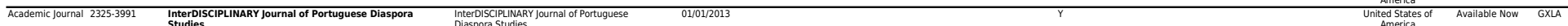

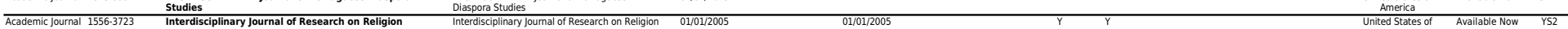

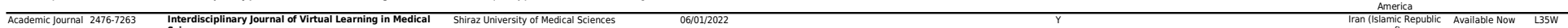

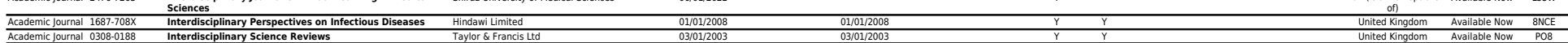

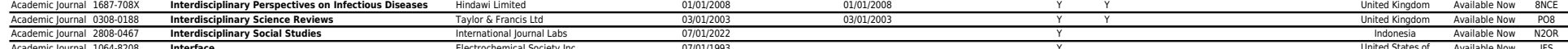

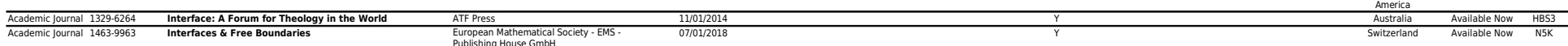

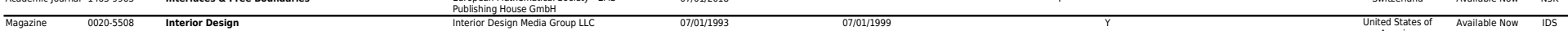

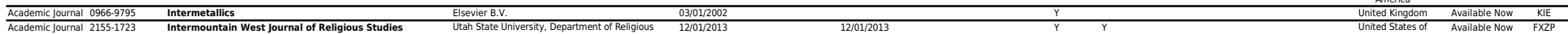

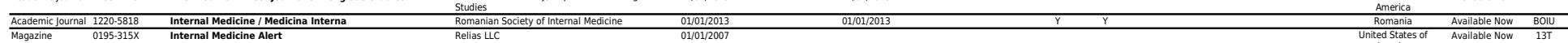

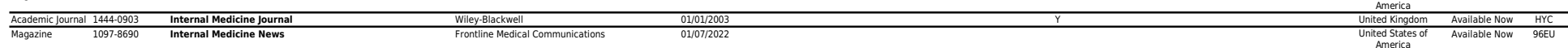

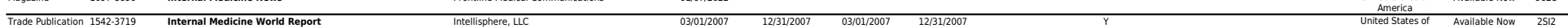

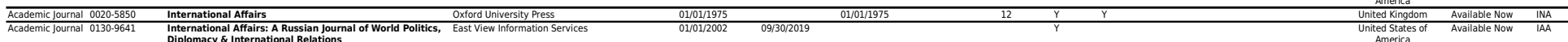

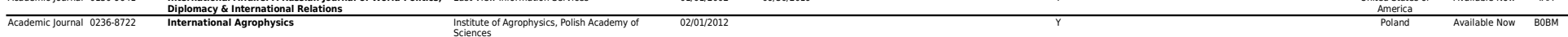

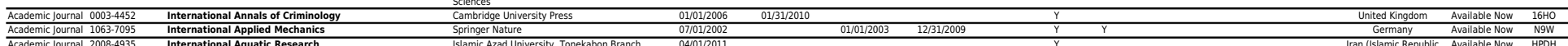

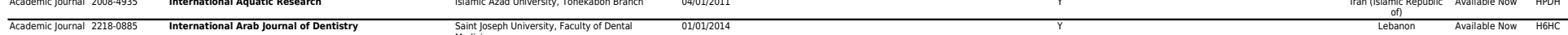

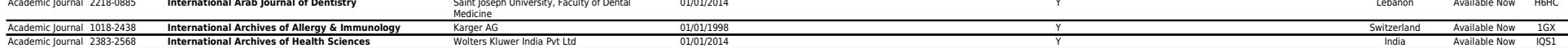

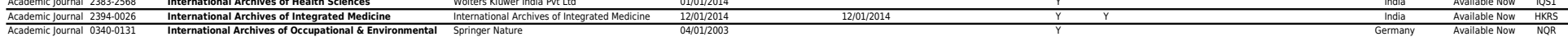

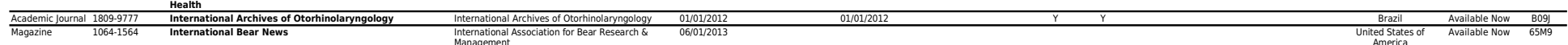

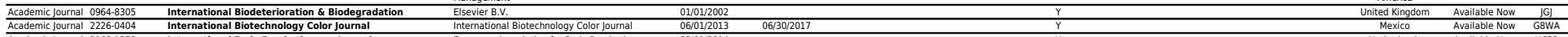

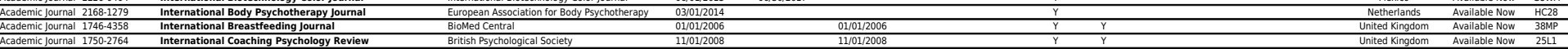

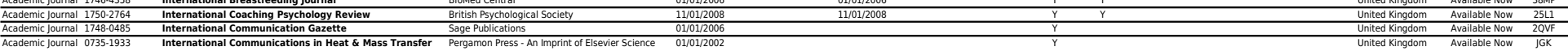

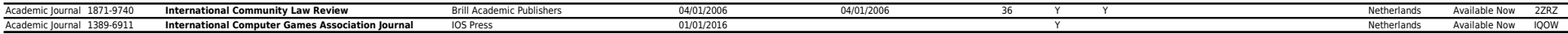

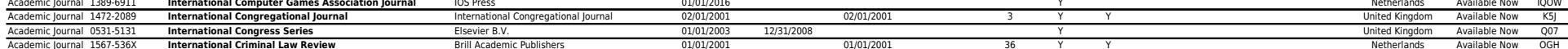

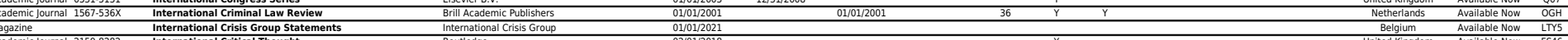

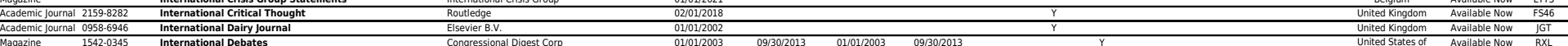

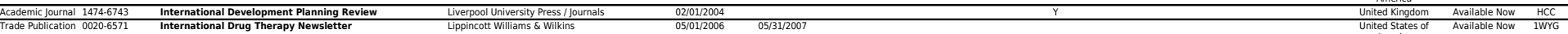

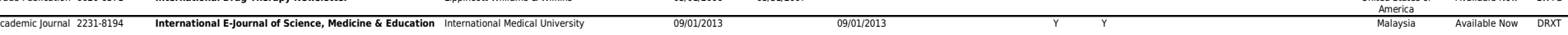

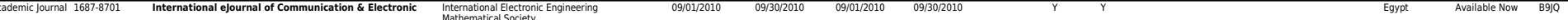

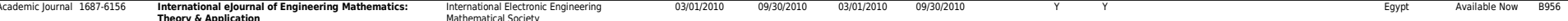

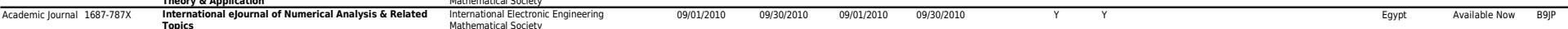

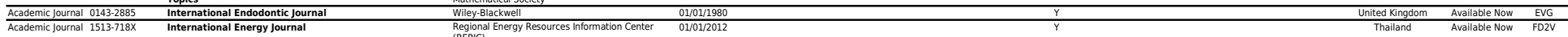

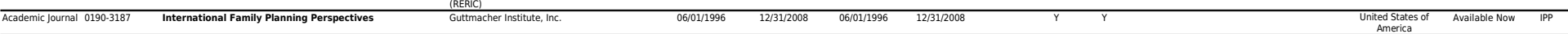

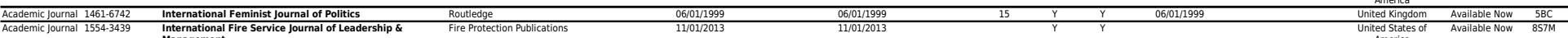

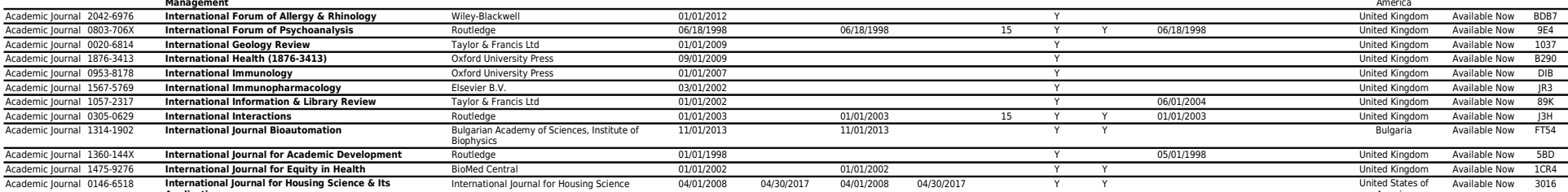




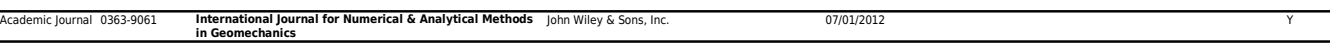

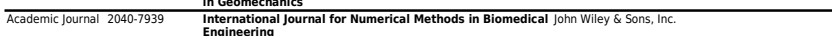

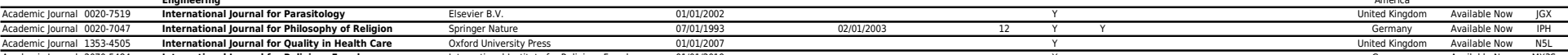

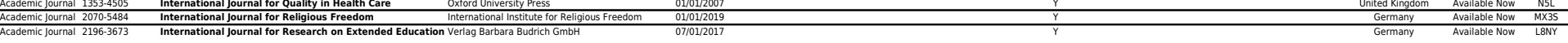

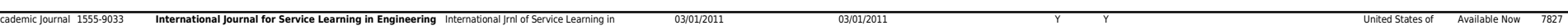

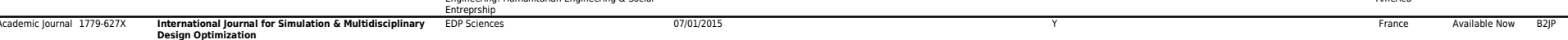

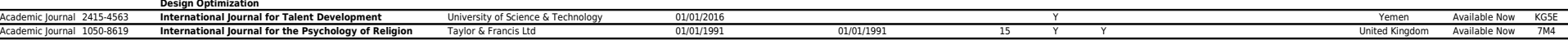

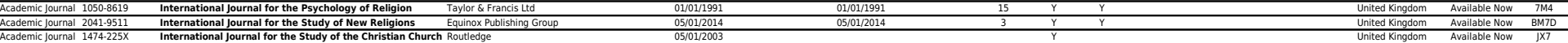

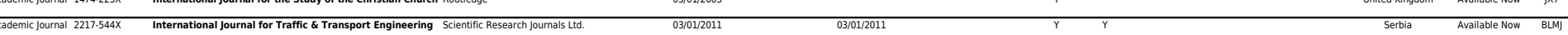

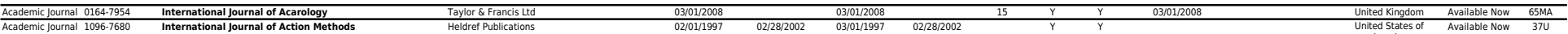

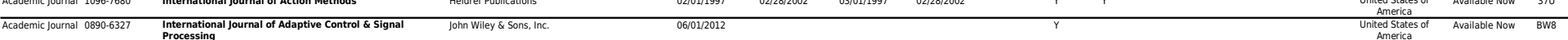

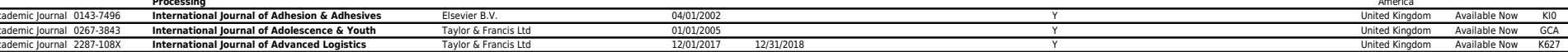

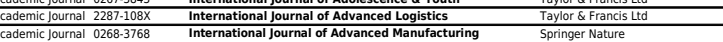

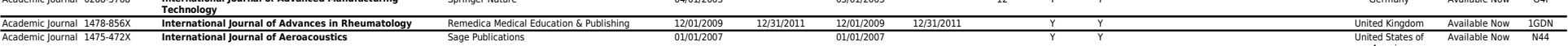

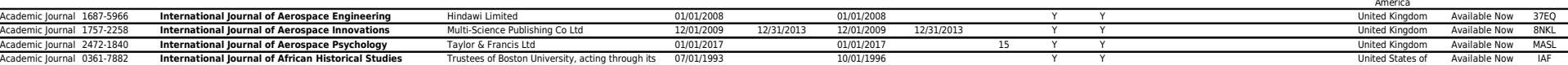

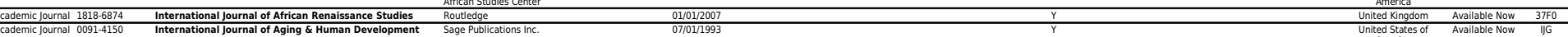

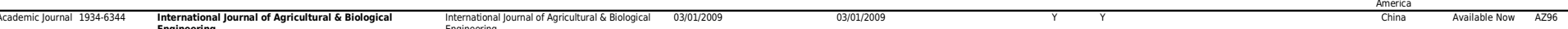

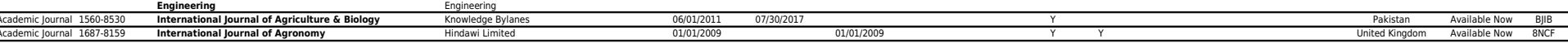

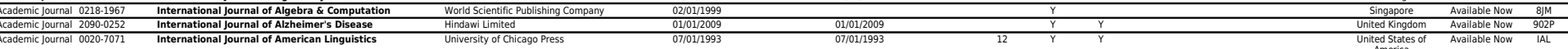

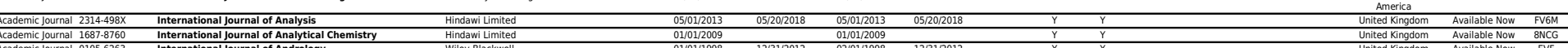

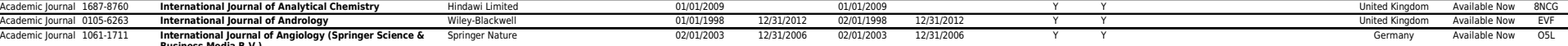

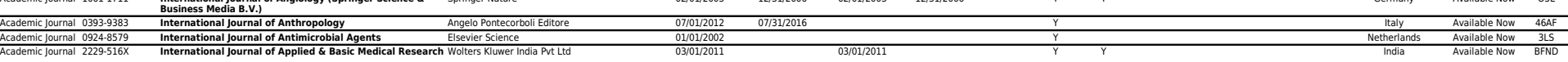

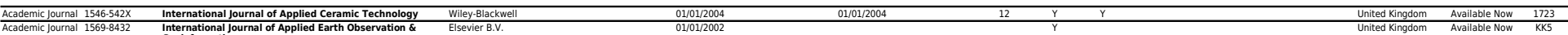

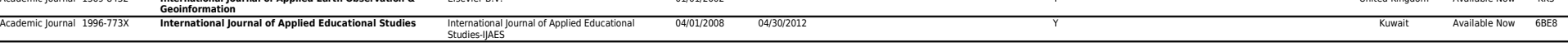

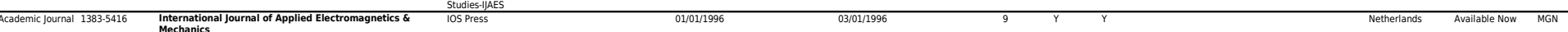

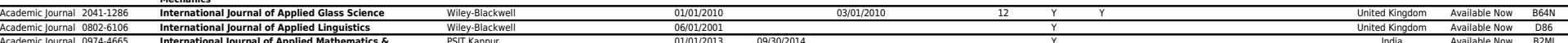

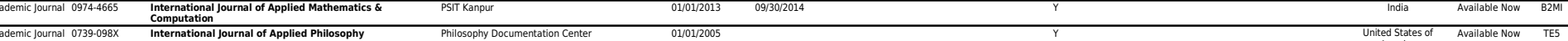

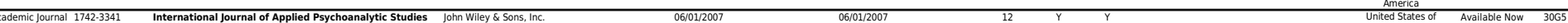

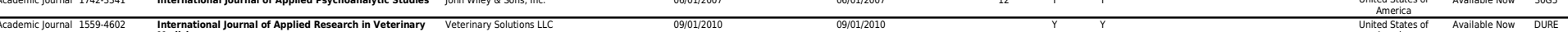

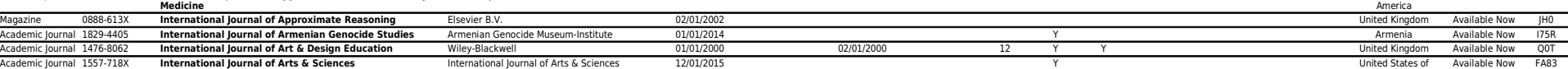

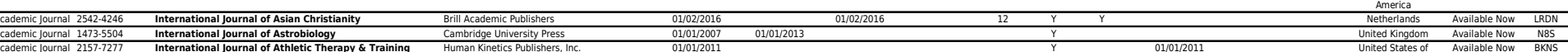

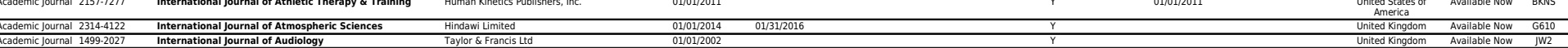

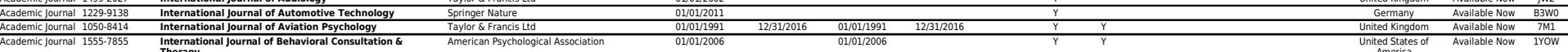

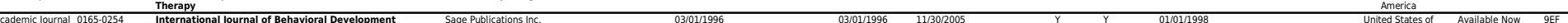

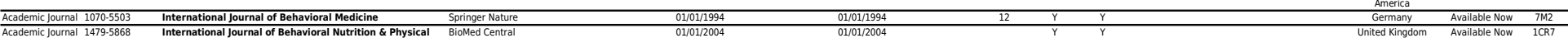

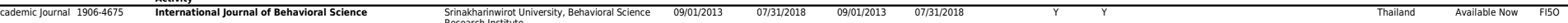

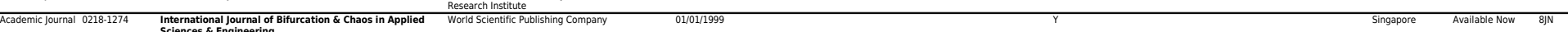

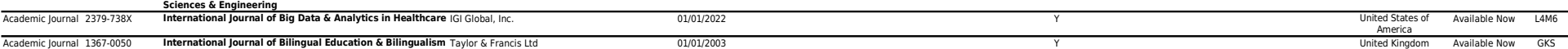

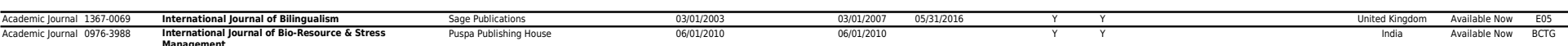

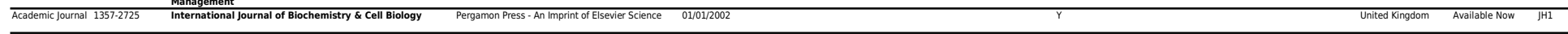




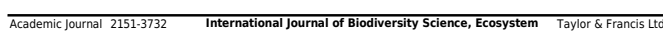

Unted Kngogom Avalable Now DBK9

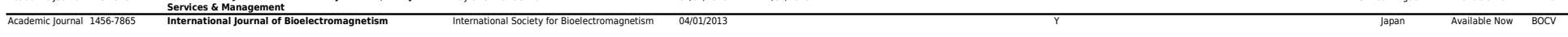

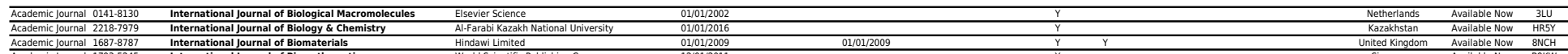

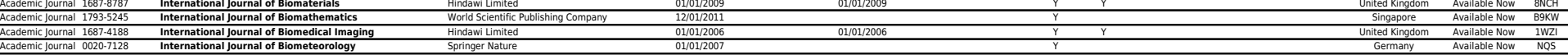

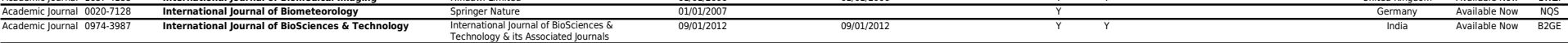

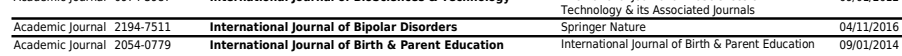

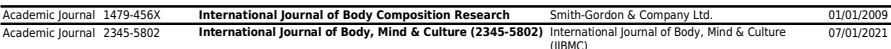

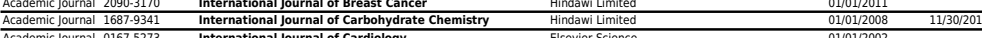

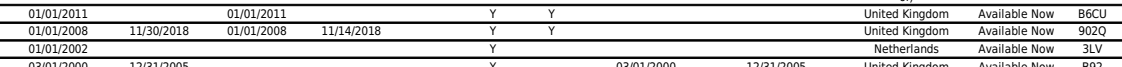

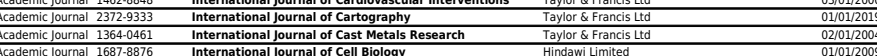

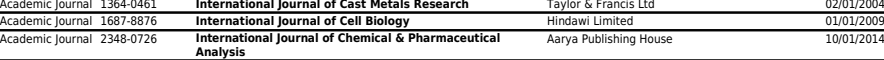

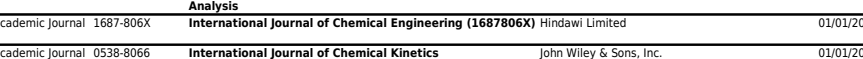

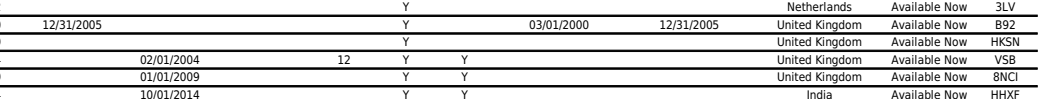

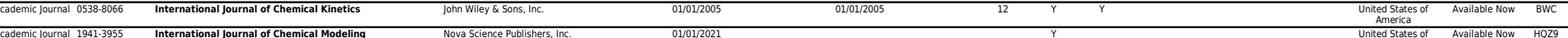

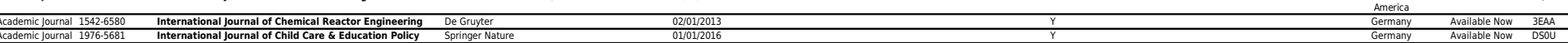

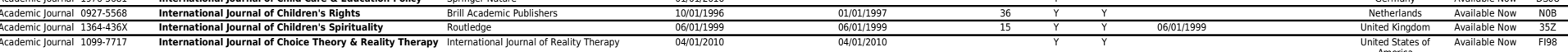

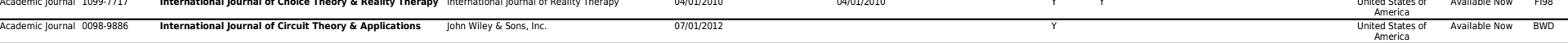

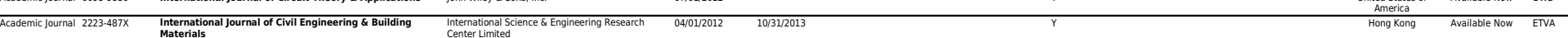

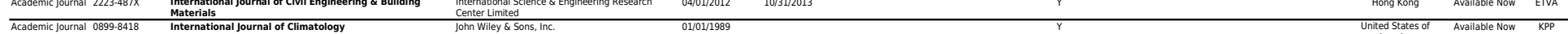

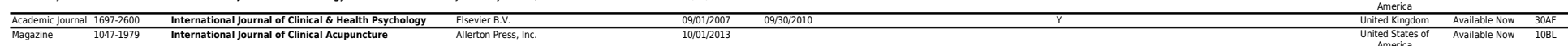

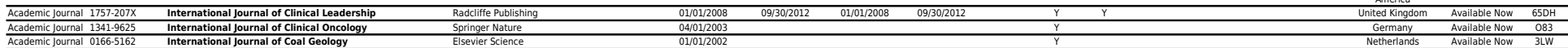

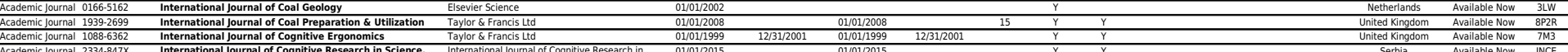

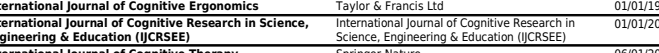

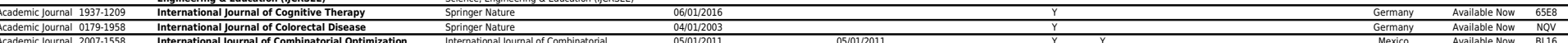

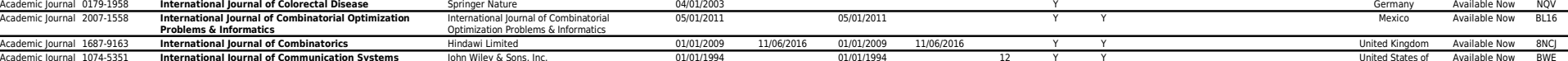

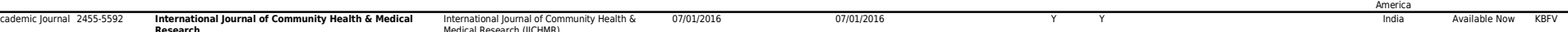

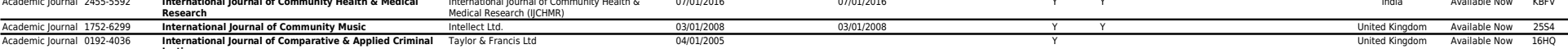

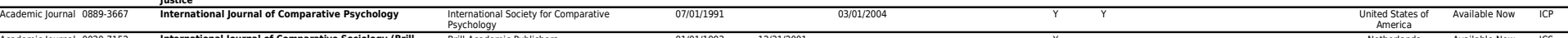

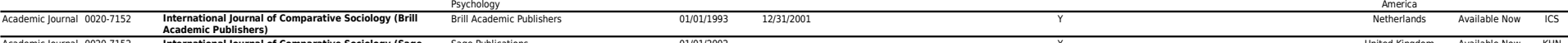

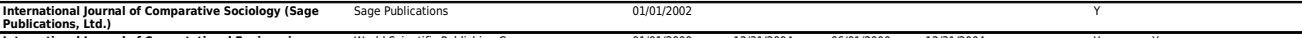

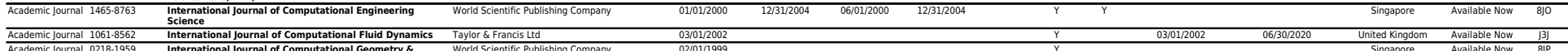

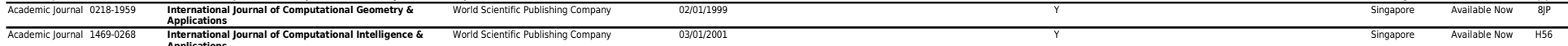

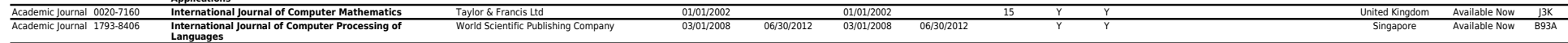

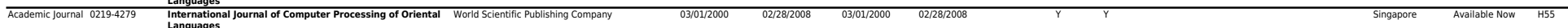

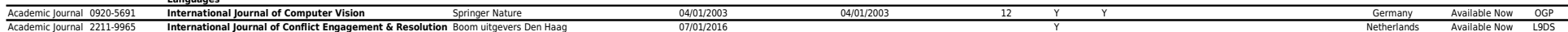

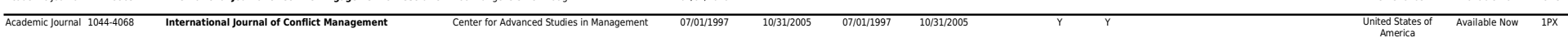

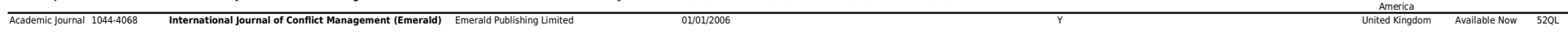

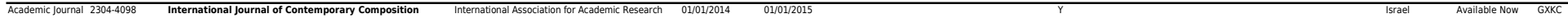

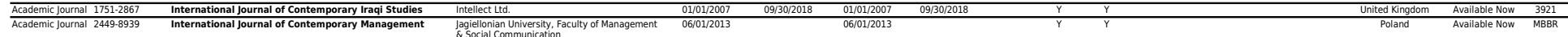

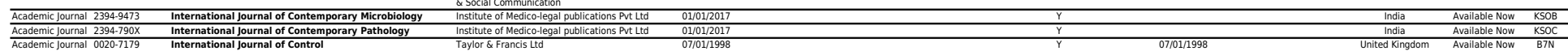

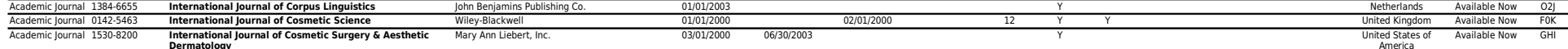

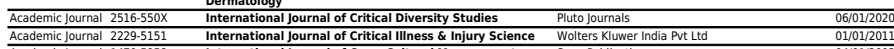

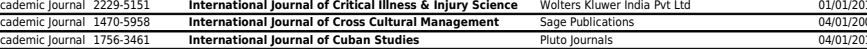

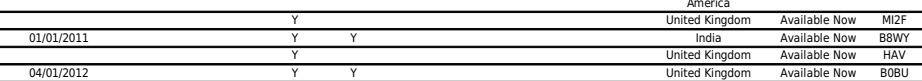




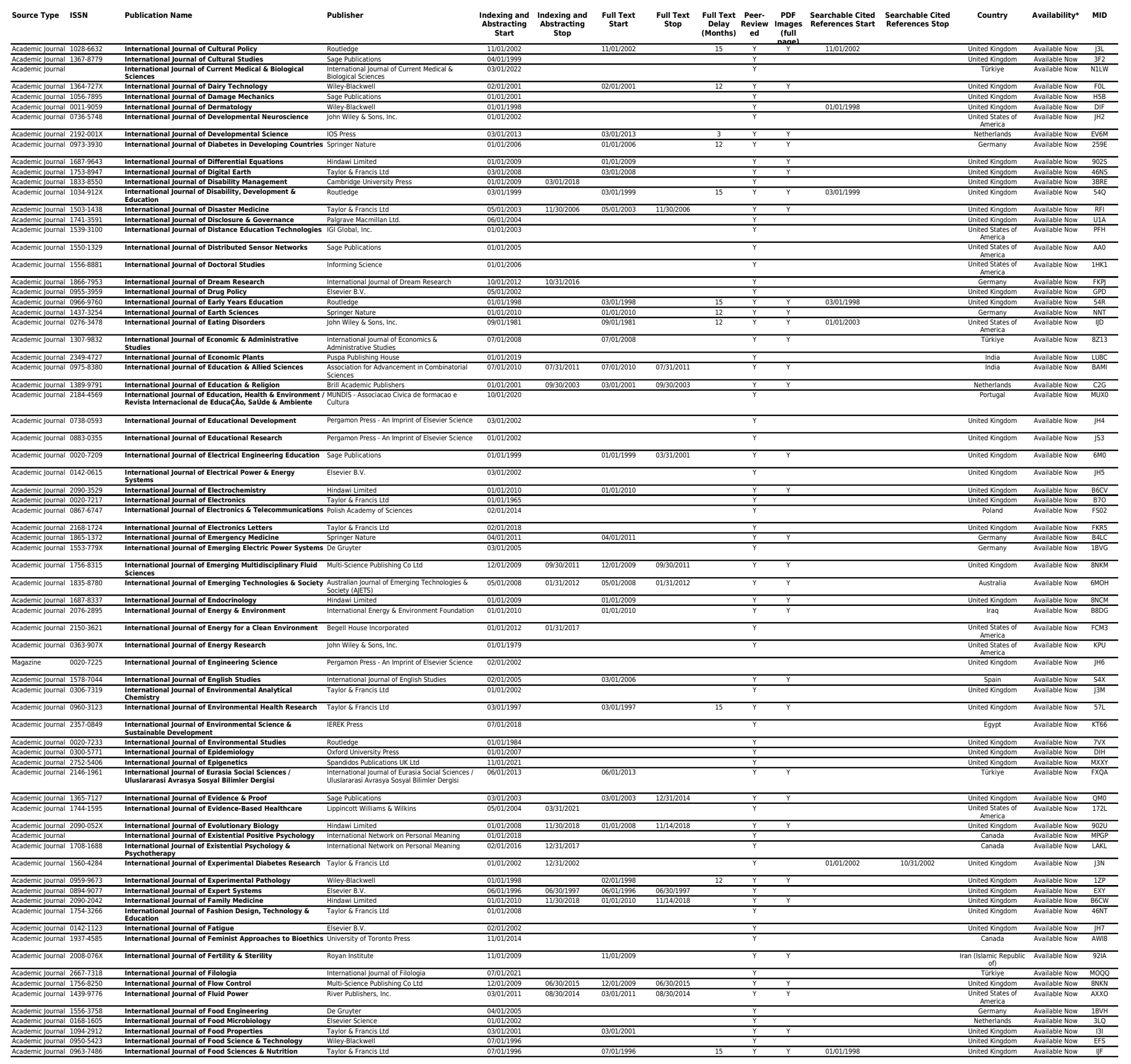




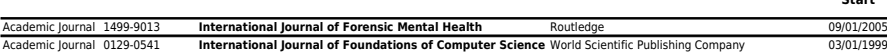

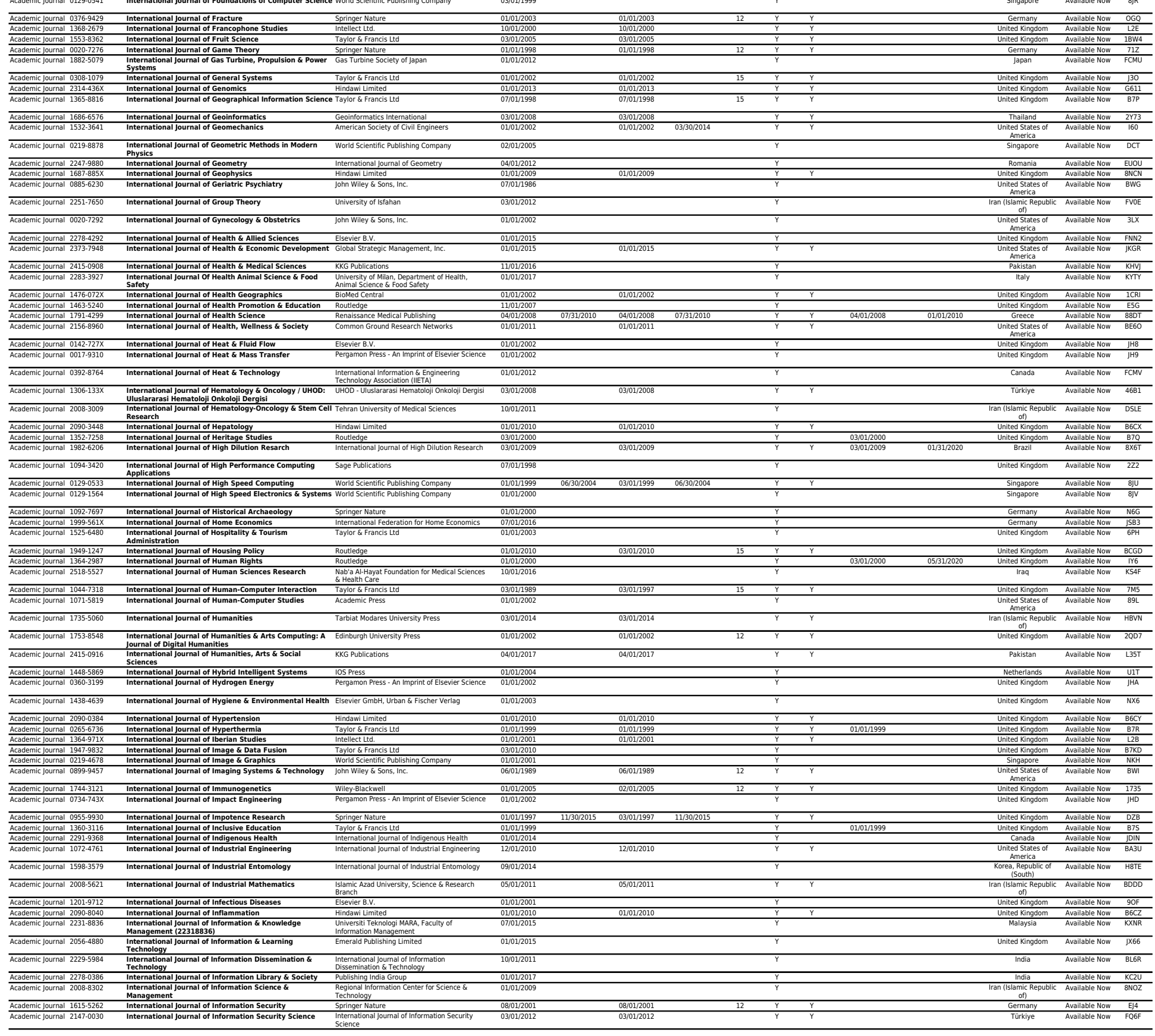




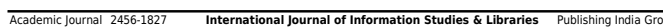
T1012012010

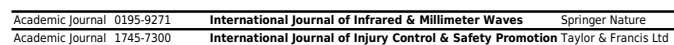

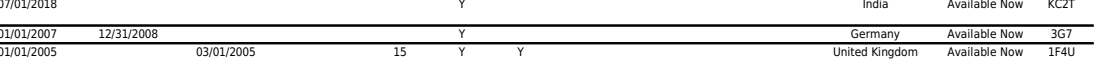

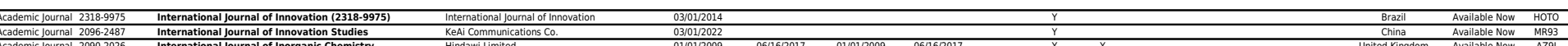

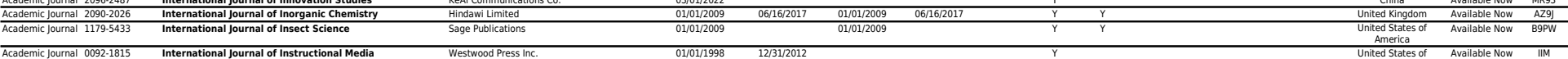

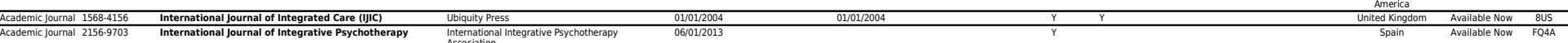

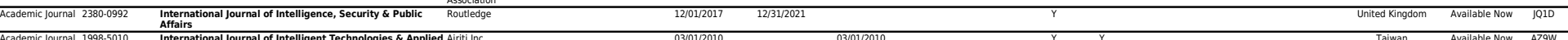

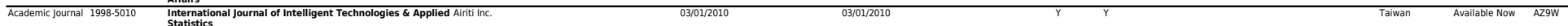

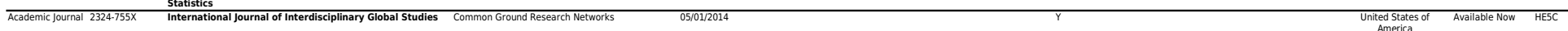

International Journal of Intercisiscipinaryy social sciences common Ground Research Networks $\begin{array}{lllll}123112012 & 010012010 & 123112012 & Y & Y\end{array}$

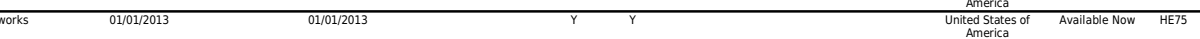

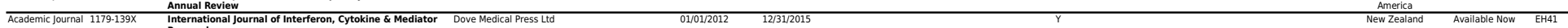

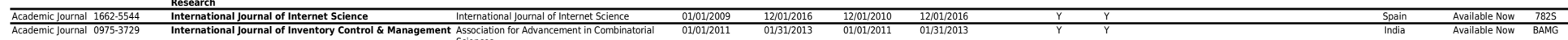

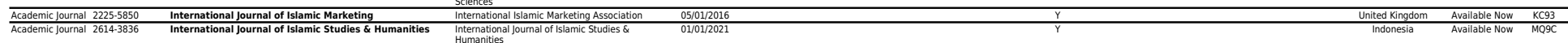

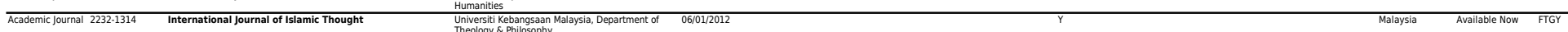

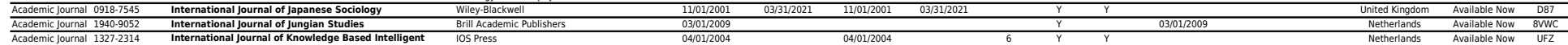

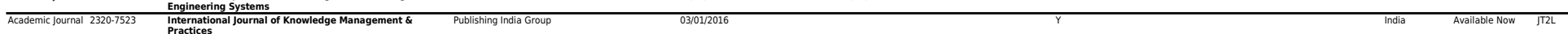

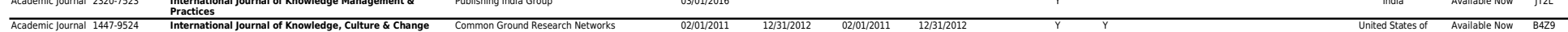

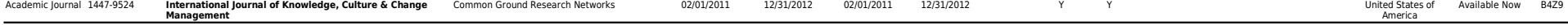
Academ

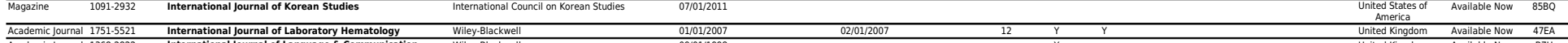
Chorders

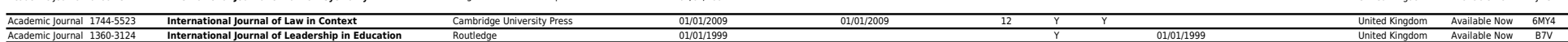

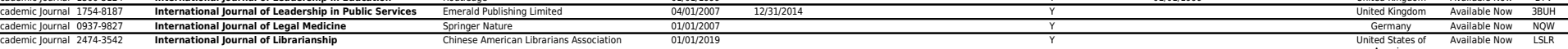
Intemational Journal of Library \& Information Services IGI Giobal, Inc.

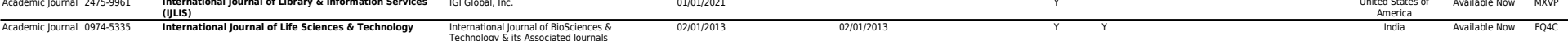

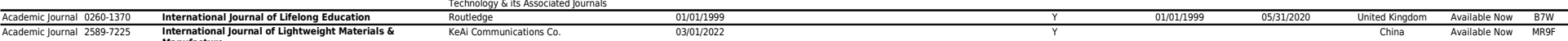

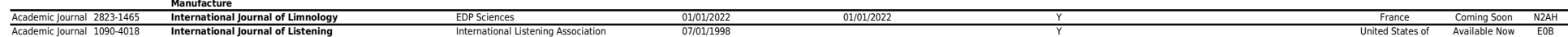

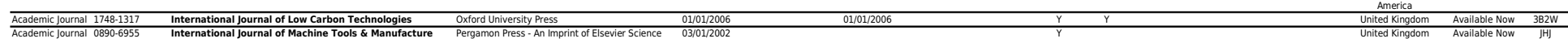

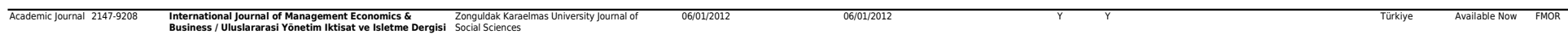

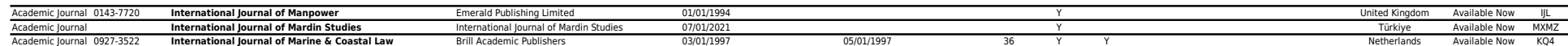

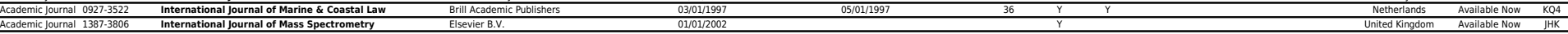
10012008

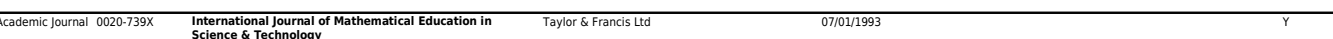

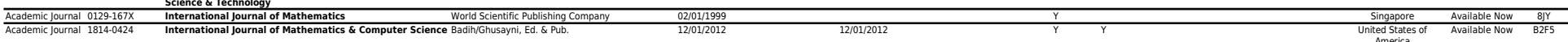

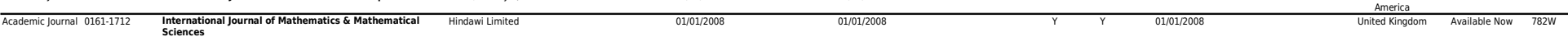

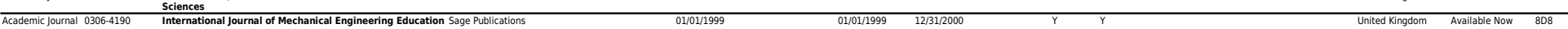

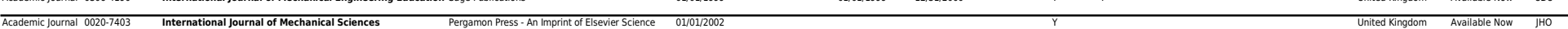

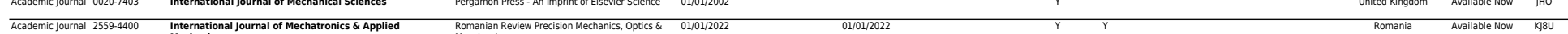

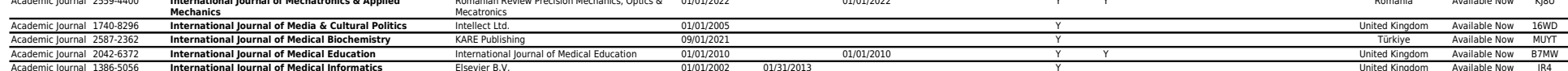

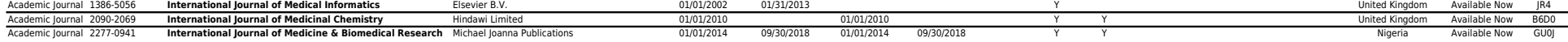

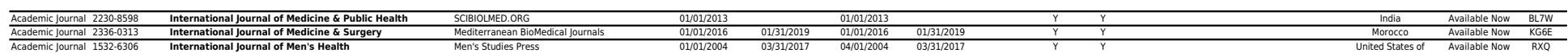

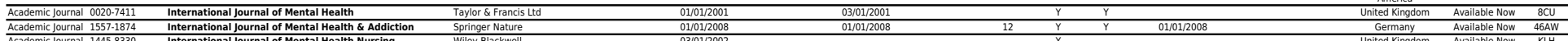

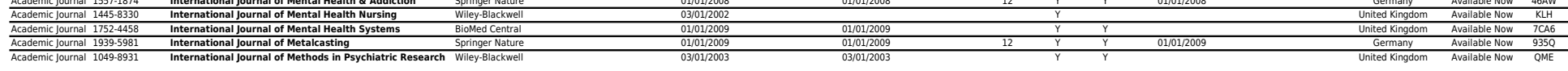


Accodemic Journal 2107-6839 International Journal of Metrology \& Quality Engineering EDP Scener

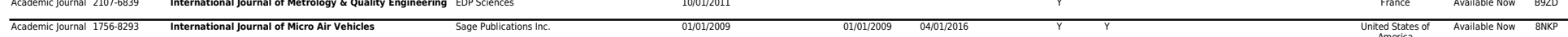

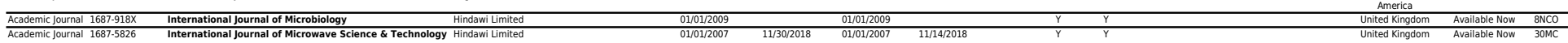

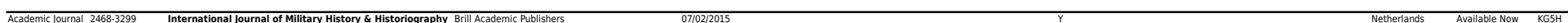

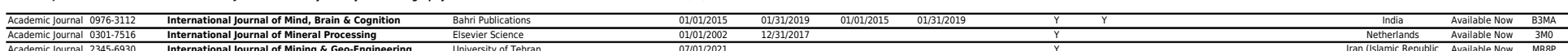

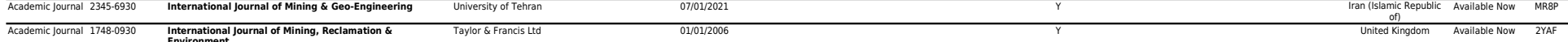

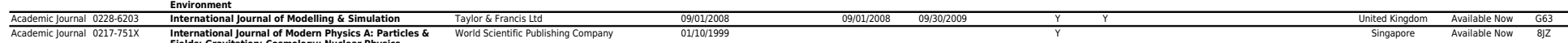

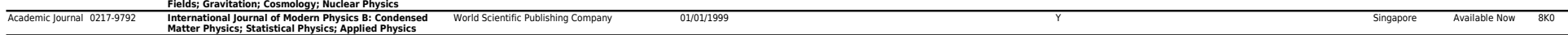
0101012000 Contific Publishing company

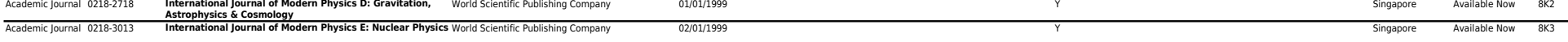

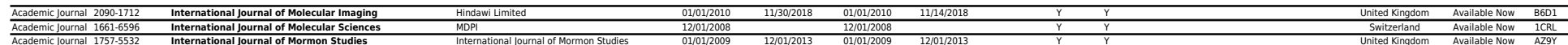

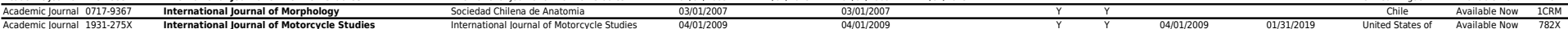
ccademic Journal Fiture Science

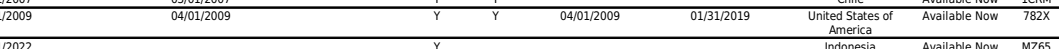

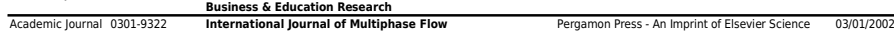

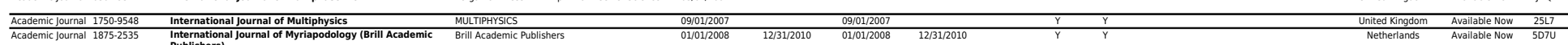

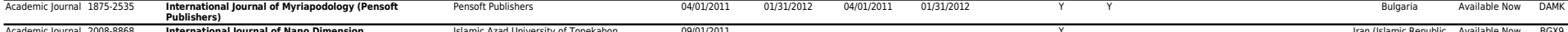

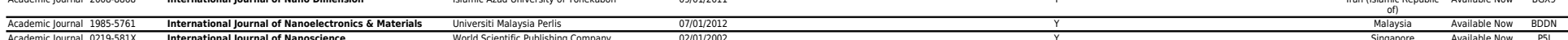

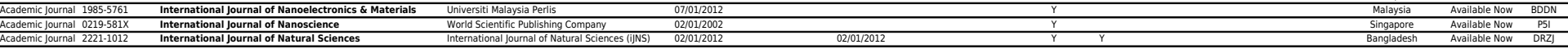

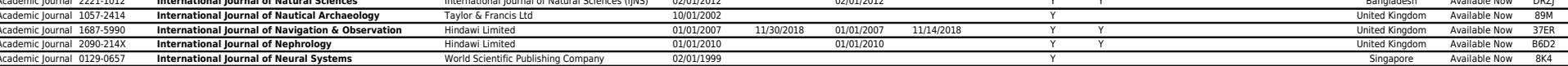

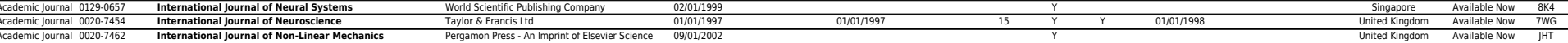

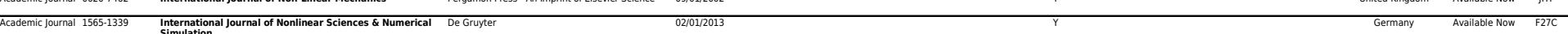

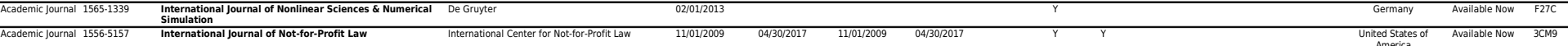

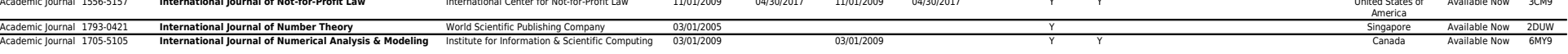

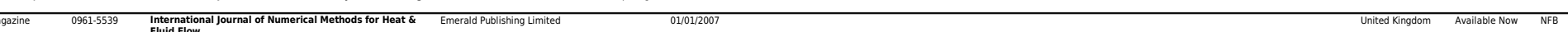

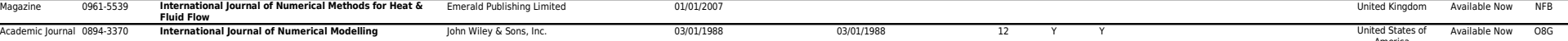

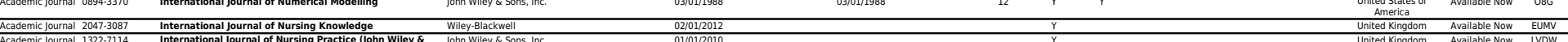

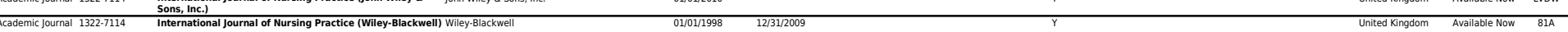

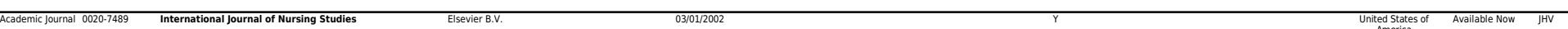

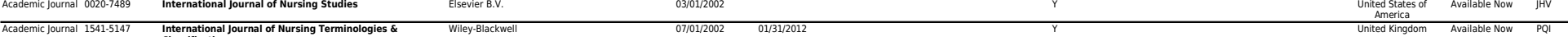

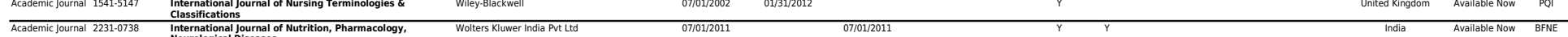

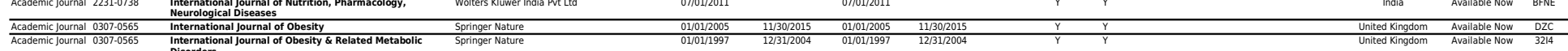

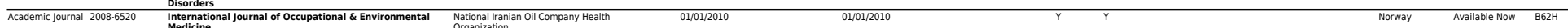

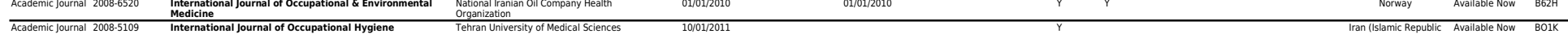

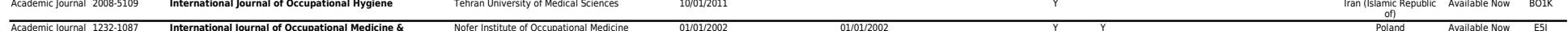

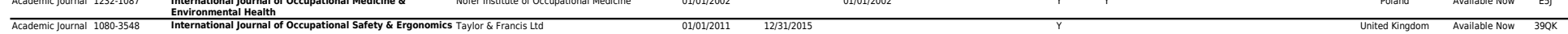

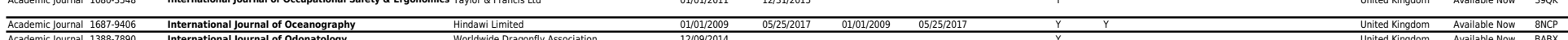

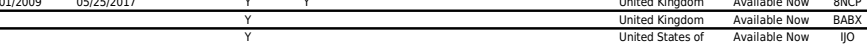

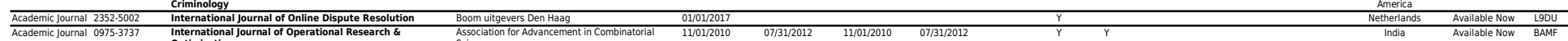

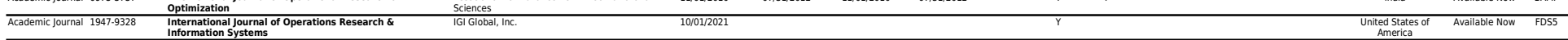

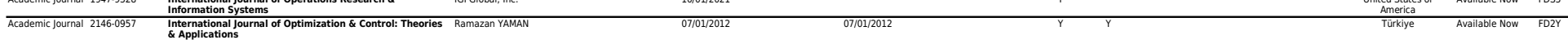

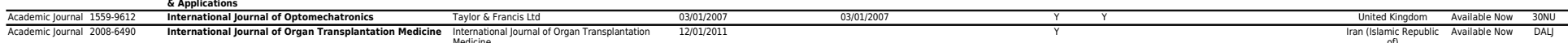

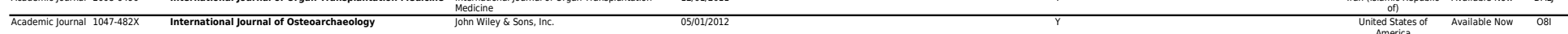

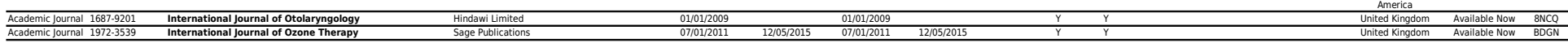

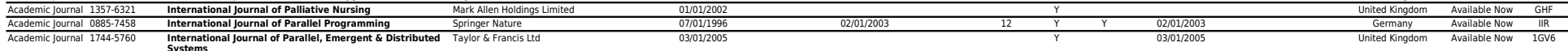

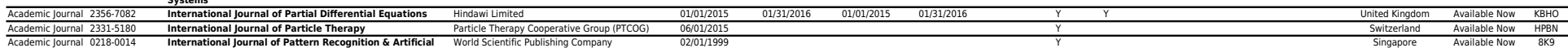




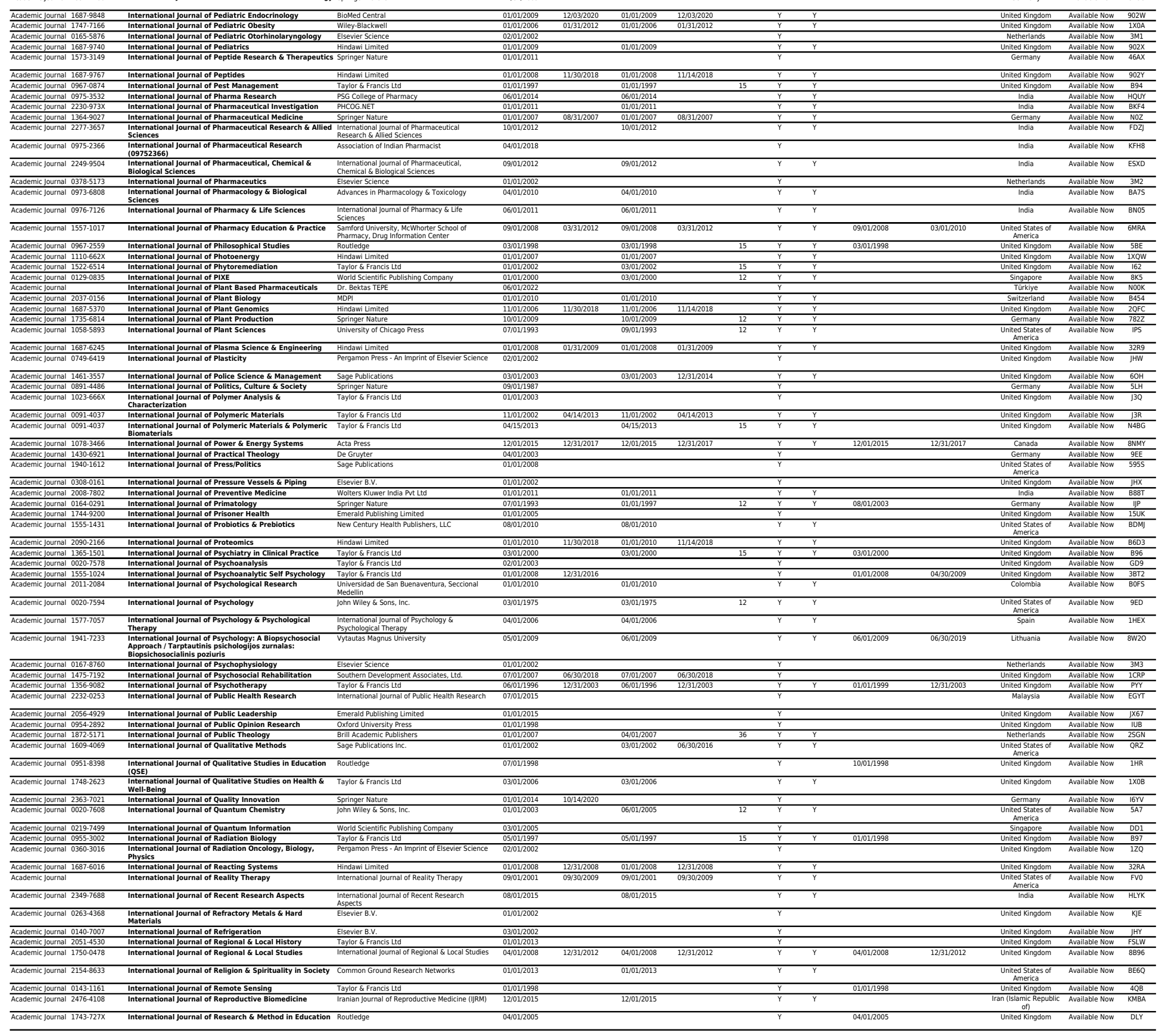




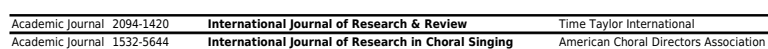

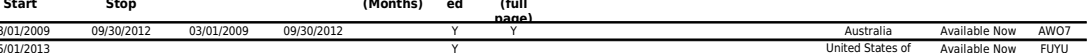

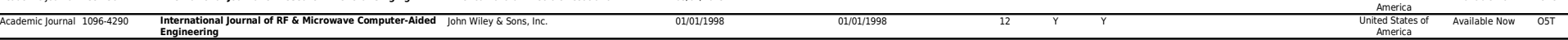

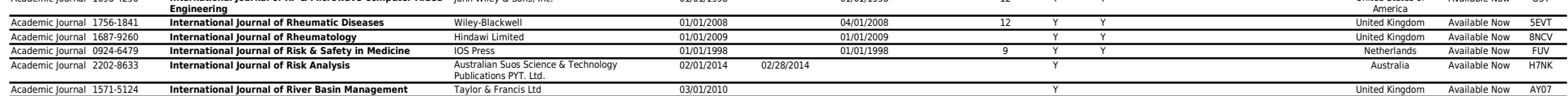

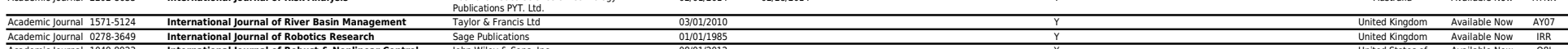

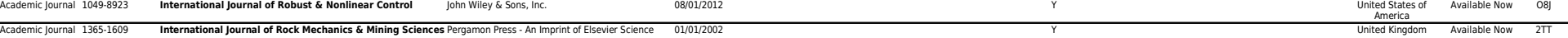

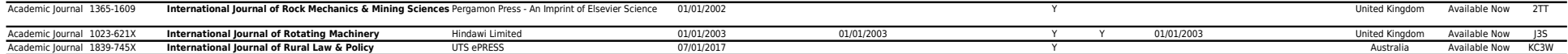

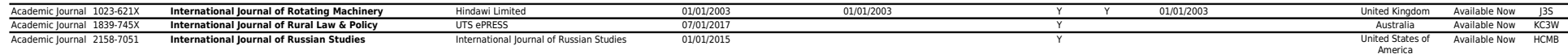

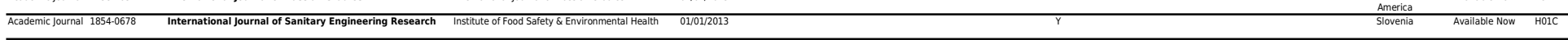

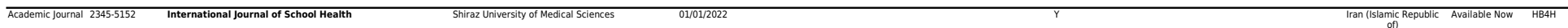

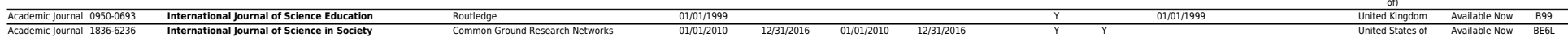

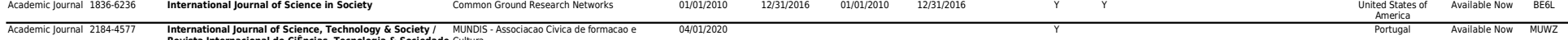

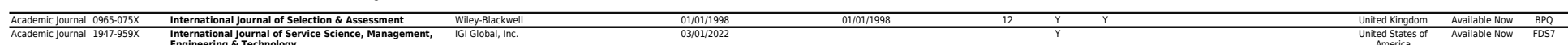

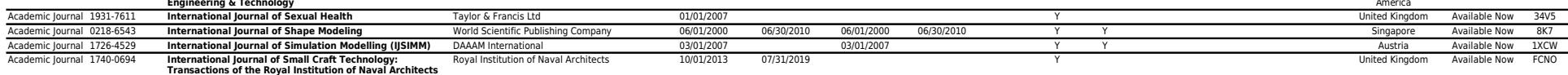

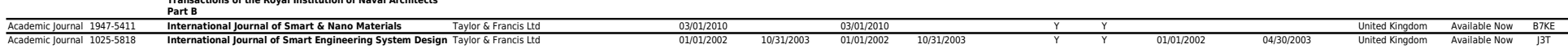

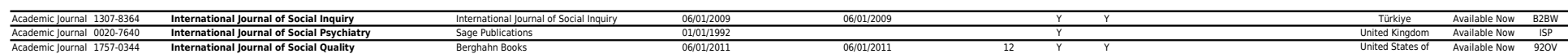

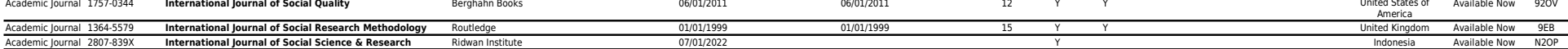

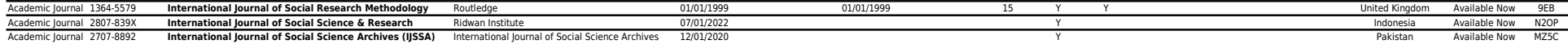

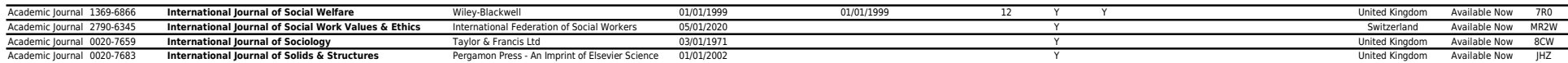

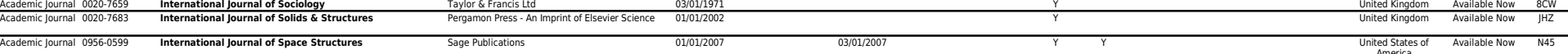

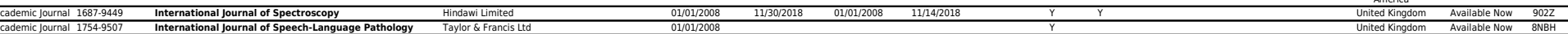

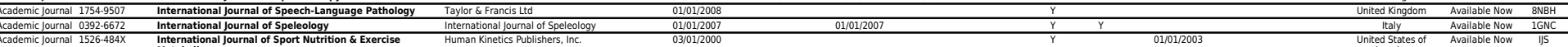

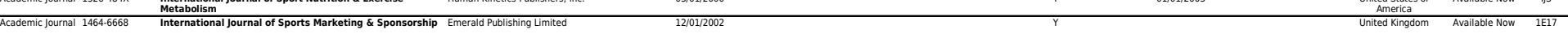

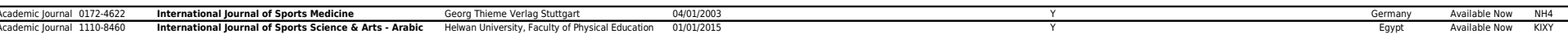

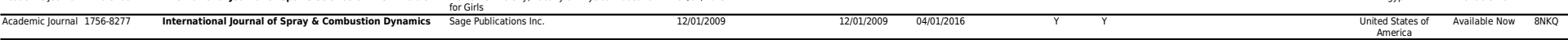

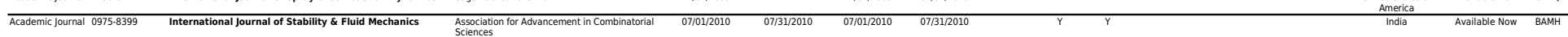

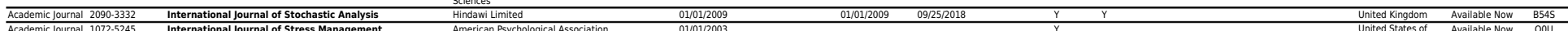

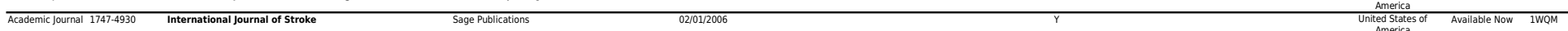

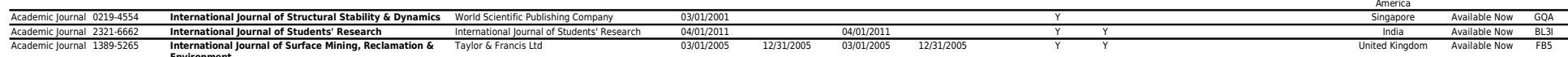

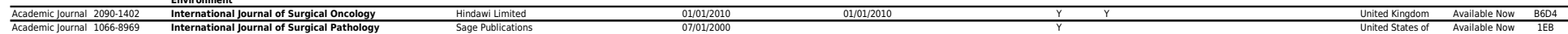

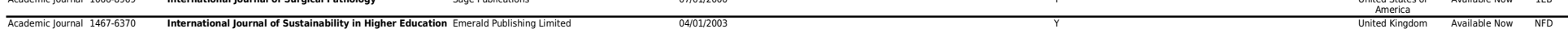

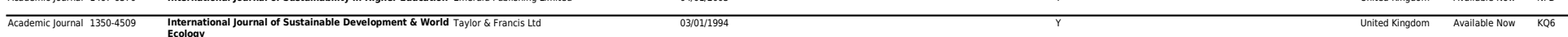

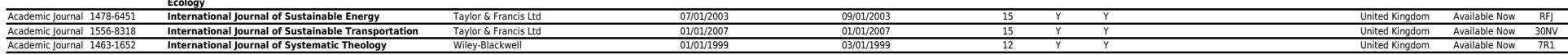

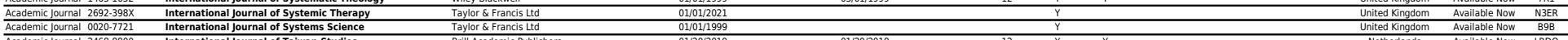

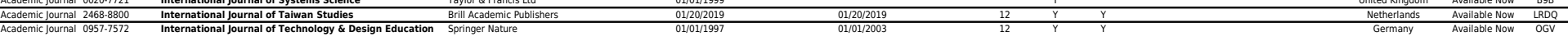

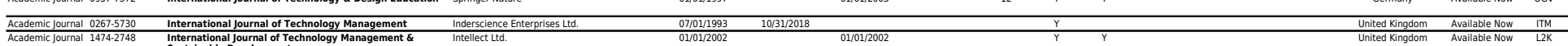

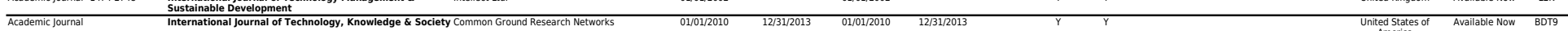

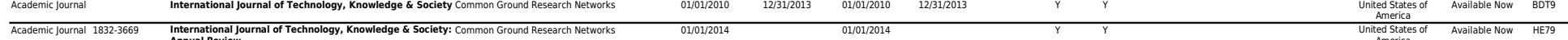

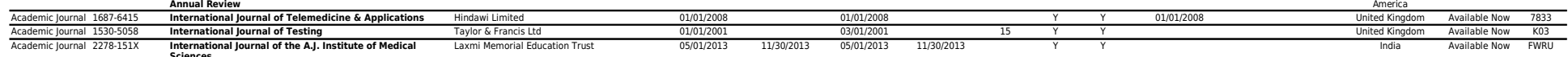

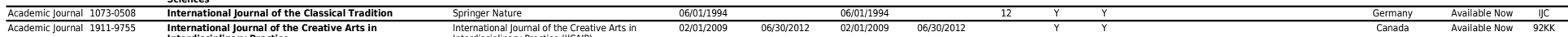

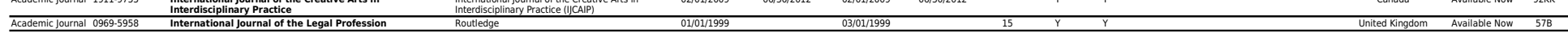




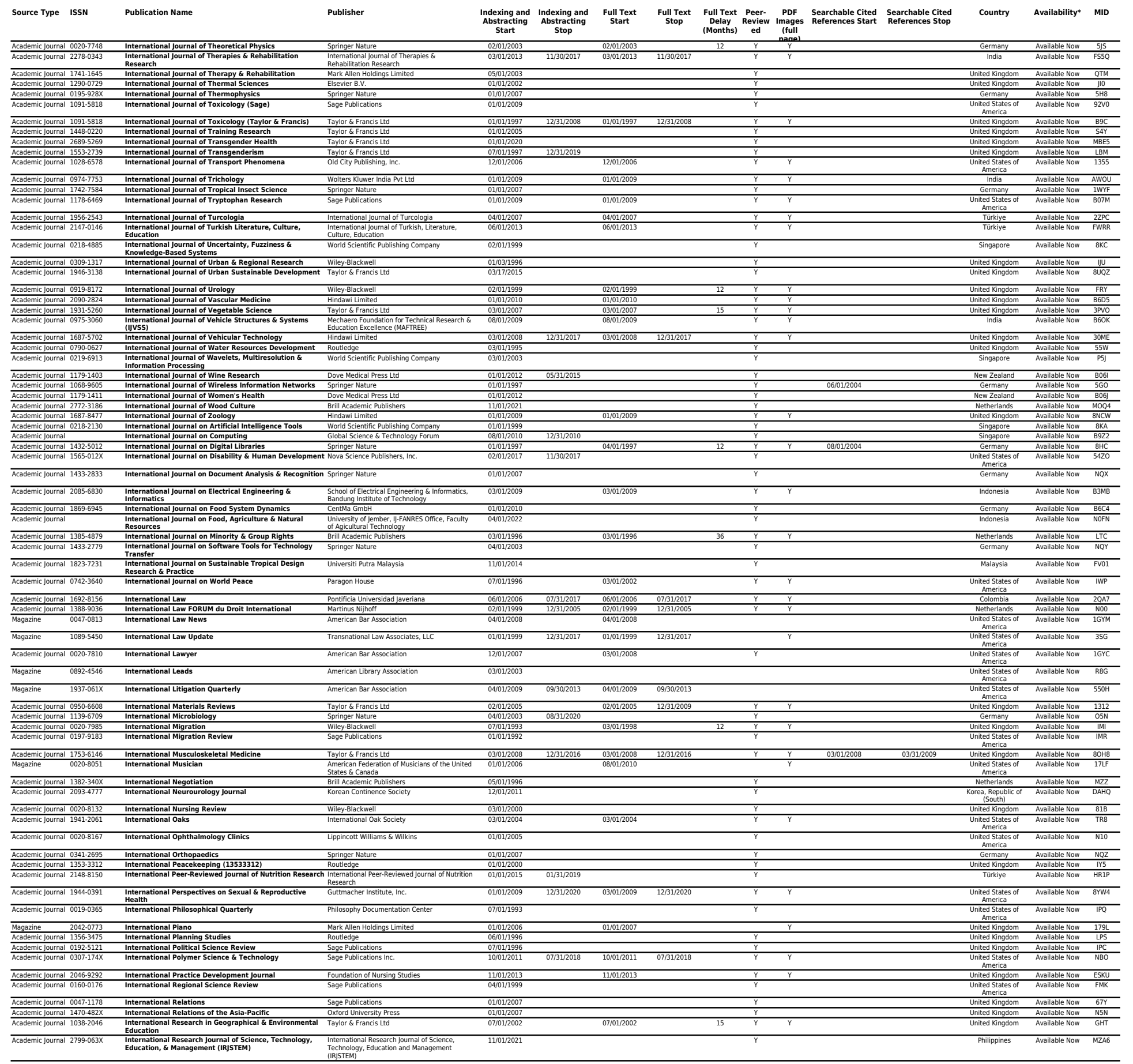




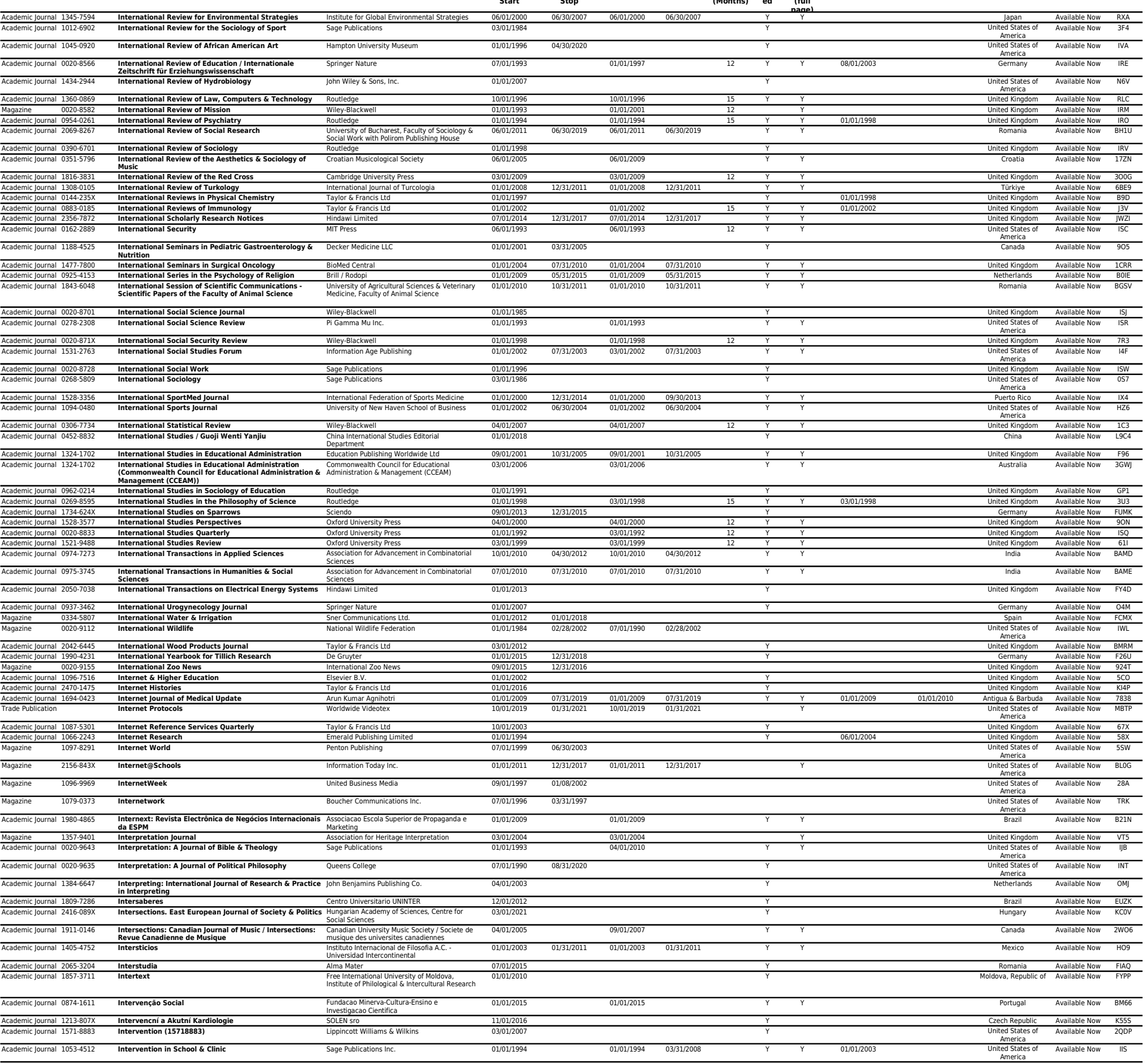




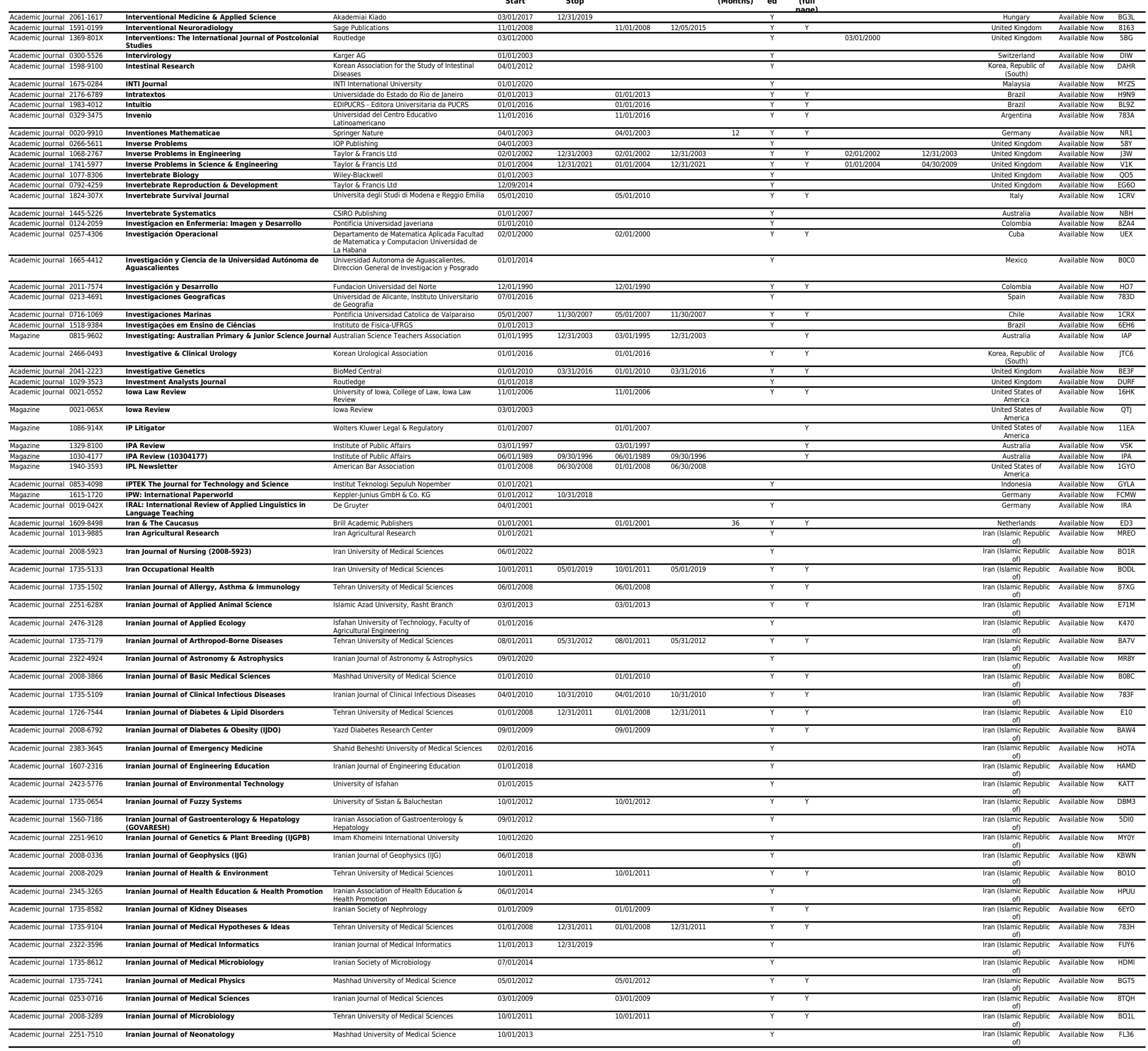




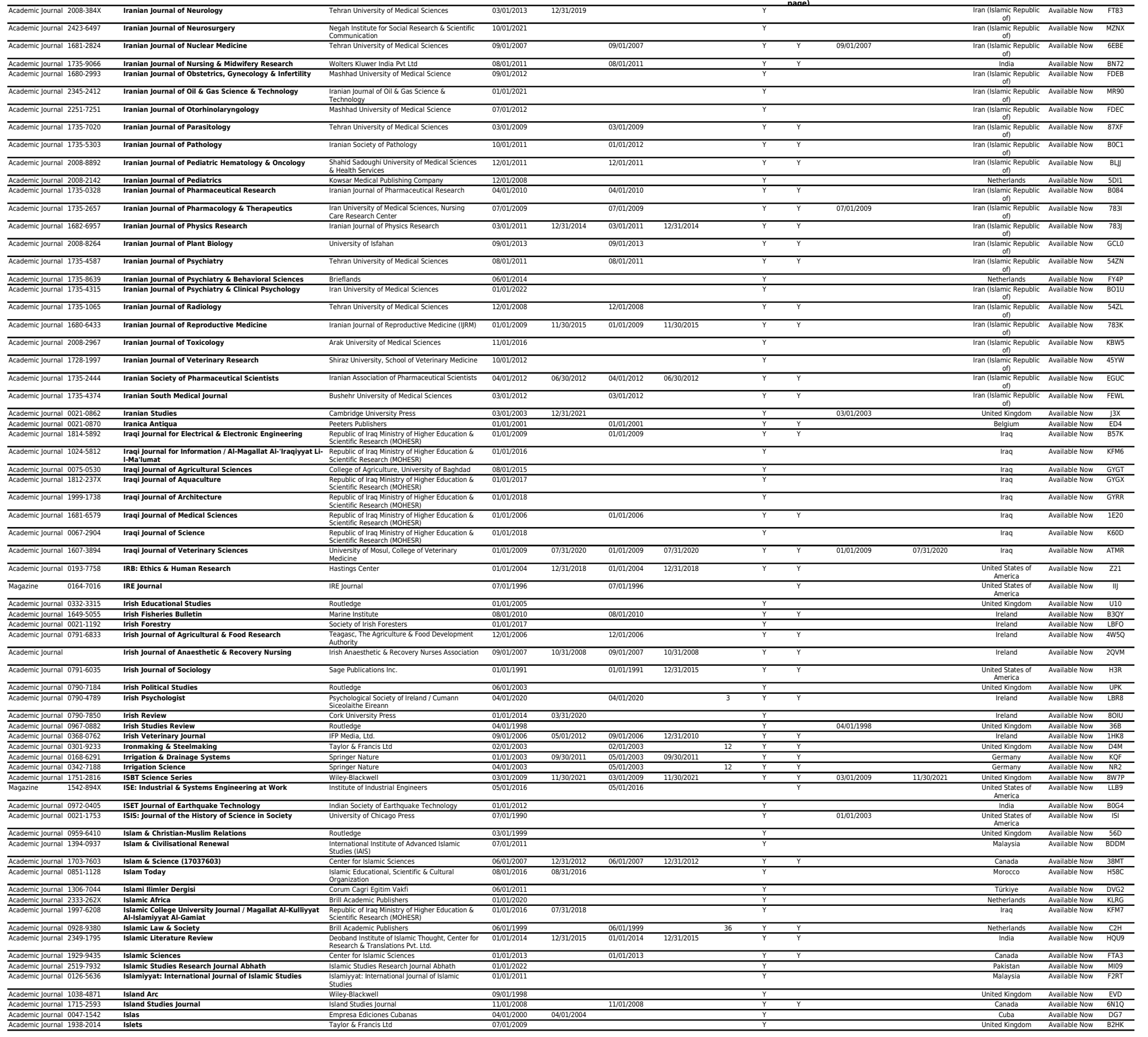




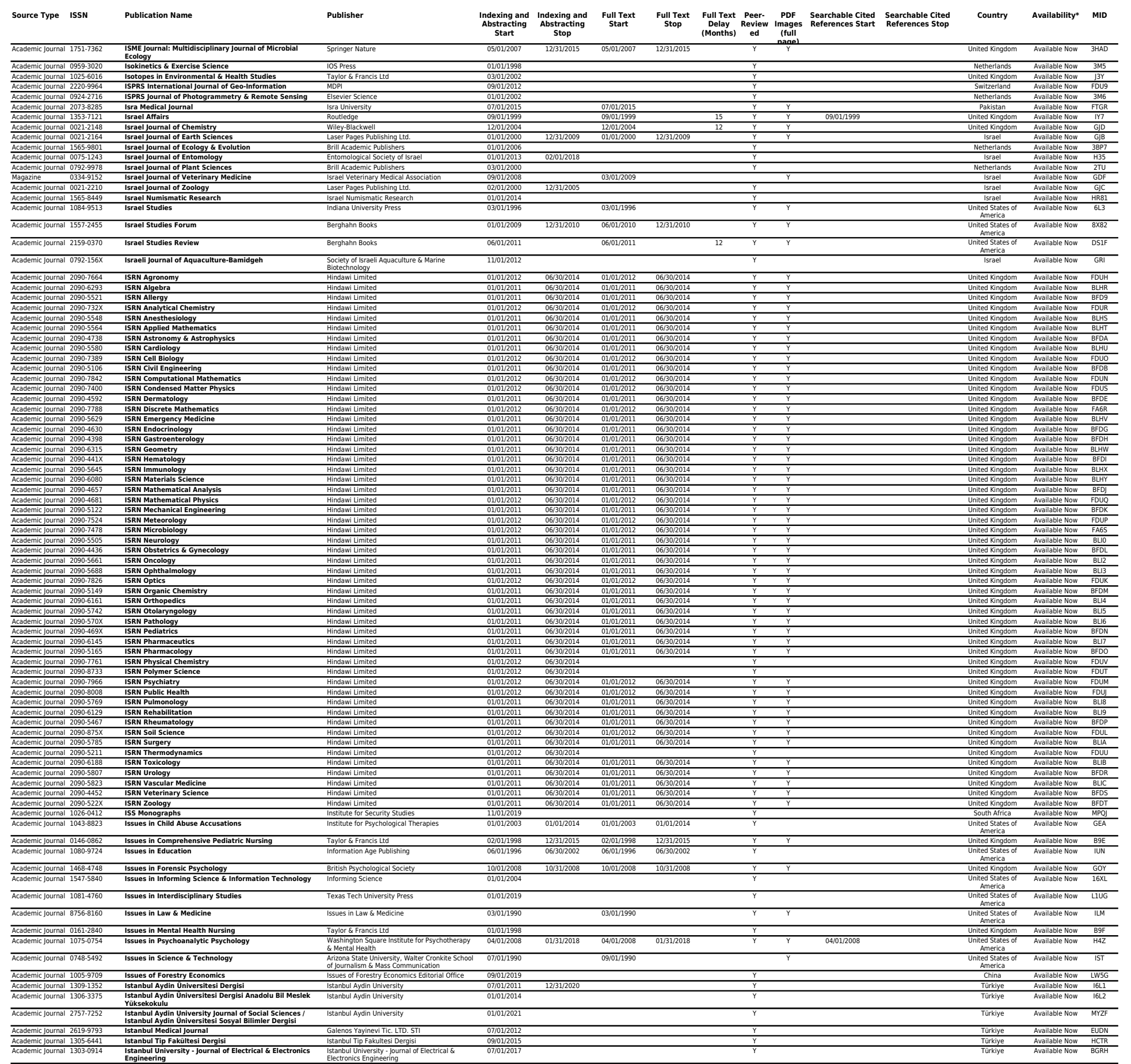




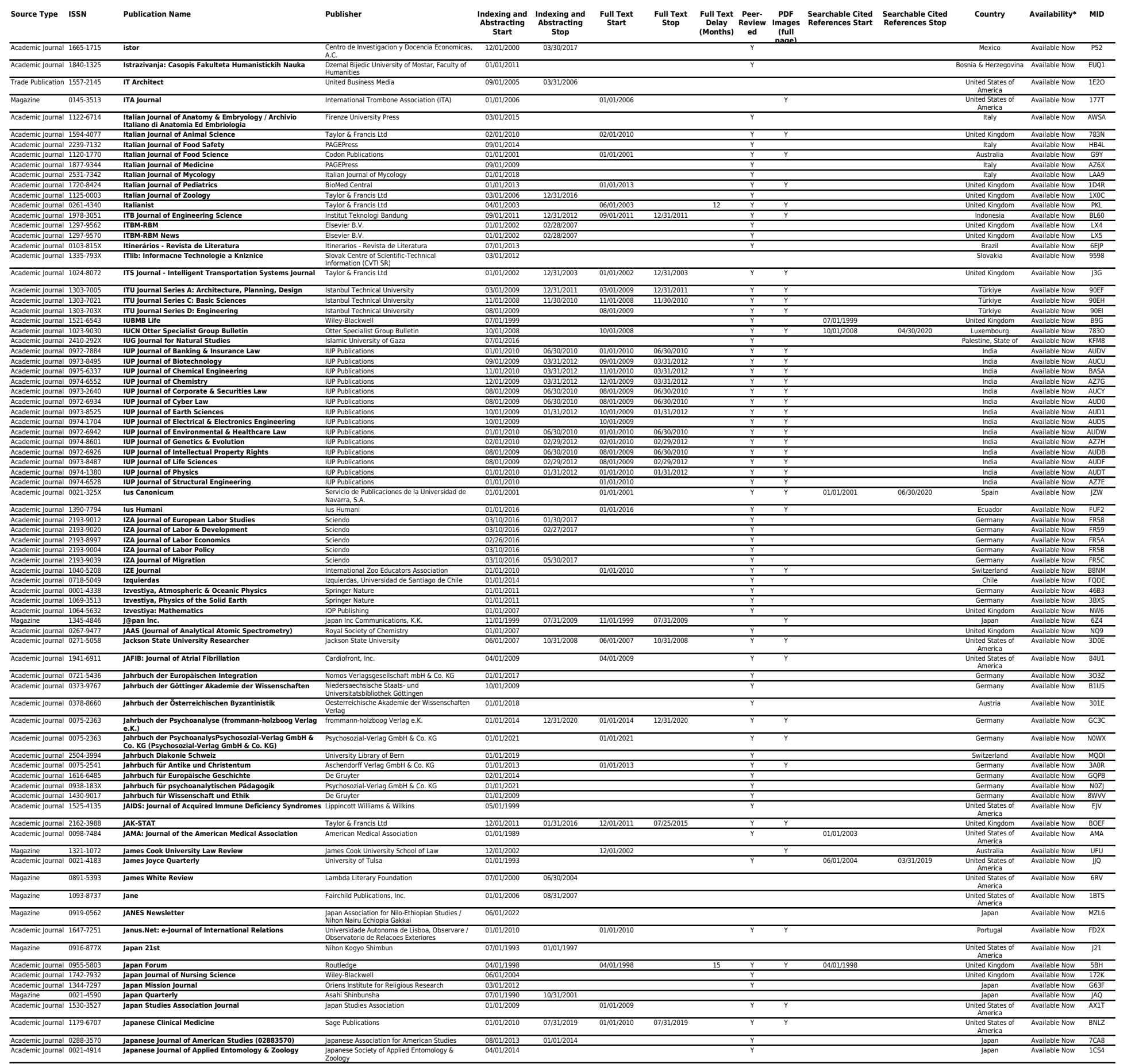




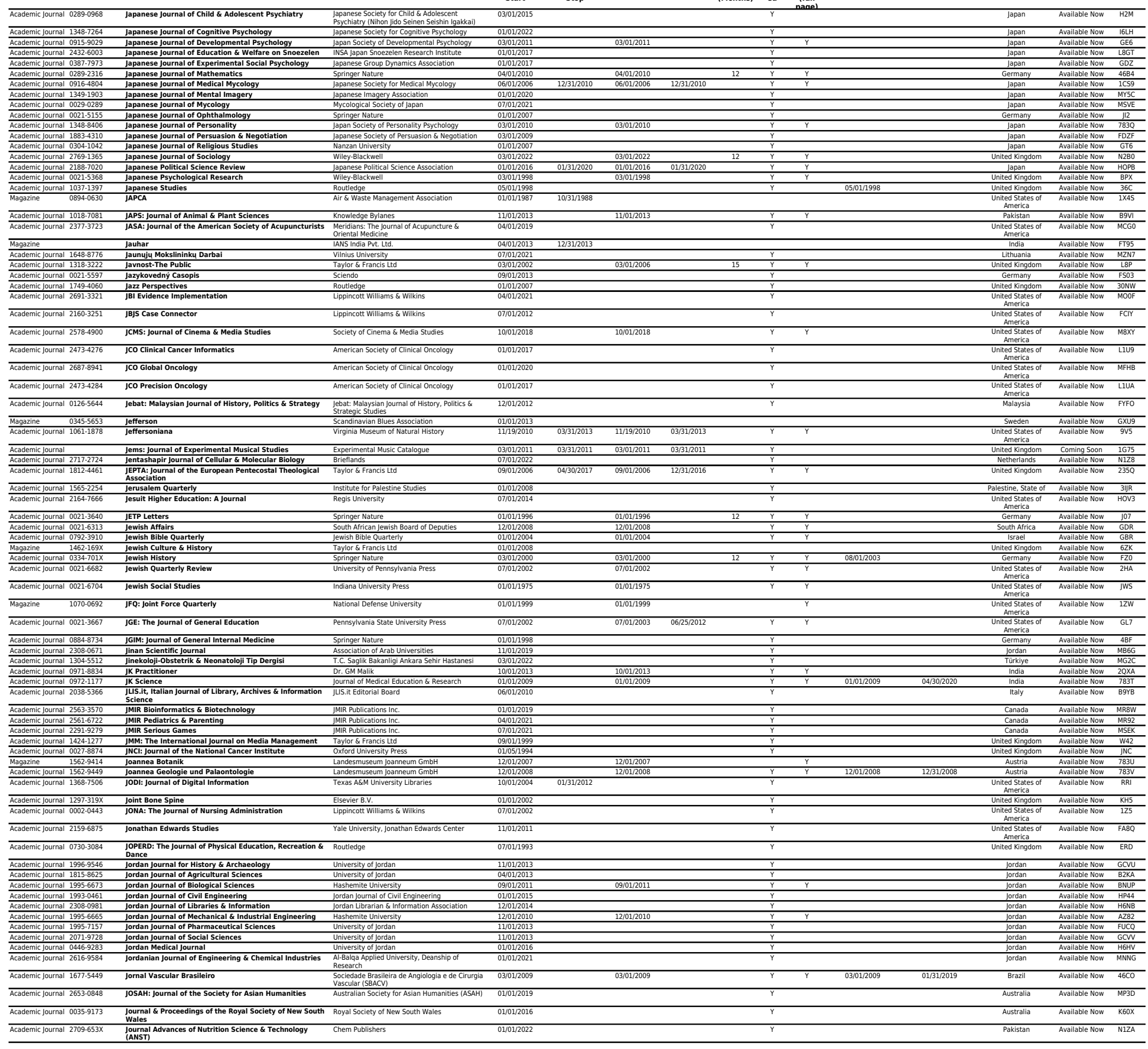




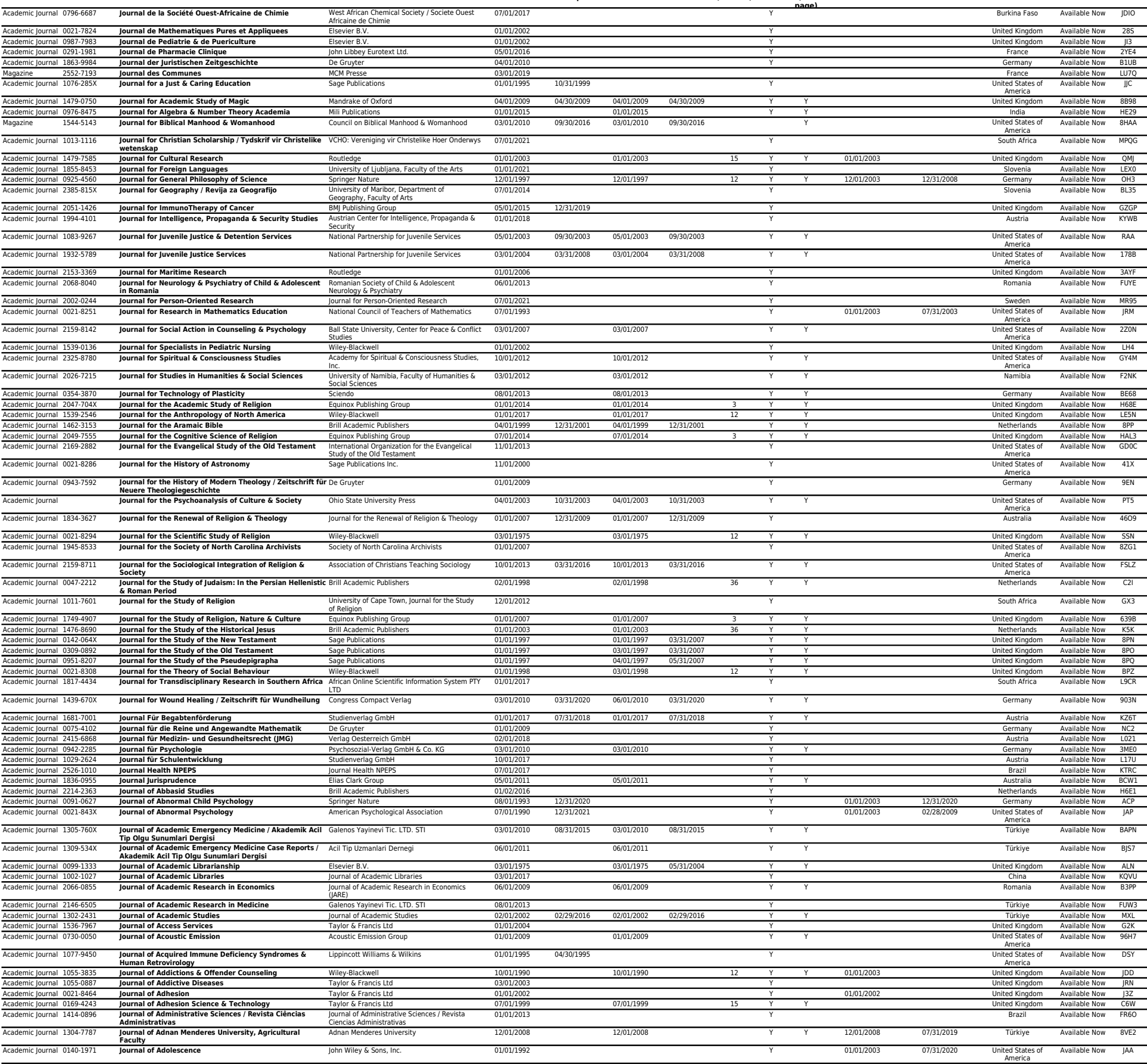




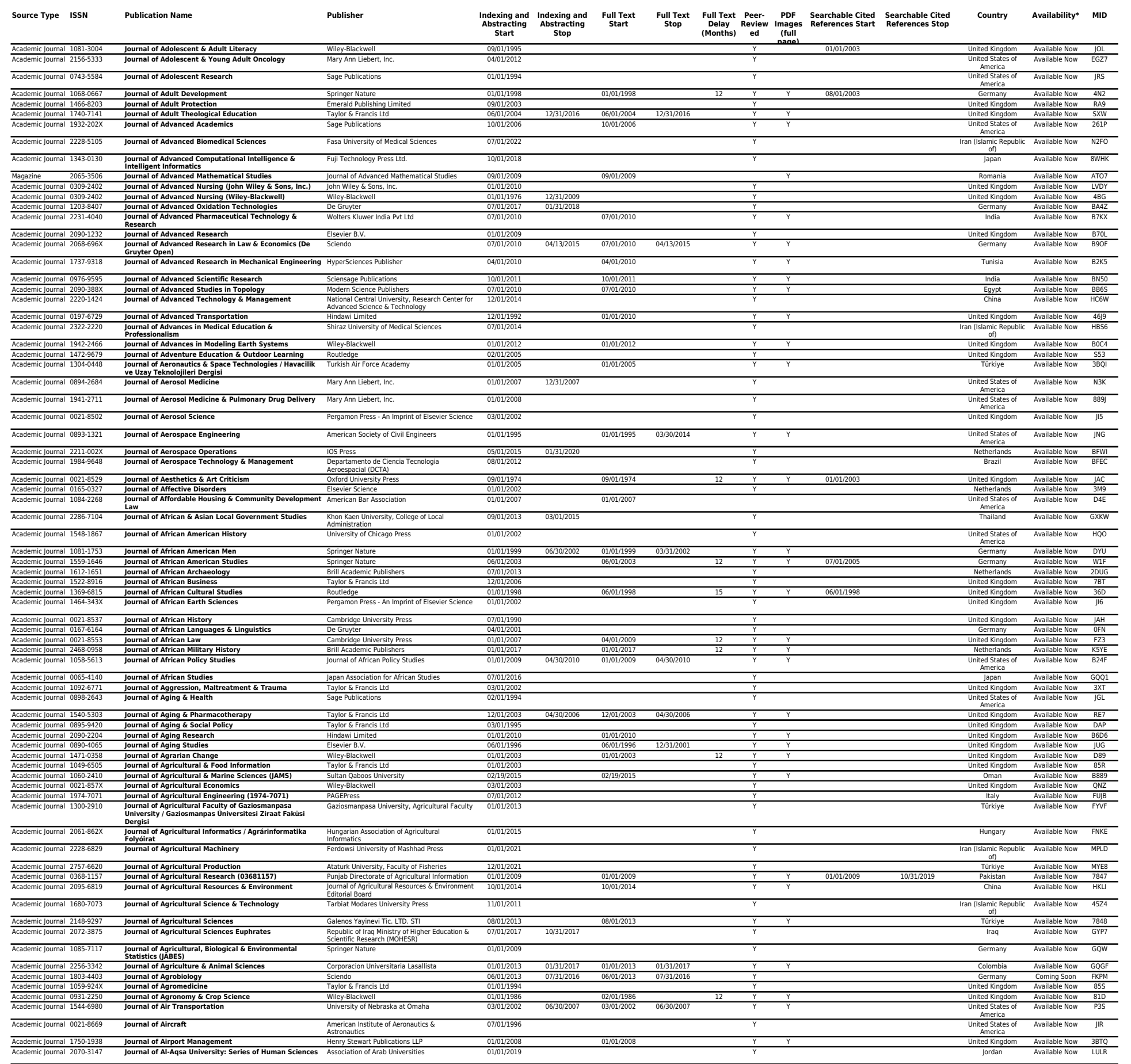




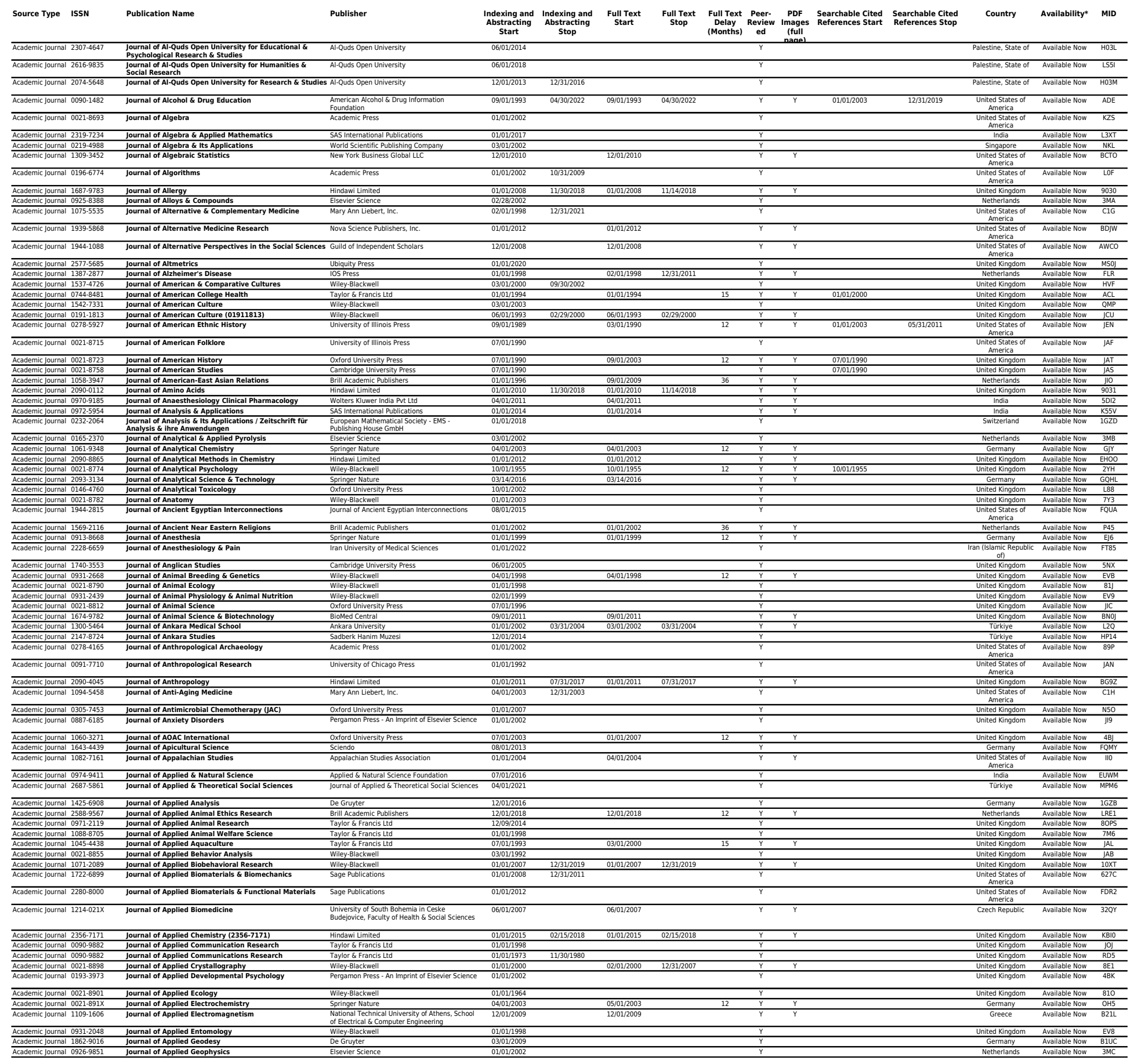




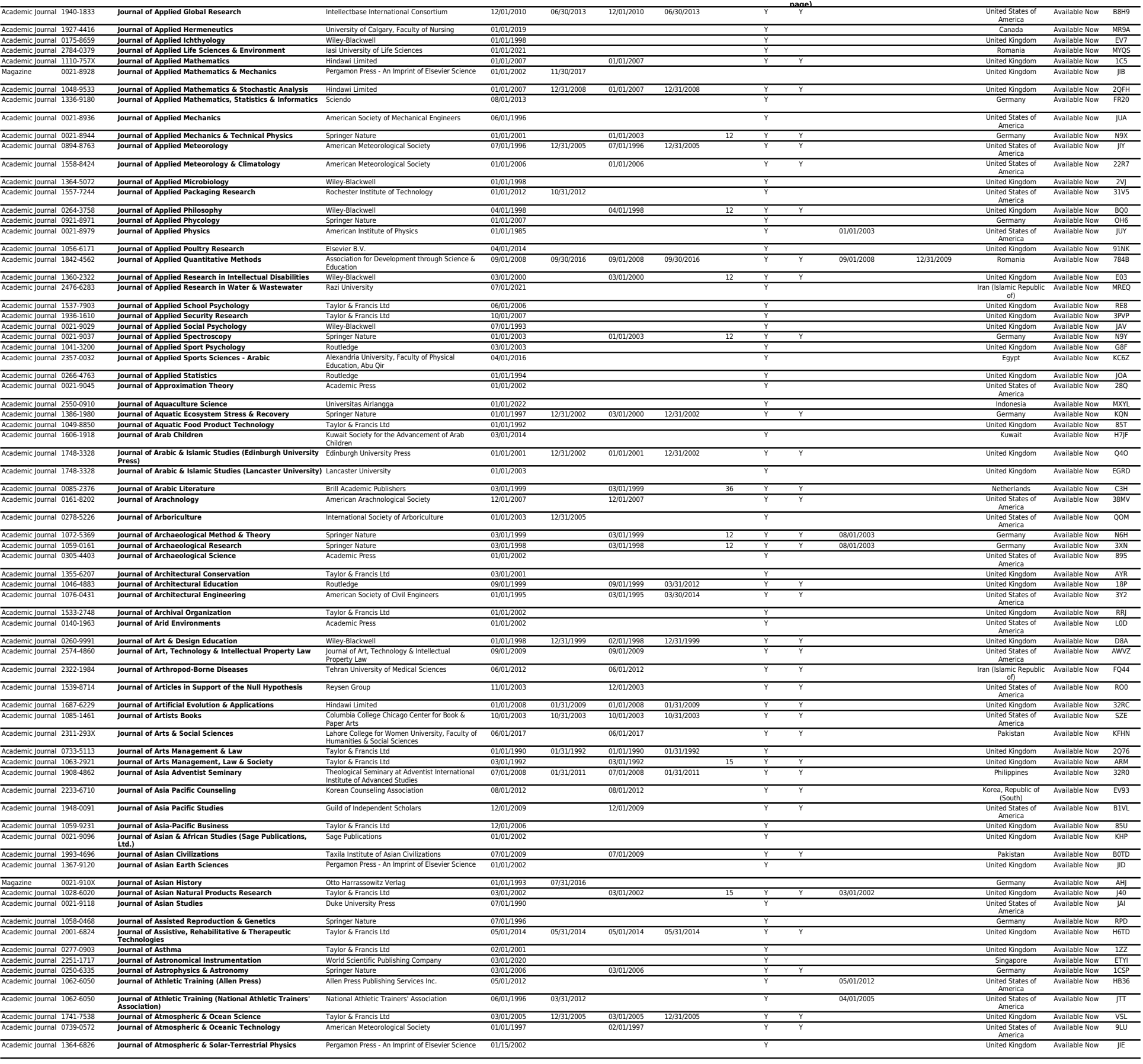




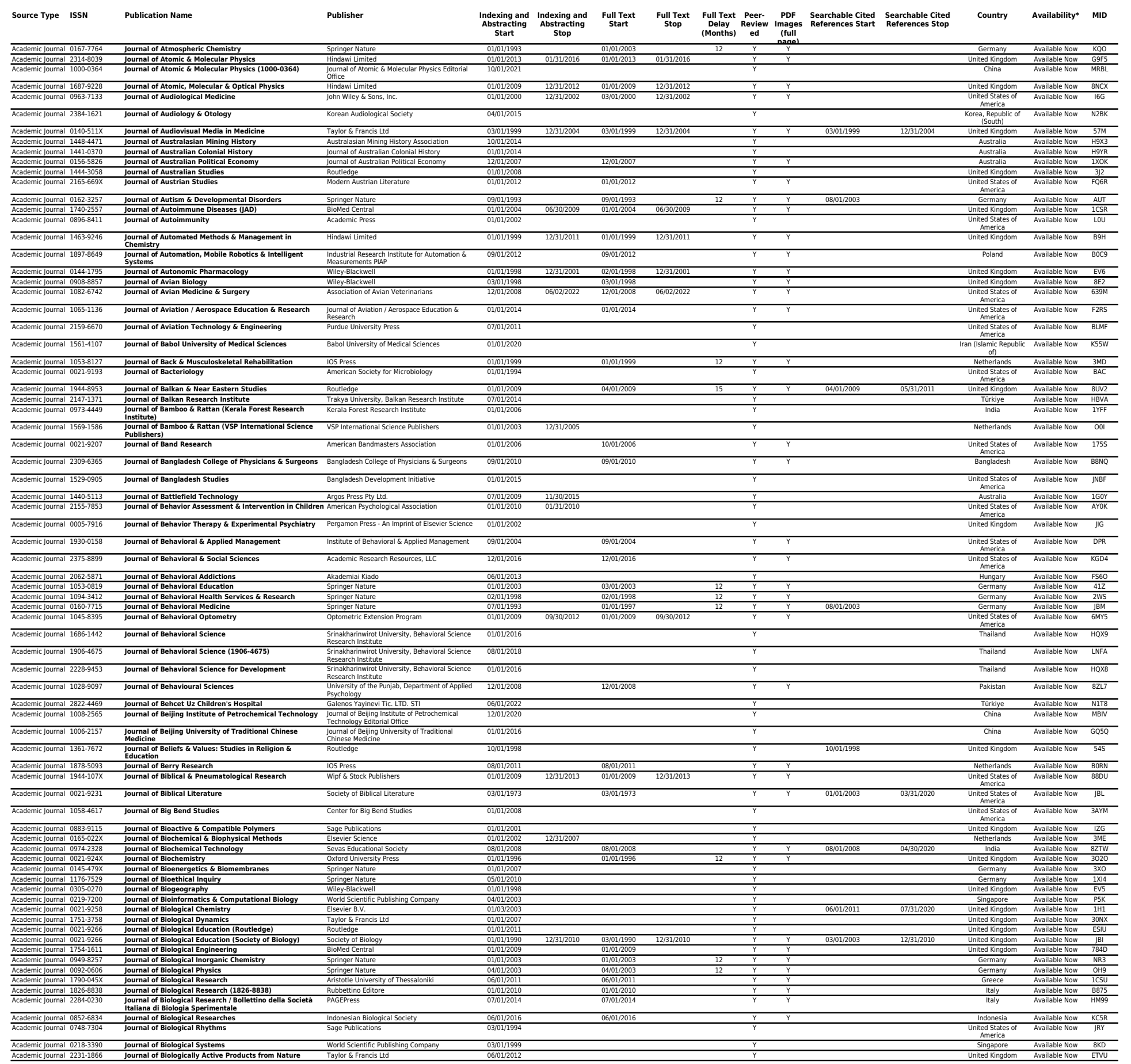




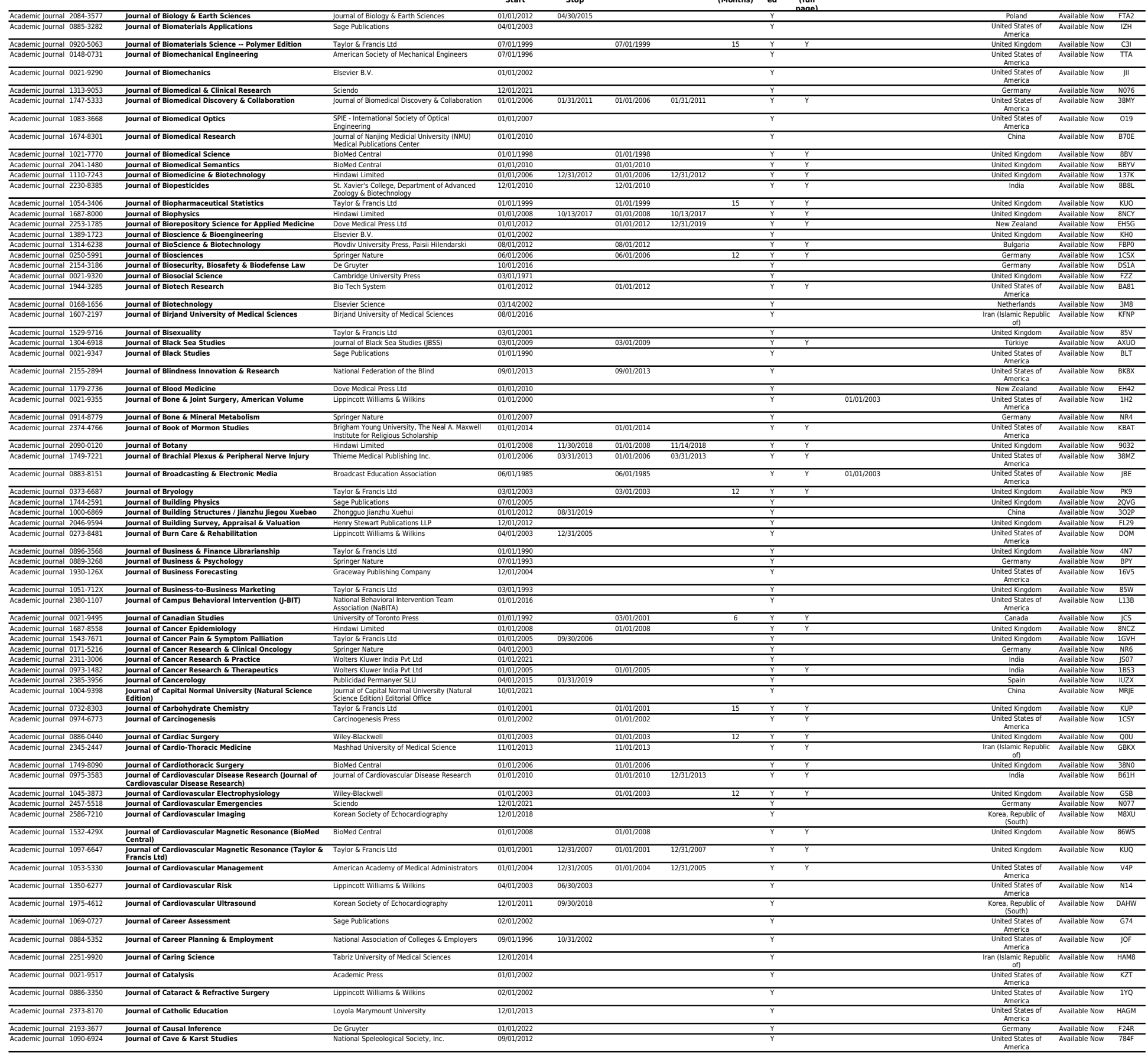




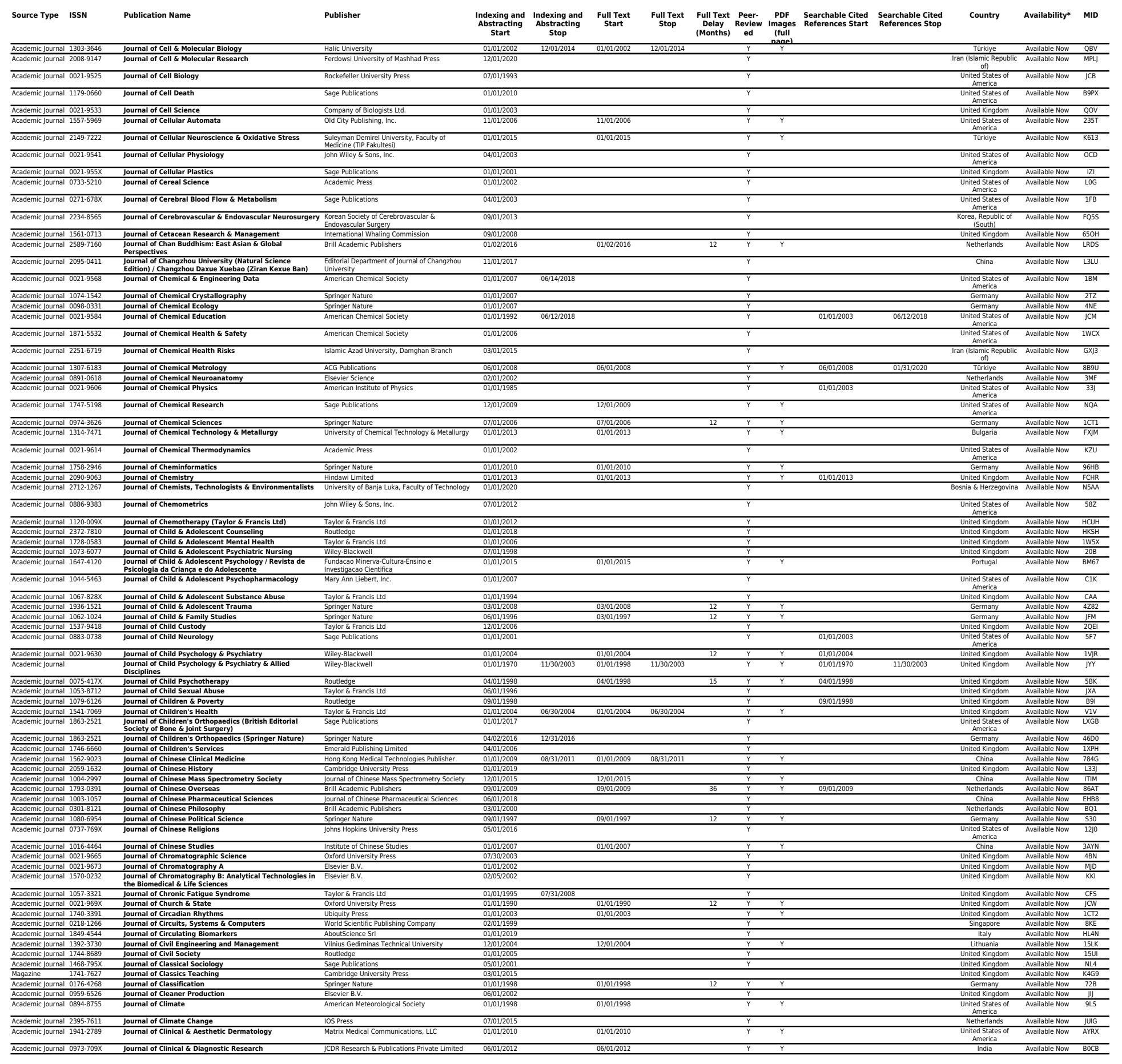




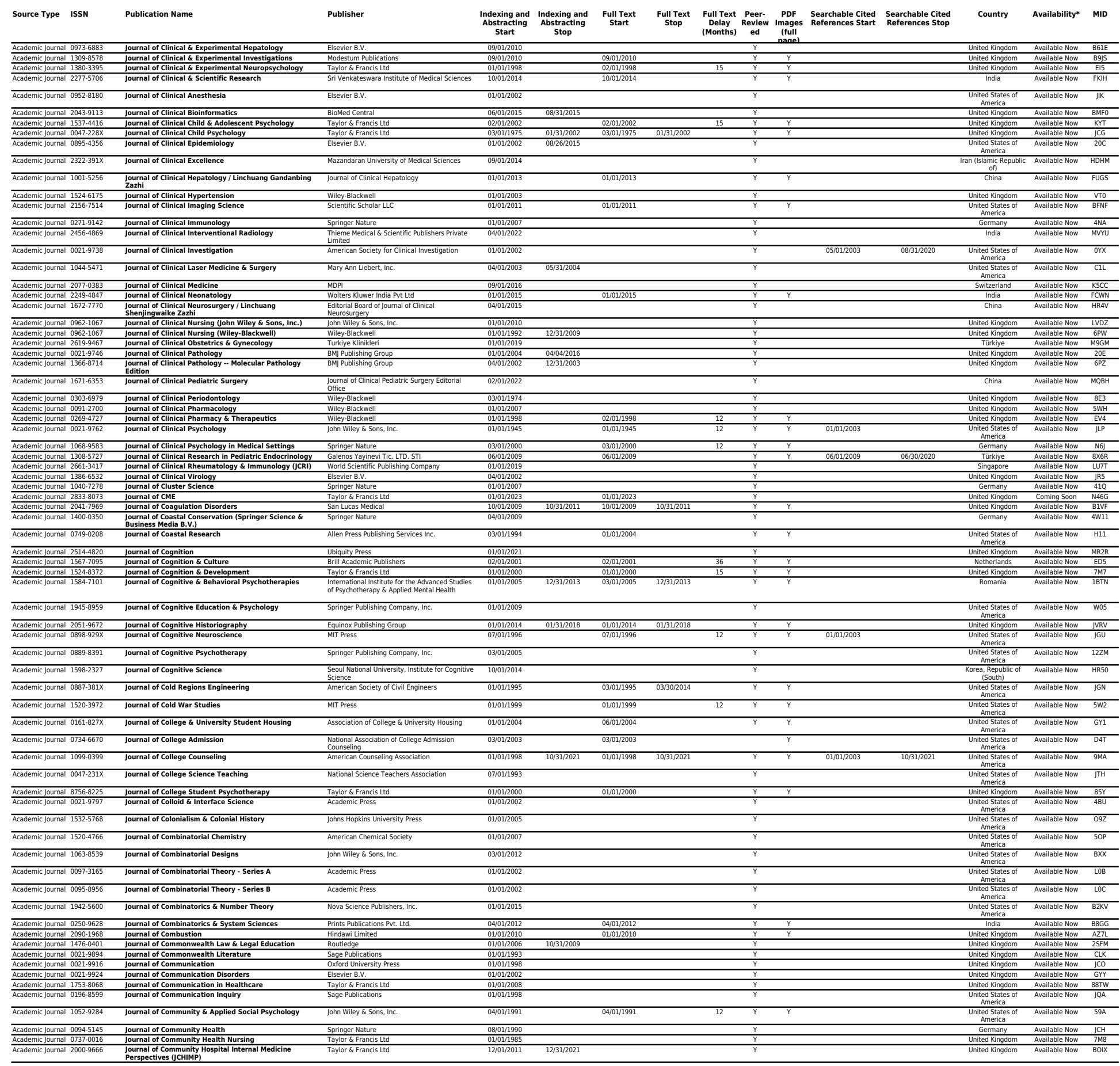


Academic Journal 1884-3007 Journal of Community Pharmacy \& Pharmaceutical

pharmacy Soceley of apent

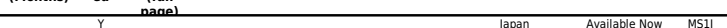

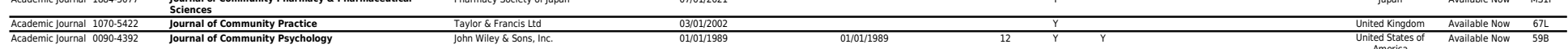

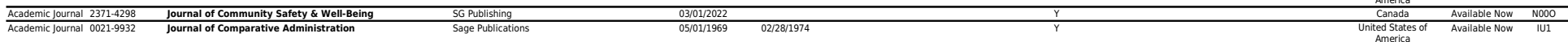

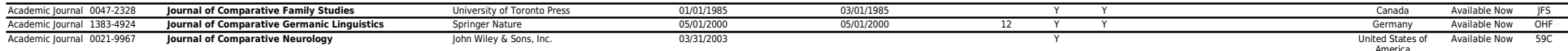

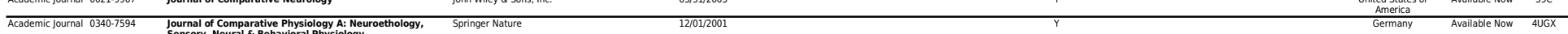

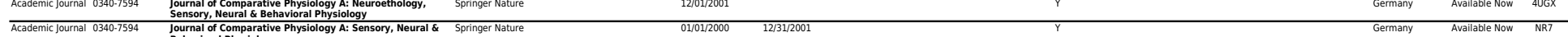

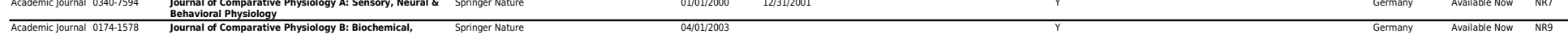

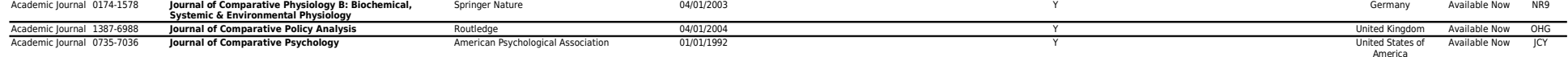

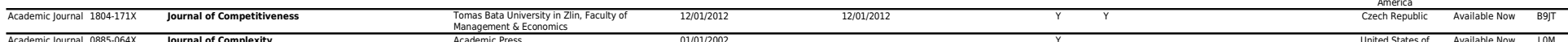

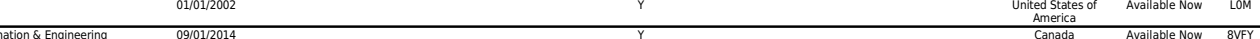

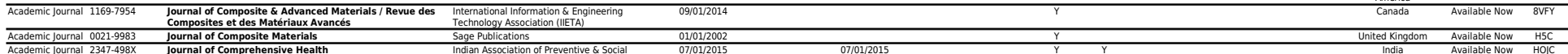

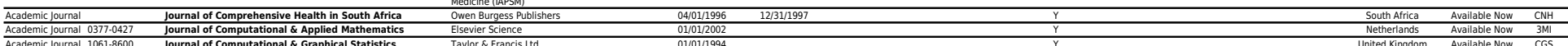

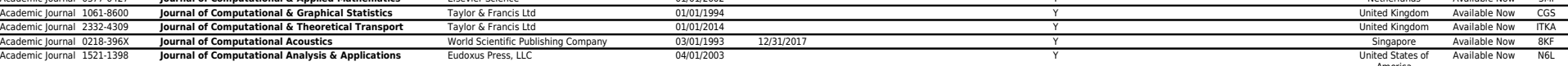

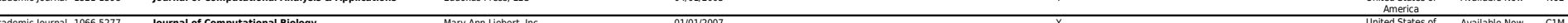

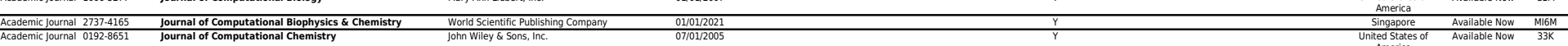

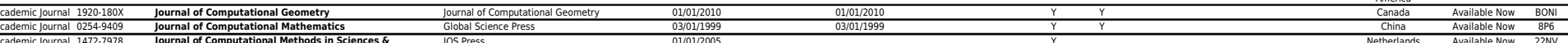
Enginering

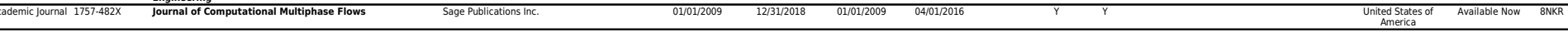

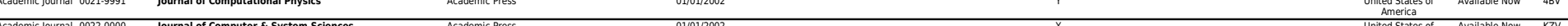

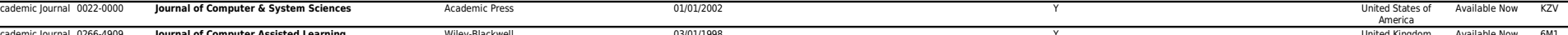

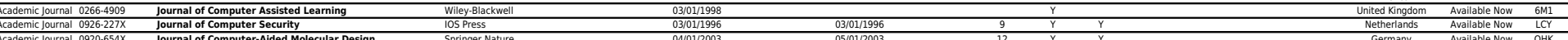

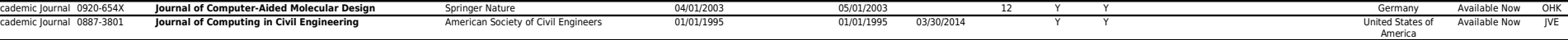

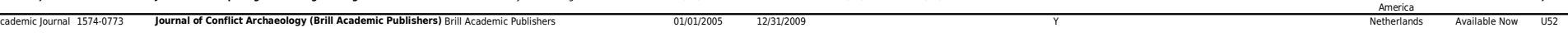

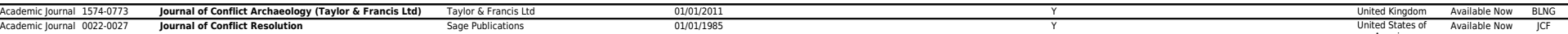

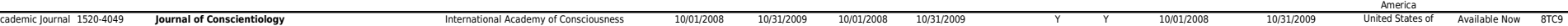

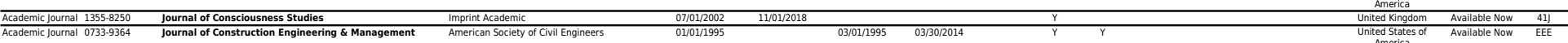

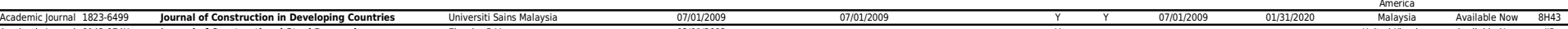

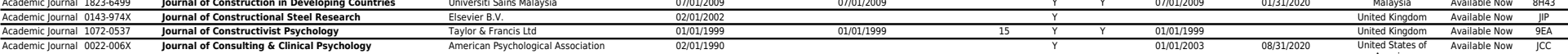

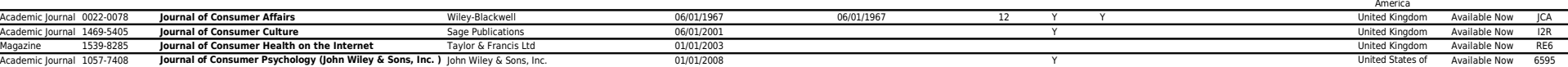

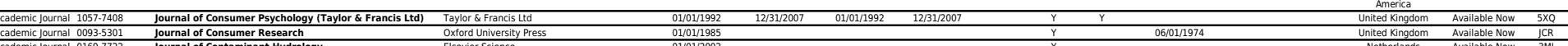

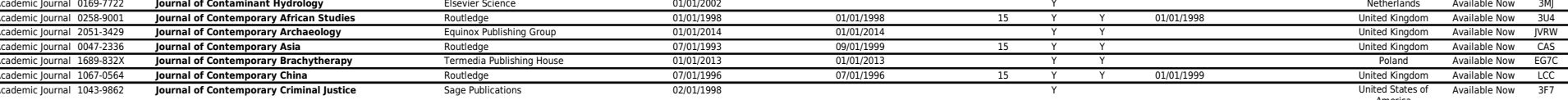

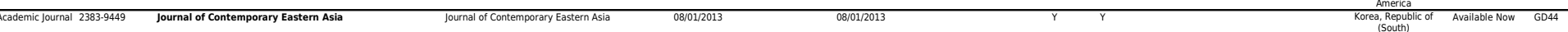

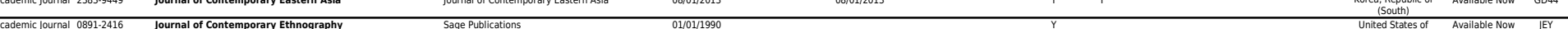

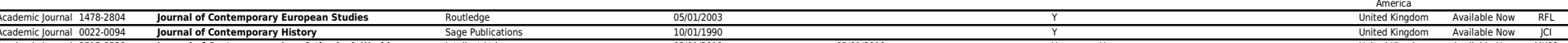

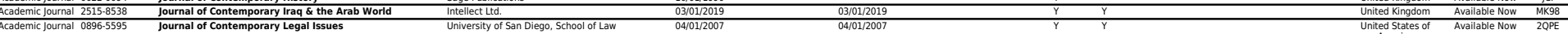

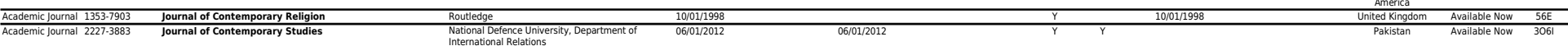

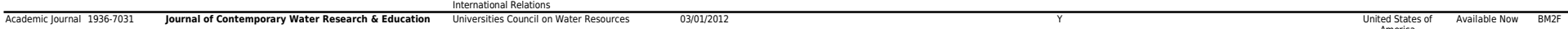

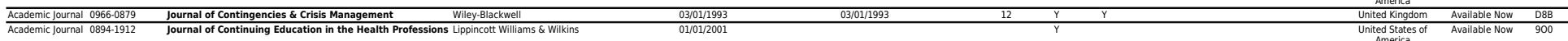

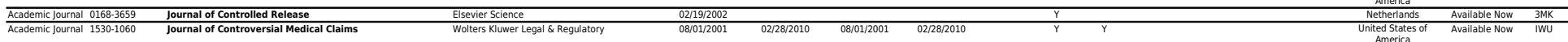

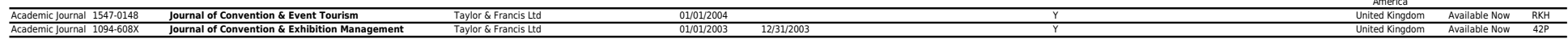




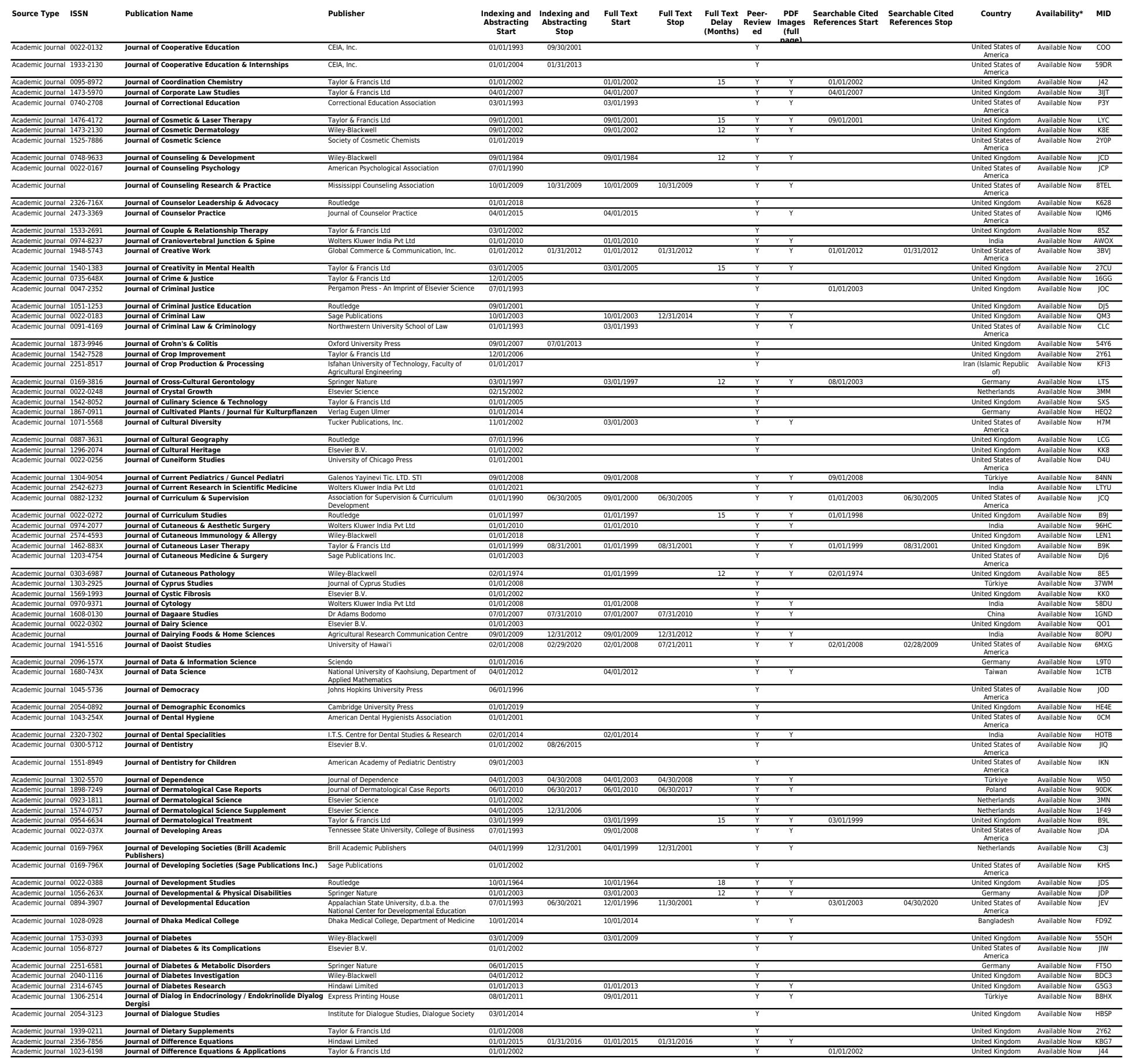




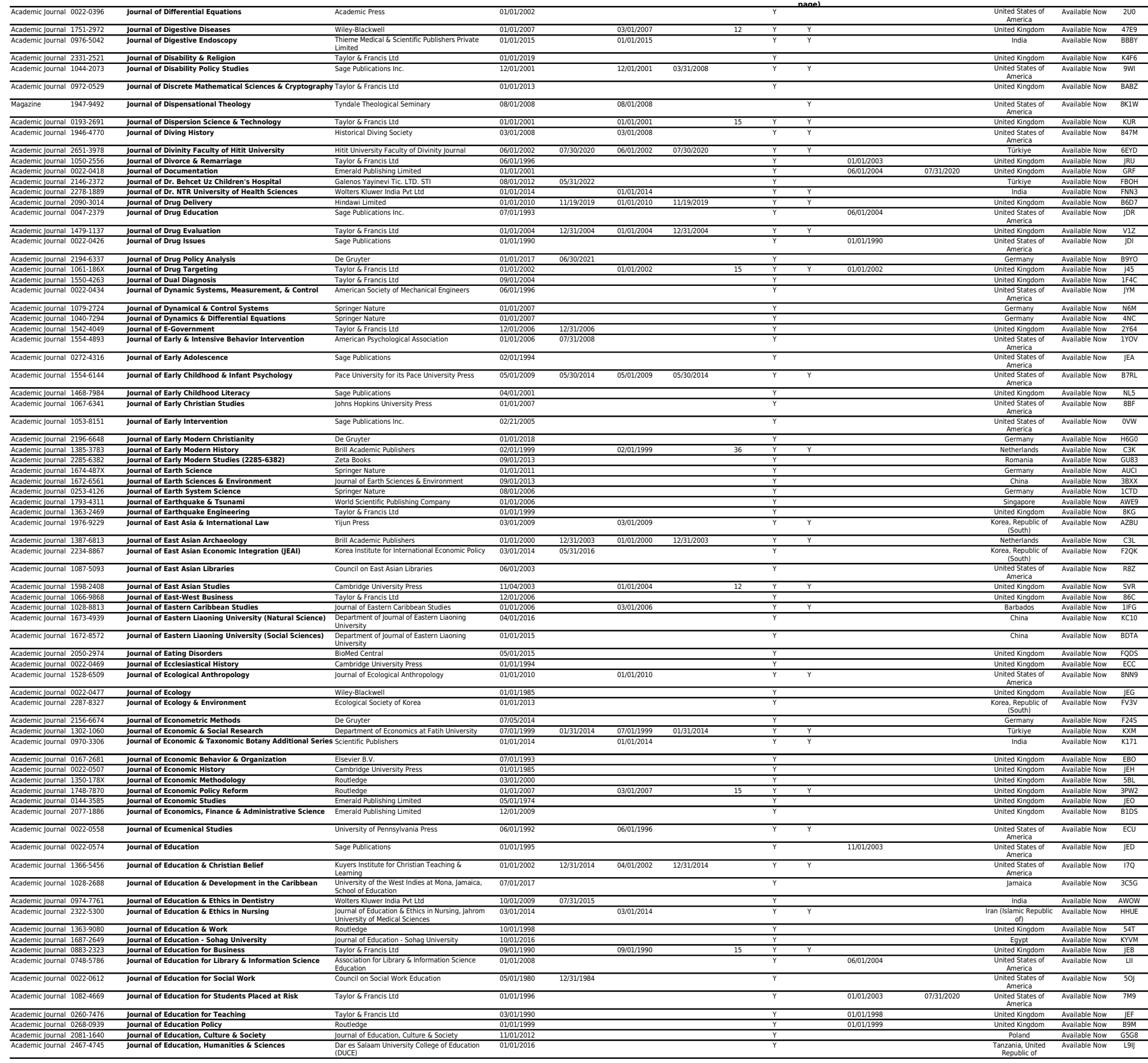




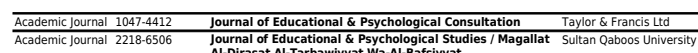

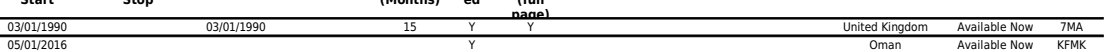

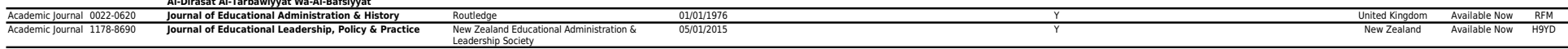

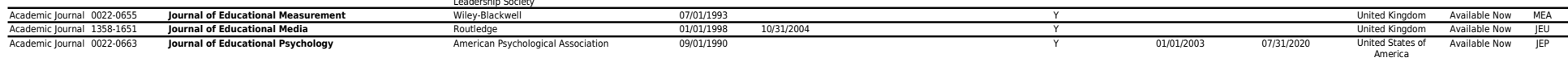

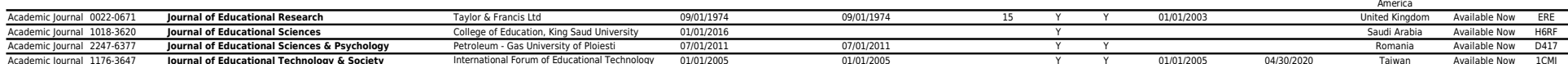

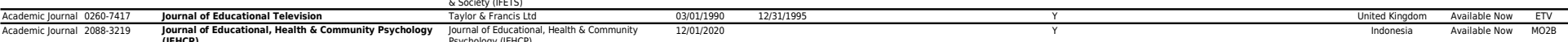

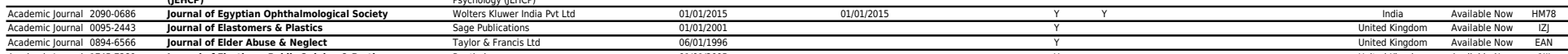

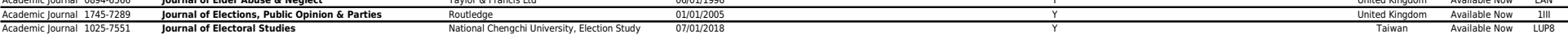

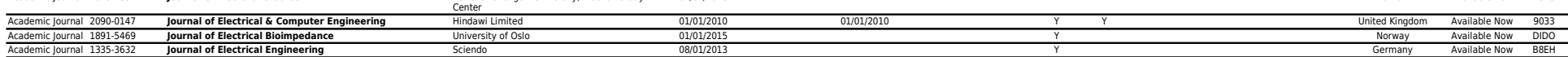

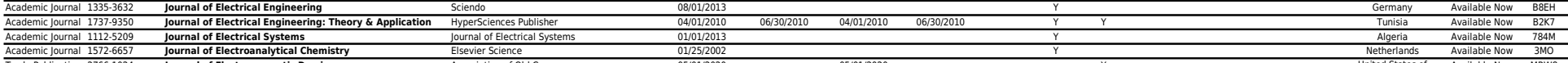

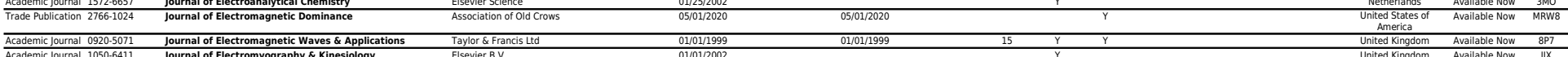

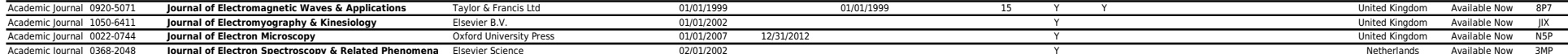

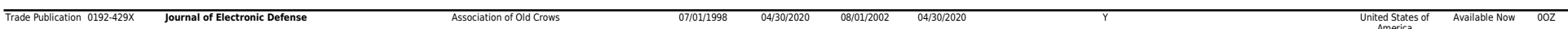

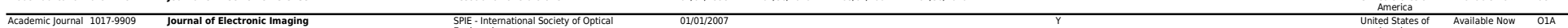

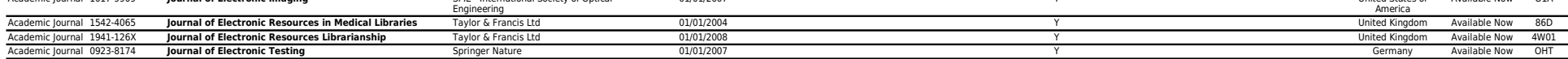

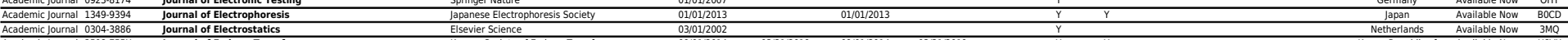

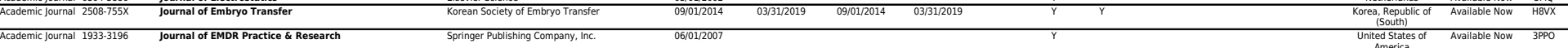

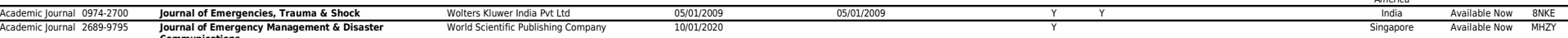

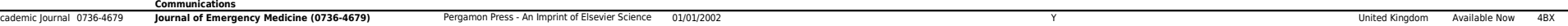

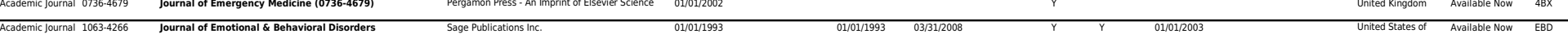

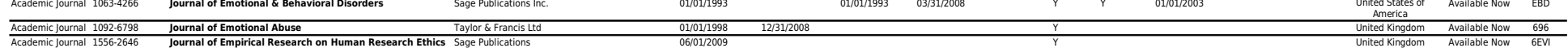

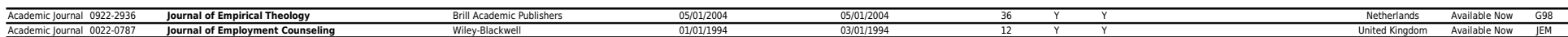

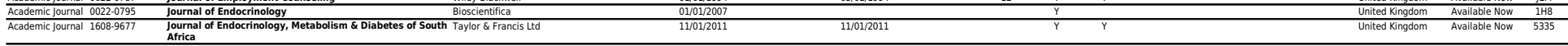

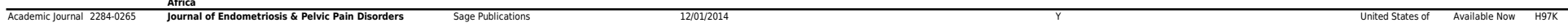

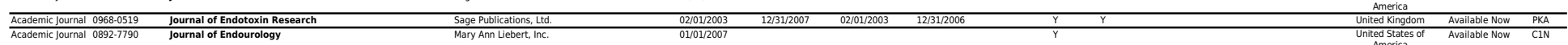

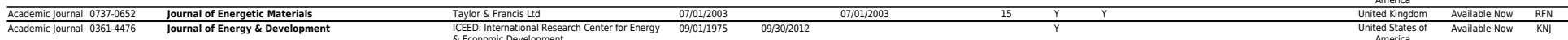

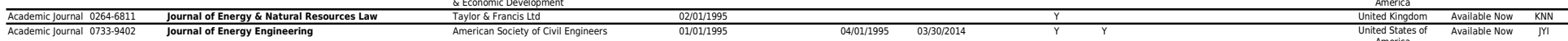

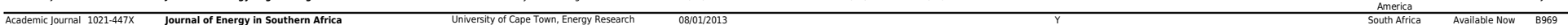

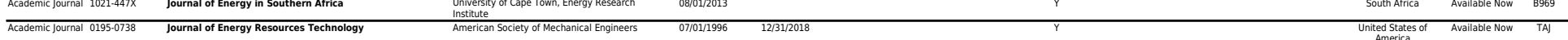

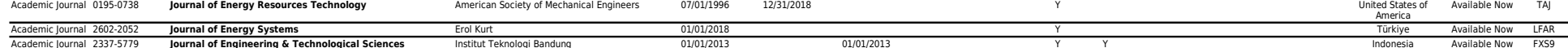

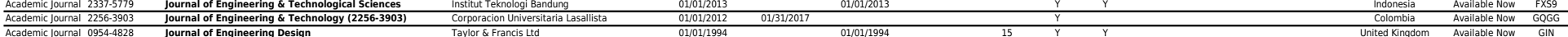

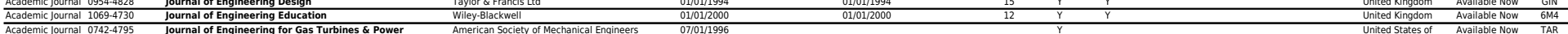

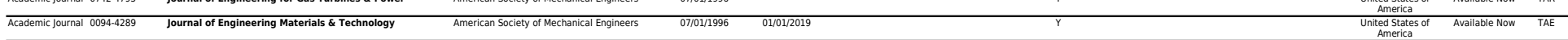

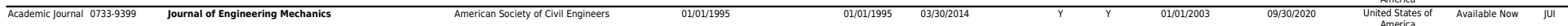

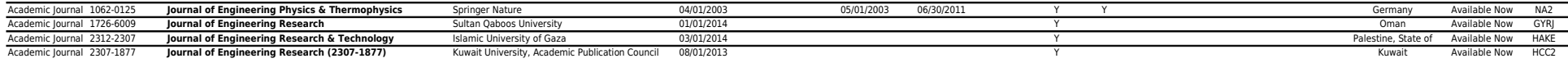

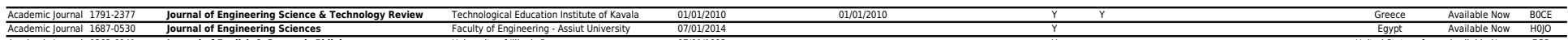

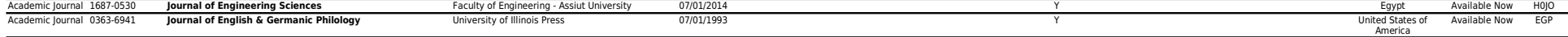

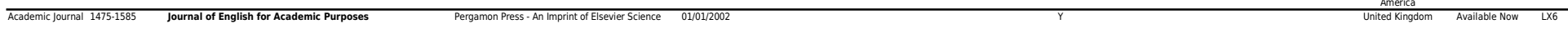

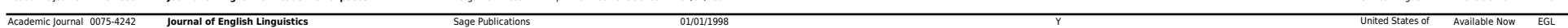

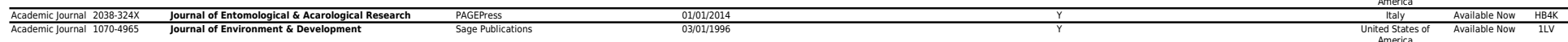

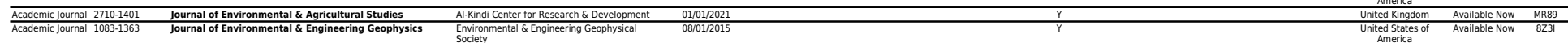




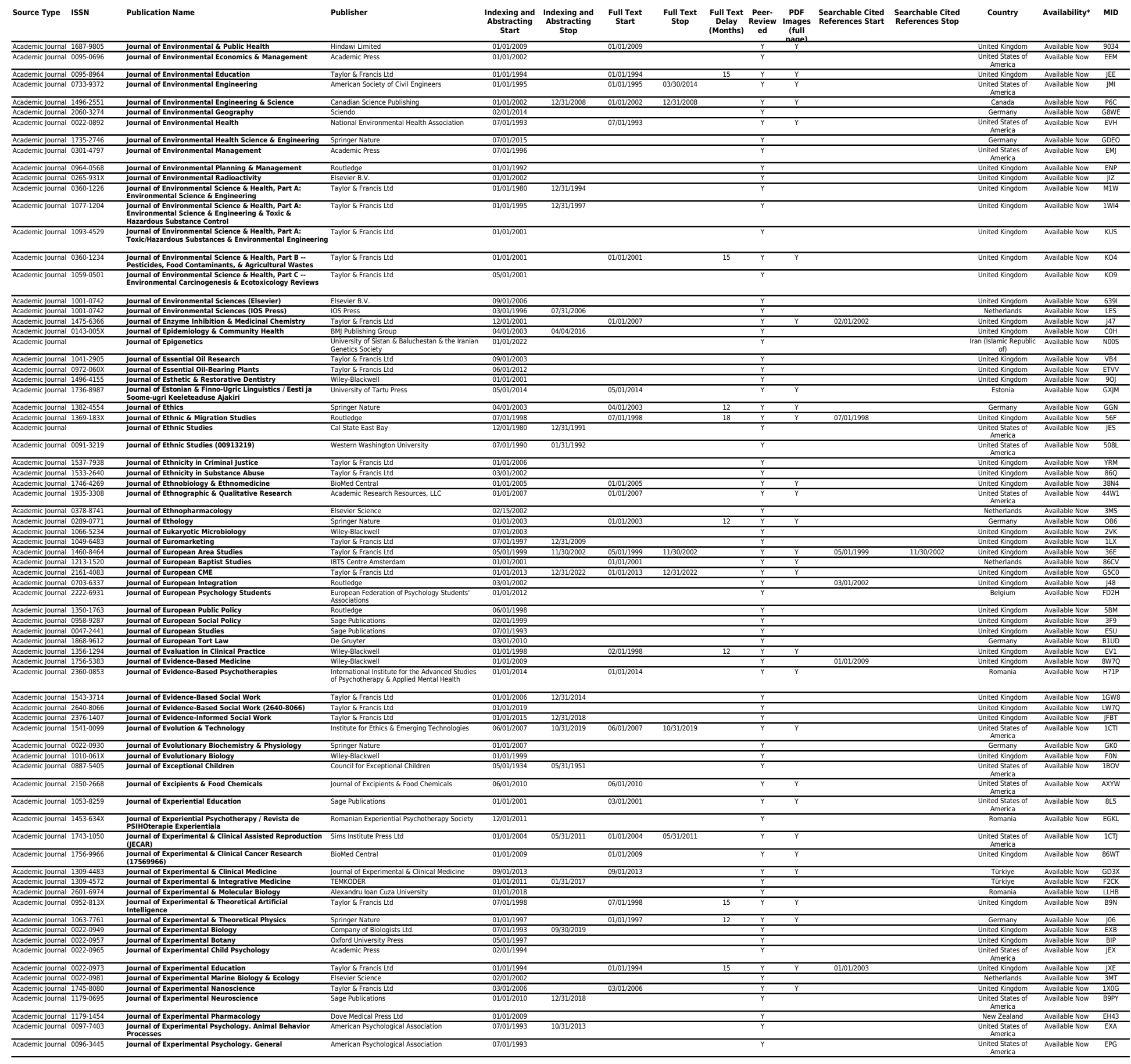




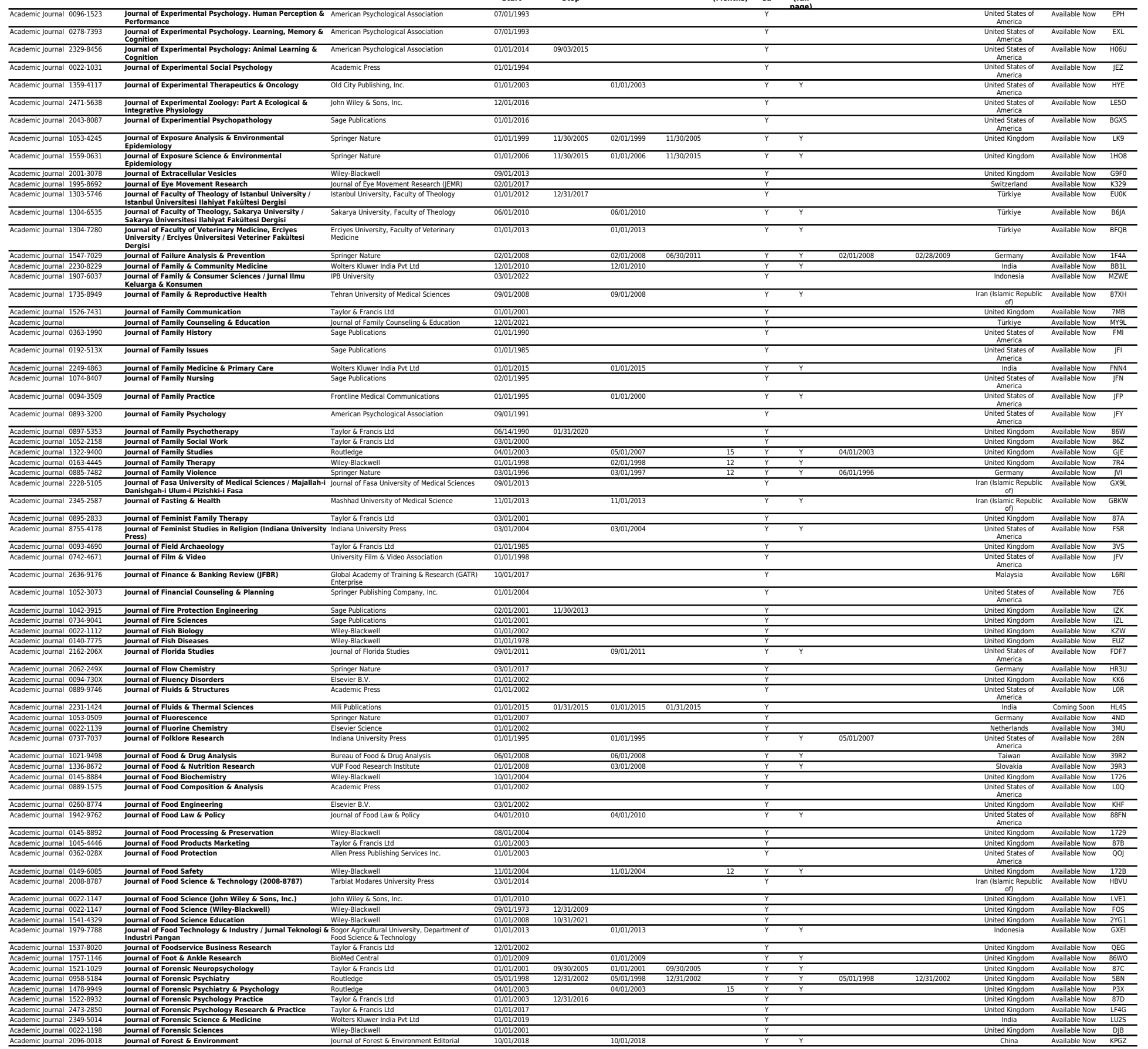




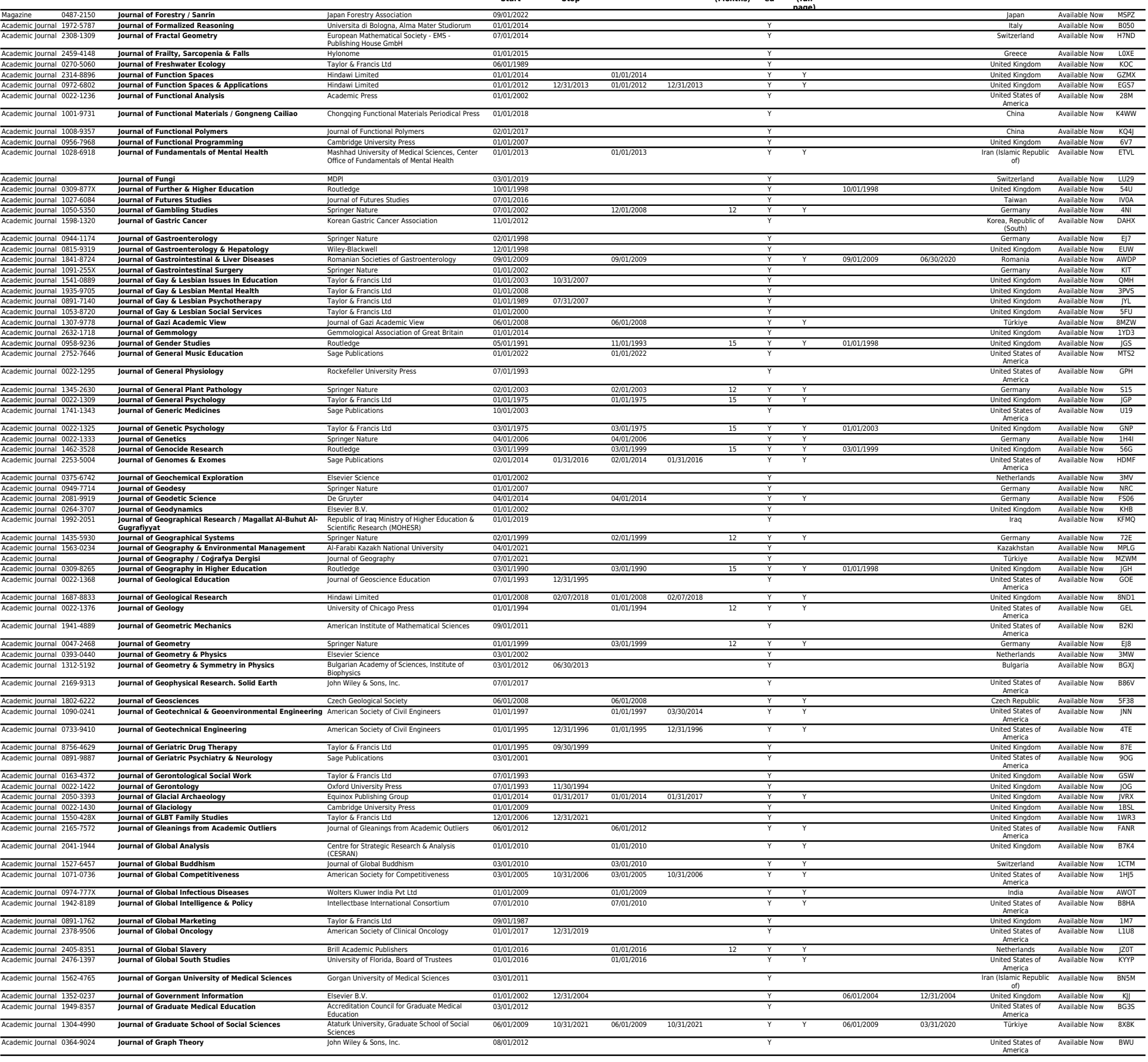




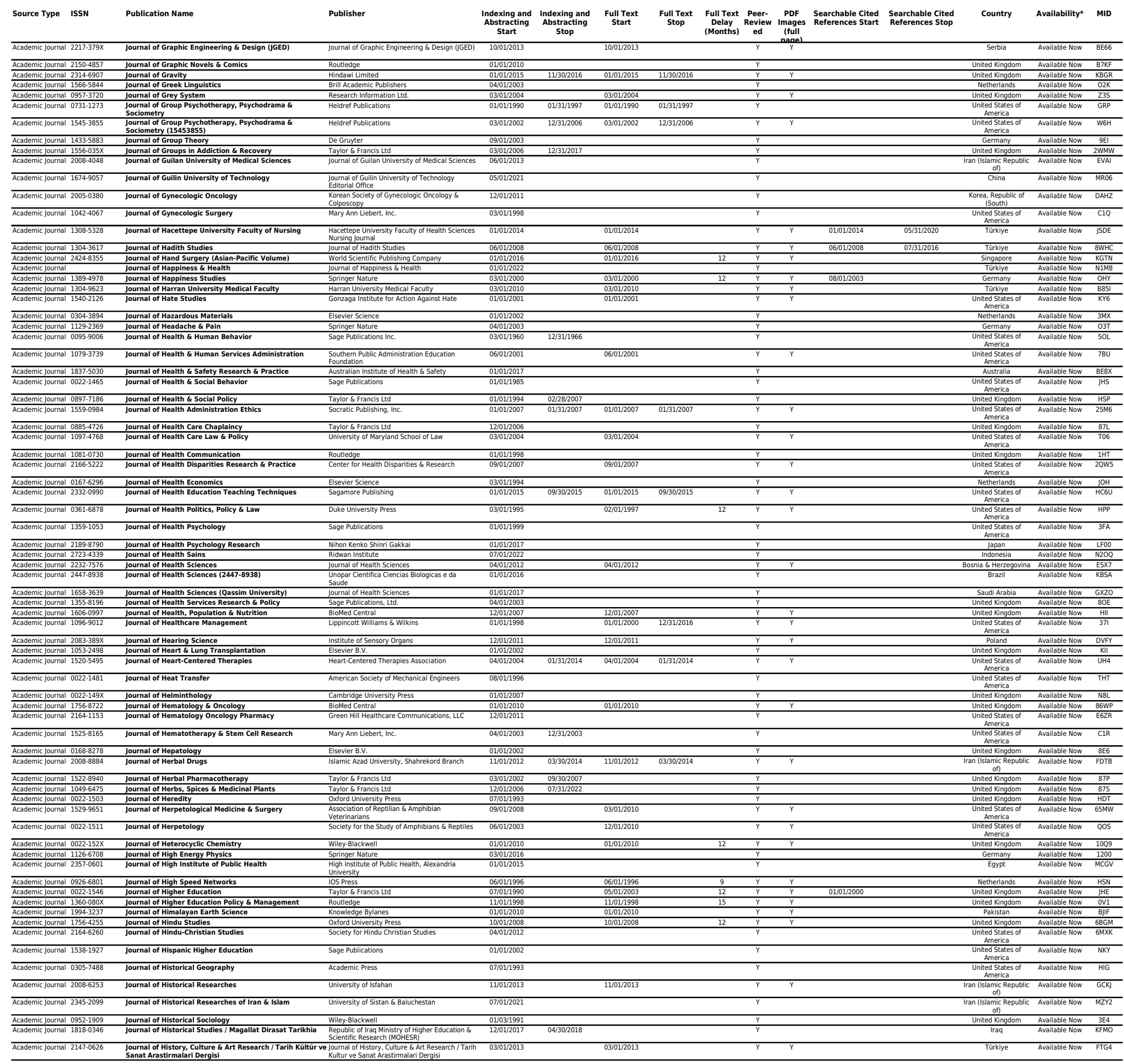




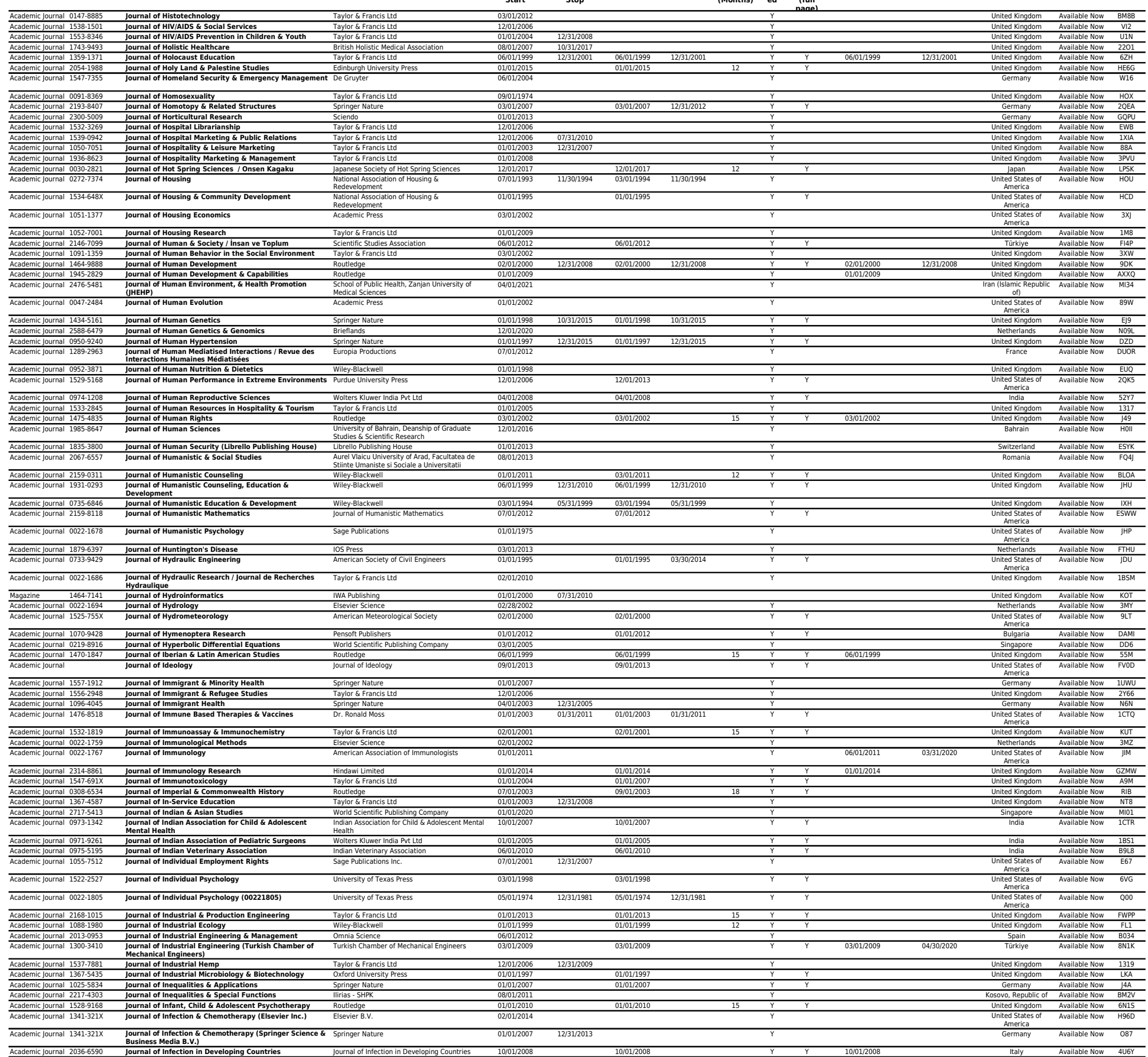




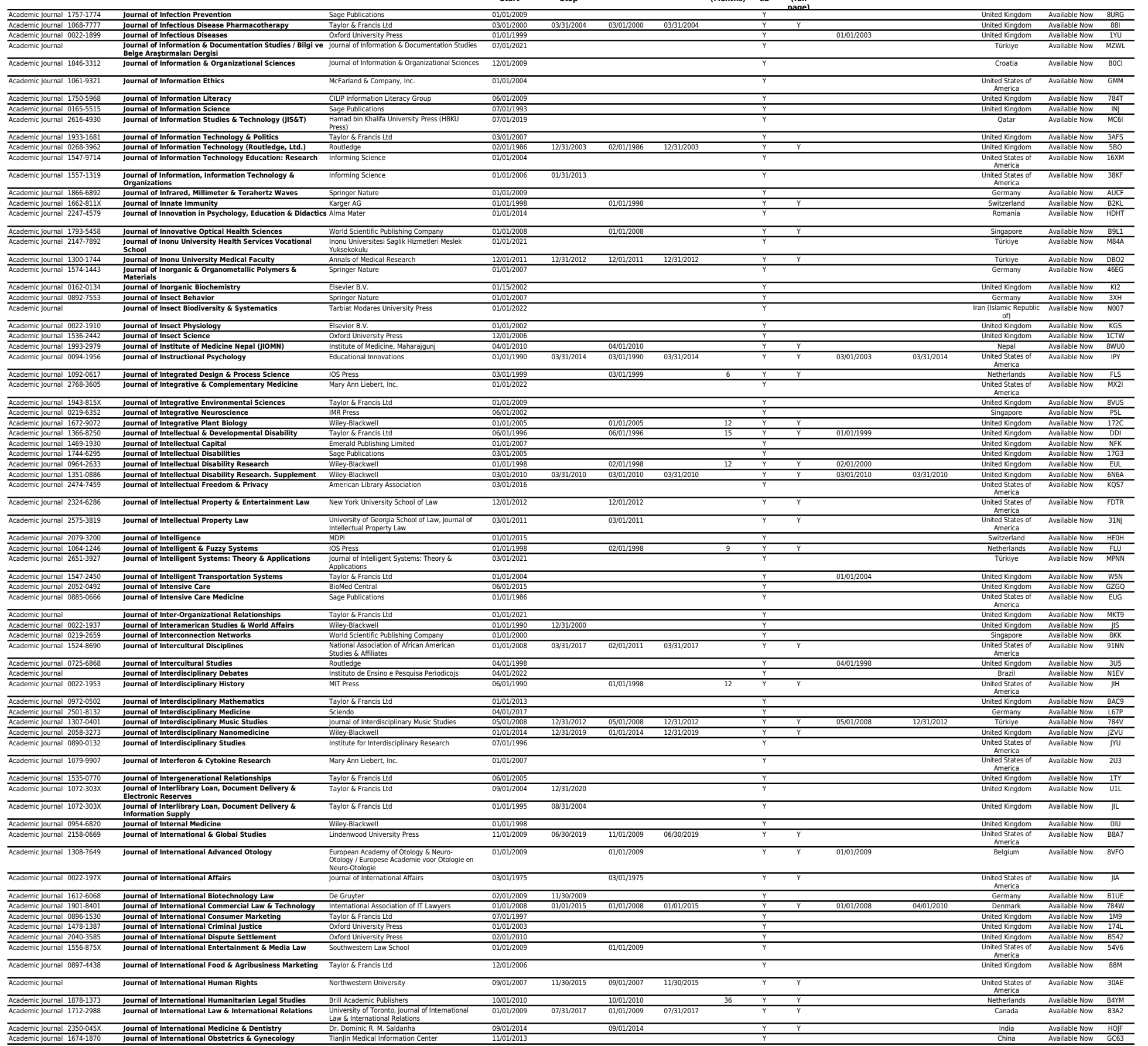




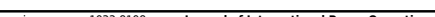
intermational Peace Operations Association

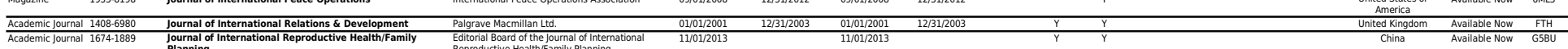

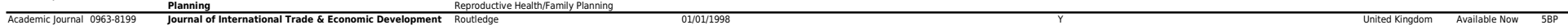

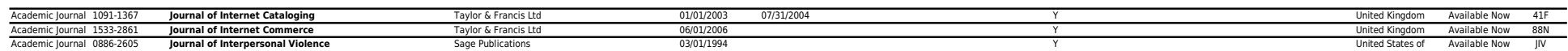

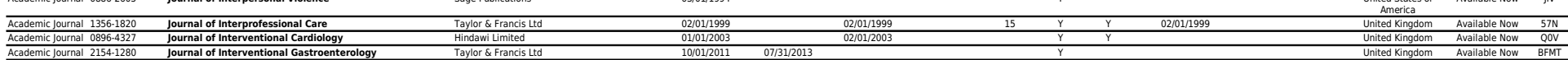

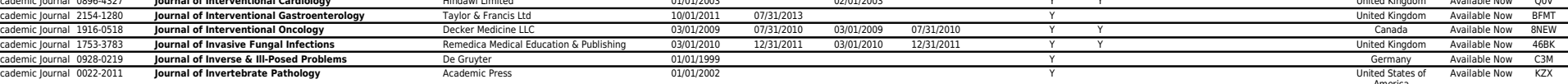

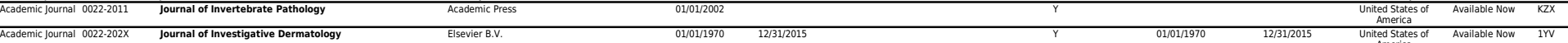

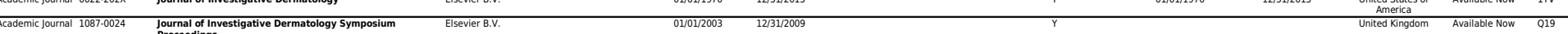

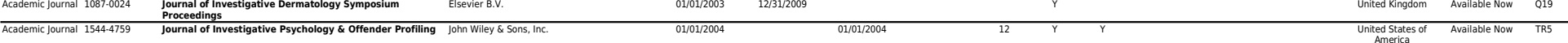

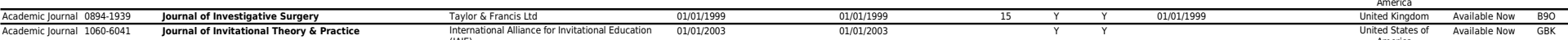

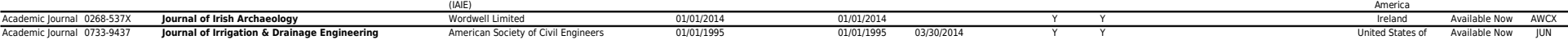

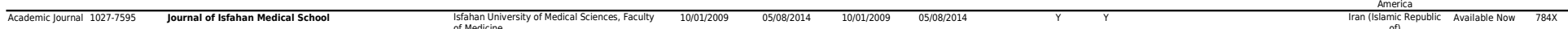

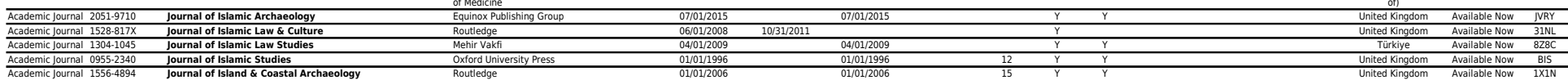

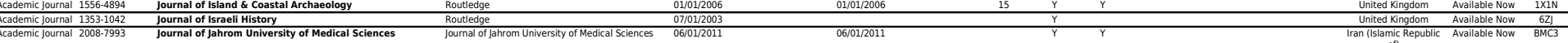

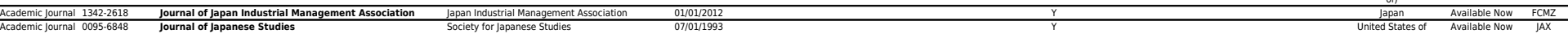

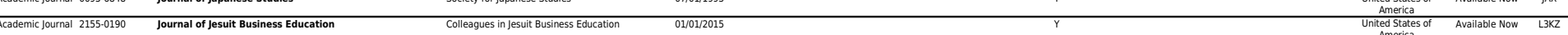

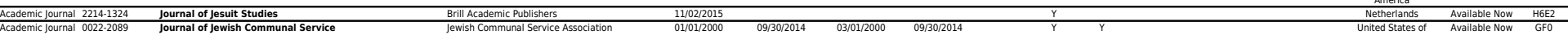

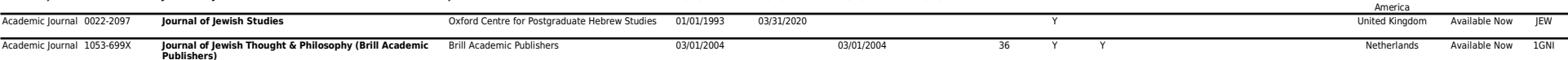

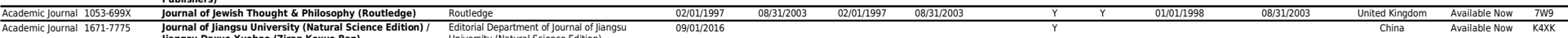

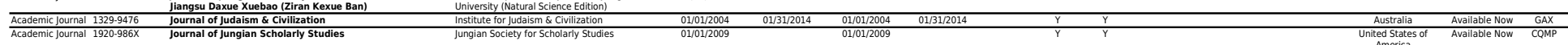

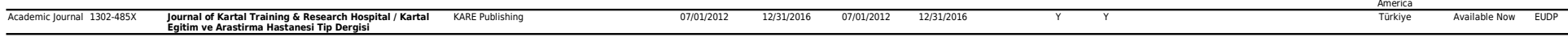

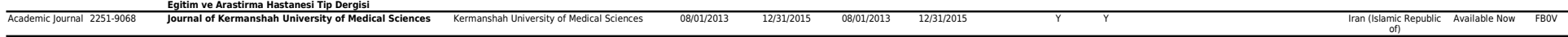

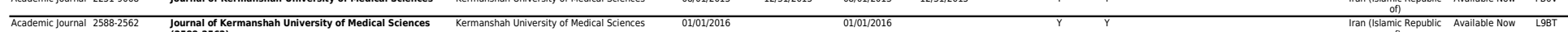

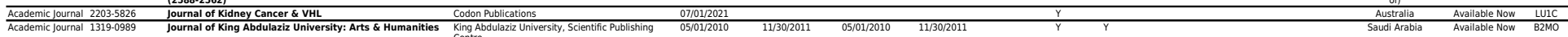

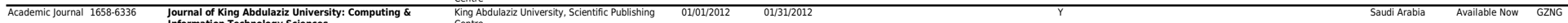

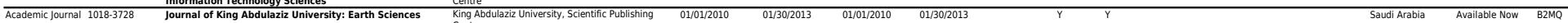

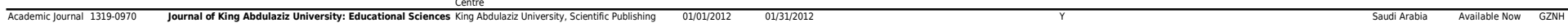

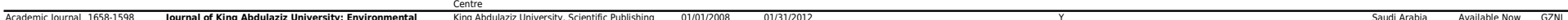

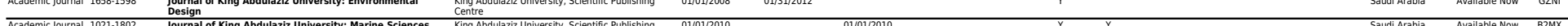
Cente Cente

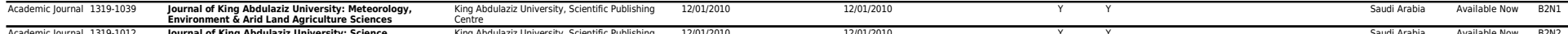

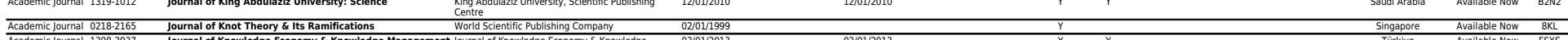

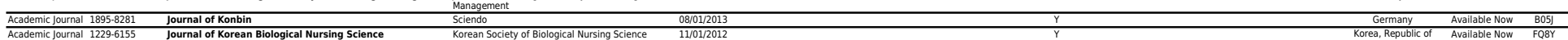

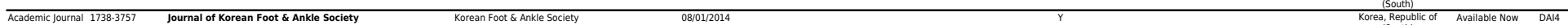

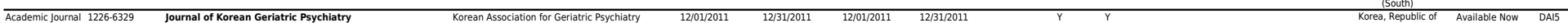

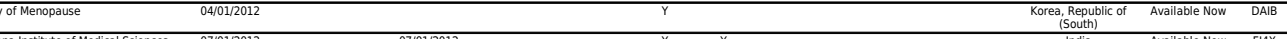

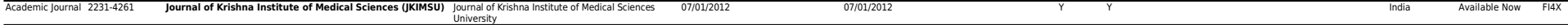

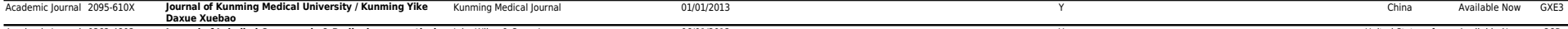

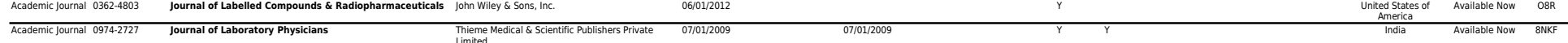

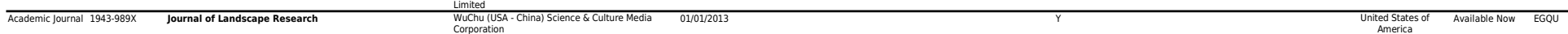

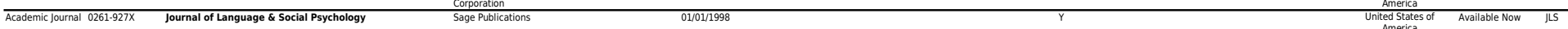




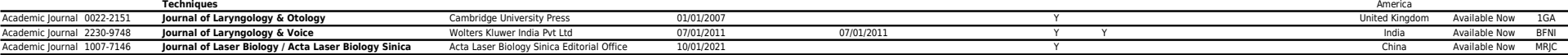

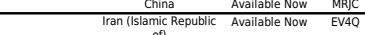

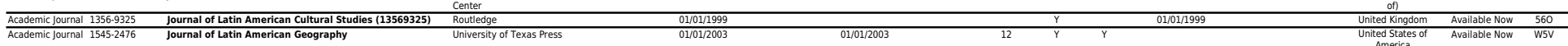

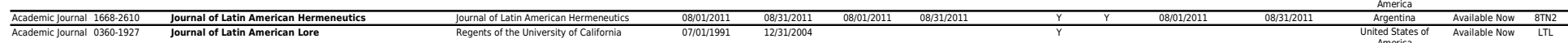

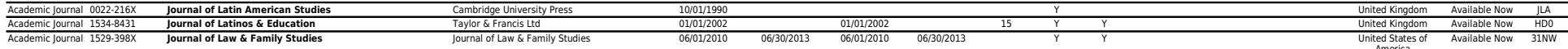

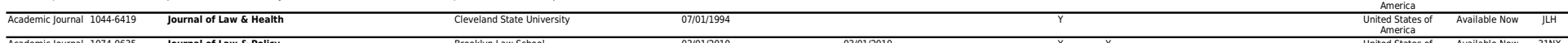

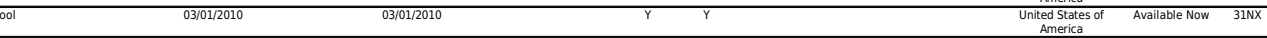

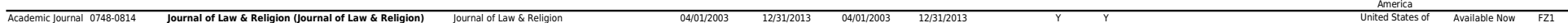

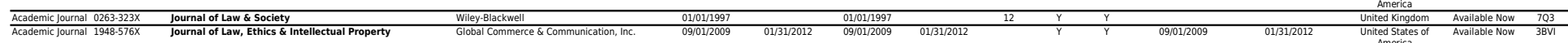

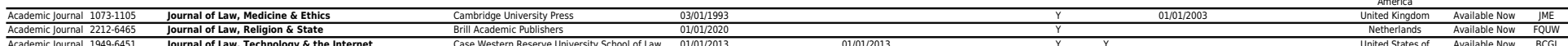

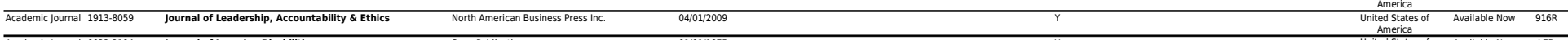

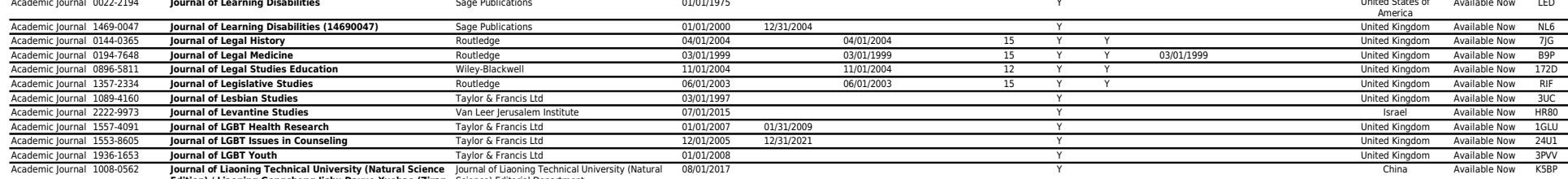

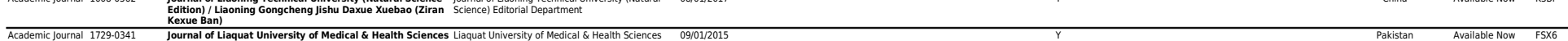

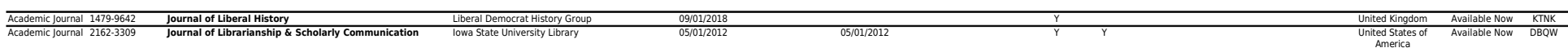

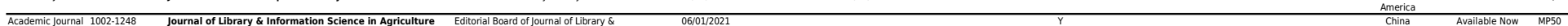

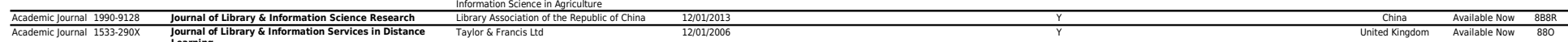

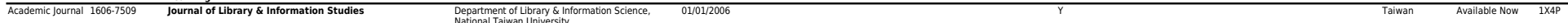

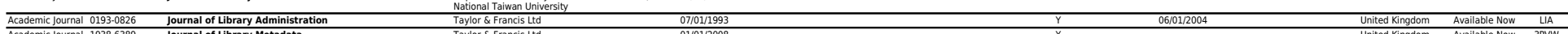

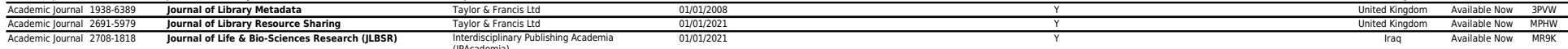

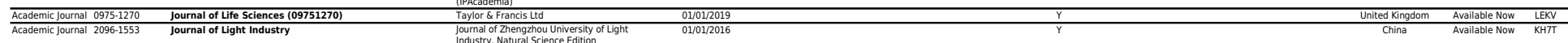

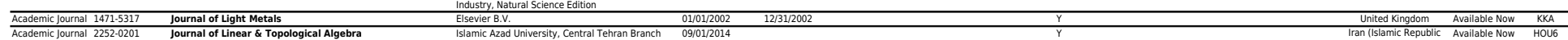

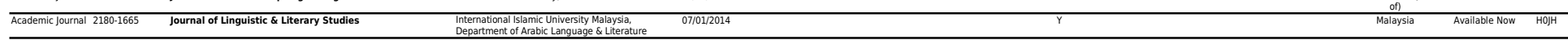

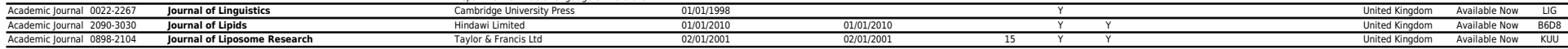

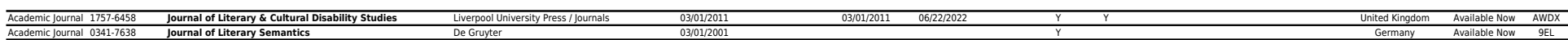

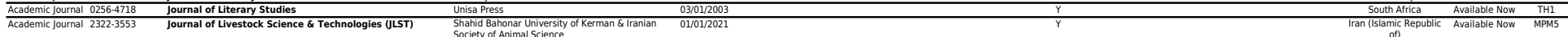

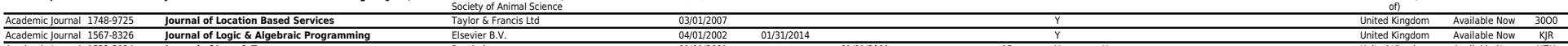

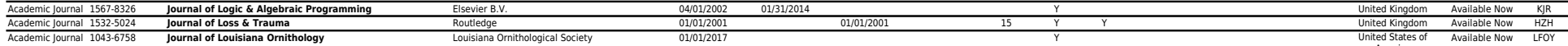

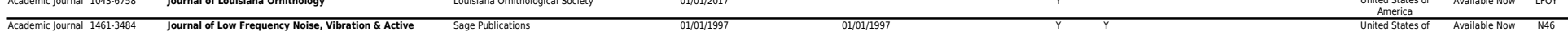

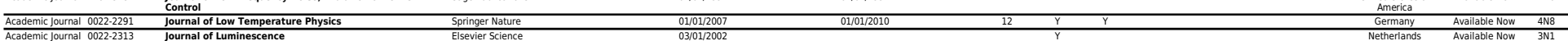

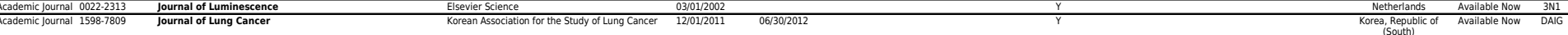

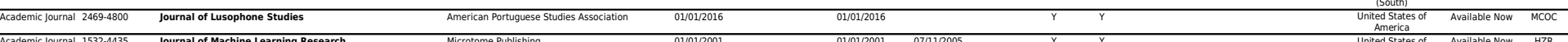
Academic Juural 1532-4435 Journal of Machine Learning Research $\quad$ Microtome Publishing 010112001

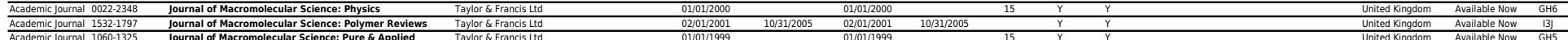

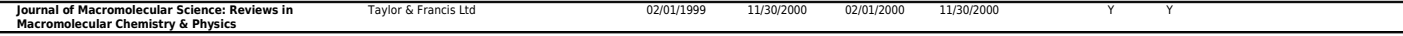

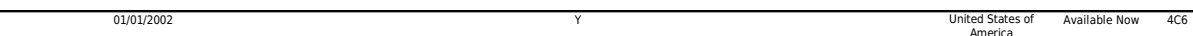

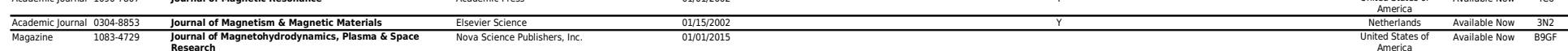

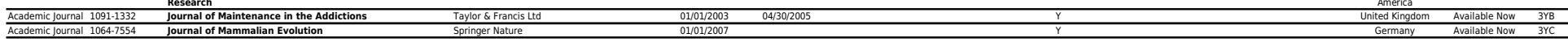




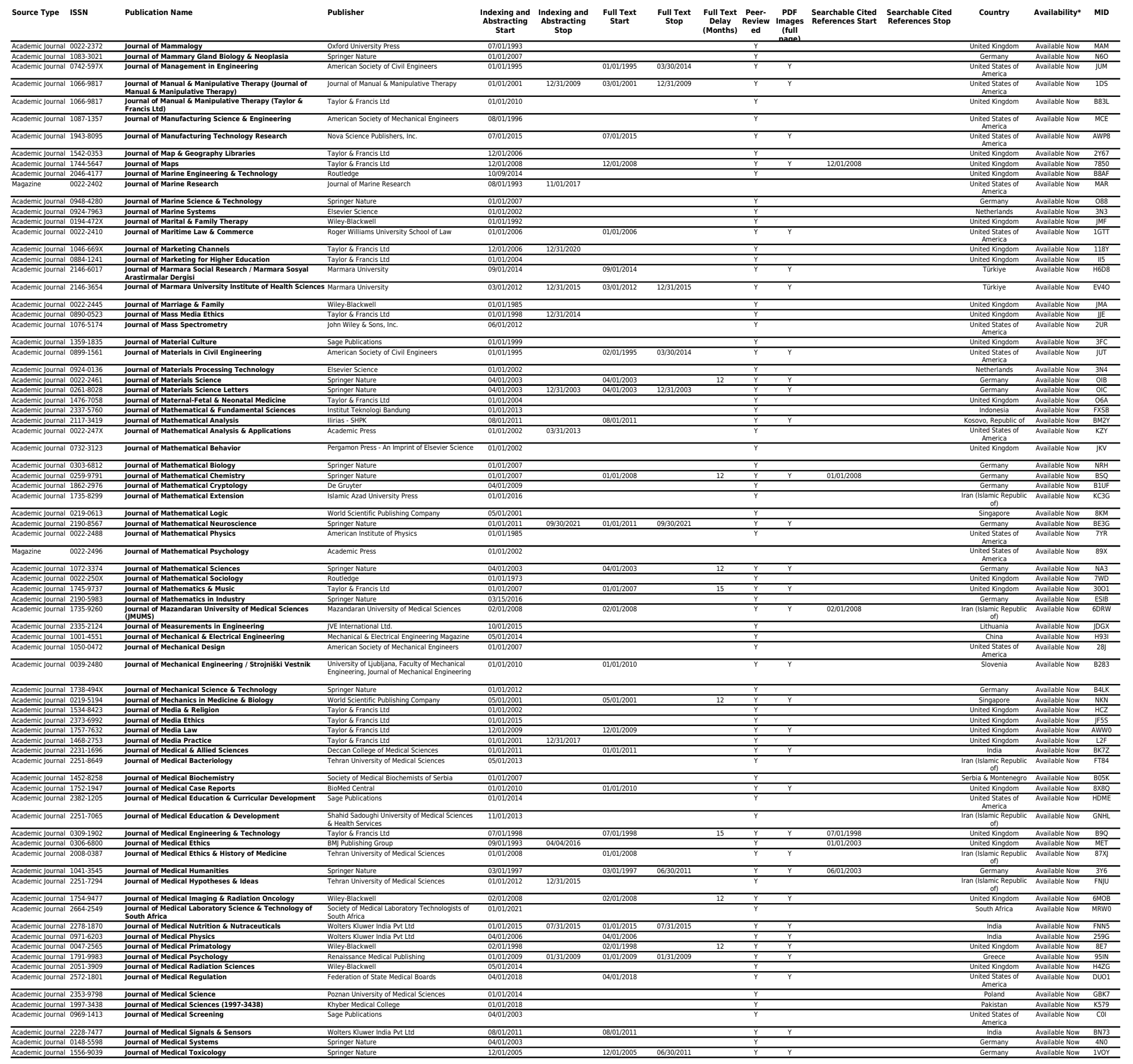




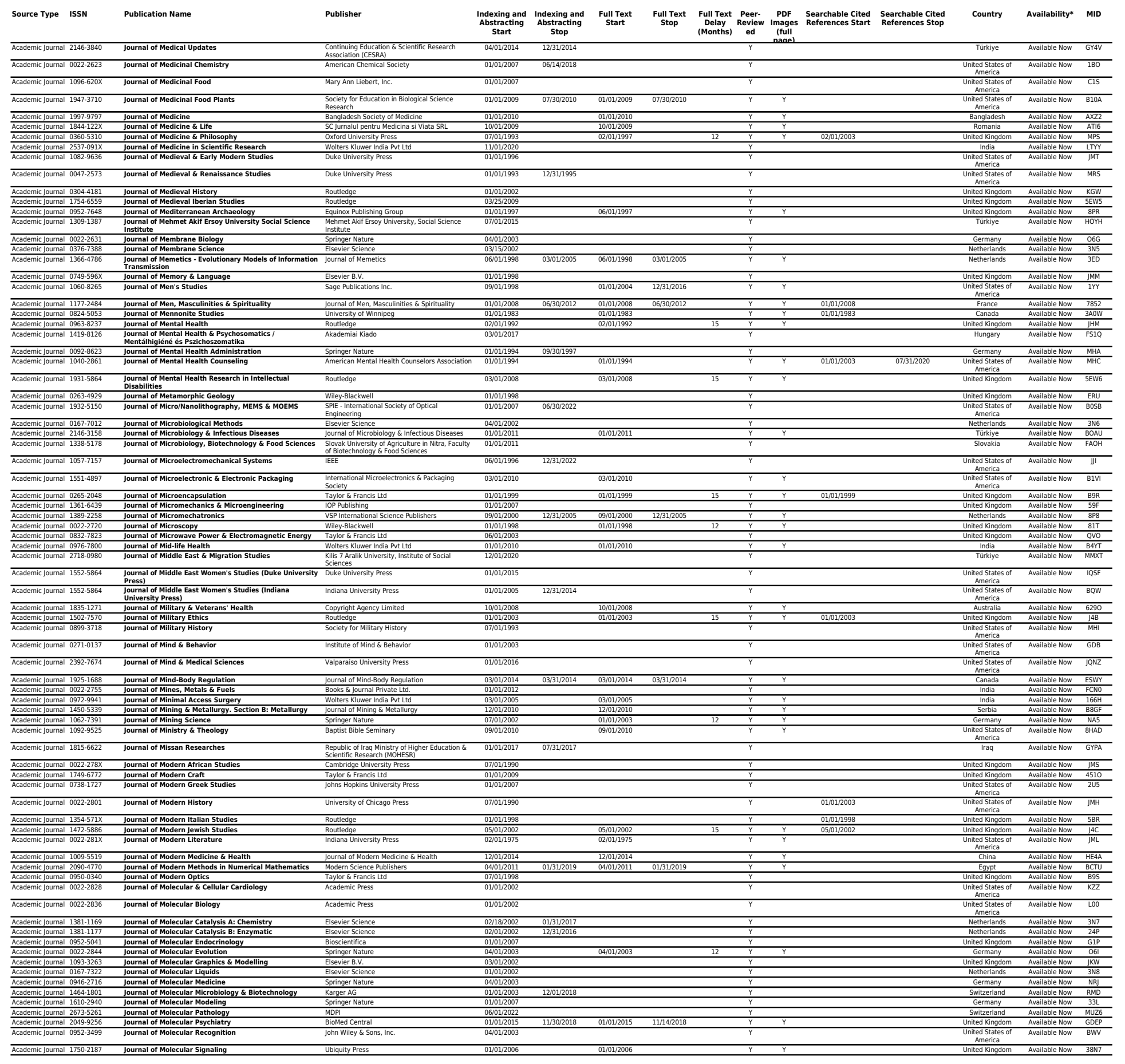




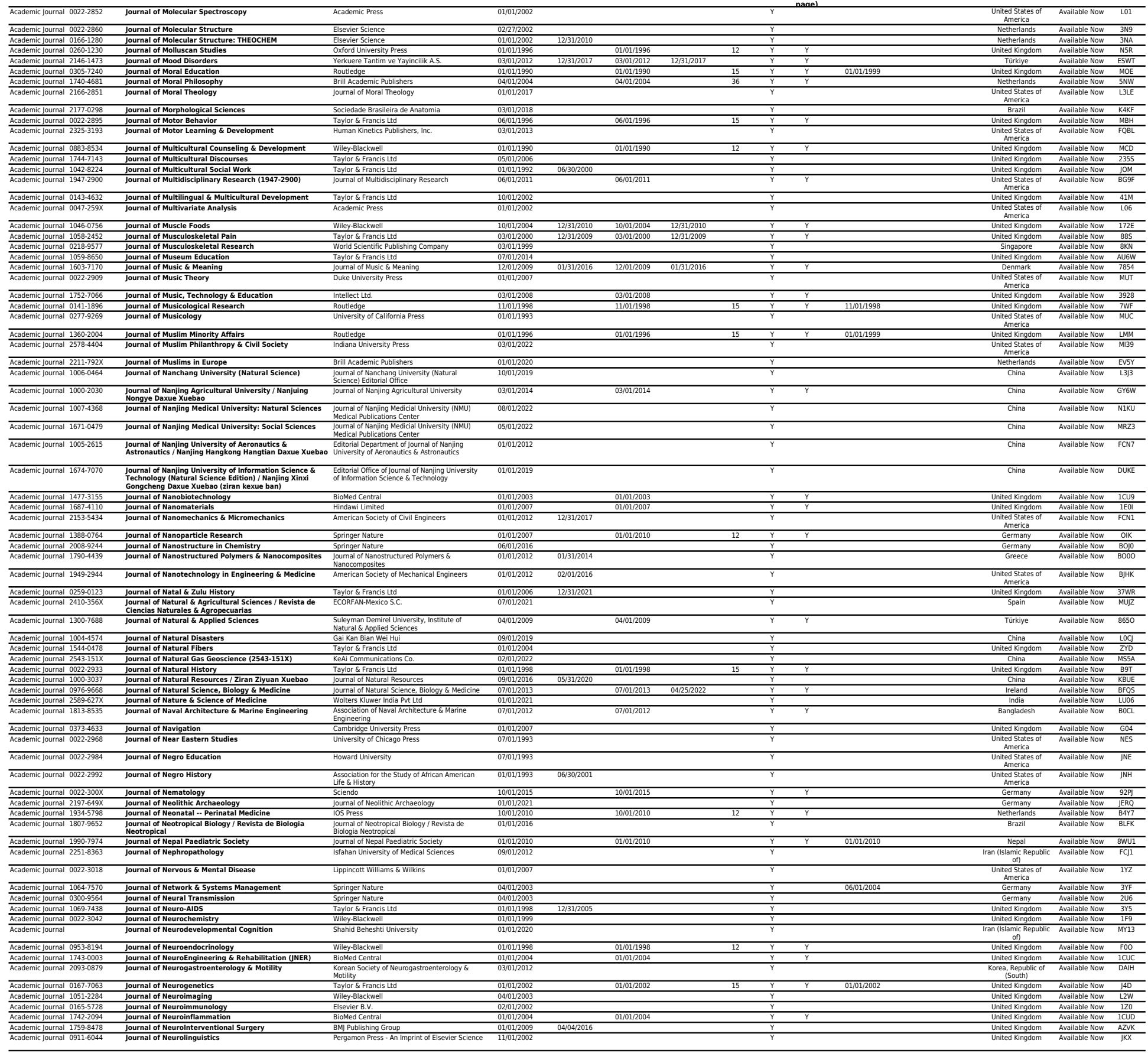




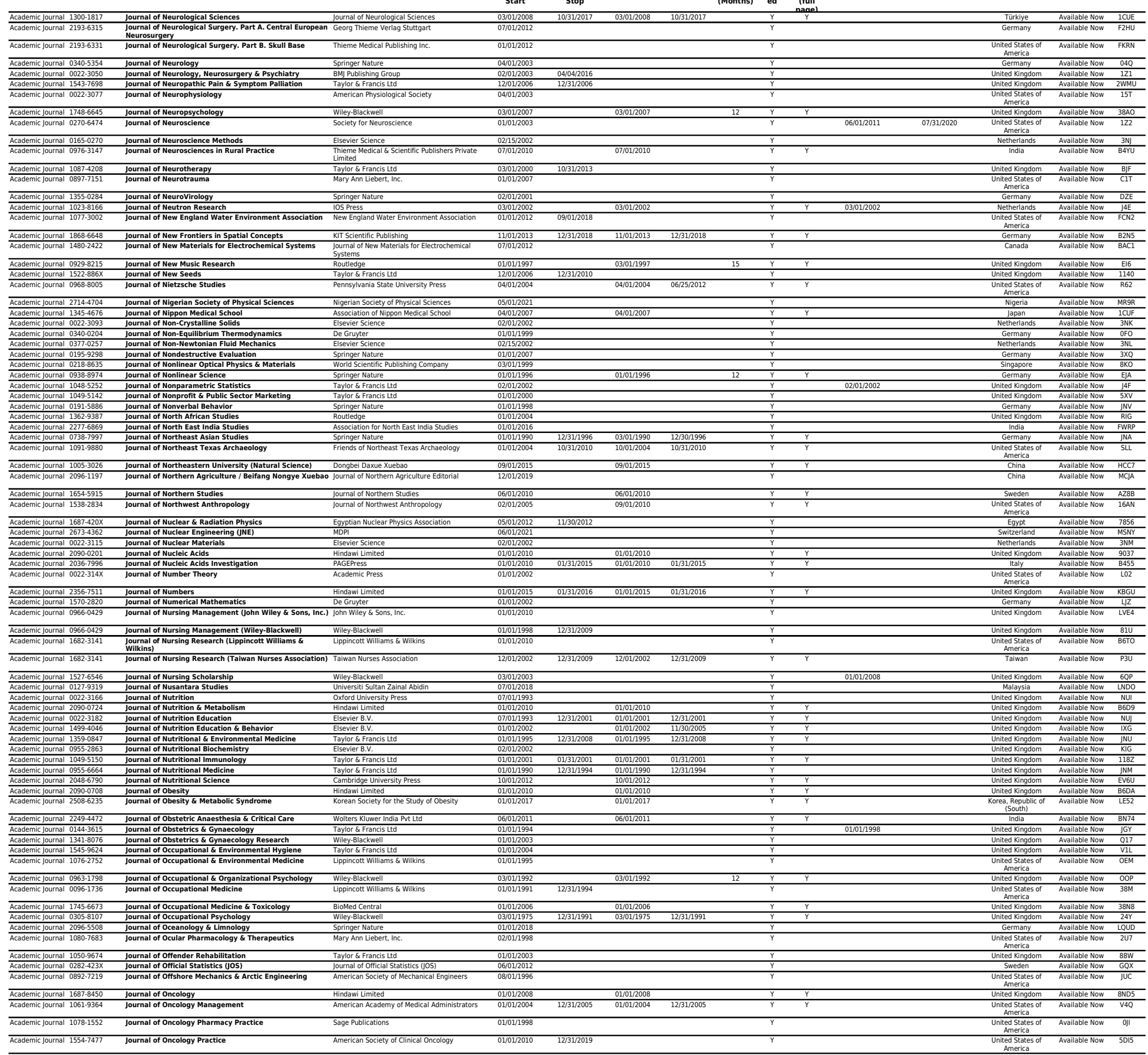




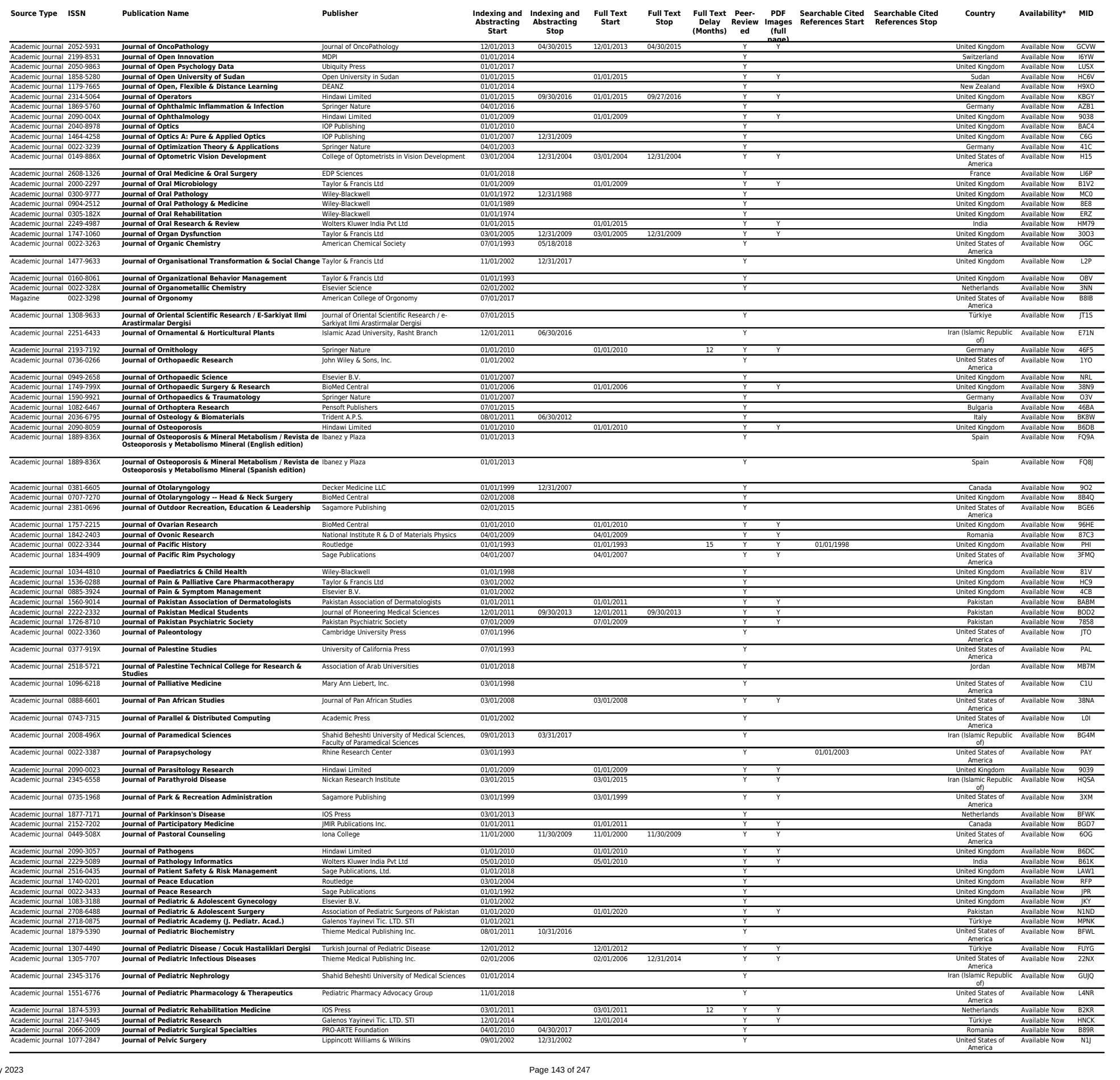




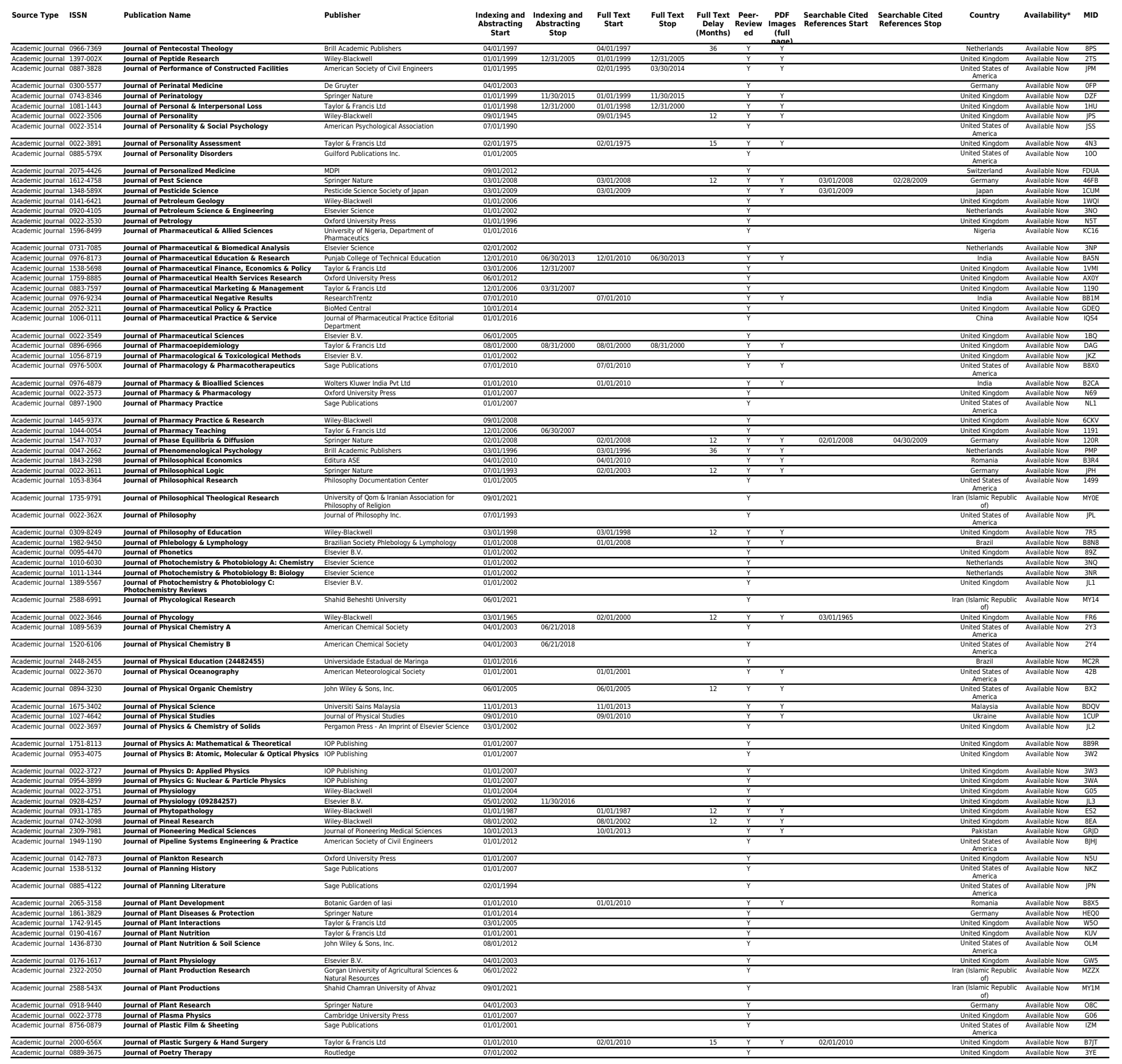




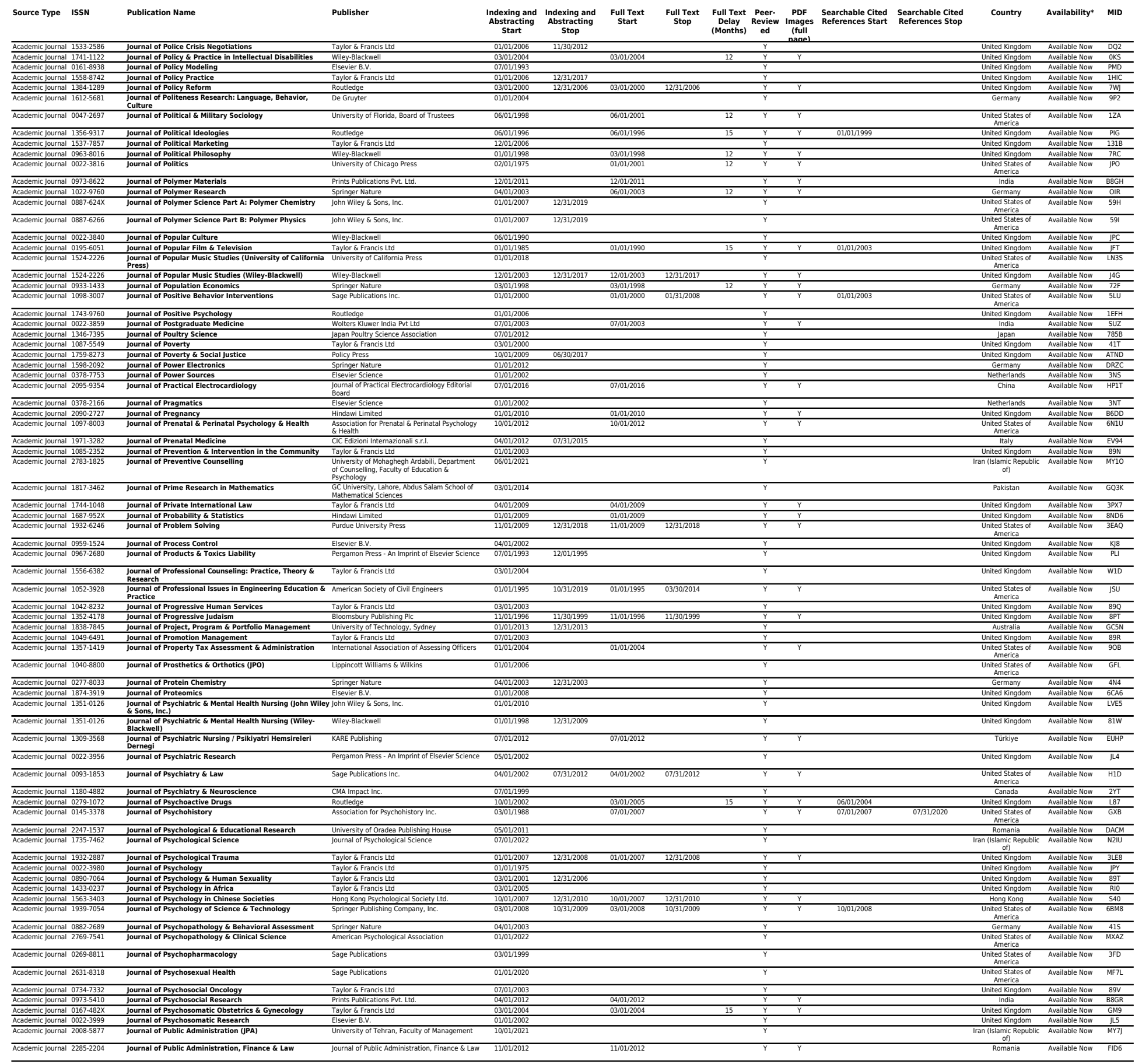




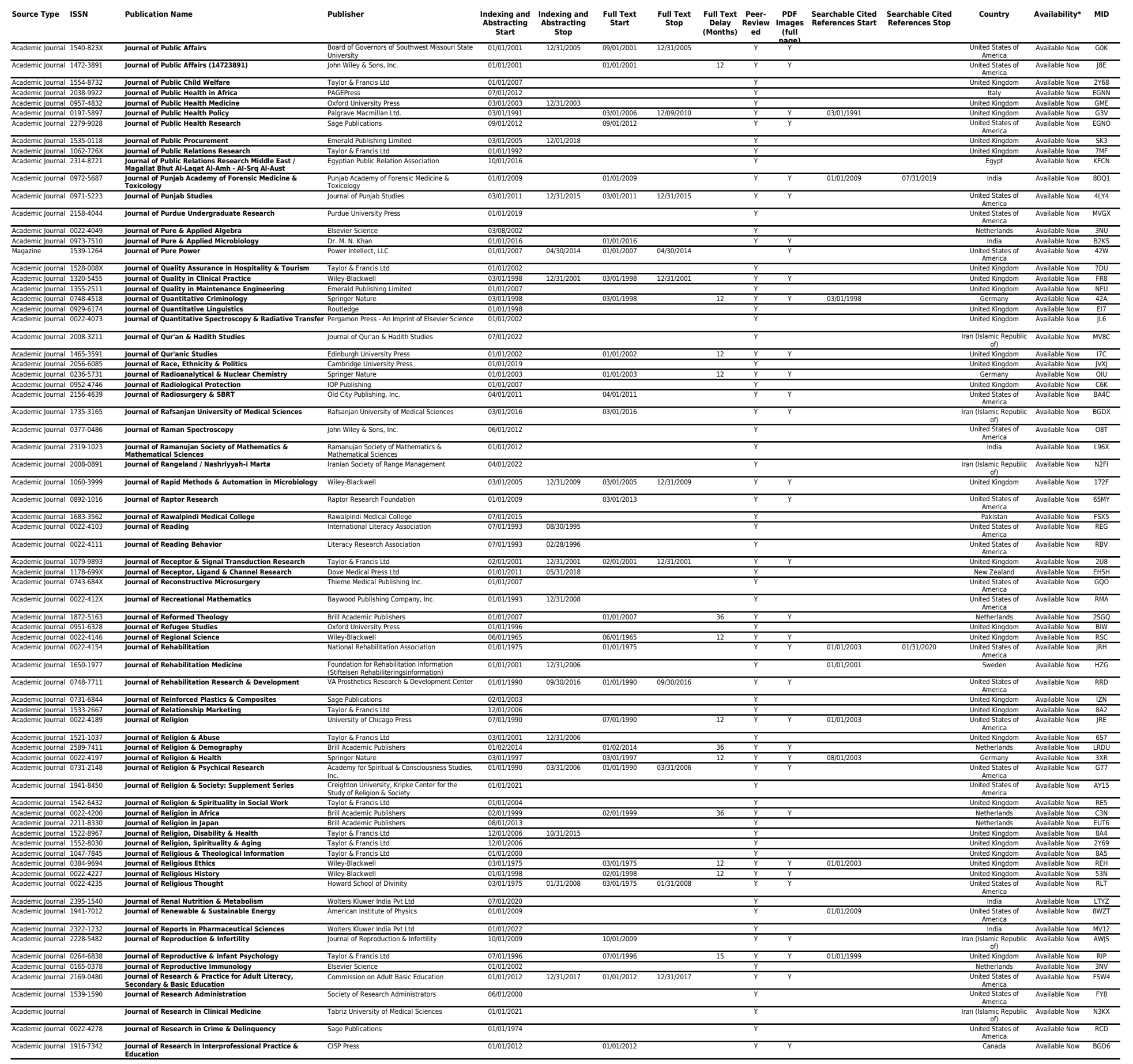




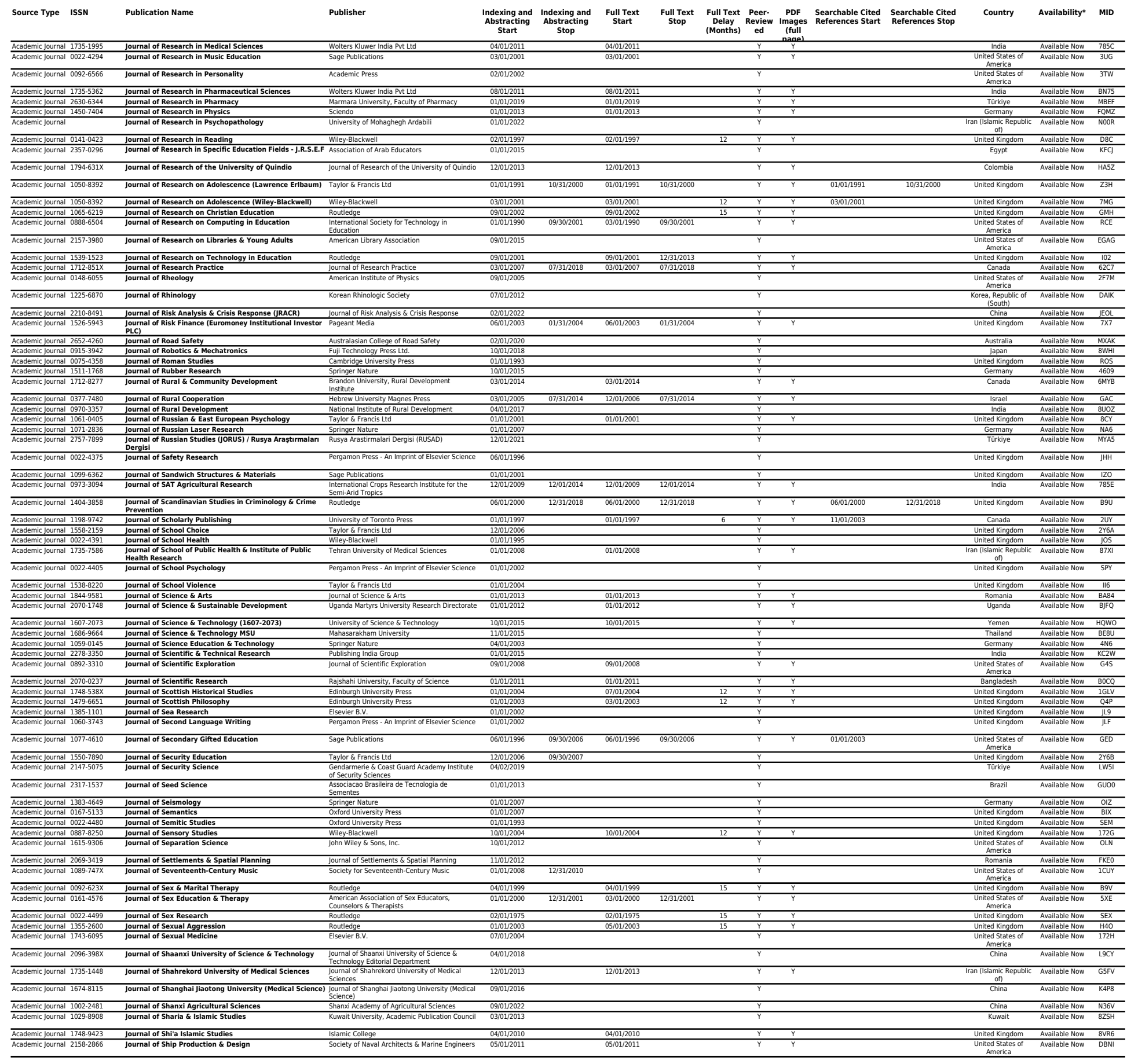




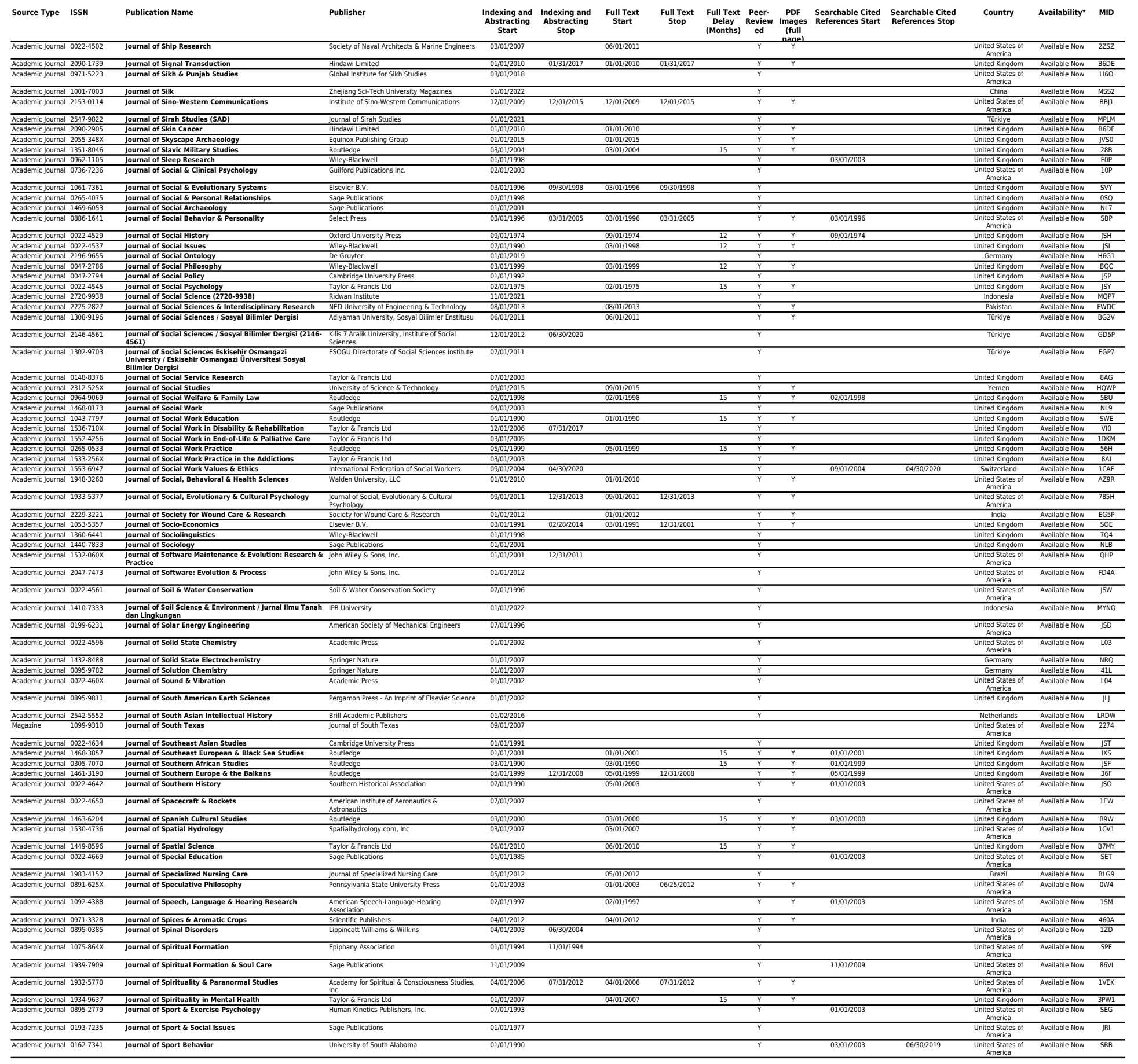




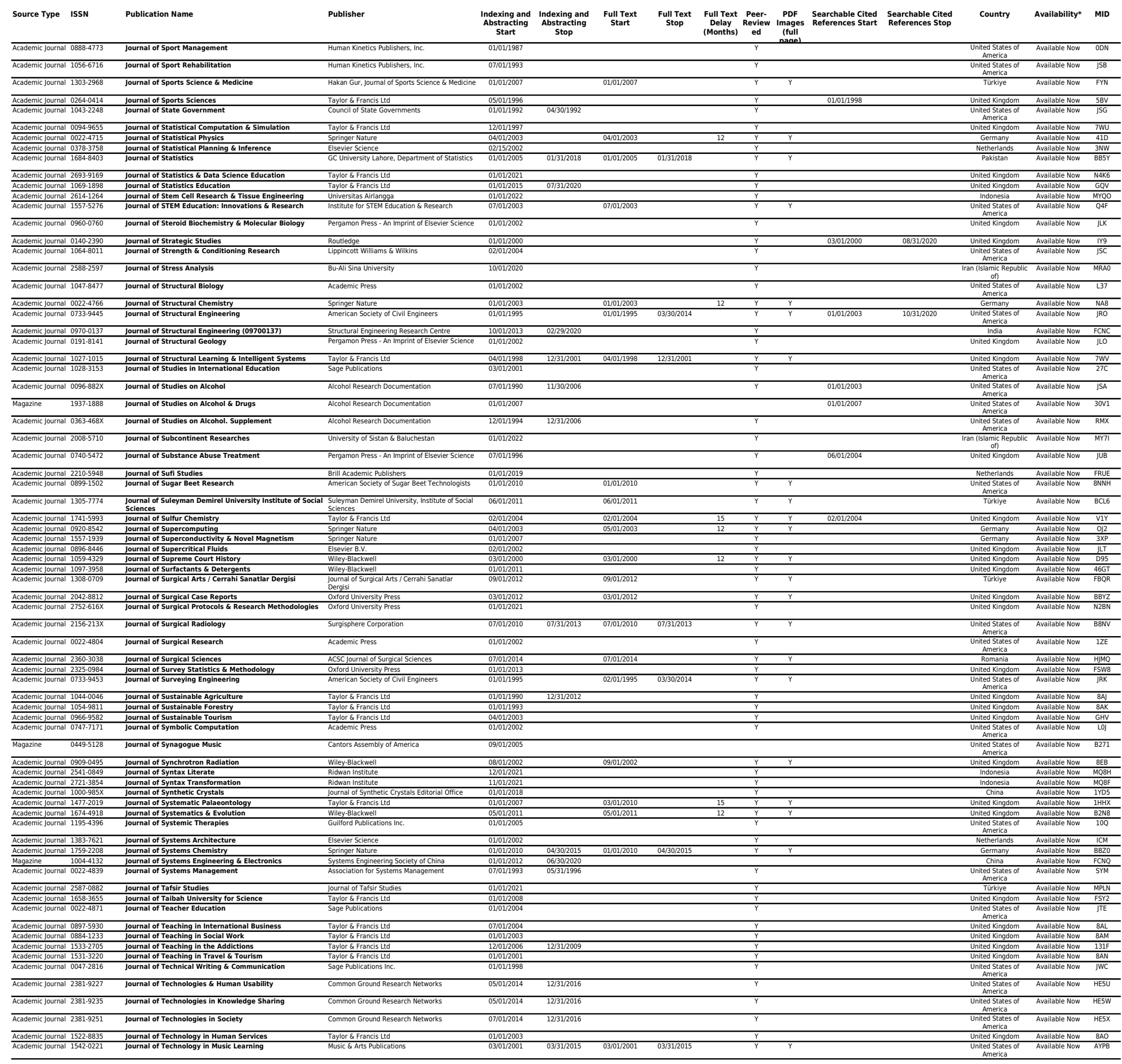




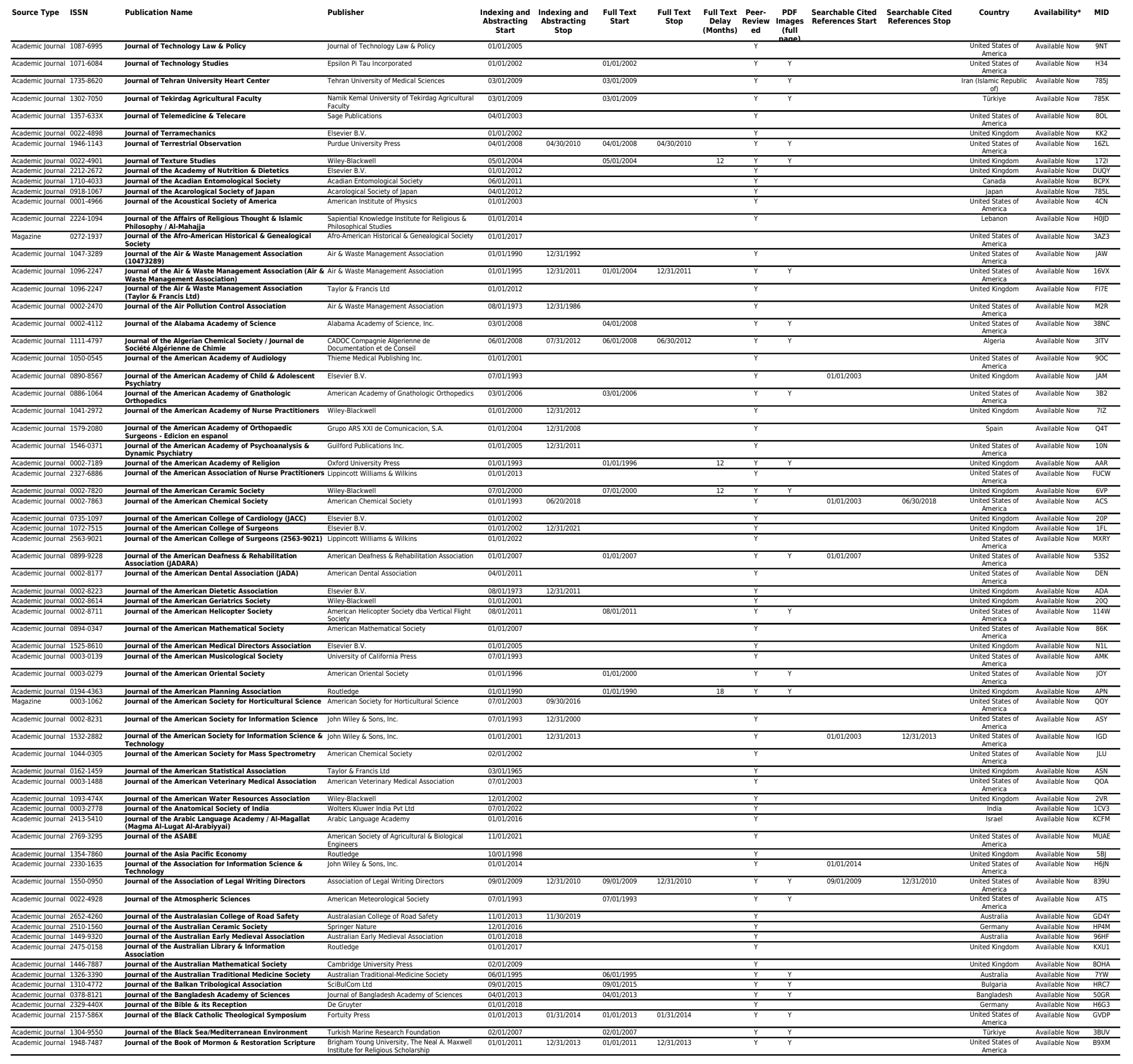




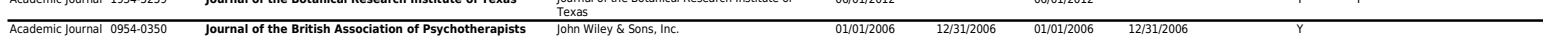

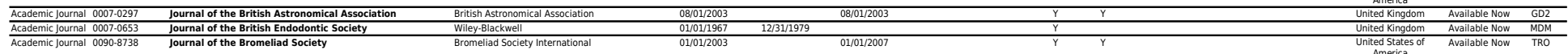

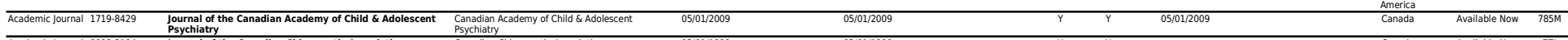

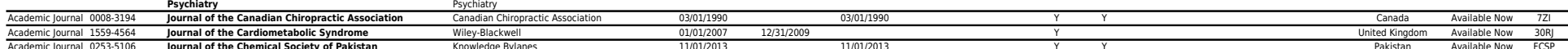

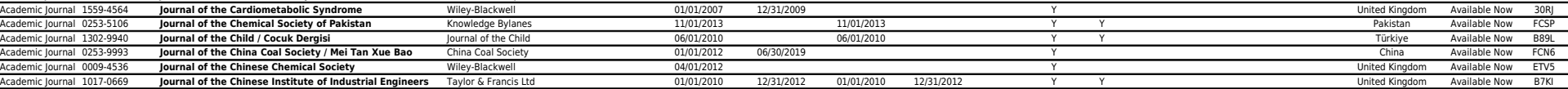

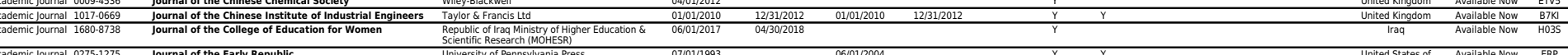

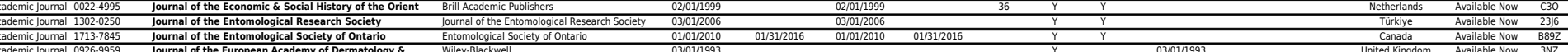

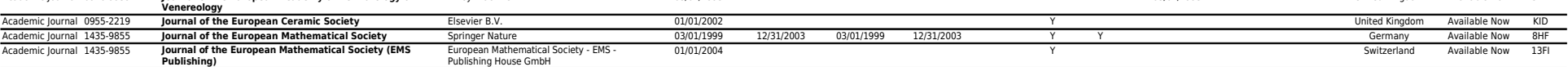

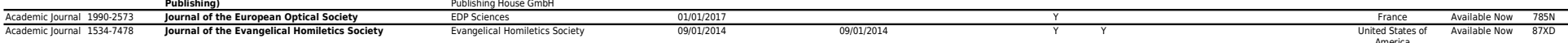

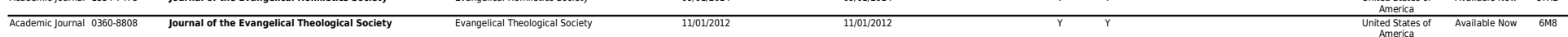

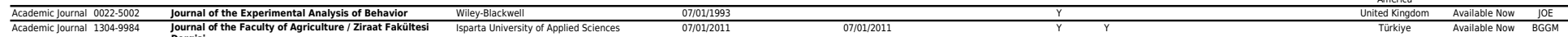

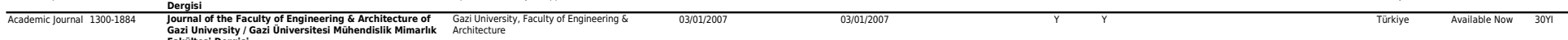

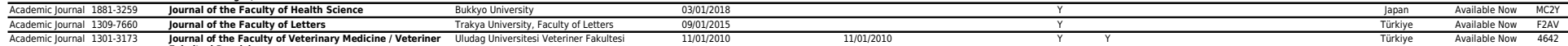

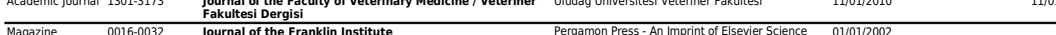
(a)

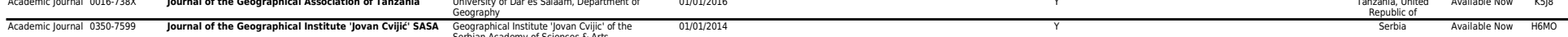

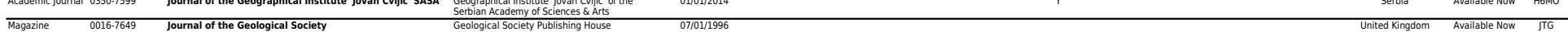

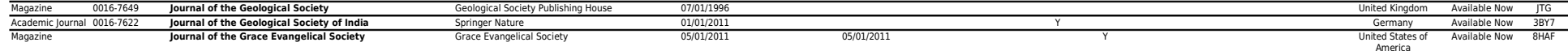

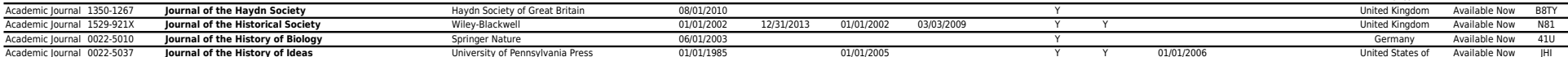

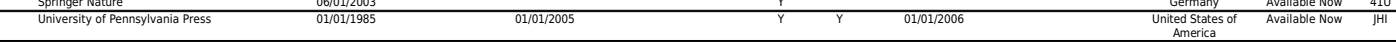

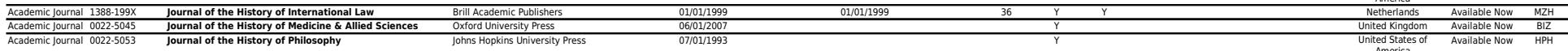

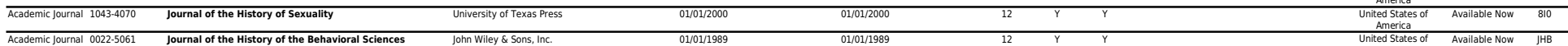

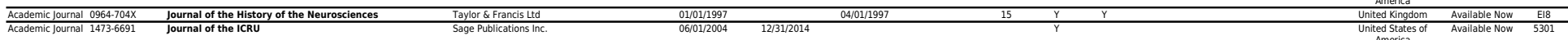

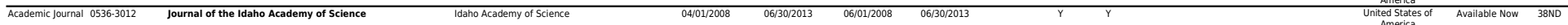

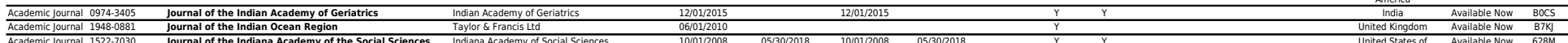

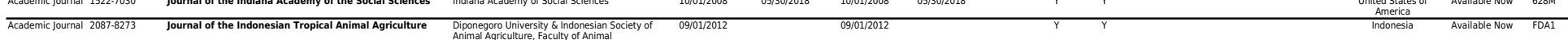

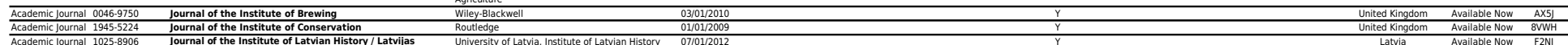

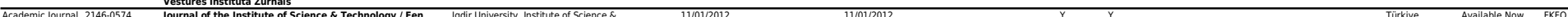

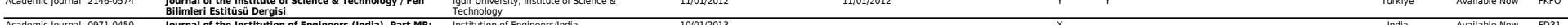
Macadm Joun

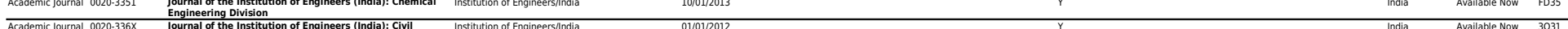

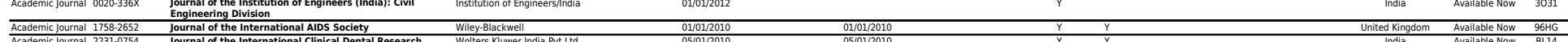

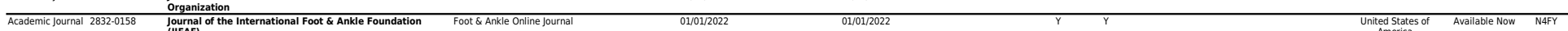

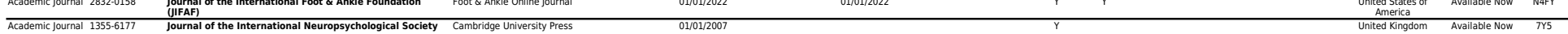

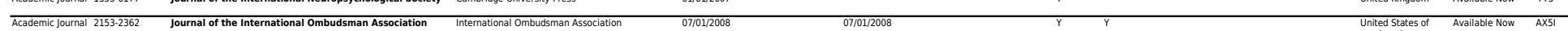

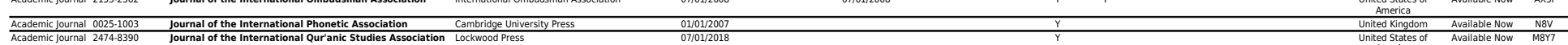

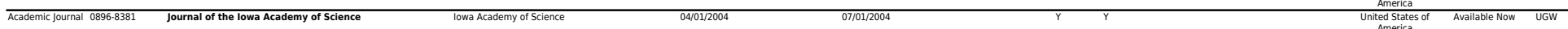

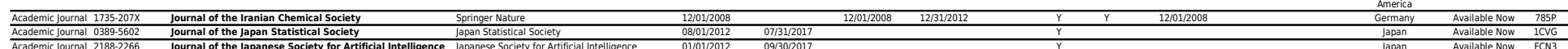

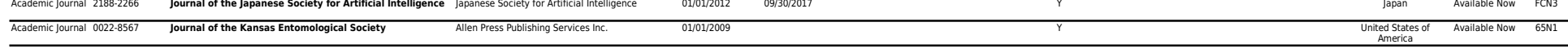




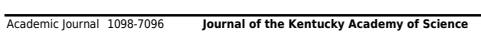

(20)

(20)

kentuch academy orscence

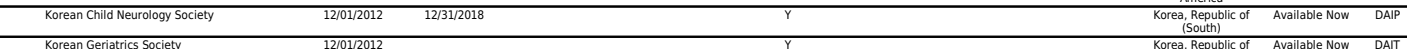

The

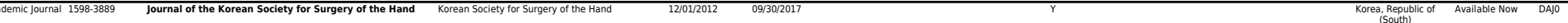

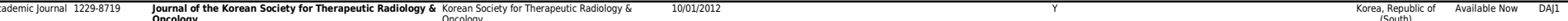

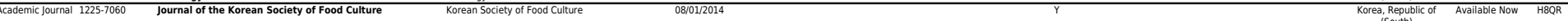

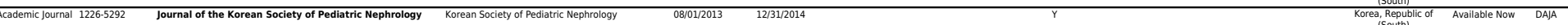

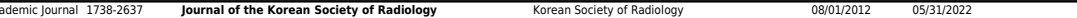

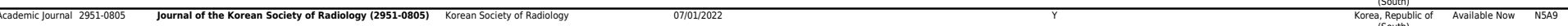

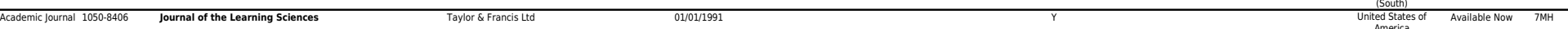

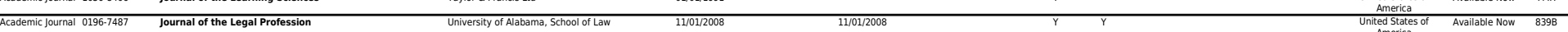

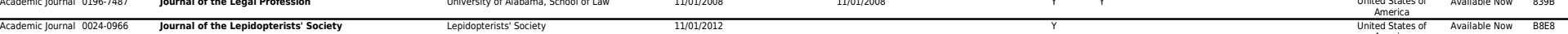

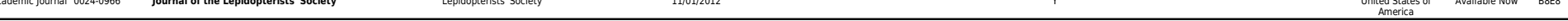

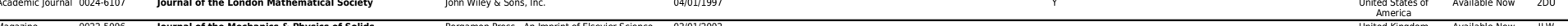
Tagazine

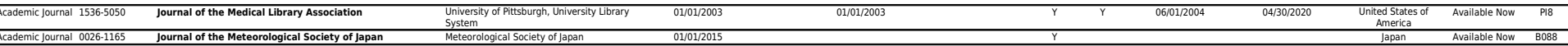

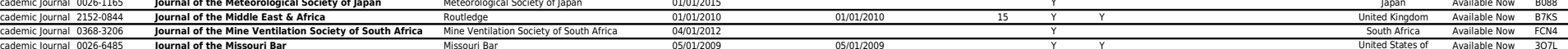
America

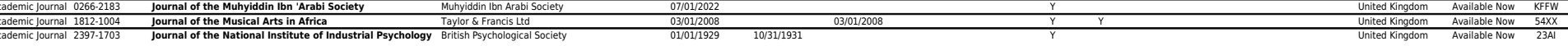

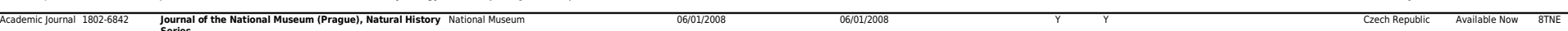

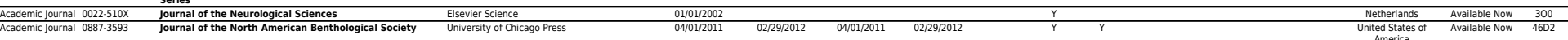

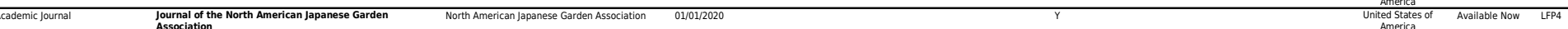

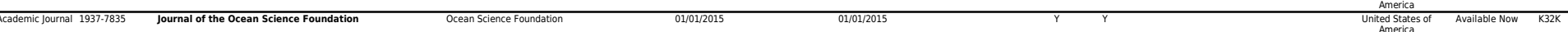

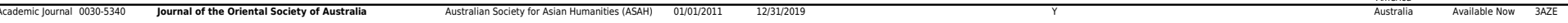

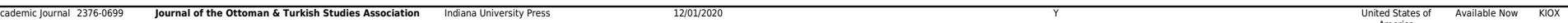

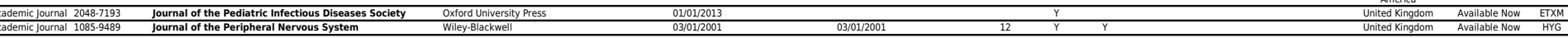

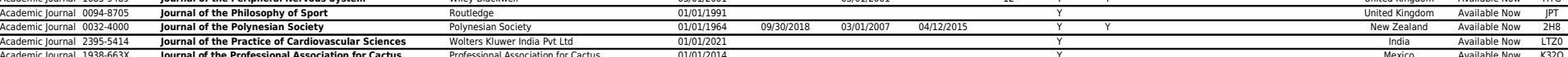

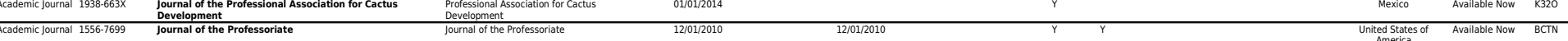

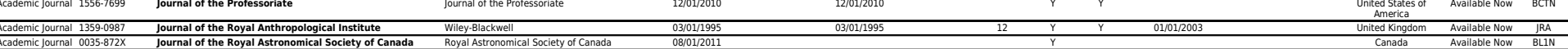

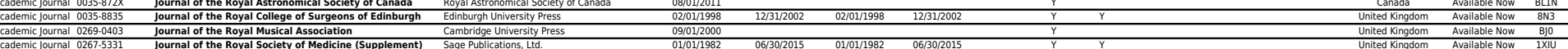

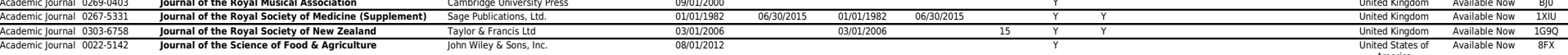

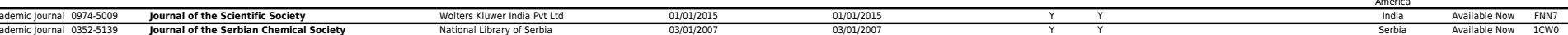

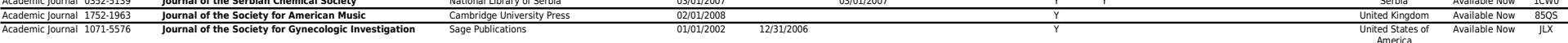

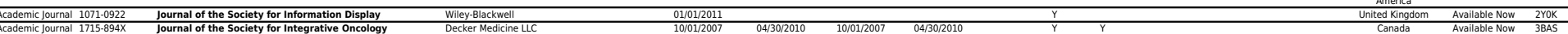

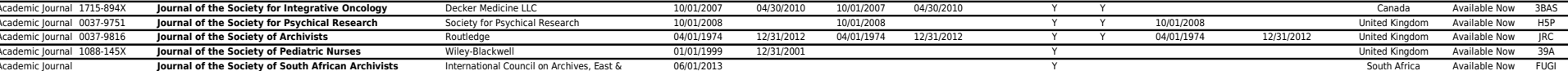

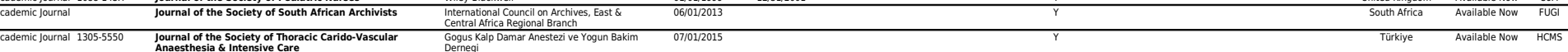

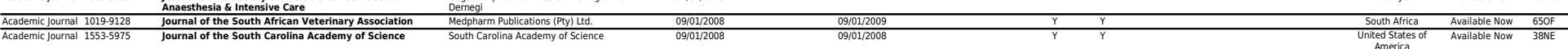

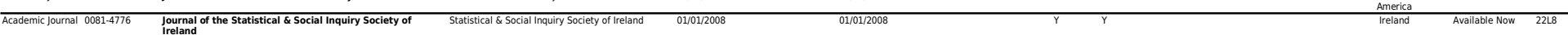

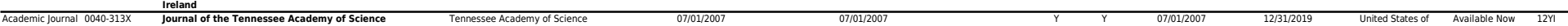

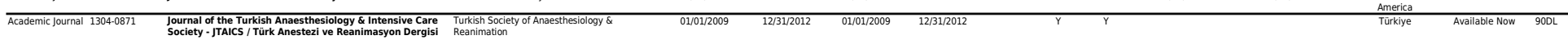

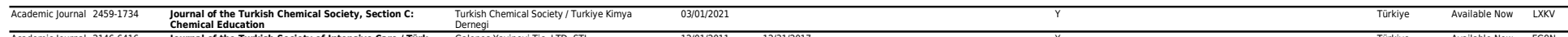

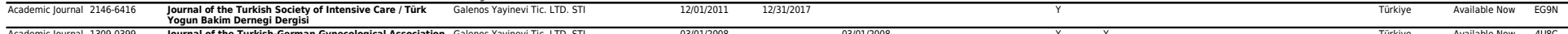
Academic Journal 1309.0399 Journal of the Turkis

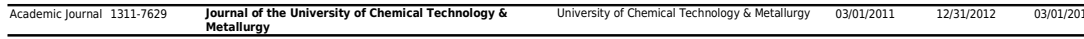

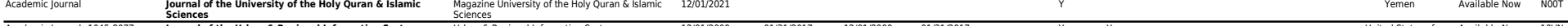

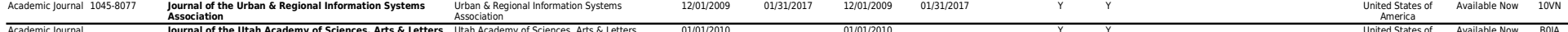

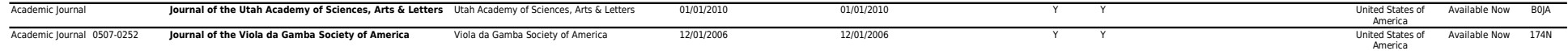




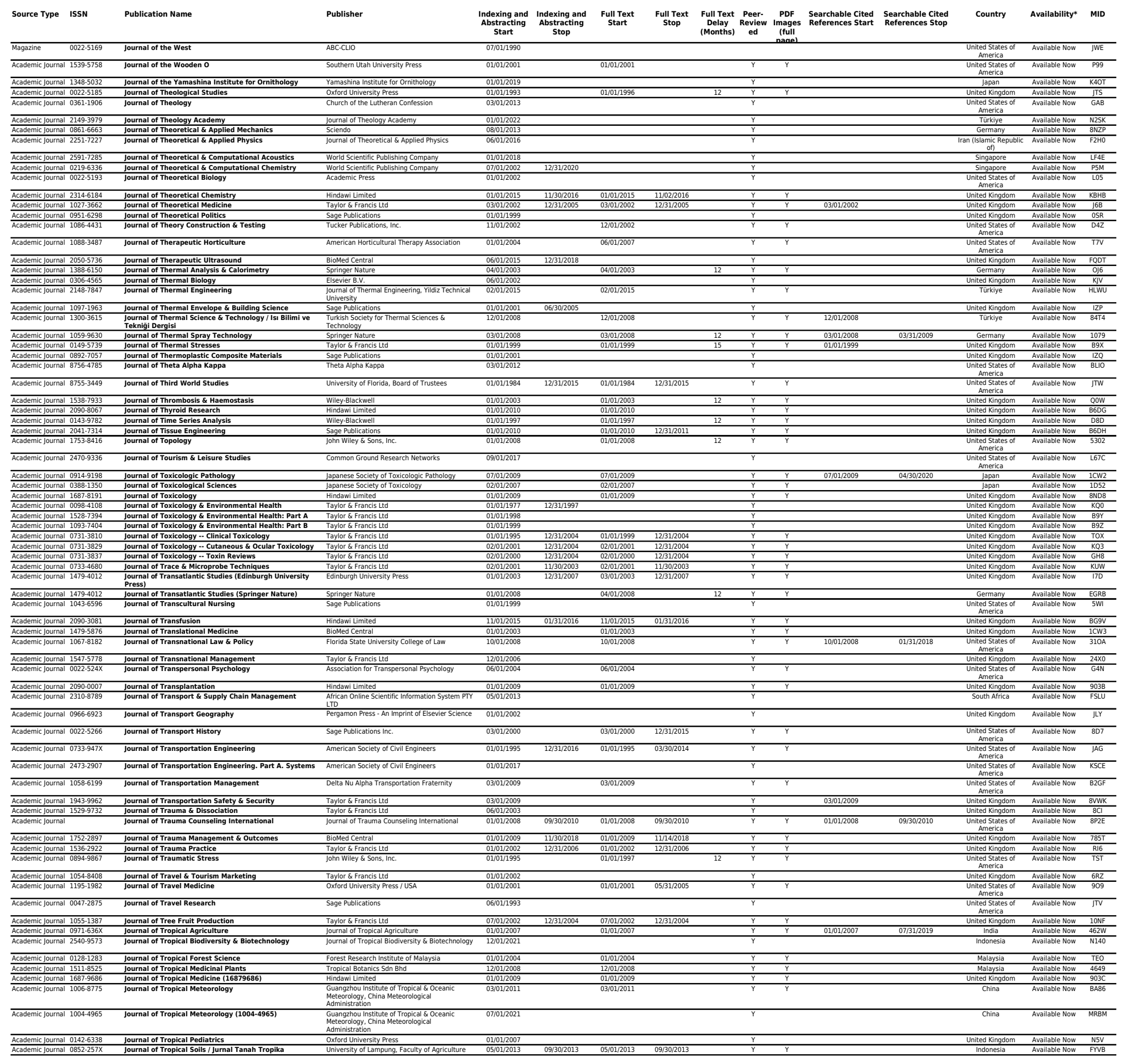




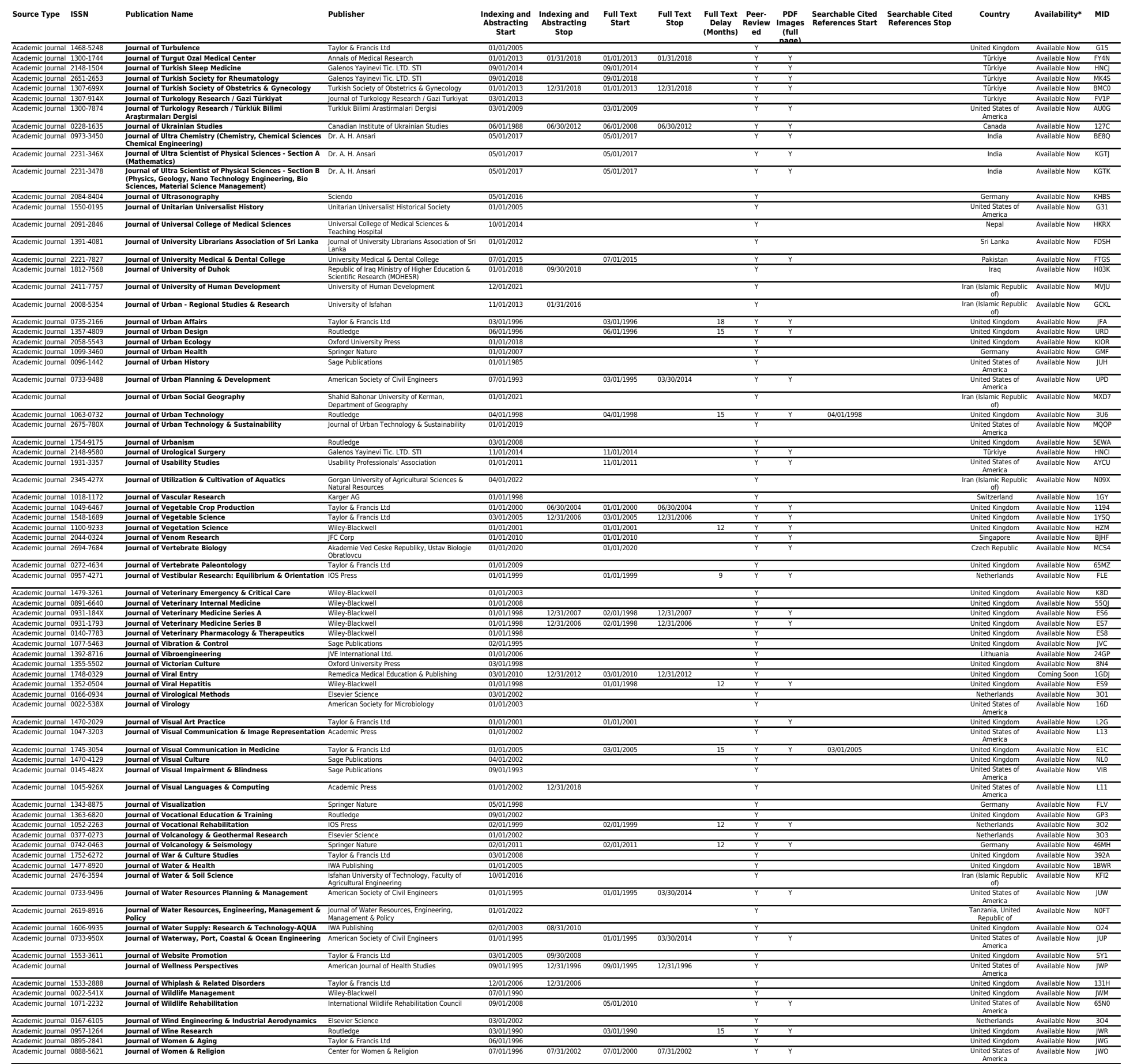




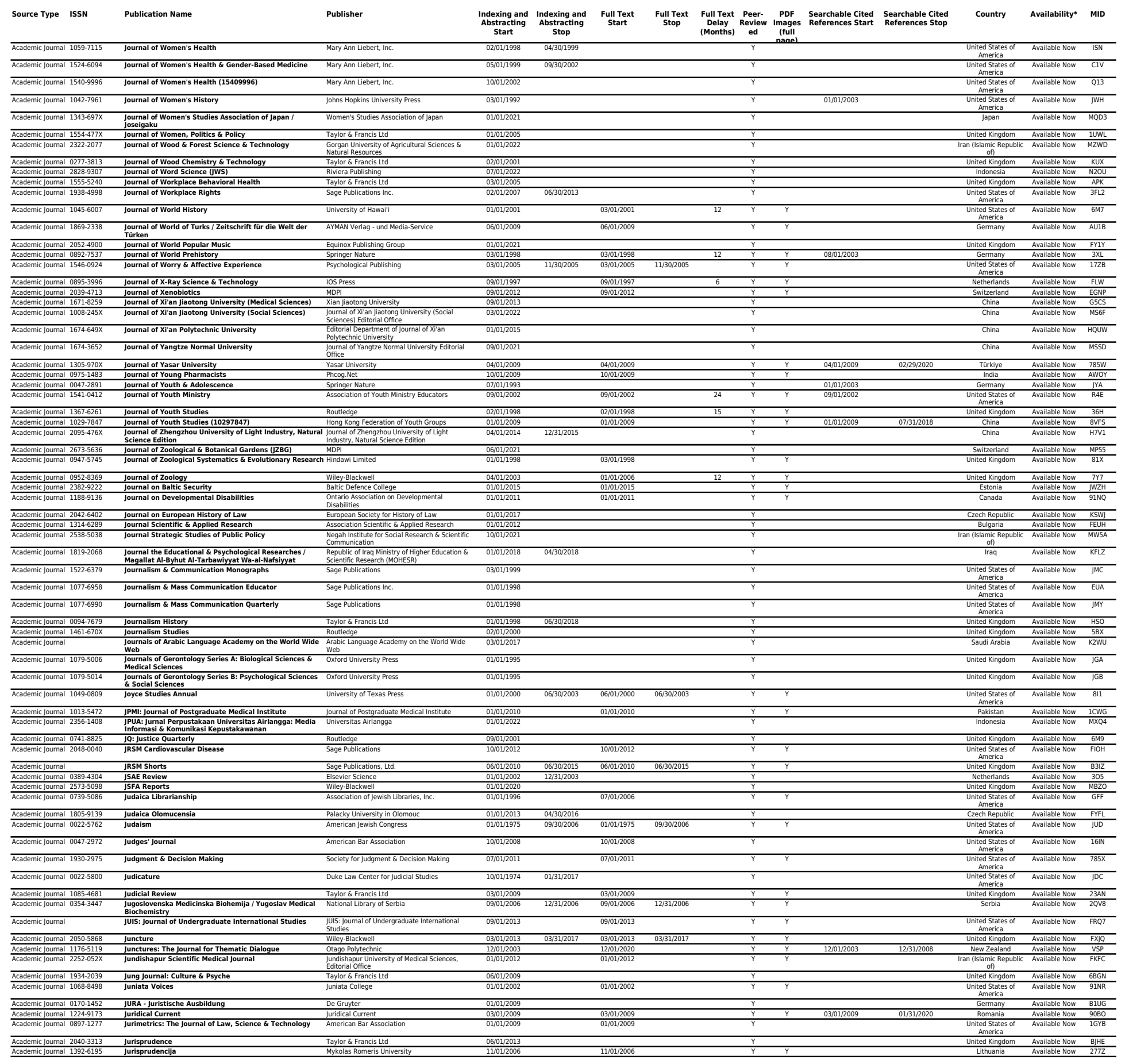




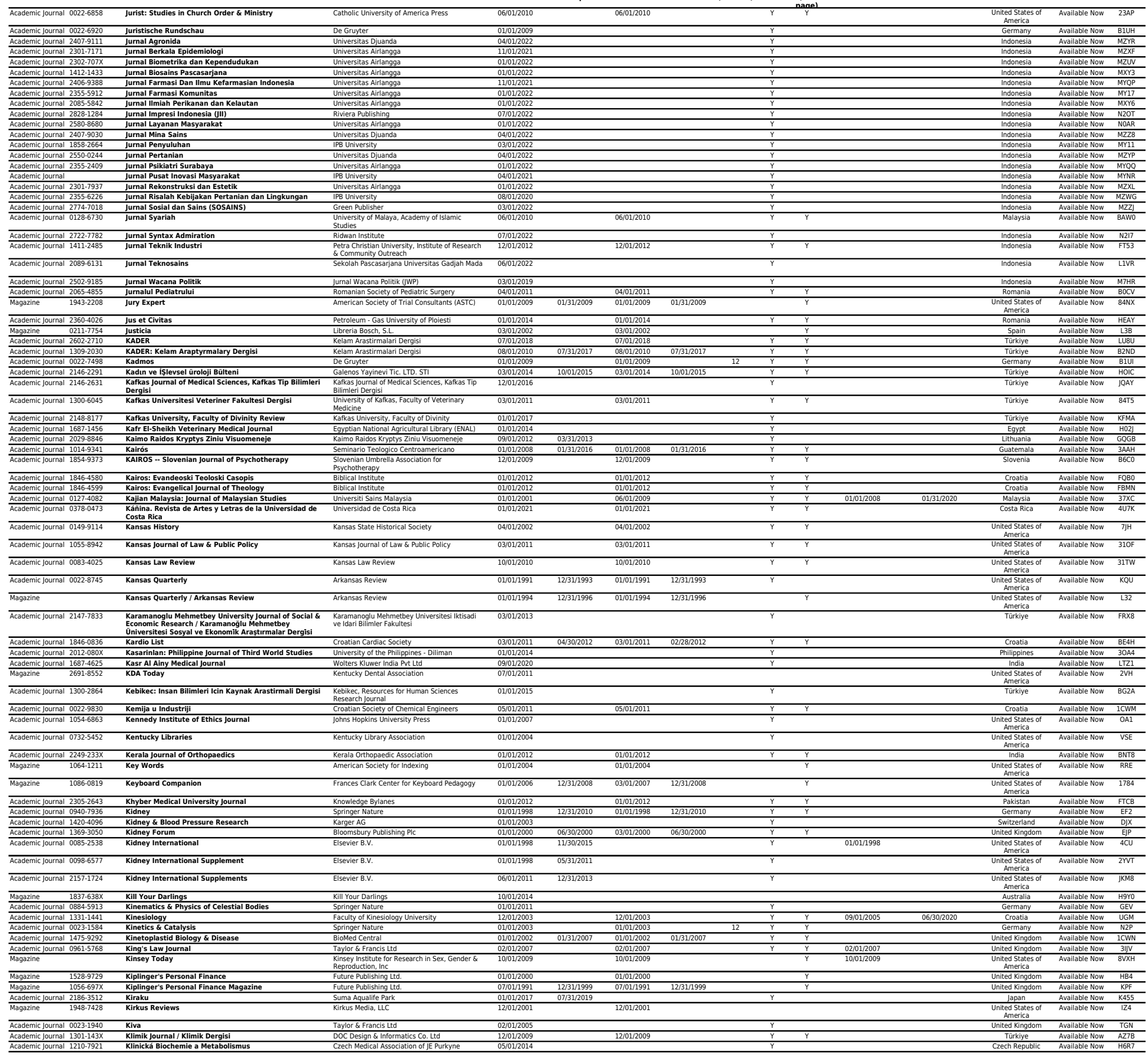




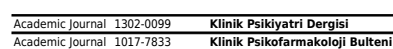

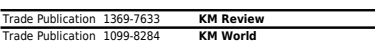

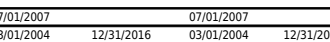

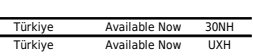

\begin{tabular}{ll}
\hline Academic J Jurnal 0968-0160 & Knee \\
\hline Academic J Jurnal 2234-0726 & Knee Surgery \& Related Research
\end{tabular} Knowledge EDMCC
Elsevier B.V.

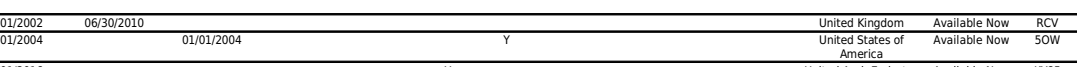

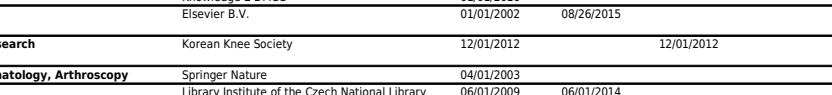

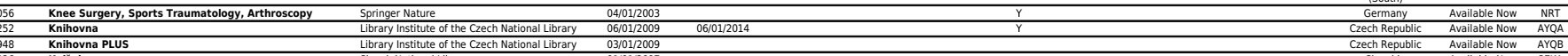

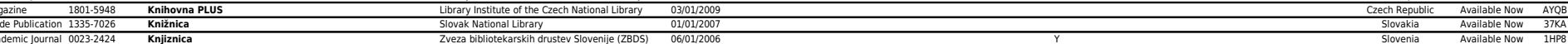

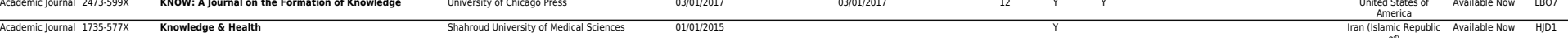

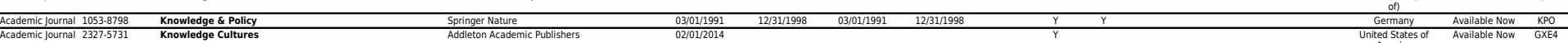

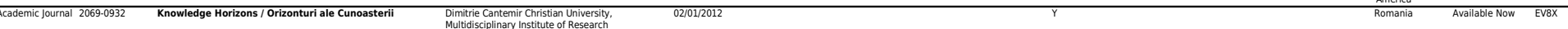

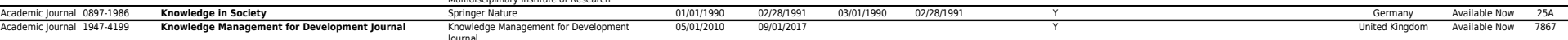

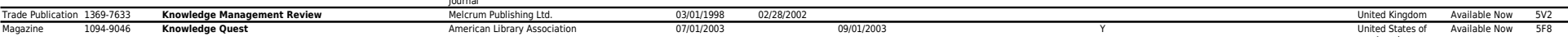

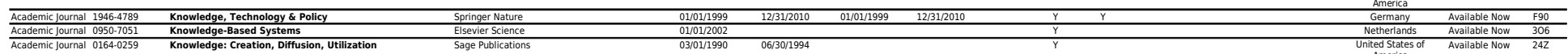

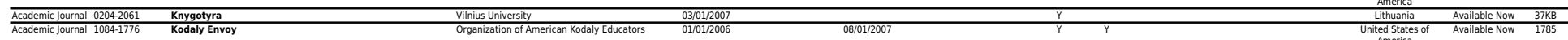

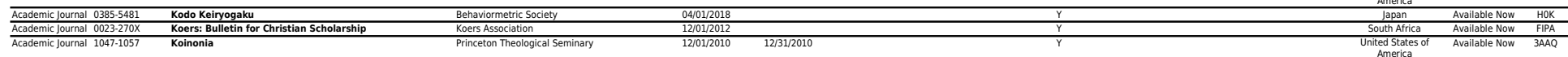

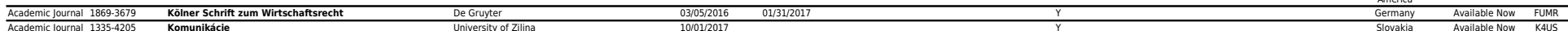

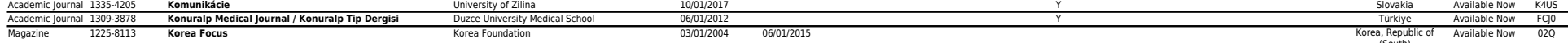

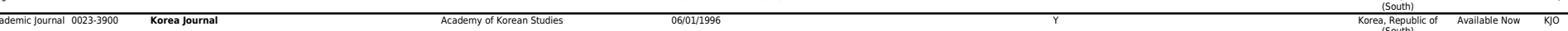

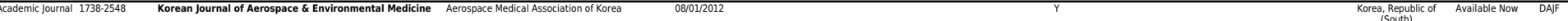

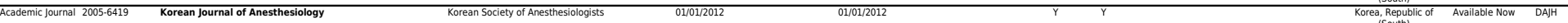

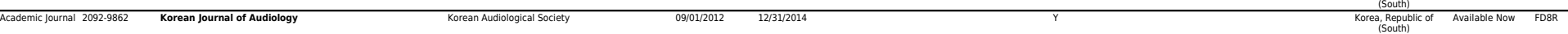

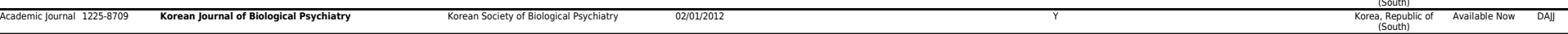

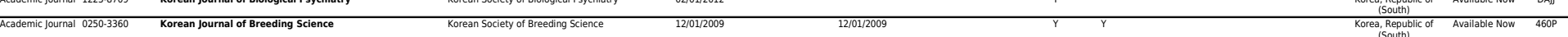

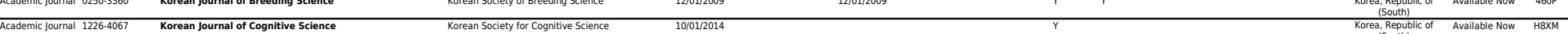

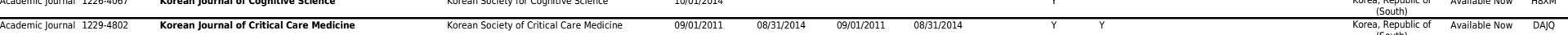

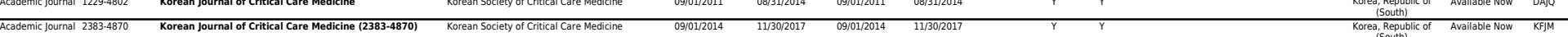

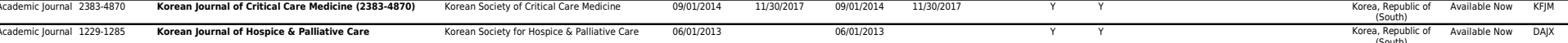

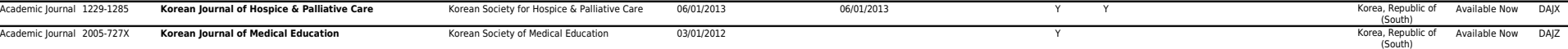

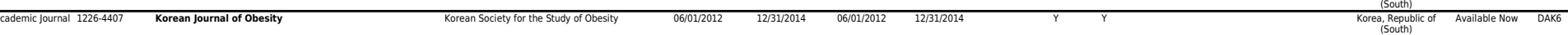

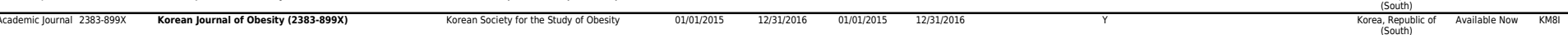

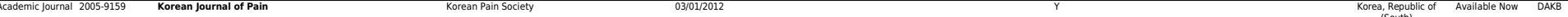

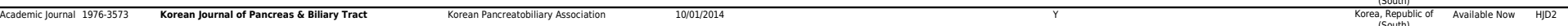

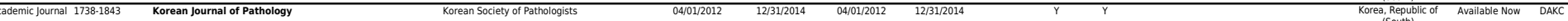

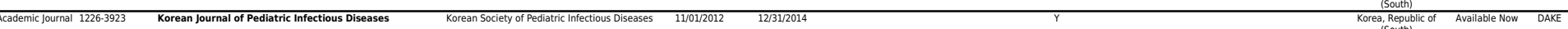

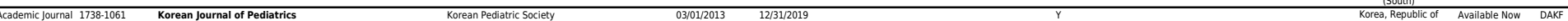

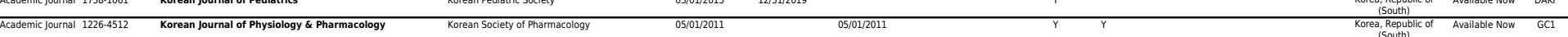

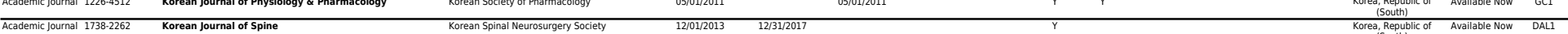

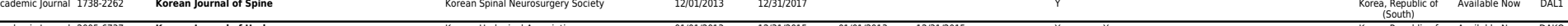

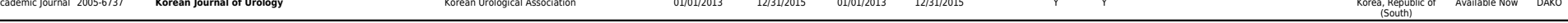

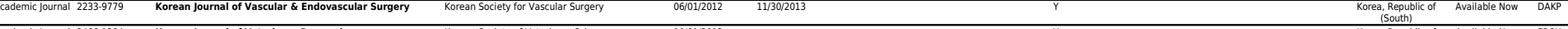

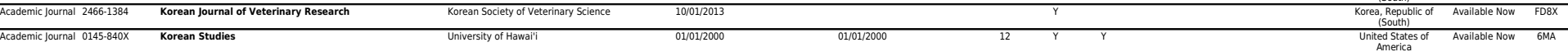

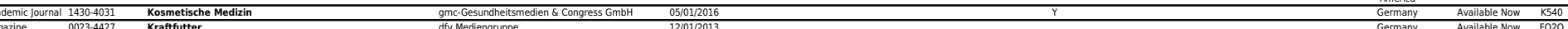

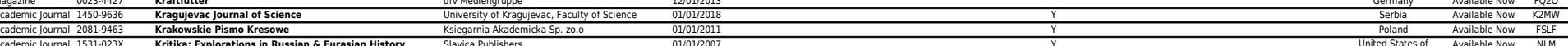

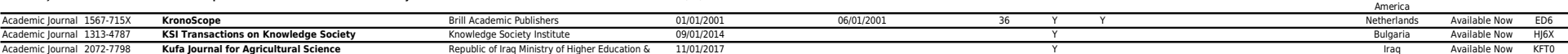

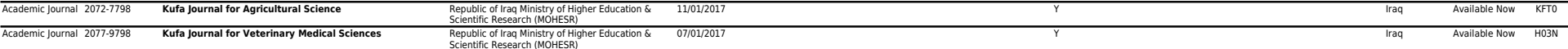

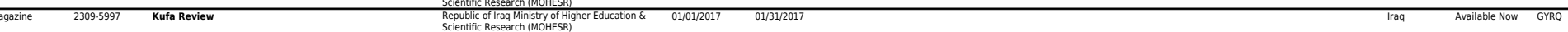

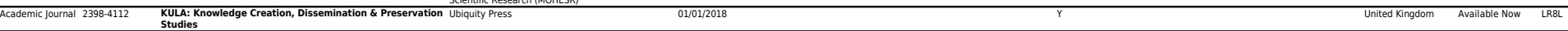

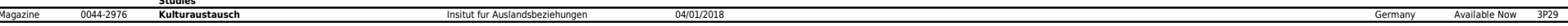




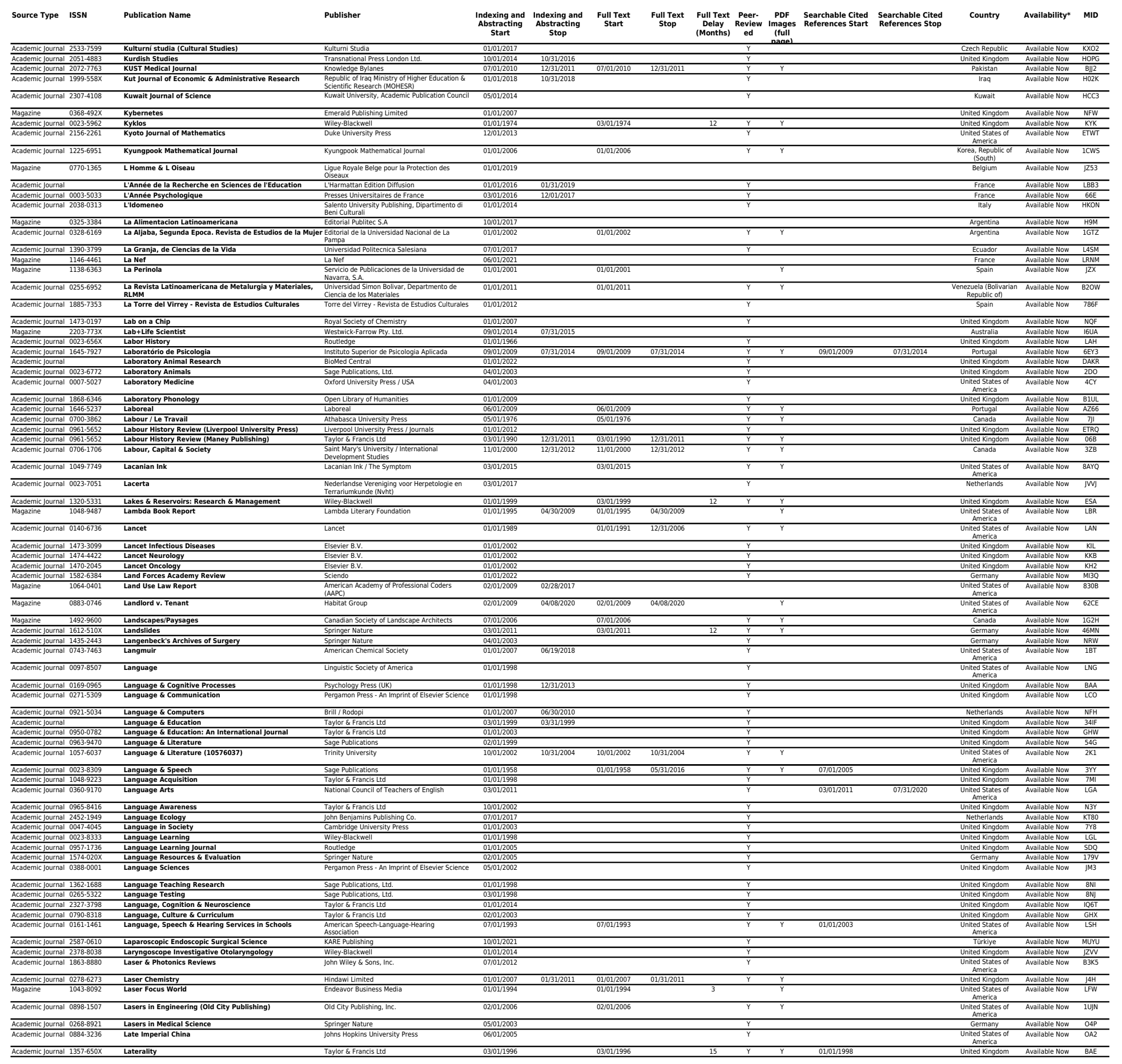




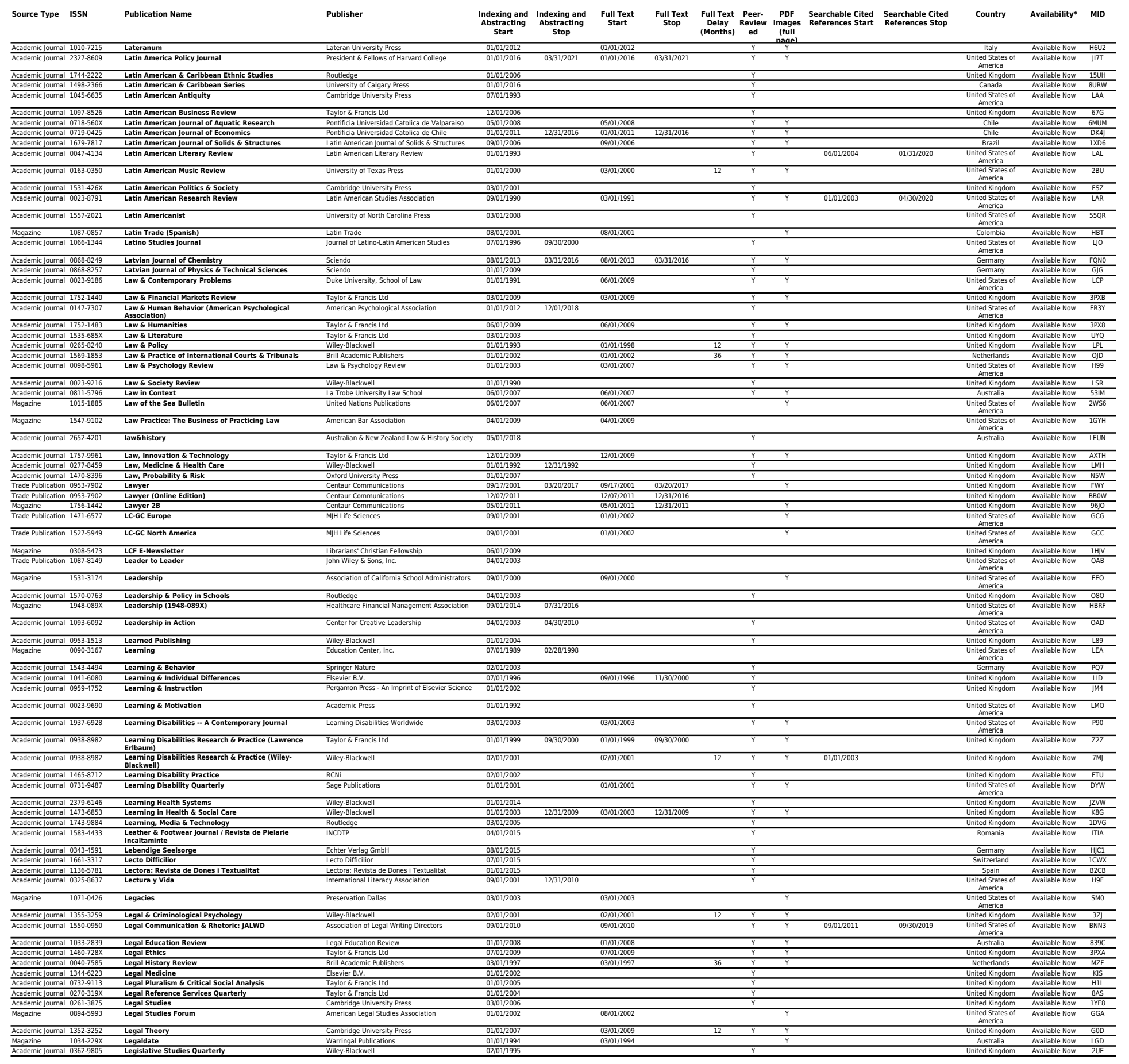




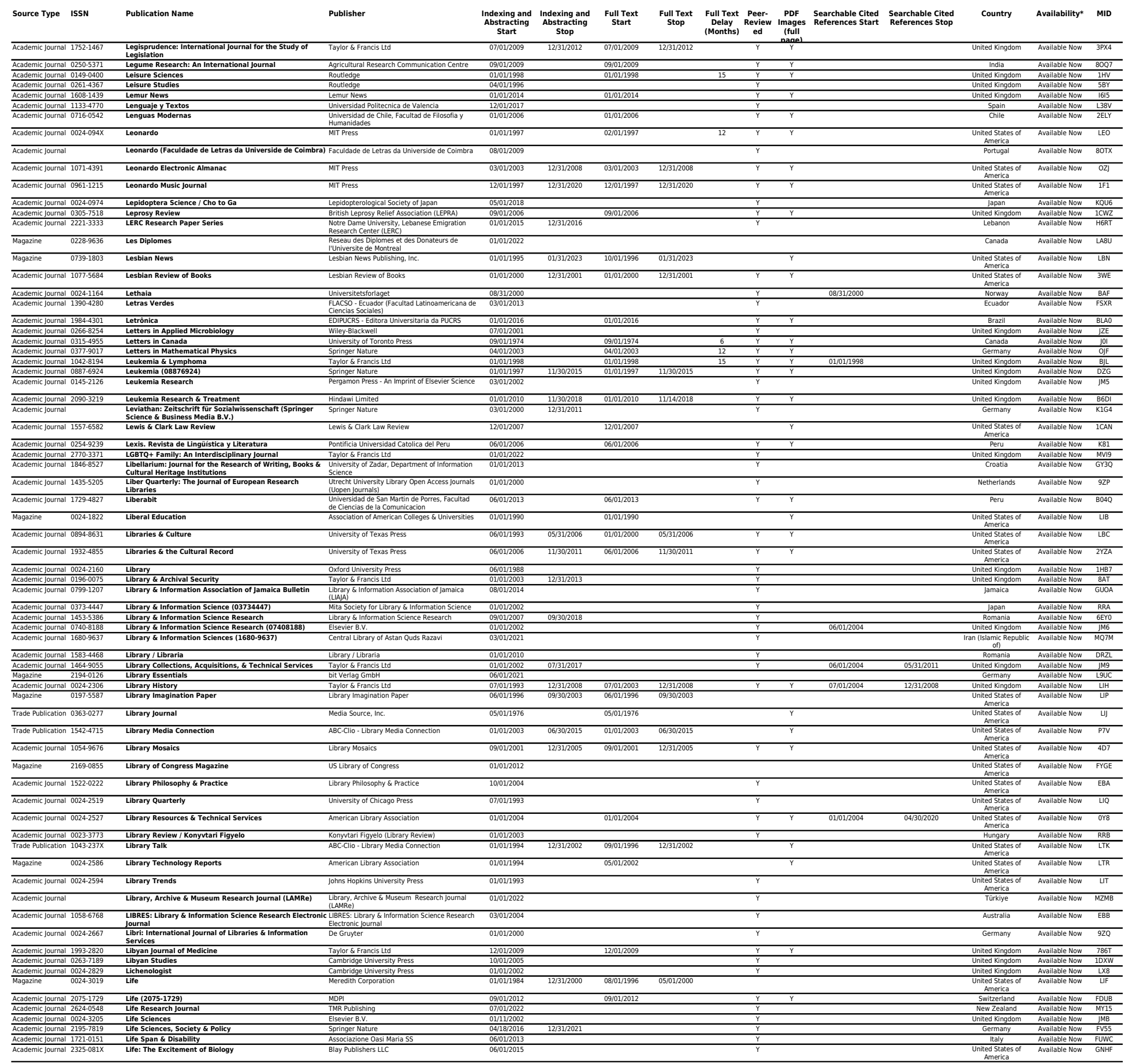




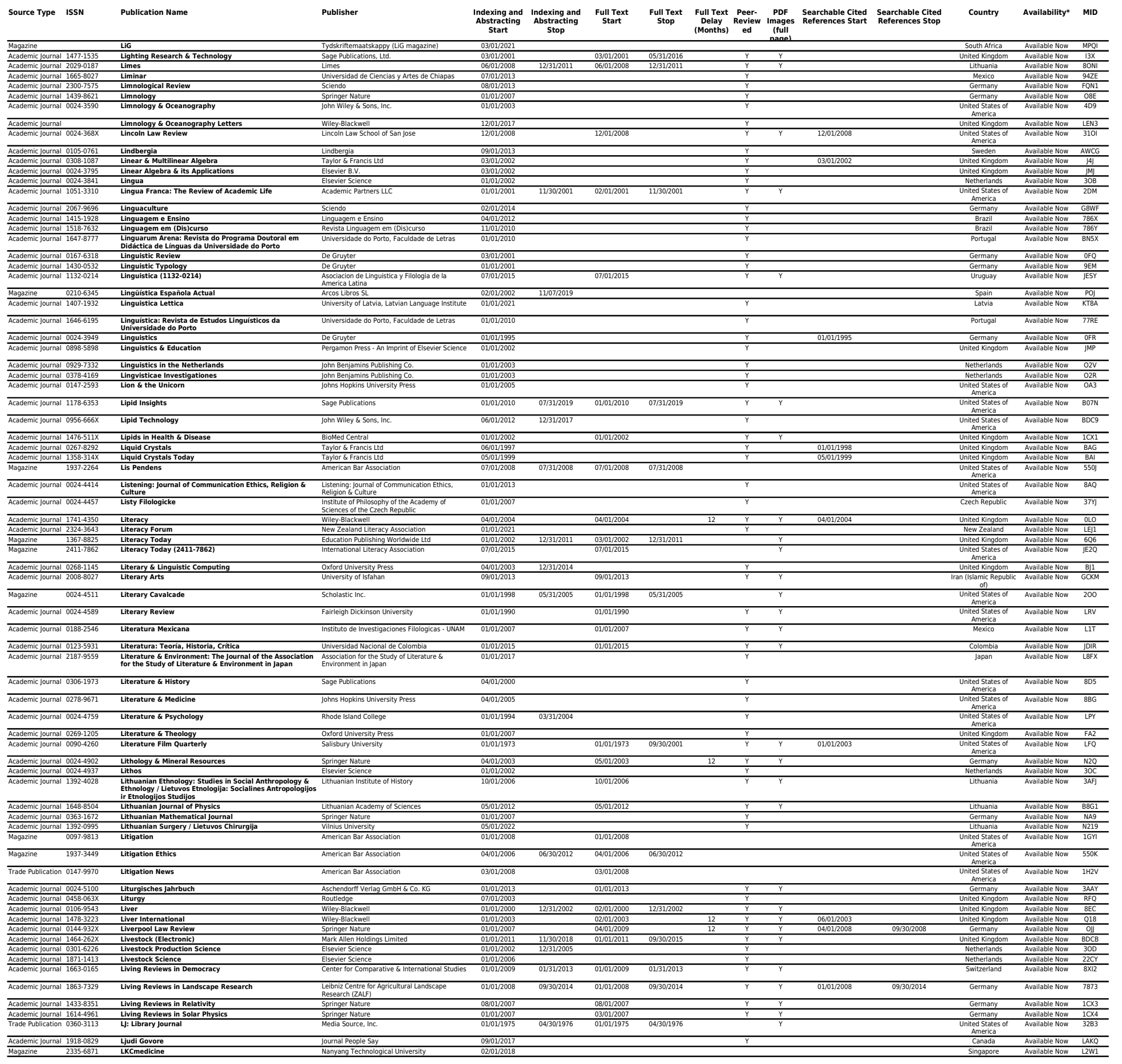




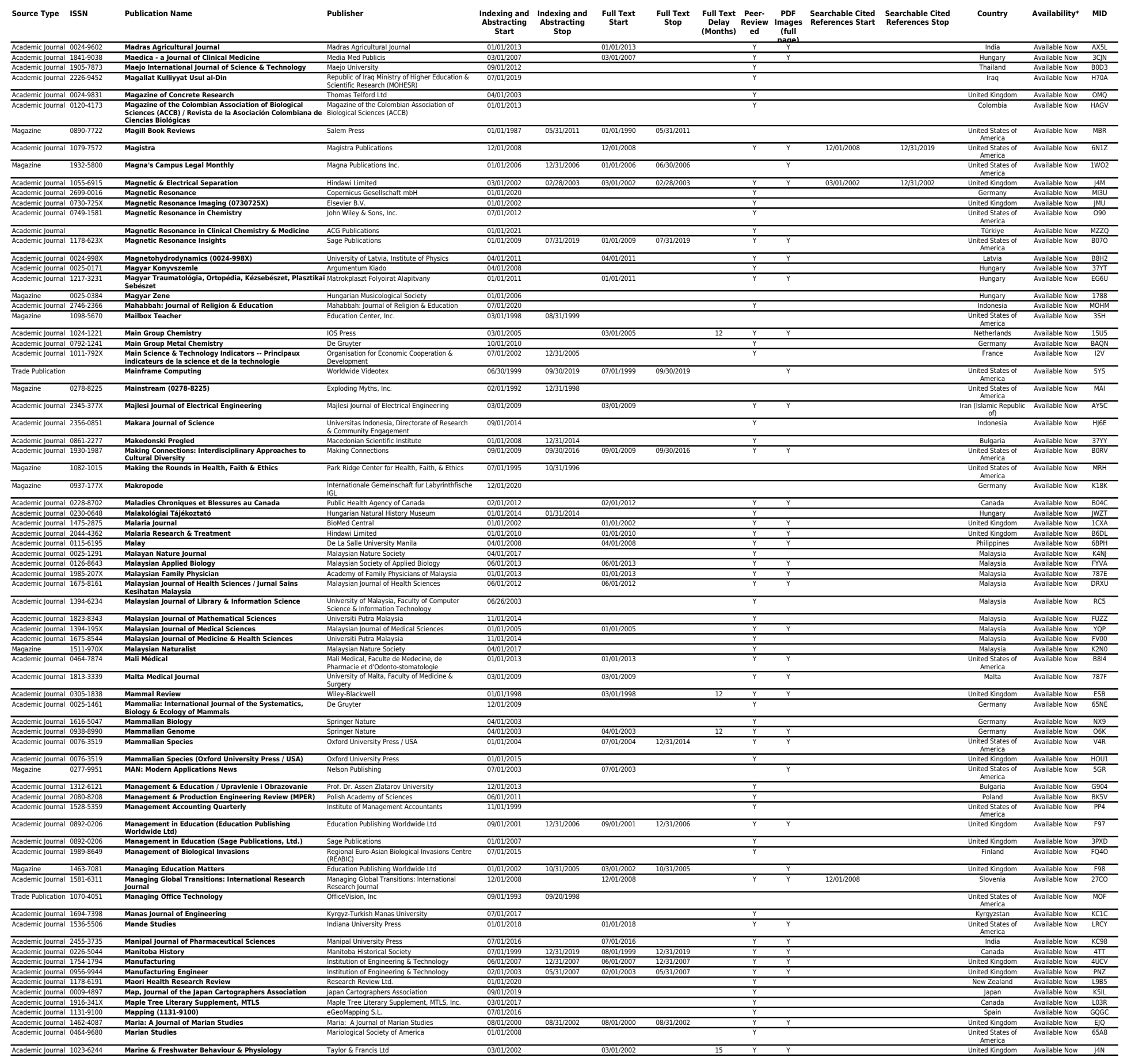




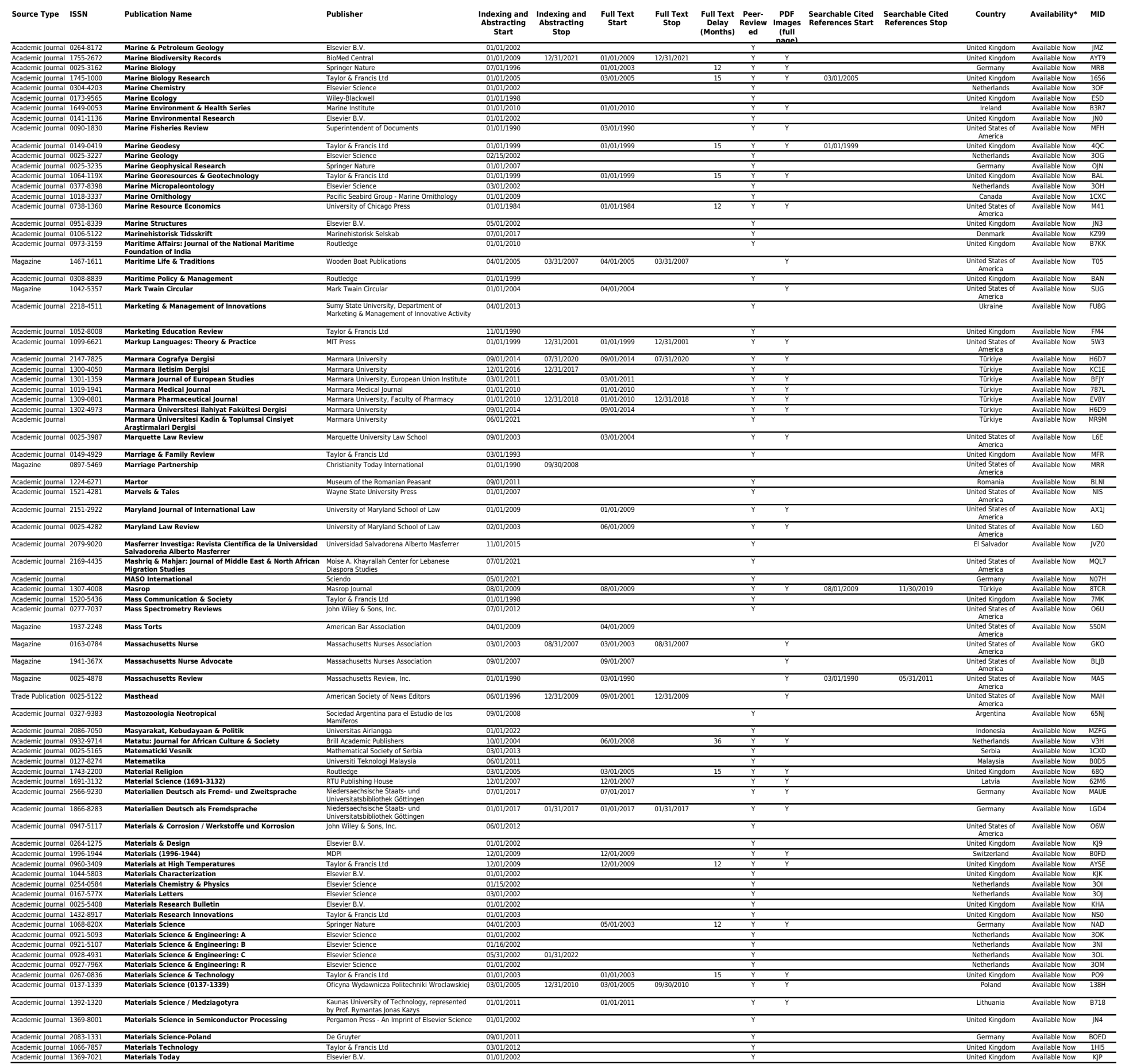




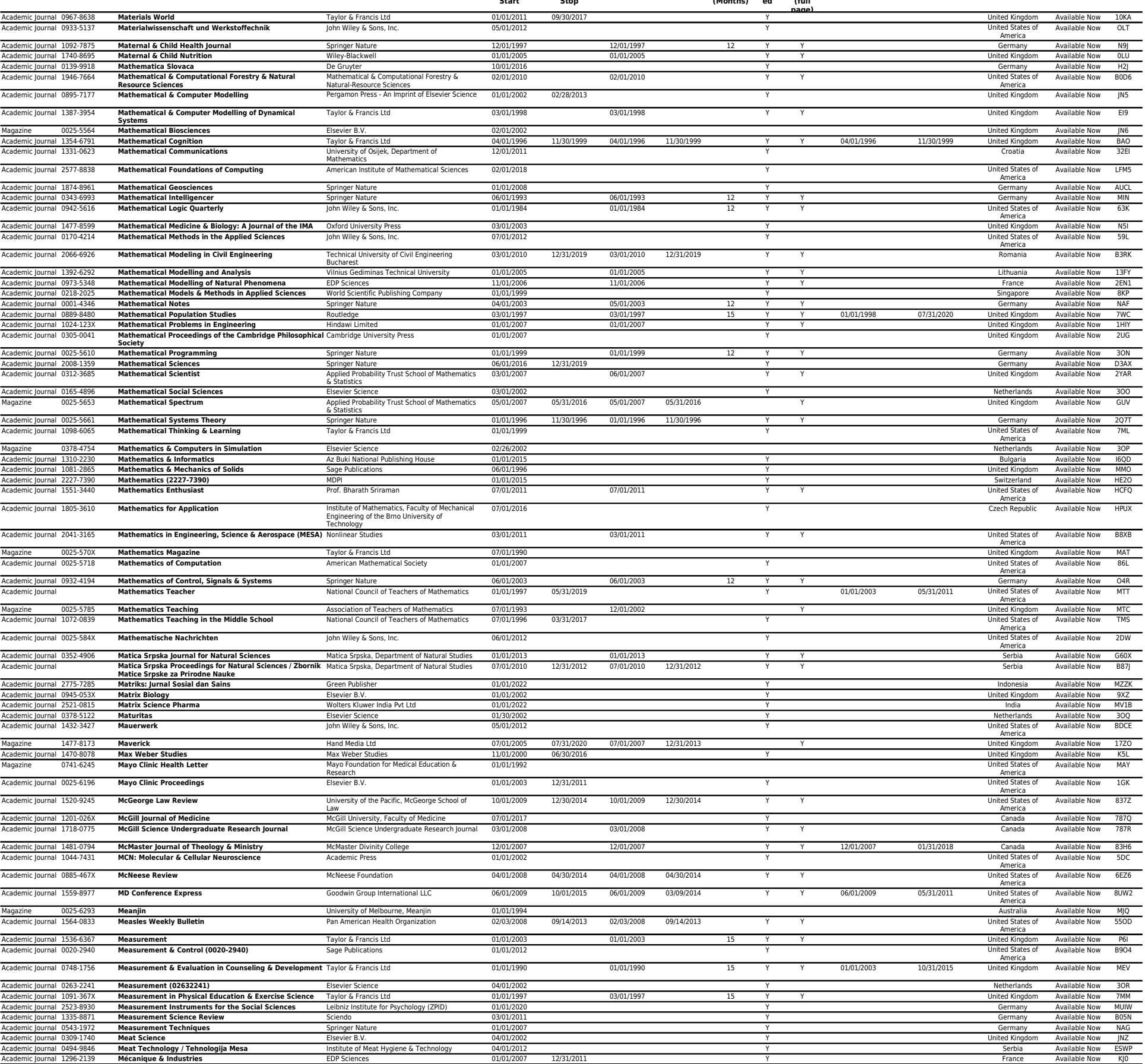




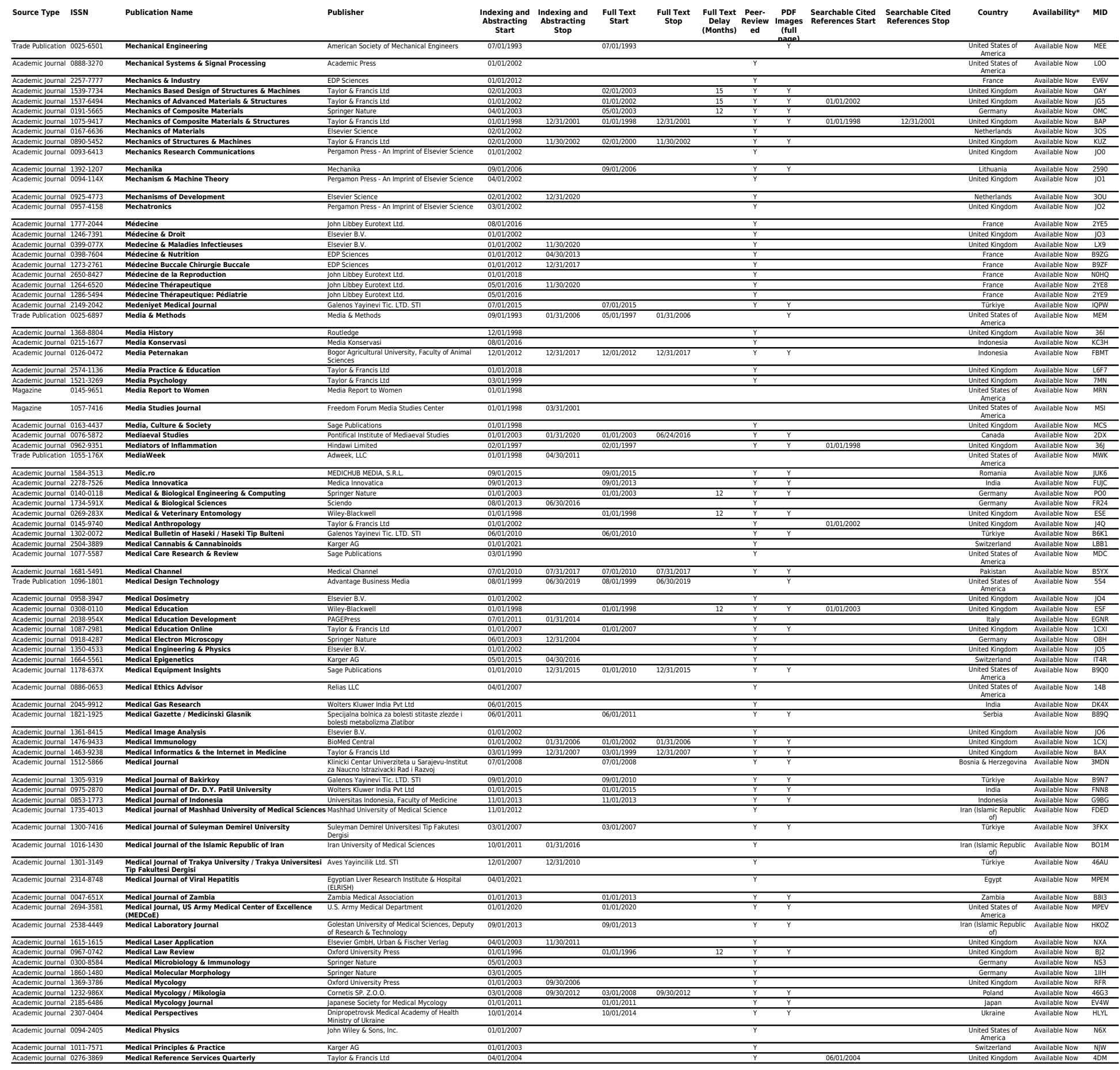




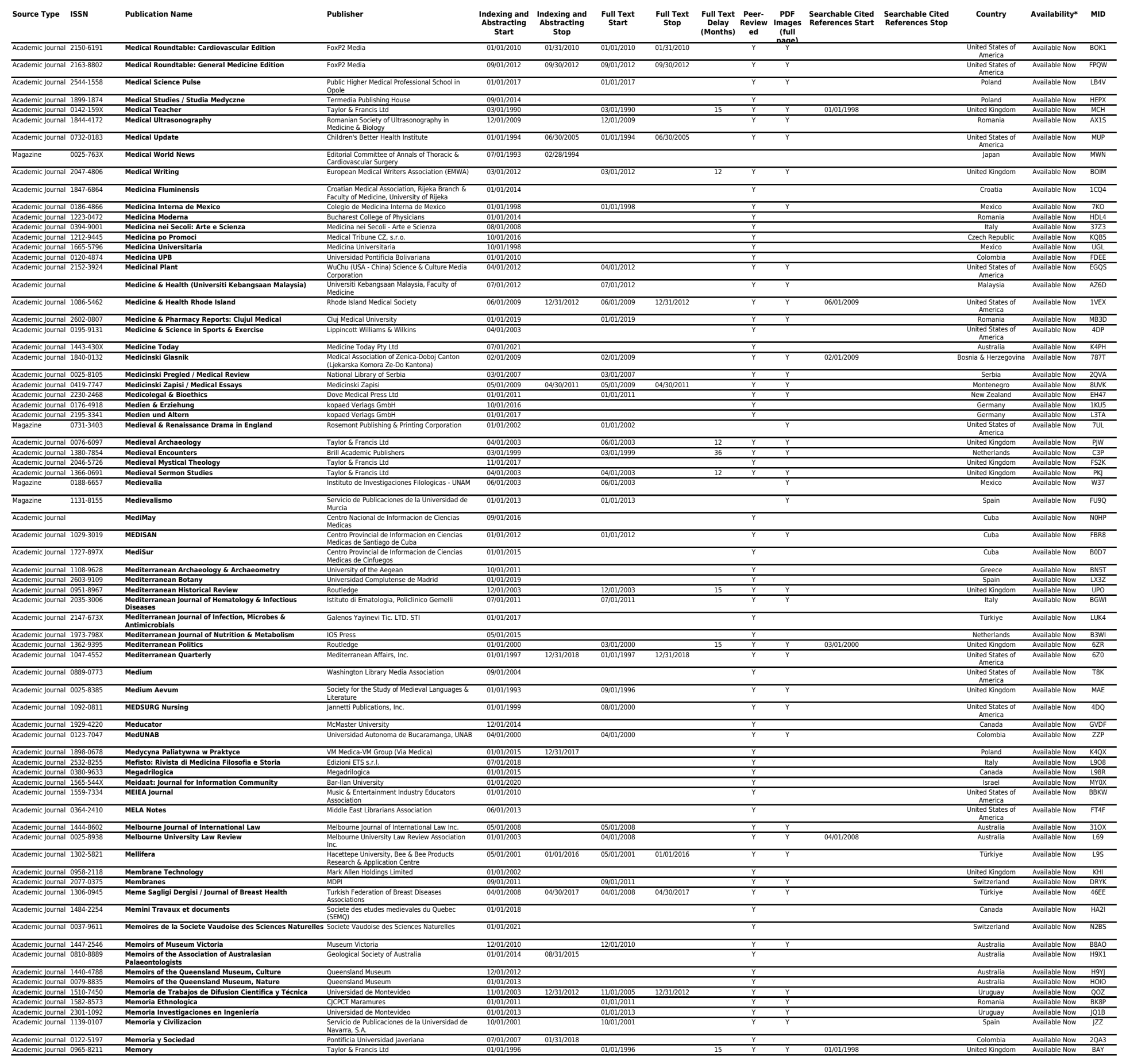




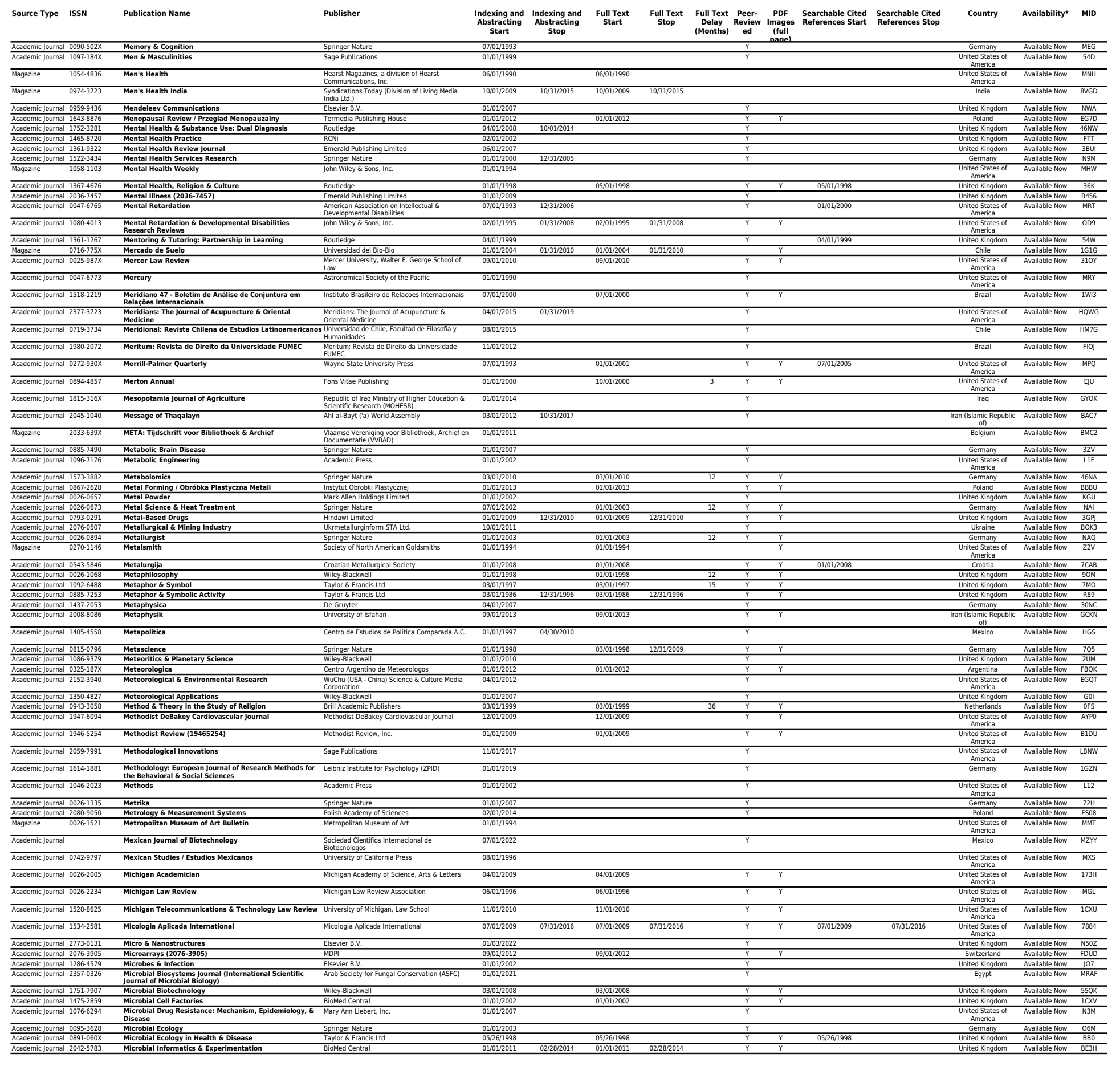


Academic Journal 0882-4010 Microbial Pathogenesis Academic Press

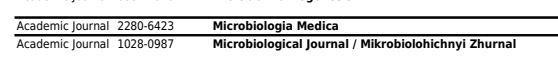

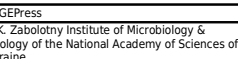

\begin{tabular}{ccc}
\hline Academic lournal $0944-5013$ & Microbilogical Research \\
\hline Academic Journal & $146-0749$ & Microbiological Reviews \\
\hline
\end{tabular}

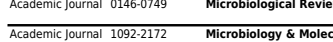

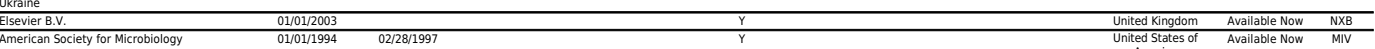

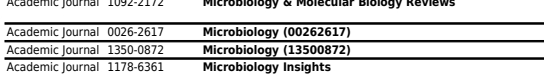

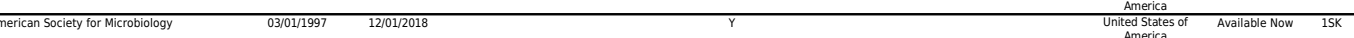

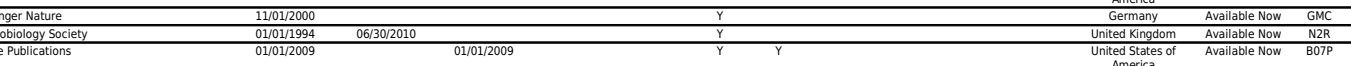

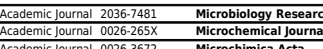

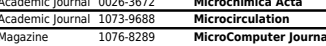

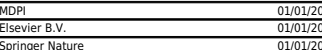

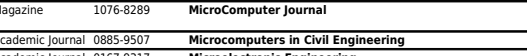

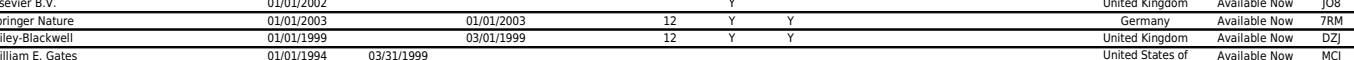

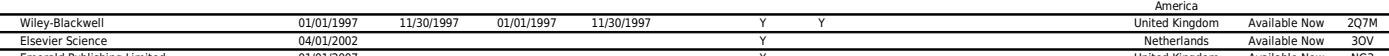

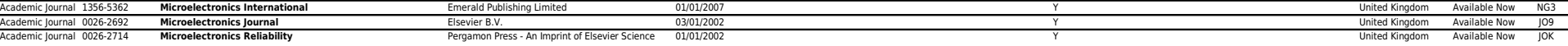

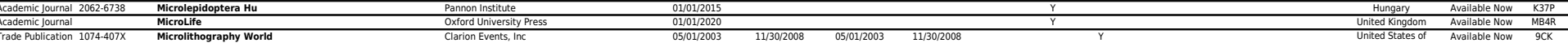

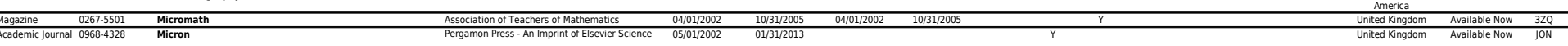

Micropaleontology 01012003

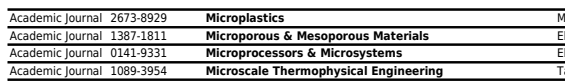

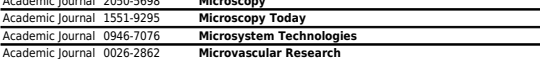

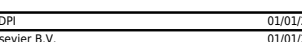

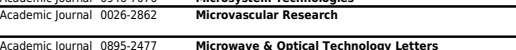

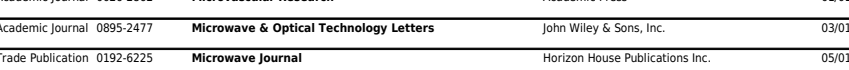

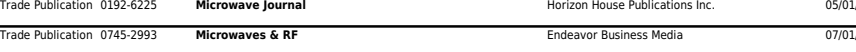

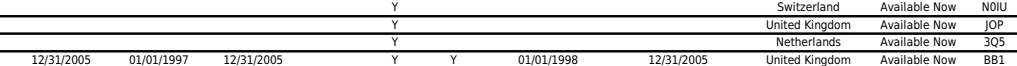
Mid Yorks Medical Journal

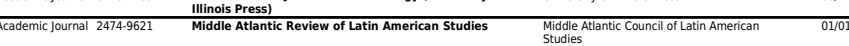

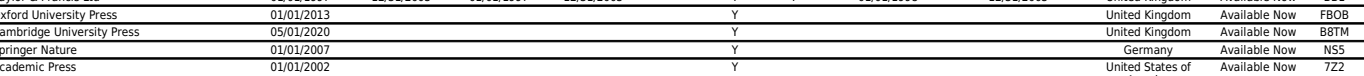

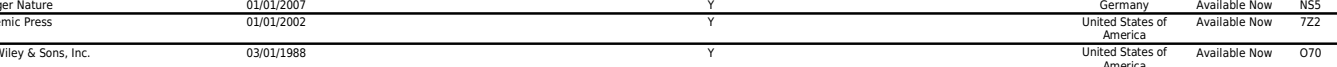

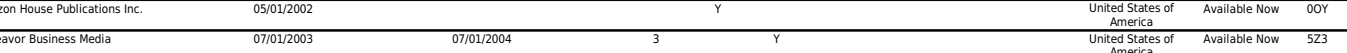

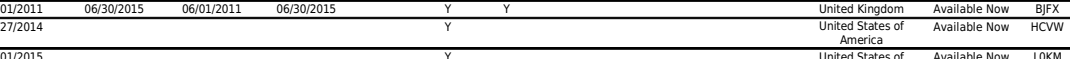

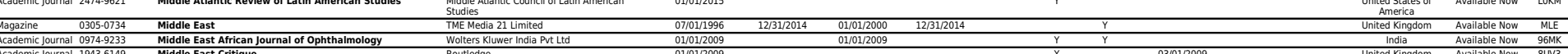

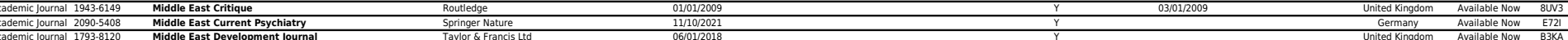

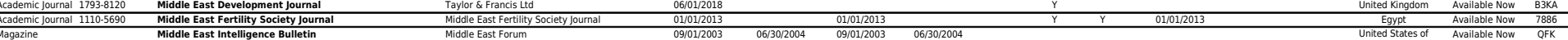

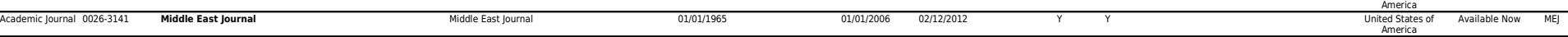

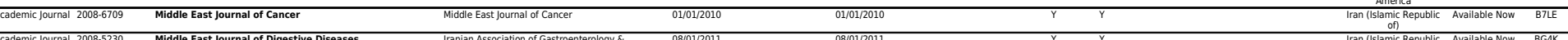

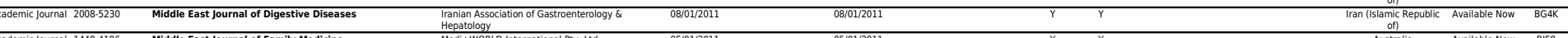

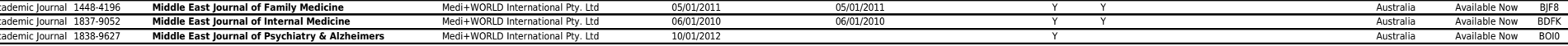

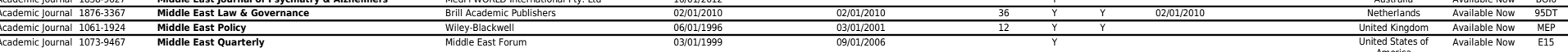

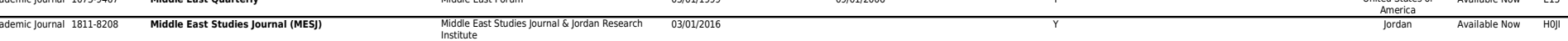

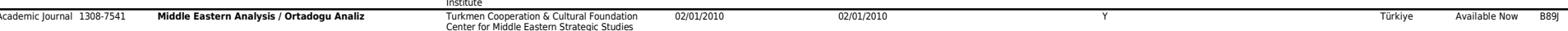

Middle Easterm Literatures

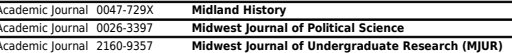
Mademic J Jưral 0026-3451 Midwest Quartent

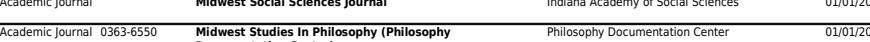

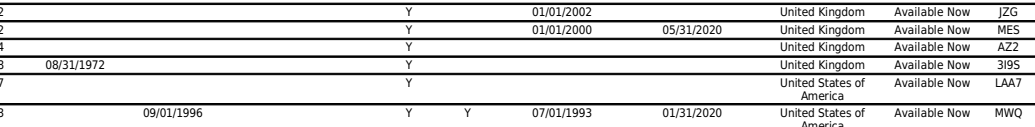

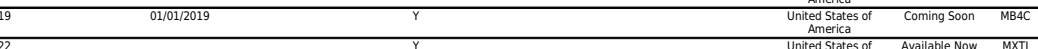

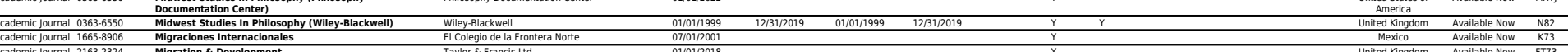

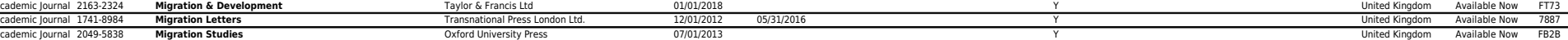
Oxterd University Press
Center for Migration Studies

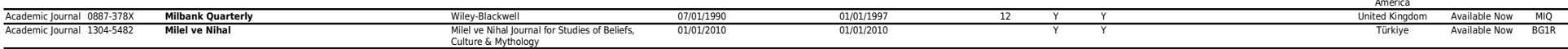

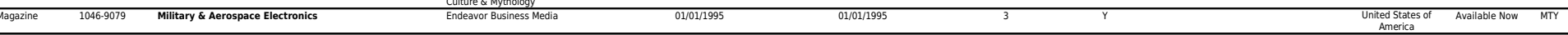

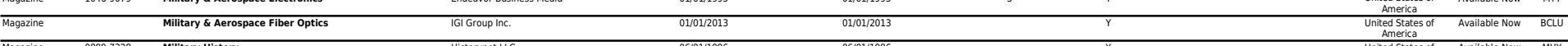

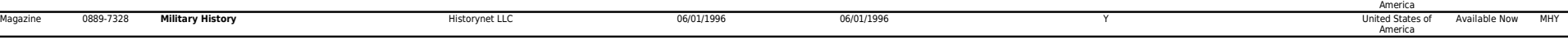




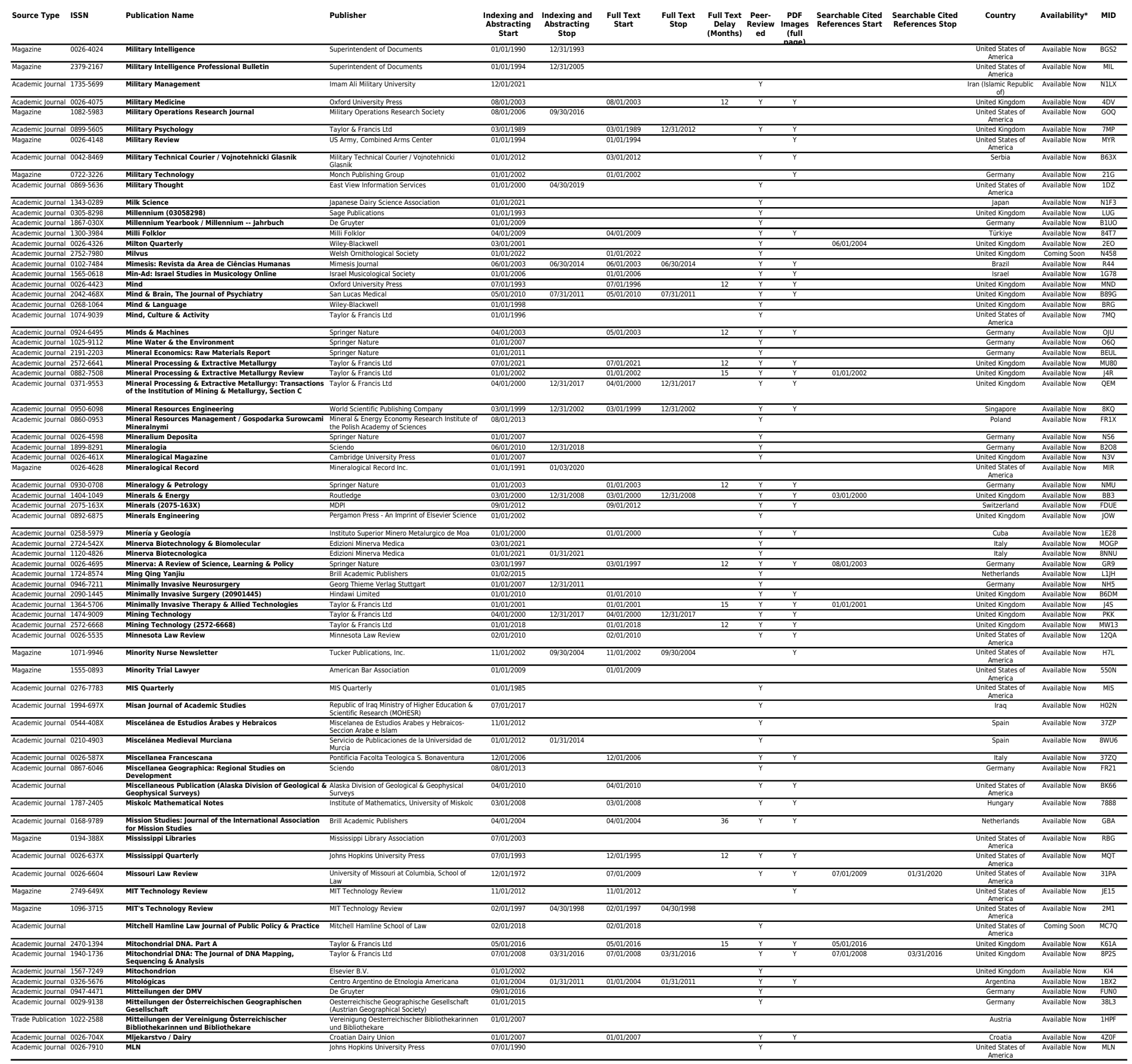




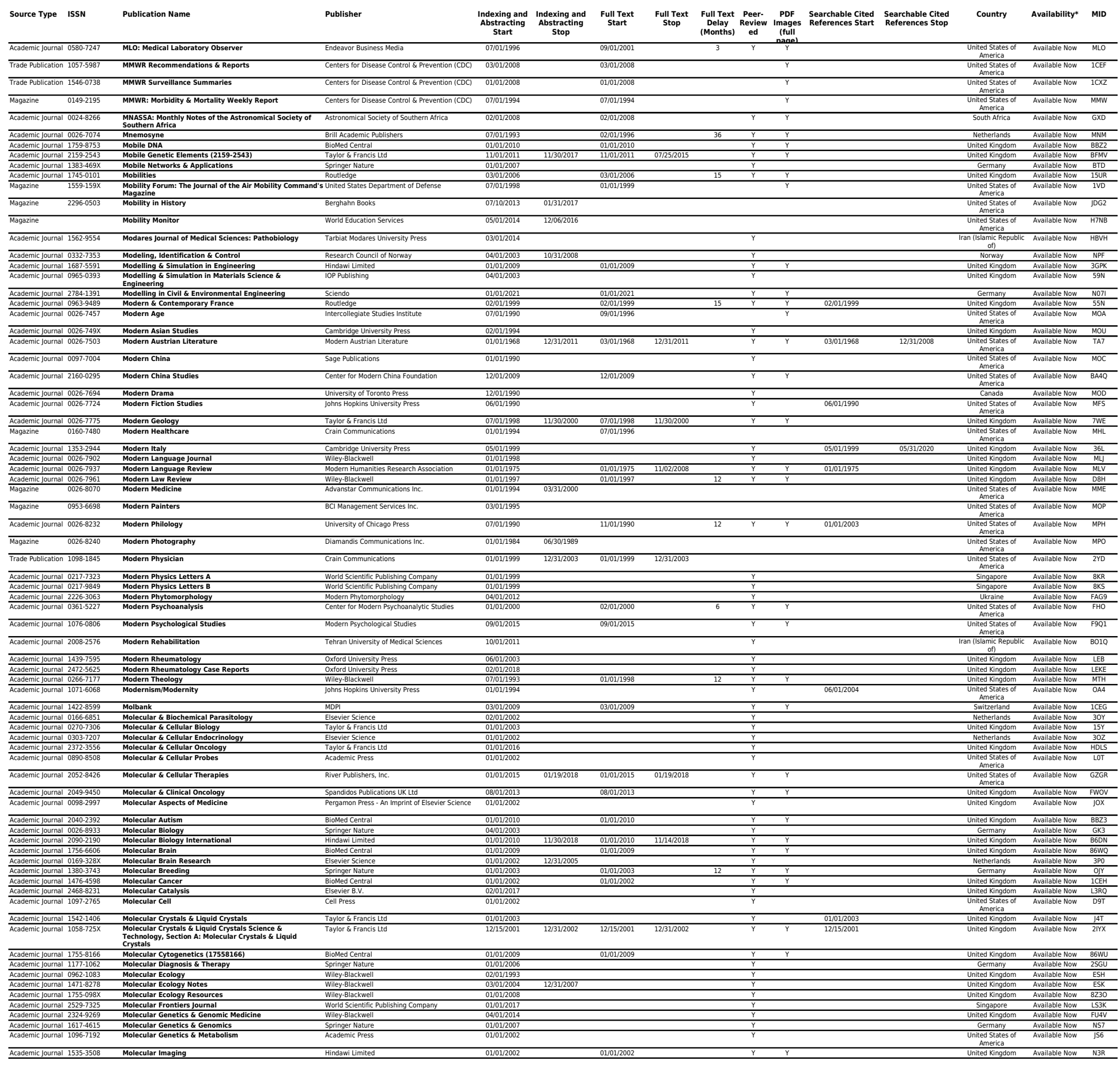




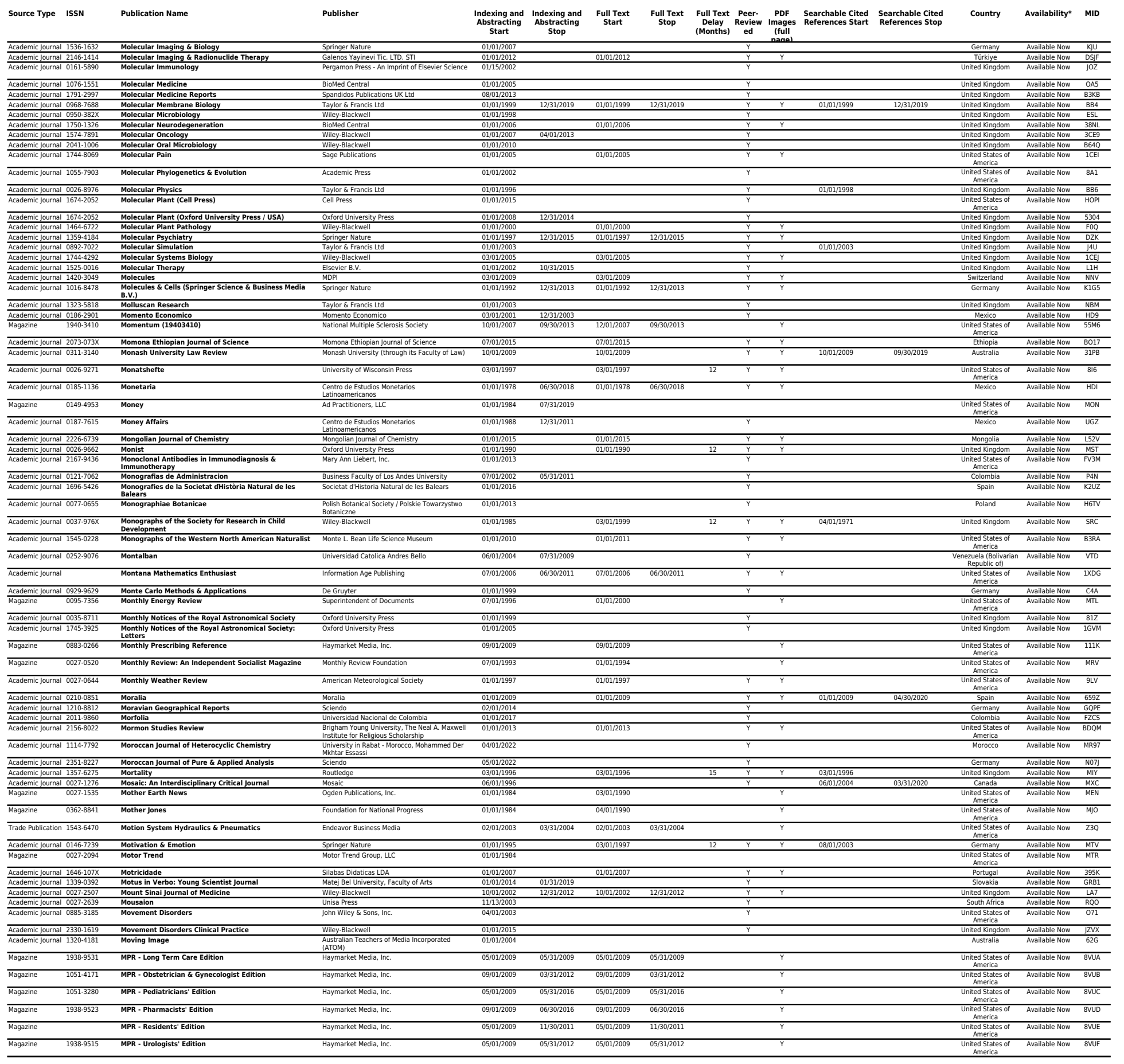




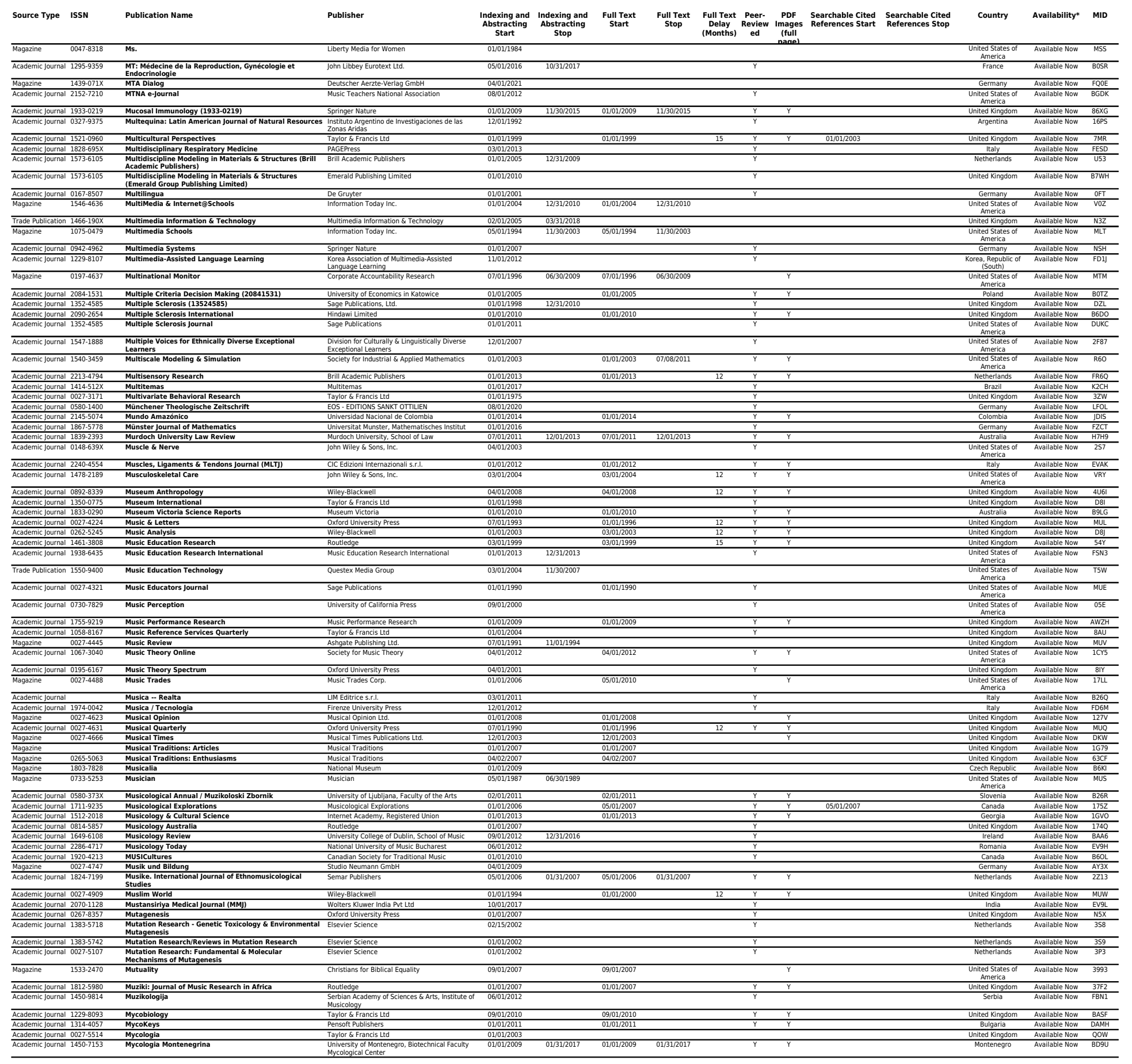




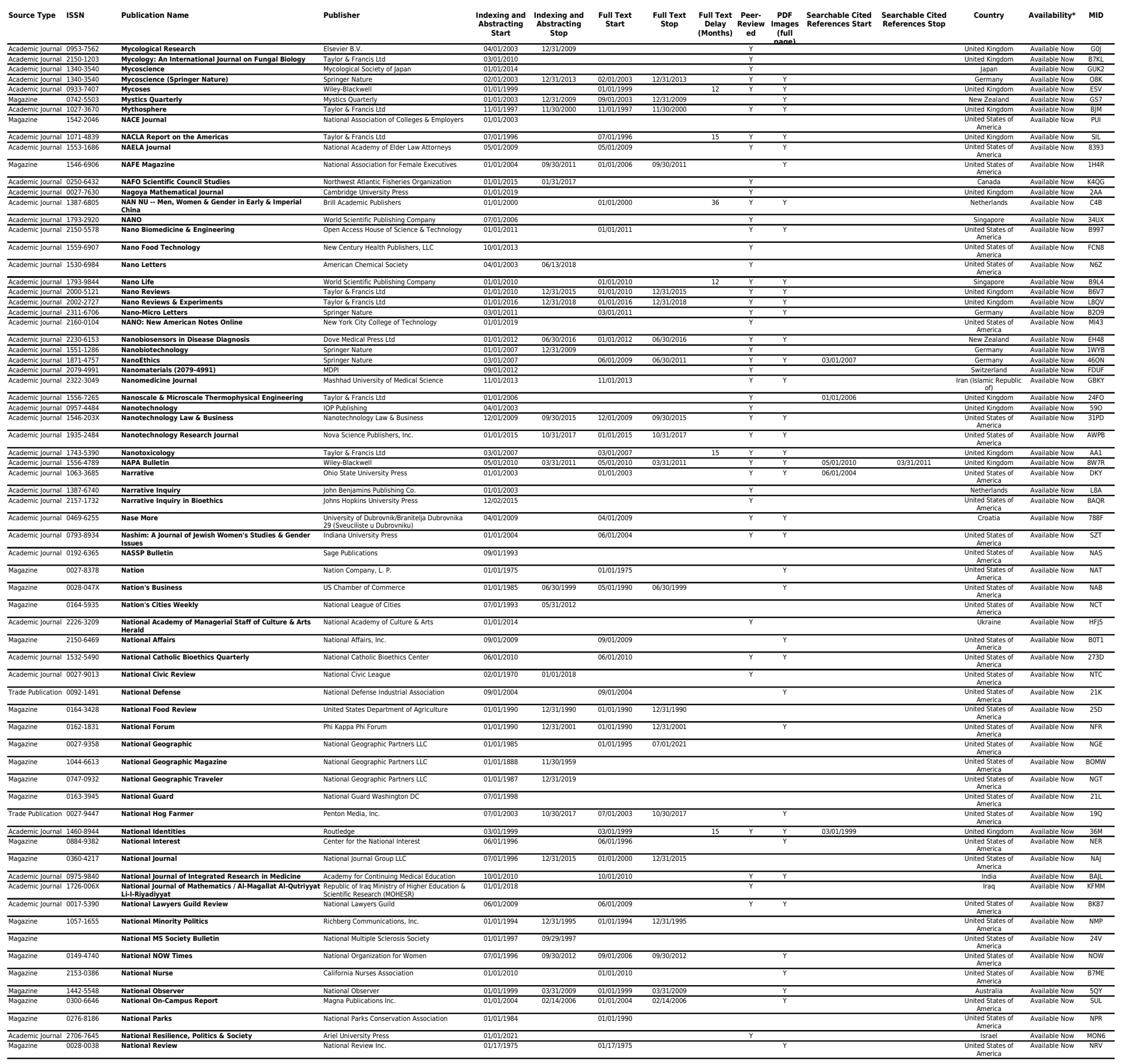




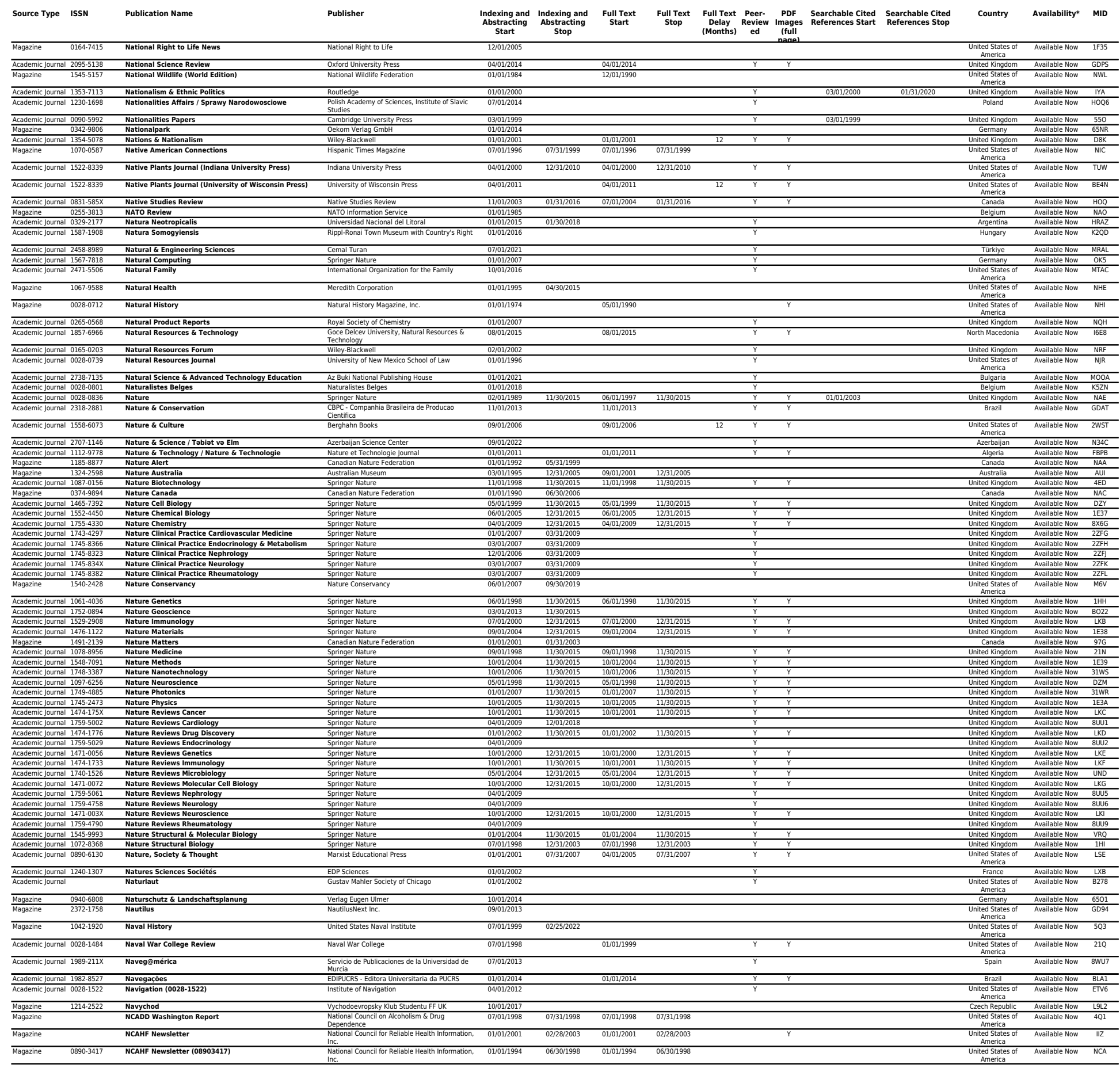




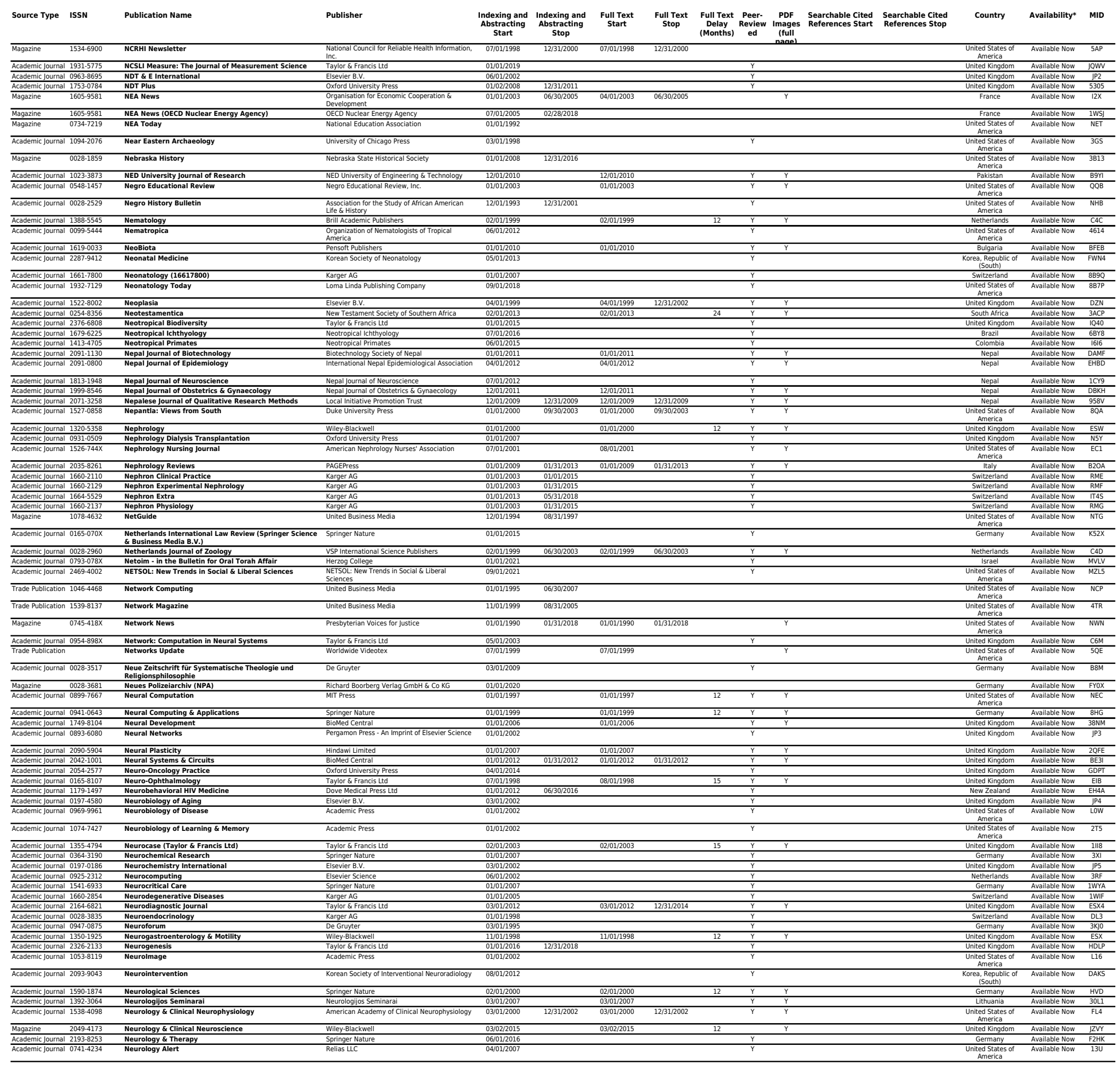




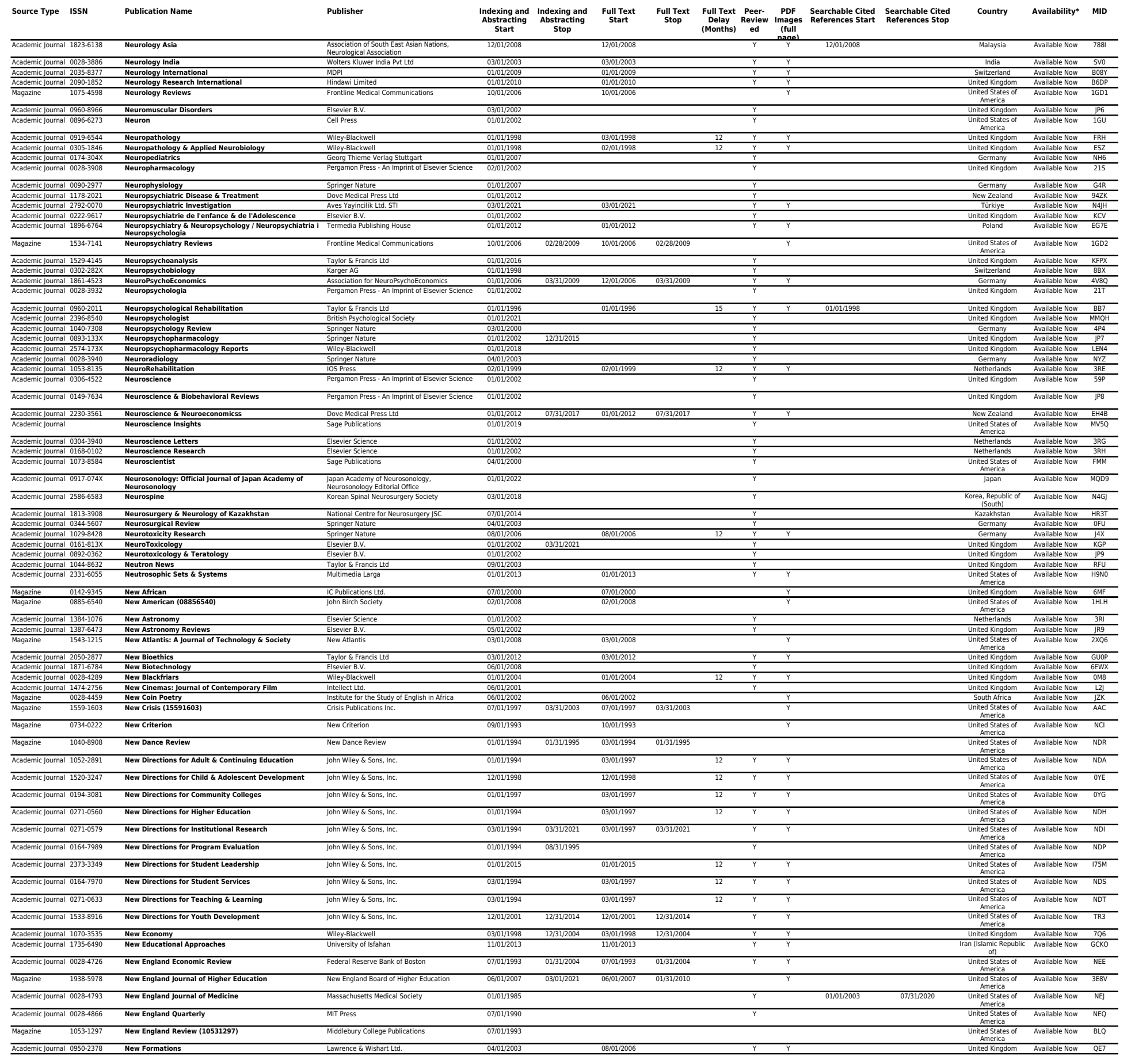




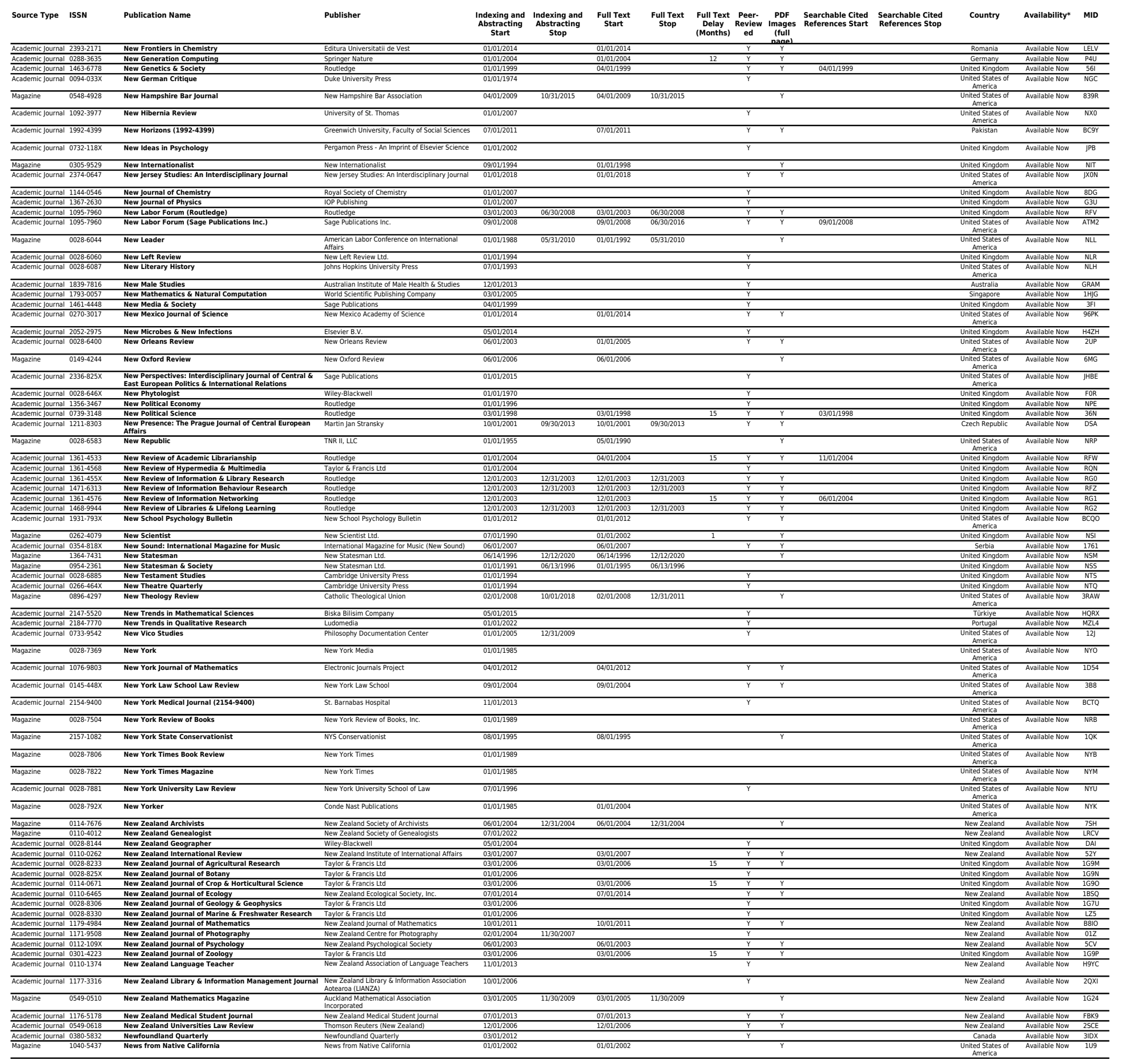




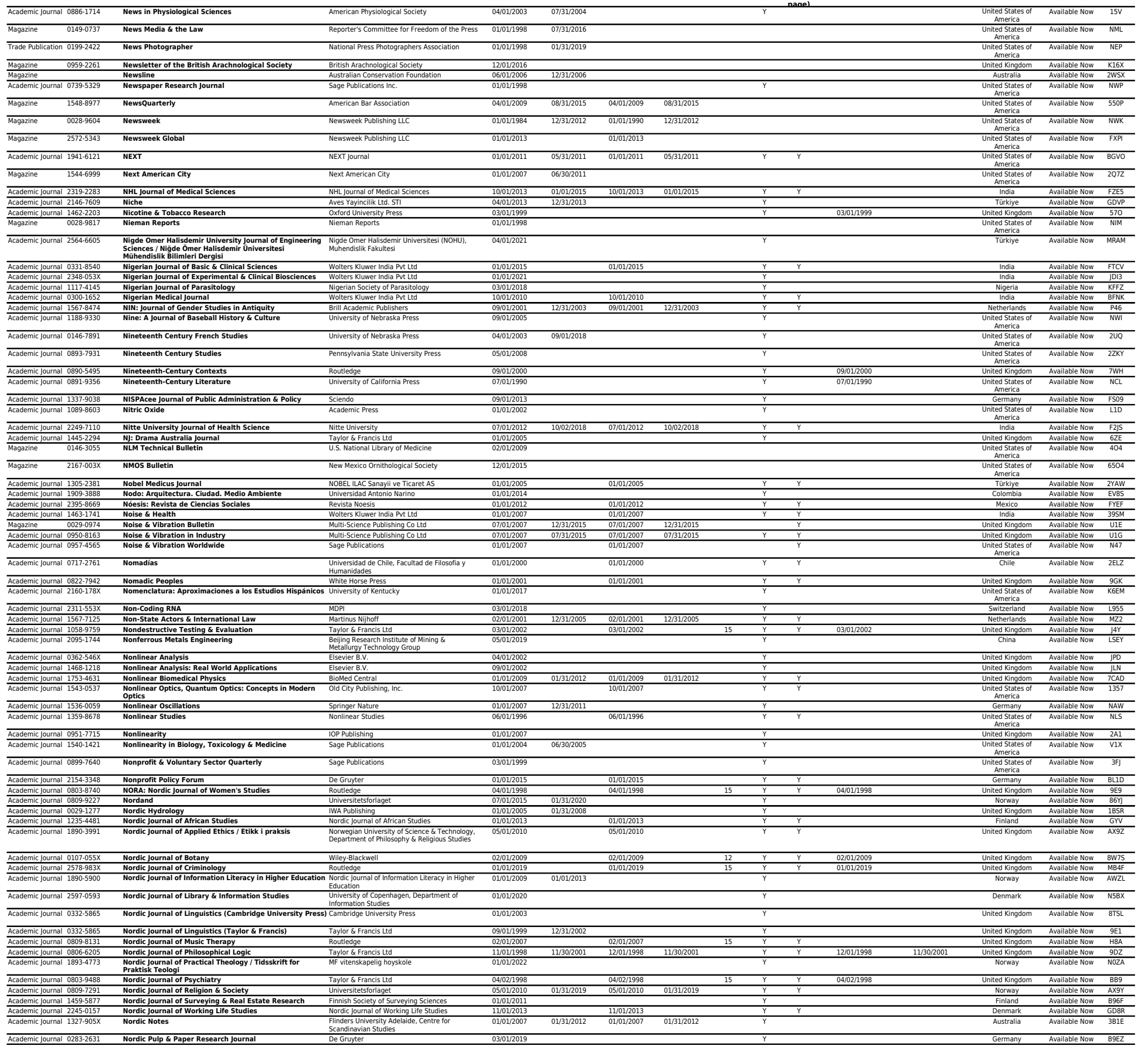




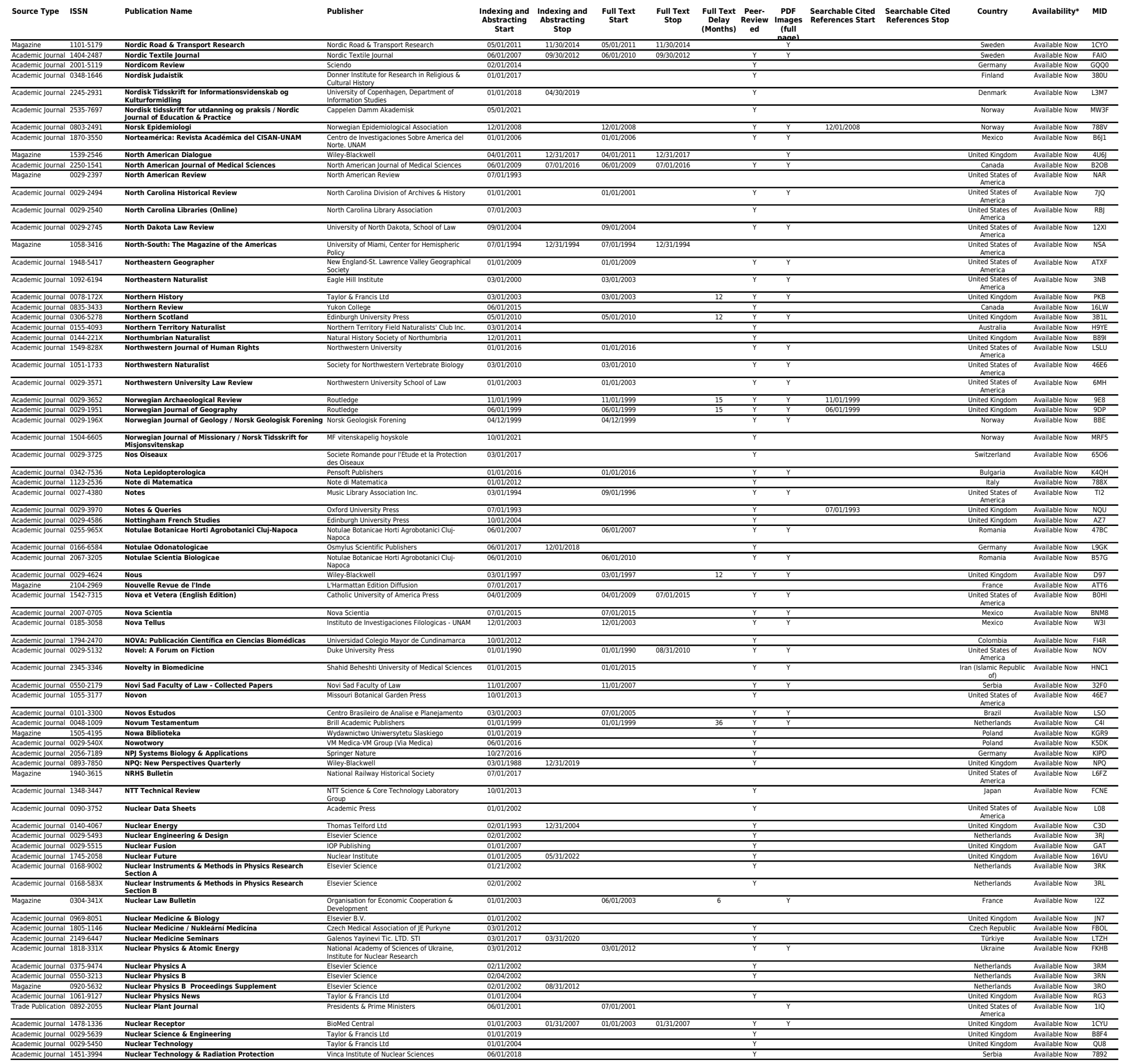




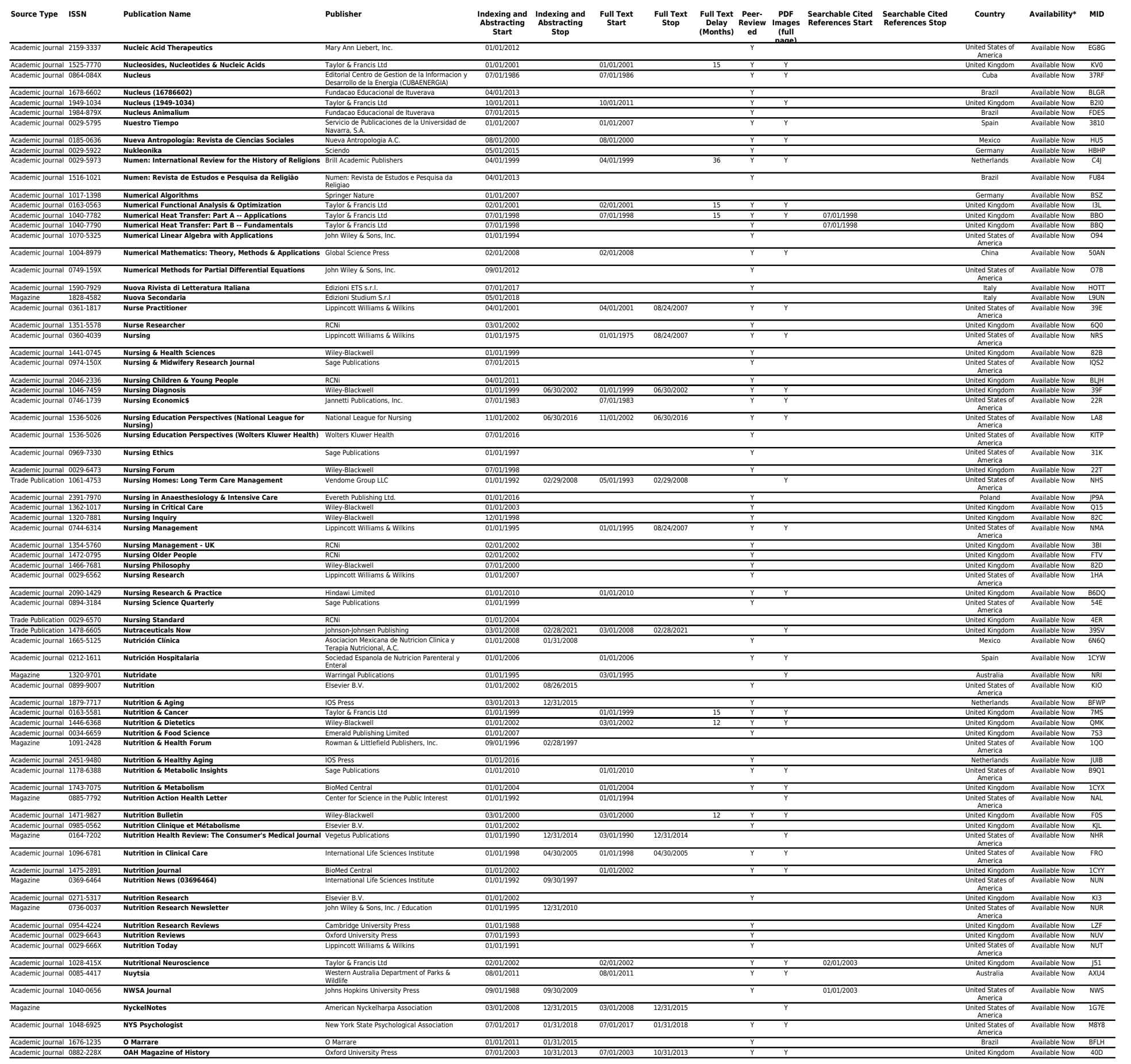




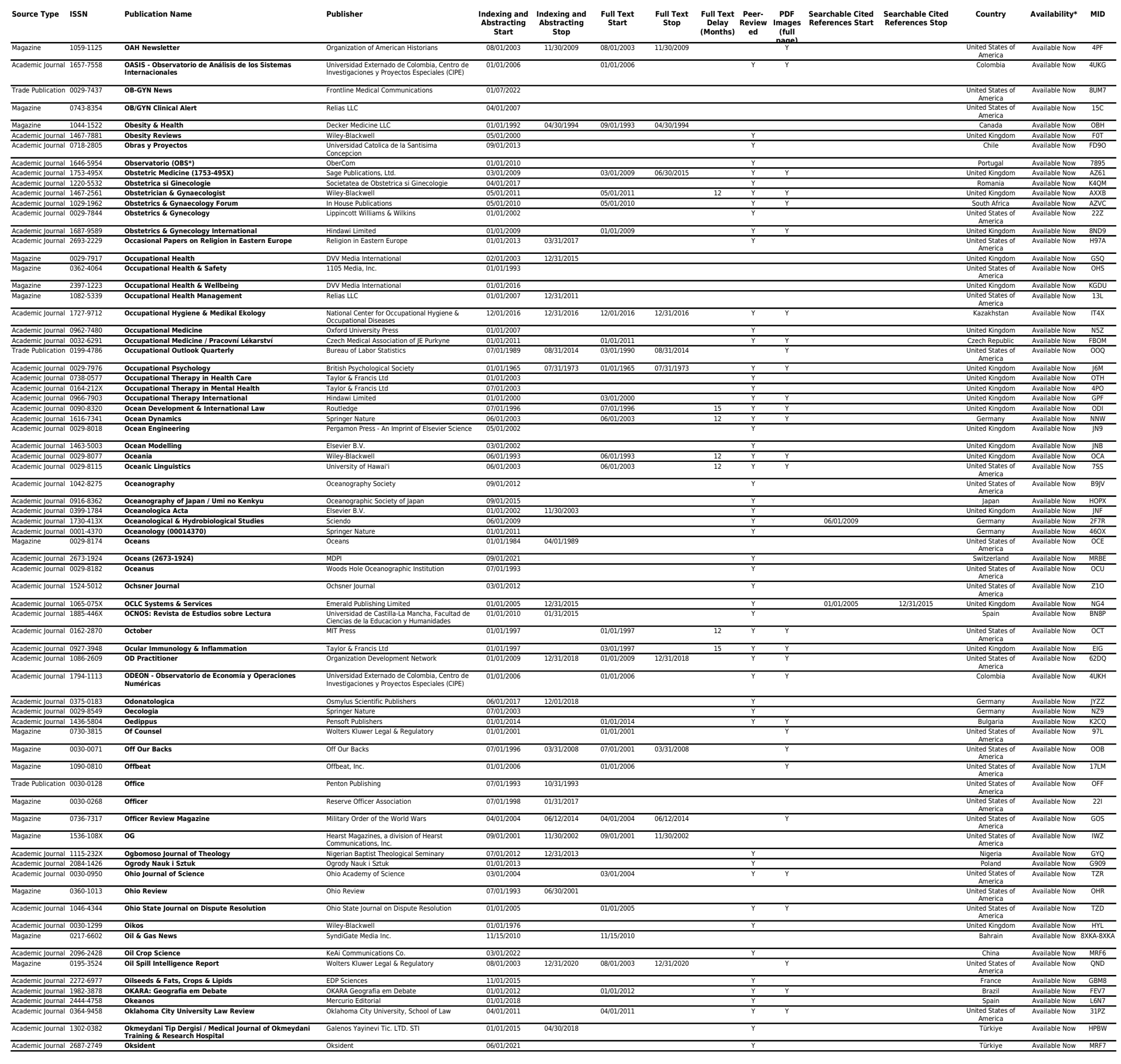




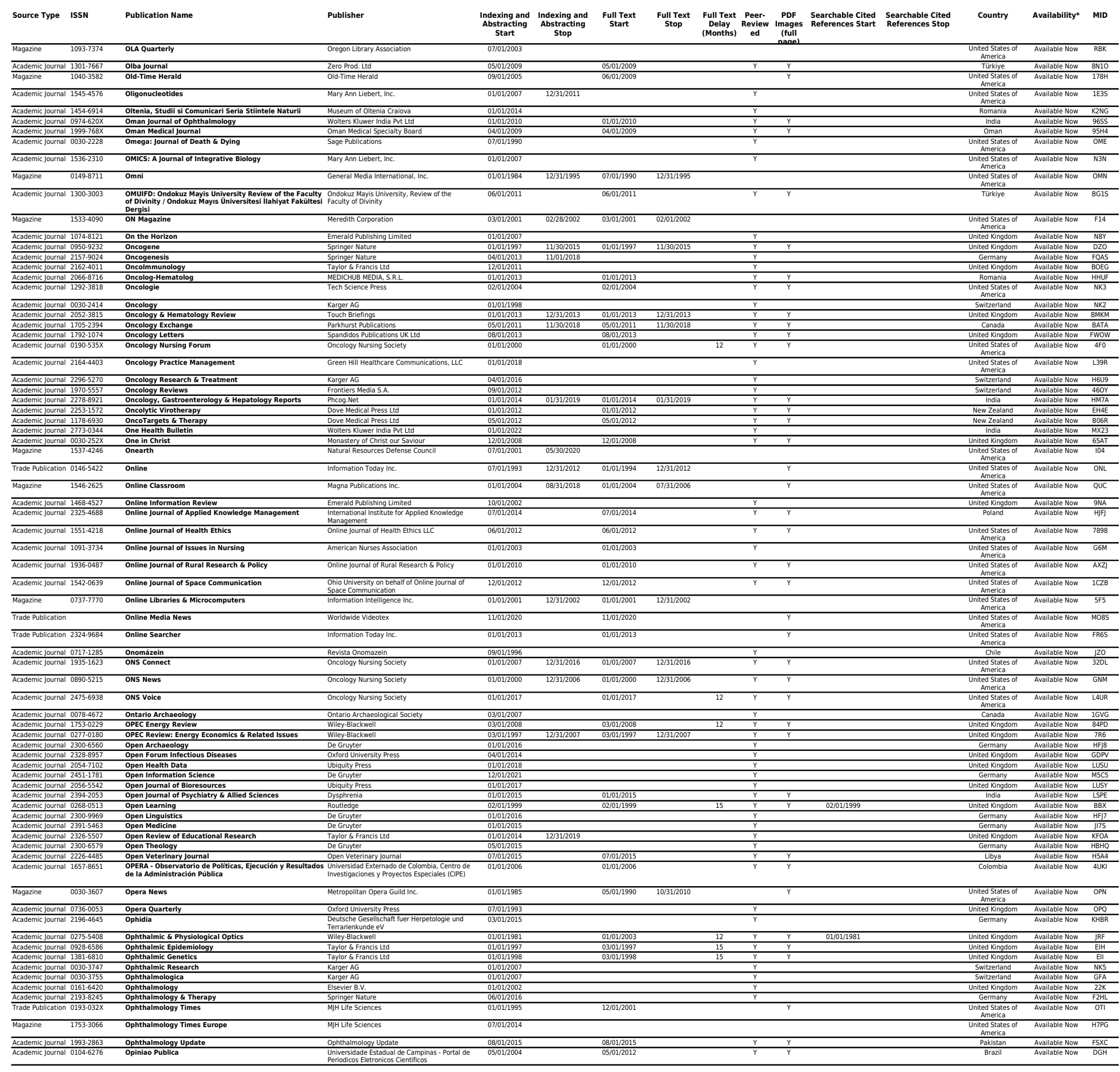




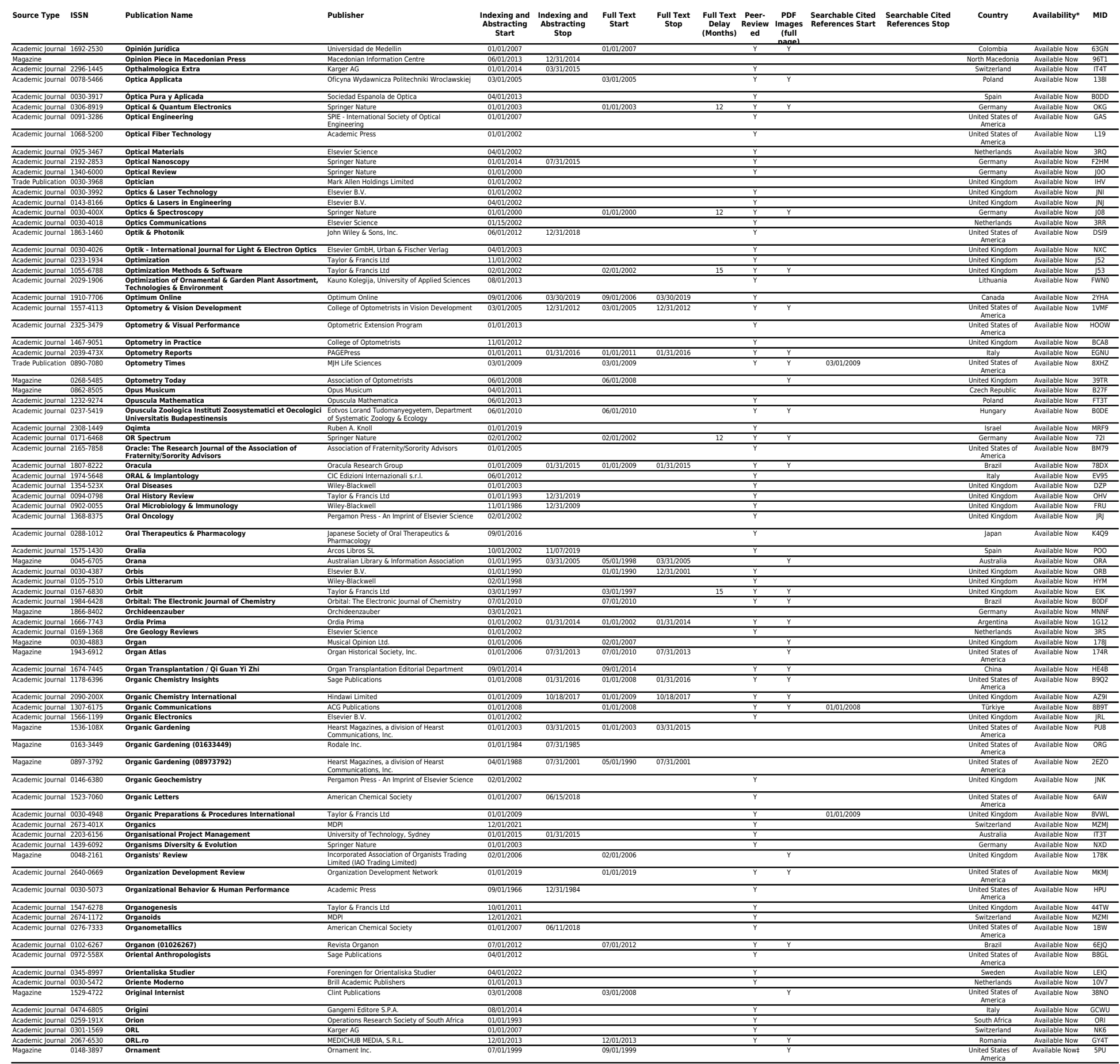




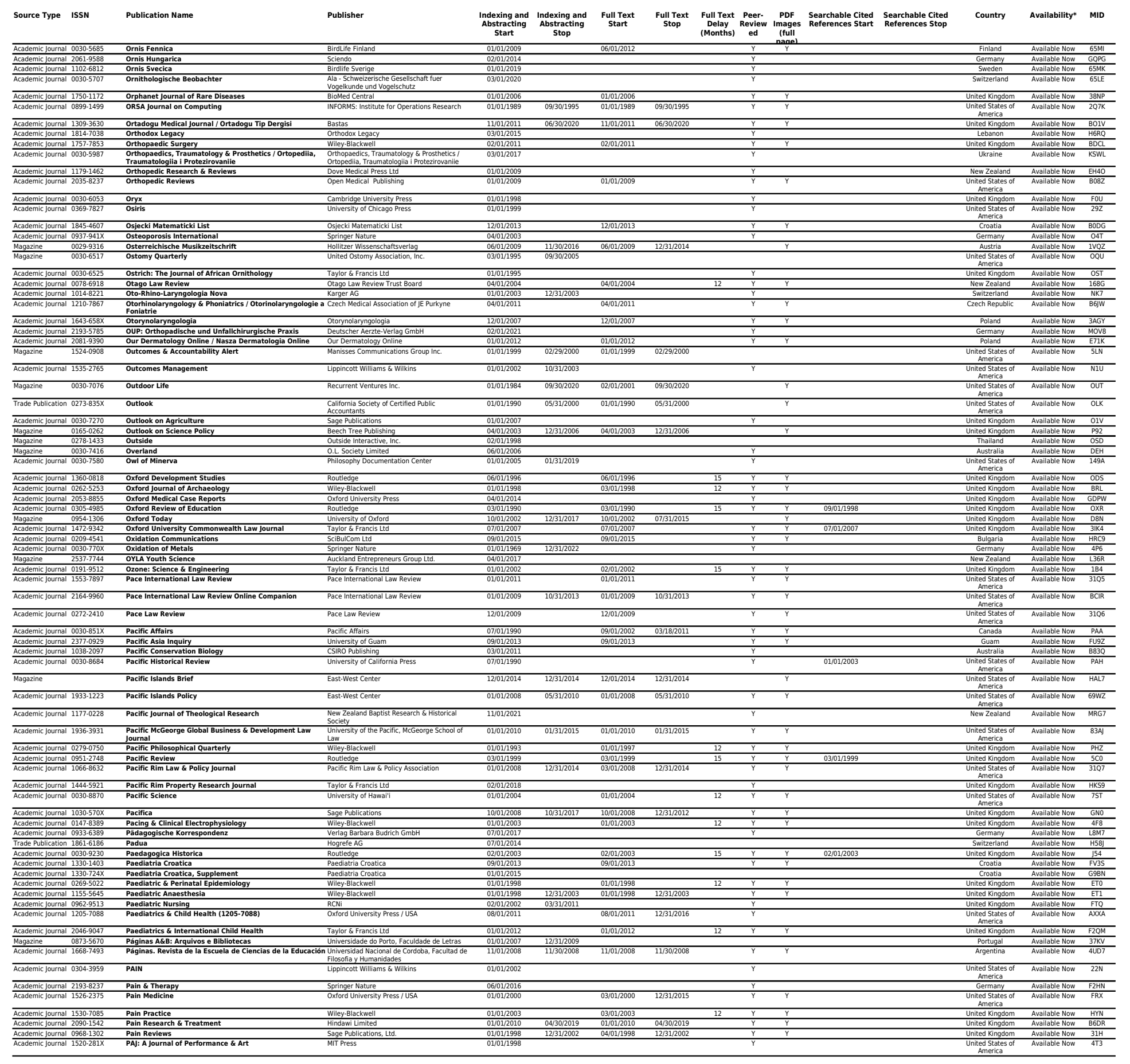




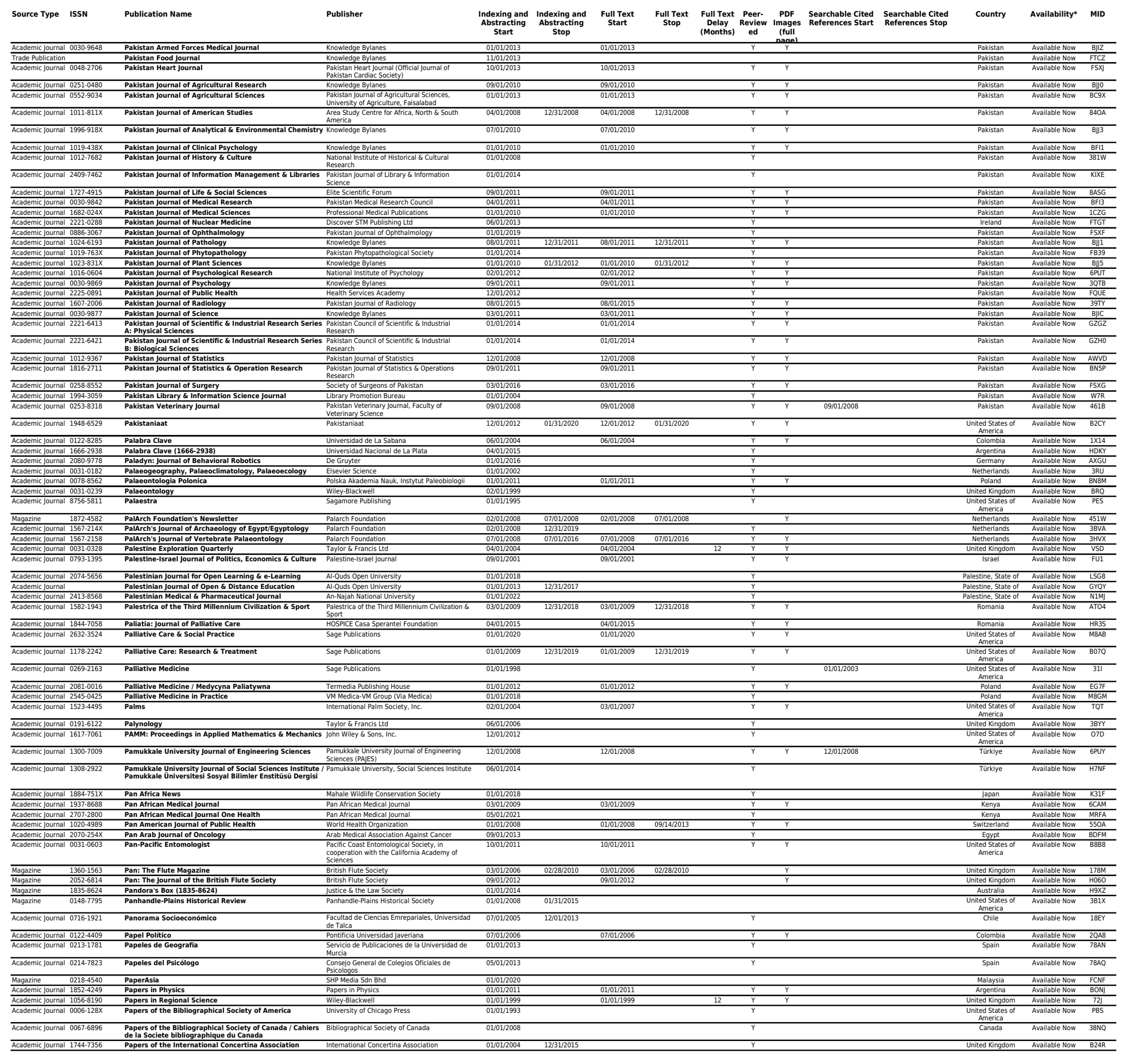


Academic Journal $1406-0.040$ Papers on Anthropology University of Tartu, center of Physical

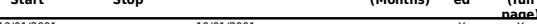

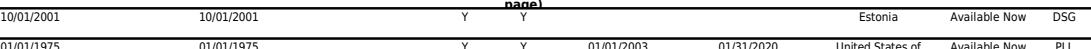

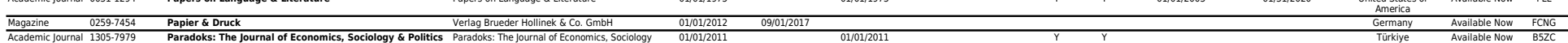

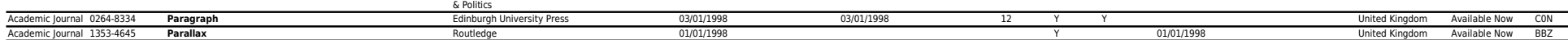

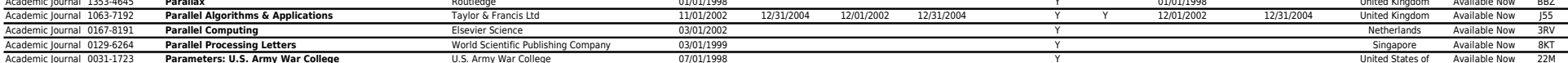

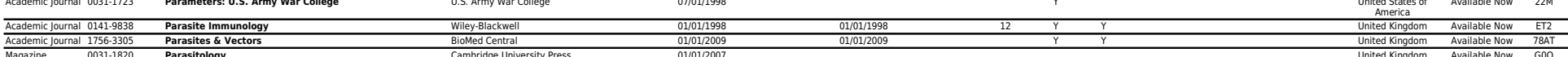

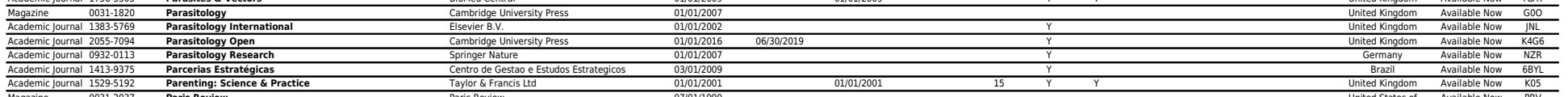

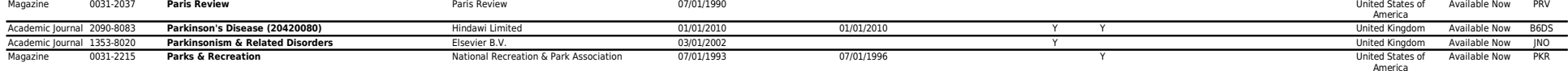

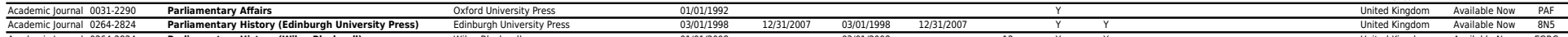

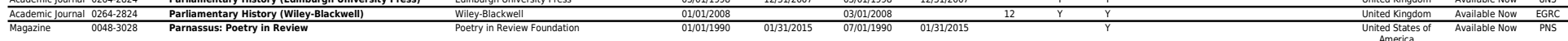

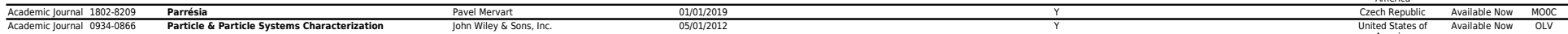

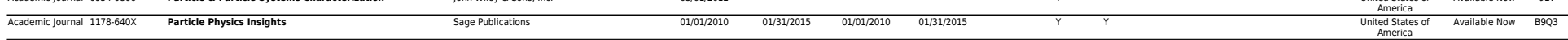

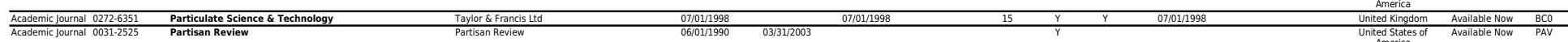

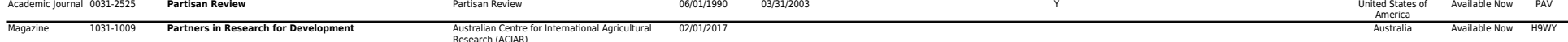

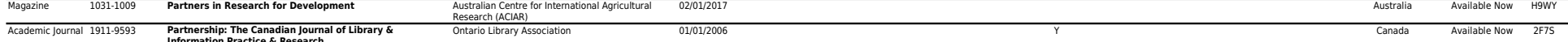

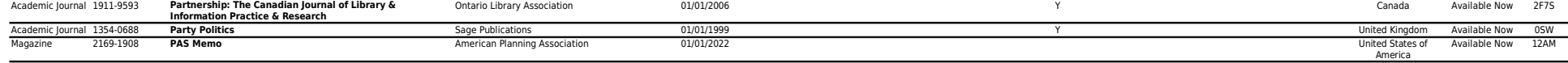

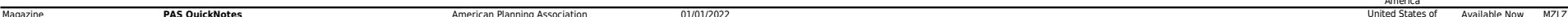

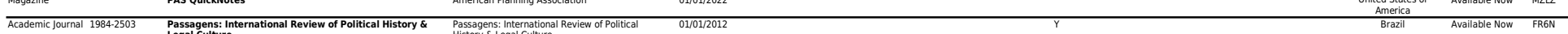

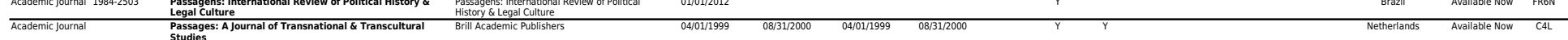

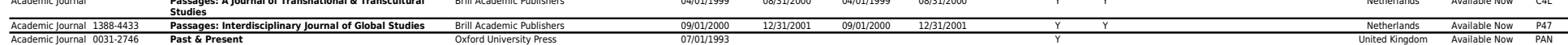

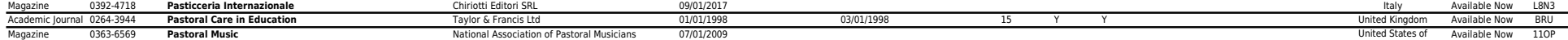

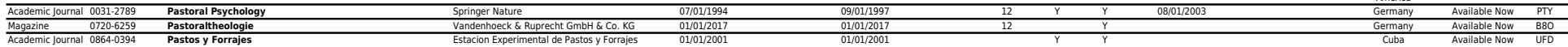

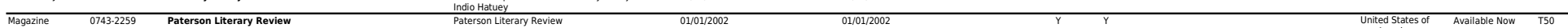

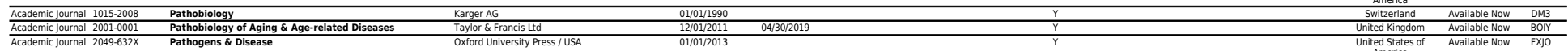

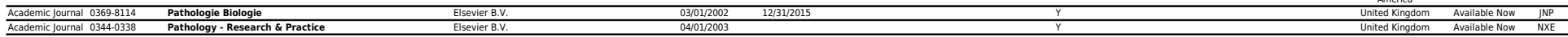

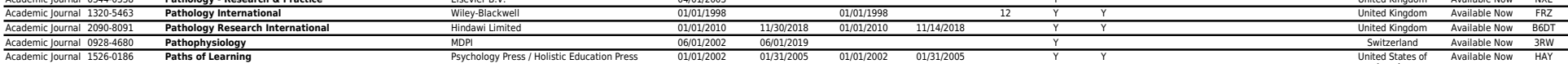

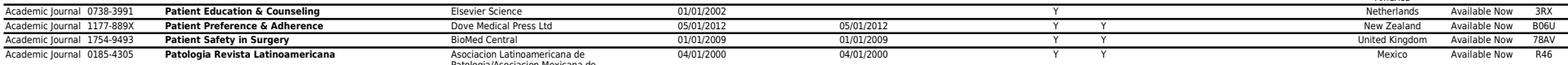

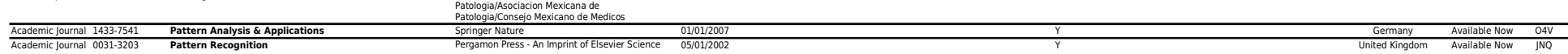

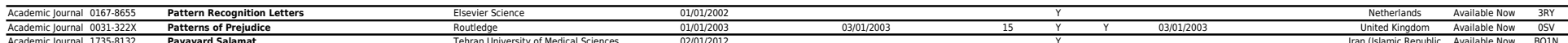

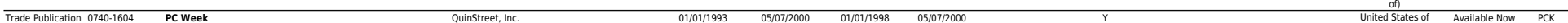
America

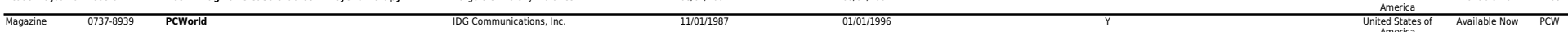

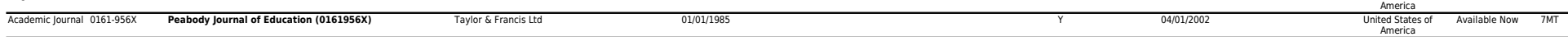

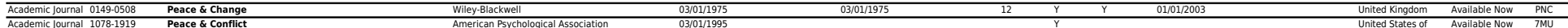

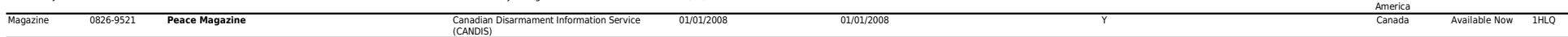

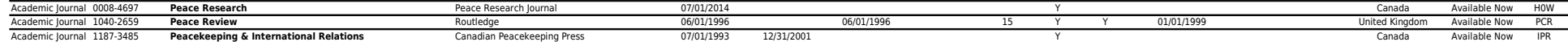

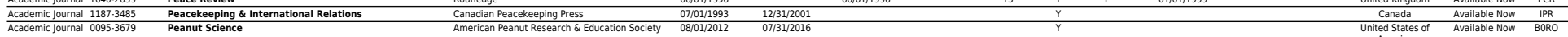

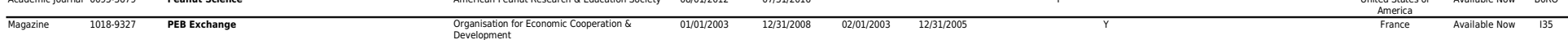




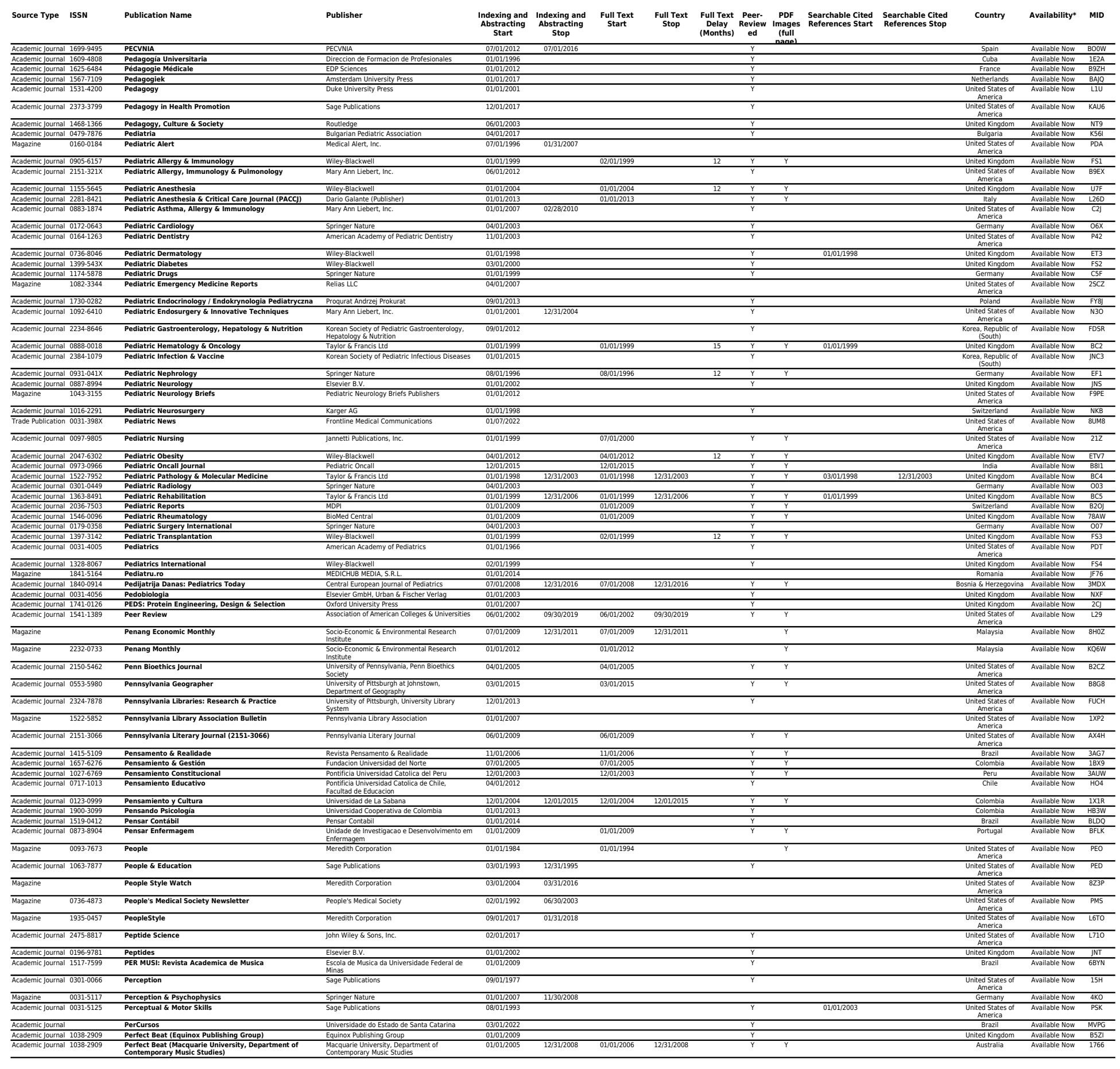




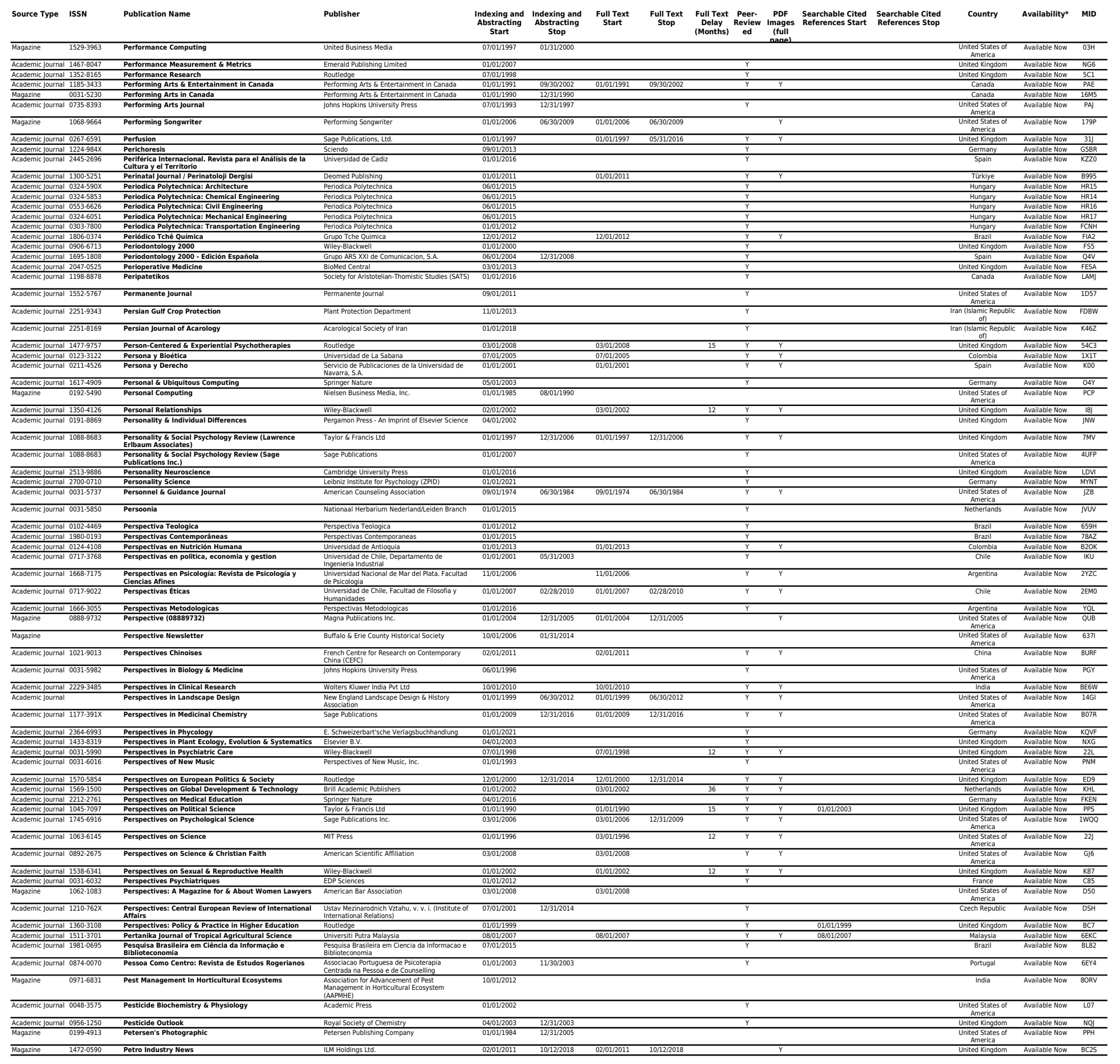




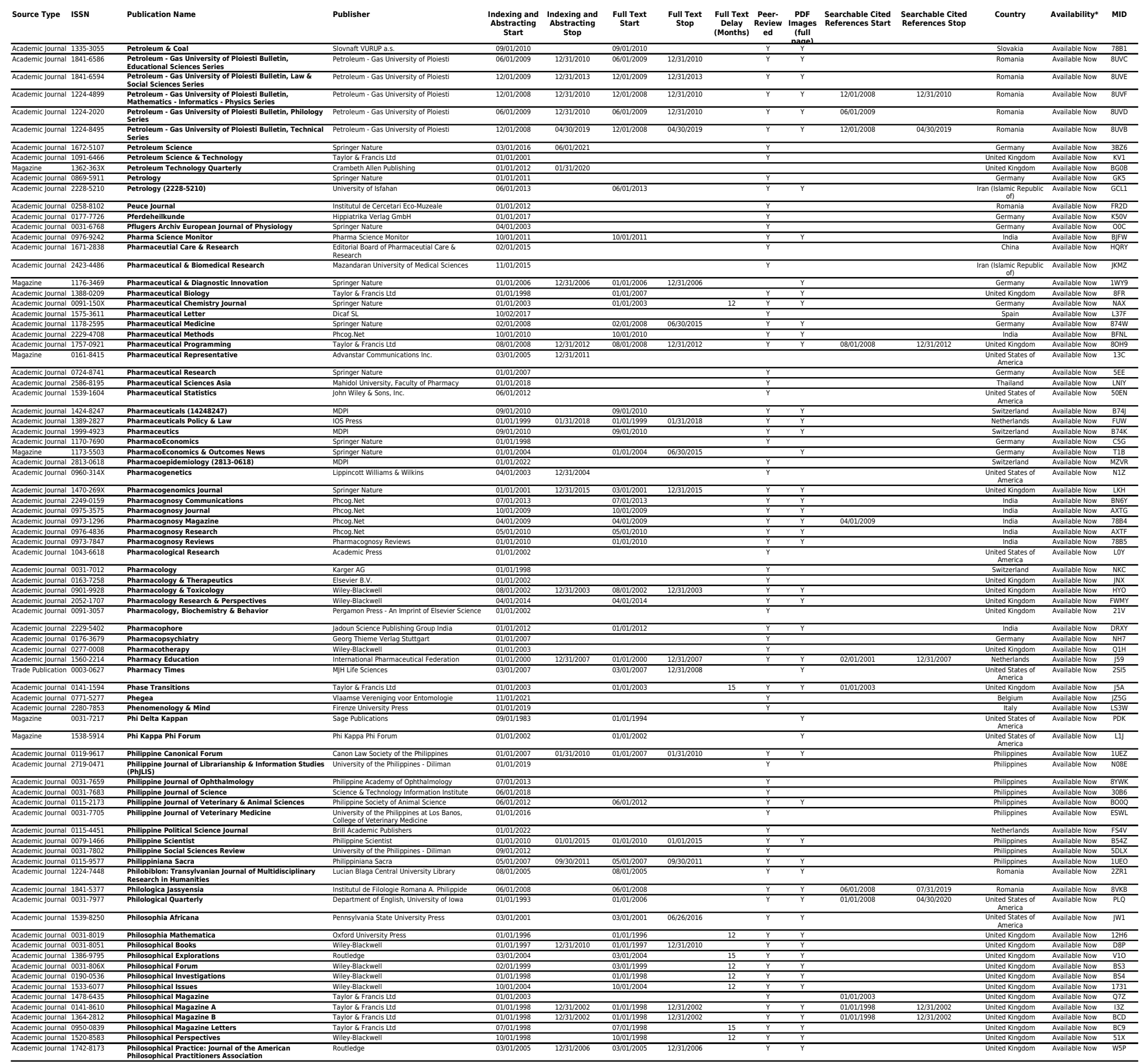




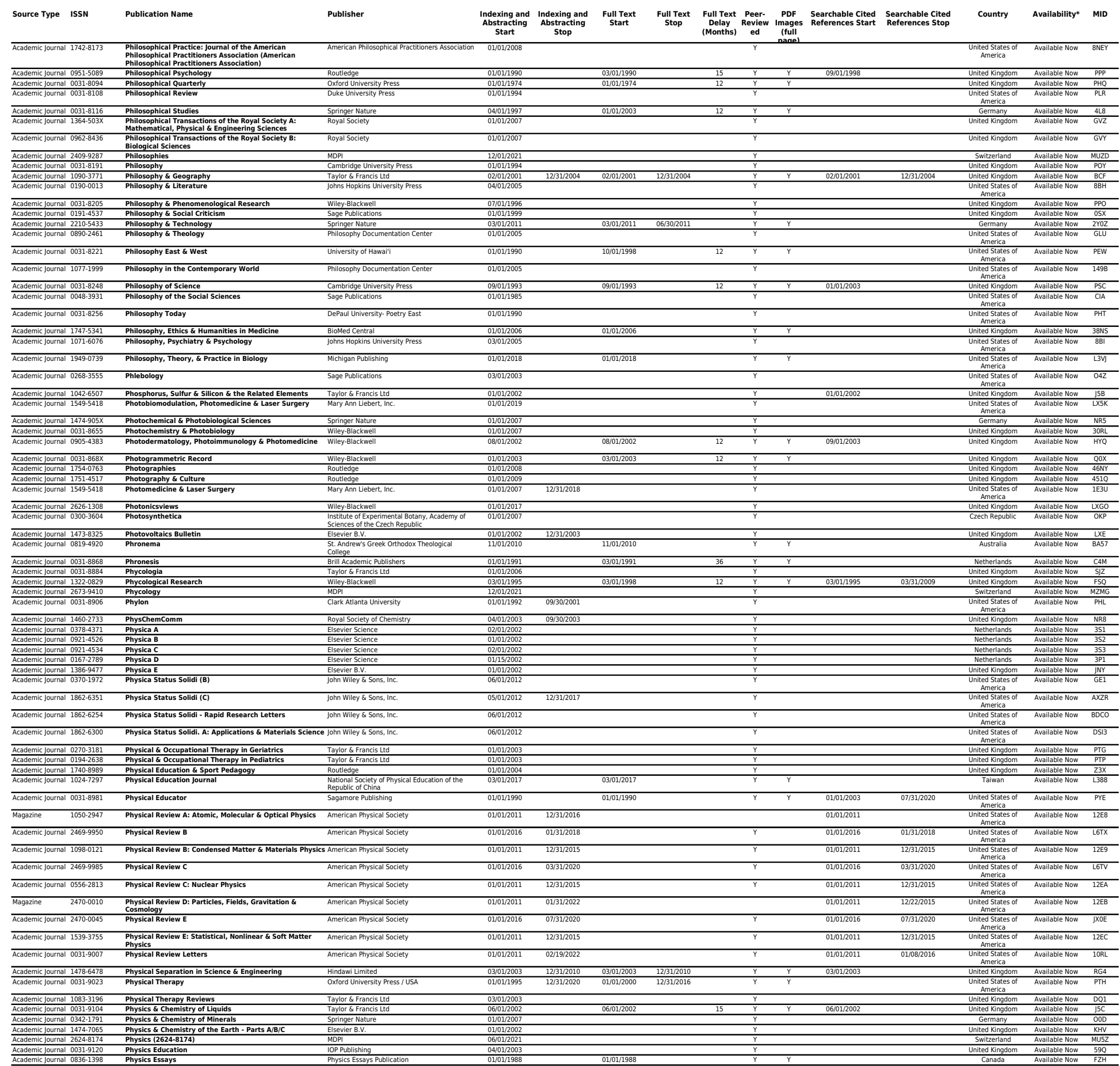




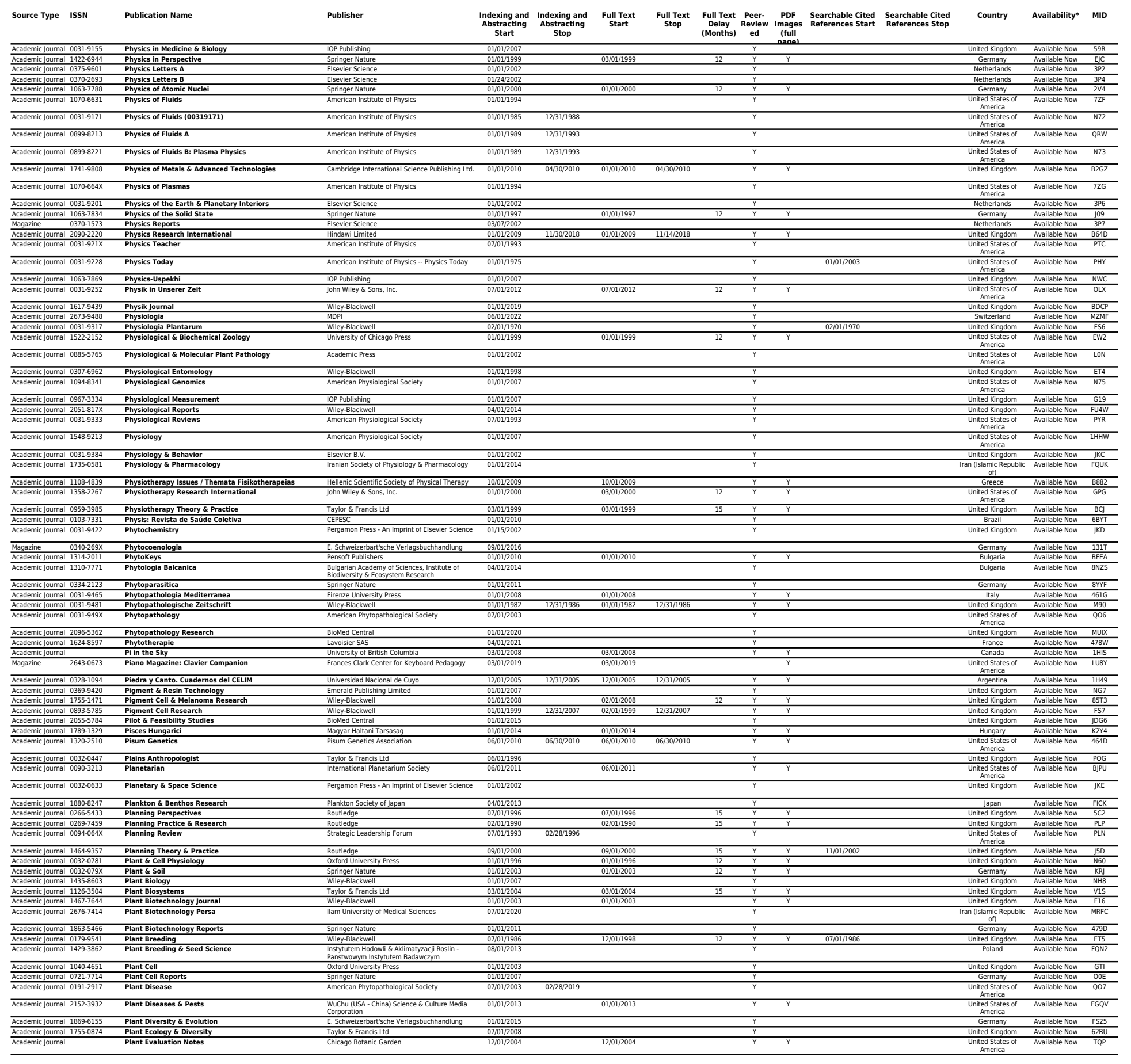




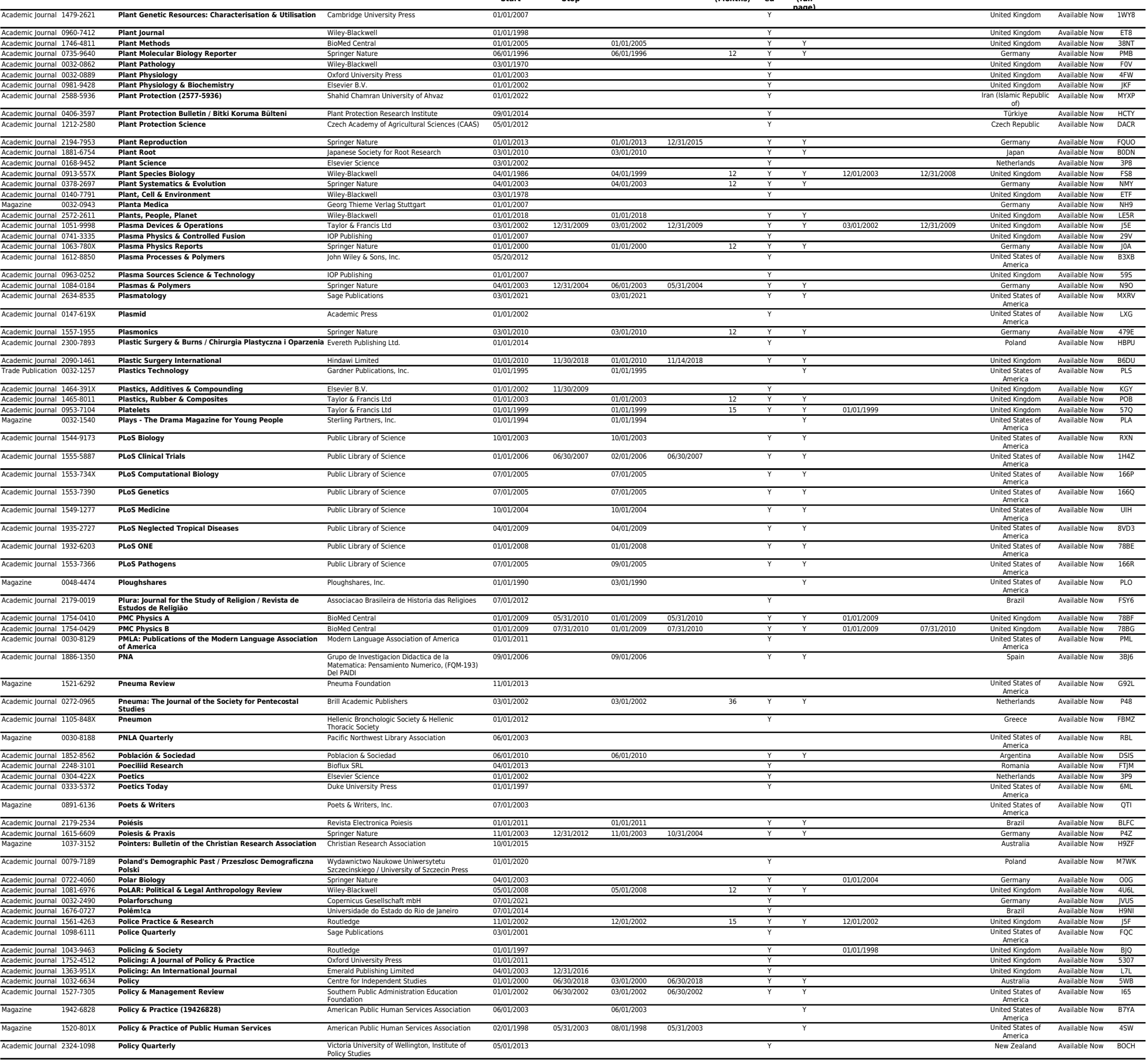




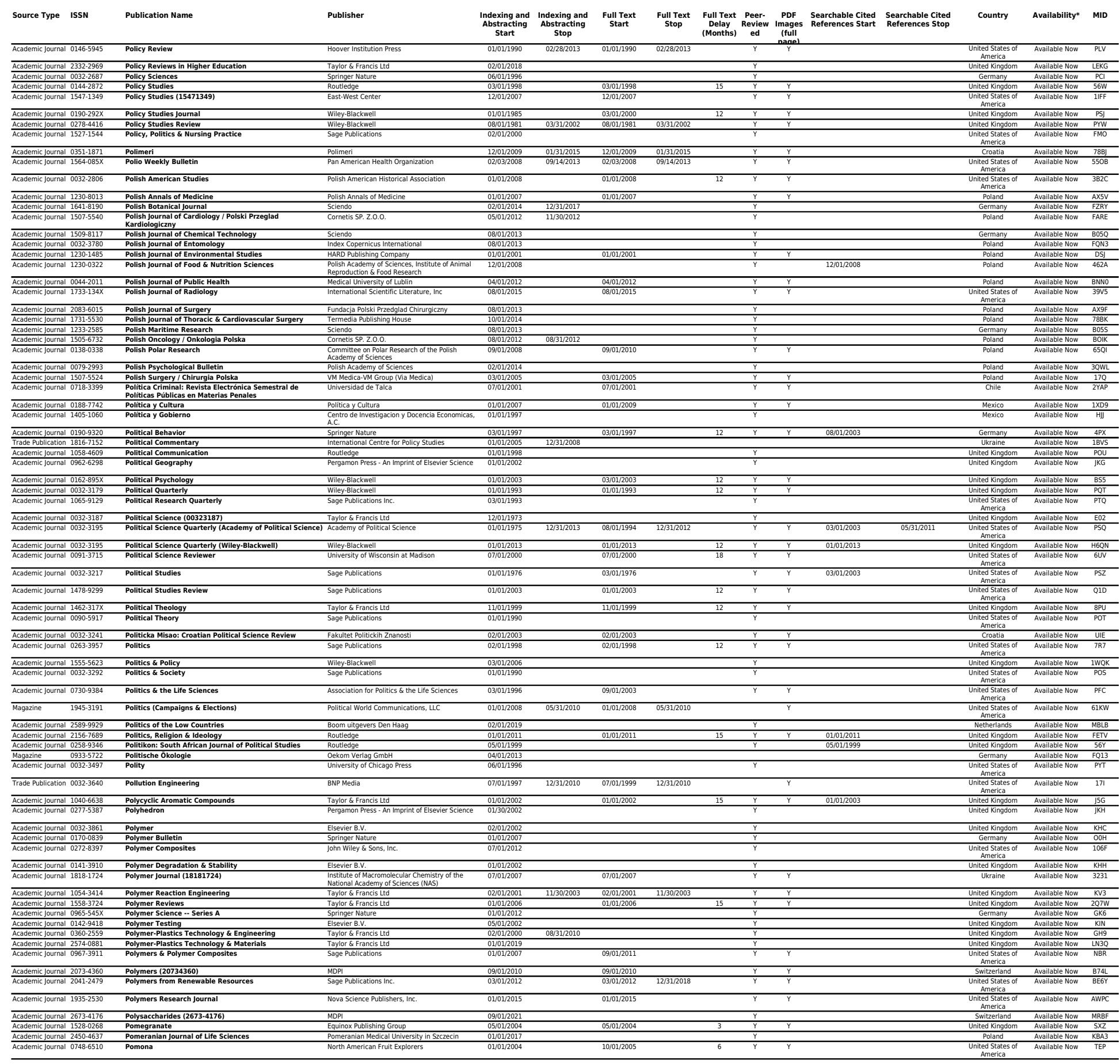




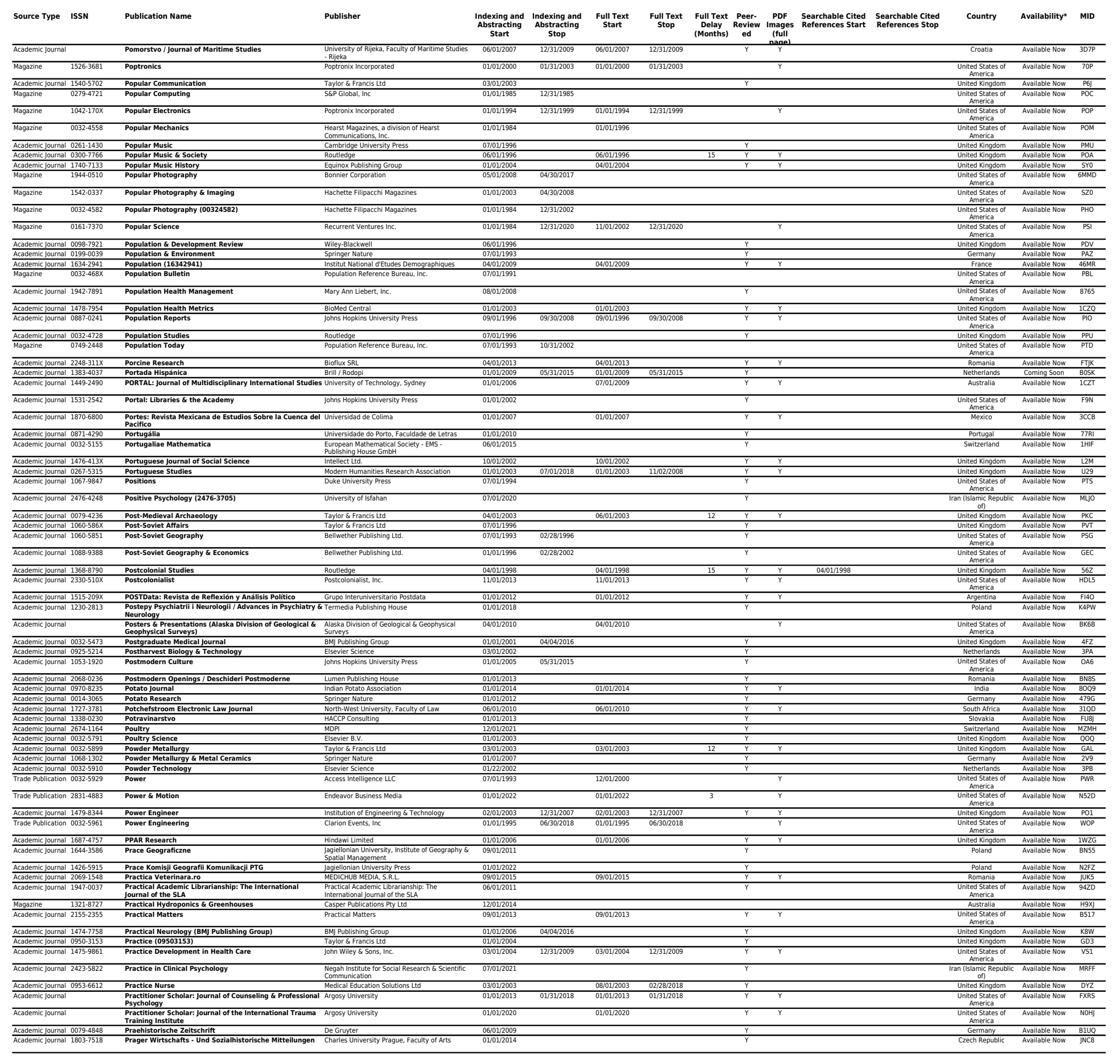




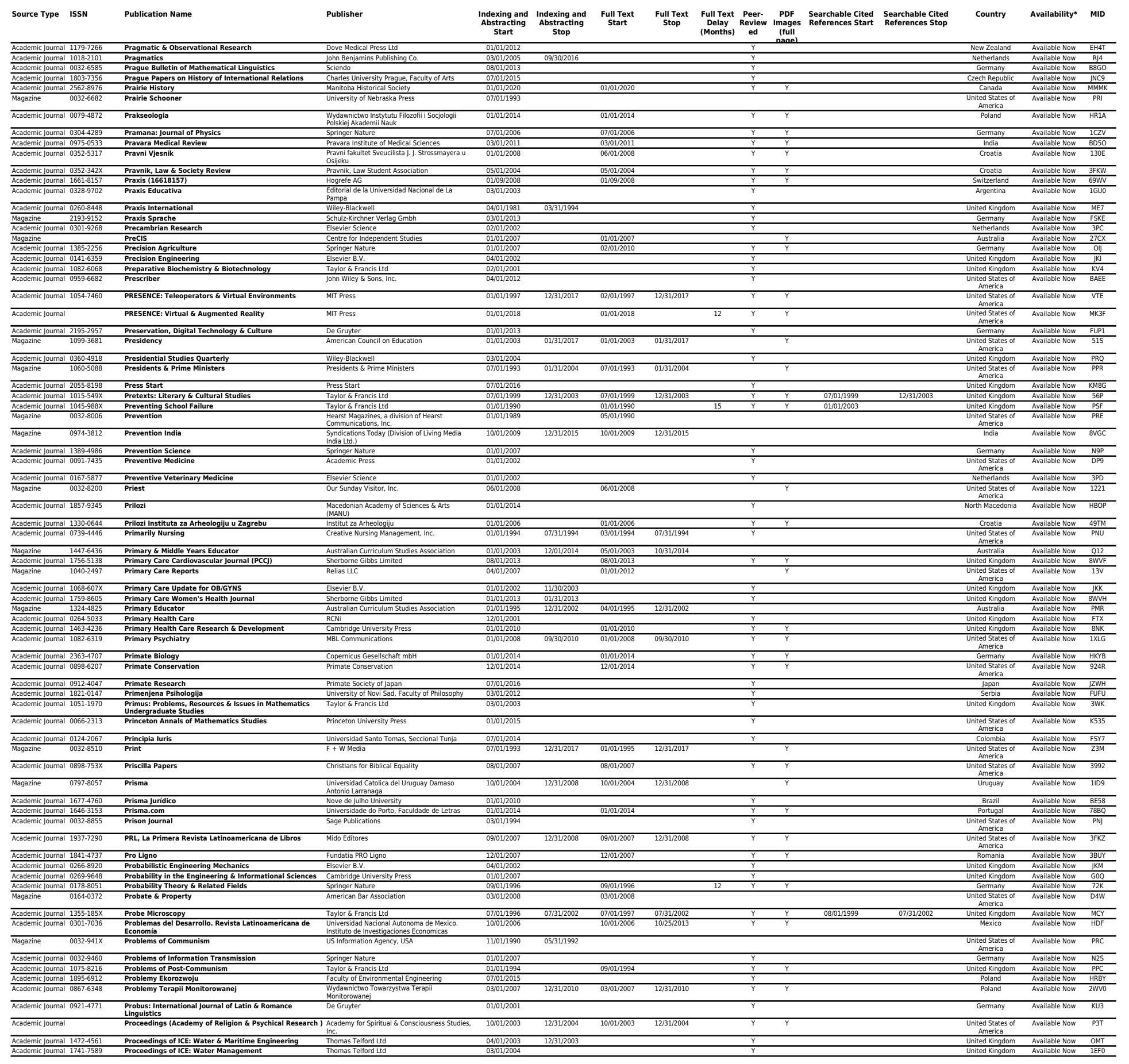




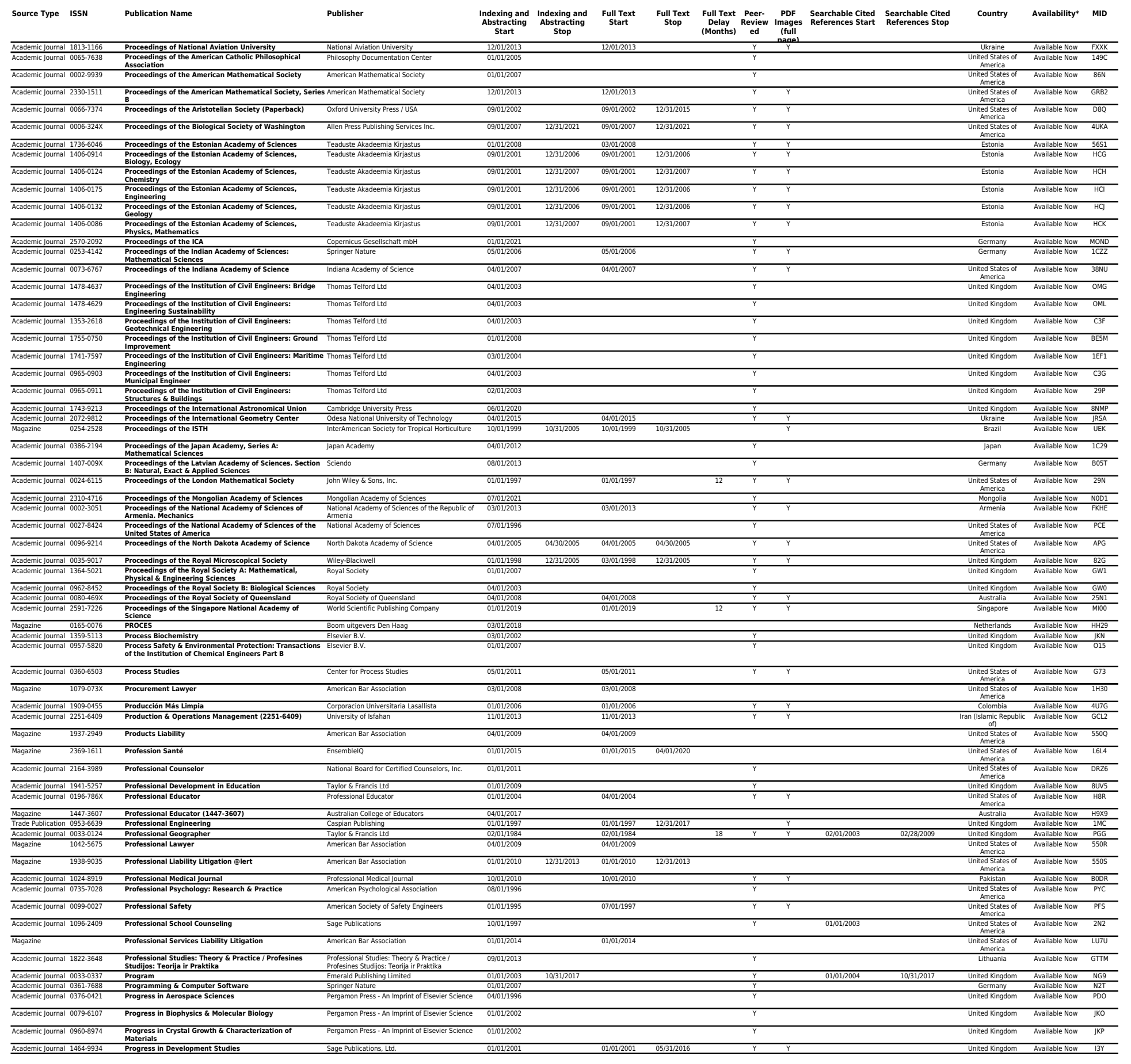


Accademic Journal 0360-1285 Progress in Energy \& combustion Science Pergamon Press-An Imprint of Elesever Science 0110

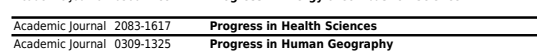

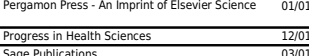
United Kngdom Avalable Now 29L.

Accodemic Journal $0163-7827 \quad$ Progress in Lipid Research

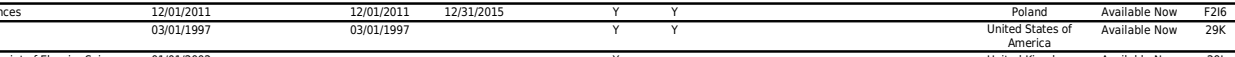
\begin{tabular}{lll}
\hline Academic Journal 0079.6425 & Progress in Materials science \\
\hline Academic licurnal $1673-6273$ & Progress in Modern Biomedicine \\
\hline
\end{tabular}

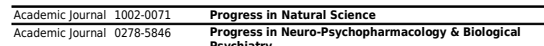

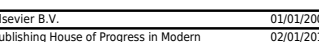

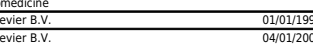

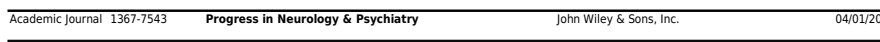

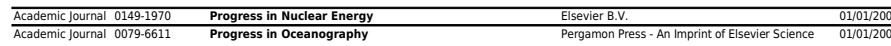

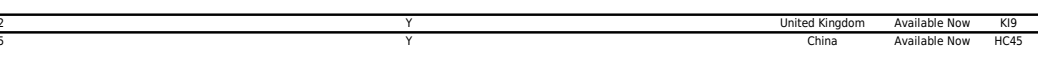

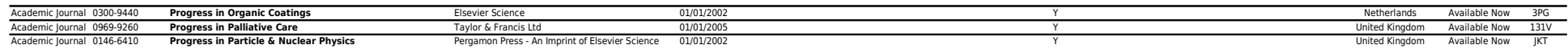

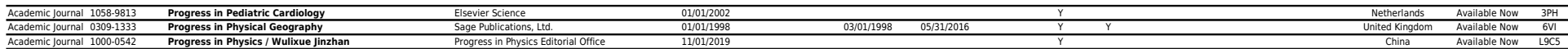

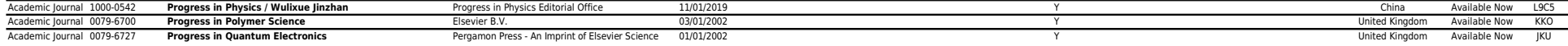

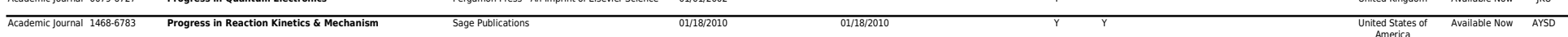

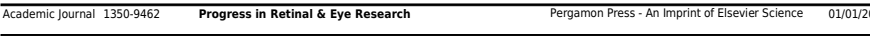

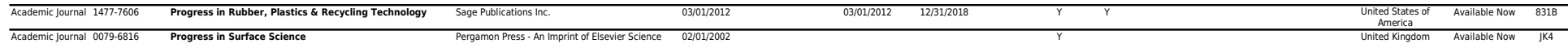

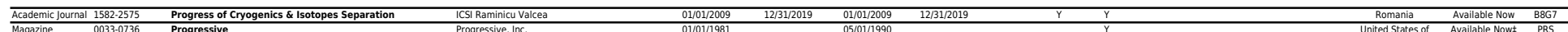

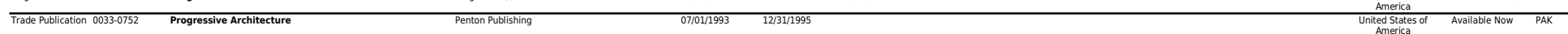

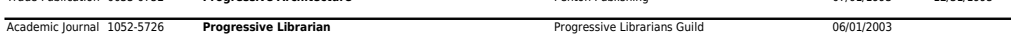

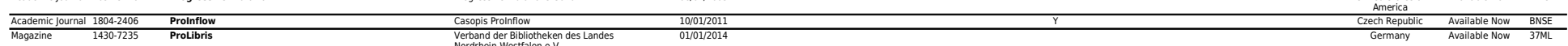

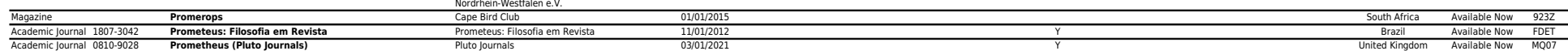

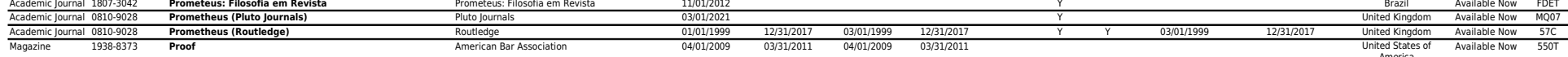

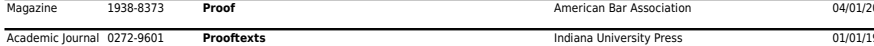

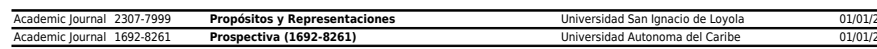
mic Journal 1358-6785

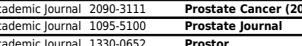
\begin{tabular}{|lll} 
& Springer Nature \\
Hindawi Limite \\
\hline
\end{tabular}

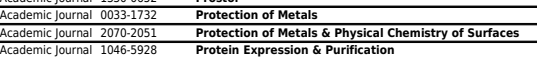

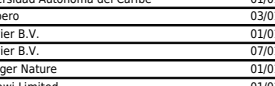


Academic Journal 0103-5564 Psicologia USP

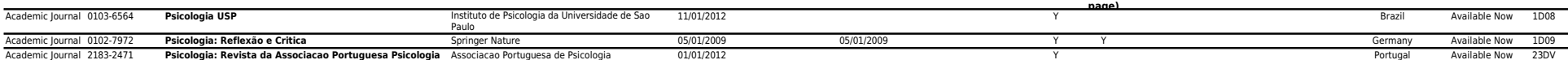

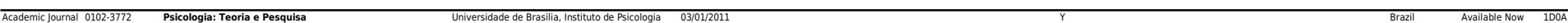

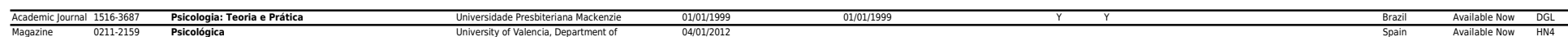

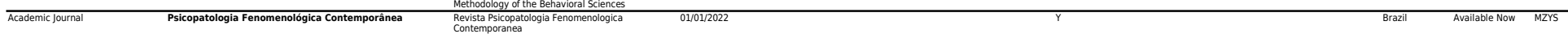

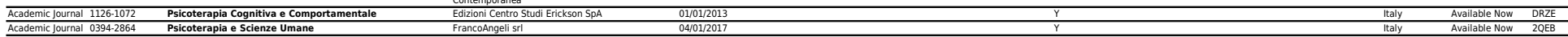

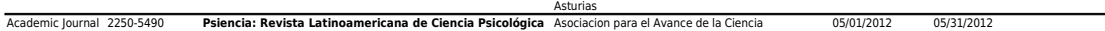

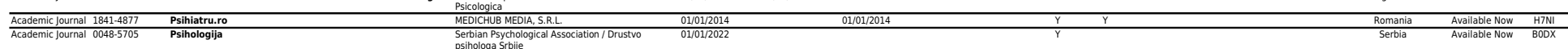

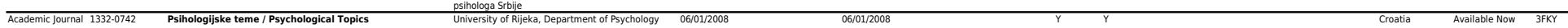

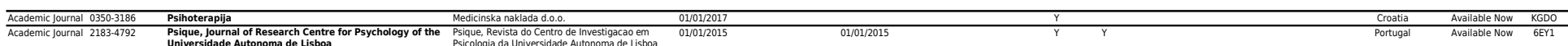

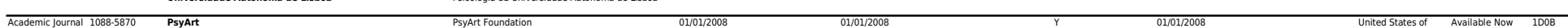

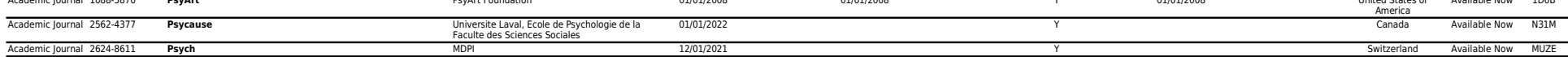

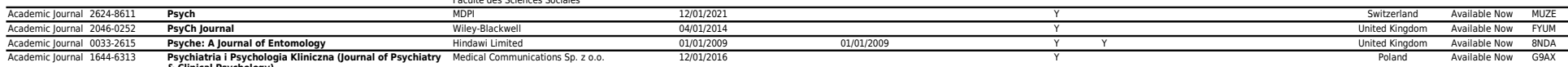

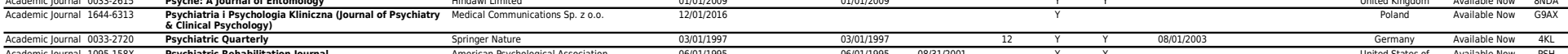

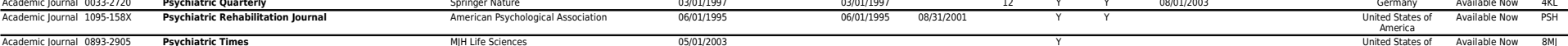

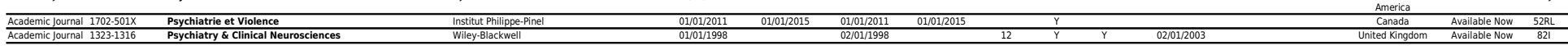

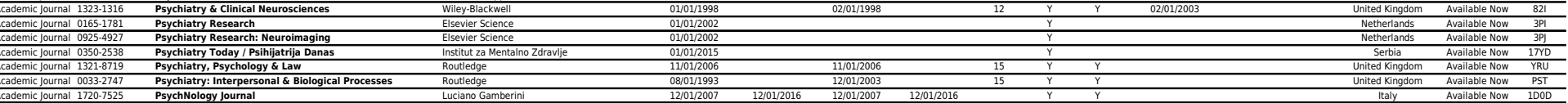

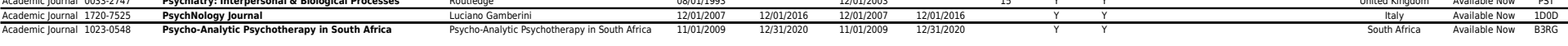

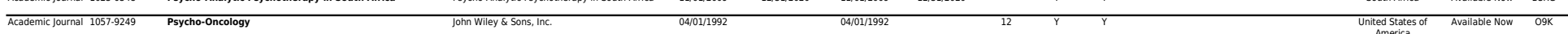

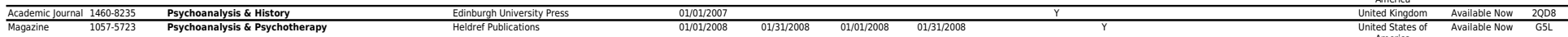

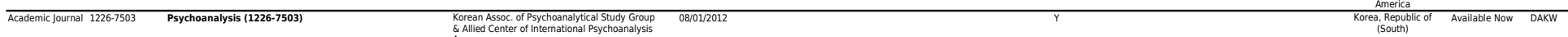

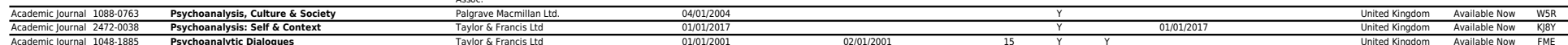

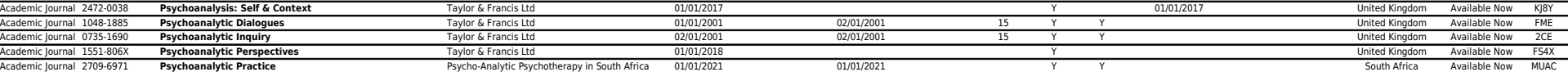

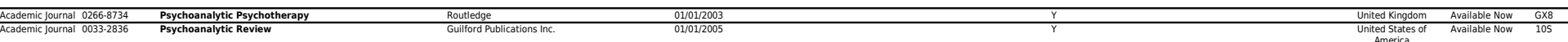

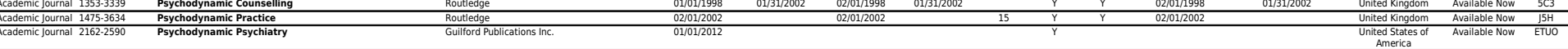

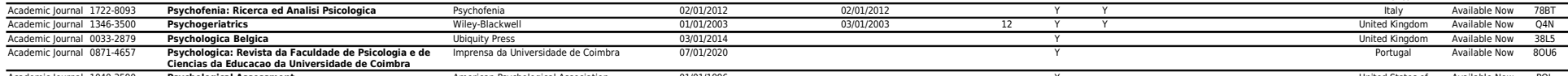

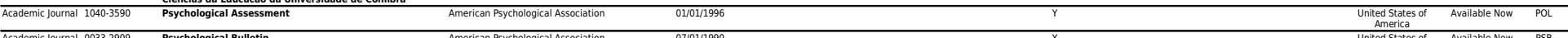

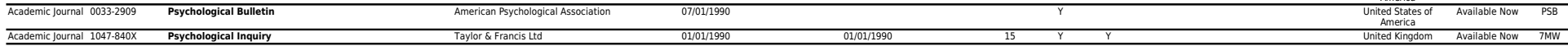

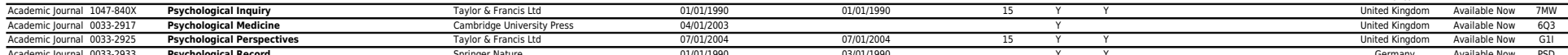

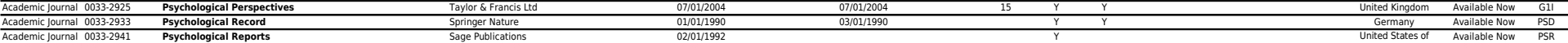

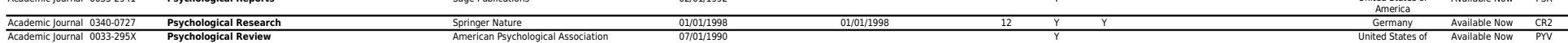

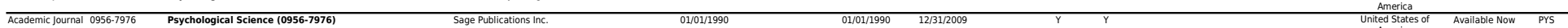

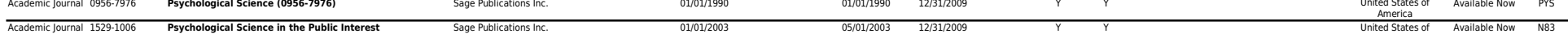

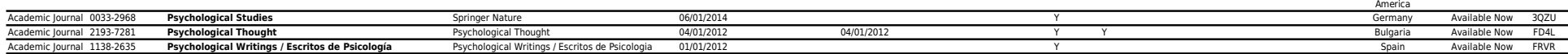

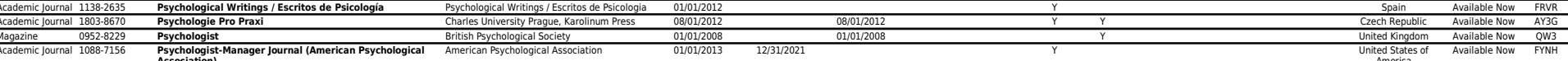

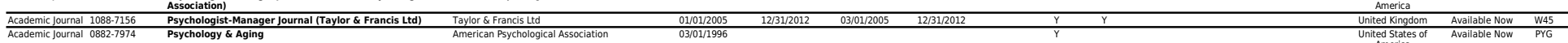

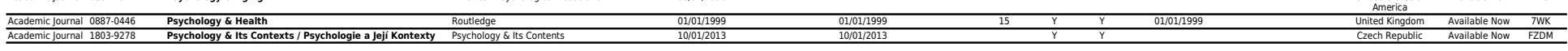




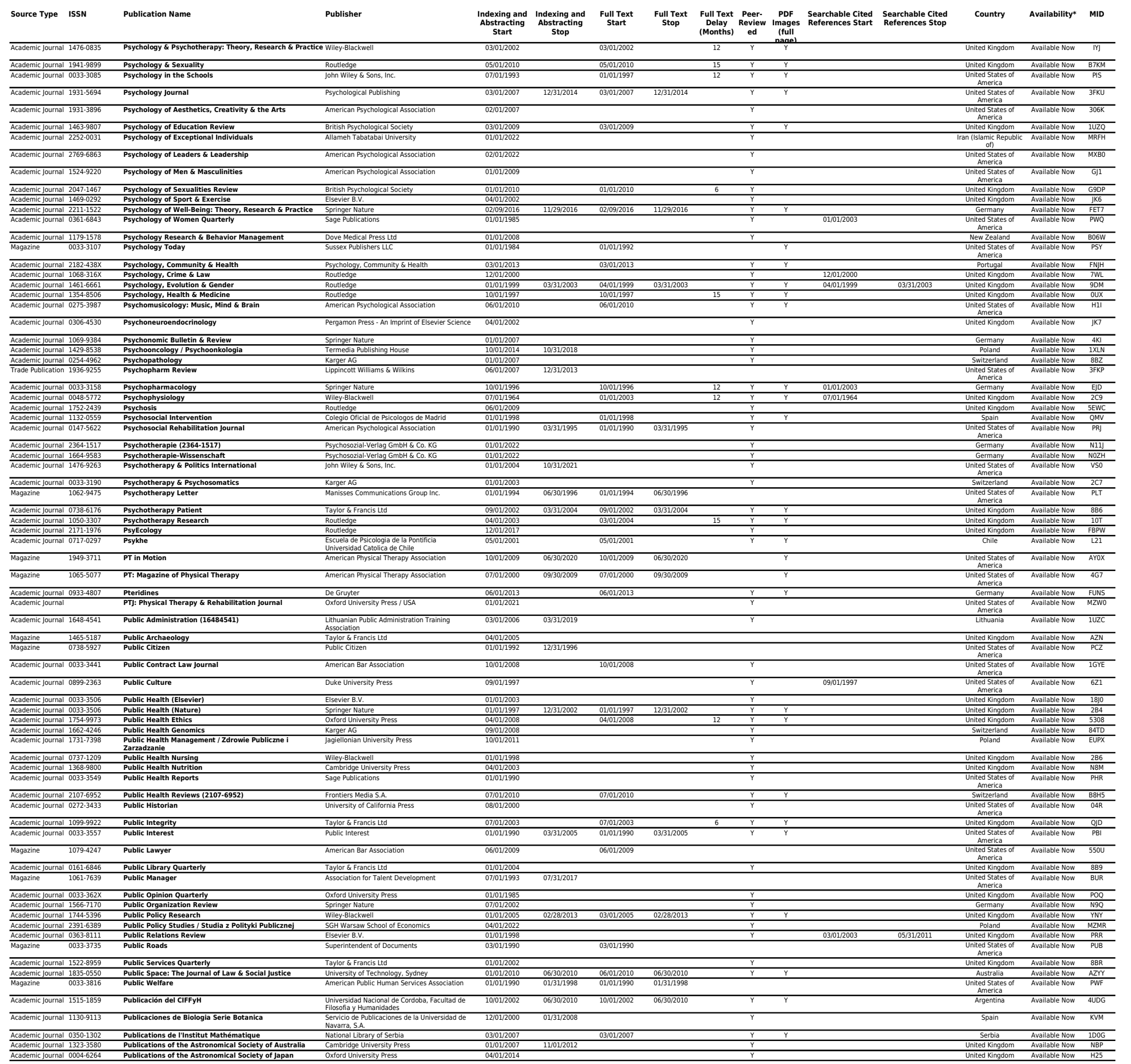




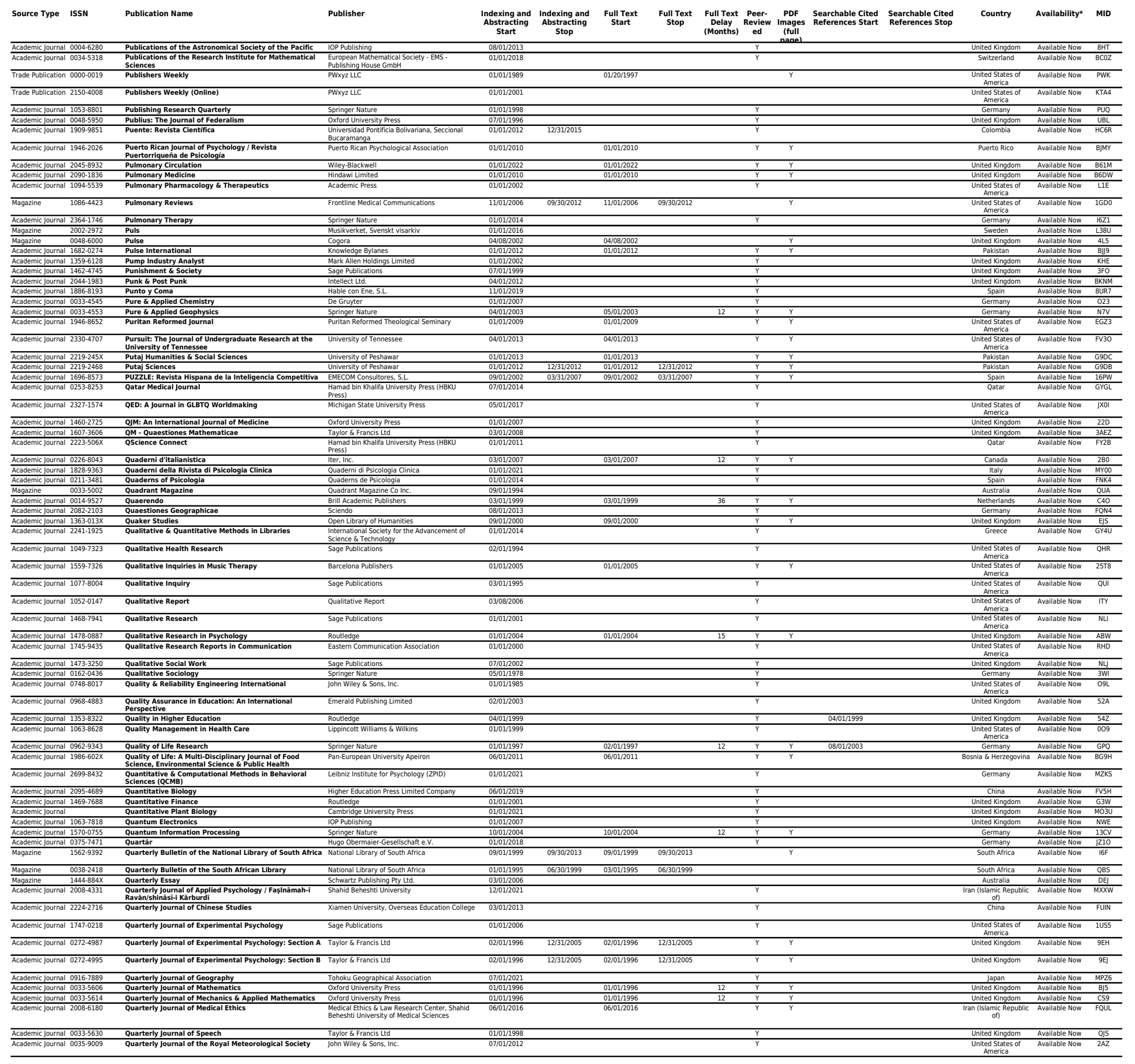




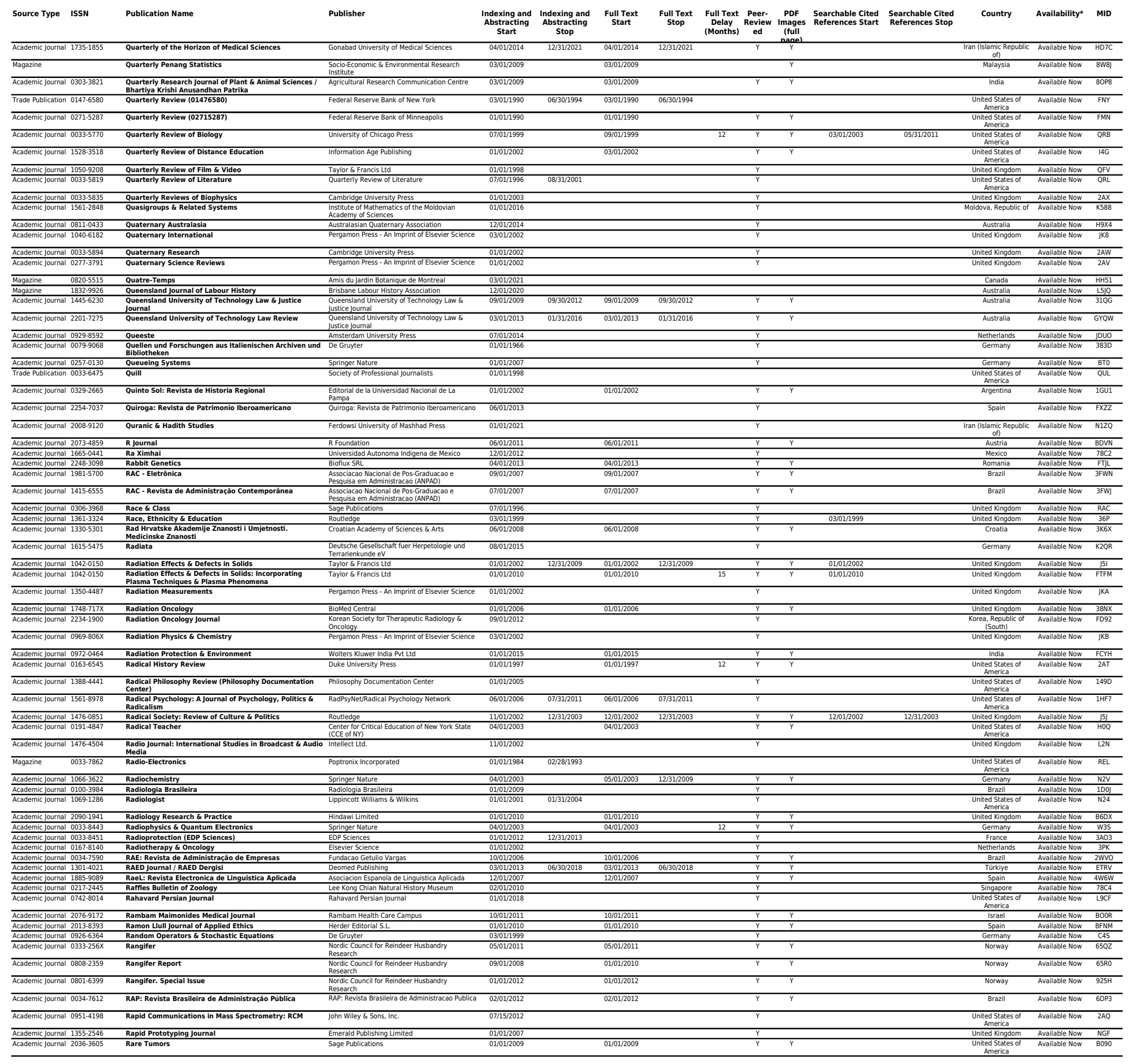




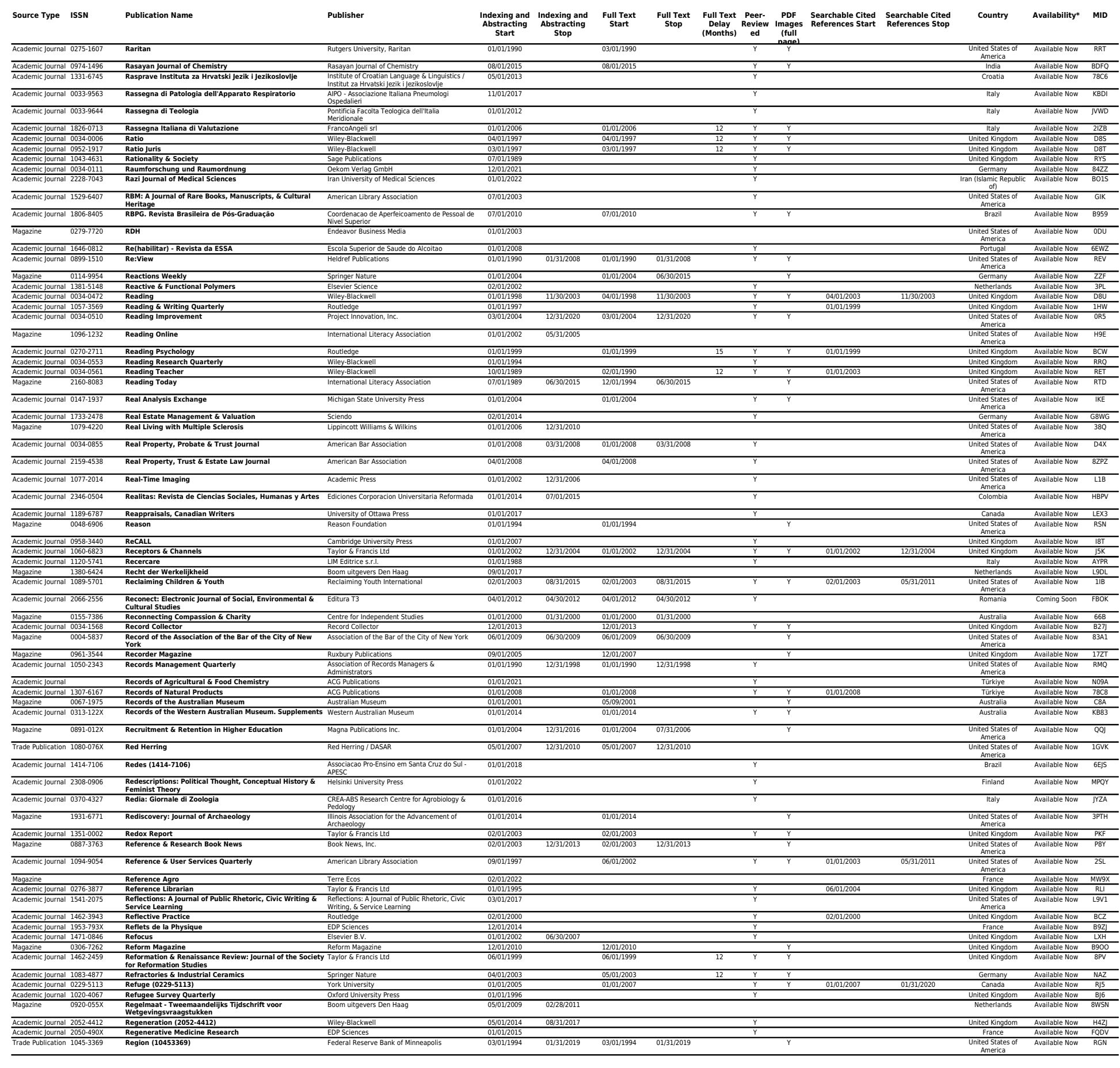




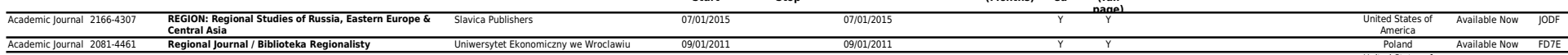

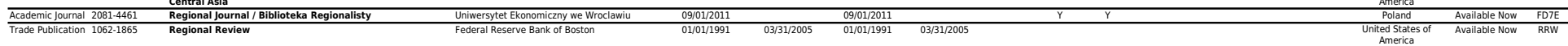

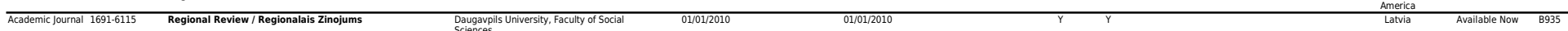

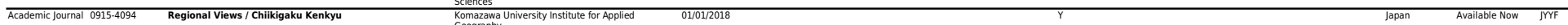

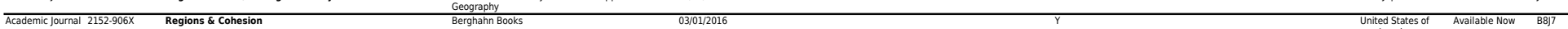

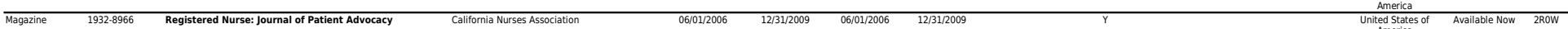

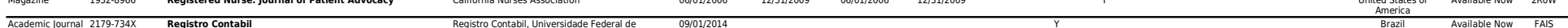

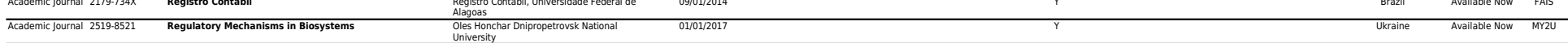

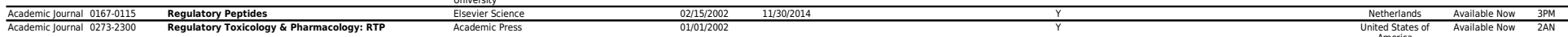

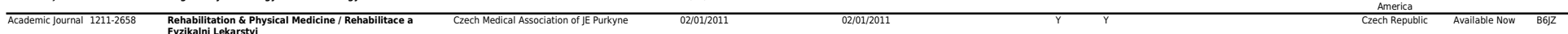

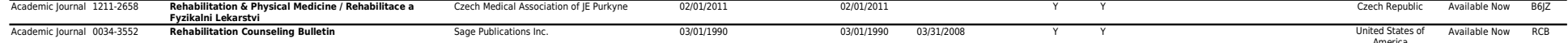

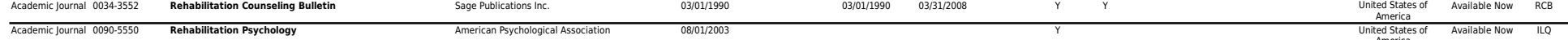

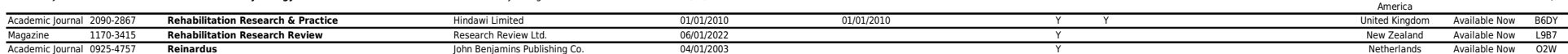

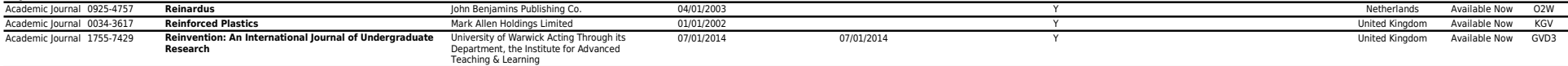

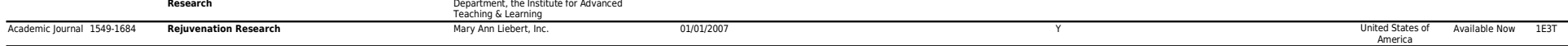

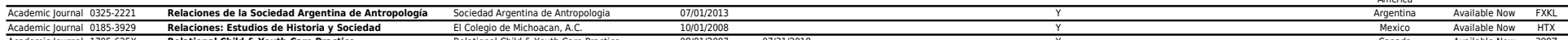

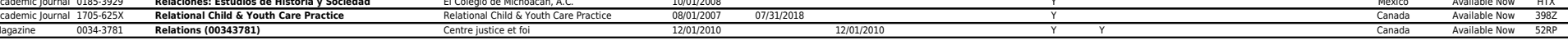

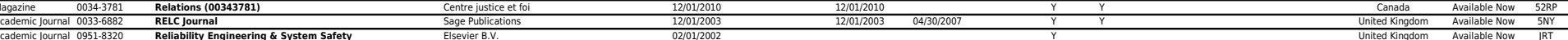

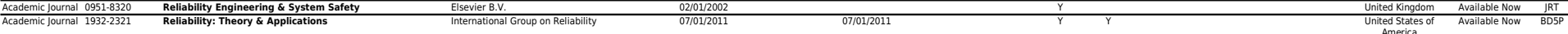

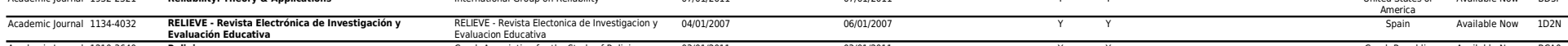

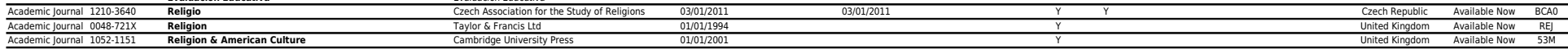

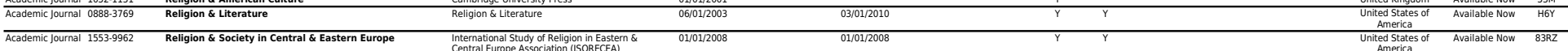

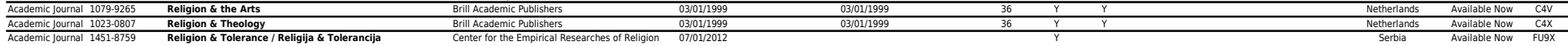

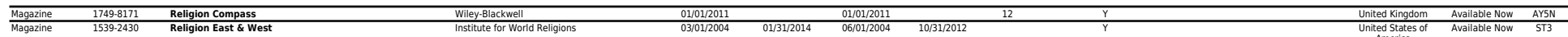

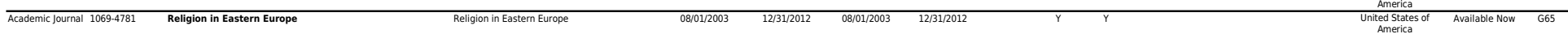

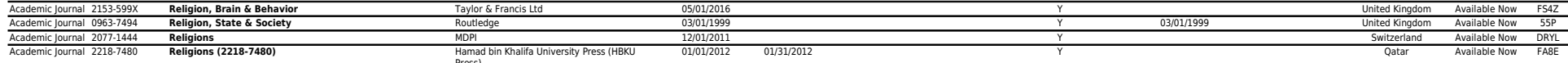

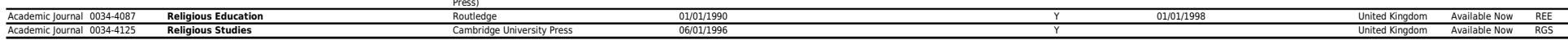

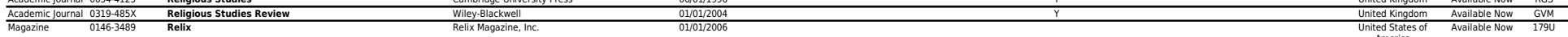

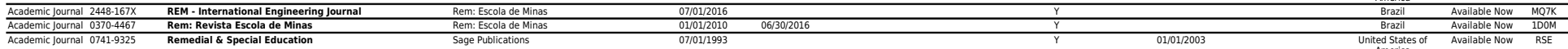

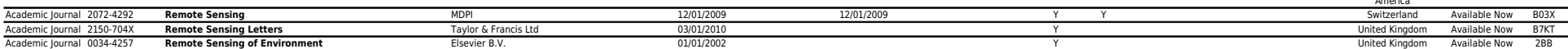

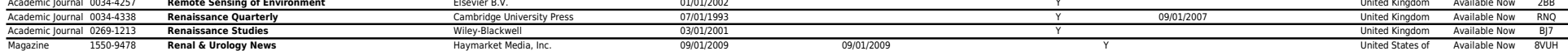

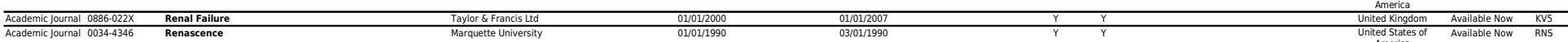

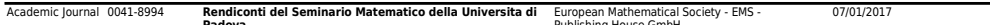

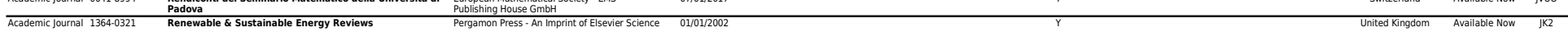

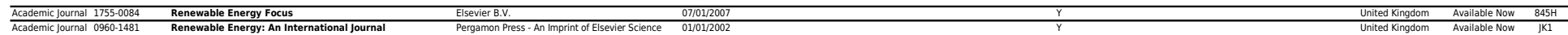

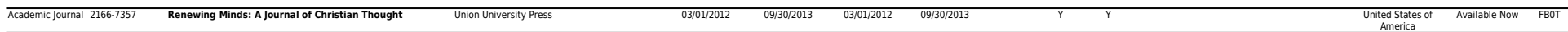

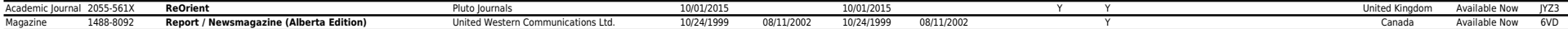

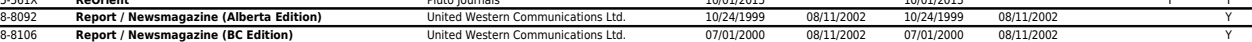

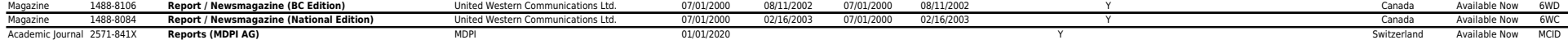

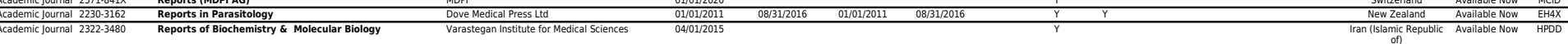

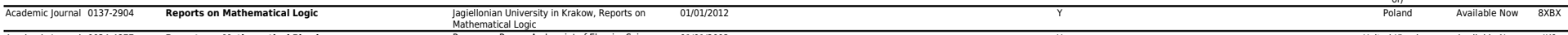

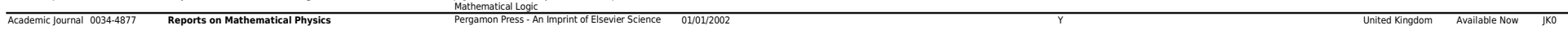

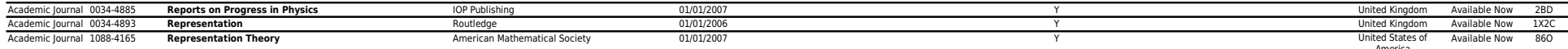




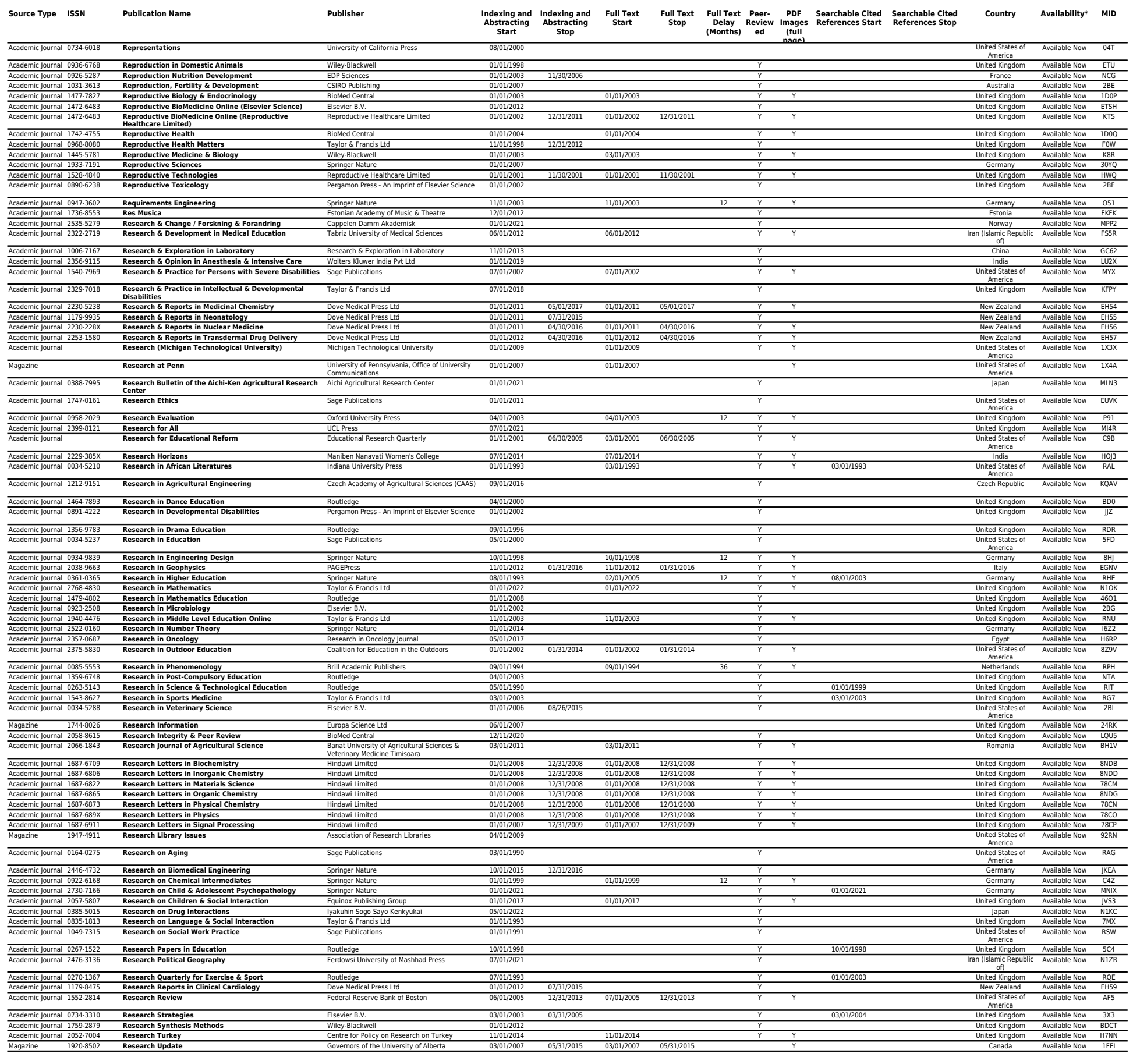




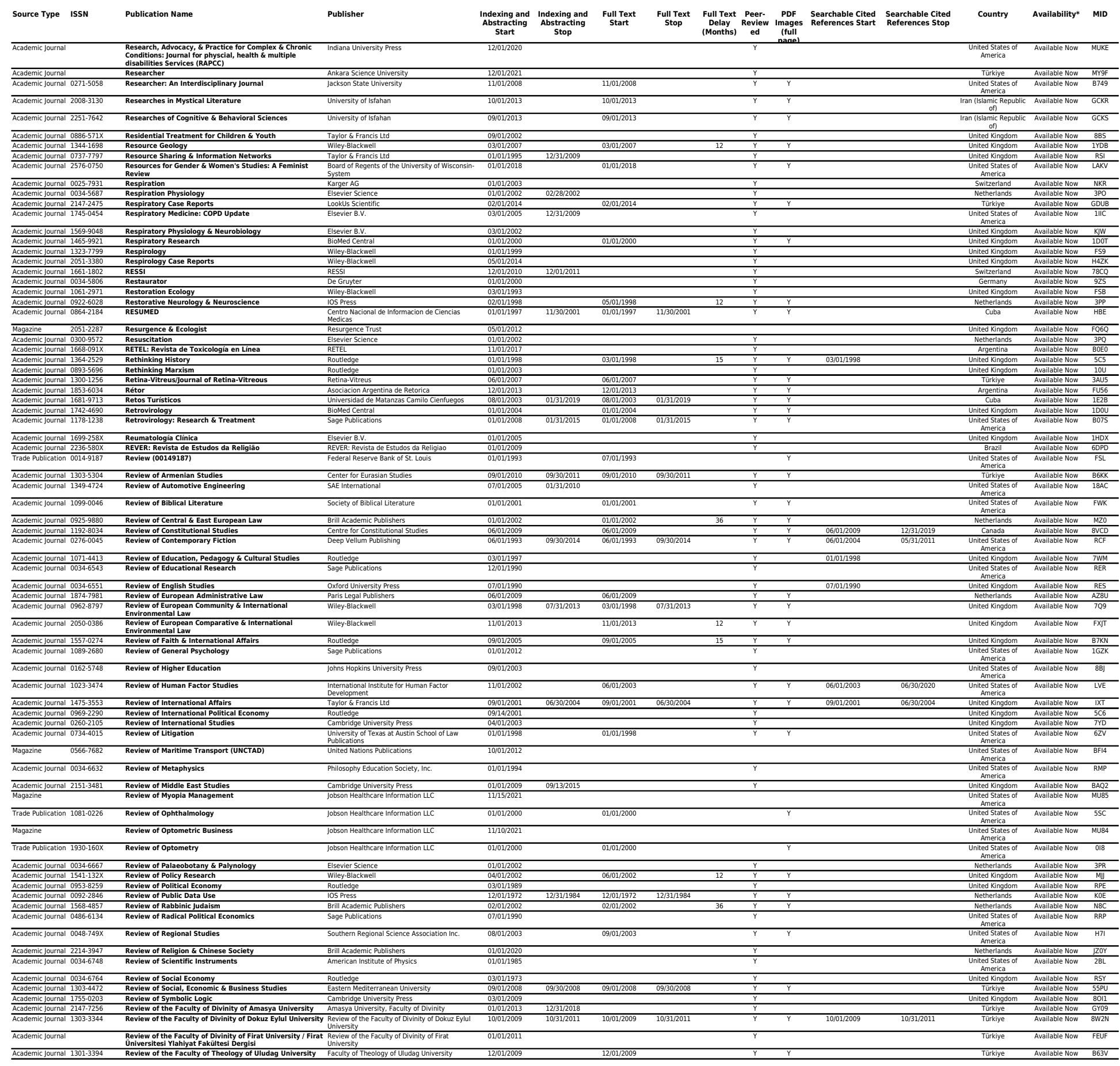




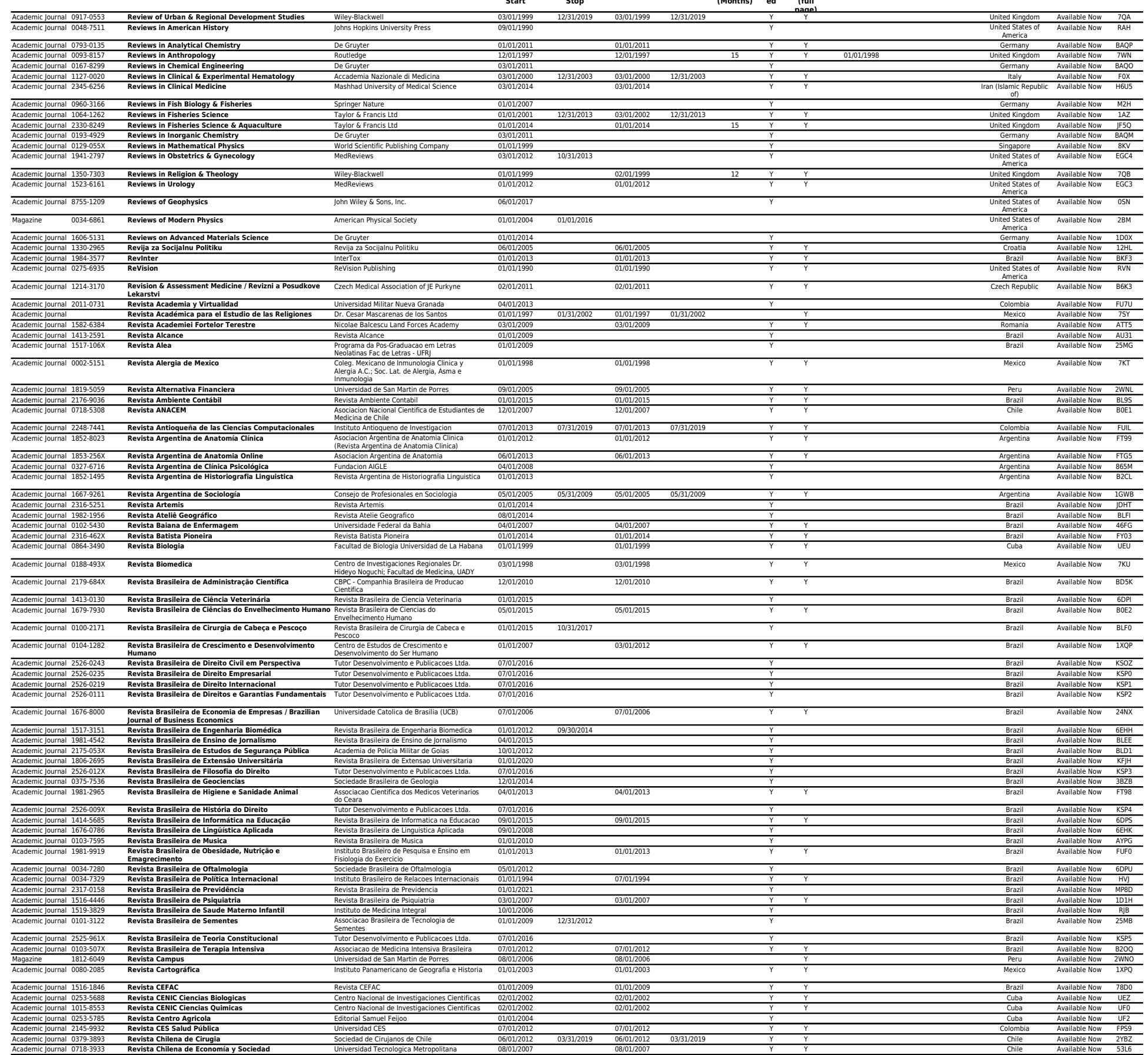




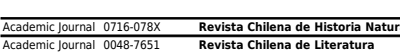

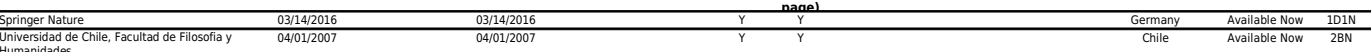

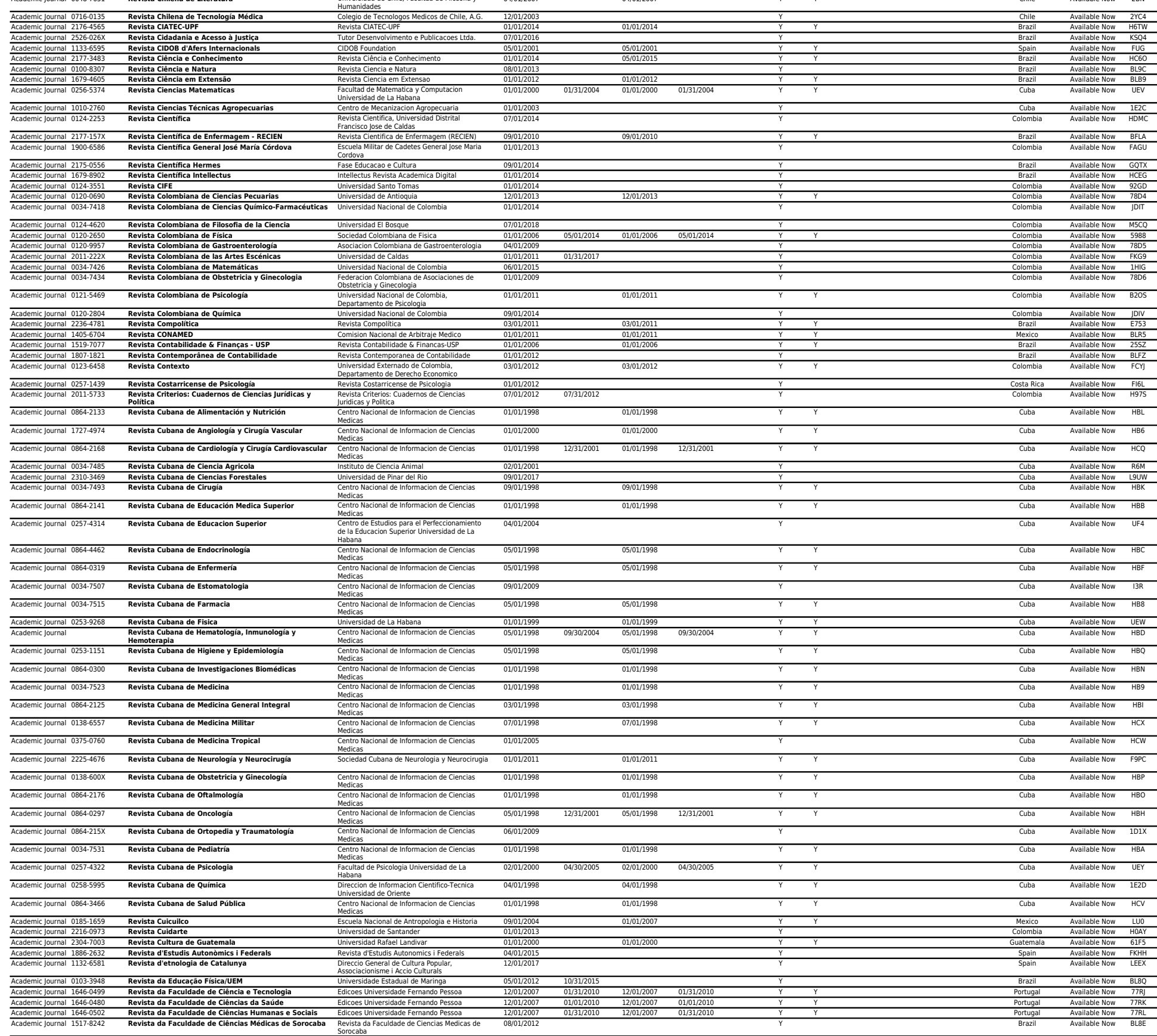




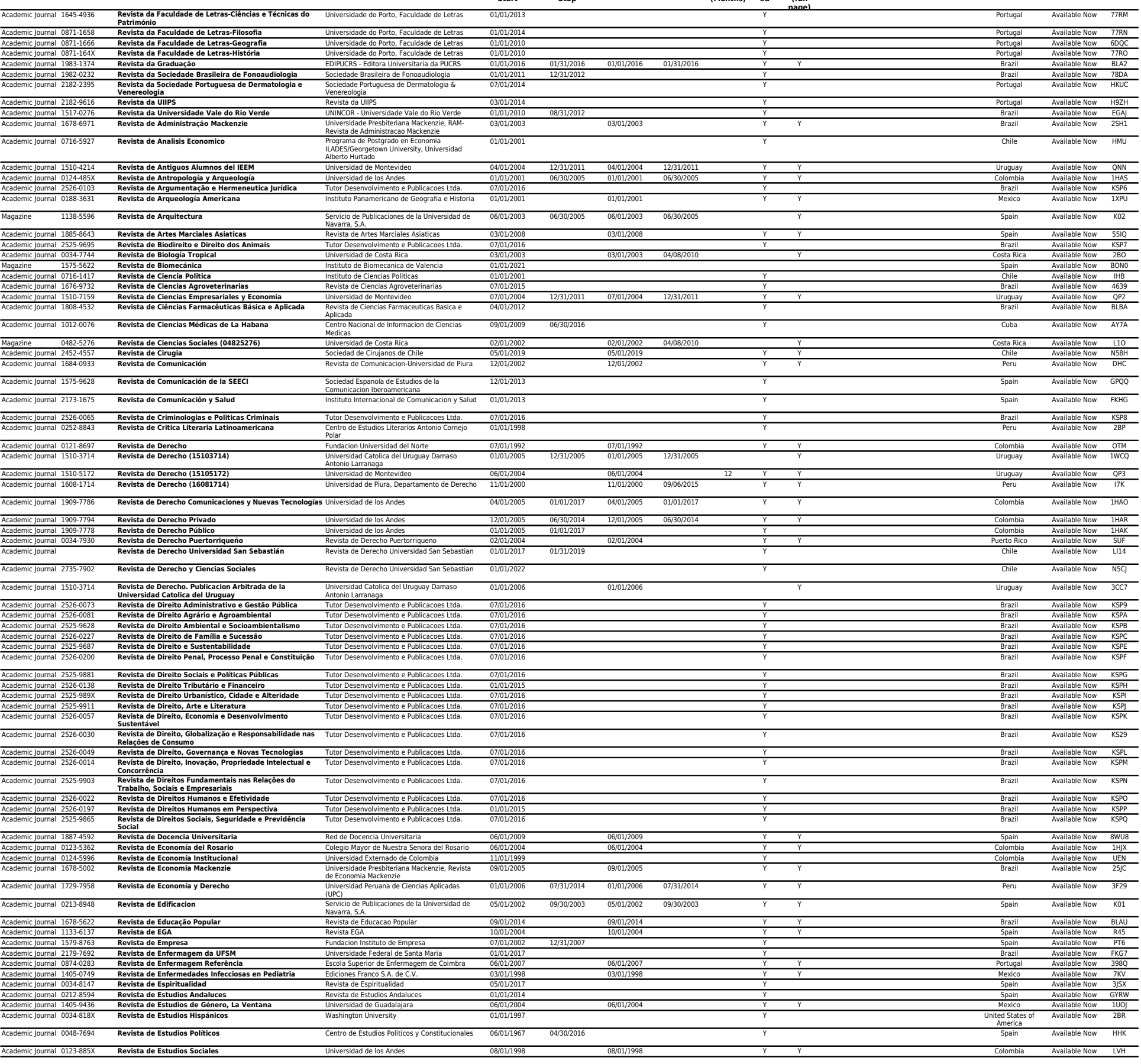




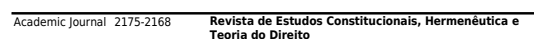

Universidade do vale co Rio dos S S Inos

Brazll ${ }_{\text {Avalable Now BBCF }}$

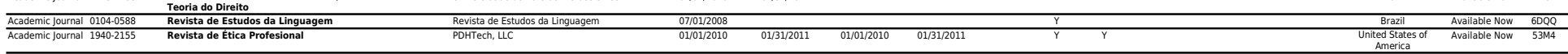

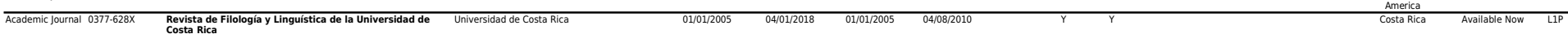

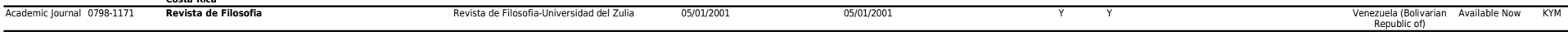

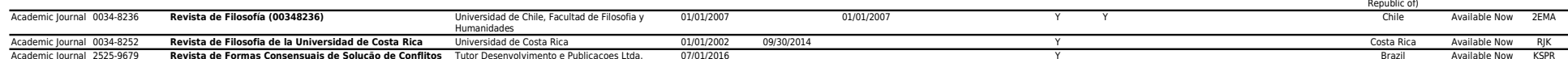

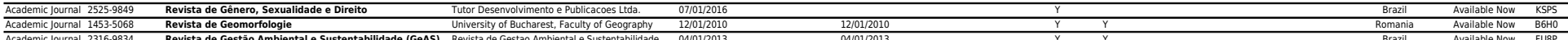

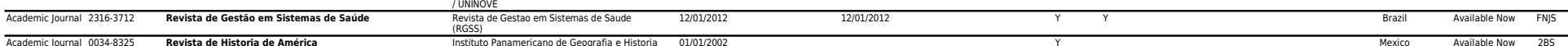

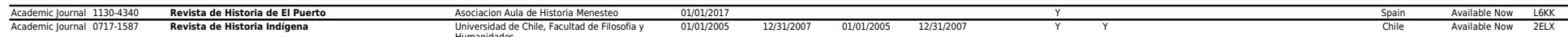
ardeniclom

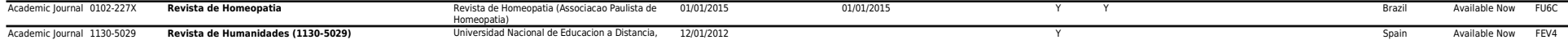

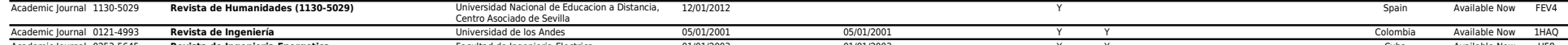

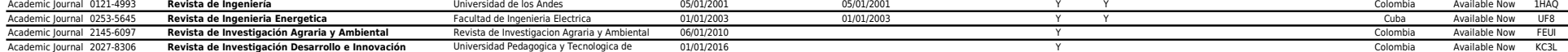

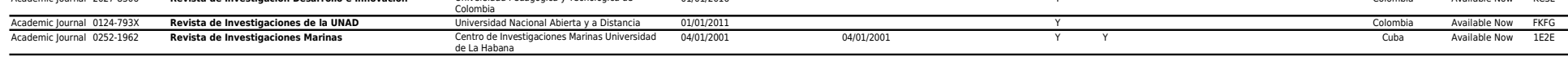

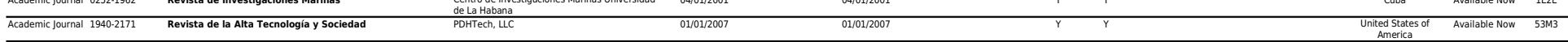

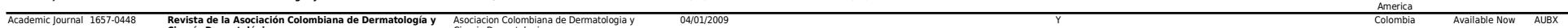

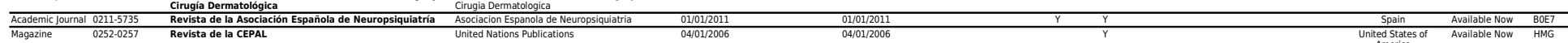

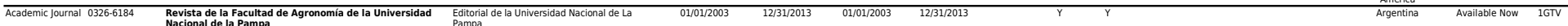

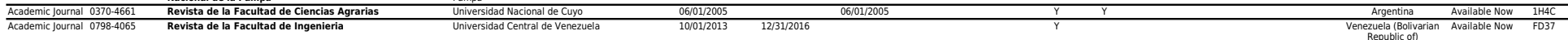

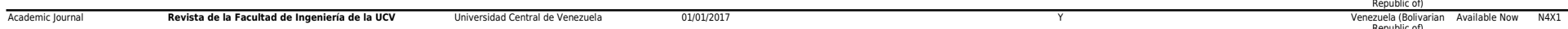

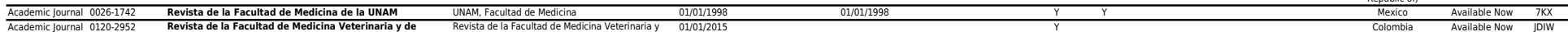

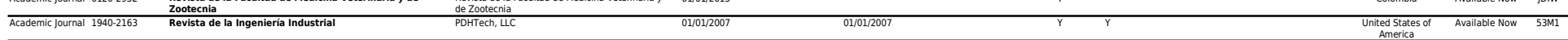

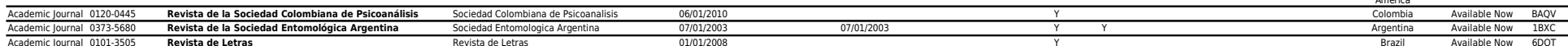

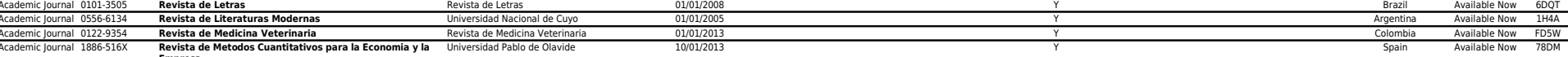

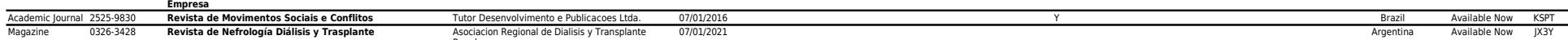

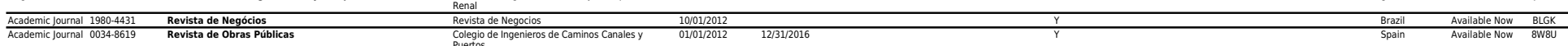

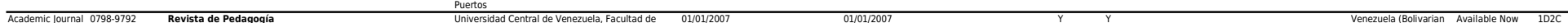

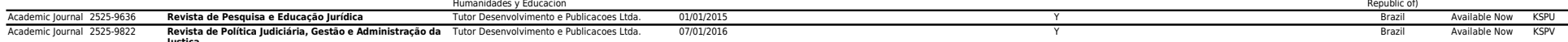

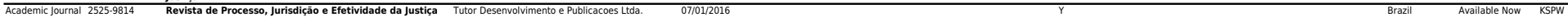

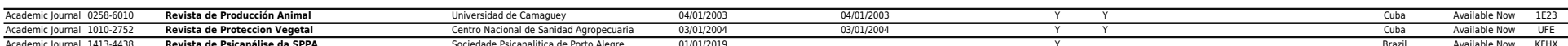

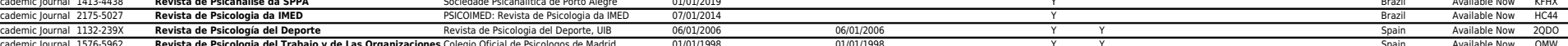

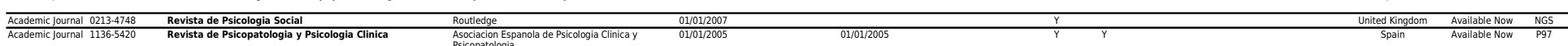

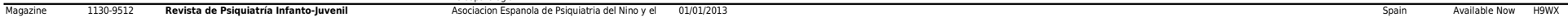

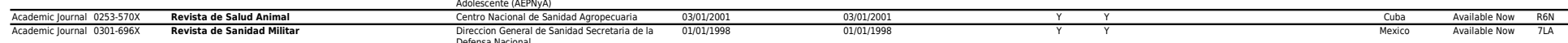

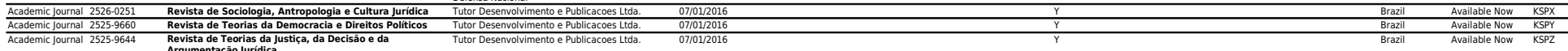

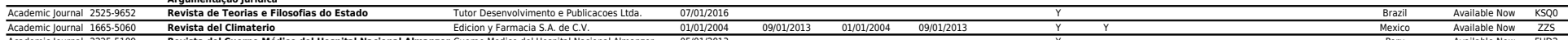
Aggunaga a senjo

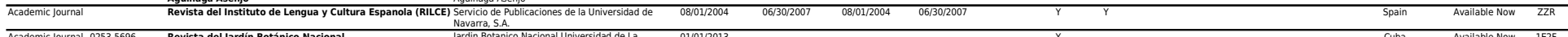

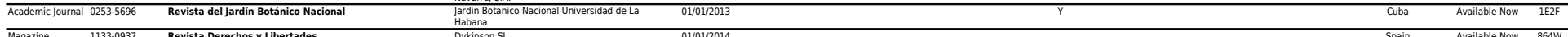

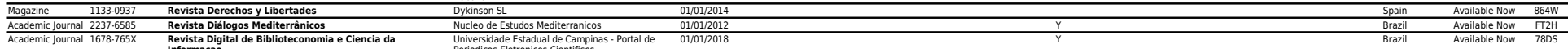

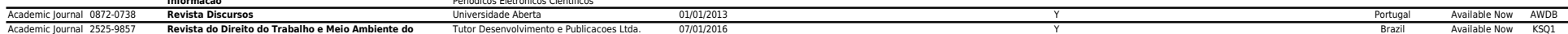

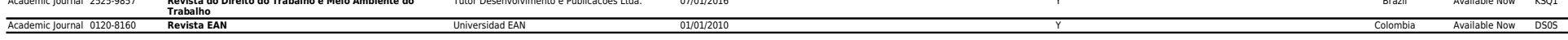




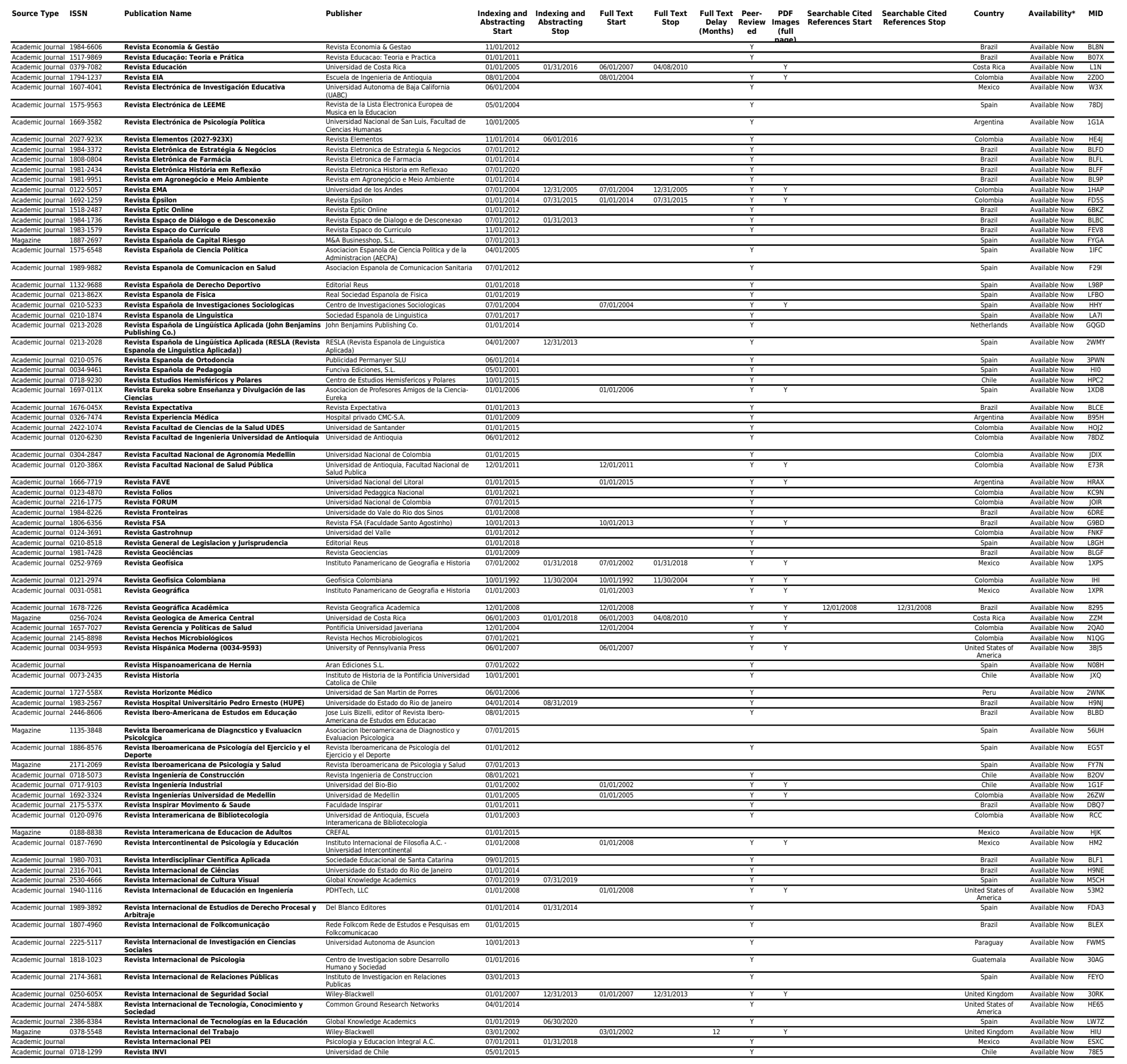




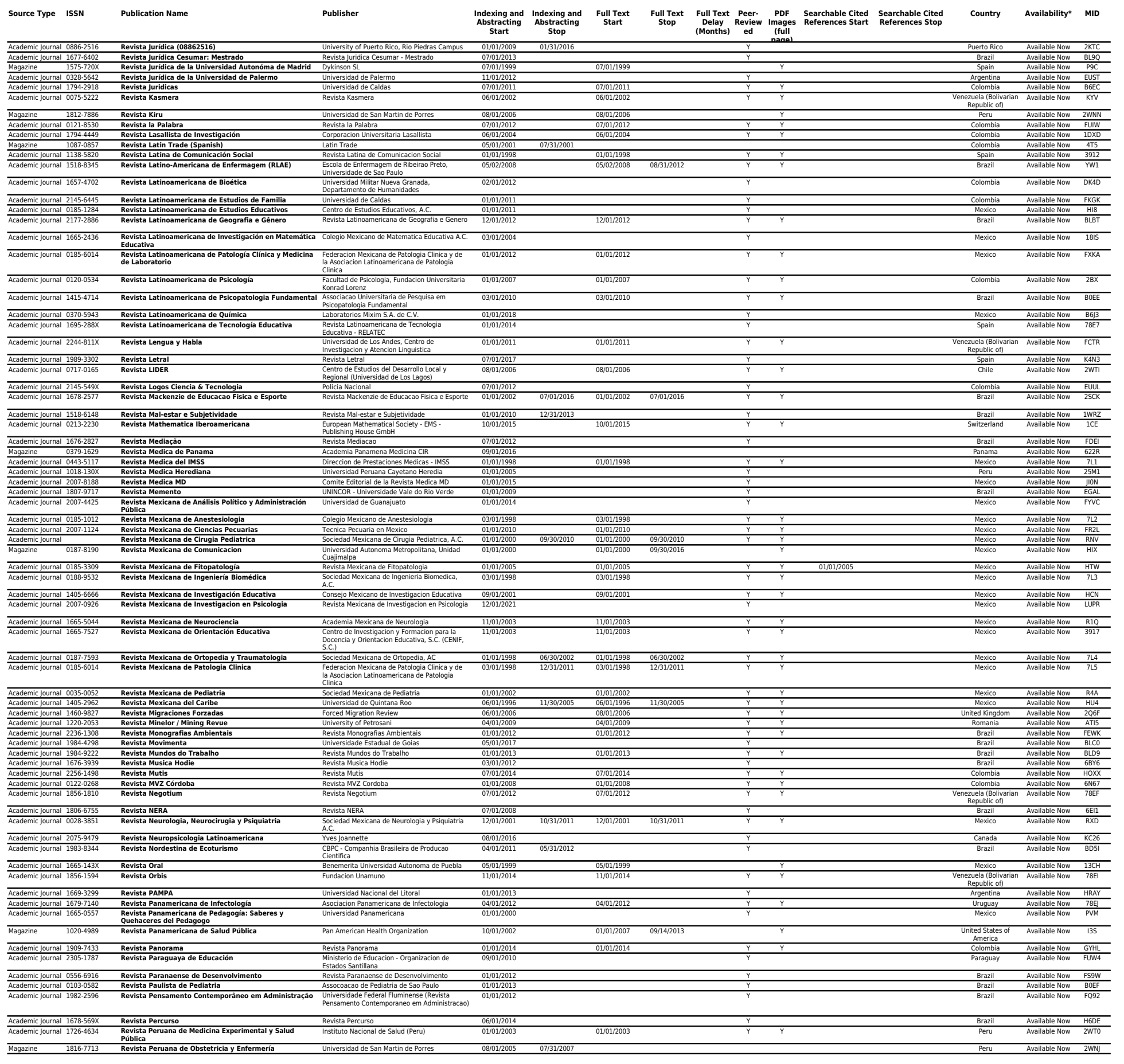




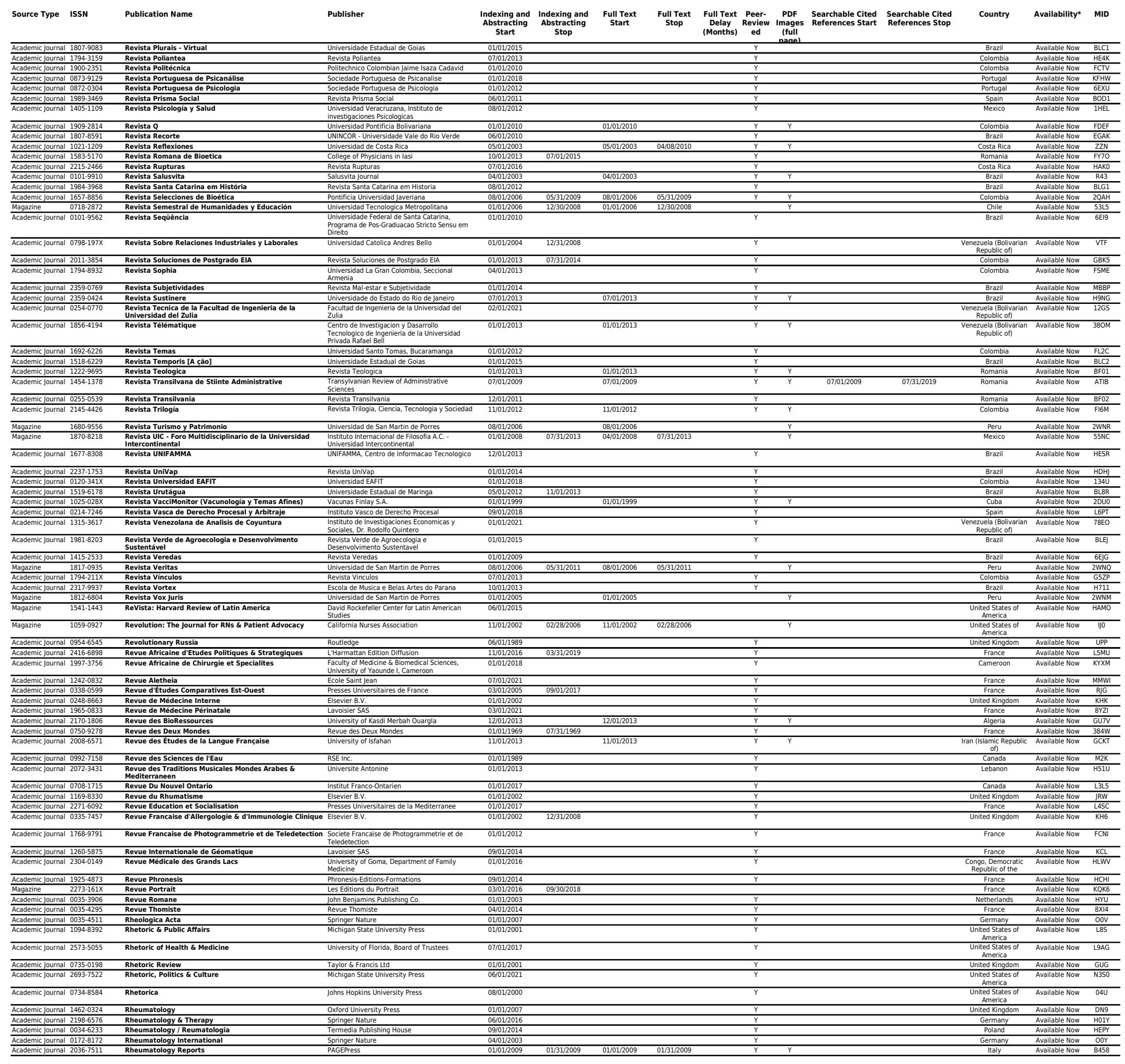




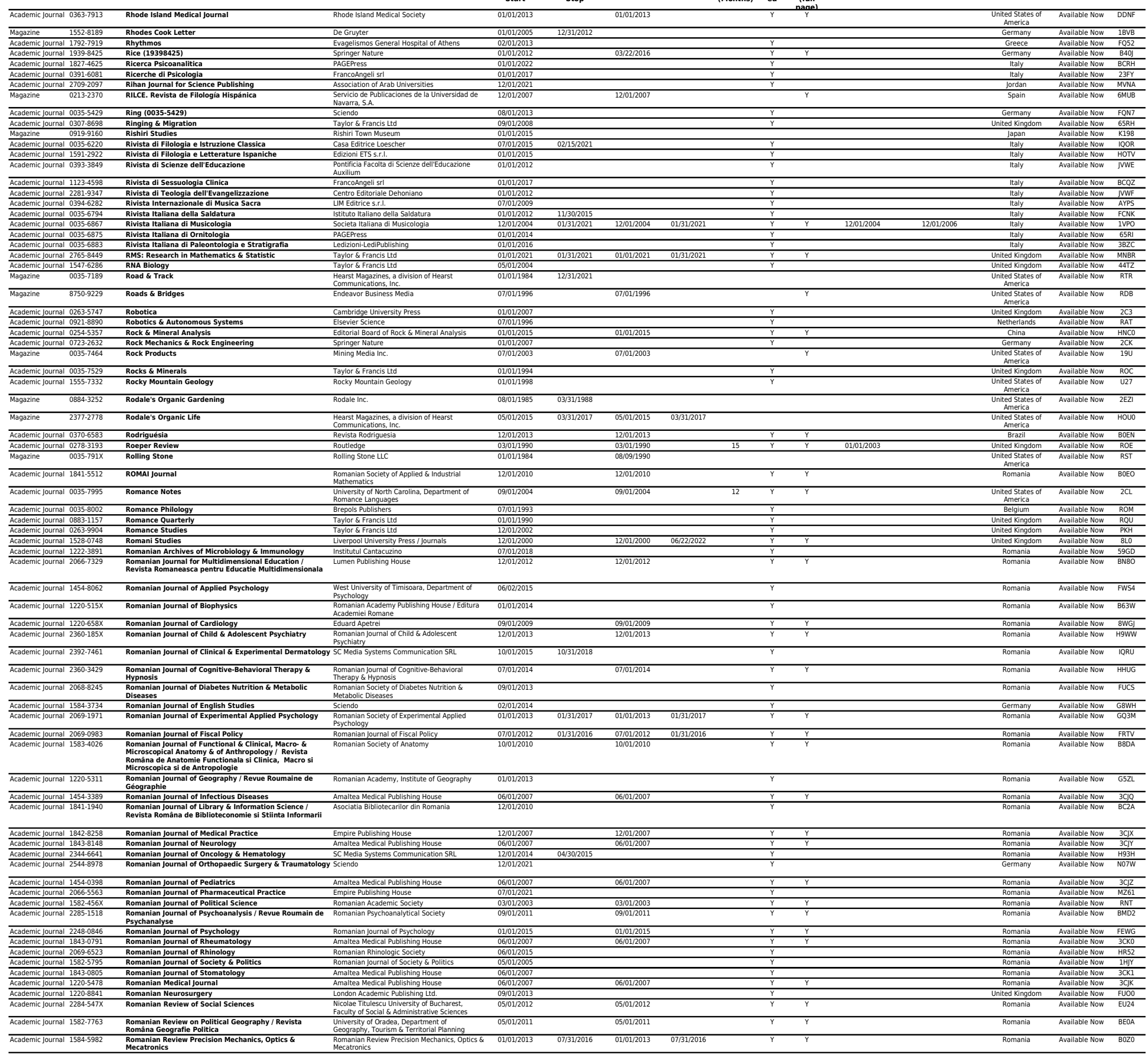




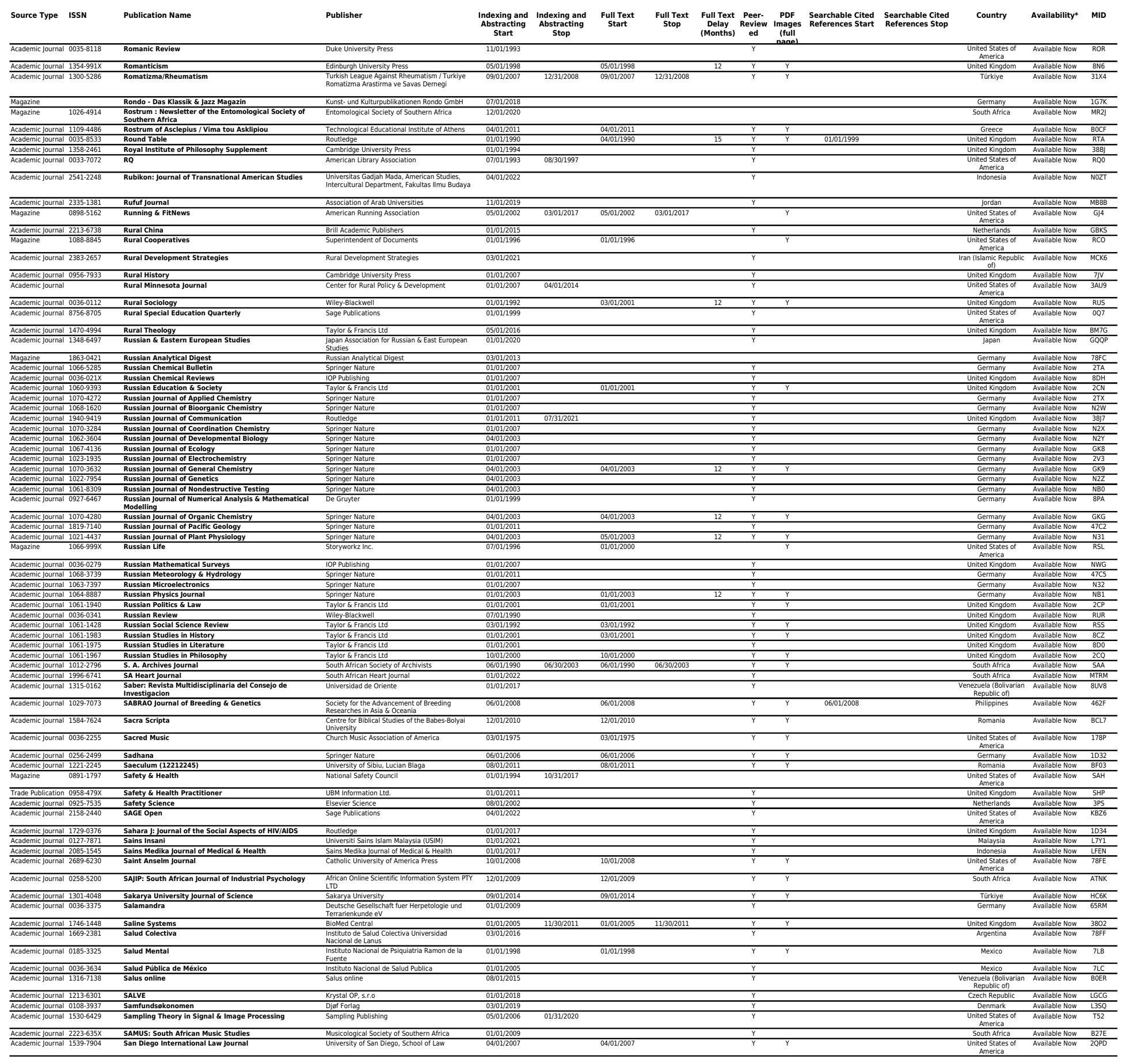


Academic J Jurnal 0036-4037 San Diego Law Review Unversity of San Diego, School of Law

01010199727 (Months) ed (a)

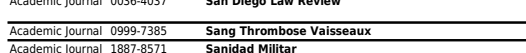
Magazne

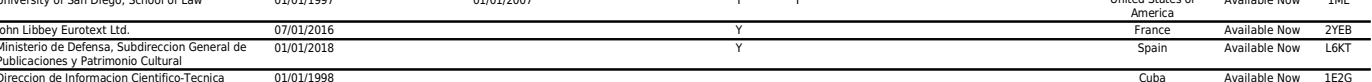

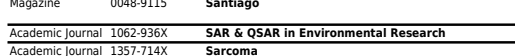

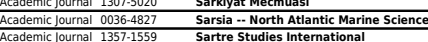

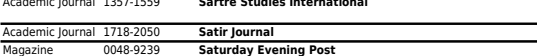
Accodemic Journal 1664:-9704

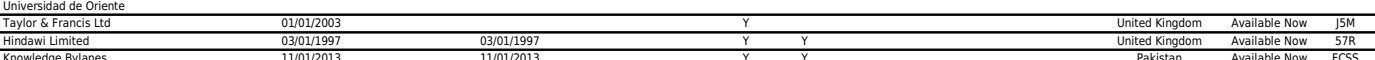

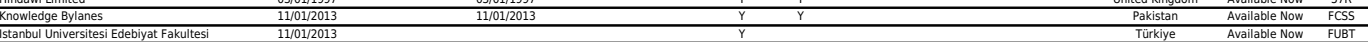

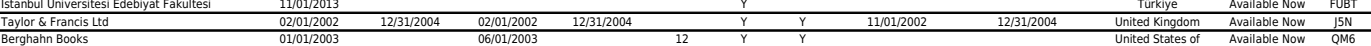

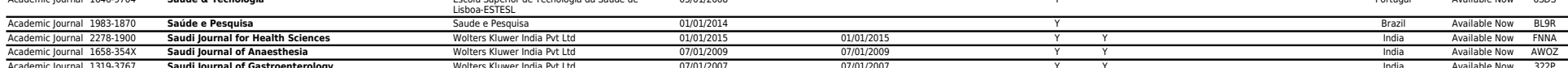

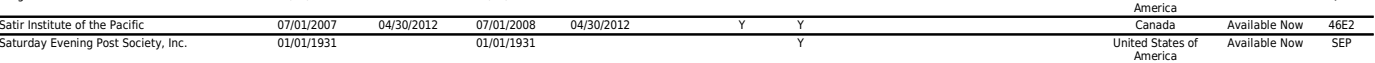

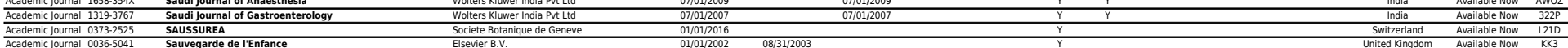

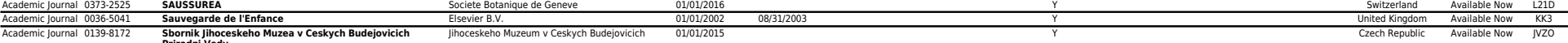

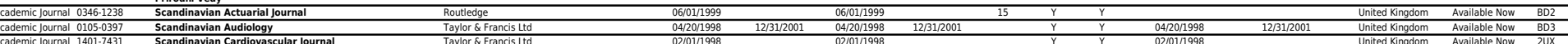

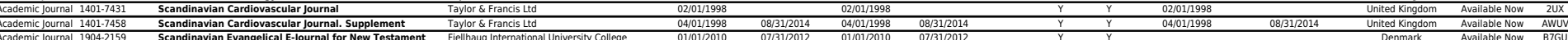

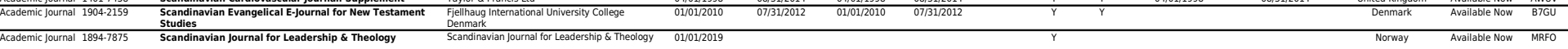

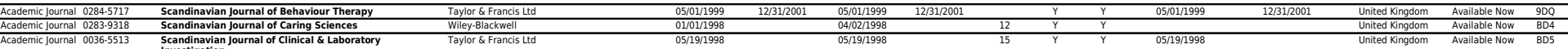

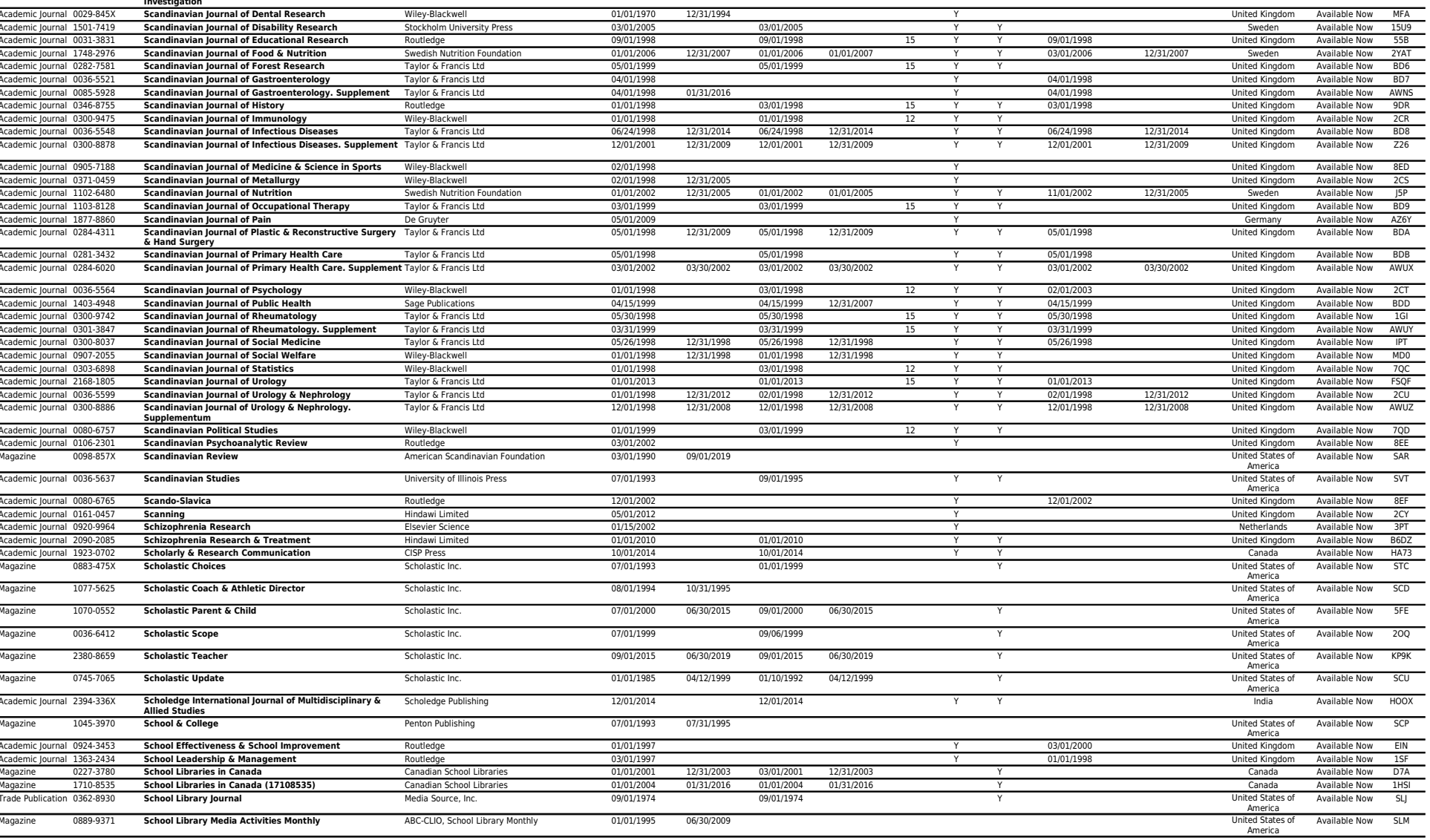




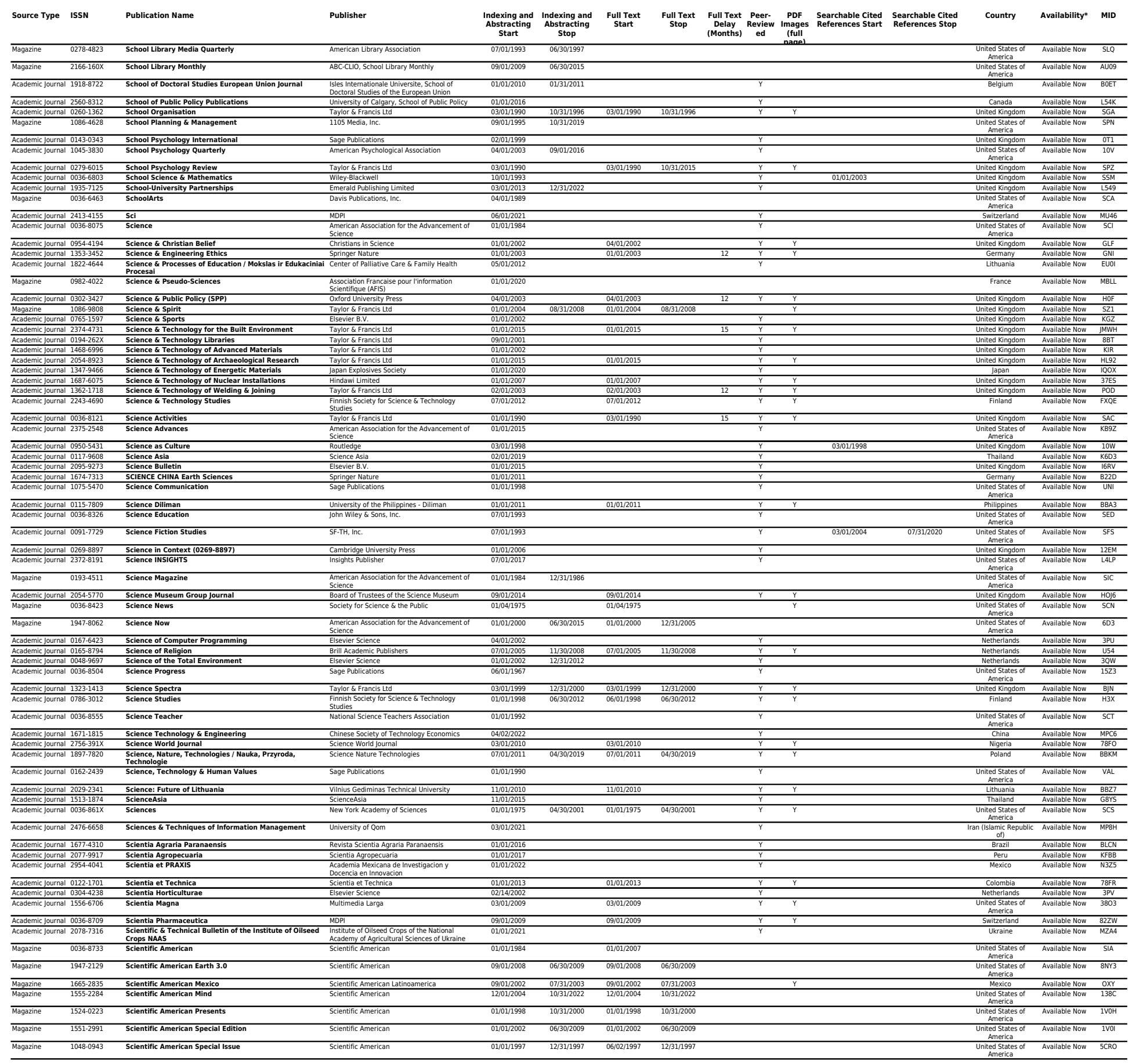




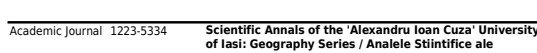

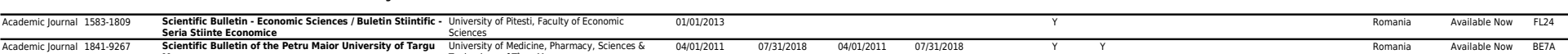

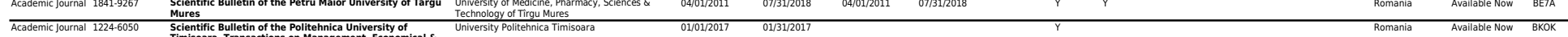

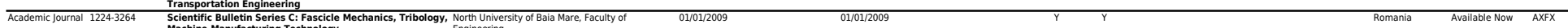

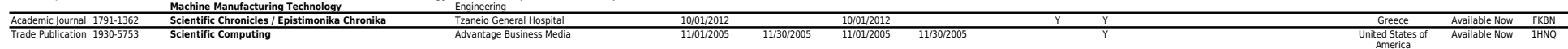

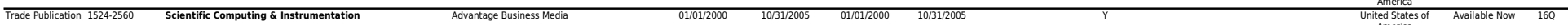

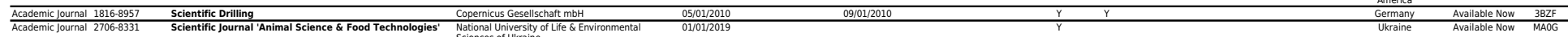

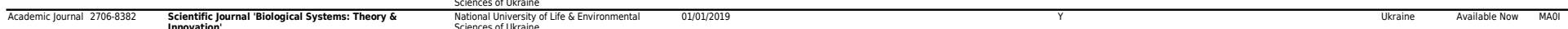

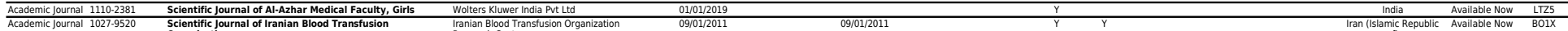

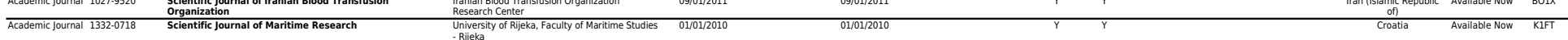

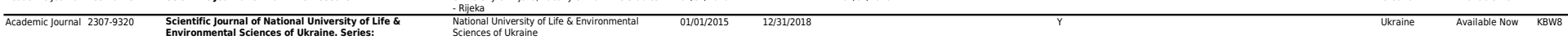

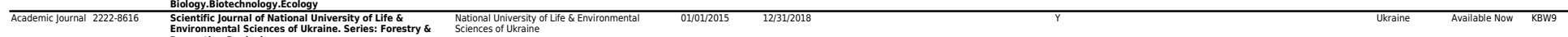

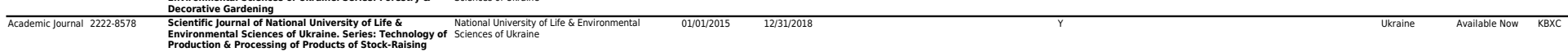

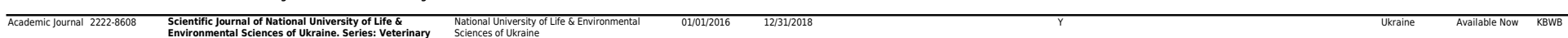

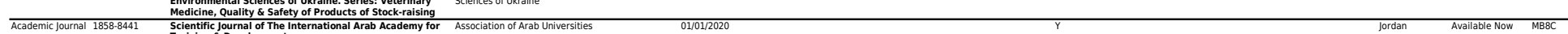

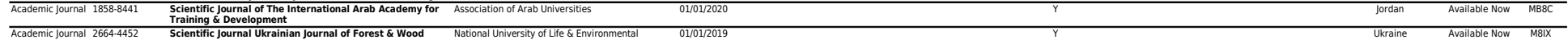

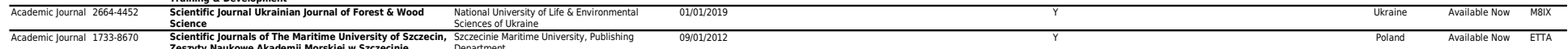

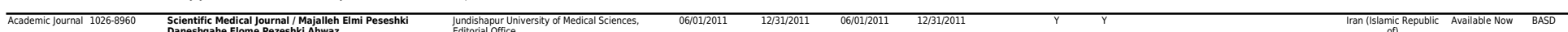

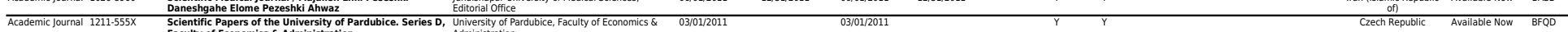

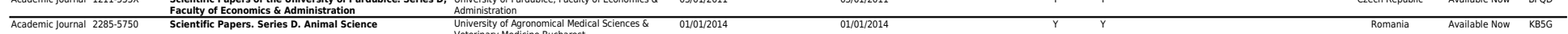

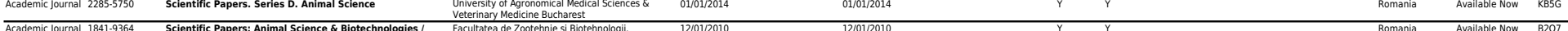

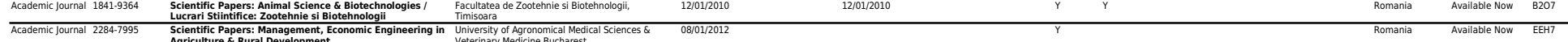

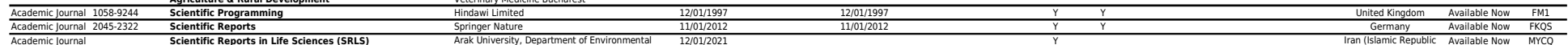

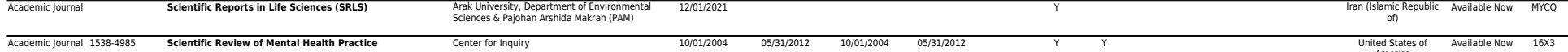

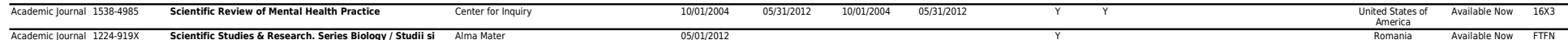

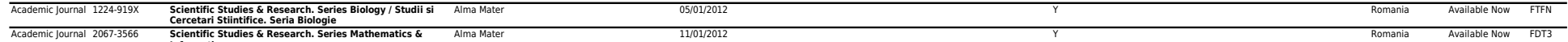

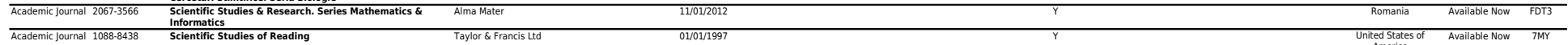

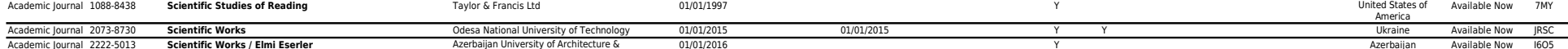

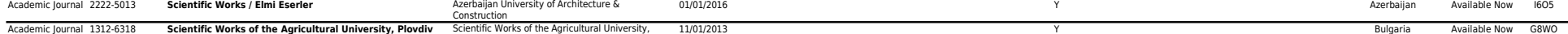
Avalable Now GewO

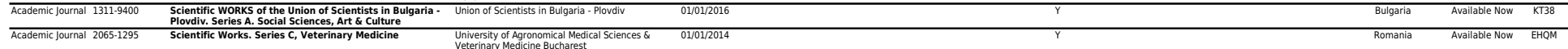

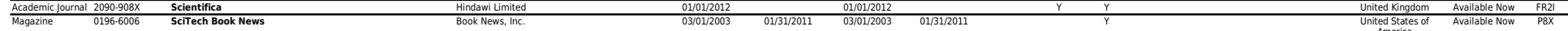

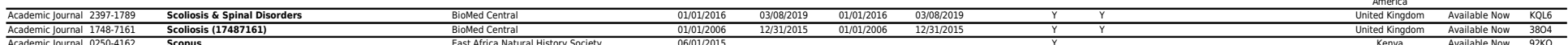

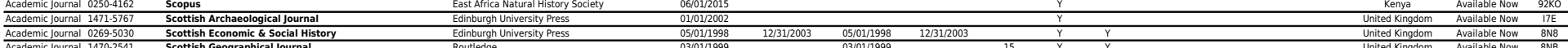

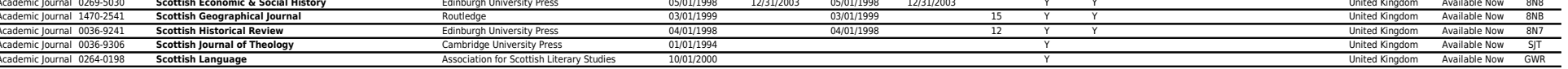

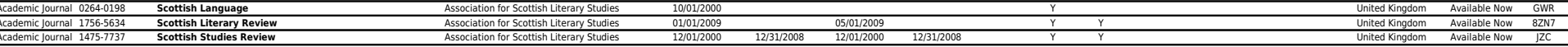

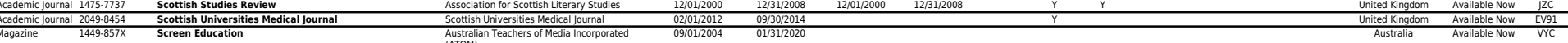

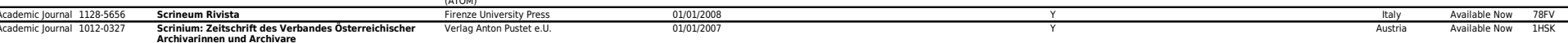

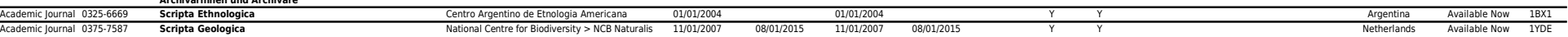

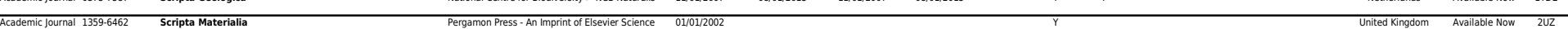

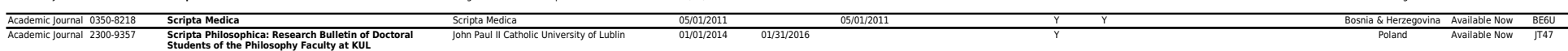

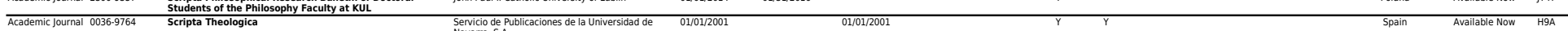

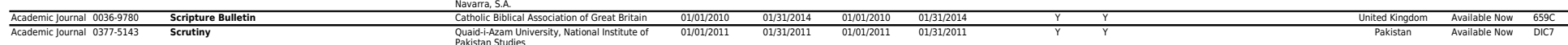

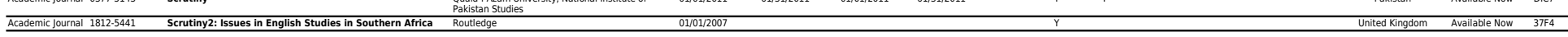




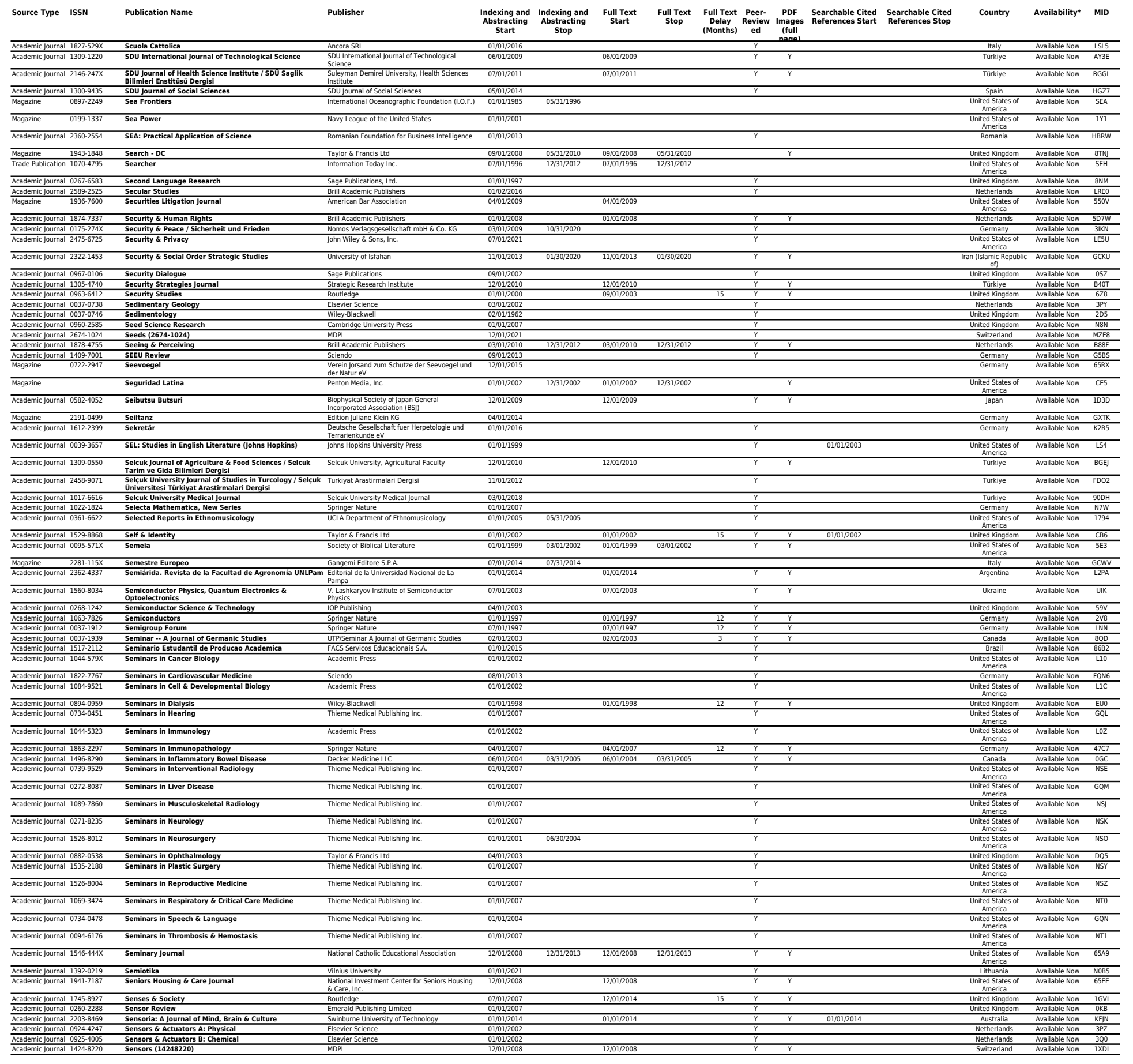




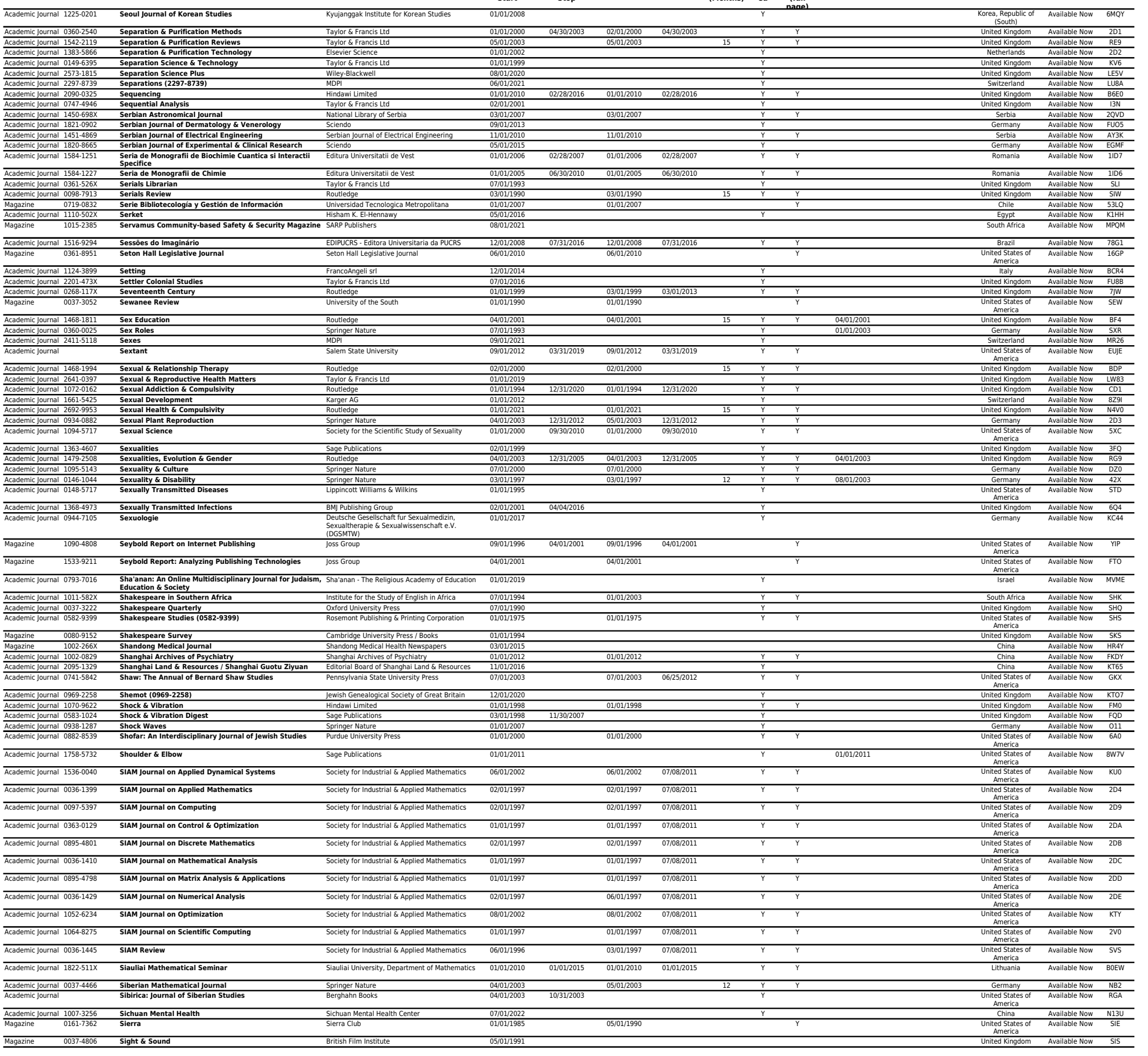




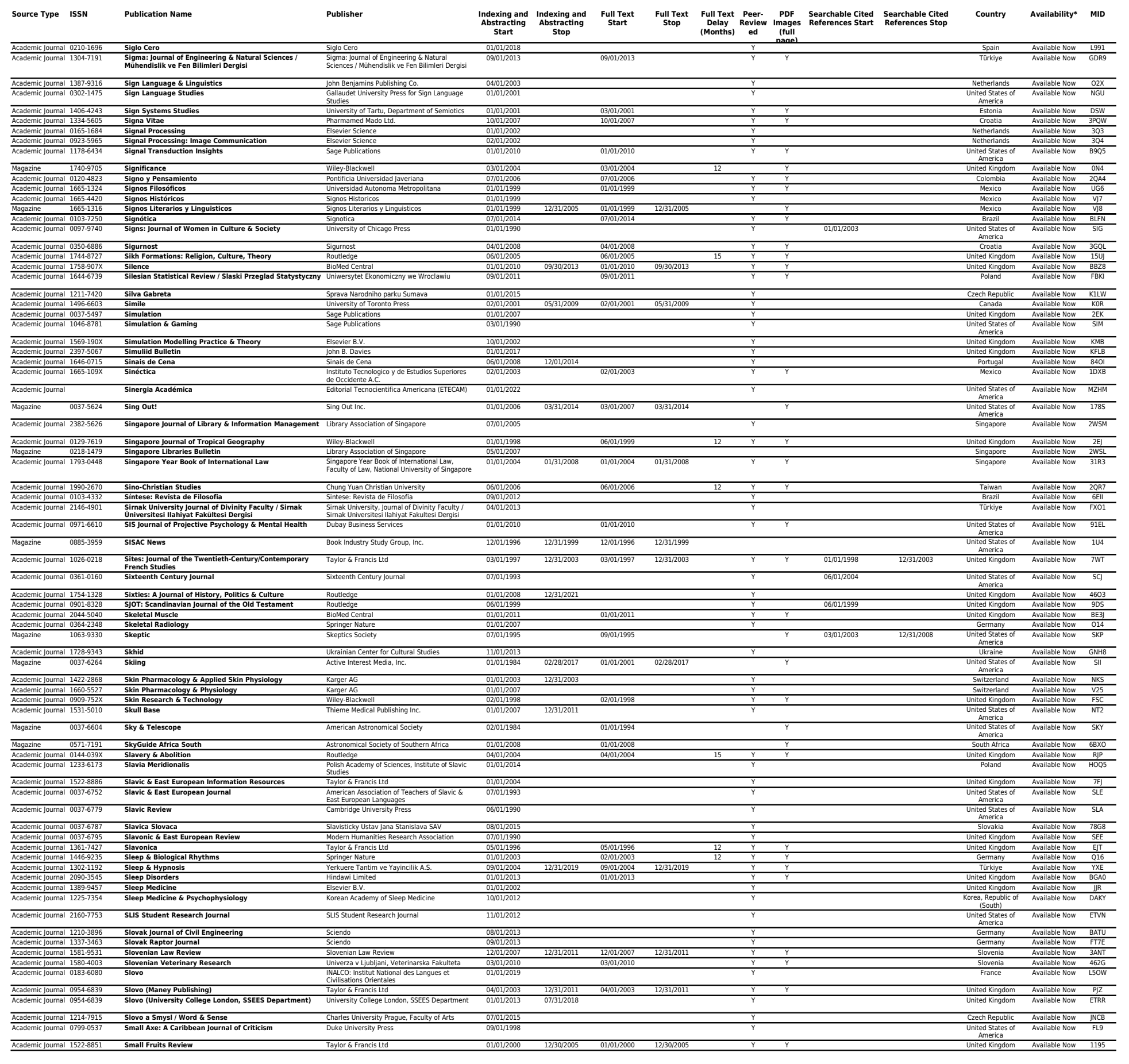




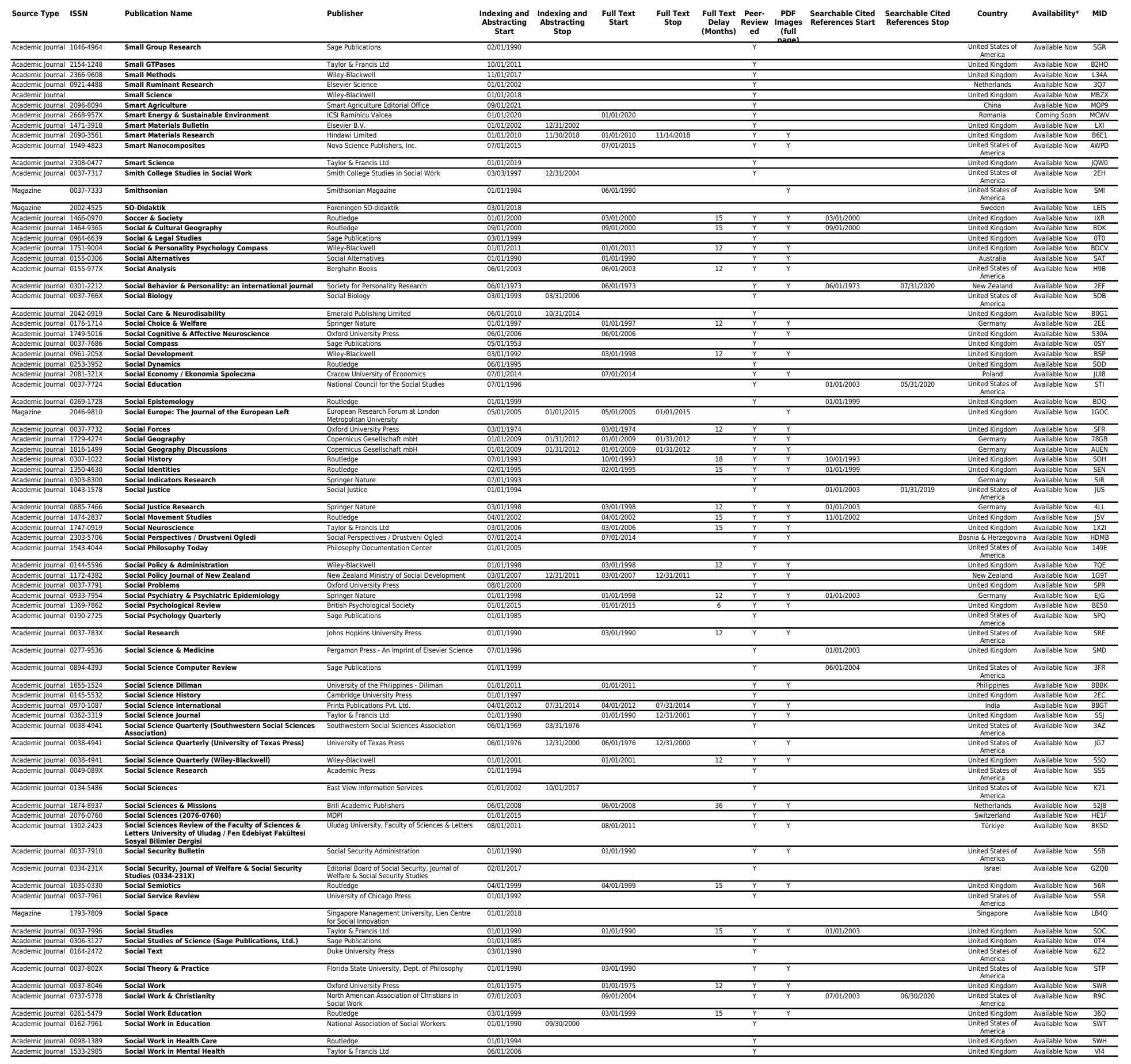




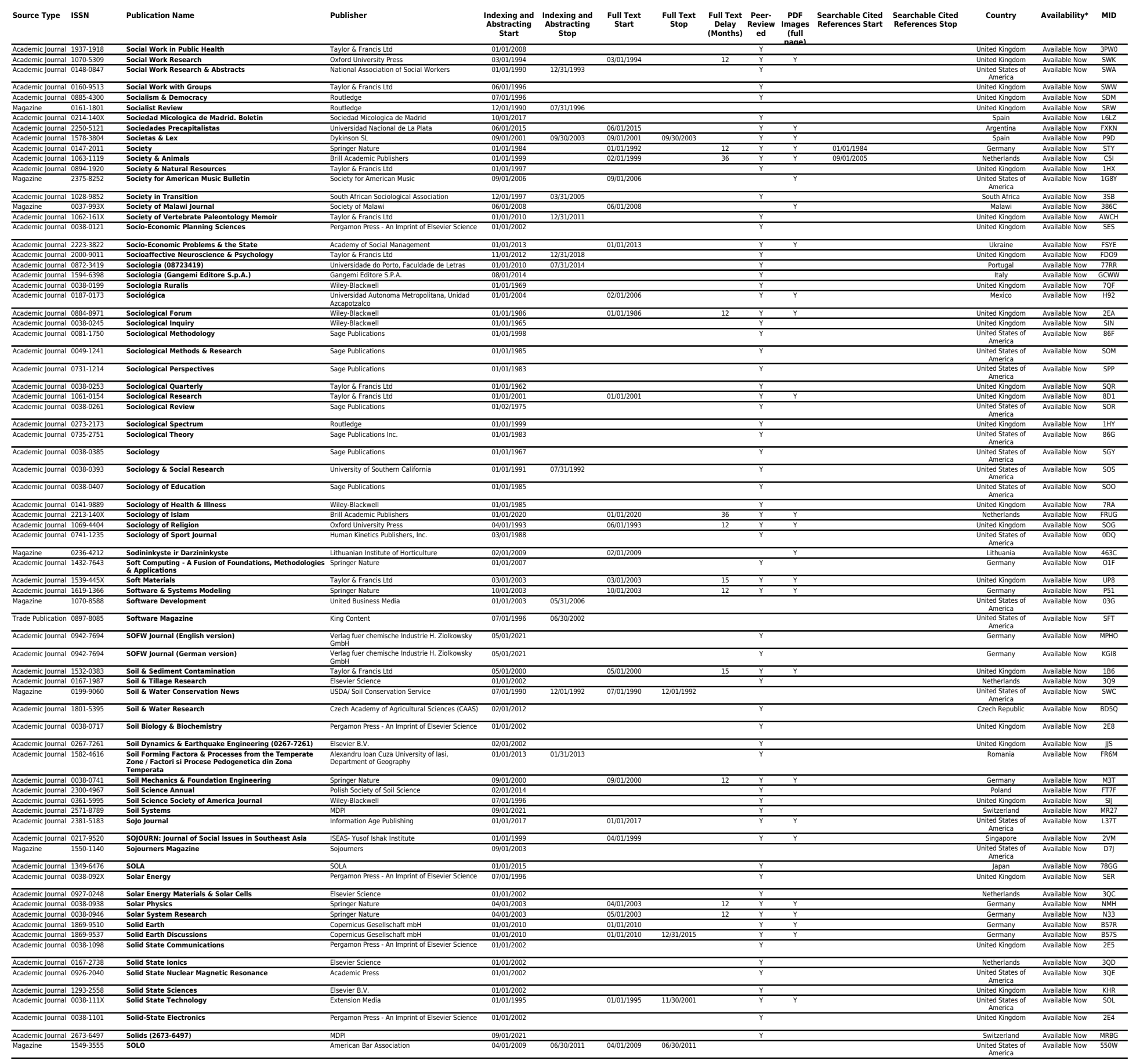




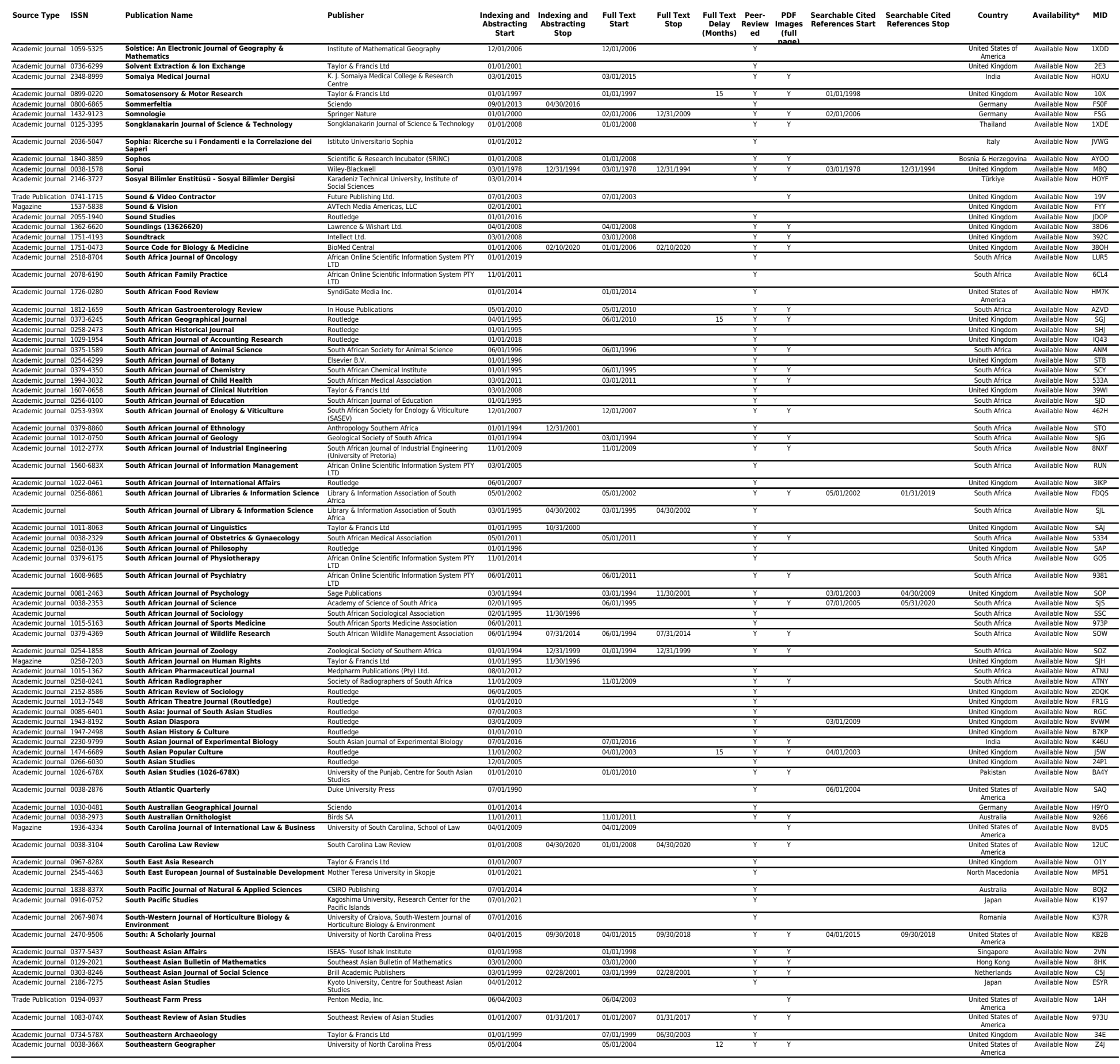




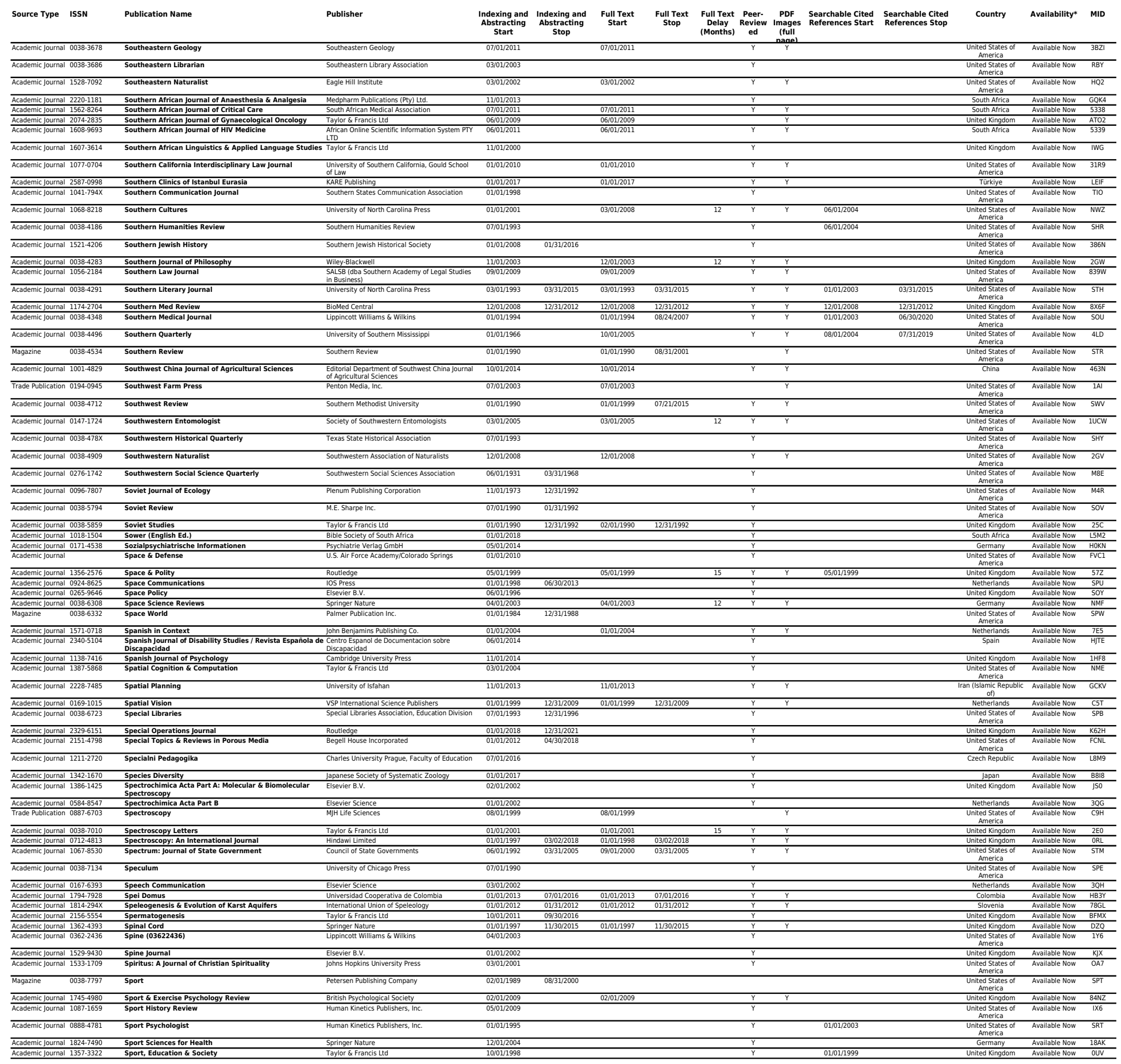




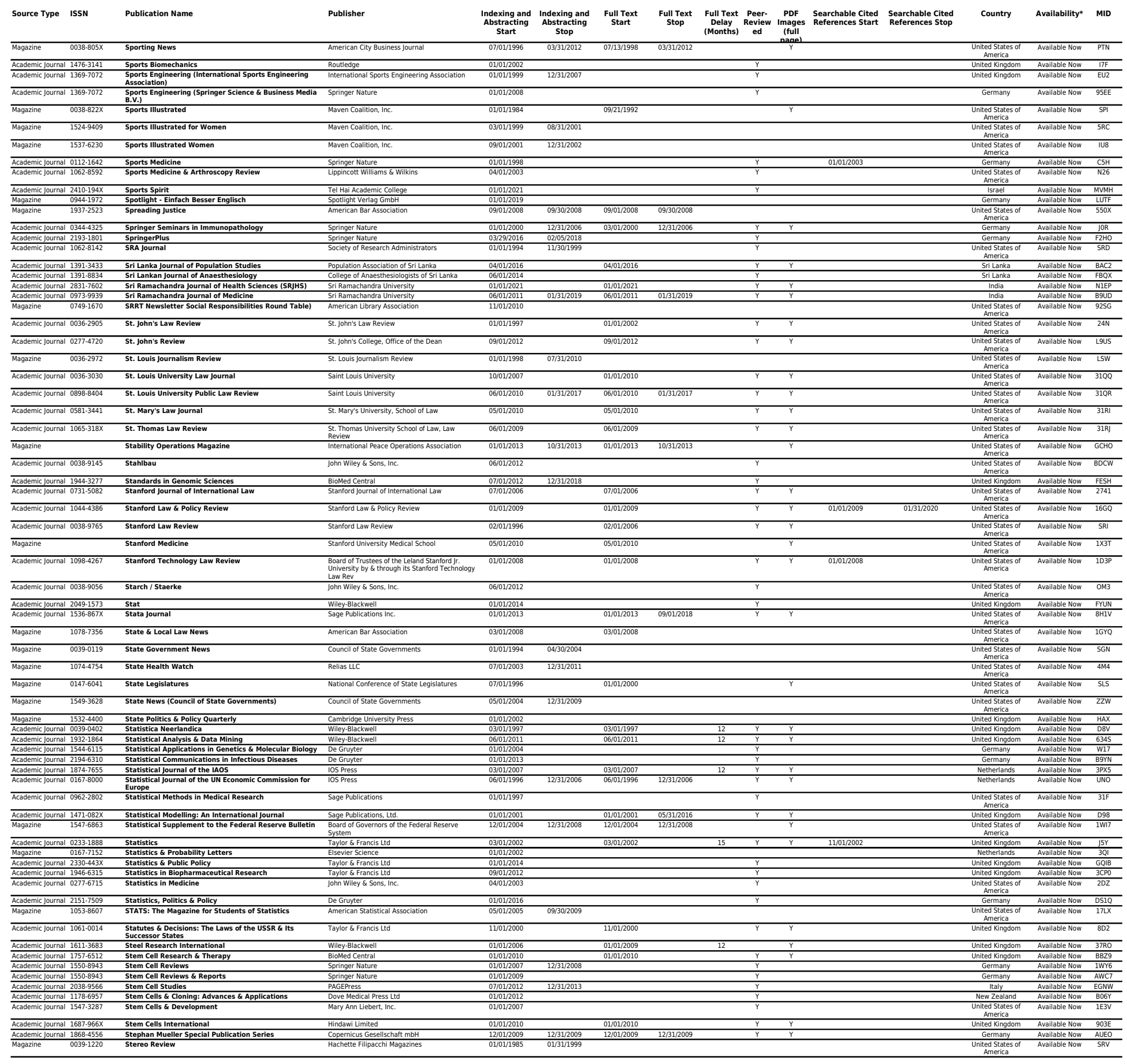




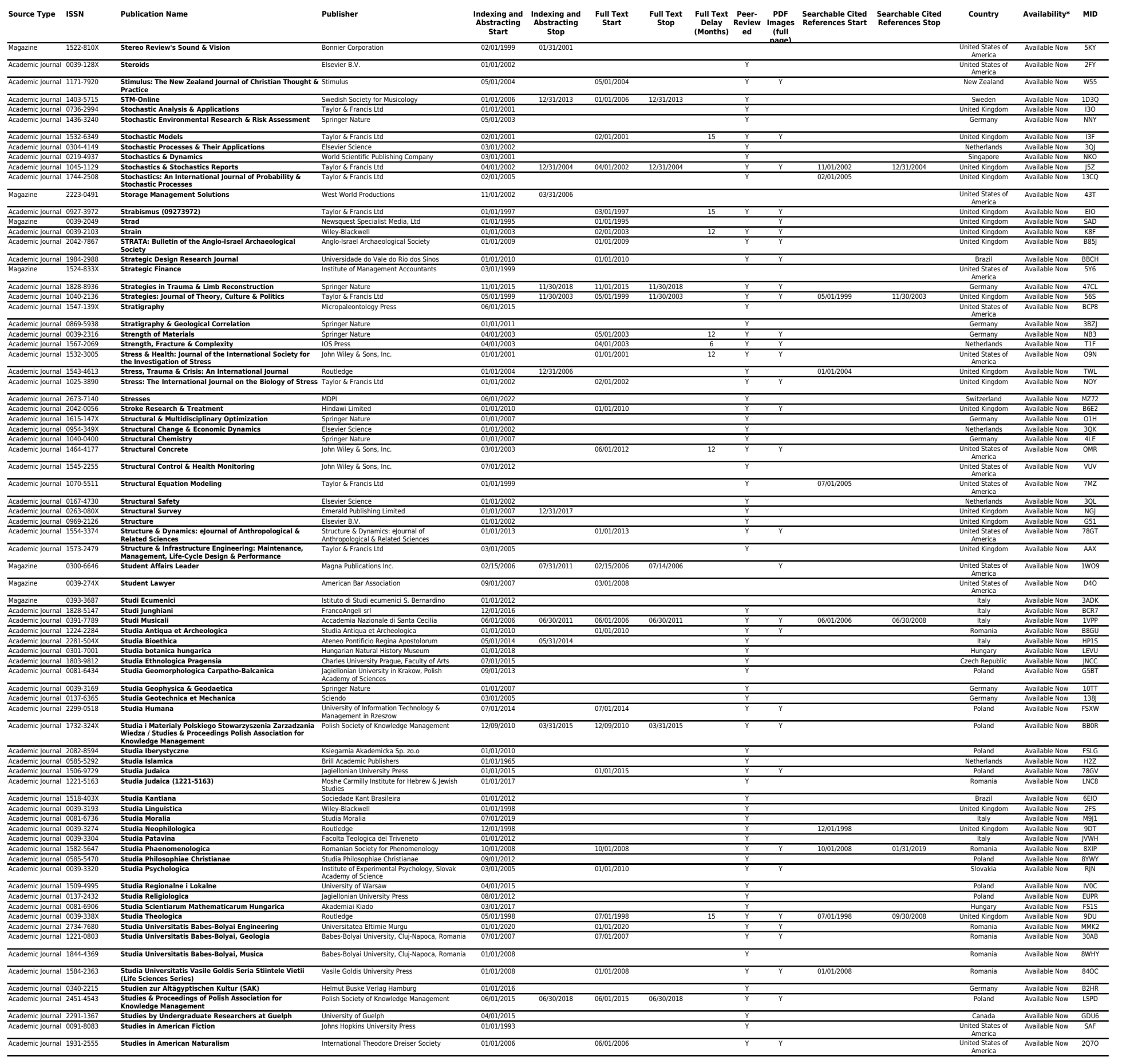




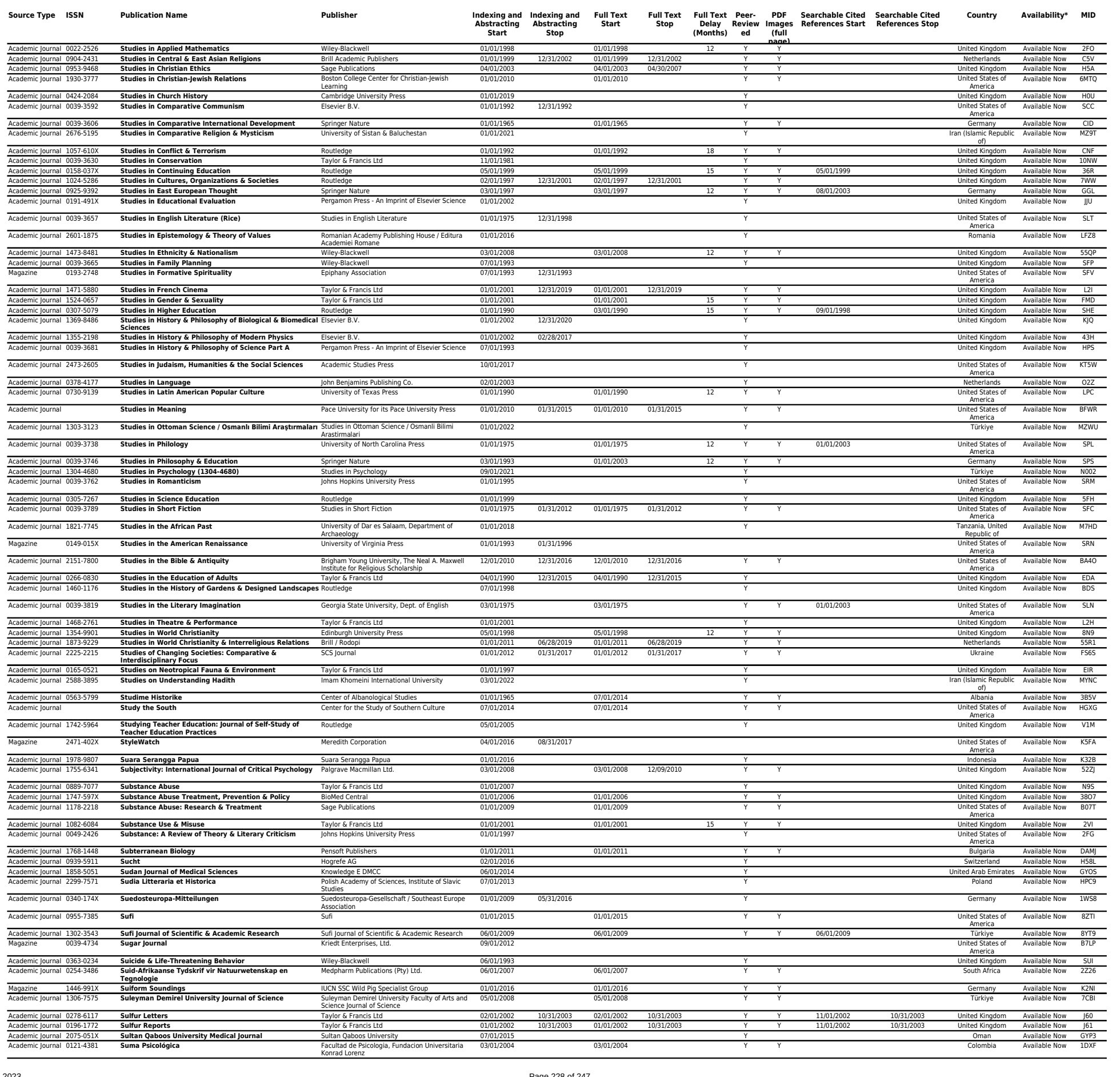




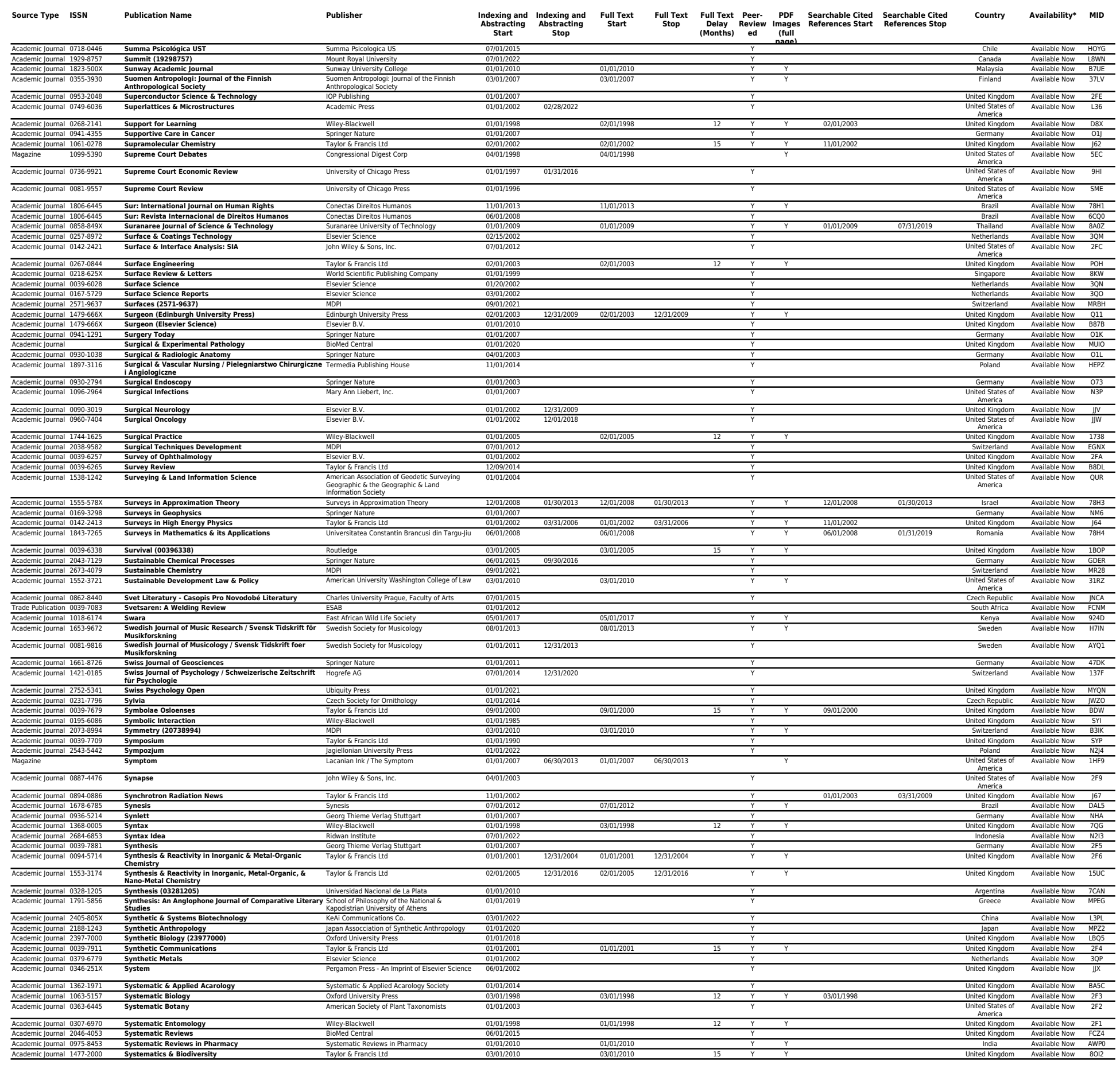




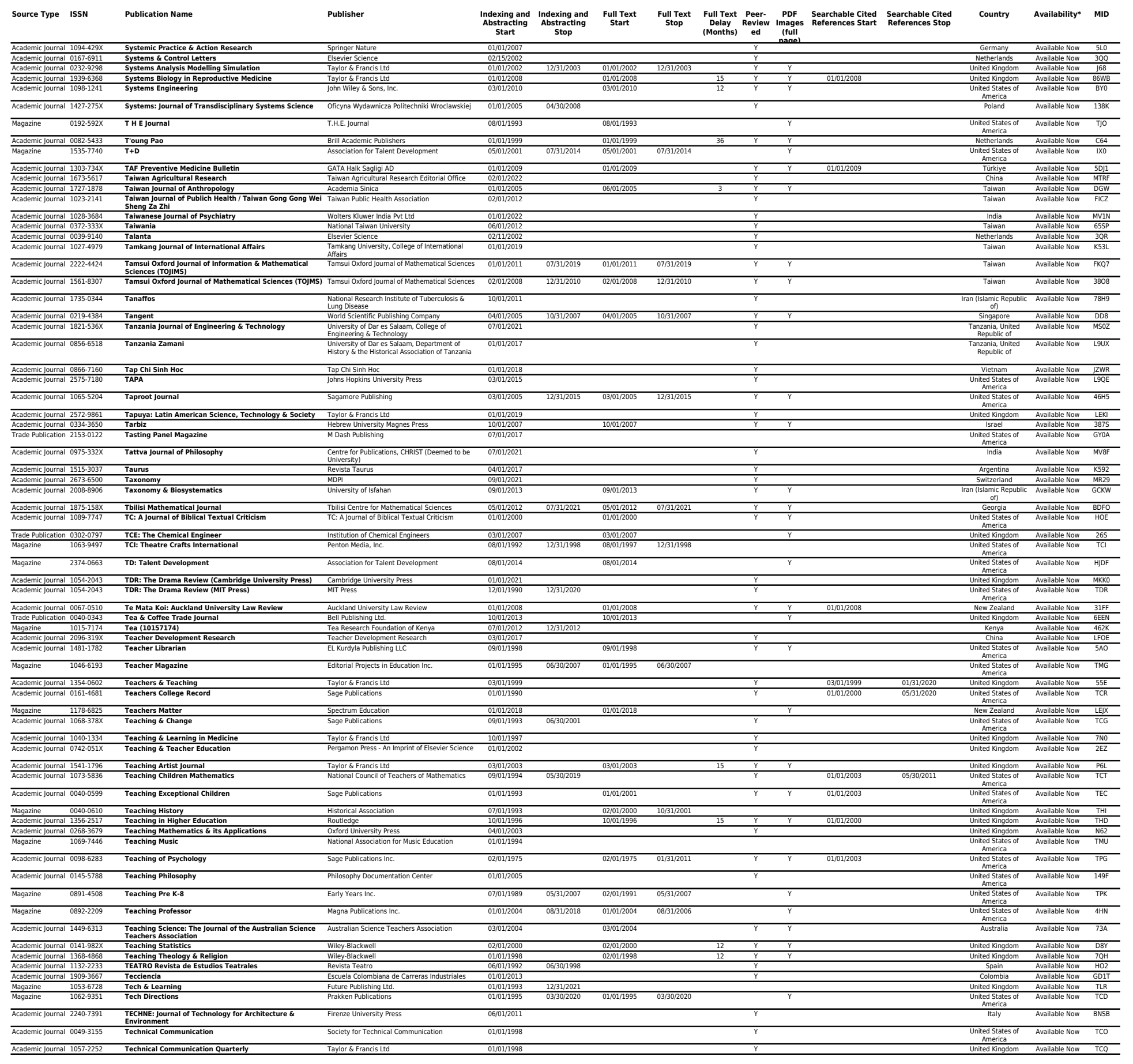


Tedemic J Jurnal 1063.7842 Technical Physics

Springer Nature
Springer Dature

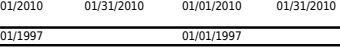

$\frac{12}{12} \frac{r}{r}$

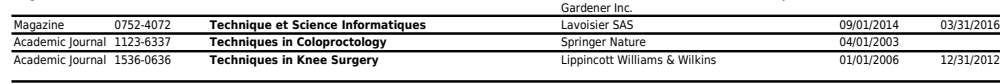

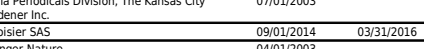

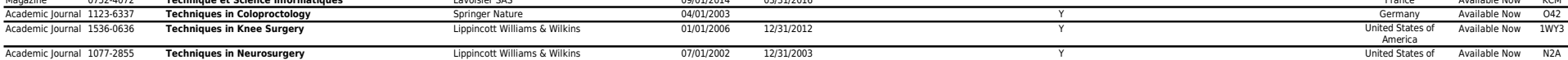

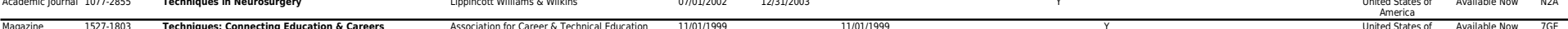

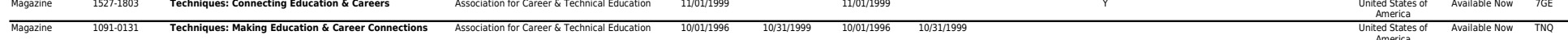

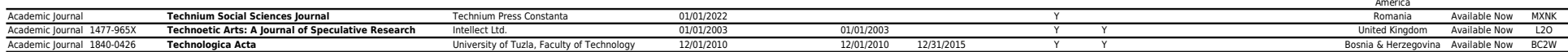

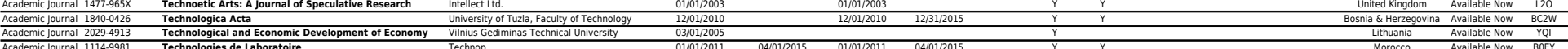

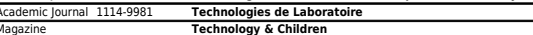
Aecademic Dournal $0040-165 x$ Technology \& Cutture

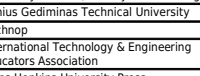

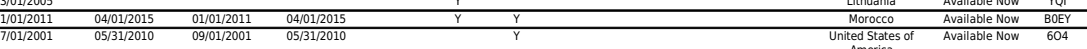

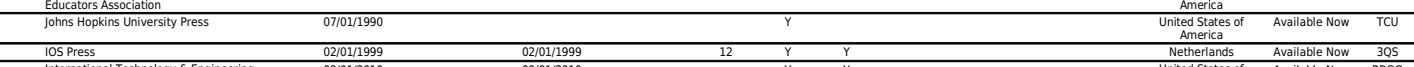

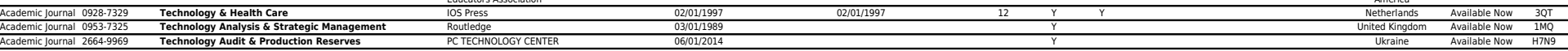

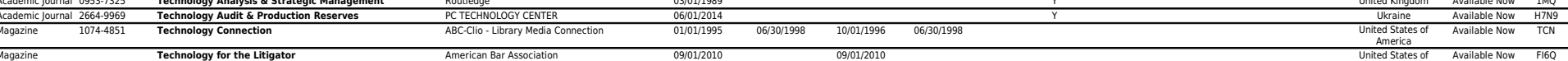

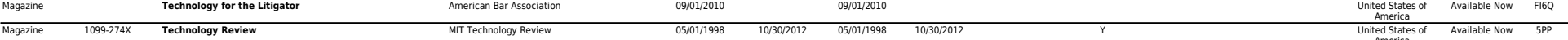

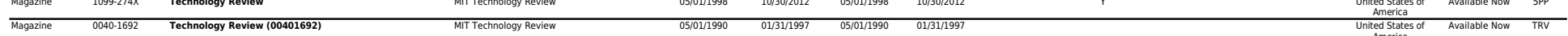

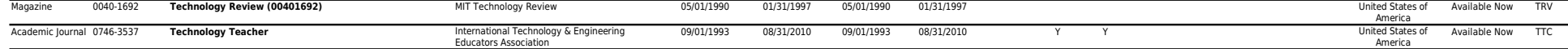

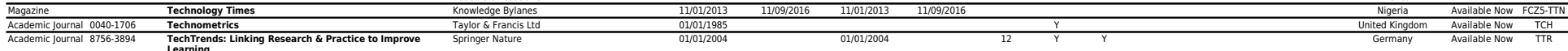

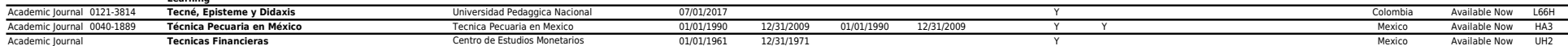

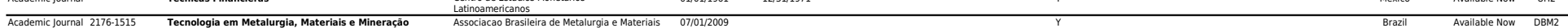

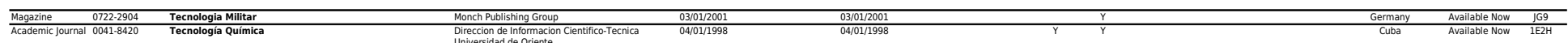

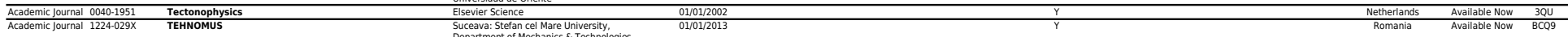

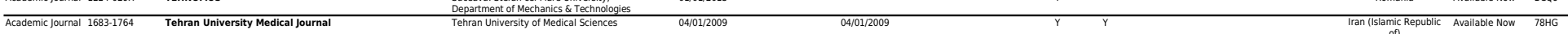

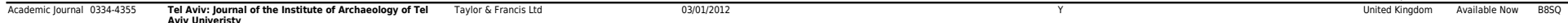

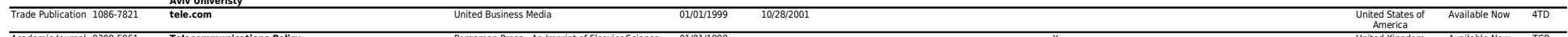

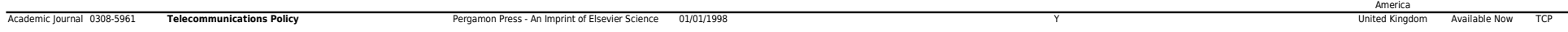

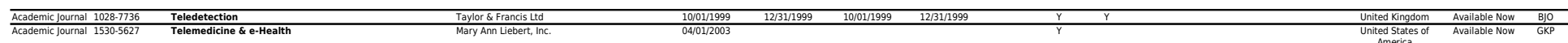

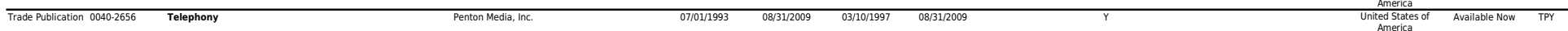

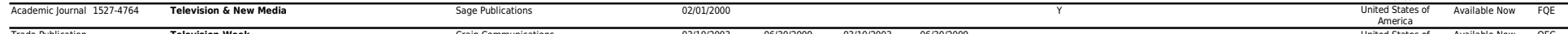

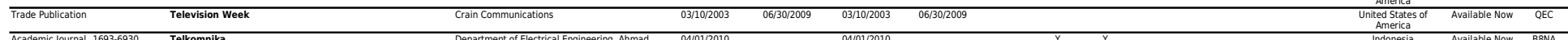

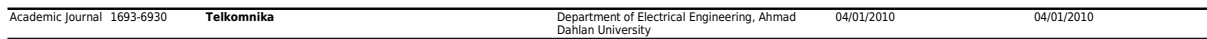

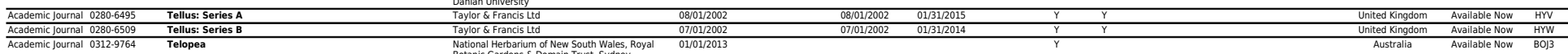

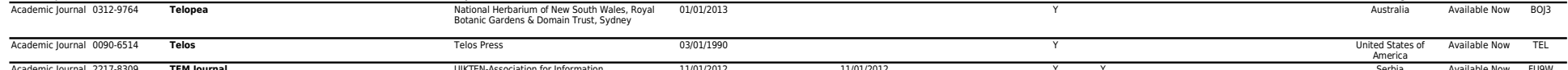

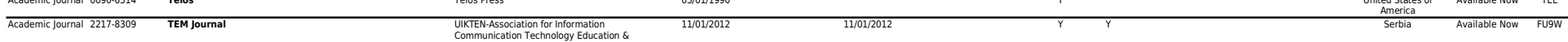

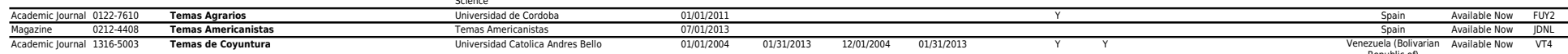

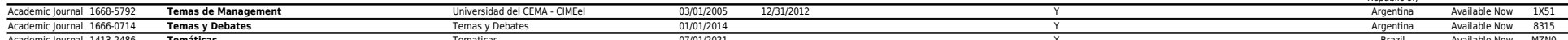

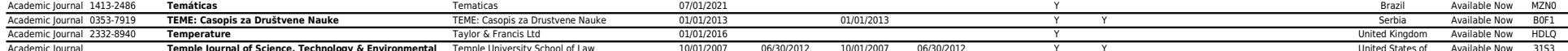

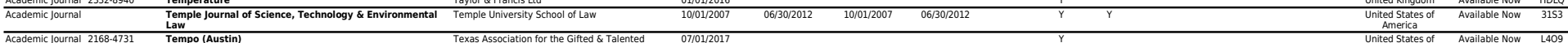

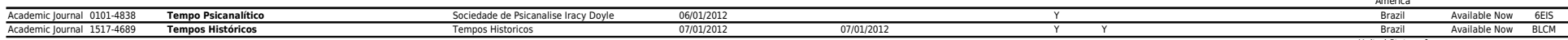

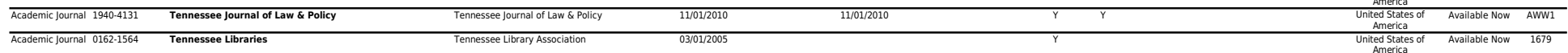

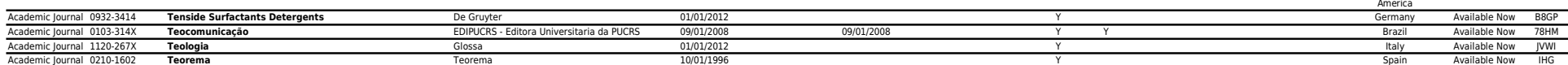




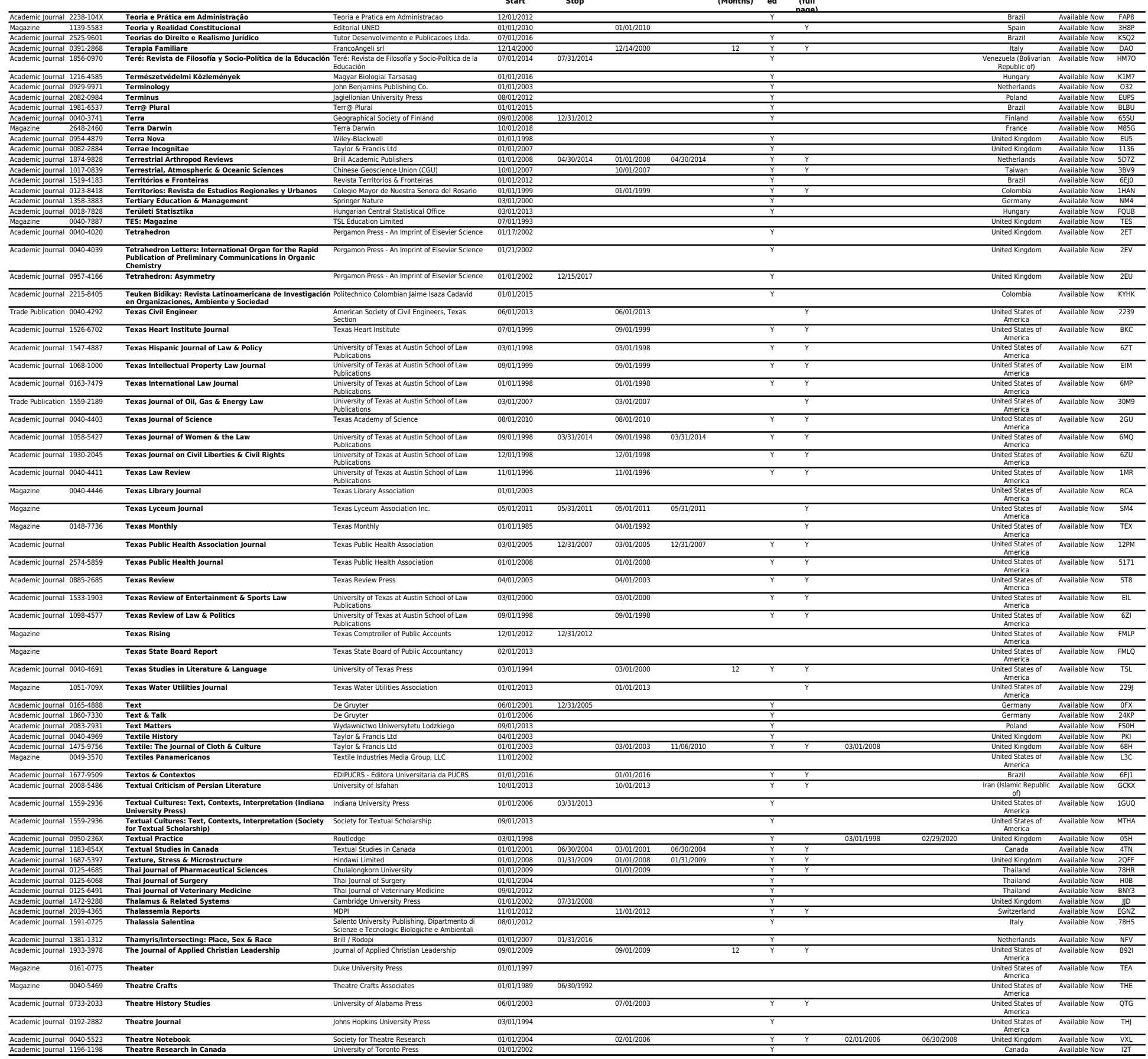

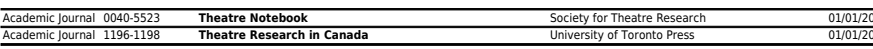




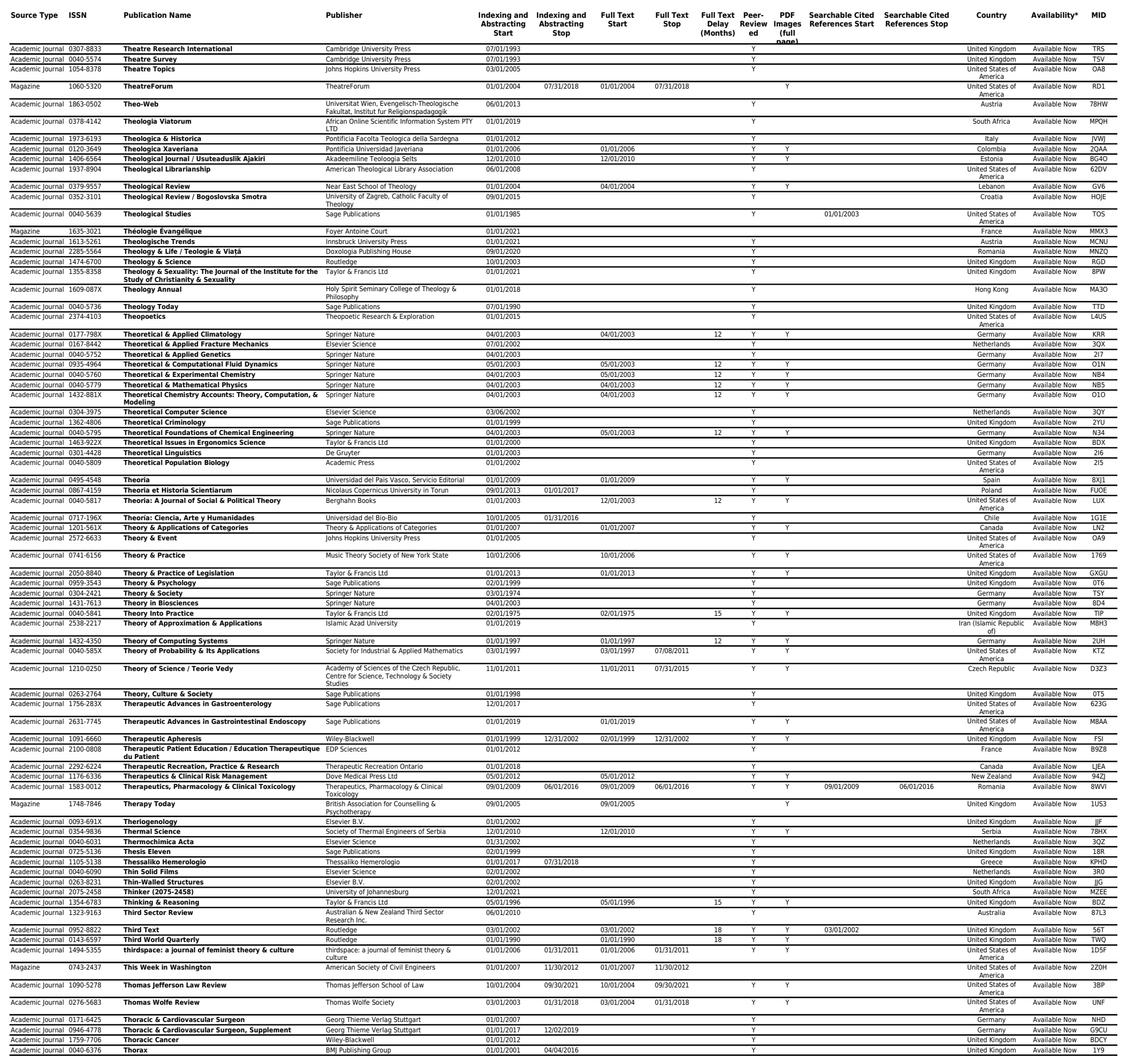




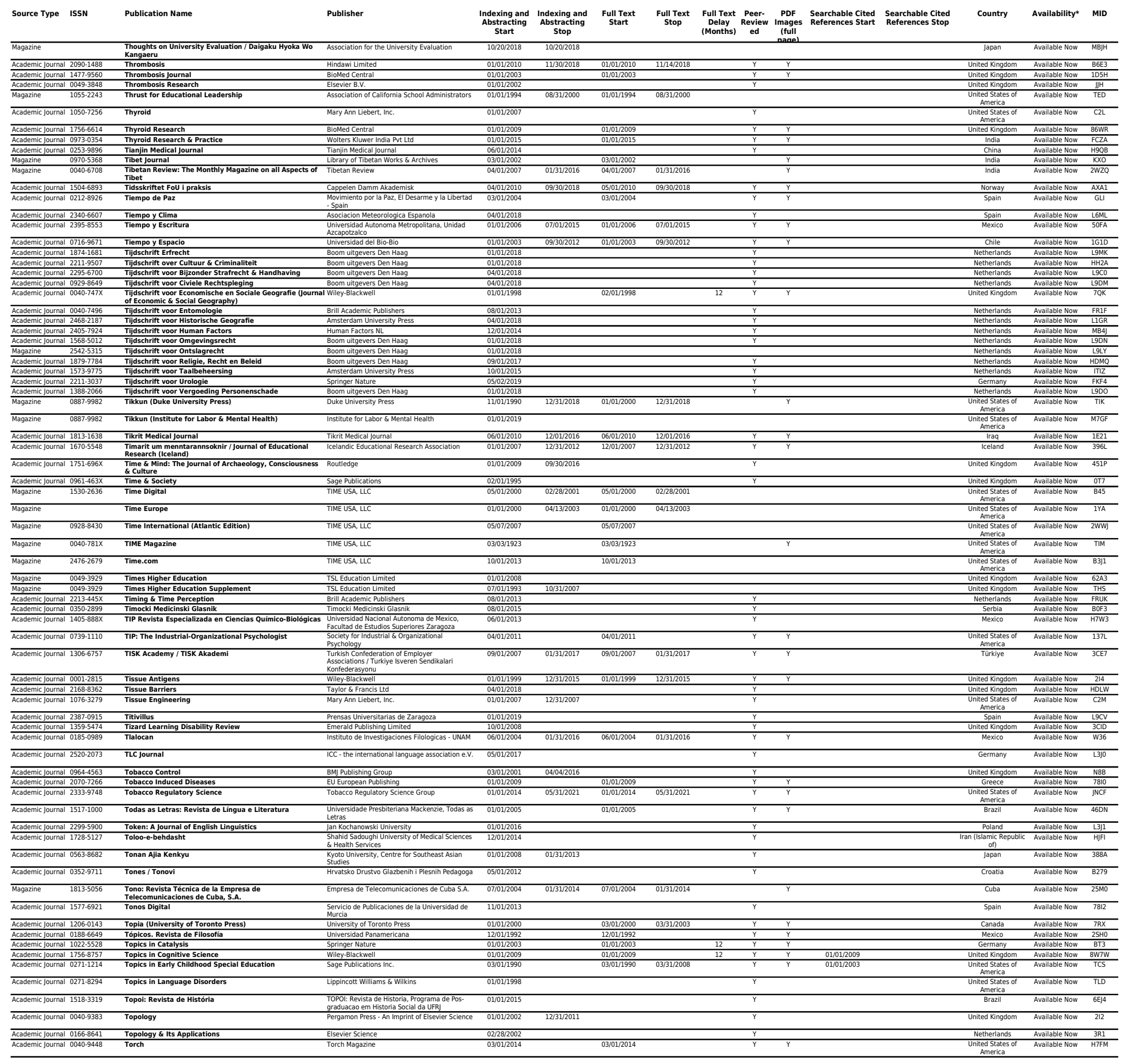




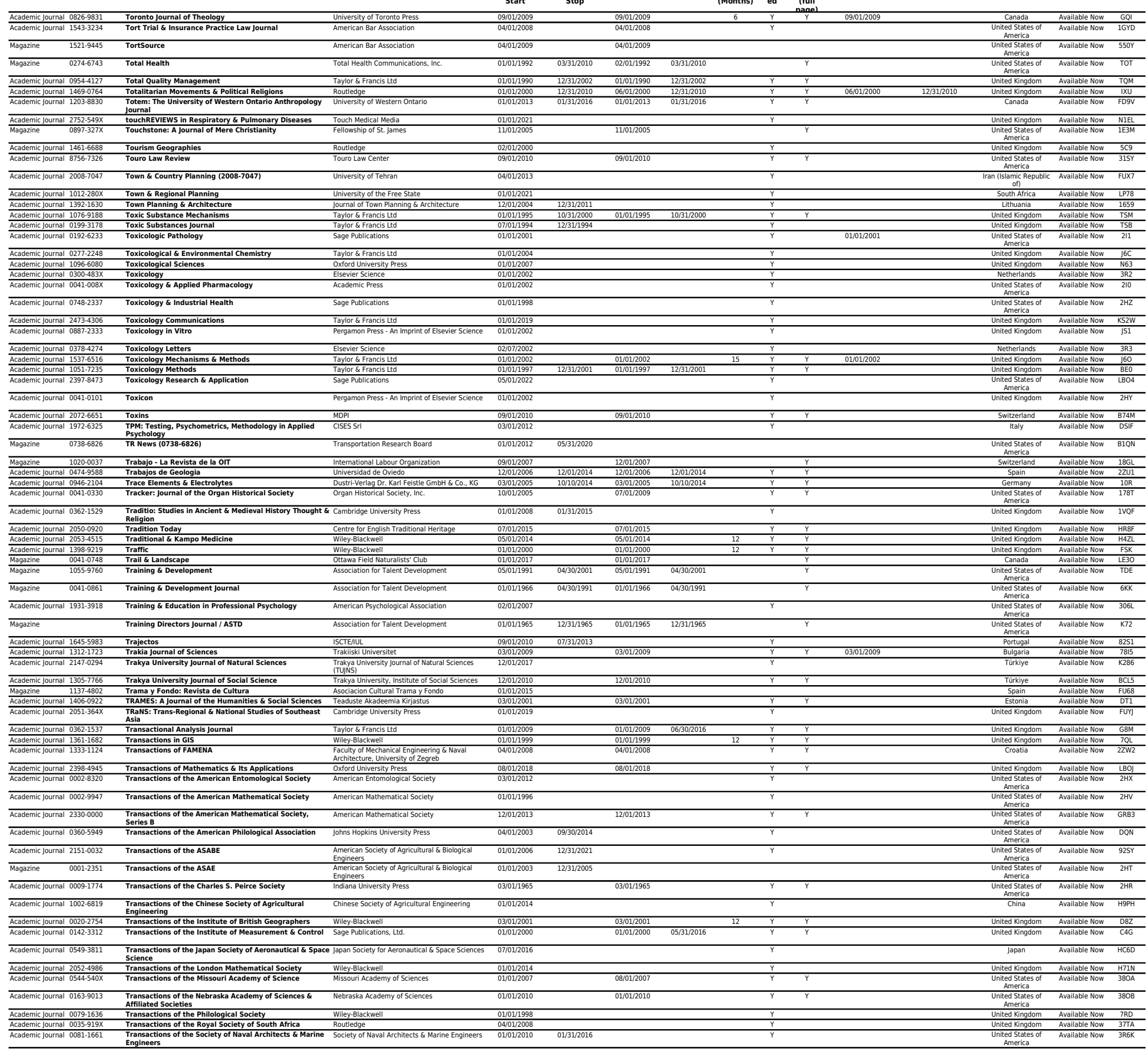


Academic Jurral 2251-8657 Transactions on Combinatorics

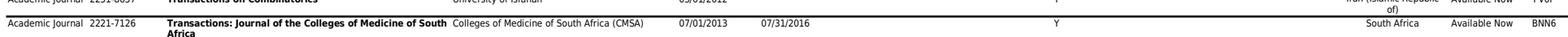

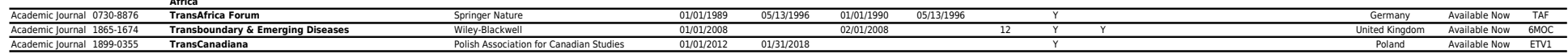

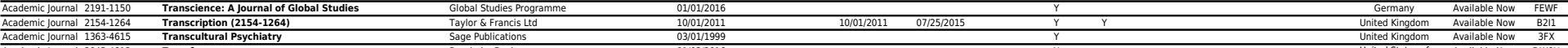

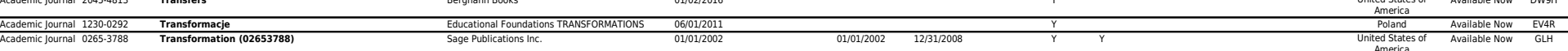

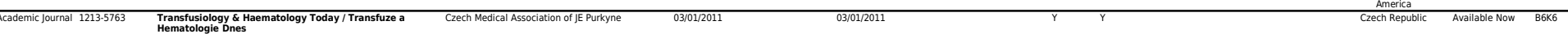

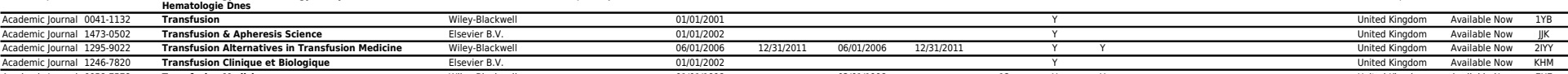

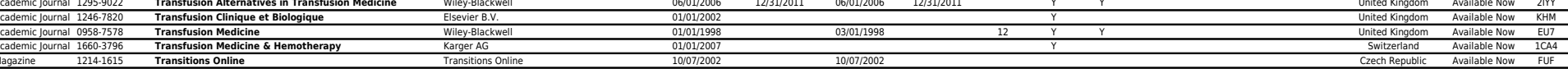

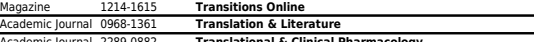

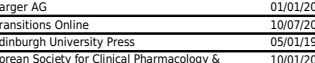

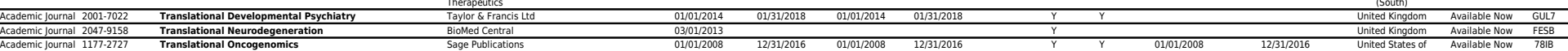

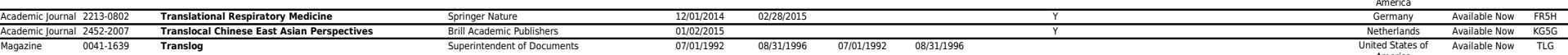

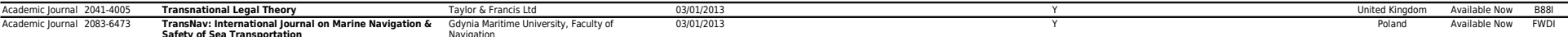

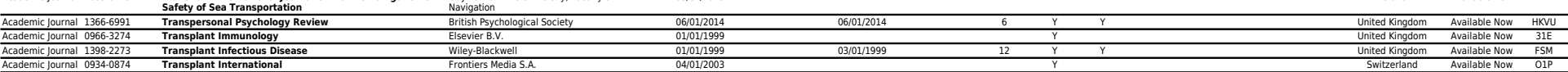

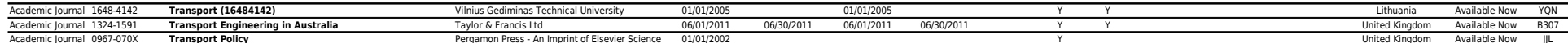

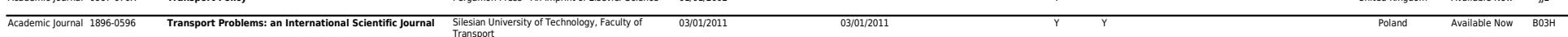

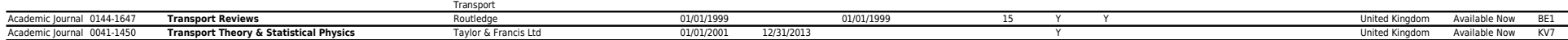

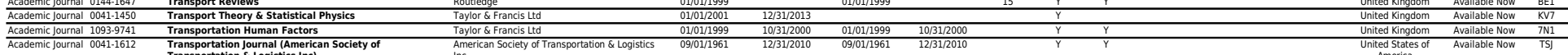

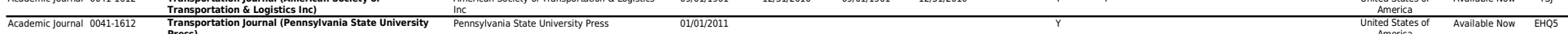

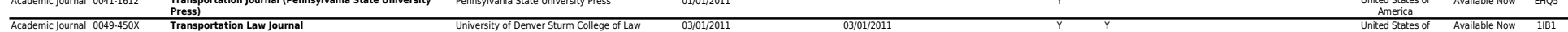

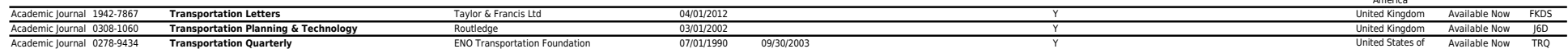

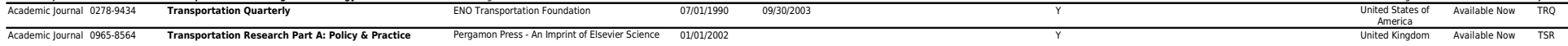

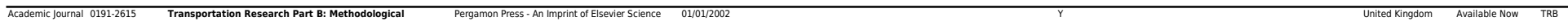

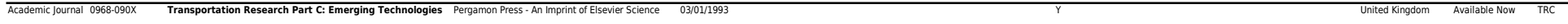

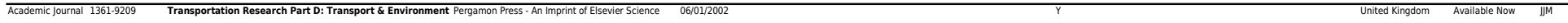

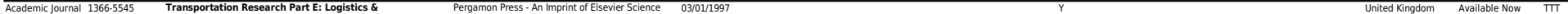

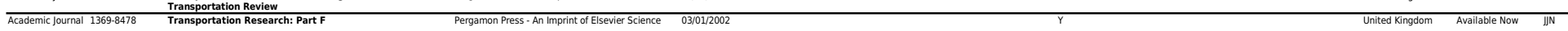

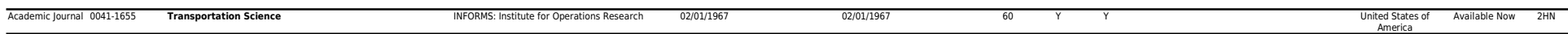

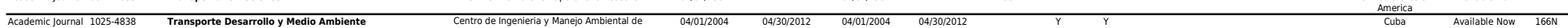

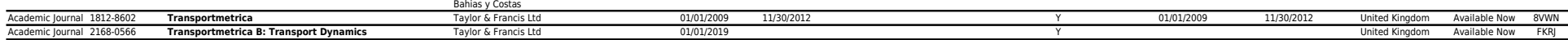

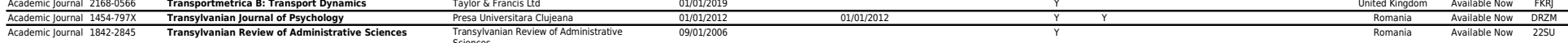

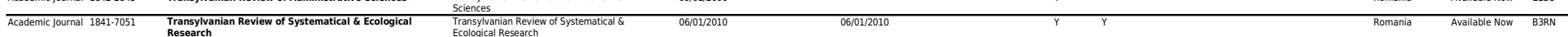

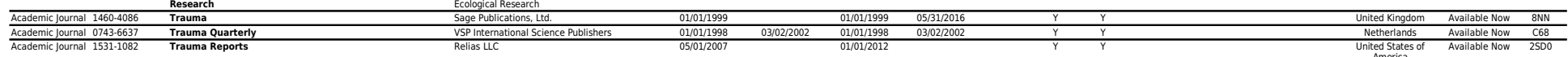

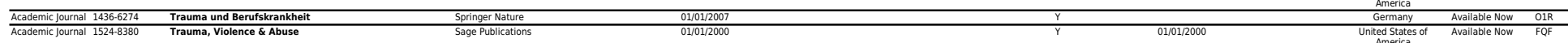

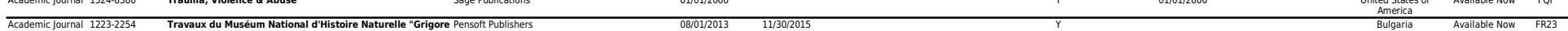

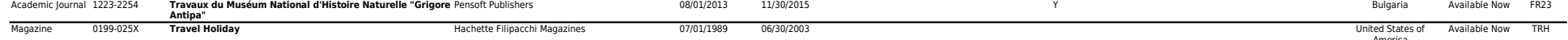

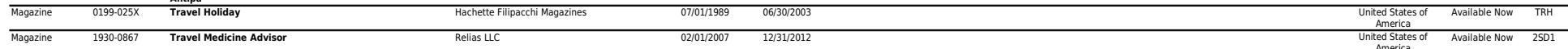

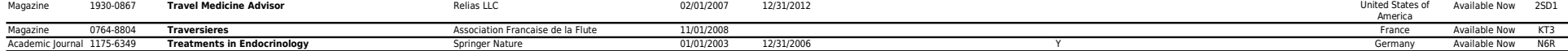

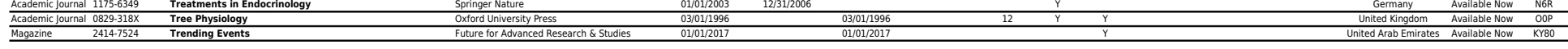




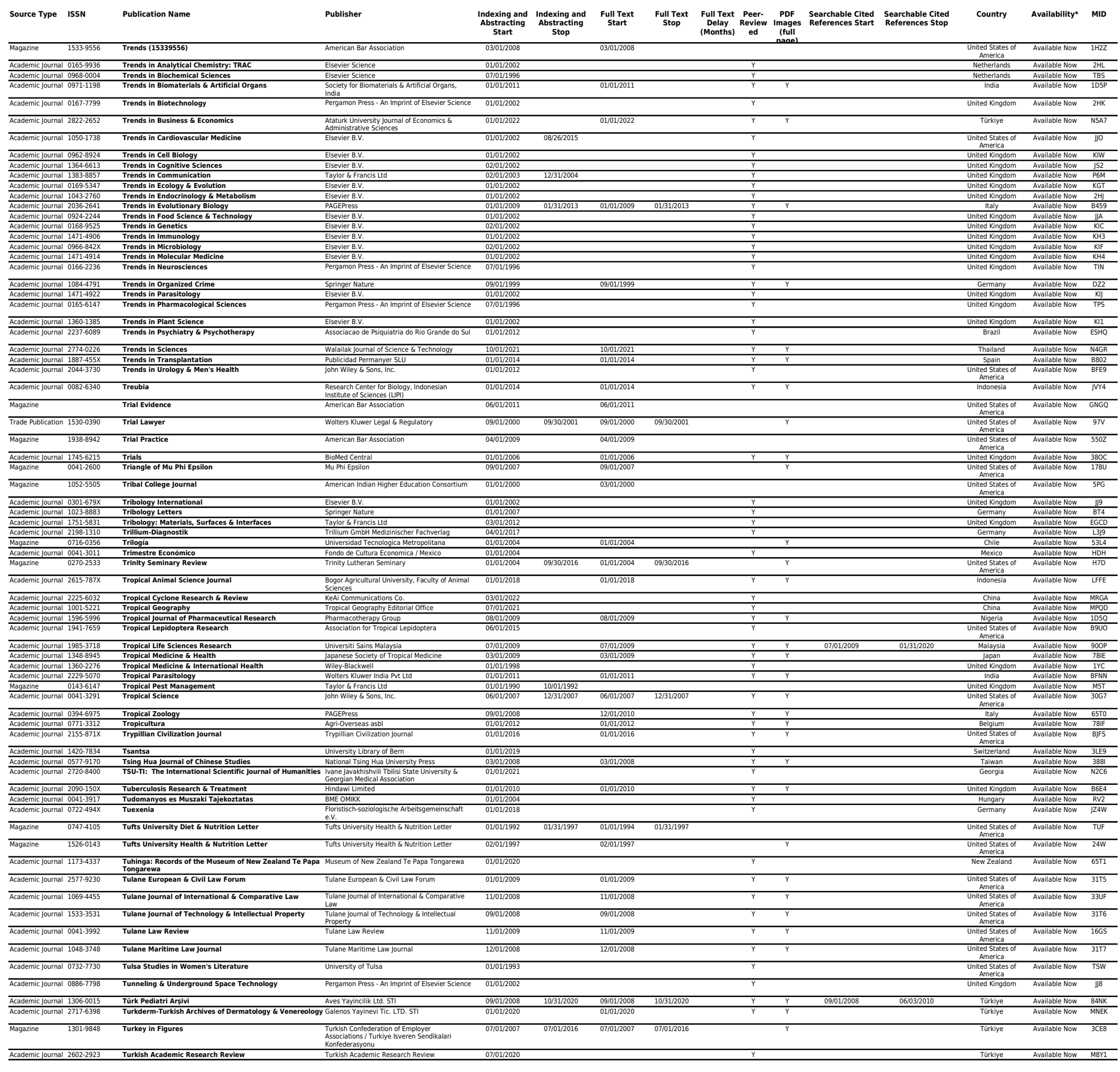




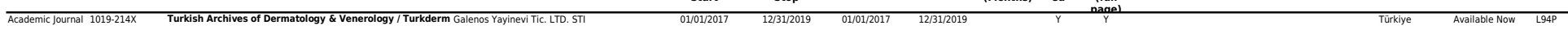

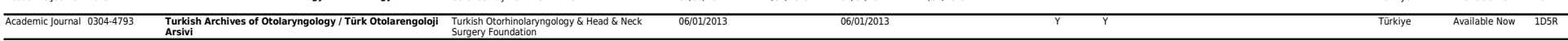

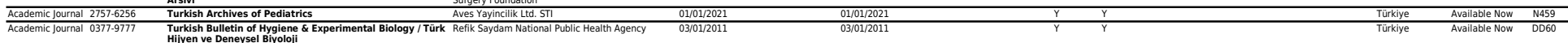

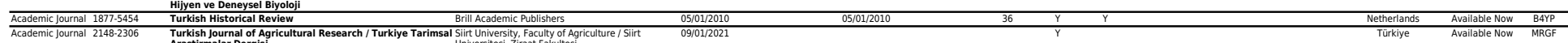

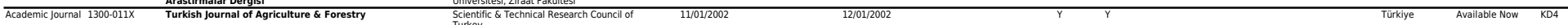

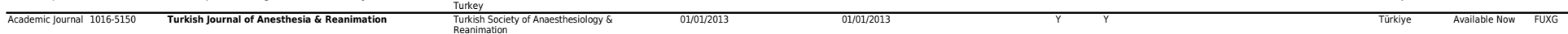

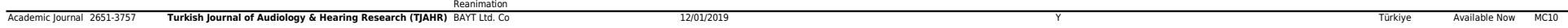

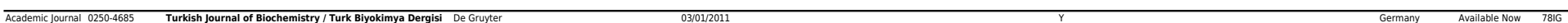

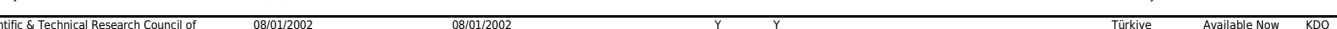
Tutrey

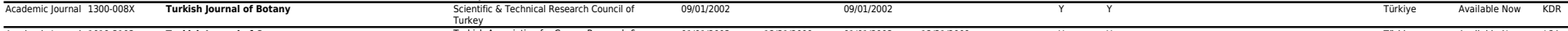

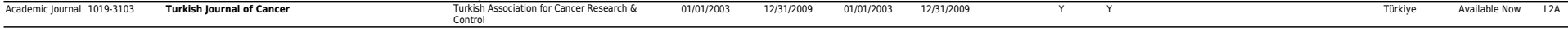

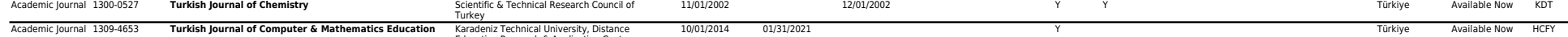

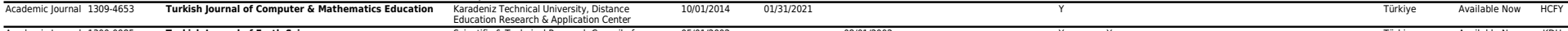

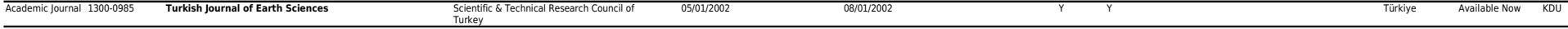

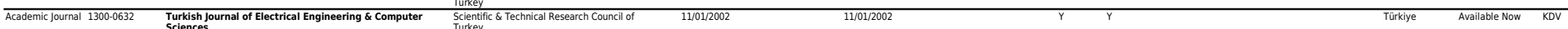

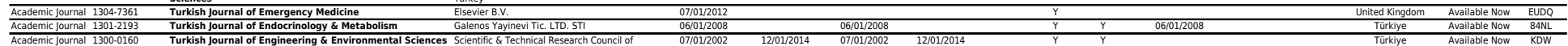
Tutey

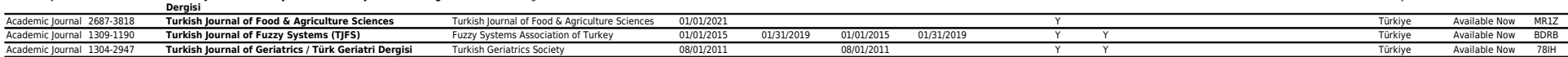

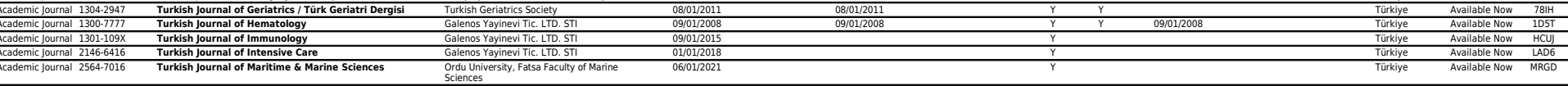

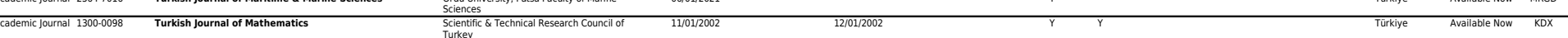

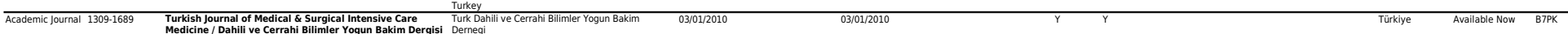

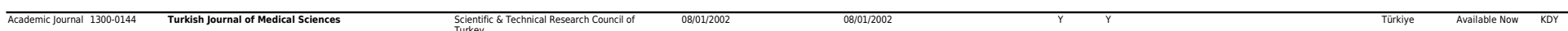

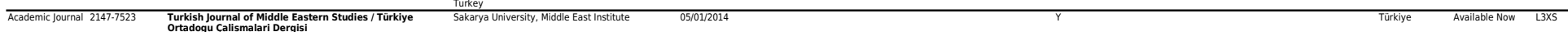

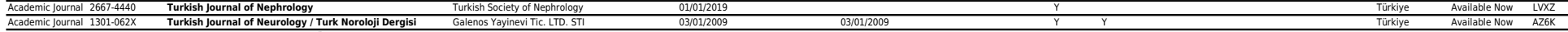

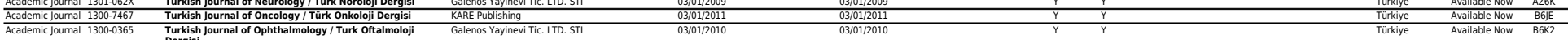

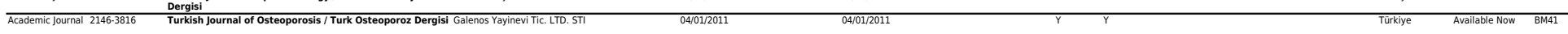

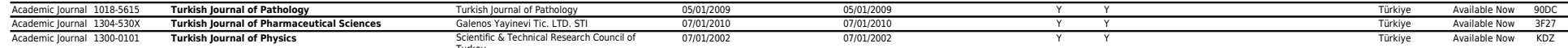

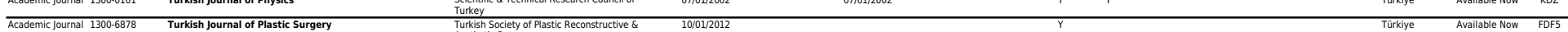

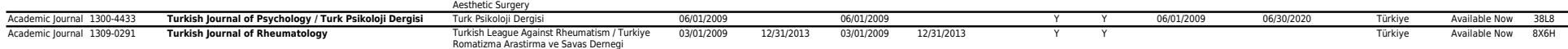

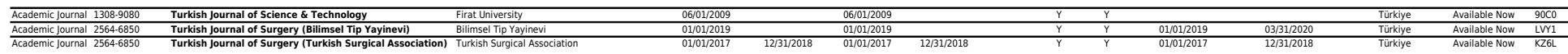

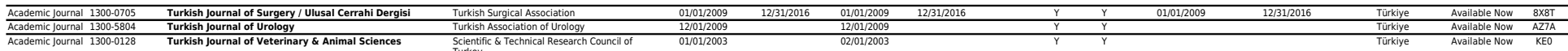

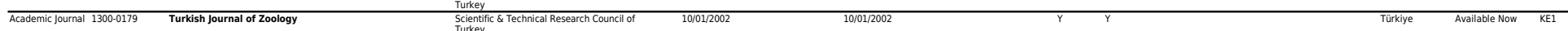

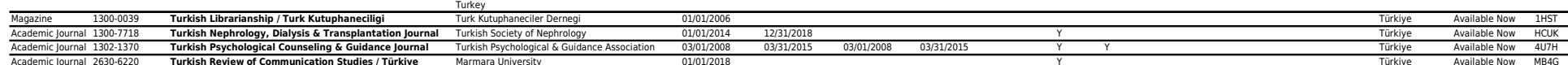

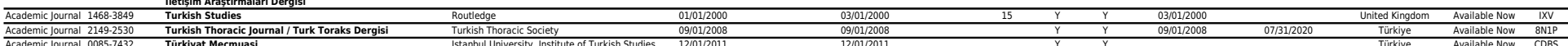

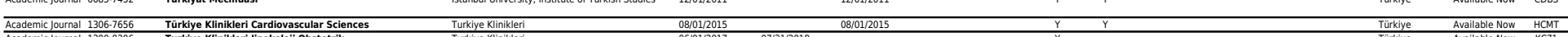

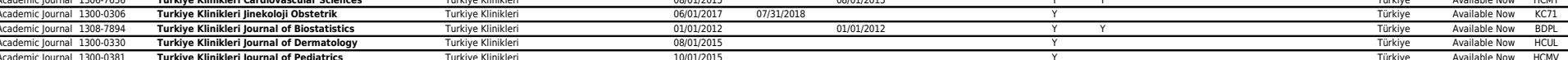

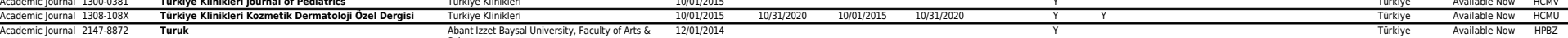

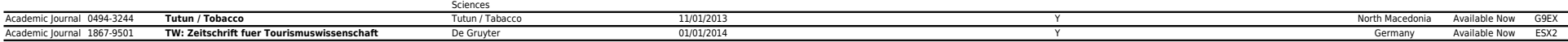

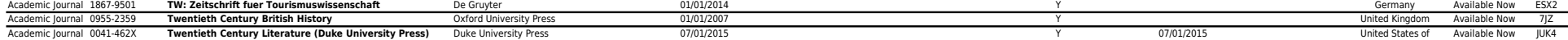

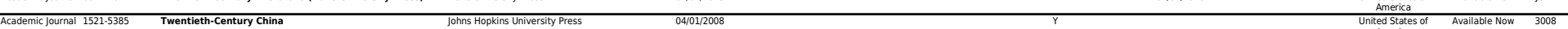

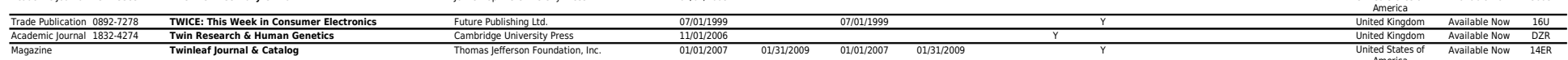




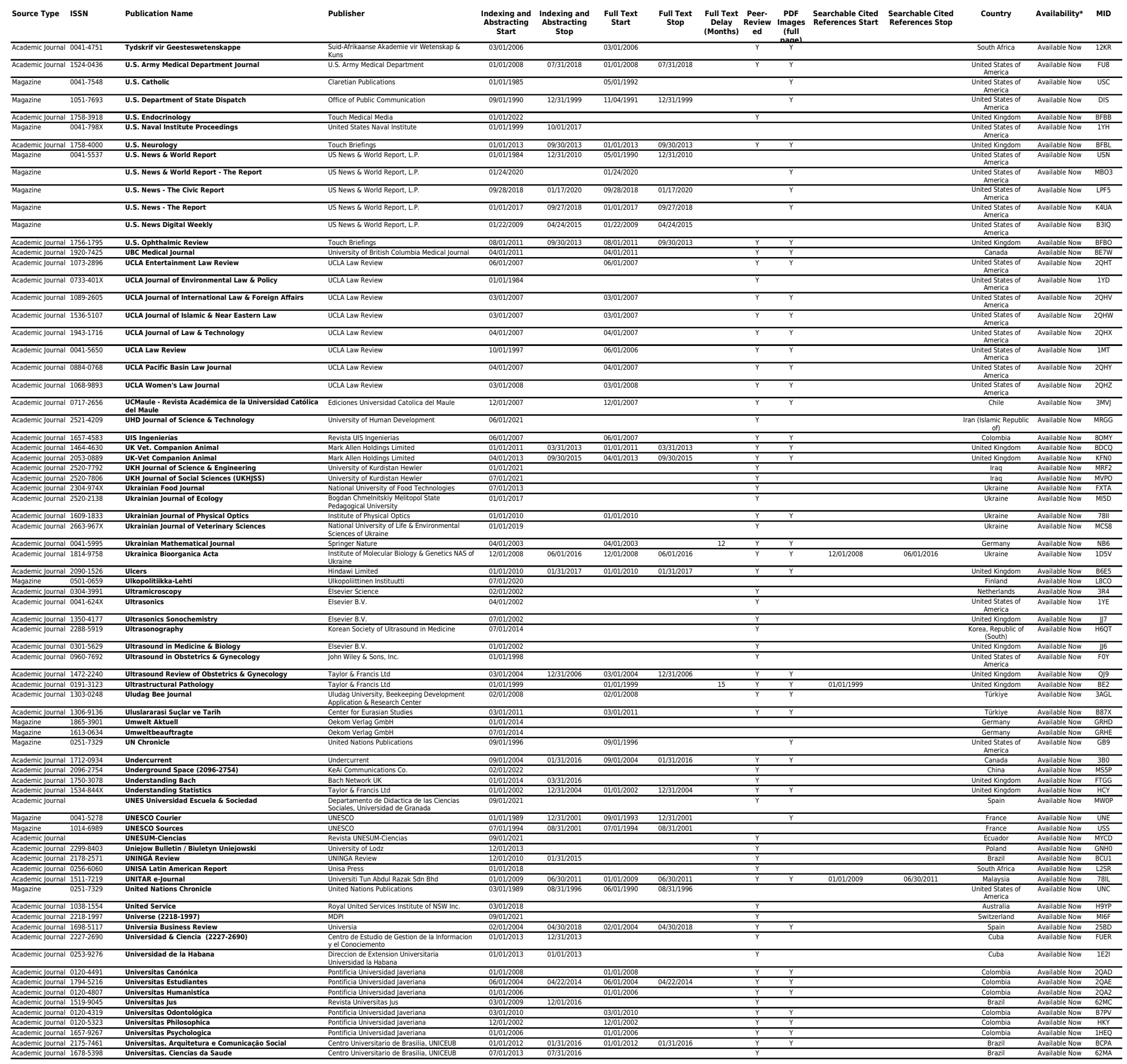




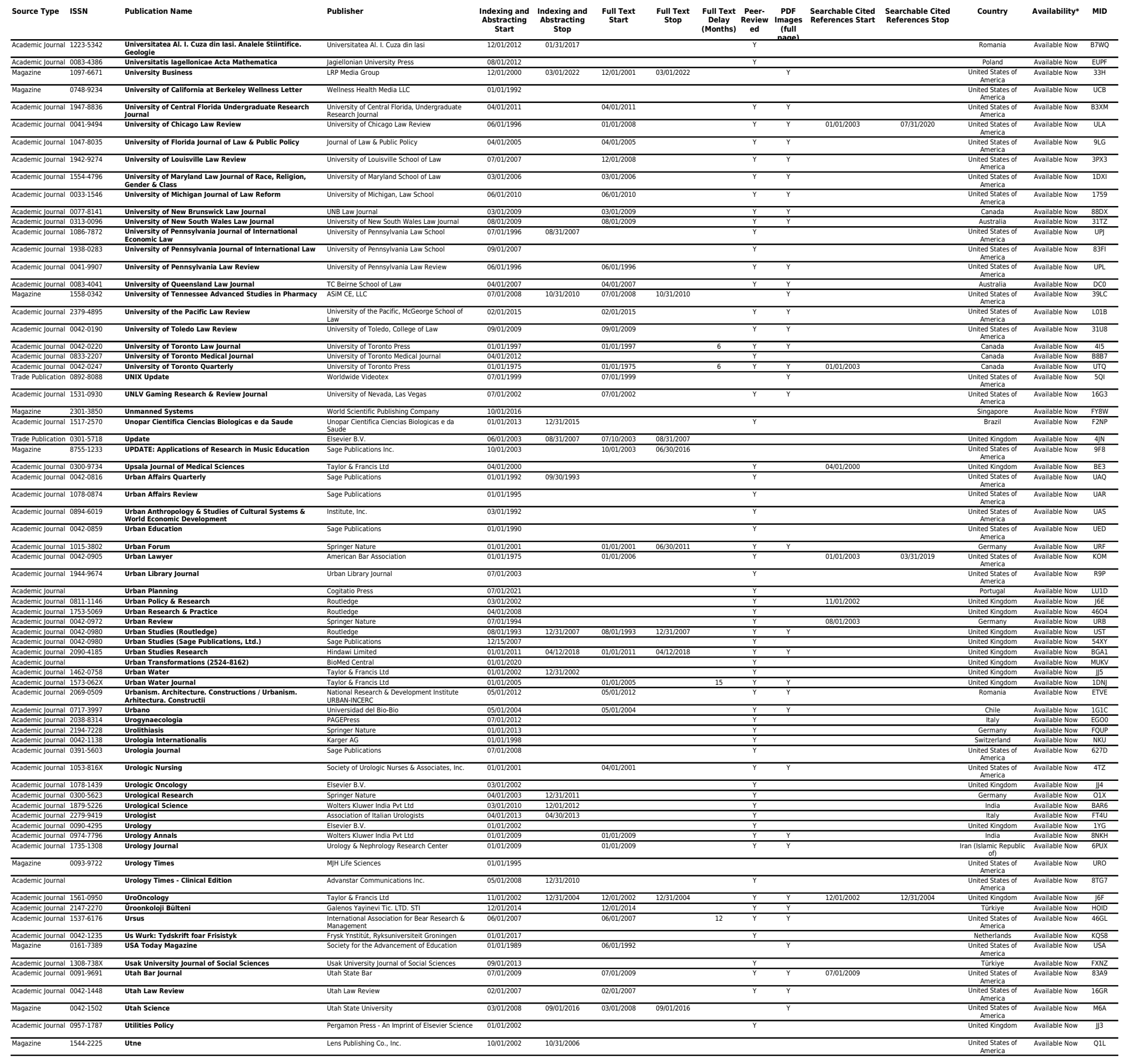




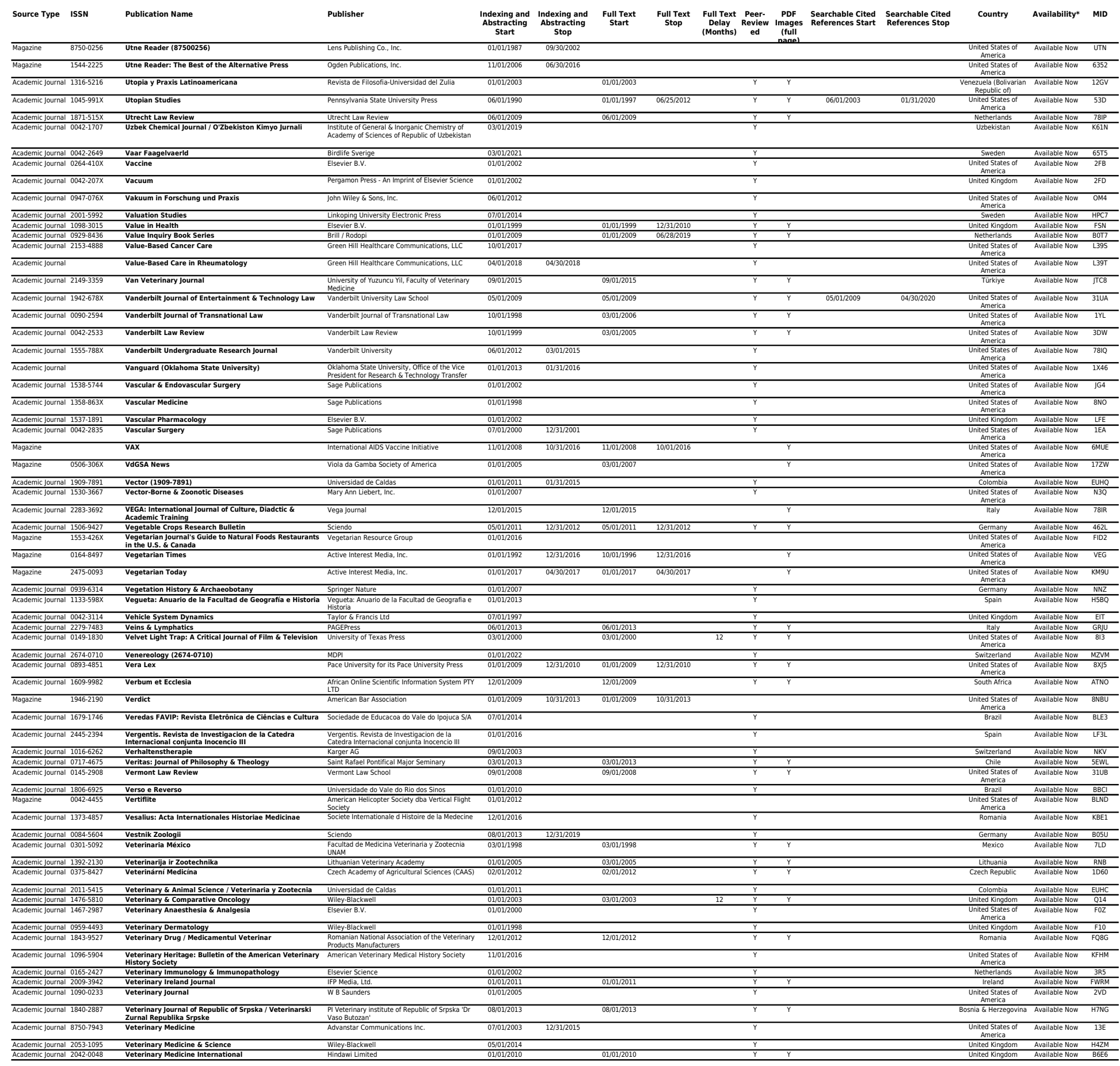




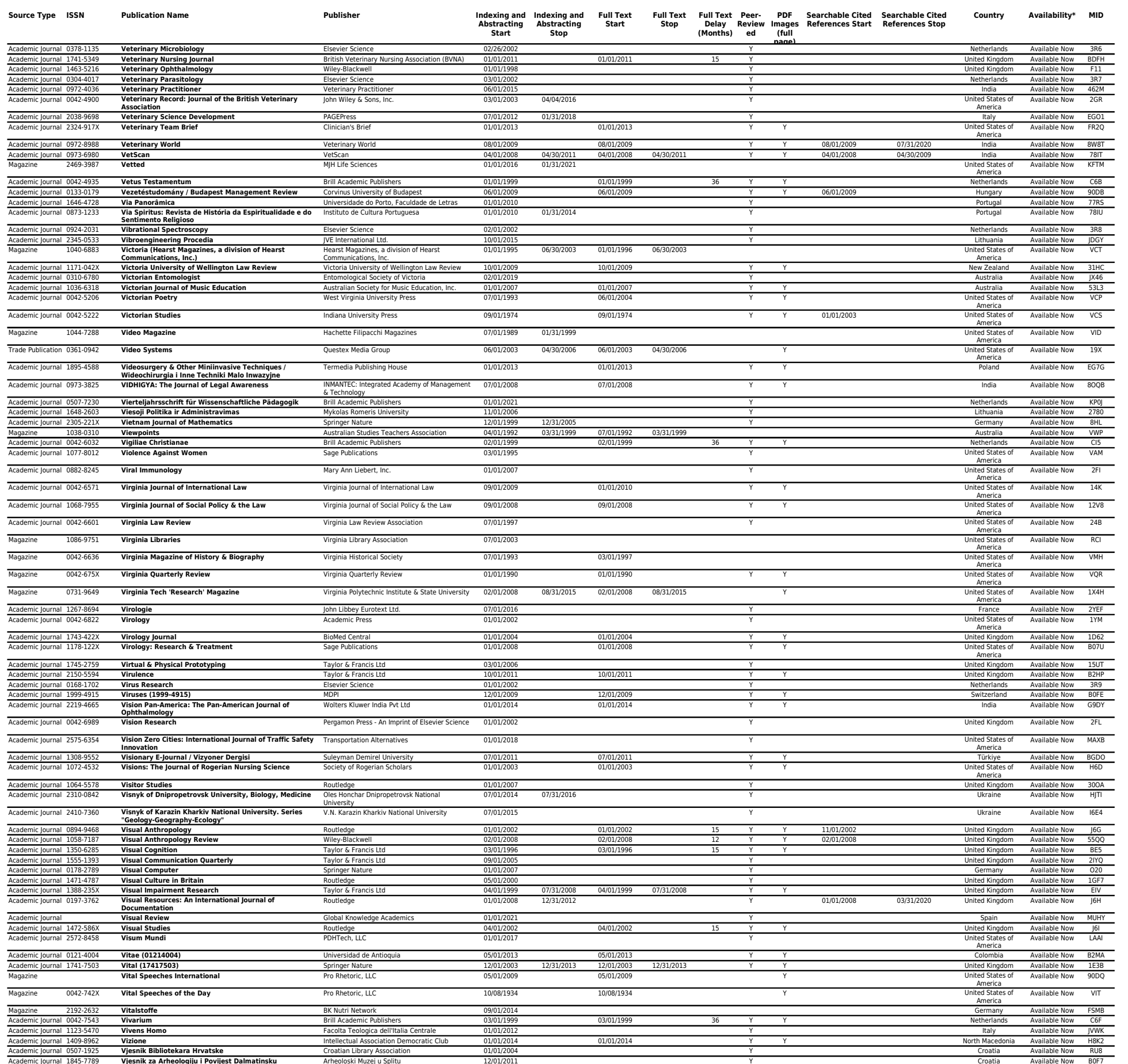




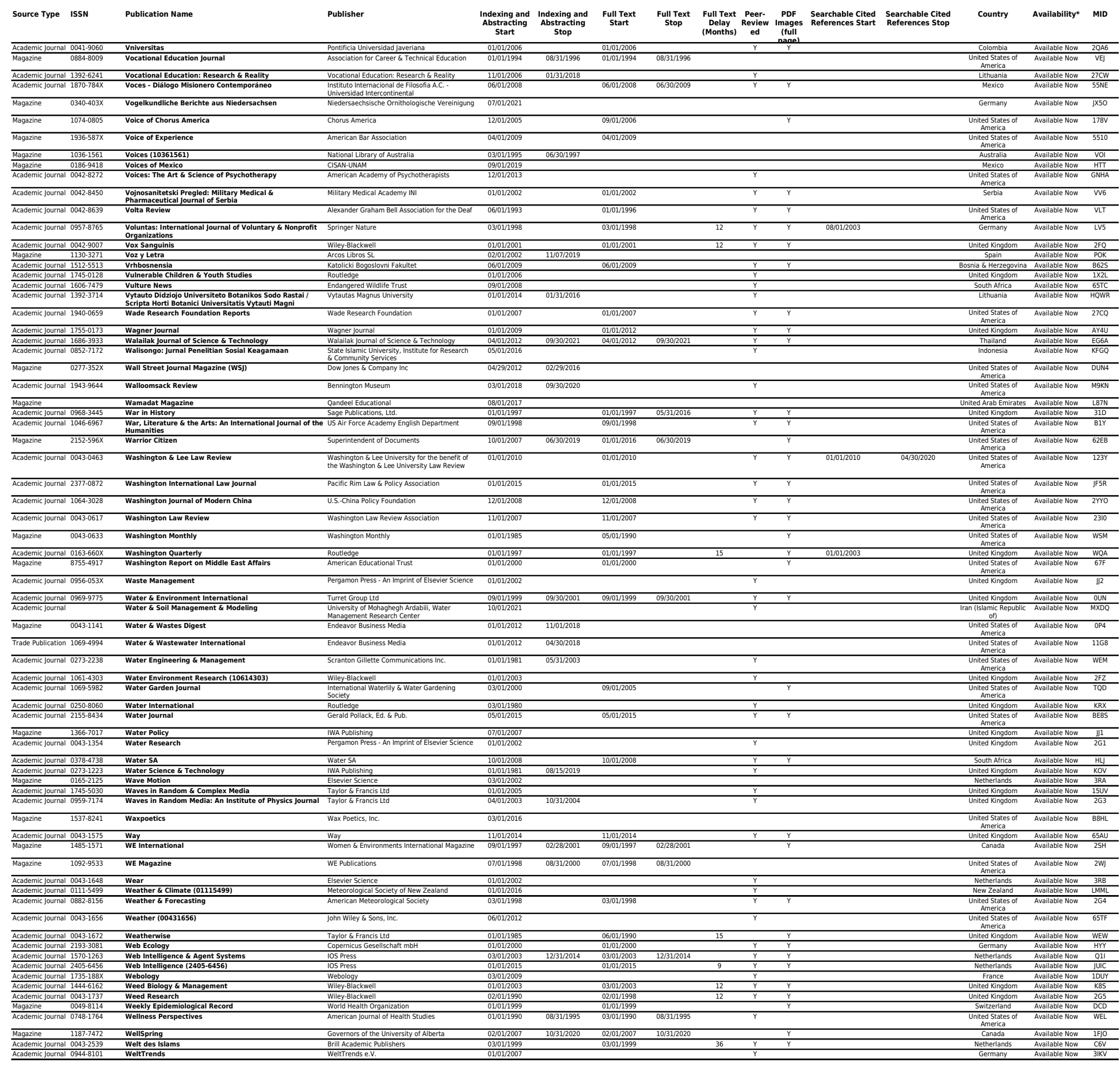




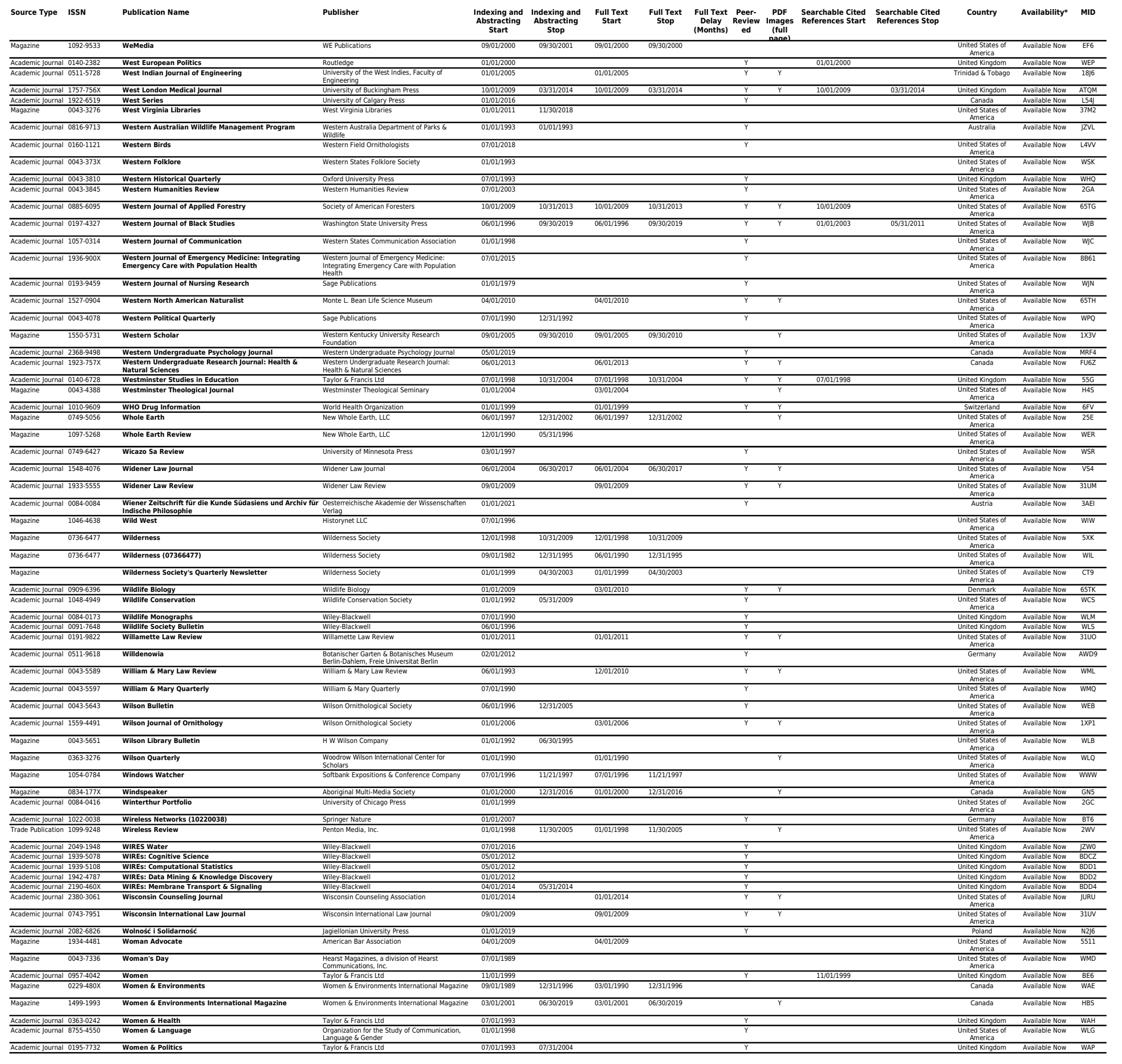




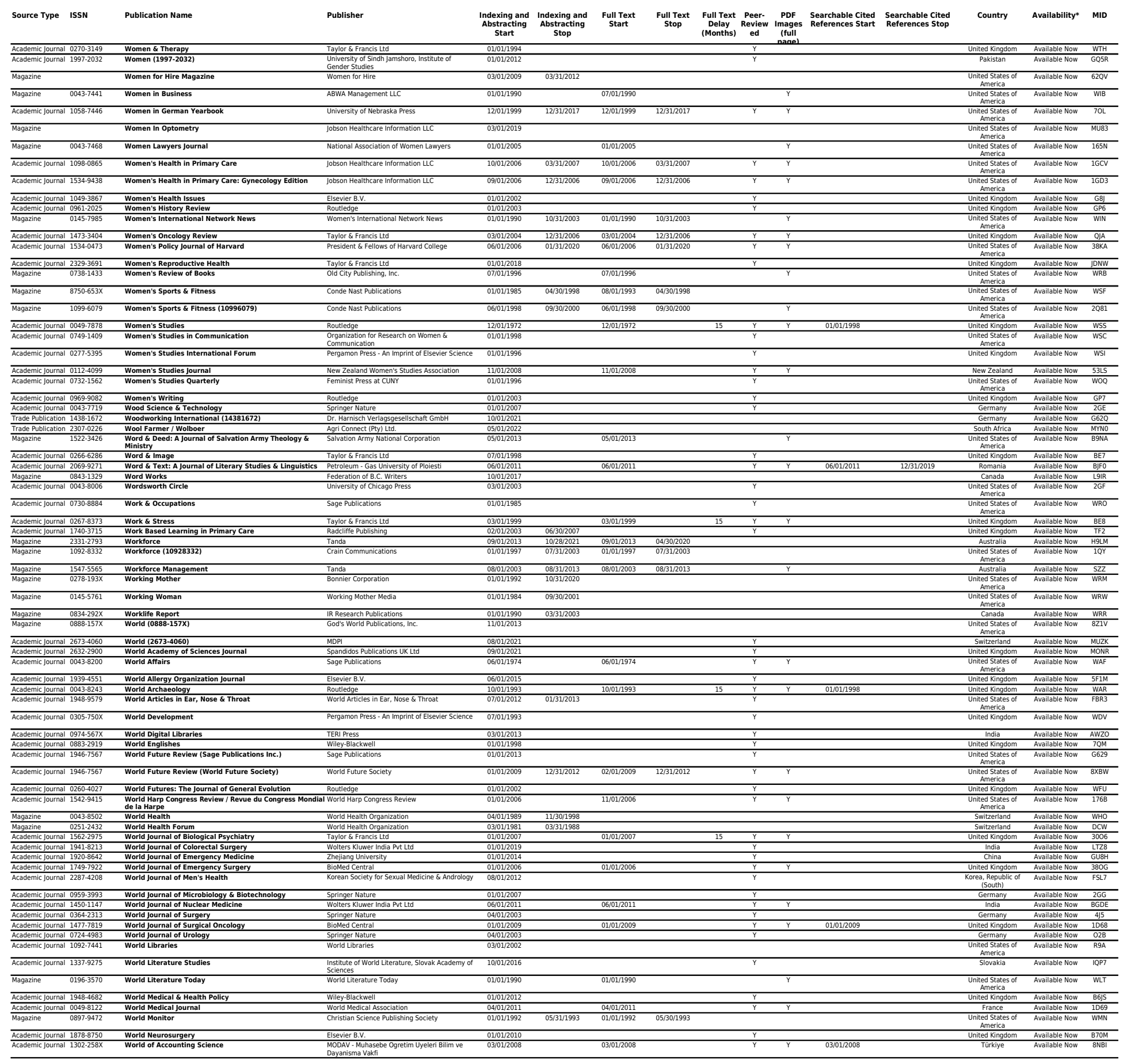




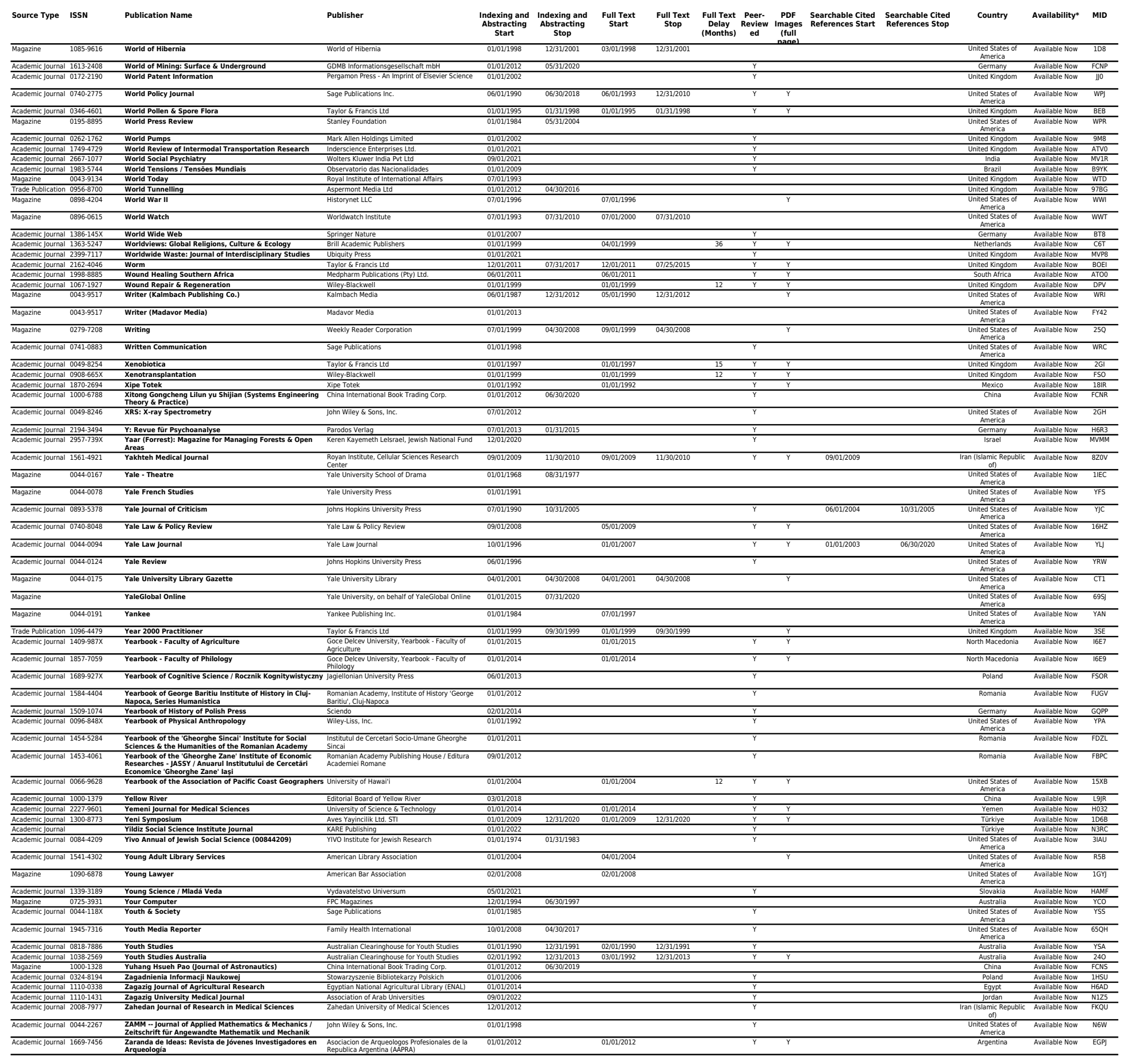




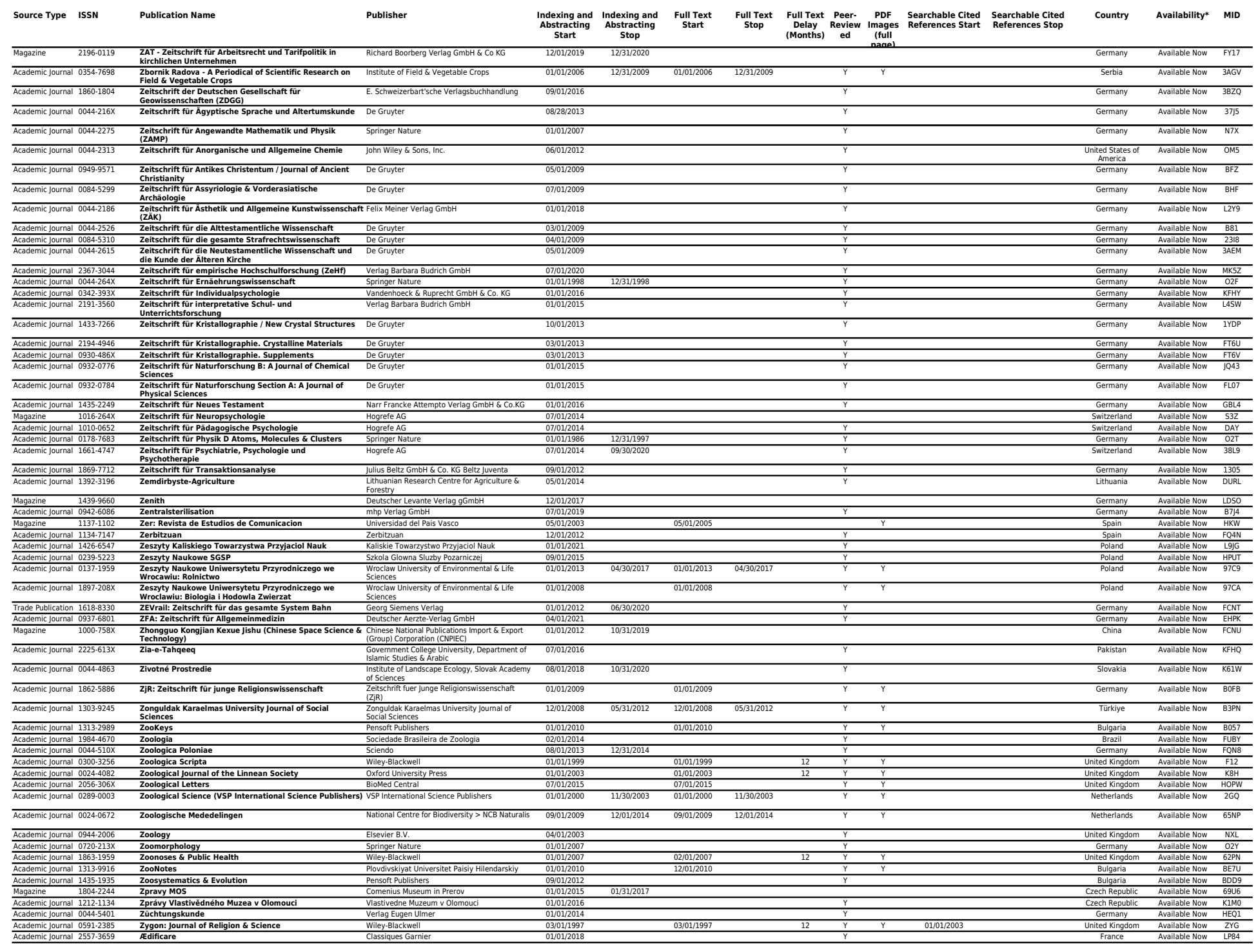

